\title{
ANTARCTIC AND SOUTHERN OCEAN DUST TRANSPORT \\ PATHWAYS: FORWARD-TRAJECTORY MODELING AND \\ RARE EARTH ELEMENT SOURCE CONSTRAINTS FROM THE \\ RICE ICE CORE
}

BY

PETER D. NEFF
A thesis submitted to the Victoria University of Wellington
in fulfillment of the requirements for the degree of
Doctor of Philosophy
in Geology

Victoria University of Wellington

$(2015)$ 


\begin{abstract}
Mineral dust fertilization of Southern Ocean surface waters, and mixing with Antarctic deep-water, influences oceanic uptake of carbon dioxide and draws down global atmospheric concentrations during glacial periods. Quantifying modern variability in dust source and transport strength, especially with respect to high- and low-latitude climate phenomena (e.g. the Southern Annular Mode, El Niño Southern Oscillation), will improve understanding of this important aspect of the global carbon cycle. Using high-order geochemical provenance techniques can also reveal in greater detail what aspects of dust transport are recorded in Antarctic ice core records, allowing for better interpretation of glacial-interglacial dust records at individual sites.
\end{abstract}

First, using forward trajectories and climate reanalysis data, this work explores modern variability (1979-2013) in atmospheric transport of mineral dust from Southern Hemisphere potential source areas (PSA) - primarily Australia, southern South America and southern Africa. Estimates of the relative source and transport strength of New Zealand are also discussed, and compared with other dust PSA to evaluate New Zealand's potential contribution to Southern Ocean and Antarctic dust deposition. Extra-Antarctic dust PSA distributions are detailed for individual ice core sites, including the newly recovered Roosevelt Island Climate Evolution (RICE) ice core $\left(79.36^{\circ} \mathrm{S}, 161.71^{\circ} \mathrm{W}, 550 \mathrm{~m}\right.$ a.s.1.). This approach - applicable to many types of aerosol-reveals persistent, strong transport from New Zealand and Patagonia to the southern high-latitudes during all seasons. It also demonstrates that southward transport of air masses from pan-Pacific dust sources is affected by circulation variability initiated in the central tropical Pacific Ocean.

High-resolution discrete sampling of the RICE core allows for unprecedented analysis of trace elements at sub-annual to annual scales. The rare earth elements (REE, lanthanide elements Lanthanum to Lutetium) can preserve the signature of their original source material and thus provide provenance constraints for dust preserved in Antarctic snow and ice. While challenging, measurements of REE concentration to the single femtogram per gram $\left(10^{-15} \mathrm{~g}\right.$ $\mathrm{g}^{-1}$ ) level have been made by combining efficient sample introduction and a jet-interface sector-field inductively coupled plasma mass spectrometer. The methodology and fidelity of these measurements are presented, in addition to results for other low-concentration elements associated with natural and anthropogenic aerosols.

REE data from the RICE ice core are then used to explore possible modern sources of dust in the Ross Sea sector of Antarctica, testing hypothesized trajectory model distributions. Twentieth-century and late-Holocene ( $2.3 \mathrm{ka}$ - present) REE data from the RICE ice core represent the first measurements of this kind from the Pacific sector of Antarctica. RICE data are compared with Holocene REE data from the Drønning Maud Land and Dome C ice cores, with consideration of REE signatures in dust samples from PSA. Data from the RICE ice core indicate fewer than 5\% contributions of dust from South America, and show strong negative trends in crustal-normalized REE signatures suggesting contributions from local Antarctic dust. 


\section{Acknowledgements}

Thank you very much to my supervisor, Nancy Bertler, who has provided endless support for all of us working on the RICE ice core project. Ross Edwards, your help and advice on traceelement laboratory work is second to none-you truly rescued this project and pushed us to raise the bar.

To Andrea Tuohy, my Ph.D. "twin," I feel lucky to have worked with you so closely for the past three years. How is it that we never had a disagreement? I wish you all the best and hope to share a trail somewhere soon with you and Ollie.

Alex Pyne and Darcy Mandeno have been very kind to include me as (what I consider) an honorary member of the Science Drilling Office. I have learned much from both of you. Darcy, our many therapy sessions on bikes, over beers and at Makara Beach have been indispensible and unforgettable. Huw Horgan, Ruzica Dadic and little Ivan have also been great supporters, neighbors and friends. The Antarctic Research Centre community is a true gem; thanks heaps to everyone.

I must thank my M.Sc. supervisor and friend Eric Steig for his enthusiasm, for continually including me in exciting ice core projects and engaging me as a colleague since I was a wee undergraduate. To all the University of Washington glaciologists, know that the foundation of knowledge that I gained (and continue to gain) through you has provided me with the confidence to tackle all things icy. Twit Conway especially has kept an eye on me since Glaciology 101 many years ago, and for that I am very grateful.

Of course, above all I wish to thank my constant partner (and sometimes office mate) in this adventure and this life, my fiancée, Heidi for her endless care and love. In a close second comes our shadow, Kuna, who has endured many days of insufficient ball-throwing during both of our Ph.D.'s. We have had amazing support and many great video calls with Connie and Peter (Blue) Roop. I can't wait to spend more time around the campfire with you two. My parents and family have of course always provided support and encouragement without question. Have fun reading this thesis, Mom. 


\section{Table of Contents}

Abstract

$$
\begin{gathered}
\text { ii } \\
\text { iii } \\
\text { iv - v } \\
\text { vi }- \text { vii } \\
1-14 \\
1-2 \\
3-4 \\
4-7 \\
7-8 \\
9-14
\end{gathered}
$$

Acknowledgements

Table of Contents

Foreword

Chapter 1: Introduction

1.1 The Roosevelt Island Climate Evolution (RICE) project

1.2 Dust provenance in Antarctic ice cores

1.3 Thesis outline

1.4 Selected conference presentations

1.5 References

Chapter 2: Trajectory modeling of modern dust transport to the Southern Ocean and Antarctica

2.1 Introduction

2.2 Methods

$19-21$

2.3 Results

$22-25$

2.3.1 Trajectory distribution

22

2.3.2 Trajectory seasonality

$22-24$

2.3.3 Ten-day trajectory evolution

$24-25$

2.4 Discussion

$25-42$

2.4.1 Source strength and transport efficiency

$25-28$

2.4.2 Southern Ocean trajectory distribution

$29-31$

2.4.3 Atmospheric transport to Antarctic ice core sites

$32-40$

2.4.3.1 Dust transport to the East Antarctic Ice Sheet

$32-36$

2.4.3.2 Dust transport to the West Antarctic Ice Sheet

$37-40$

2.4.4 Drivers of interannual transport variability

$41-47$

2.5 Conclusions

$47-49$

2.6 References

$50-61$

2.7 Supporting figures

$62-66$

Chapter 3: Low-femtogram elemental analysis of Antarctic ice cores without preconcentration

$67-82$

3.1 Introduction

$67-68$

3.2 Experimental

$68-73$

3.2.1 Materials, reagents and standards

$68-69$ 
3.2.2 Ice core sampling

3.2.3 Sample acidification

$69-72$

3.2.4 Analytical environment 72

3.2.5 Instrument setup $72-73$

3.2.6 Run structure 73

3.2.7 Calibration 73

3.3 Results and discussion $73-77$

3.3.1 Quality control recoveries and stability at the low $\mathrm{pg} \mathrm{g}^{-1}$ to $\mathrm{fg} \mathrm{g}^{-1}$ level $73-75$

3.3.2 Oxide formation 75

3.3.3 Limits of quantification and concentration in Antarctic ice samples

3.4 References $75-79$ $80-82$

Chapter 4: Rare earth element dust signatures over the past two thousand years in the RICE ice core, Pacific sector, West Antarctica $83-121$

4.1 Introduction $83-86$

4.2 Methods $86-88$

4.3 Results $88-96$

4.4 Discussion

$96-108$

4.4.1 Sample acidification biases towards LREE enrichment 96 4.4.2 RICE REE comparison to EDC and EDML

4.4.3 Modern/Holocene dust PSA contributions to ice core sites

$100-104$ 4.4.3.1 RICE $100-102$ 4.4.3.2 EDC 102 4.4.3.3 EDML $102-104$ 4.4.4 PSA REE signatures $105-106$ 4.4.5 RICE ice core REE indications of dust provenance $106-108$ 4.5 Conclusions $108-109$

4.6 References $110-116$

4.7 Supplementary Figures

$117-121$

Chapter 5: Summary and Future Work

$122-125$

Appendix A: A review of the brittle ice zone in polar ice cores

$126-152$

Appendix B: RICE REE data

$153-192$ 


\section{Foreword}

One of the primary reasons that ice core projects produce such transformative scientific results, and why I find contributing to such projects so personally rewarding, is because they are highly interdisciplinary and require collaborative work at all stages. An ice core scientist must simultaneously be proficient at individual and team work, must be able to quickly understand information from diverse research fields, and be equally willing to shovel snow, write papers or design aircraft loads around getting many pounds of heavy cream to a remote drill site. My trace element work on the RICE ice core was particularly collaborative, requiring task sharing with fellow $\mathrm{PhD}$ candidate A. Tuohy at every step from sample preparation through to data interpretation. For these reasons, below are detailed my contributions to the RICE project over the last three years.

\section{Field work}

I participated in the 2012-2013 RICE field season as an assistant driller, helping to complete deep drilling from $130 \mathrm{~m}$ to $764 \mathrm{~m}$. I undertook little additional science work because of drilling duties, but collected the $19.5 \mathrm{~m}$ "12/13 B" firn core with D. Mandeno and H. Berge, which was used in annual layer counting to connect the January 2013 snow surface with the top of the deep core (which begins at $8 \mathrm{~m}$ depth below the 2011-2012 snow surface due to trenching required for drill infrastructure).

\section{Ice core processing}

I assisted in ice core continuous flow analysis (CFA) campaigns during the austral winters of 2012, 2013 and 2014 (1-2 months each). During the latter two campaigns I led freezer sampling of the RICE ice core (40 m - $764 \mathrm{~m})$, cutting samples for CFA and other analyses with the help of 2-3 assistants. I also made electrical conductivity measurements along the length of the core and recorded core quality. Electrical measurements were used to identify volcanic events, alerting CFA operators to remove these sections of ice from analysis (both for additional sampling and to protect CFA equipment from high particle concentrations in these layers).

\section{Sample preparation}

A. Tuohy and I shared many tasks in preparing trace element samples, including design and execution of an 8-week acid leaching experiment, transferring frozen samples between the freezer storage facility and the university, cleaning thousands of sample vials, and finally 
combining $\sim 10,000$ RICE samples into 621 approximately 3-year average samples. These 621 samples, an additional 784 from the top $40 \mathrm{~m}$ of the RICE ice core, and 200 surface snow and snowpit samples were then acidified prior to analysis (and this over a very short period of time, splitting a 24-hour work schedule with A. Tuohy).

\section{ICPMS analysis}

Preliminary ICPMS work at Victoria University of Wellington involved setting up a new Element 2. Within a short span of time, we coordinated an in-lab course with a Thermo Scientific technician, purchased an autosampler, and following this I left for the RICE deep drilling season. A. Tuohy continued to work on instrumental development during this time. On my return we shared analytical duties, eventually measuring all samples at the Curtin University TRACE lab working around the clock for a three-week period.

\section{Data calibration}

Custom calibration of ICPMS trace element data was designed with A. Tuohy and R. Edwards. A. Tuohy completed the coding and quality assurance required for this step (while I was completing the 2014 RICE core processing line). Later iterations between A. Tuohy and myself resulted in the final version of these data to be published, with myself leading paper writing (Chapter 3).

\section{Agescale development}

Together with A. Tuohy and D. Emanuelsson I determined preliminary annual layer counts based on water stable isotopes and sulfur/sulfate in the 12/13B RICE firn core and the top 40 $\mathrm{m}$ of the deep RICE ice core (representing the $20^{\text {th }}$ Century). These counts have since been refined by the RICE community and through further work by D. Emanuelsson. 


\section{Chapter 1: Introduction}

\subsection{The Roosevelt Island Climate Evolution (RICE) project}

The RICE project is a recently completed Antarctic ice core drilling effort, which in December 2012 collected a $764 \mathrm{~m}$ long ice core from the summit of Roosevelt Island, a grounded ice dome at the northeastern margin of the Ross Ice Shelf (Figure 1). Roosevelt Island has been the site of glaciological research for more than 50 years, and is an ideal site for an ice core both due to its location within the Ross Ice Shelf and because of its stable ice flow geometry. Located near the Bay of Whales and Little America bases used by early Antarctic explorers, Roosevelt Island was the site of early glaciological investigations conducted during the International Geophysical Year [Crary, 1961; Crary et al., 1962]. More recent work details ice flow geometry and heat flux at the site [Thomas et al., 1980], with icepenetrating radar data demonstrating long-term ice flow divide stability at the site and constraining the timing of Holocene retreat of the West Antarctic Ice Sheet (WAIS) [Conway et al., 1999; Martín et al., 2006]. Ice drilling at such a divide is ideal, as these flow conditions up-warp isochrones directly below, forming a "Raymond bump" which allows an ice core to capture older layers at shallower depths than would be possible at another site [Nereson and Waddington, 2002; Raymond, 1983].

Roosevelt Island is subject to the synoptic weather systems which characterize the Amundsen Sea Low (ASL), a center of low pressure affecting the Ross, Amundsen and Bellingshausen seas which efficiently advects marine air onto the WAIS - bringing with it moisture (e.g. latent heat) and aerosols [Cohen et al., 2013; Hosking et al., 2013; Turner et al., 2013]. This strong southward moisture transport is seen in the mean $(1979-2012)$ vertically-integrated moisture flux output of the European Centre for Medium-Range Weather Forecasts (ECMWF) ERA-Interim climate reanalysis dataset (Figure 1). This arrangement is in part caused by the relatively shallow slope of the WAIS and the axial asymmetry of the Antarctic continent, geographically offset from the South Pole by $\sim 10^{\circ}$ [Lachlan - Cope et al., 2001; Nicolas and Bromwich, 2011]. It is additionally significant that the Pacific Ocean basin lies to the north of this region, facilitating a unique teleconnection to the lower-latitudes which may be responsible for recent warming observed across the WAIS [Bromwich et al., 2013; Ding et al., 2011; Nicolas and Bromwich, 2014; Steig et al., 2009; Turner, 2004]. 

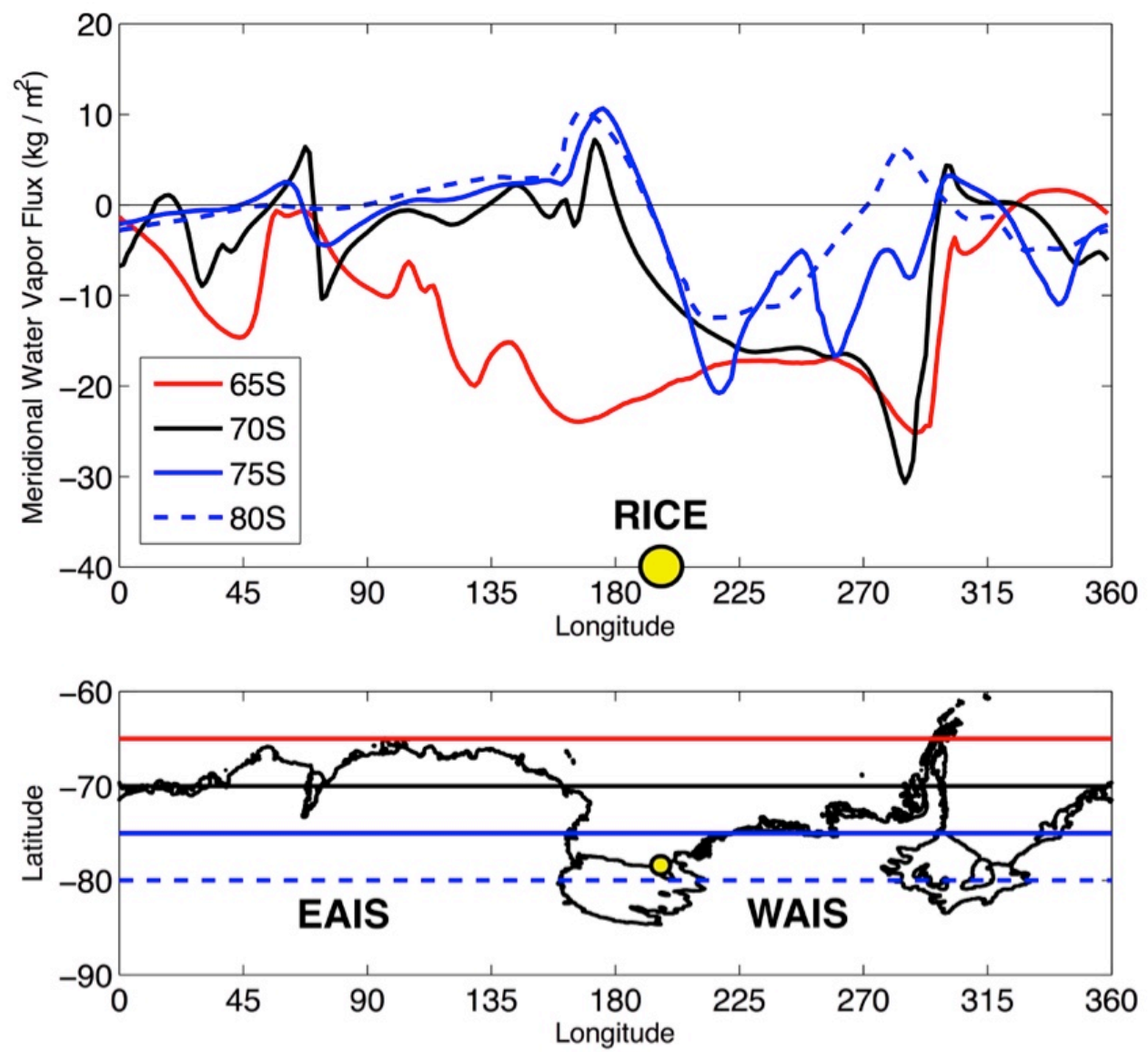

Figure 1. ERA-Interim reanalysis 1979-2012 mean vertically-integrated meridional (northward positive, southward negative) water vapor flux $\left(\mathrm{kg} / \mathrm{m}^{2}\right)$ at southern high-latitudes. Latitudes plotted in top panel are marked in bottom panel. Strongest southward (negative) flux south of $65^{\circ}$ latitude is seen in the vicinity of the WAIS.

The RICE ice core thus lies at the intersection of two critical aspects of Antarctic glaciology and climate. Aspects of the ice core record may provide additional insight into rates of change characteristic of the Ross Ice Shelf, a major stabilizing feature of the marine WAIS, grounded below sea-level and possibly prone to collapse, as hypothesized by Mercer [1978]. Such collapse may already be underway in the Thwaites and Pine Island Glacier basins $\left(\sim 75^{\circ} \mathrm{S}, 260^{\circ} \mathrm{E}\right)$, where rapid glacier thinning and retreat has been observed in recent decades [Joughin et al., 2014; Pritchard et al., 2012; Rignot et al., 2014]. The RICE ice core record is also well-positioned to contribute better understanding of tropical teleconnections affecting Antarctic climate variability, which are seen in comparisons of West Antarctic ice core records and meteorological data [Kreutz et al., 2000; Küttel et al., 2012; Okumura et al., 
2012; Schneider et al., 2006], and are also implicated in recent glaciological change (e.g. Dutrieux et al. [2014]; Steig et al. [2012]).

\subsection{Dust provenance in Antarctic ice cores}

These same atmospheric transport mechanisms controlling advection of heat into West Antarctica are also of interest for their role in bringing terrestrial mineral particles (dust) from mid-latitude continents to the Southern Ocean and Antarctica. Antarctic ice core records show twenty- to thirty-fold increases in dust concentrations during cold glacial periods, suggesting large fluctuations in dust production, atmospheric loading and deposition [Lambert et al., 2008; Thompson and Mosley-Thompson, 1981; Wolff et al., 2010]. Dust exerts significant control on atmospheric radiative balance, as suspended insoluble particles both absorb and reflect incoming radiation, and fertilizing effects of dust deposited over remote ocean areas affects carbon uptake and atmospheric greenhouse gas concentrations (e.g. Maher et al. [2010] and references therein). This latter effect is of particular importance over areas of the Southern Ocean where downwelling Antarctic Bottom Water originates, facilitating atmosphere-ocean carbon exchange [Orsi et al., 1999]. Antarctic ice core records of dust transported from Southern Hemisphere mid-latitude sources may therefore provide some constraint as to the timing and magnitude of this important aspect of the global carbon cycle. However, fluctuating dust concentrations preserved in Antarctic ice are possibly the result of environmental change at individual dust source regions or represent background dust loading of the atmosphere from multiple sources. Dust deposition is additionally affected by changing precipitation and wind patterns altering particle atmospheric lifetime [Albani et al., 2012; Mahowald et al., 1999].

Geochemical dust provenance efforts can elucidate additional details of these processes, reducing possible causes of fluctuating dust concentrations. Isotopic studies of $\mathrm{Sr}$ and $\mathrm{Nd}$, as well as $\mathrm{Pb}$ suggest a coherent South American dust source during dusty glacial periods but analyses are challenged by low dust concentrations during interglacials [Delmonte et al., 2008; Delmonte et al., 2004; Vallelonga et al., 2010]. Local Antarctic dust and volcanic input overprint extra-Antarctic source signals during interglacial periods of low dust input, but there is indication of greater input from additional Southern Hemisphere sources at these times (e.g. Australia, southern Africa, New Zealand [Delmonte et al., 2010; Revel-Rolland et al., 2006]). Advancements in the analysis of trace elemental species have spurred the development of new geochemical provenance tools, as sensitive measurements at sub picogram per gram (pg $\mathrm{g}^{-1}$, part per trillion) concentrations can now be made simultaneously for many elements [Barbante et al., 1997]. 
This thesis is designed to explore one such measure of Antarctic dust provenance, the Rare Earth Elements (REE). These fourteen elements (Lanthanum to Lutetium, atomic numbers 57-71) are abundant in crustal materials and inert through sedimentary processes, retaining the original REE abundance of parent rocks [Cullers et al., 1987; Gaiero et al., 2004; Henderson, 1984]. As such, the REE are an ideal system with a large number of variables to be used to identify individual dust sources from which Antarctic dust may originate. Work using this elemental system in Antarctic ice cores is in relatively early stages: Gabrielli et al. [2006] and Gabrielli et al. [2009] present the initial concept and analytical capabilities, with Gabrielli et al. [2010] developing interpretations from the European Project for Ice Coring in Antarctica (EPICA) Dome C ice core and forming a database of dust PSA signatures. Most recent work by Wegner et al. [2012] adds a glacialinterglacial REE sequence from the EPICA Drønning Maud Land ice core and collates additional dust PSA signatures. Once a dust potential source area (PSA) is suggested or positively identified in an ice core record, this better establishes the dust transport pathway from the location of emission to the ice core site, allowing further investigation through atmospheric modeling. Such an approach is taken in this thesis, although perhaps in the reverse direction, as detailed below.

\subsection{Thesis outline}

Chapters 2, 3 and 4 of this thesis are written as independent papers, the first two of which are currently in review for publication. The most recent work, Chapter 4, will undergo review by coauthors prior to submission to Climate of the Past in upcoming months. As these are stand-alone works, the reader should expect a certain amount of repetition in introductory material and motivation at the beginning of each chapter. Reference formatting and section structure varies depending on individual journal requirements. Appendix A is a published paper not strictly within the research themes of this thesis but highly relevant for development of future ice coring targets, especially coastal Antarctic sites similar to RICE. Appendix B contains all ICPMS trace element data discussed in Chapters 3 and 4 . Below is a synopsis of each chapter, with explanation of specific motivation and detailing contributions from any co-authors in addition to the primary thesis supervisor. 
Chapter 2: Trajectory modeling of modern dust transport to the Southern Ocean and Antarctica

Neff, P. D., and N. A. N. Bertler (2015), Trajectory modeling of modern dust transport to the Southern Ocean and Antarctica, Journal of Geophysical Research: Atmospheres, doi: 10.1002/2015JD023304.

This trajectory model study of daily 1979-2013 atmospheric transport from Southern Hemisphere dust sources explores seasonality and drivers of interannual variability in dust transport, as well as distribution across southern high-latitudes and at all Antarctic ice core sites. Specific consideration is given to potential dust sources in New Zealand, which are directly upwind from the RICE site in the circumpolar westerly circulation. Dust emissions from New Zealand are not well-quantified at present, but are regularly observed in glacial river valleys on either side of the New Zealand Southern Alps (see example photo, Figure 2). Especially during glacial periods, when ice was more extensive and glacial erosion more active in New Zealand, this area may represent a significant contributor to dust deposition especially over the South Pacific Ocean, as suggested by marine sediment core data [Lamy et al., 2014]. Both high- and low-latitude climate patterns are seen to affect the southward extension of Southern Hemisphere dust transport pathways, illustrating the complexity of dust transport to the Antarctic.

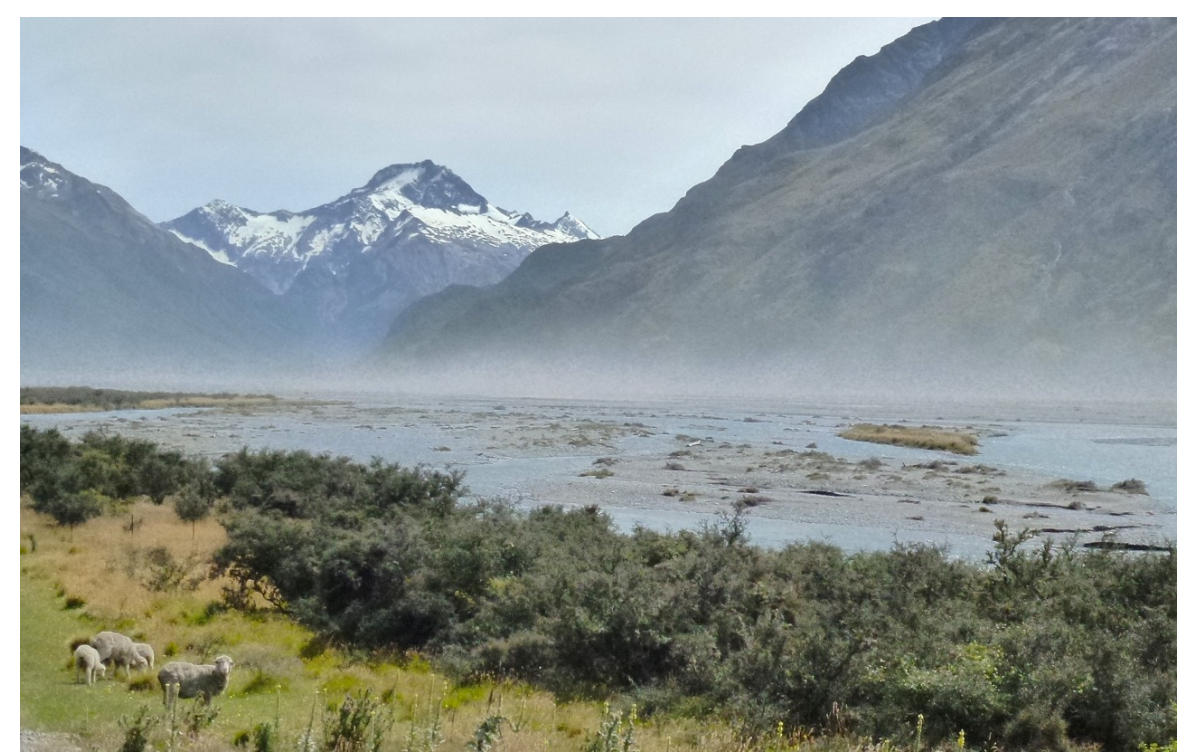

Figure 2. Windblown dust over the Hopkins River near Lake Ohau, South Island, New Zealand. T. Baisden, photo. 
Chapter 3: Low-femtogram elemental analysis of Antarctic ice cores without preconcentration

Neff, P. D., A. Tuohy, R. Edwards, and N. A. N. Bertler (in preparation), Low-femtogram elemental analysis of Antarctic ice cores without preconcentration.

A detailed methodology for measurement of trace elements in the RICE ice core is presented, including tests for sample stability through acidification, with particular focus on quality of sub-pg $\mathrm{g}^{-1}$ species. This is only the second analytical setup specifically optimized for REE analysis, sensitive to single $\mathrm{fg}^{-1}$ (part per quadrillion) concentrations. A. Tuohy shared in sample preparation, laboratory measurements, data calibration and provided comment on the manuscript. R. Edwards provided laboratory facilities, assisted and advised laboratory measurements, data calibration and presentation of results.

Chapter 4: Rare earth element dust signatures over the past two thousand years in the RICE ice core, Pacific sector, West Antarctica

Neff, P. D., N. A. N. Bertler, A. Tuohy, R. Edwards, D. Emanuelsson, J. Lee, E. Brook, T. Blunier, and P. Mayewski (in preparation), Rare earth element dust signatures over the past two thousand years in the RICE ice core, Pacific sector, West Antarctica.

Following the development of possible modern dust transport contributors to the RICE ice core and other sites (Chapter 2), possible rare earth element (REE) dust provenance is discussed for samples from the RICE ice core, measured using methods detailed in Chapter 3. Additional consideration is given to existing REE data from the Dome $\mathrm{C}$ and Drønning Maud Land ice cores, using dust PSA REE signatures presented by Wegner et al. [2012]. Because of considerable analytical uncertainties in Holocene samples with low dust concentrations, conservative interpretations of observed REE patterns are made, making use of large numbers samples achieved using this technique. A. Tuohy shared in sample preparation, laboratory measurements and data calibration. R. Edwards provided laboratory facilities, assisted and advised laboratory measurements and data calibration. D. Emanuelsson, J. Lee, E. Brook and T. Blunier provided age control points and otherwise assisted in developing the RICE $2 \mathrm{k}$ v1 agescale. P. Mayewski supported sampling of the RICE ice core for trace element analysis. 
Appendix A: A review of the brittle ice zone in polar ice cores

Neff, P.D. (2014). A review of the brittle ice zone in polar ice cores, Annals of Glaciology, 55(68), 72-82, doi: 10.3189/2014AoG68A023.

This published manuscript collects all available information concerning the brittle ice zone of reduced ice core quality - a challenging aspect of deep/intermediate ice core drilling - and considers possible physical processes controlling onset and relief of this behavior. Initiated by experiences processing the RICE ice core, which exhibited damaging brittle behavior below $475 \mathrm{~m}$, this paper is the result of a poster presented at the $7^{\text {th }}$ International Workshop on Ice Drilling Technology. It is designed as a tool for the ice coring community as future ice core sites are selected to achieved targeted science goals, keeping in mind that at coastal Antarctic sites brittle behavior affects a large fraction of recovered ice core samples and $>90 \%$ of dated ice core records.

\section{Appendix B: RICE REE data}

Concentration and relative standard deviation of all RICE trace element samples spanning 8 $\mathrm{m}$ to $320 \mathrm{~m}$ depth.

\subsection{Selected conference presentations}

Neff, P., A. Tuohy, N. Bertler, and R. Edwards. Antarctic and Southern Ocean Mineral Dust Aerosol Transport Pathways: Forward-Trajectory Modeling and Source Constraints Derived from the RICE Ice Core. (Poster) American Geophysical Union Fall 2014 Meeting, San Francisco, California, USA, December 15-19, 2014.

Kjær, H.A., P. Vallelonga, M. Simonsen, P. Neff, N. Bertler, A. Svensson and D. DahlJensen. Initial Continuous Chemistry Results From The Roosevelt Island Ice Core (RICE). (Poster) American Geophysical Union Fall 2014 Meeting, San Francisco, California, USA, December 15-19, 2014.

Tuohy, A., P. Neff, N. Bertler, and R. Edwards. 1000 Year Record of Heavy Metal Contamination from the RICE Ice Core, Roosevelt Island, Antarctica. (Poster) American Geophysical Union Fall 2014 Meeting, San Francisco, California, USA, December 15-19, 2014.

Kjær, H.A., P. Vallelonga, M. Simonsen, P. Neff, N. Bertler, A. Svensson, I. Seierstad, P. Albert, and A. Bourne. Re-evaluating the $1257 \mathrm{AD}$ eruption using annually-resolved ice core chemical analyses. (Poster) American Geophysical Union Fall 2014 Meeting, San Francisco, California, USA, December 15-19, 2014. 
Neff, P., T. J. Fudge, B. Medley. Amundsen Sea coastal domes: high-resolution Holocene ice core sites. Scientific Committee on Antarctic Research 2014 Open Science Conference, Auckland, NZ, August 25-28, 2014.

Neff, P., A. Tuohy, N. Bertler, and R. Edwards. Exploring extra-Antarctic air transport pathways using Rare Earth Element concentrations in dust from the RICE ice core, Roosevelt Island, Ross Sea Sector. (Poster) Scientific Committee on Antarctic Research 2014 Open Science Conference, Auckland, NZ, August 25-28, 2014.

Neff, P., N. Bertler, R. Edwards, and A. Tuohy. Lanthanide element studies of aerosol particles in an ice core from Roosevelt Island, Antarctica. New Zealand Snow and Ice Research Group Meeting, Aoraki Mt. Cook National Park, NZ, July 2-4, 2014.

Neff, P., T.J. Fudge, B. Medley. Amundsen Sea coastal domes: high resolution Holocene ice core sites. IDPO Community Workshop on Ice Coring, Irvine, California, USA, February 2627, 2014.

Neff, P., N. Bertler, and RICE Community. Roosevelt Island Climate Evolution (RICE) project update. (Poster) 2013 WAIS Divide Ice Core Science Meeting, La Jolla, California, USA, September 24-25, 2013.

Neff, P., N. Bertler, A. Pyne, D. Mandeno, and RICE Community. Roosevelt Island Climate Evolution (RICE) project: ice core quality at an intermediate depth site. (Poster) $7^{\text {th }}$ International Workshop on Ice Drilling Technology, Madison, Wisconsin, USA, September 9-13, 2013.

Mandeno, D., A. Pyne, N. Bertler, and P. Neff. Ice coring at Roosevelt Island: Drill design, performance and refrigeration solutions at a low altitude "warm coastal" Antarctic location. $7^{\text {th }}$ International Workshop on Ice Drilling Technology, Madison, Wisconsin, USA, September 9-13, 2013. 


\subsection{References}

Albani, S., N. M. Mahowald, B. Delmonte, V. Maggi, and G. Winckler (2012), Comparing modeled and observed changes in mineral dust transport and deposition to Antarctica between the Last Glacial Maximum and current climates, Climate Dynamics, 38(9-10), 17311755, doi:10.1007/s00382-011-1139-5.

Barbante, C., T. Bellomi, G. Mezzadri, P. Cescon, G. Scarponi, C. Morel, S. Jay, K. van de Velde, C. Ferrari, and C. F. Boutron (1997), Direct determination of heavy metals at picogram per gram levels in Greenland and Antarctic snow by double focusing inductively coupled plasma mass spectrometry, Journal of Analytical Atomic Spectrometry, 12(9), 925931, doi:10.1039/A701686G.

Bromwich, D. H., J. P. Nicolas, A. J. Monaghan, M. A. Lazzara, L. M. Keller, G. A. Weidner, and A. B. Wilson (2013), Central West Antarctica among the most rapidly warming regions on Earth, Nature Geoscience, 6(2), 139-145.

Cohen, L., S. Dean, and J. Renwick (2013), Synoptic weather types for the Ross Sea region, Antarctica, Journal of Climate, 26(2), 636-649.

Conway, H., B. Hall, G. Denton, A. Gades, and E. Waddington (1999), Past and future grounding-line retreat of the West Antarctic ice sheet, Science, 286(5438), 280-283.

Crary, A. (1961), Glaciological regime at Little America Station, Antarctica, Journal of Geophysical Research, 66(3), 871-878.

Crary, A., E. S. Robinson, H. F. Bennett, and W. W. Boyd (1962), Glaciological regime of the Ross ice shelf, Journal of Geophysical Research, 67(7), 2791-2807.

Cullers, R. L., T. Barrett, R. Carlson, and B. Robinson (1987), Rare-earth element and mineralogic changes in Holocene soil and stream sediment: a case study in the Wet Mountains, Colorado, USA, Chemical Geology, 63(3), 275-297.

Delmonte, B., P. Andersson, M. Hansson, H. Schöberg, J. R. Petit, I. Basile - Doelsch, and V. Maggi (2008), Aeolian dust in East Antarctica (EPICA - Dome C and Vostok): Provenance during glacial ages over the last 800 kyr, Geophysical Research Letters, 35(7), doi:10.1029/2008GL033382. 
Delmonte, B., C. Baroni, P. S. Andersson, H. Schoberg, M. Hansson, S. Aciego, J. R. Petit, S. Albani, C. Mazzola, and V. Maggi (2010), Aeolian dust in the Talos Dome ice core (East Antarctica, Pacific/Ross Sea sector): Victoria Land versus remote sources over the last two climate cycles, Journal of Quaternary Science, 25(8), 1327-1337, doi:10.1002/jqs.1418.

Delmonte, B., J. Petit, K. K. Andersen, I. Basile-Doelsch, V. Maggi, and V. Y. Lipenkov (2004), Dust size evidence for opposite regional atmospheric circulation changes over east Antarctica during the last climatic transition, Climate Dynamics, 23(3-4), 427-438, doi:10.1007/s00382-004-0450-9.

Ding, Q., E. J. Steig, D. S. Battisti, and M. Küttel (2011), Winter warming in West Antarctica caused by central tropical Pacific warming, Nature Geoscience, 4(6), 398-403, doi:10.1038/NGEO1129.

Dutrieux, P., J. De Rydt, A. Jenkins, P. R. Holland, H. K. Ha, S. H. Lee, E. J. Steig, Q. Ding, E. P. Abrahamsen, and M. Schröder (2014), Strong sensitivity of pine island ice-shelf melting to climatic variability, Science, 343(6167), 174-178.

Gabrielli, P., C. Barbante, C. Turetta, A. Marteel, C. Boutron, G. Cozzi, W. Cairns, C. Ferrari, and P. Cescon (2006), Direct determination of rare earth elements at the subpicogram per gram level in antarctic ice by ICP-SFMS using a desolvation system, Analytical Chemistry, 78(6), 1883-1889, doi:10.1021/ac0518957.

Gabrielli, P., F. Planchon, C. Barbante, C. F. Boutron, J. R. Petit, S. Bulat, S. Hong, G. Cozzi, and P. Cescon (2009), Ultra-low rare earth element content in accreted ice from subglacial Lake Vostok, Antarctica, Geochimica et Cosmochimica Acta, 73(20), 5959-5974.

Gabrielli, P., A. Wegner, J. R. Petit, B. Delmonte, P. De Deckker, V. Gaspari, H. Fischer, U. Ruth, M. Kriews, and C. Boutron (2010), A major glacial-interglacial change in aeolian dust composition inferred from Rare Earth Elements in Antarctic ice, Quaternary Science Reviews, 29(1), 265-273, doi:10.1016/j.quascirev.2009.09.002.

Gaiero, D. M., P. J. Depetris, J.-L. Probst, S. M. Bidart, and L. Leleyter (2004), The signature of river-and wind-borne materials exported from Patagonia to the southern latitudes: a view from REEs and implications for paleoclimatic interpretations, Earth and Planetary Science Letters, 219(3), 357-376. 
Henderson, P. (1984), Rare earth element geochemistry, Elsevier.

Hosking, J. S., A. Orr, G. J. Marshall, J. Turner, and T. Phillips (2013), The influence of the Amundsen-Bellingshausen Seas low on the climate of West Antarctica and its representation in coupled climate model simulations, Journal of Climate, 26(17), 6633-6648.

Joughin, I., B. E. Smith, and B. Medley (2014), Marine ice sheet collapse potentially under way for the Thwaites Glacier Basin, West Antarctica, Science, 344(6185), 735-738.

Kreutz, K., P. A. Mayewski, I. Pittalwala, L. Meeker, M. Twickler, and S. Whitlow (2000), Sea level pressure variability in the Amundsen Sea region inferred from a West Antarctic glaciochemical record, Journal of Geophysical Research: Atmospheres (1984-2012), 105(D3), 4047-4059.

Küttel, M., E. J. Steig, Q. Ding, A. J. Monaghan, and D. S. Battisti (2012), Seasonal climate information preserved in West Antarctic ice core water isotopes: Relationships to temperature, large-scale circulation, and sea ice, Climate Dynamics, 39(7-8), 1841-1857, doi:10.1007/s00382-012-1460-7.

Lachlan - Cope, T. A., W. M. Connolley, and J. Turner (2001), The role of the non axisymmetric antarctic orography in forcing the observed pattern of variability of the Antarctic climate, Geophysical Research Letters, 28(21), 4111-4114.

Lambert, F., B. Delmonte, J.-R. Petit, M. Bigler, P. R. Kaufmann, M. A. Hutterli, T. F. Stocker, U. Ruth, J. P. Steffensen, and V. Maggi (2008), Dust-climate couplings over the past 800,000 years from the EPICA Dome C ice core, Nature, 452(7187), 616-619, doi:10.1038/nature06763.

Lamy, F., R. Gersonde, G. Winckler, O. Esper, A. Jaeschke, G. Kuhn, J. Ullermann, A. Martínez-Garcia, F. Lambert, and R. Kilian (2014), Increased dust deposition in the Pacific Southern Ocean during glacial periods, Science, 343(6169), 403-407, doi:10.1126/science.1245424.

Maher, B., J. Prospero, D. Mackie, D. Gaiero, P. Hesse, and Y. Balkanski (2010), Global connections between aeolian dust, climate and ocean biogeochemistry at the present day and at the last glacial maximum, Earth-Science Reviews, 99(1), 61-97, doi:10.1016/j.earscirev.2009.12.001. 
Mahowald, N., K. Kohfeld, M. Hansson, Y. Balkanski, S. P. Harrison, I. C. Prentice, M. Schulz, and H. Rodhe (1999), Dust sources and deposition during the last glacial maximum and current climate: A comparison of model results with paleodata from ice cores and marine sediments, Journal of Geophysical Research: Atmospheres (1984-2012), 104(D13), 1589515916, doi:10.1029/1999JD900084.

Martín, C., R. C. Hindmarsh, and F. J. Navarro (2006), Dating ice flow change near the flow divide at Roosevelt Island, Antarctica, by using a thermomechanical model to predict radar stratigraphy, Journal of Geophysical Research: Earth Surface (2003-2012), 111(F1).

Mercer, J. H. (1978), West Antarctic ice sheet and CO 2 greenhouse effect- A threat of disaster, Nature, 271(5643), 321-325.

Nereson, N. A., and E. D. Waddington (2002), Isochrones and isotherms beneath migrating ice divides, Journal of Glaciology, 48(160), 95-108.

Nicolas, J. P., and D. H. Bromwich (2011), Climate of West Antarctica and influence of marine air intrusions, Journal of Climate, 24(1), 49-67, doi:10.1175/2010JCLI3522.1.

Nicolas, J. P., and D. H. Bromwich (2014), New Reconstruction of Antarctic Near-Surface Temperatures: Multidecadal Trends and Reliability of Global Reanalyses, Journal of Climate, 27(21), 8070-8093, doi:10.1175/JCLI-D-13-00733.1.

Okumura, Y. M., D. Schneider, C. Deser, and R. Wilson (2012), Decadal-interdecadal climate variability over Antarctica and linkages to the tropics: Analysis of ice core, instrumental, and tropical proxy data, Journal of Climate, 25(21), 7421-7441.

Orsi, A., G. Johnson, and J. Bullister (1999), Circulation, mixing, and production of Antarctic Bottom Water, Progress in Oceanography, 43(1), 55-109, doi:10.1016/S00796611(99)00004-X.

Pritchard, H., S. Ligtenberg, H. Fricker, D. Vaughan, M. Van den Broeke, and L. Padman (2012), Antarctic ice-sheet loss driven by basal melting of ice shelves, Nature, 484(7395), 502-505.

Raymond, C. F. (1983), Deformation in the vicinity of ice divides, Journal of Glaciology, 29(103), 357-373. 
Revel-Rolland, M., P. De Deckker, B. Delmonte, P. Hesse, J. Magee, I. Basile-Doelsch, F. Grousset, and D. Bosch (2006), Eastern Australia: a possible source of dust in East Antarctica interglacial ice, Earth and Planetary Science Letters, 249(1), 1-13, doi:10.1016/j.eps1.2006.06.028.

Rignot, E., J. Mouginot, M. Morlighem, H. Seroussi, and B. Scheuchl (2014), Widespread, rapid grounding line retreat of Pine Island, Thwaites, Smith, and Kohler glaciers, West Antarctica, from 1992 to 2011, Geophysical Research Letters, 41(10), 3502-3509.

Schneider, D. P., E. J. Steig, T. D. van Ommen, D. A. Dixon, P. A. Mayewski, J. M. Jones, and C. M. Bitz (2006), Antarctic temperatures over the past two centuries from ice cores, Geophysical Research Letters, 33(16).

Steig, E. J., Q. Ding, D. Battisti, and A. Jenkins (2012), Tropical forcing of Circumpolar Deep Water inflow and outlet glacier thinning in the Amundsen Sea Embayment, West Antarctica, Annals of Glaciology, 53(60), 19-28, doi:10.3189/2012AoG60A110.

Steig, E. J., D. P. Schneider, S. D. Rutherford, M. E. Mann, J. C. Comiso, and D. T. Shindell (2009), Warming of the Antarctic ice-sheet surface since the 1957 International Geophysical Year, Nature, 457(7228), 459-462.

Thomas, R. H., D. R. Macayeal, C. R. Bentley, and J. L. Clapp (1980), The creep of ice, geothermal heat flow, and Roosevelt Island, Antarctica, Journal of Glaciology, 25, 47-60.

Thompson, L. G., and E. Mosley-Thompson (1981), Microparticle concentration variations linked with climatic change: evidence from polar ice cores, Science, 212(4496), 812-815.

Turner, J. (2004), The El Niño-Southern Oscillation and Antarctica, International Journal of Climatology, 24(1), 1-31, doi:10.1002/joc.965.

Turner, J., T. Phillips, J. S. Hosking, G. J. Marshall, and A. Orr (2013), The Amundsen Sea low, International Journal of Climatology, 33(7), 1818-1829, doi:10.1002/joc.3558.

Vallelonga, P., P. Gabrielli, E. Balliana, A. Wegner, B. Delmonte, C. Turetta, G. Burton, F. Vanhaecke, K. Rosman, and S. Hong (2010), Lead isotopic compositions in the EPICA Dome C ice core and Southern Hemisphere Potential Source Areas, Quaternary Science Reviews, 29(1), 247-255, doi:10.1016/j.quascirev.2009.06.019. 
Wegner, A., P. Gabrielli, D. Wilhelms-Dick, U. Ruth, M. Kriews, P. De Deckker, C. Barbante, G. Cozzi, B. Delmonte, and H. Fischer (2012), Change in dust variability in the Atlantic sector of Antarctica at the end of the last deglaciation, Climate of the Past, 8, 135147, doi:10.5194/cp-8-135-2012.

Wolff, E., C. Barbante, S. Becagli, M. Bigler, C. Boutron, E. Castellano, M. De Angelis, U. Federer, H. Fischer, and F. Fundel (2010), Changes in environment over the last 800,000 years from chemical analysis of the EPICA Dome C ice core, Quaternary Science Reviews, 29(1), 285-295, doi:10.1016/j.quascirev.20 09.06.013. 


\section{Chapter 2: Trajectory modeling of modern dust transport to the Southern}

\section{Ocean and Antarctica}

\section{Abstract}

Aerosol deposition over the Southern Ocean and Antarctica has the potential to alter marine productivity and thus ocean carbon uptake while also impacting radiative balance due to scattering and absorption from atmospheric particulates. Quantification of modern emission, transport and deposition of terrestrial dust and other airborne material from Southern Hemisphere sources is challenging due to low emission levels and poor detection from remote sensing platforms. Here, forward trajectory modeling is used to explore atmospheric transport, independent of deposition processes, from 1979 to 2013. Trajectories are initiated from known arid dust source areas in South America (Patagonia), Australia, and southern Africa, with detailed consideration of New Zealand as a potential source. Results suggest that Patagonian and New Zealand dust sources - and other aerosol emissions - share strong atmospheric transport during all seasons, allowing even potentially small New Zealand emissions to contribute significantly to Southern Ocean and Antarctic aerosol loading. We find that atmospheric dust transport controlling distribution of dust and other aerosols shows distinct spatial variability. New Zealand and Patagonia rapidly contribute a high proportion of trajectories to West Antarctica, while in interior East Antarctica source contributions are limited and highly mixed. The sensitivity of existing deep ice core sites to modern atmospheric transport is discussed. Finally, interannual variability of poleward trajectory extension over the Pacific and Atlantic sectors of the Southern Ocean highlights the association of both tropical Pacific sea-surface temperature and high-latitude wind variability (e.g. the Southern Annular Mode) with transport of dust and other aerosols to the Southern Ocean and Antarctica.

\subsection{Introduction}

Atmospheric suspension, transport and deposition of terrestrial mineral aerosols (dust) plays an important role in the climate system by directly affecting radiative balance, impacting cloud formation and structure, and fertilizing ocean areas characterised by high nutrient, low phytoplankton conditions due to a deficiency of bioavailable iron [Mahowald et al., 2009; Mahowald et al., 1999; Miller and Tegen, 1998]. The fertilization effect of terrestrial dust is especially significant in surface waters of the Southern Ocean (SO, ocean areas south of $50^{\circ} \mathrm{S}$ ), where phytoplankton blooms near areas of Antarctic Bottom Water 
formation can transfer atmospheric carbon into the deep ocean, potentially reducing atmospheric carbon dioxide concentrations [Martin et al., 1990; Martínez-Garcia et al., 2011; Orsi et al., 1999; Winton et al., 2014]. Marine sediment and Antarctic ice cores show large increases in dust flux during glacial periods-greater than twenty-fold in the Antarctic - in concert with temperature and atmospheric carbon dioxide decreases [Lamy et al., 2014; Petit et al., 1999; Winckler et al., 2008; Wolff et al., 2006]. While Holocene variability is less pronounced, ice core records from coastal sites in the Ross Sea region link an increase in dust loading during the Little Ice Age to stronger wind speed, leading to enhanced phytoplankton blooms and Antarctic Bottom Water formation [Bertler et al., 2011; Rhodes et al., 2012].

Primary contributions to SO and Antarctic dust deposition are thought to be from two dominant Southern Hemisphere (SH) dust Potential Source Areas (PSA): southern South America (Patagonia), due to its mid-latitude location and efficient transport, and Australia due to large dust emissions [Albani et al., 2012; Ginoux et al., 2012; Li et al., 2008; 2010]. However, there is not consensus as to which of these PSA dominates modern or paleo dust deposition, particularly over Antarctica, nor how relative contributions vary regionally and temporally. Satellite observation platforms struggle to quantify modern concentrations of dust and other particulates in the $\mathrm{SH}$ atmosphere. This is in part due to low levels of emissions, poor detection of dust in cloudy conditions common in the mid-latitudes, and reduced measurement sensitivity for aerosols in the boundary layer [Gassó and Stein, 2007; Maher et al., 2010; Torres et al., 2002].

Modern general circulation model (GCM) experiments suggest large regional variation in PSA dust distribution over the SO and Antarctica, with largest contributions immediately downwind of PSA following circumpolar westerly winds. Li et al. [2008; 2010] and Albani et al. [2012] suggest that modern Australian dust dominates deposition over the Pacific SO and downwind coastal regions of Antarctica (e.g. Wilkes Land, Victoria Land, the Ross Ice Shelf and Marie Byrd Land), while Patagonian dust prevails over the Atlantic SO, the Antarctic Peninsula and much of the East Antarctic Ice Sheet (EAIS). Although southern Africa is a significant dust emission source, material from this location is deposited largely in the South Atlantic and Indian Oceans, contributing only $~ 5 \%$ of the total dust burden over the SO and Antarctica [Albani et al., 2012; Li et al., 2008]. However, modeled emission fluxes for SH dust PSA vary by as much as a factor of four, with estimates for Australia, for instance, ranging from $37 \mathrm{Tg} \mathrm{a}^{-1}$ (teragrams or $10^{12}$ grams per year) [Zender et al., 2003] to $148 \mathrm{Tg} \mathrm{a}^{-1}$ [Miller et al., 2004]. Relative contributions to the global dust budget are similarly 
inconsistent, with estimates for Australian contributions ranging from 2.5\% to $15 \%$ [Tanaka and Chiba, 2006].

During the Last Glacial Maximum (LGM), GCM results suggest that Patagonian dust dominated deposition over Antarctica [Albani et al., 2012] and large glacial outwash plains in Patagonia have been shown to activate coincident in time with dust peaks found in Antarctic ice cores [Sugden et al., 2009]. Geochemical analyses of dust in Antarctic ice cores are consistent with dominance of Patagonian dust [Basile et al., 1997; Delmonte et al., 2008; Delmonte et al., 2004a; Delmonte et al., 2004b; Gabrielli et al., 2010; Gaiero, 2007; Vallelonga et al., 2010; Vallelonga et al., 2005], but these studies stem exclusively from the EAIS and most samples are taken from glacial periods, when dust concentration is significantly enriched and provides enough sample for geochemical analyses. This bias in sample selection towards glacial samples from East Antarctica limits the representation of the actual spatial and temporal variability of Antarctic dust deposition. Recent progress in ultralow-concentration $\left(10^{-12}\right.$ to $\left.10^{-15} \mathrm{~g} / \mathrm{g}\right)$ elemental analysis of small ice core samples and new ice core records outside the EAIS (e.g. WAIS Divide, RICE, Fletcher Promontory) provide an opportunity to improve the spatial and temporal representation of drivers and fluxes of dust deposition to Antarctica and the Southern Ocean.

Ocean sediment core data from the Pacific SO raise the consideration of New Zealand as a significant dust PSA for this region, possibly contributing to dust deposition three times larger during glacial periods than during interglacials [Lamy et al., 2014]. New Zealand has also been specifically identified as a potential source of dust at two Antarctic ice core sites. Holocene-age samples from the European Project for Ice Coring in Antarctica (EPICA) Drønning Maud Land and Dome C ice cores in East Antarctica suggest multiple and more variable dust source contributions, possibly including Antarctic, Australian and New Zealand sources [De Deckker et al., 2010; Gabrielli et al., 2010; Vallelonga et al., 2010; Wegner et al., 2012]. A larger role for Australian dust during interglacial periods has also been interpreted from dust geochemistry in East Antarctic ice core samples [Revel-Rolland et al., 2006].

Although New Zealand dust emissions are not quantified at present in GCM simulations, during the LGM the extensively-glaciated Southern Alps eroded large volumes of sediment due to efficient glacial action [Hallet et al., 1996], and the resultant aggrading river floodplains supplied material forming extensive loess deposits [Eden and Hammond, 2003]. At this time the rivers of New Zealand's South Island also extended further east across a sparsely-vegetated coastal plain broadened by $\sim 120 \mathrm{~m}$ eustatic sea level lowering, 
increasing the amount of sediment available for aeolian dispersal [Alloway et al., 2007; Carter et al., 2000]. Highly active mountain uplift and extreme erosion rates [Adams, 1980; Koons, 1990], in addition to ongoing lacustrine/riverine wind erosion and dust deposition make New Zealand a compelling region to consider as a contributor to the SH dust budget. This presents a challenge for model experiments, as New Zealand dust emissions occur in relatively narrow bands along river beds and glacial valleys, surrounded by often dense vegetation and with annual average precipitation rates above model thresholds for dust emission-all processes below grid resolution in many GCMs (i.e. $2^{\circ}$ latitude $\times 2.5^{\circ}$ longitude, Geophysical Fluid Dynamics Laboratory, GFDL AM2) [Freidenreich et al., 2004]. Glaciogenic dust sources have been overlooked for these reasons, and considered insignificant because they are geographically restricted compared to regions of arid dust emission. However, glaciogenic dust deposition rates can be very high: deposition rates of $\sim 250 \mathrm{~g} \mathrm{~m}^{-2} \mathrm{a}^{-1}$ are observed in river valleys in the lee of the New Zealand Southern Alps, comparable to those observed in the Sahara Desert [Bullard, 2013; McGowan et al., 1996].

The attribution of SH dust PSA is complicated by the interplay of source (emission), transport and sink (deposition) processes which are difficult to observe, quantify, and model. Here, we isolate modern atmospheric transport of air parcels from four SH dust PSA, using the HySPLIT model to calculate daily forward-trajectories from 1979 to 2013. This paper 1) highlights significant differences in transport between possible SH dust PSA, including New Zealand for the first time, 2) details regional distribution of modern forward trajectories from SH dust PSA over quadrants of the Southern Ocean and in the vicinity of all Antarctic ice core sites where continuous LGM-present dust records exist, and 3) explores modern interannual variability of atmospheric transport pathways from SH terrestrial dust sources to the southern high latitudes. While applicable to transport of many aerosol materials (e.g. anthropogenic pollutants and black carbon), this work focuses particularly on terrestrial dust for its considerable role in the carbon cycle, because dust modeling studies and ice core dust records exist against which to test this approach, and to inform expectations of possible dust source signatures present in the Roosevelt Island Climate Evolution (RICE) ice core recovered from Antarctica in $2013\left(79.364^{\circ} \mathrm{S}, 161.706^{\circ} \mathrm{W}\right)$. This allows for generation of hypothetical modern dust source contributions to the site, which may be testable using geochemical provenance methods such as strontium/neodymium ratios and rare earth element signatures [Delmonte et al., 2008; Gabrielli et al., 2010; Wegner et al., 2012]. 


\subsection{Methods}

The Hybrid Single-Particle Lagrangian Integrated Trajectory (HySPLIT) model is a free resource (http://ready.arl.noaa.gov/HYSPLIT.php, National Oceanic and Atmospheric Administration Air Resources Laboratory, Silver Spring, MD, USA) for calculating air parcel trajectories advected through three-dimensional National Centers for Environmental Prediction / National Center for Atmospheric Research (NCEP/NCAR) climate reanalysis data (hereafter NCEP1) [Draxler and Hess, 1998; Kalnay et al., 1996]. Calculations include three-dimensional variables for geopotential height, temperature, zonal, meridional and vertical winds, and relative humidity. Surface temperature $(2 \mathrm{~m}), 10 \mathrm{~m}$ zonal and meridional winds, and surface geopotential are also included. Performance of NCEP1 is robust for the SH from the beginning of the satellite era, 1979-present, with high correlations to highlatitude station measurements [Bromwich and Fogt, 2004; Bromwich et al., 2007; Renwick, 2004]. Comparison of a number of reanalysis data sets, including the NCEP1 and European Centre for Medium Range Weather Forecasts ERA-40 and ERA-Interim (ERAi) reanalyses [Dee et al., 2011], demonstrates that interannual to decadal variability of pressure fields is reproducible across datasets [Bracegirdle, 2013; Bromwich et al., 2007]. Duplicating the HySPLIT results presented here using a five-year period of ERAi (2006-2010) yields very similar results to those obtained using NCEP1 data. As ERAi is the most recent and complete global climate reanalysis dataset, we use ERAi mean sea level pressure, geopotential height and sea-surface temperatures to investigate interannual variability observed in the NCEP1 trajectory results.

Here, ten-day forward trajectories are initiated from four SH terrestrial dust PSA, daily from January 1, 1979 to December 31, 2013. Ten days approximates the maximum lifetime of the smaller dust size fraction in model studies, particles from 0.1-2.5 $\mu \mathrm{m}$ in diameter, while larger particle lifetimes are only 1-3 days [Luo et al., 2003; Tanaka and Chiba, 2006]. Particle lifetime in other studies, using $2.5 \mu \mathrm{m}$ mass mean diameter, is approximately four days for both modern and LGM simulations [Mahowald et al., 1999; Tegen and Fung, 1994]. In their modern GCM simulation, Mahowald et al. [1999] found dust particle lifetimes of eleven days due to wet deposition alone, reducing to nine days in LGM conditions (dry deposition lifetime was seven days in both simulated climates). Typical dust size distributions observed in Antarctic ice cores have mode diameters of 2-8 $\mu \mathrm{m}$, with total size range from $\sim 0.5-20 \mu \mathrm{m}$ diameter (larger particles are likely from isolated Antarctic sources) [Albani et al., 2012; Delmonte et al., 2004b; Koffman et al., 2014]. We suggest that ten days is a suitable length of time for considering transport of smaller size fractions of dust 
(as well as other aerosols), while transport of larger particles is likely restricted to the first several days of the forward trajectories considered here.

PSA trajectory initiation points were chosen near largest regional dust sources identified using satellite remote sensing techniques [Ginoux et al., 2012]. This "point-source" approach is justifiable for the $\mathrm{SH}$, as dust sources on the southern continents have relatively more concentrated areas of emission compared to the Northern Hemisphere, which is characterized by large, geographically extensive dust sources. In Australia (AUS) a point near the large ephemeral Lake Eyre is chosen, $29^{\circ} \mathrm{S}, 137.5^{\circ} \mathrm{E}$, to be representative of this very active dust storm region and an area between the split dust transport pathways previously identified for Australia [Bowler, 1976; McGowan and Clark, 2008; Revel-Rolland et al., 2006]. Patagonia (PAT) is responsible for perhaps $75 \%$ of dust emitted from South America [Li et al., 2008], and the point $49^{\circ} \mathrm{S}, 69^{\circ} \mathrm{W}$ is used to initiate trajectories. This location in the center of the Santa Cruz province, San Julian's Great Depression, is in the lee of the Patagonian Andes and characterized by arid to semiarid drainages rich in glaciogenic sediment supplied by the erosive power of Andean glaciers [Gaiero, 2007; Li et al., 2010]. In southern Africa (SAF) emissions are concentrated in arid regions near the border of Namibia and South Africa, $28^{\circ} \mathrm{S}, 21^{\circ} \mathrm{E}$ [Ginoux et al., 2012; Li et al., 2008]. An additional dust PSA in New Zealand (NZ), is considered here for the first time, $43.5^{\circ} \mathrm{S}, 172^{\circ} \mathrm{E}$, chosen to be representative of the eastern drainages of the Southern Alps, which cut through extensive loess deposits (e.g. the Waitaki, Rangitata, Rakaia, Waimakariri rivers). The locations of trajectory initiation points have been chosen such that they lie near the center of the PSA. Synoptic surface wind conditions in the vicinity of all four chosen points are consistent across surrounding regions of elevated dust emission, with zonal and meridional correlationdistances extending for hundreds of kilometers or more (not shown). This suggests limited sensitivity of model results to the idealized dust PSA trajectory initiation points used here. Trajectories were initiated at $100 \mathrm{~m}$ to capture near-surface wind, model height was set to 20 $\mathrm{km}$ and the data-based vertical motion method used.

Forward-trajectory modeling has previously been used to investigate dust transport from source areas including those in Australia [McGowan and Clark, 2008], Patagonia [Gassó and Stein, 2007; Li et al., 2010] and Asia [Creamean et al., 2014; Uno et al., 2009] and to track large dust plumes from exceptional events [Gassó and Stein, 2007; Wang et al., 2011]. While this approach is limited by lack of constraints on dust emission and deposition schemes, the latter of which likely results in the calculations here representing an upper bound with respect to dust transport, it nonetheless provides an opportunity to investigate the 
characteristics and drivers of atmospheric transport controlling dust distribution (especially those considered as long-term averages). Dust emission, transport and deposition processes are complex, and while empirical and model data constrain some aspects of these processes, long-range transport of dust remains poorly understood [Betzer et al., 1988; Maher et al., 2010]. As we do not prescribe rates of dust emission and deposition, forward trajectory modeling is a computationally inexpensive way to explore aspects of atmospheric transport in isolation from these processes.

\subsection{Results}

\subsubsection{Trajectory Distribution}

Atmospheric transport to the $\mathrm{SO}$ and Antarctica is dominated by the influence of persistent mid-latitude circumpolar westerly winds, more specifically transient low-pressure systems traveling eastward over the SO [Hoskins and Hodges, 2005]. This is especially relevant for dust PSA in Patagonia and New Zealand for their more southerly location in latitudes of peak wind speed. Figures 1 and 2 display five-day forward trajectory endpoints for each SH dust PSA (one endpoint for each trajectory initiated daily from 1979 to 2013). Five days is the minimum time in which trajectories from all four dust PSA reach Antarctica, and also represents a more conservative mean particle lifetime, keeping in mind deposition processes as discussed above.

Persistent southeastward transport from higher-latitude PAT and NZ is observed, with dominant particle transport in the boundary-layer extending $\sim 30^{\circ}$ south and $\sim 90^{\circ}$ east of trajectory initiation points after five days (Figure 2). Lower-latitude dust PSA in SAF and AUS, positioned equatorward of the strongest mid-latitude westerly winds, exhibit both a northwest and southeast pathway and transport more trajectories in the mid-troposphere than PAT and NZ (Figure 2). This result agrees well with the 1979-1998 mean distribution observed by Li et al. [2008] using a GCM (GFDL-AM2) approach, which also located South American and Australian dust transport in the boundary layer and mid-troposphere, respectively.

\subsubsection{Trajectory Seasonality}

Strength of atmospheric transport from PSA to the SO and Antarctica shows limited seasonality, although greatest southward transport from AUS and to a lesser extent SAF occurs during austral winter months (Figure 3). Lunt and Valdes [2001] explored thirty-day backward trajectories from the Dome C, Antarctica ice core site to SH dust PSA and found similar seasonality. SAF and AUS trajectories also extend further eastward during winter and 
spring (Figure 3). NZ and PAT trajectories show limited seasonality, with generally strong south and eastward transport all year. Transport from higher-latitude PSA (NZ and PAT) is consistently in the boundary layer, while monthly mean pressure of lower-latitude SAF and AUS trajectories exhibits strong seasonality with transport in the boundary layer during austral winter and in the mid-troposphere during summer (Figure 3). Full-resolution 35-year timeseries of trajectory latitude, longitude and pressure are presented in Figures S1-S3.

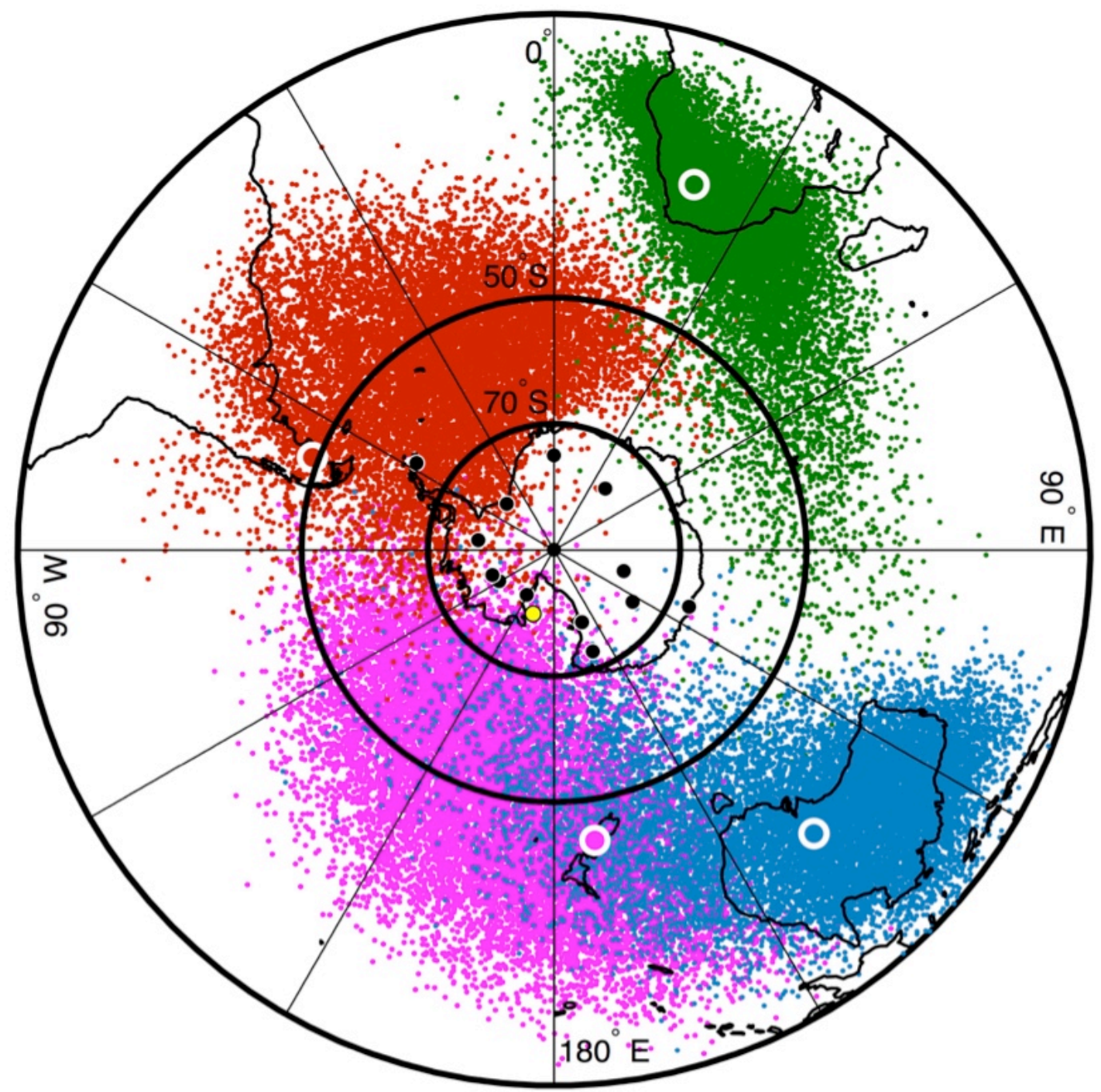

Figure 1. Five-day HySPLIT forward trajectory endpoints, initiated every day from 19792013 for each dust PSA: New Zealand (magenta), Patagonia (orange), southern Africa (green) and Australia (cyan). Larger colored circles denote trajectory initiation points (dust PSA); black circles mark Antarctic ice core sites, with the yellow circle marking the RICE ice core site. Bold parallels mark northern boundaries of the Southern Ocean $\left(50^{\circ} \mathrm{S}\right)$ and Antarctica $\left(70^{\circ} \mathrm{S}\right)$ as considered in Figures 4 and 5. 


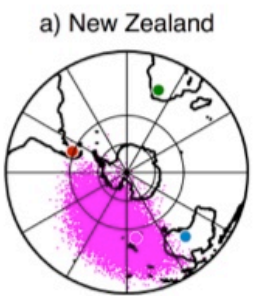

d) Patagonia

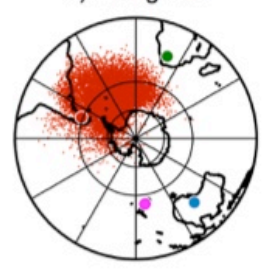

g) southern Africa
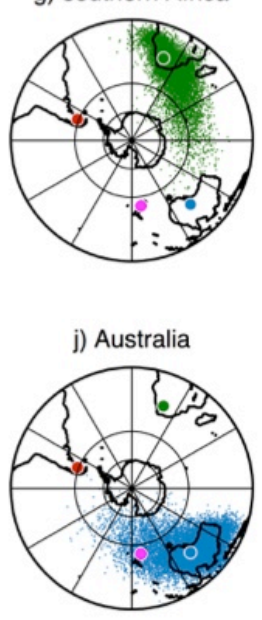

b)

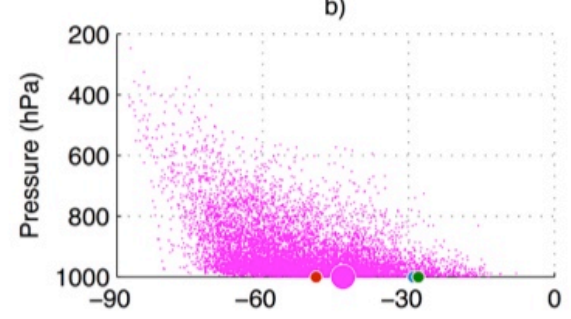

e)

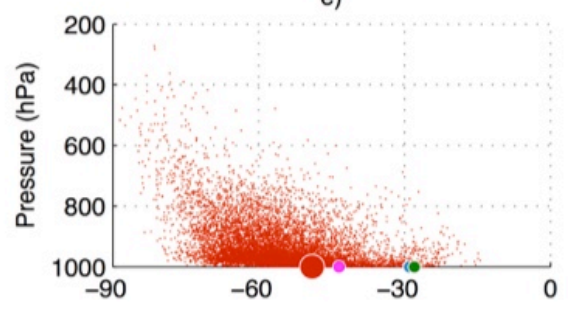

h)

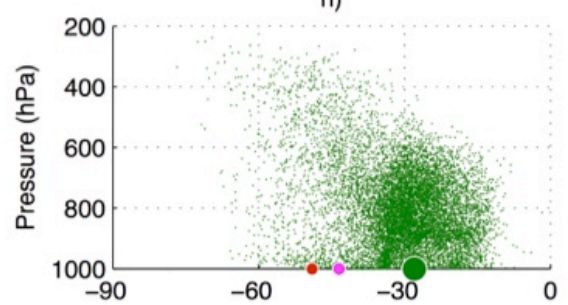

k)

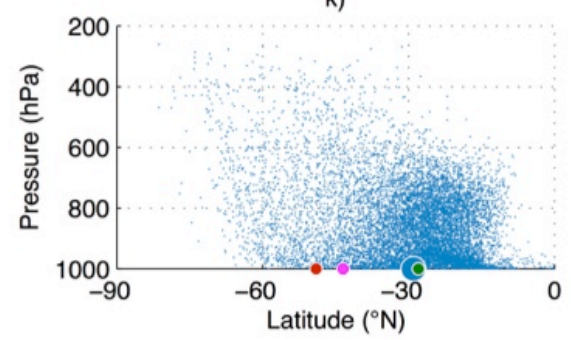

c)

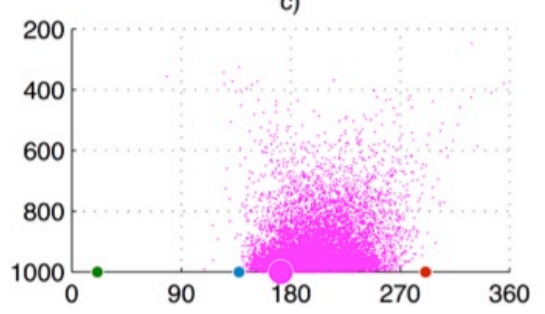

f)

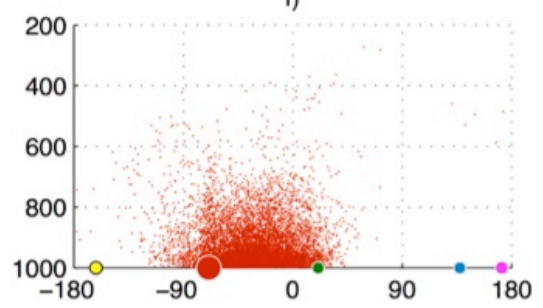

i)

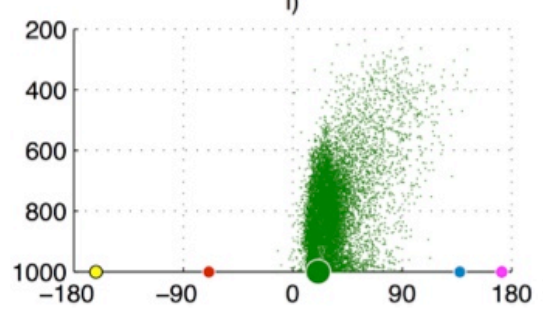

I)

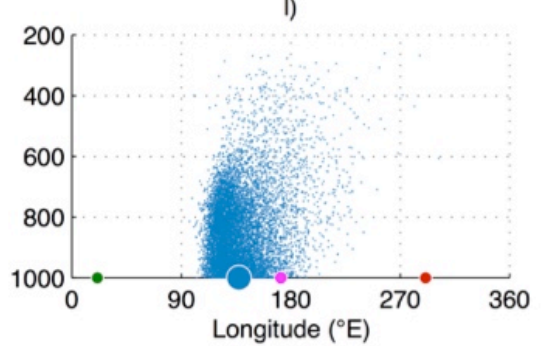

Figure 2. Five-day HySPLIT forward trajectory endpoints calculated daily from 1979-2013 for dust PSA: New Zealand ( $a, b, c$, magenta), Patagonia (d, e, f, orange), southern Africa (g, $h, i$, green) and Australia ( $j, k, l$, cyan). Trajectory data are displayed in map view ( $a, d, g, j)$, degrees of latitude versus atmospheric pressure ( $\mathrm{PPa} ; b, e, h, k)$ and longitude versus atmospheric pressure $(c, f, i, l)$. Larger colored circles denote trajectory initiation points (dust PSA). Note changes in $x$-axis of longitude plots to center data: centered on $0^{\circ}$ longitude for Patagonia and southern Africa, and centered on $180^{\circ}$ longitude for Australia and New Zealand. 

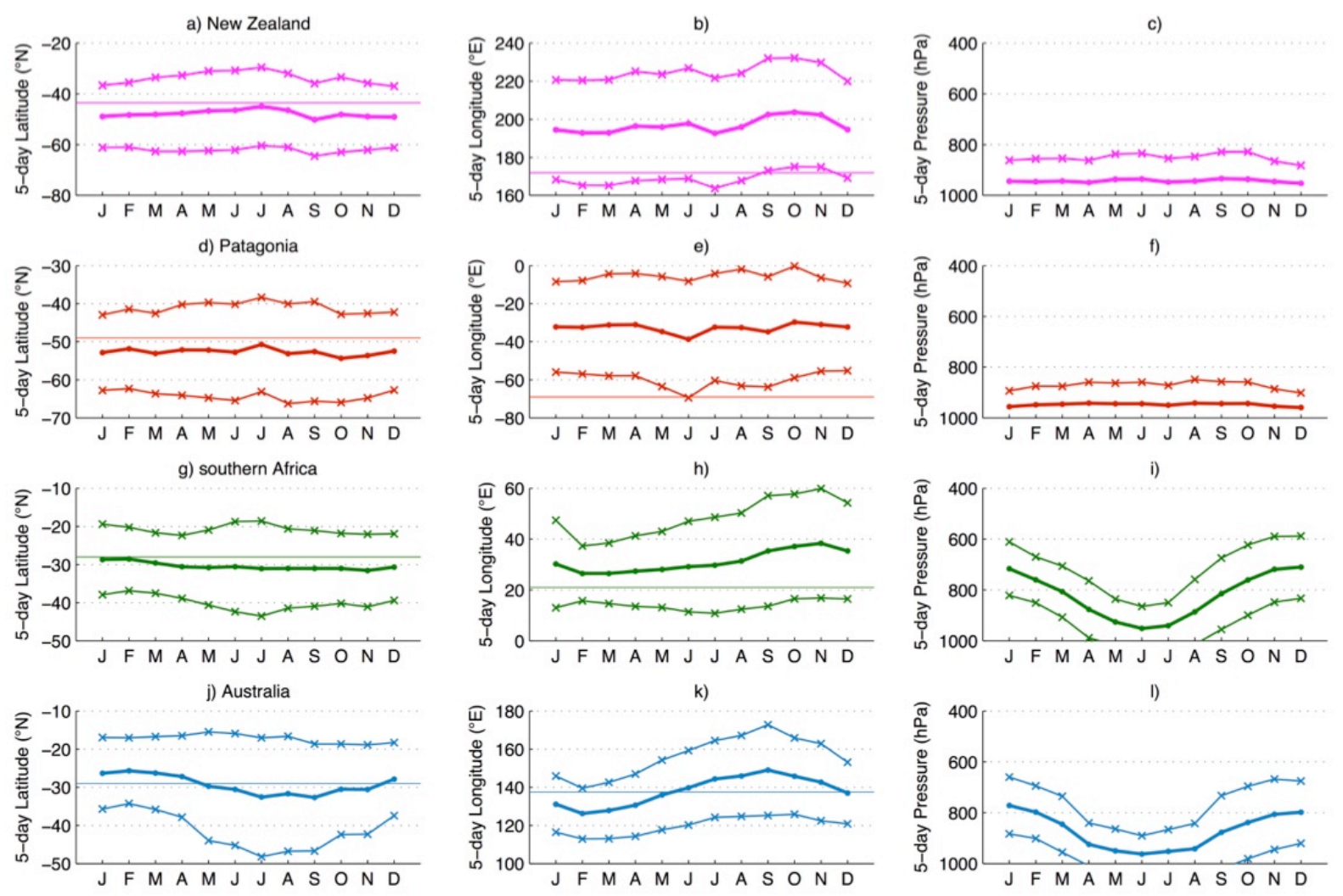

Figure 3. Monthly means (bold line, circles) and one standard deviation (x's) of daily 19792013 five-day forward trajectory latitude, longitude and pressure (hPa) from PSAs. New Zealand ( $a, b, c$, magenta), Patagonia (d, e, f, orange), southern Africa ( $g, h, i$, green) and Australia (j, $k, l$, cyan). Horizontal lines mark trajectory initiation latitude or longitude.

\subsubsection{Ten-Day Trajectory Evolution}

During the 35-year period considered here, higher-latitude PSA contribute a significant proportion of trajectories to the SO within 1-2 days (Figure 4a), with trajectories arriving over Antarctica $\left(>70^{\circ} \mathrm{S}\right.$, here) after 2-3 days (Figure $\left.4 \mathrm{~b}\right)$. Sixty percent of PAT trajectories pass over the SO after only three days, as the PAT initiation point is very near the SO, and the PAT contribution remains at this level through the ten-day model time. Transport from NZ rises more gradually over the ten days, after which nearly $50 \%$ of NZ trajectories have passed over the SO. More than $5 \%$ of trajectories from both PAT and NZ move over Antarctica after five days, rising to a maximum of approximately $8 \%$ of PAT trajectories after seven days and $>10 \%$ of NZ trajectories after eight days.

Far fewer trajectories from low-latitude PSA extend within ten days to the SO and Antarctica. Five-day transport from AUS and SAF to the SO represents an approximately $2 \sigma$ event (i.e. two standard deviations, $7.6 \%$ and $4.1 \%$ of all AUS and SAF trajectories, 
respectively). At the end of the ten-day model runtime, low-latitude PSA only transport 13\% (SAF) and 16\% (AUS) of trajectories over the SO, and a correspondingly low percentage of transport from low-latitude PSA ends in the Antarctic. Initial trajectories from SAF and AUS arrive over Antarctica after four days (Figure $4 b$ ), with a maximum of $2.4 \%$ of all AUS trajectories traveling to the Antarctic and slightly less than $1 \%$ of all SAF trajectories.

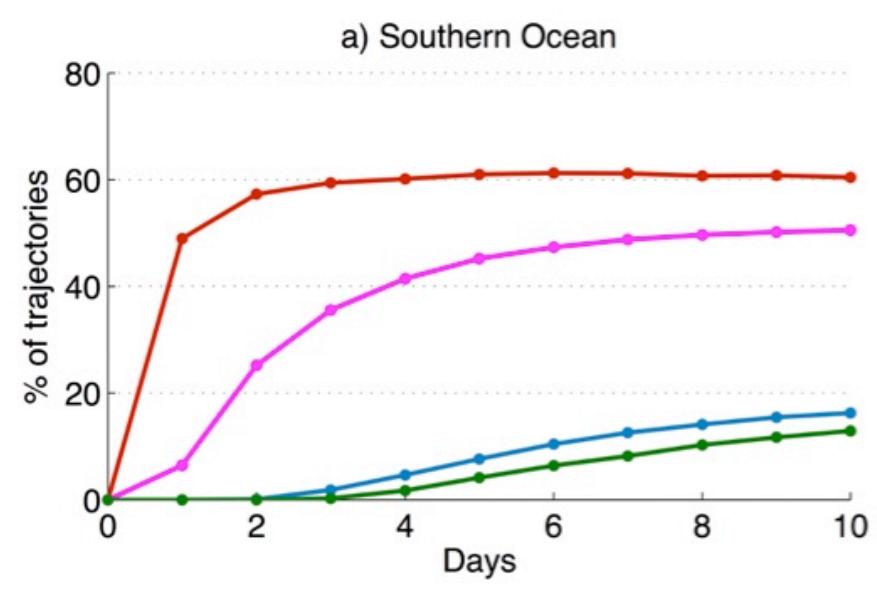

b) Antarctica

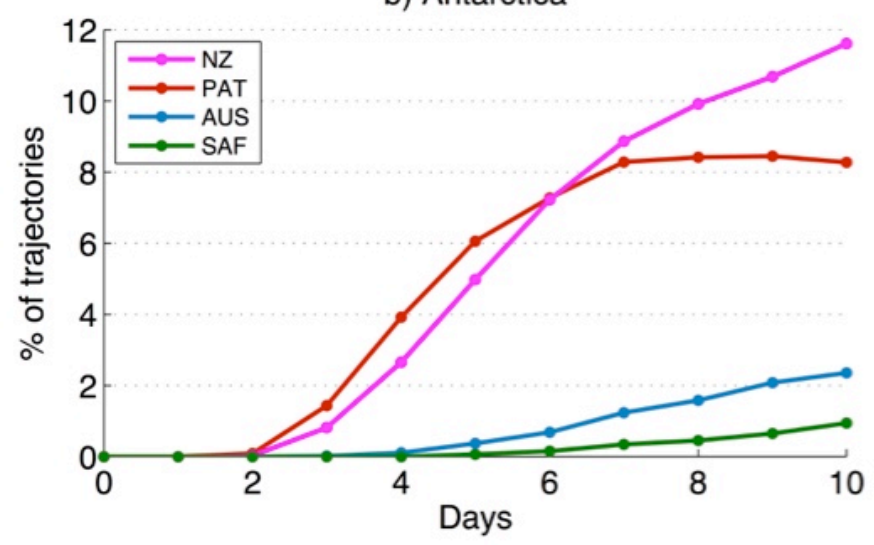

Figure 4. Percent of 1979-2013 daily forward-trajectories (12,775 total) passing over a) the Southern Ocean (trajectories ending south of $50^{\circ} \mathrm{S}$ ) and b) Antarctica (trajectories ending south of $70^{\circ}$ S) at daily increments for all PSA.

\subsection{Discussion}

\subsubsection{Source Strength and Transport Efficiency}

Due to stronger southward atmospheric transport in the SH mid-latitudes and shorter transport distance, atmospheric pathways for terrestrial aerosols from higher-latitude PSA (NZ and PAT) deliver three to four times more trajectories to the SO and Antarctica than lower-latitude PSA (SAF and AUS, Figure 4). While AUS and PAT are considered the 
primary contributors of dust aerosol to the SO and Antarctica [Albani et al., 2012; Li et al., 2008], these results demonstrate that unquantified dust emissions from NZ sources are transported southward with efficiency comparable to that of PAT. Air parcels leaving SAF are least efficiently transported southward, and similarly to the GCM results of Li et al. [2008] and Albani et al. [2012], this work suggests very limited influence of SAF dust on the SO and Antarctica (with the possible exception of coastal regions in the Indian Ocean sector of Antarctica, discussed below).

An estimation of relative dust source contributions can be made by taking into account atmospheric transport as modeled here, and applying linear weighting according to modeled dust emission rates. Model dust emission estimates are wide-ranging, as mentioned above, but we choose to use the emission rates of Li et al. [2008] because of their efforts to specifically investigate modern (1979-1998) dust transport to the SO and Antarctica. To explore possible contribution of New Zealand dust, a range of annual dust emissions are used to weight NZ trajectories: $10 \mathrm{Tg} \mathrm{a}^{-1}, 20 \mathrm{Tg} \mathrm{a}^{-1}$ and $30 \mathrm{Tg} \mathrm{a}^{-1}$. While the upper limit of this range likely exceeds modern emissions from New Zealand, which are not observed by remote sensing techniques or modeled in GCM studies, it facilitates consideration of the potential relative strength of a NZ dust source. This simple linear approach ignores dust deposition due to gravitational settling and precipitation, and assumes all emissions come from a single point source. However, estimates of relative dust PSA contributions to the Antarctic are comparable to computationally-expensive GCM results.

Table 1 compares SH dust PSA percent contributions to regional dust deposition calculated here with the GCM results of Li et al. [2008]. This is done for latitudinal zones as defined by Li et al. [2008]: the SO $\left(50^{\circ}-75^{\circ} \mathrm{S}\right)$ and "inland" Antarctica $\left(75^{\circ} \mathrm{S}-90^{\circ} \mathrm{S}\right)$. All emissions from South America, AUS and SAF in Li et al. [2008] are assumed to originate at the respective trajectory initiation point in this study. To facilitate this comparison, the weight of PAT trajectories is increased by $25 \%$ to include the full $50 \mathrm{Tg} \mathrm{a}^{-1}$ emitted by all South American dust sources (e.g. including the Atacama Desert, Bolivian Altiplano, etc.). This is required because $L i$ et al. [2008] do not model Patagonian emissions in isolation. Weighting of PAT trajectories for figures and discussion below remains $38 \mathrm{Tg} \mathrm{a}^{-1}$, a figure more appropriate for reflecting only Patagonian dust emissions in the vicinity of the trajectory initiation point. 
Table 1. PSA contribution to total dust deposition over the Southern Ocean (SO, $\left.50^{\circ}-75^{\circ} S\right)$ and inland Antarctica $\left(A N T, 75^{\circ} \mathrm{S}-90^{\circ} \mathrm{S}\right) *$

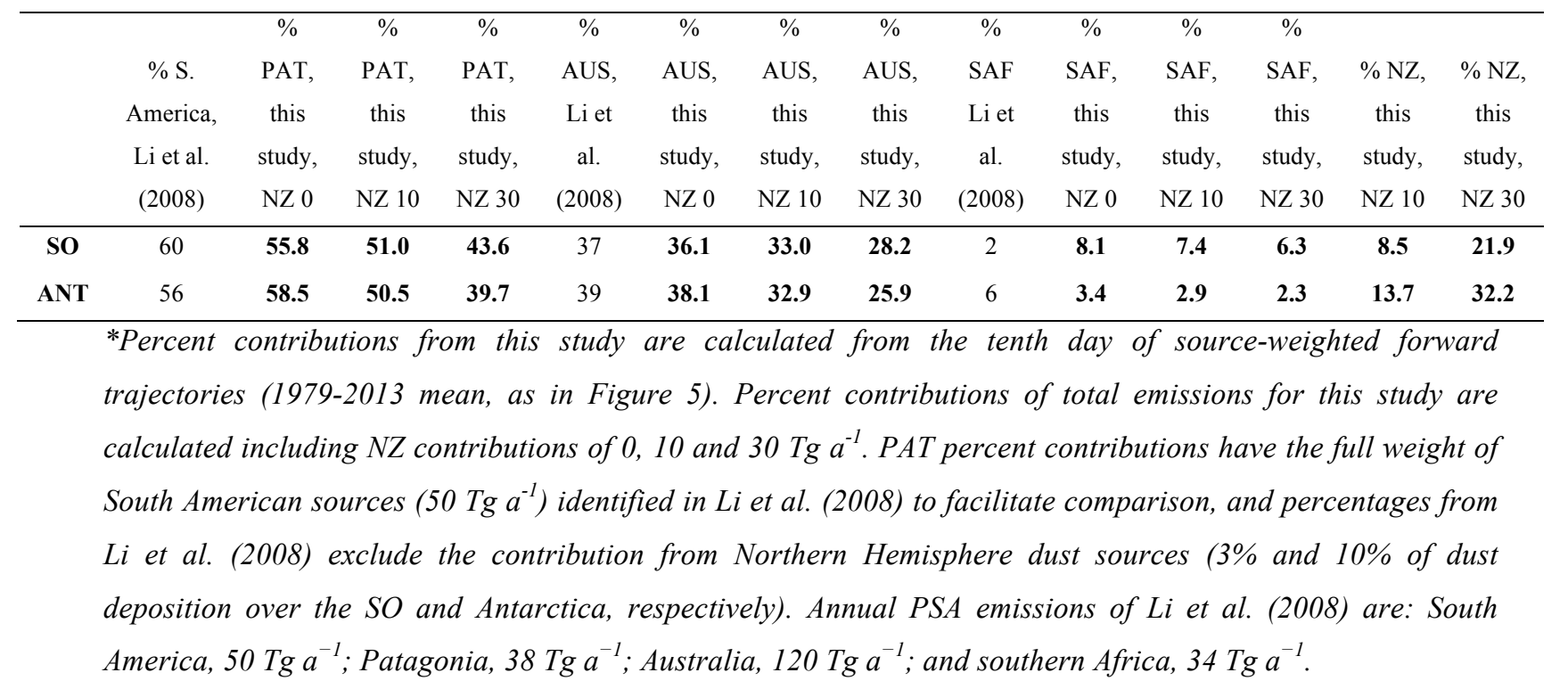

The results of this approach suggest that, even as the smallest dust source in the $\mathrm{SH}$, NZ may contribute a significant fraction of total dust deposited over portions of the SO and Antarctica. With a very modest dust emission weight of $10 \mathrm{Tg} \mathrm{a}^{-1}$, dust transported from NZ possibly contributes as much as $8.5 \%$ of total deposition over the $\mathrm{SO}$, and $13.7 \%$ over interior Antarctica (Table 1). Increasing NZ dust emission weighting to $30 \mathrm{Tg} \mathrm{a}^{-1}$, a high estimate of present conditions but perhaps analagous to LGM emission rates with New Zealand glacial systems activated in a manner similar to Patagonia (e.g Sugden et al. [2009]), brings the relative contribution of $\mathrm{NZ}$ to $21.9 \%$ of dust deposition over the $\mathrm{SO}$ and $32.2 \%$ over Antarctica (maintaining modern emission weighting for other PSA).

The weighted ten-day forward-trajectory evolution (Figure 5) illustrates the dominance of dust source-weighted PAT trajectories, likely due to a combination of proximity and direct, efficient transport despite relatively modest dust emissions $\left(38 \mathrm{Tg} \mathrm{a}^{-1}\right)$. Although large AUS dust emissions (120 $\left.\mathrm{Tg} \mathrm{a}^{-1}\right)$ may be an overestimate, as dust is emitted over a broad region of central Australia and not only in the vicinity of the trajectory initiation point and Lake Eyre Basin, source-weighted trajectories from this PSA rise to levels similar to those of PAT after two additional days of transport. As suggested above, while the $34 \mathrm{Tg}$ $\mathrm{a}^{-1}$ modeled modern SAF dust emission rate is essentially equal to PAT emissions $\left(38 \mathrm{Tg} \mathrm{a}^{-1}\right)$ within reported model error of $\pm 2-3 \mathrm{Tg} \mathrm{a}^{-1}$, inefficient transport and long transport distance relegate SAF to a more limited role in atmospheric transport of dust to the SO and Antarctica. 


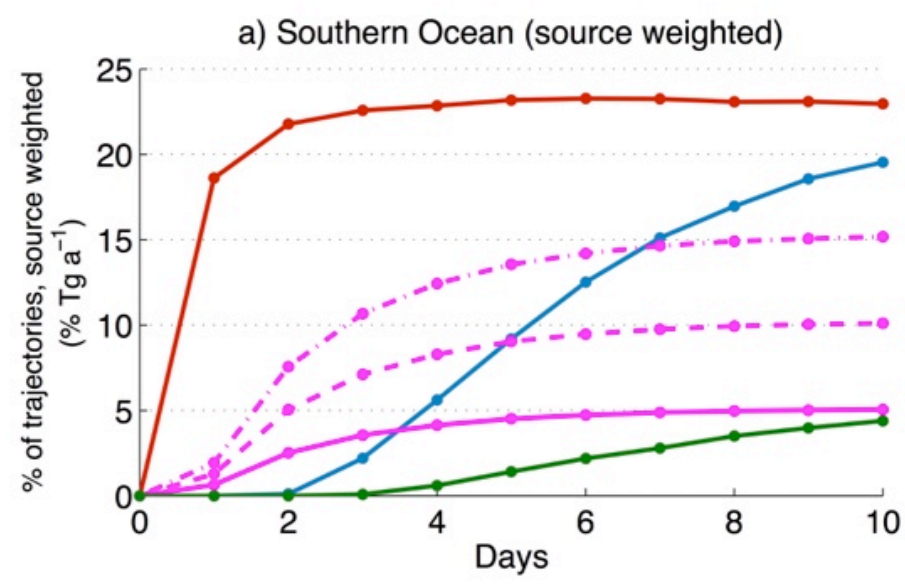

b) Antarctica (source weighted)

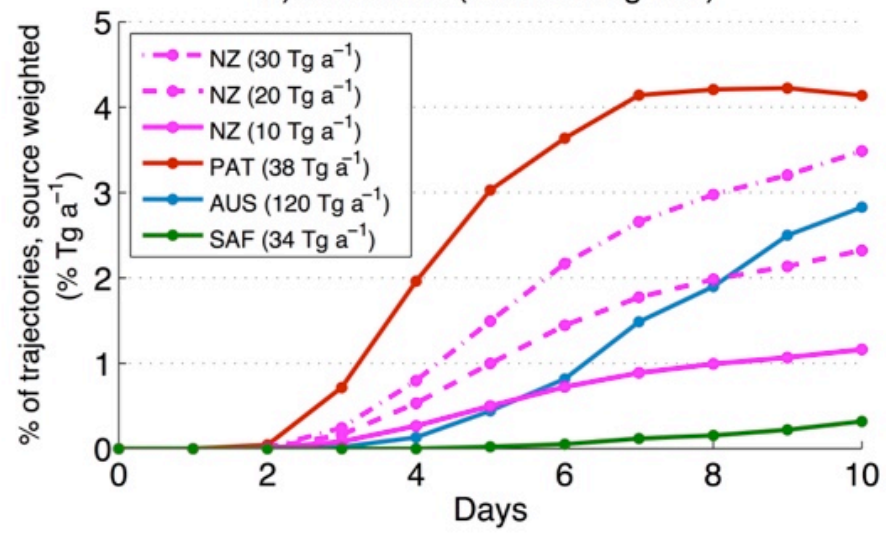

Figure 5. Terrestrial dust emission-weighted percent (\% Tg $\left.a^{-1}\right)$ of 1979-2013 daily forwardtrajectories passing over a) the Southern Ocean (trajectories ending south of $50^{\circ} S$ ) and b) Antarctica (trajectories ending south of $70^{\circ}$ S) at daily increments for all dust PSA. Emission estimates are as in Li et al. (2008), with a range of assumed emission rates for unquantified New Zealand dust sources. 


\subsubsection{Southern Ocean Trajectory Distribution}

In considering the distribution of trajectories from SH terrestrial dust PSA across more specific regions of the SO and at Antarctic ice core sites, both unweighted and dust emission-weighted trajectory distributions are of interest. The unweighted trajectories lend insight into relative atmospheric transport strength from $\mathrm{SH}$ terrestrial sources with respect to many types of aerosol, while the emission-weighting approach allows specific consideration of potential dust provenance across the $\mathrm{SH}$ high latitudes. Both approaches can aid interpretation of marine sediment and ice core records.

Figure 6 displays trajectory contributions over quadrants of the SO. As above, PSA trajectories dominate downwind areas of the SO. About $60 \%$ of all PAT trajectories move over the Atlantic SO after three days (Figure 6d), with 30\% of trajectories continuing into the Indian Ocean sector of the SO after ten days, although likely depleted of larger dust and aerosol particles due to deposition (Figure 6a). Approximately 35\% of NZ trajectories travel over the Pacific SO after five days (Figure 6c), with more than $20 \%$ continuing eastward to the Atlantic SO after ten days - albeit overshadowed by dominant PAT trajectories (Figure 6d). Far fewer trajectories from AUS and SAF travel south, but when weighted for dust emissions AUS is the largest contributor to SO areas south of Australia in the first 6-7 days of travel, as well as the Pacific SO after ten days (Figure 6f, g). SAF contributes a small fraction of trajectories to the SO, both unweighted and dust emission-weighted, but it does represent the second largest emission-weighted contribution to remote SO areas off the Antarctic coast near Wilkes Land (Figure 6f). It is significant that transport from these lowerlatitude PSA is preferentially located in the mid-troposphere during austral spring and summer (Figure 3), as this may alleviate boundary-layer dust deposition during these seasons and promote further transport and deposition further from PSA. Such seasonality is not captured by the 35-year average transport results considered here. 
Figure 6. (Following page) Percent of 1979-2013 daily forward-trajectories, both unweighted $(\%, a-d)$ and terrestrial dust emission-weighted $\left(\% \operatorname{Tg} a^{-1}, e-h\right)$, passing over quadrants of the Southern Ocean at daily increments for all Southern Hemisphere dust PSA. Maps of 1979-2013 trajectory endpoints after five days $(i-l)$ detail areas considered in panels above, outlined by black boxes. Southern Ocean quadrants are $50^{\circ}$ to $70^{\circ} \mathrm{S}, 0$ to $90^{\circ} \mathrm{E}$ $(a, e, i), 50^{\circ}$ to $70^{\circ} \mathrm{S}, 90$ to $180^{\circ} \mathrm{E}(b, f, j), 50^{\circ}$ to $75^{\circ} \mathrm{S},-180$ to $-90^{\circ} \mathrm{E}(\mathrm{c}, \mathrm{g}, \mathrm{k})$, and $50^{\circ}$ to $75^{\circ} \mathrm{S}$, 90 to $0^{\circ} E(d, h, l)$. Emission estimates are as in Figure 5, taken from Li et al. (2008), with Patagonia emitting $38 \mathrm{Tg} \mathrm{a}^{-1}$, Australia $120 \mathrm{Tg}^{-1}$, southern Africa $34 \mathrm{Tg}^{-1}$ and a range of emission rates for unquantified New Zealand dust sources. 

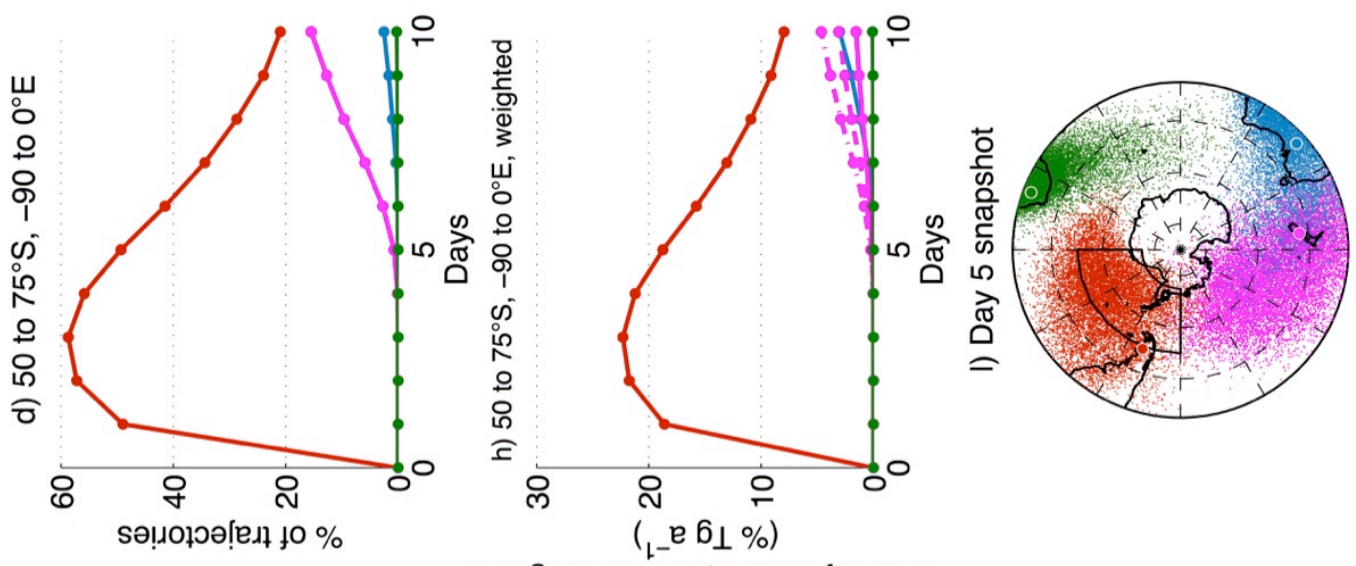

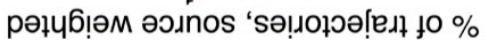
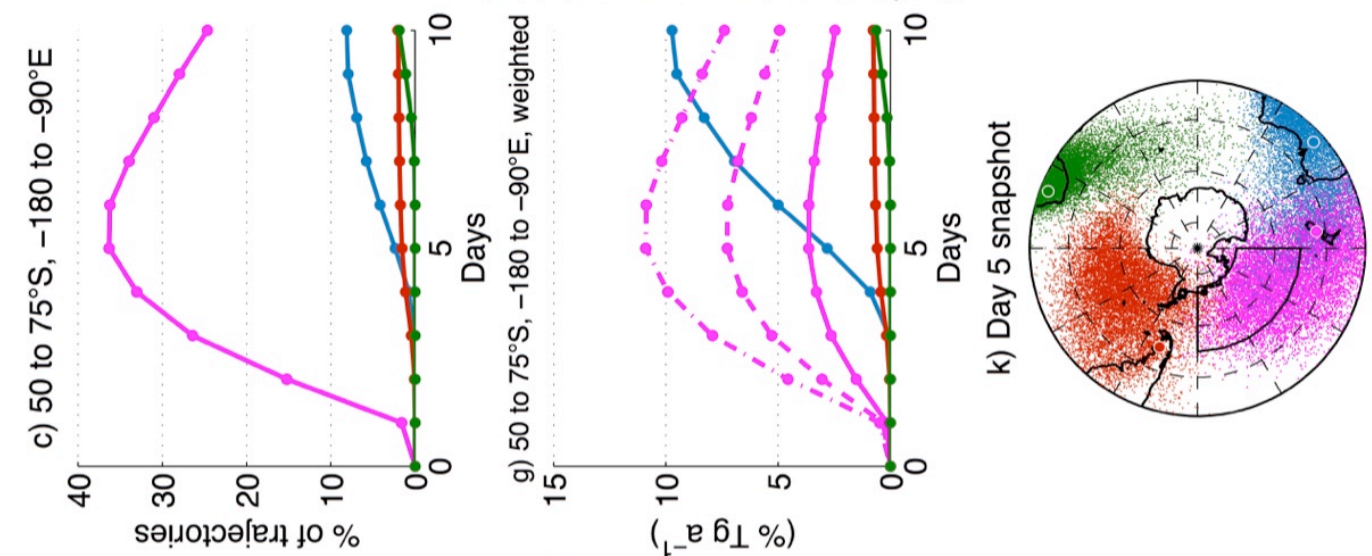

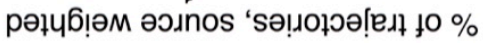

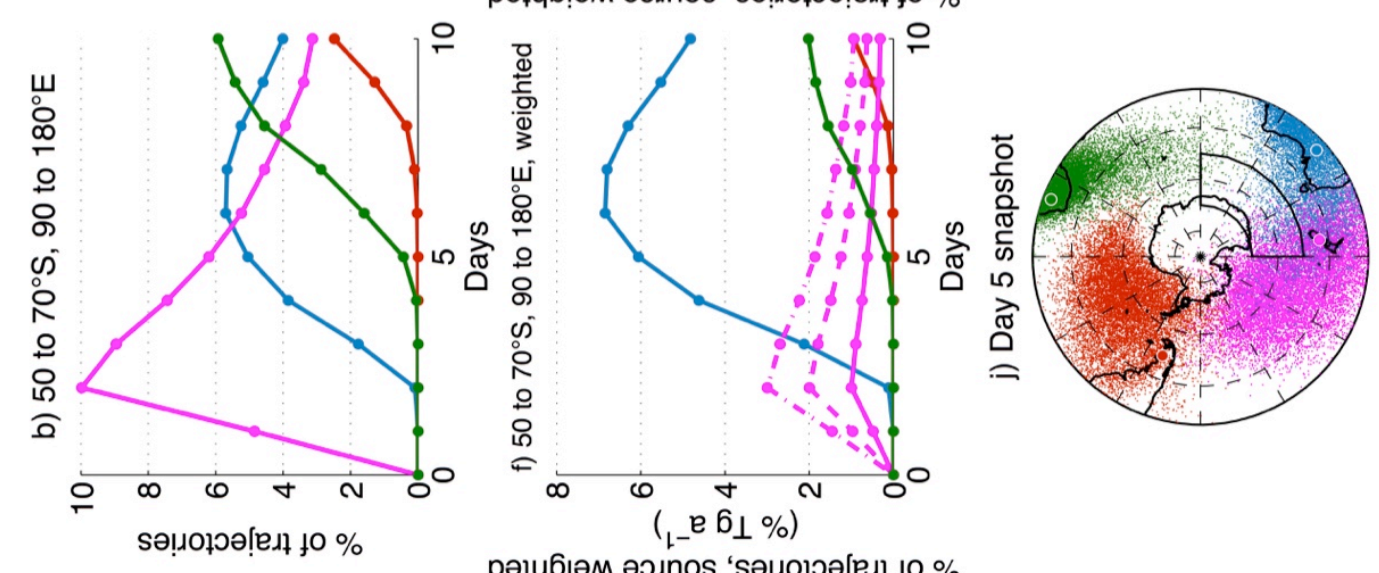

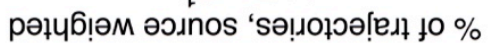
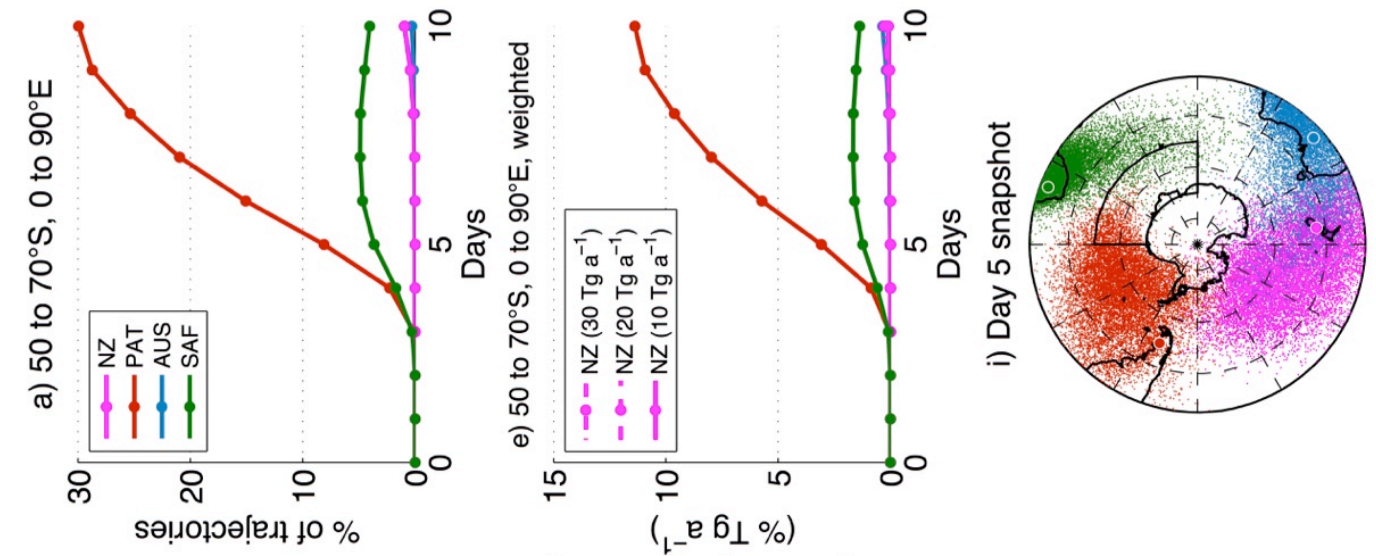

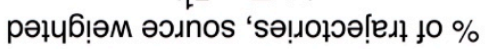




\subsubsection{Atmospheric Transport to Antarctic Ice Core Sites}

Antarctic ice cores provide the opportunity to construct a record of dust transport to the SO and Antarctica where no observations exist, and also facilitate testing of model simulations of this process. To utilize these records fully, it is important to identify and quantify which one or several dust sources influences a particular ice core site. Dust records from Antarctic ice cores are likely to show significant differences both in their lithology and particle size distribution depending on which PSA the particular ice core site receives material from. The following sub-sections investigate aspects of modern dust transport possibly captured and recorded by deep Antarctic ice cores (Figures 7-10). During the thirtyfive years considered here, fewer than $6 \%$ of all ten-day dust PSA forward trajectories reach the Antarctic continent, with less than $1 \%$ of trajectories traveling over any individual ice core site (excluding the Antarctic Peninsula, which receives up to 3\% of PAT trajectories). Ice core sites on the high-elevation $(\sim 3000-4000 \mathrm{~m})$ EAIS plateau are particularly isolated from extra-Antarctic dust sources, and GCM experiments struggle to reproduce dust concentrations measured in ice core samples [Albani et al., 2012; Li et al., 2008; Mahowald et al., 1999].

\subsubsection{Dust Transport to the East Antarctic Ice Sheet}

The EAIS plateau ice core sites EPICA Drønning Maud Land (EDML), Dome Fuji, Vostok, South Pole, EPICA Dome C (EDC), Taylor Dome and Talos Dome (Figure 7 and 8) receive less than $0.15 \%$ of trajectories from any single PSA. This equates to approximately 20 of 12,775 daily trajectories spanning 1979 to 2013 . However, there is considerable regional variability of relative dust PSA trajectory contributions.

The EDML ice core site, relatively coastal and downwind of the strong Patagonian dust source, is dominated by PAT trajectories by a factor of two, increasing to a factor of three to four when weighted for dust emissions (Figure 7). EDML dust provenance analysis, comparing rare earth element characteristics in ice core samples with those of dust samples taken directly from PSA, suggests a Holocene dust regime dominated by South American contributions but with larger AUS, NZ and local Antarctic contributions than during the LGM [Wegner et al., 2012]. The modern dust-emission weighted and unweighted trajectory results here support this interpretation, with NZ contributing fewer trajectories than PAT, while a small AUS contribution is only observed on the tenth day of forward-trajectories.

Remote EAIS plateau ice core sites Dome Fuji, Vostok, South Pole, EDC and Taylor Dome (Figure 7 and 8) show mixed and very few dust PSA trajectory contributions, although source-weighted trajectories from the AUS dust PSA exhibit some dominance at Vostok, 
South Pole and especially the EDC ice core site. AUS trajectories arrive at EDC as soon as four days after initiation, while transport to Vostok and South Pole takes more than eight days. Australian dust contribution specifically from Lake Eyre to the EAIS has been suggested using strontium/neodymium isotope geochemistry in EDC and Vostok ice core samples [Delmonte et al., 2004b; Revel-Rolland et al., 2006]. Rare earth element studies of EDC ice core samples, similar to the EDML ice core, show a shift from dominant South American contributions during the LGM to a more mixed Holocene dust regime with possible contributions from Australia and New Zealand sources [Gabrielli et al., 2010; Wegner et al., 2012]. However, provenance work using all of these geochemical systems is complicated by low sample concentrations in interglacial ice, overprinting of local Antarctic dust and/or volcanic input during interglacial periods, and incomplete characterization of both Antarctic and extra-Antarctic dust PSA geochemical signatures [Vallelonga, 2015].

Figure 7. (Following page) As in Figure 6, but for areas centered over Antarctic ice core sites EPICA Drønning Maud Land (EDML, a, e, i), Dome Fuji (b, $f, j)$, Vostok (c, $g, k)$ and South Pole $(d, h, l)$. Areas considered extend $2.5^{\circ}$ latitude to the north and south, and $10^{\circ}$ longitude east and west of ice core sites (excluding South Pole, which includes the area south of $\left.87.5^{\circ} \mathrm{S}\right)$. 


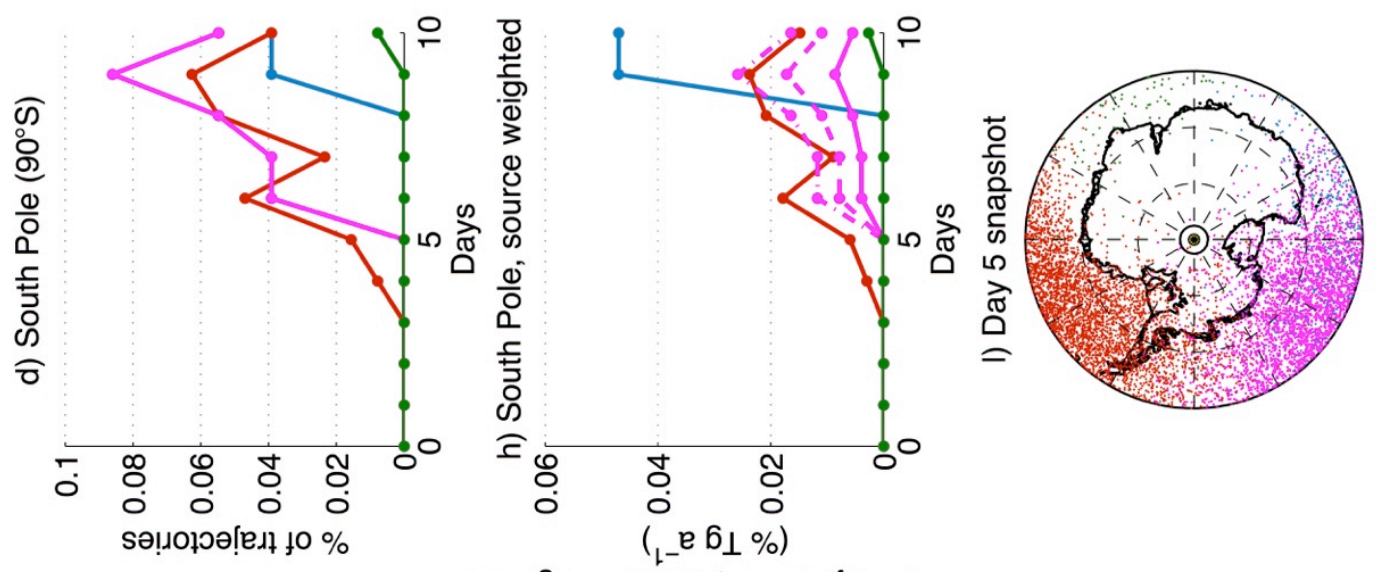

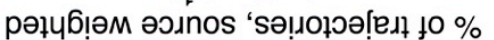
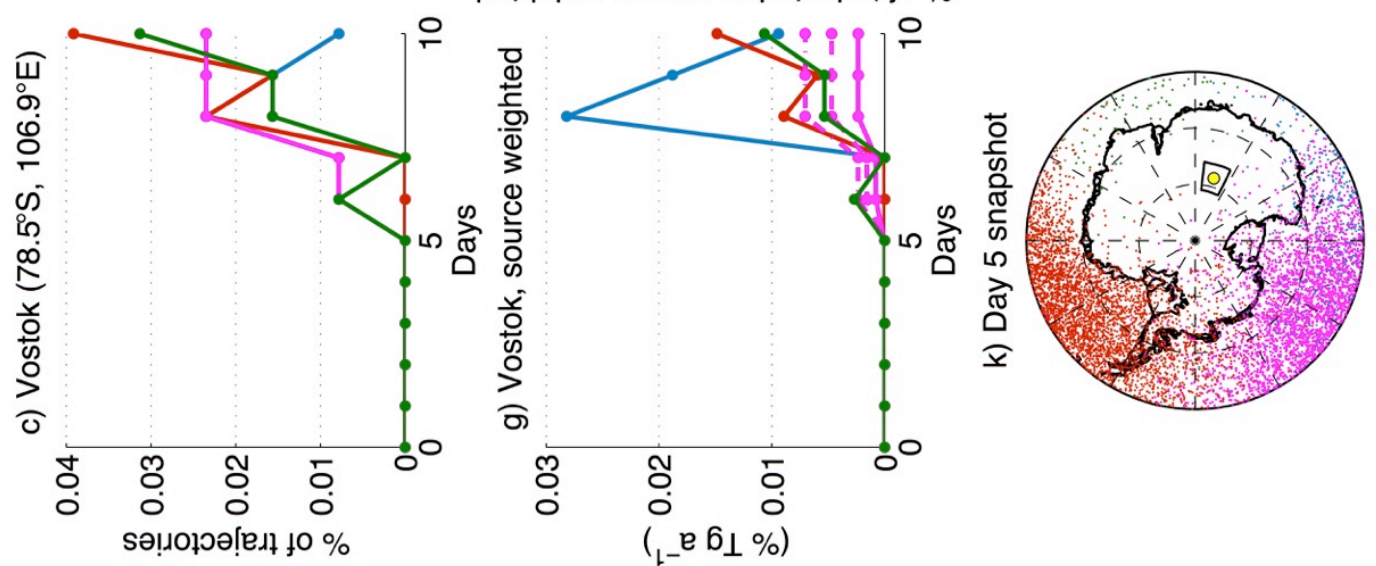

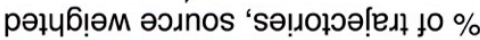
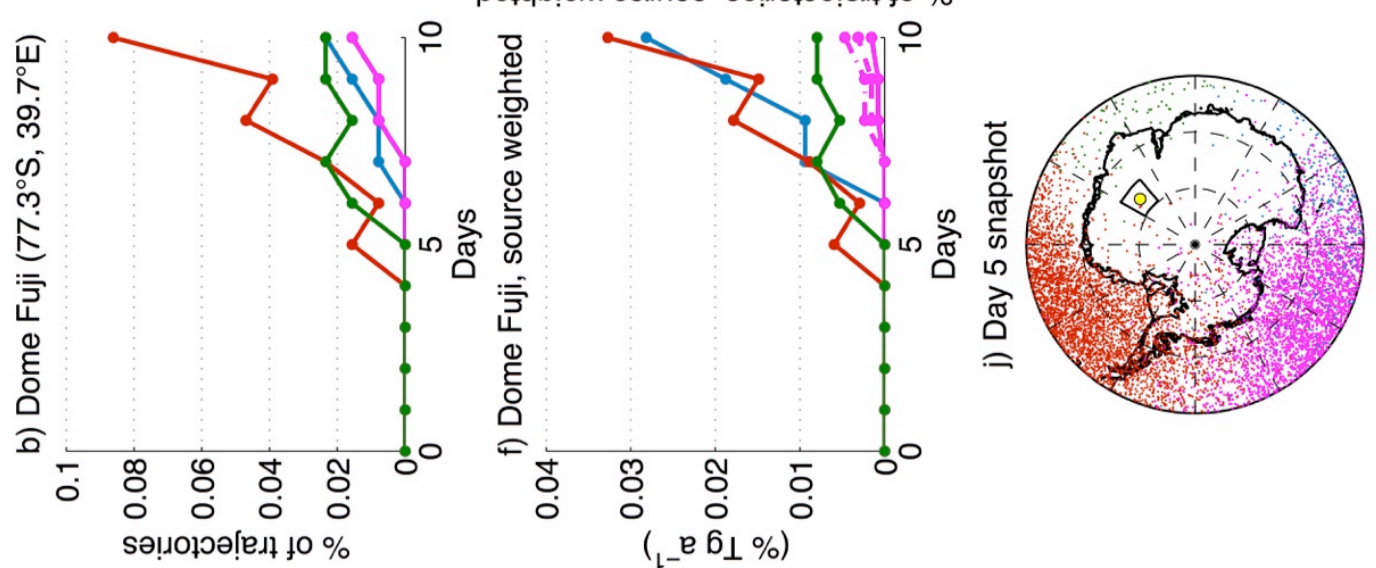

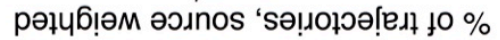
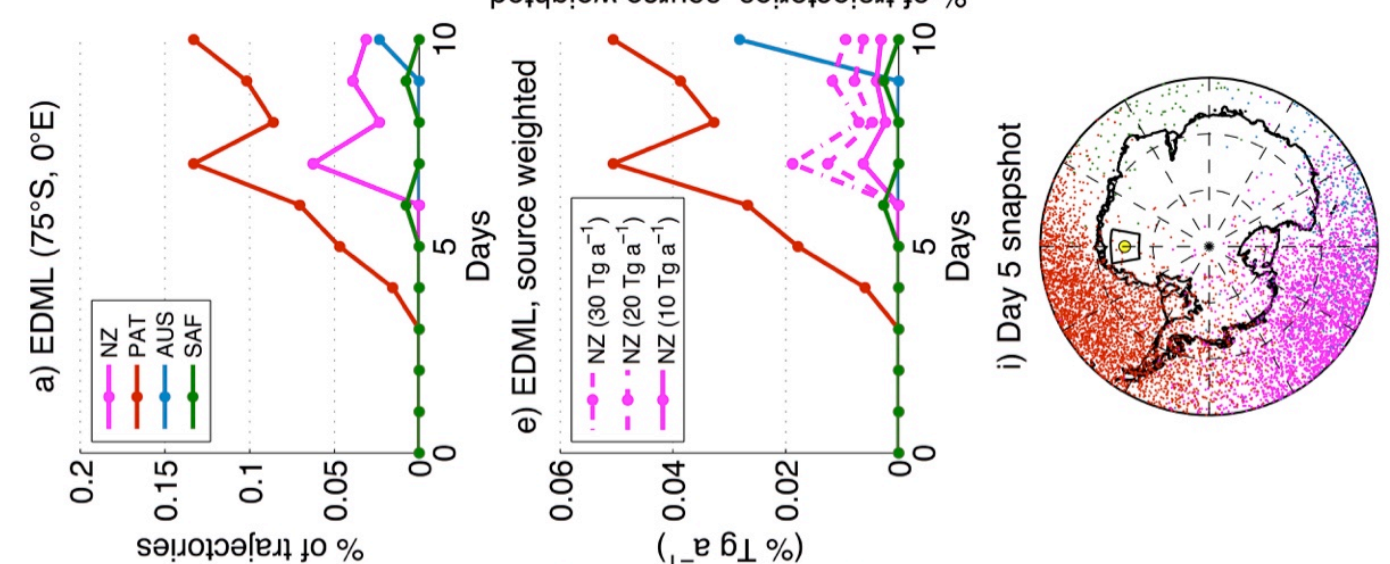

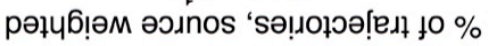


Coastal EAIS ice core sites at Law Dome and Talos Dome (Figure 8) also show dust PSA trajectory distributions with large AUS contributions as well as a significant SAF component at Law Dome. Lead $(\mathrm{Pb})$ isotope studies in the Law Dome ice core provide additional evidence for modern atmospheric transport of pollutants from Australia to coastal regions of the EAIS, as the isotopic signature of Broken Hill $\mathrm{Pb}$ from Australian mining activity was identified in $20^{\text {th }}$ century ice core samples [Vallelonga et al., 2002]. At Talos Dome, similar to EDML and EDC, South American dust strontium-neodymium signatures are dominant during the LGM, while during the Holocene strontium-neodymium ratios of dust from proximal ice-free areas upwind of the ice core site match the signature observed in ice core samples [Delmonte et al., 2010]. The NZ dust PSA is the most dominant source of unweighted trajectories arriving Talos Dome, suggesting that NZ should be considered as a potential contributor to the dust and additional aerosol budgets in the Victoria and Wilkes Land regions of East Antarctica.

Figure 8. (Following page) As in Figure 7 but for Law Dome (a, e, i), EPICA Dome C (b, $f$, $j)$, Taylor Dome (c, $g, k)$ and Talos Dome $(d, h, l)$. 

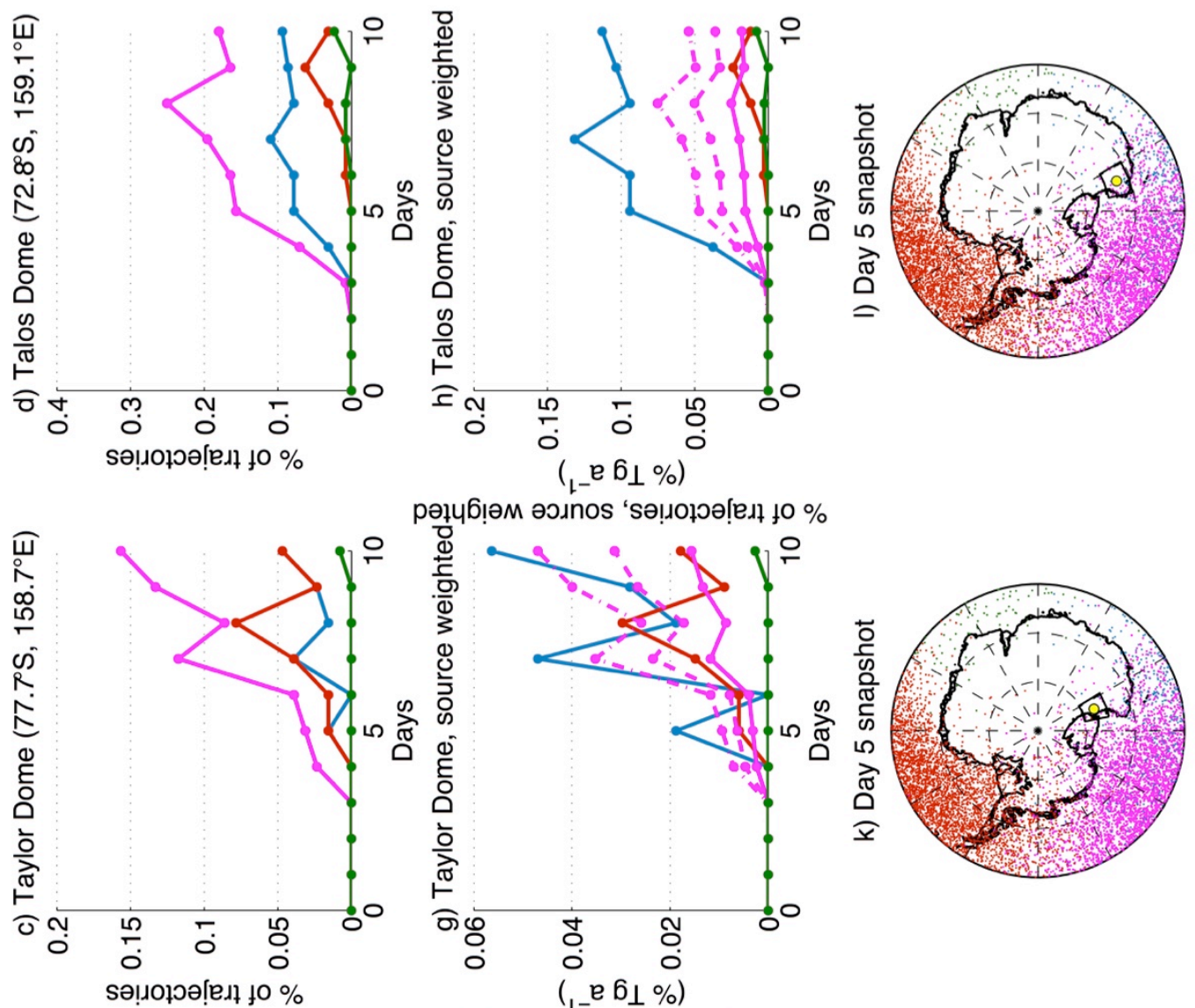

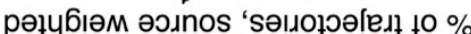
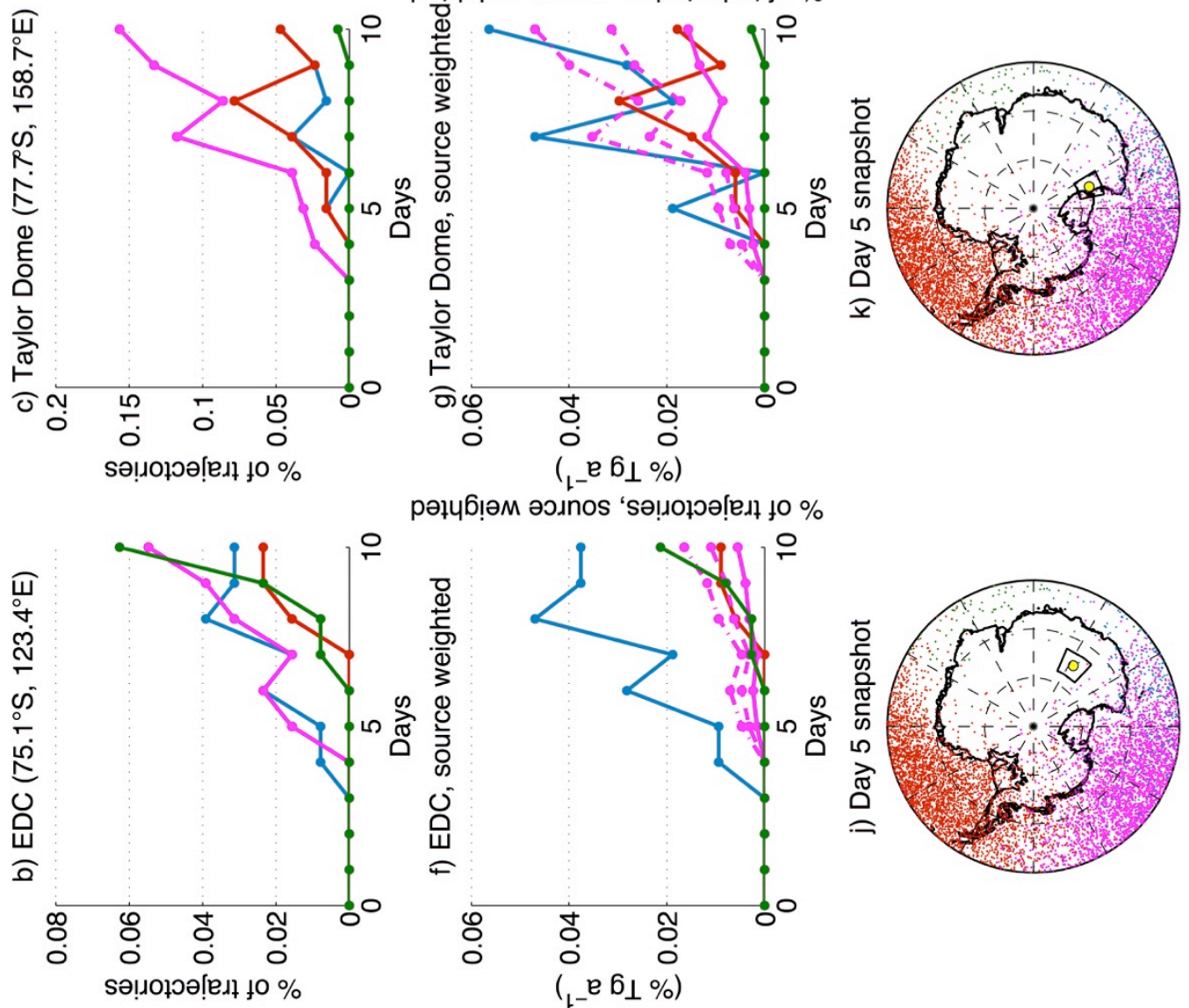

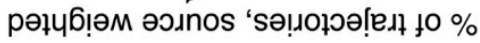

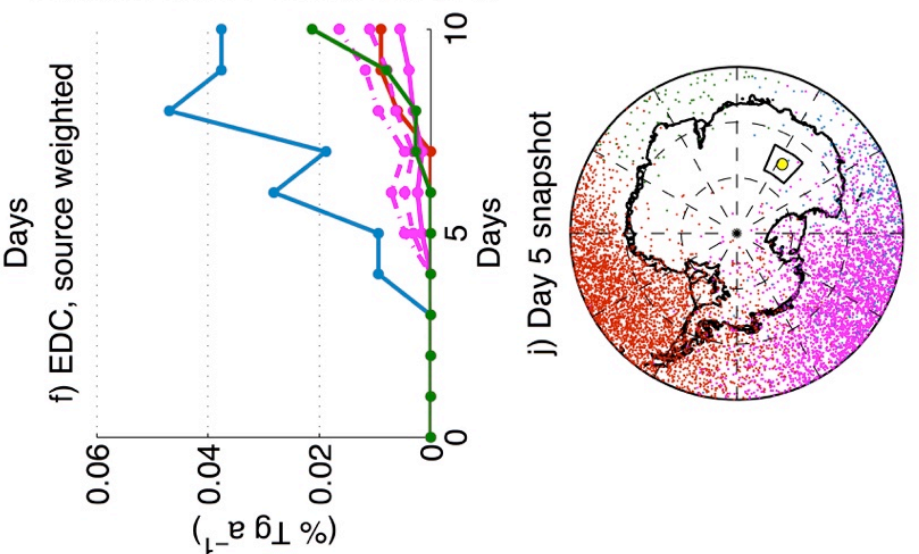

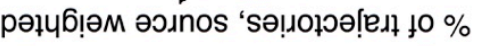
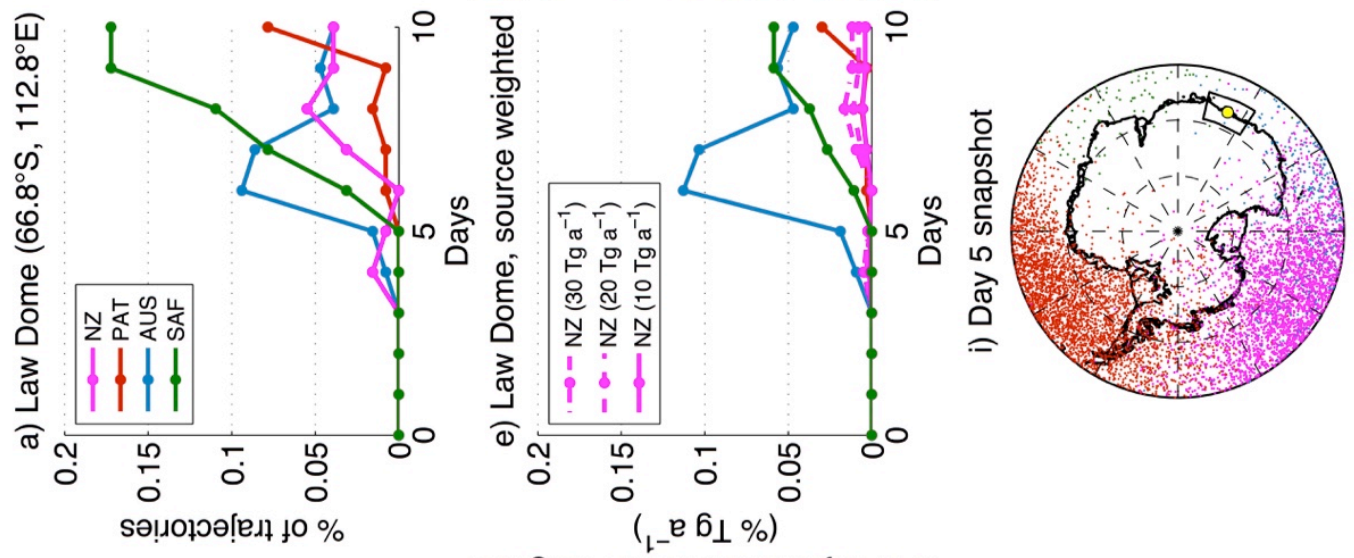

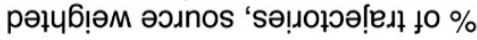




\subsubsection{Dust Transport to the West Antarctic Ice Sheet}

The lower-elevation, marine-influenced West Antarctic Ice Sheet (WAIS) [Nicolas and Bromwich, 2011] receives two- to four-times more trajectories from dust PSA than the EAIS, particularly from NZ in the Ross and Amundsen Sea sectors and from PAT across the Antarctic Peninsula and Weddell Sea region (Figure 9, 10). More efficient transport of dust onto the WAIS, and local dust input from rock outcrops (e.g. Executive Committee Range, Ford Ranges, etc.), likely are the causes of higher dust concentrations and larger particle sizes observed in modern ice core samples from the WAIS Divide ice core compared to those from East Antarctic ice cores [Koffman et al., 2014]. Few geochemical provenance studies have been undertaken using West Antarctic ice core samples, but this work is currently being undertaken using $20^{\text {th }}$ century samples from the RICE ice core. Higher concentrations of terrestrial minerals (e.g. dust) and marine salts are both observed and modeled at lowerelevation sites and across the inland WAIS than at higher elevations on the EAIS plateau, and lower concentrations of dust should be expected in regions most distal from extra-Antarctic dust sources [Bertler et al., 2005; Li et al., 2008].

At the RICE and Siple Dome ice core sites (Figure 9) in the vicinity of the Ross Ice Shelf, NZ trajectories (unweighted) dominate by up to five times more than the next largest PAT contribution. Even when the NZ dust PSA is weighted by dust source emissions as low as $10 \mathrm{Tg} \mathrm{a}^{-1}$, it contributes equally to the potential dust distribution at these coastal WAIS sites. Similar prevalence of NZ trajectories remains at the Byrd and WAIS Divide ice core sites (Figure 9) near the highest-elevation WAIS ice flow divide, although PAT trajectories become more common. Weighted for dust source emissions, NZ trajectories contribute with nearly equal strength to those from the more heavily-weighted PAT and AUS trajectories at Byrd and WAIS Divide.

Figure 9. (Following page) As in Figure 8 but for RICE (a, e, i), Siple Dome (b, f, j), Byrd Station $(c, g, k)$ and WAIS Divide $(d, h, l)$. 

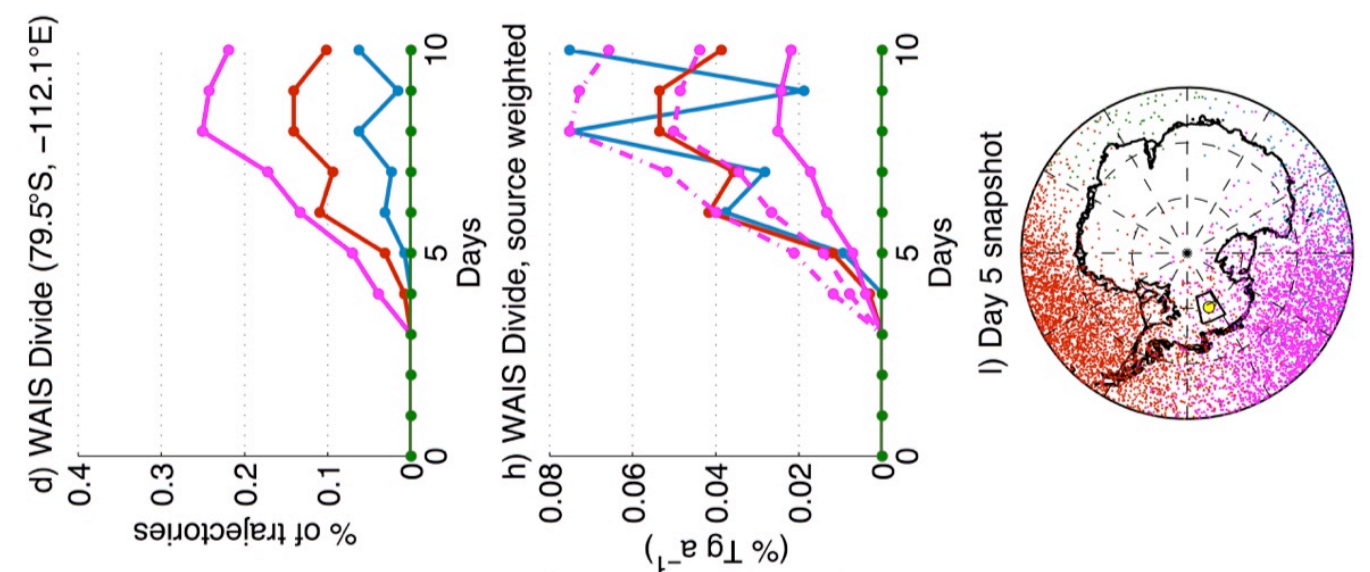

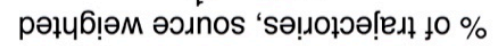

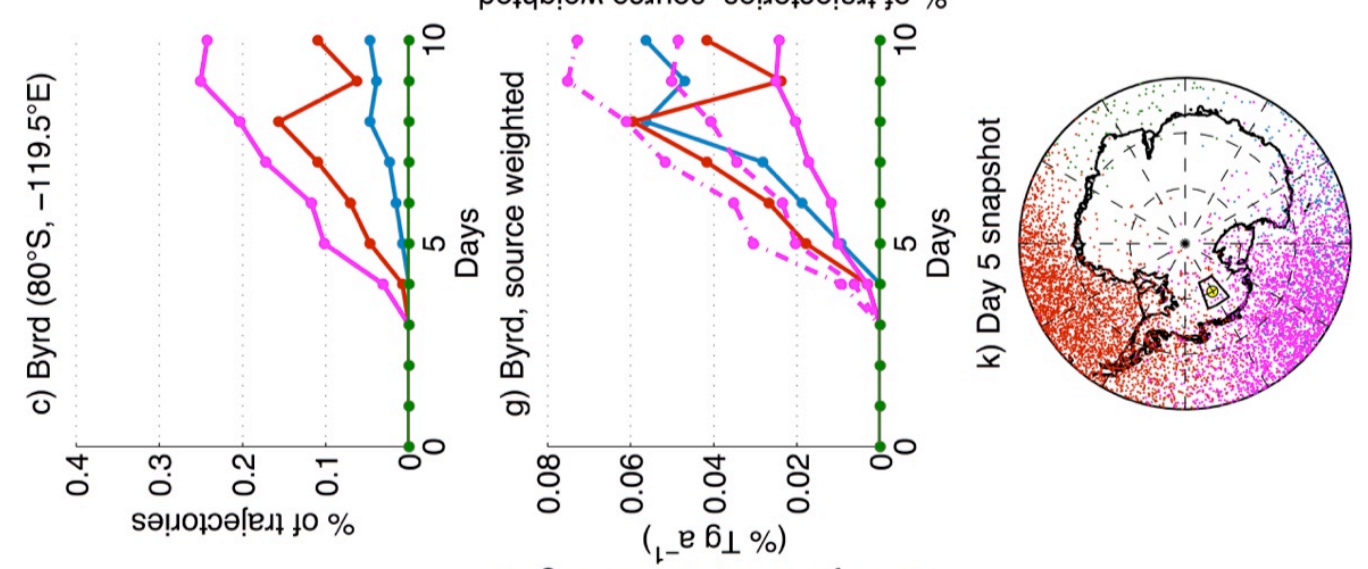

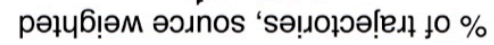
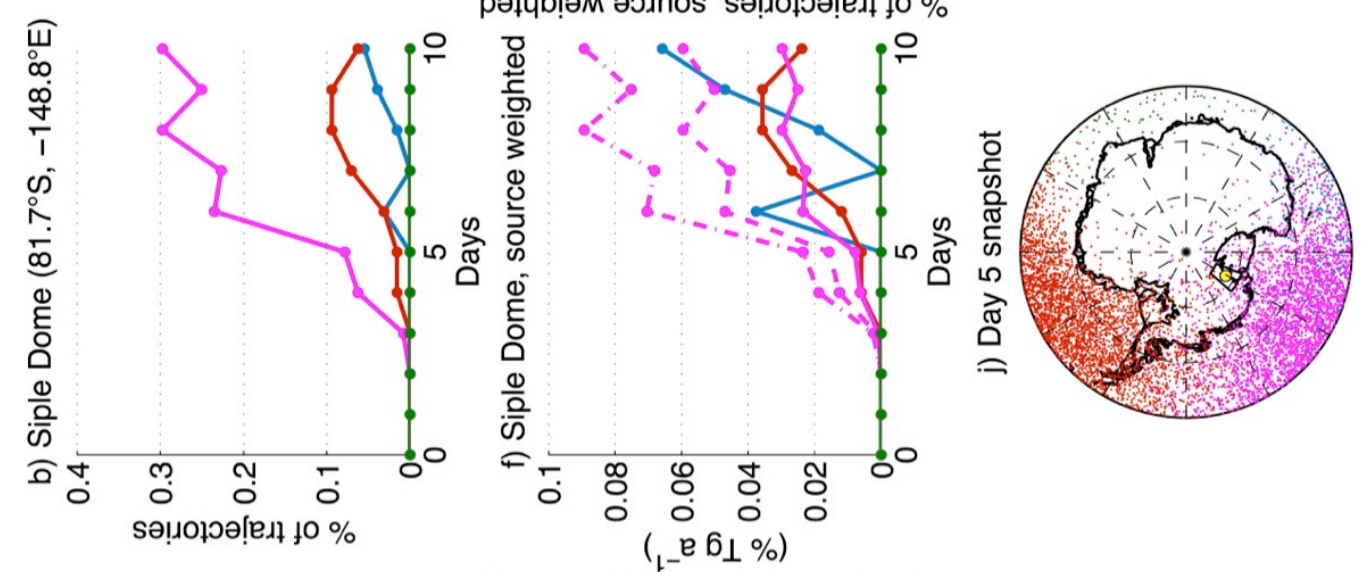

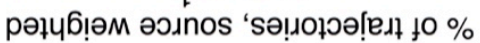
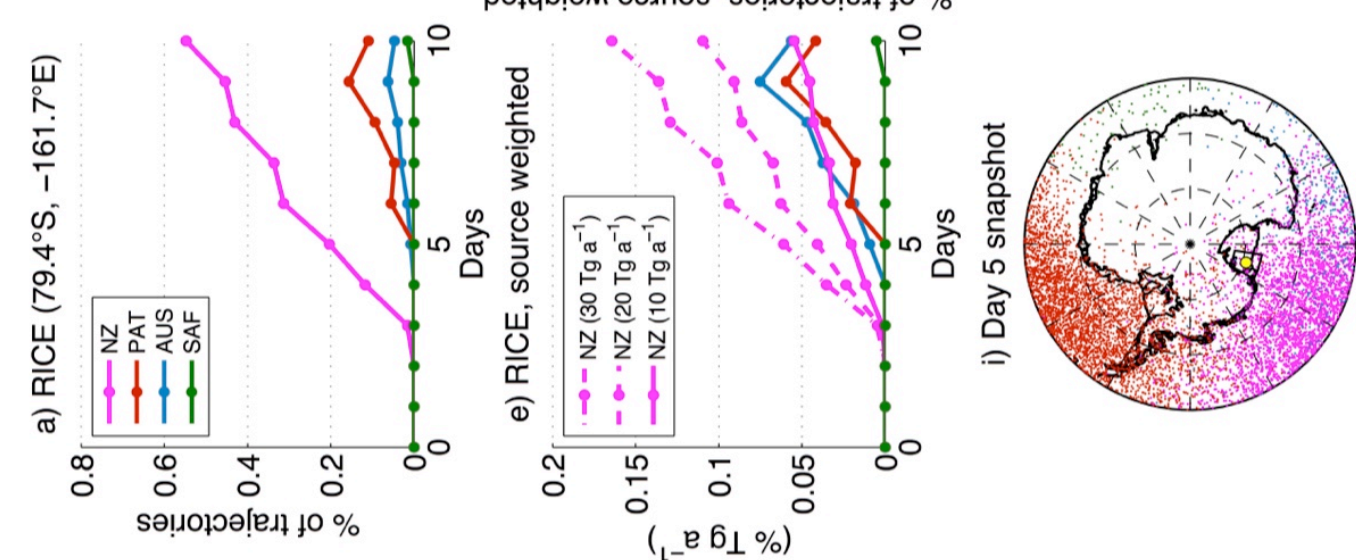

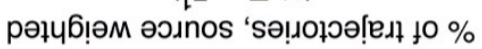


Ice core sites on the Antarctic Peninsula and in the Weddell Sea sector of the WAIS (Figure 10) are dominated by PAT trajectories, with NZ nearing equal proportions only at Fletcher Promontory. James Ross Island is relatively close to PAT dust sources $(\sim 1,800 \mathrm{~km})$, resulting in a strong dominance of PAT dust PSA trajectories which peak after three days of transport as trajectories pass over the site. Many PAT trajectories continue south, and Berkner Island shows highest PAT trajectory percentage after six to eight days but with approximately one tenth as many trajectories as the number traveling over the Antarctic Peninsula. A study of strontium/neodymium isotopes in snowpit samples at Berkner Island spanning the years 2002-2003 provided mixed provenance signatures, suggesting local Antarctic sources of dust in addition to PAT and AUS contributions [Bory et al., 2010].

The trajectory results discussed here provide a unique framework for considering atmospheric transport from SH dust PSA likely contributing to SO and Antarctic dust distribution. As this approach is exclusive of deposition processes, we caution that our results represent an idealized maximum transport efficiency with respect to atmospheric dust and other aerosols originating at SH PSA. Despite this limitation, regional variations observed in trajectory distribution from individual dust PSA provide new insight into the possible spatial variability of dust provenance in Antarctica. This simple approach also highlights the competing roles of emission strength versus efficiency of atmospheric transport, the latter of which can also be investigated for dominant modes of variability associated with synoptic climate.

Figure 10. (Following page) As in Figure 9 but for Fletcher Promontory (a, $d$, g), James Ross Island ( $b, e, h)$, and Berkner Island (c, $f, i)$. 

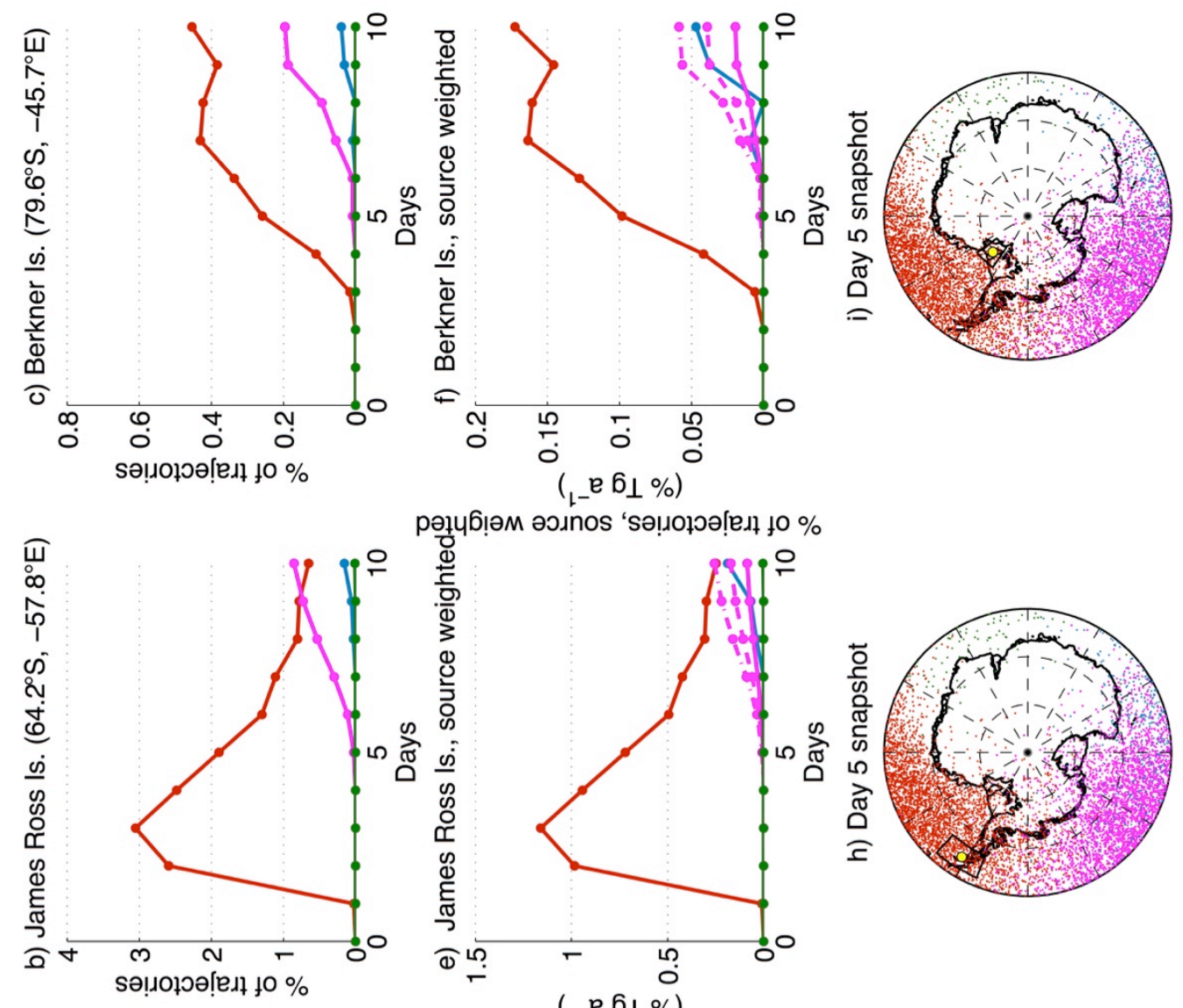

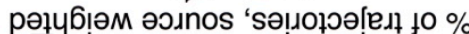

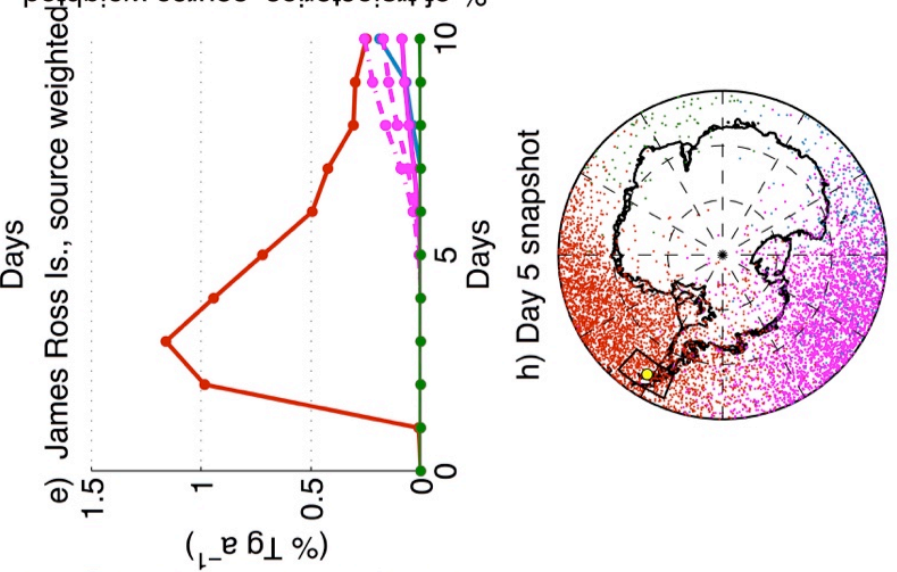

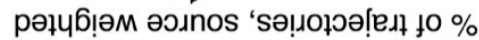
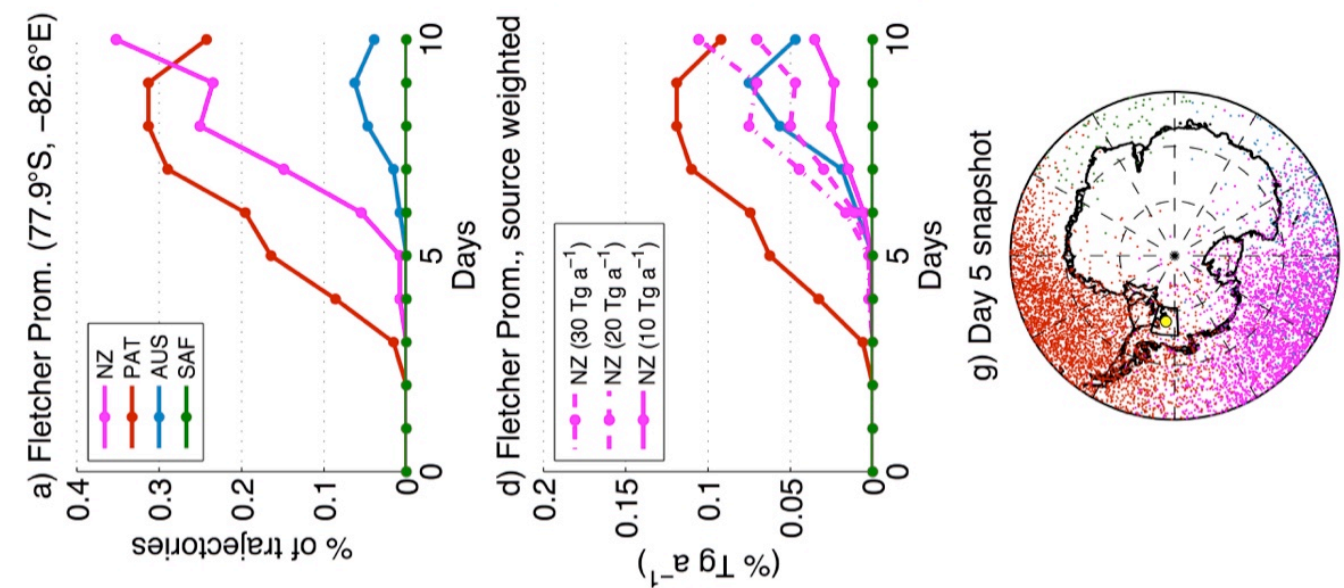

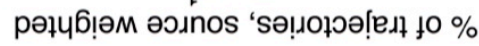




\subsubsection{Drivers of Interannual Transport Variability}

Large dust sources in Patagonia and Australia, as well as transport-efficient New Zealand, are geographically situated on either side of the South Pacific Ocean basin. This suggests that regional atmospheric circulation - and hence transport of dust and other aerosols - should be moderated by well-known Pacific ocean-atmosphere dynamics. Variability in tropical Pacific sea-surface temperatures, commonly characterized by the El Niño-Southern Oscillation (ENSO), influences atmospheric circulation in the South Pacific with effects extending into Antarctica [Bromwich et al., 2004; Karoly, 1989; Turner, 2004]. Sea-surface temperature anomalies in the central tropical Pacific Ocean-outside specific El Niño regions where strongest anomalies are observed-strongly affect deep convection associated with divergence high in the atmosphere [Lachlan - Cope and Connolley, 2006]. Resultant atmospheric Rossby wave trains influence atmospheric circulation at mid- to highlatitudes in both hemispheres, characterized as the Pacific-North America and Pacific-South America modes (i.e. leading empirical orthogonal functions of $500 \mathrm{hPa}$ height) [Mo and Paegle, 2001]. This relationship is demonstrated in Figure 11, annually and for three-month seasonal means, by regressing ERAi central tropical Pacific (CTP, $20^{\circ} \mathrm{N}-20^{\circ} \mathrm{S}, 180^{\circ}-$ $240^{\circ} \mathrm{E}$ ) sea-surface temperature (SST) against $500 \mathrm{hPa}$ geopotential height. The same is done for CTP SST versus ERAi 10-meter zonal and meridional wind in Figures S4 and S5 to illustrate relationships directly with wind fields. The Pacific-South America pattern is seen in this way as anti-correlations between CTP SST and $500 \mathrm{hPa}$ geopotential height across the SH mid-latitudes, and positive correlation over the Pacific SO. This relationship is statistically significant ( $>95 \%$ confidence) both for annual and seasonal correlations.

In the Pacific sector of the SO, specifically the Amundsen and Bellingshausen Seas, the additional impacts of both forced and possibly intrinsic variability in the Southern Annular Mode (SAM), a zonally-symmetric dipole in wind strength observed between the southern hemisphere mid- and high-latitudes, are intertwined with the meridional teleconnections initiated in the central tropical Pacific [Ding et al., 2012; Kidson, 1988; Thompson and Wallace, 2000]. The Marshall [2003] SAM index (difference between observed zonal mean sea level pressures at $40^{\circ} \mathrm{S}$ and $65^{\circ} \mathrm{S}$, http://www.antarctica.ac.uk/met/gjma/sam.html) is regressed against ERAi $500 \mathrm{hPa}$ geopotential height in Figure S6 for reference. Climate in the Pacific SO is dominated by the Amundsen Sea Low (ASL, $60^{\circ}-75^{\circ} \mathrm{S}, 170^{\circ}-290^{\circ} \mathrm{E}$ ), defined as in Hosking et al. [2013], an area of highly active transient synoptic- and smaller-scale low pressure systems which exerts 
strong control on the meridional component of atmospheric transport into West Antarctica and the Ross and Amundsen seas [Hosking et al., 2013; Hoskins and Hodges, 2005; Küttel et al., 2012; Markle et al., 2012; Nicolas and Bromwich, 2011].

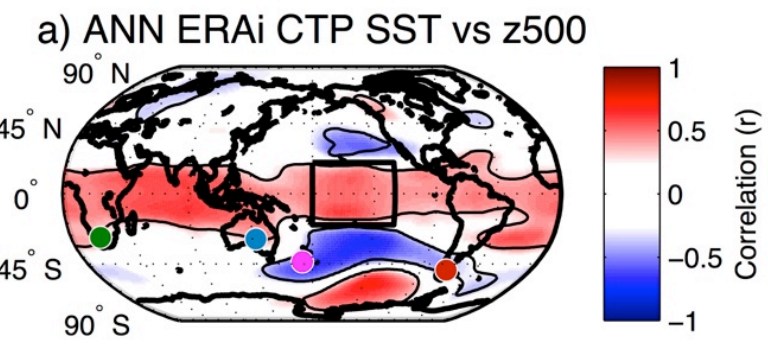

b) DJF ERAi CTP SST vs z500

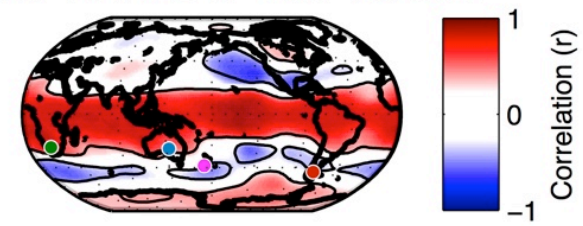

d) JJA ERAi CTP SST vs z500
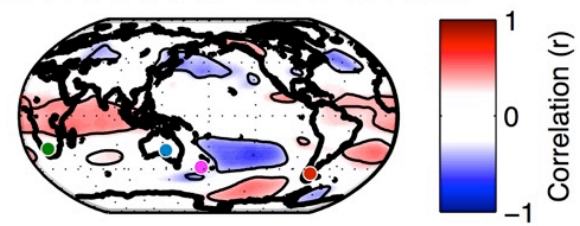

c) MAM ERAi CTP SST vs z500

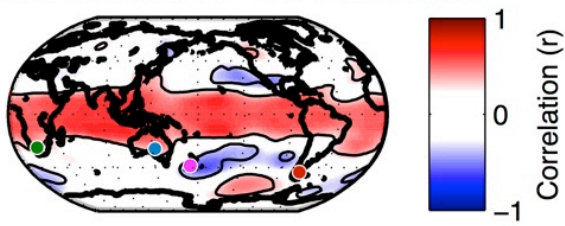

e) SON ERAi CTP SST vs z500

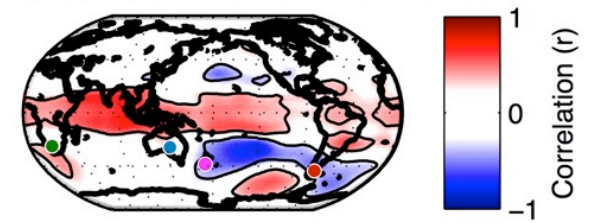

Figure 11. Spatial correlation of 1979-2013 ERA-Interim reanalysis central tropical Pacific sea-surface temperature (CTP SST, $20^{\circ} \mathrm{N}-20^{\circ} \mathrm{S}, 180^{\circ} \mathrm{E}-240^{\circ} \mathrm{E}$ ) versus $500 \mathrm{hPa}$ geopotential height. Mean annual relationsip (ANN, a), December-January-February (DJF, b), March-April-May (MAM, c), June-July-August (JJA, d), and September-OctoberNovember (SON, e). Dust PSA are marked by colored circles, New Zealand (magenta), Patagonia (orange), southern Africa (green) and Australia (cyan). Black contour indicates $>95 \%$ significance.

With respect to atmospheric transport of terrestrial dust and other aerosols, the influences of tropical Pacific SST and SAM can be considered by comparison with the mean annual minimum latitude of five-day forward trajectories (i.e. only southward-moving trajectories, negative degrees latitude in the $\mathrm{SH}$ ) from New Zealand, Patagonia and Australia. Detrending these 1979-2013 timeseries focuses investigation on natural interannual variability, removing decadal trends caused by additional dynamics (e.g. the impact of strengthening circumpolar westerly winds, which is outside the scope of this work). Typical 
interannual variability in mean annual five-day trajectory minimum latitudes for all PSA is one to two degrees latitude. When compared to the detrended annual and seasonal mean sea level pressure (MSLP) in the ASL region (ERAi data, collated by Hosking et al. [2013], available at http://www.antarctica.ac.uk/data/absl/), statistically significant correlations are found between mean annual five-day minimum trajectory latitude from these three dust PSA and both CTP SST and ASL MSLP (Figure 12). Some limited, less significant relationships exist with the SAM and the latitudinal and longitudinal position of the ASL (as isolated by Hosking et al. [2013]). Full correlation statistics are displayed in Figure 13.

Southward trajectories from NZ correlate positively with ASL MSLP during December-January-February (DJF, austral summer), with $r=0.40$ and $p<0.05$ (Figure 12a, Figure 13). Southward trajectories from PAT are anti-correlated with ASL MSLP during September-October-November (SON, austral spring), $\mathrm{r}=0.41, \mathrm{p}<0.05$ (Figure 12b, Figure 13). Annual AUS southward trajectories do not show significant correlation with ASL MSLP directly, only weak positive correlation of low significance during austral autumn, MarchApril-May (MAM), $\mathrm{r}=0.28, \mathrm{p}<0.12$ (Figure 13). However, AUS southward trajectories are strongly positively correlated with CTP SST both annually and during austral autumn and winter, March-April-May (MAM) and June-July-August (JJA), with an annual correlation of $\mathrm{r}=0.43(\mathrm{p}<0.01)$, and seasonal correlations of $\mathrm{r}=0.51(\mathrm{p}<0.01)$ during MAM and $\mathrm{r}=0.35$ $(\mathrm{p}<0.05)$ during JJA (Figure 12c, Figure 13). ERAi CTP SST (Figure 12d, dashed black) is strongly correlated with ASL MSLP in both ERAi $(r=0.57, p<0.001$, Figure 12d, solid black) and NCEP1 $(\mathrm{r}=0.55, \mathrm{p}<0.001$, Figure $12 \mathrm{~d}$, red). No statistically significant relationships are observed between SAF dust PSA southward trajectories and either CTP SST or ASL MSLP (Figure 13). The lack of correlations is perhaps not surprising as downwind areas over the Indian Ocean only show significant correlation between atmospheric circulation and CTP SST during DJF (Figure 11) and SAF trajectory distributions are far removed from the ASL region. However, some correlation between SAF trajectory southward latitude and the Marshall SAM index is observed during DJF and discussed below. 
a)

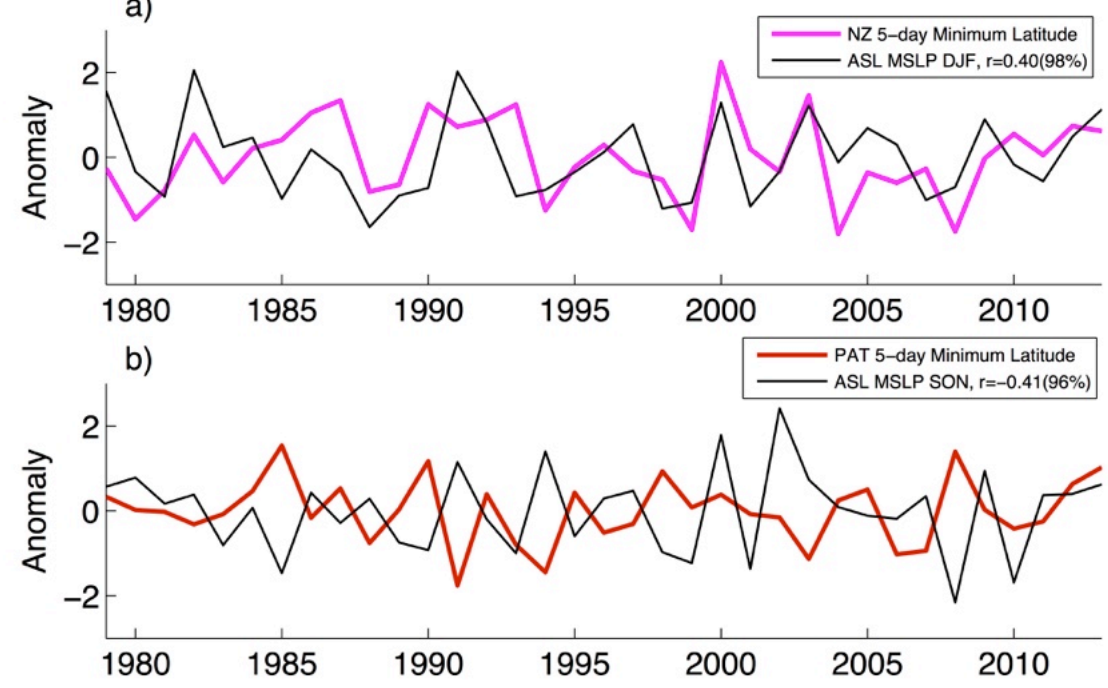

c)

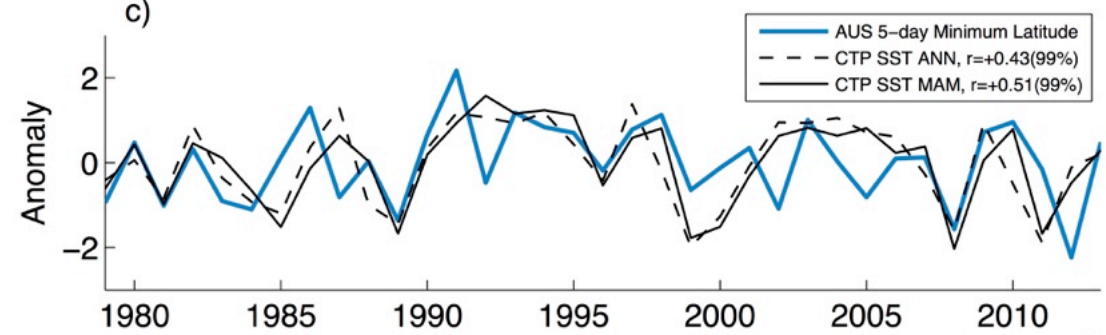

d)

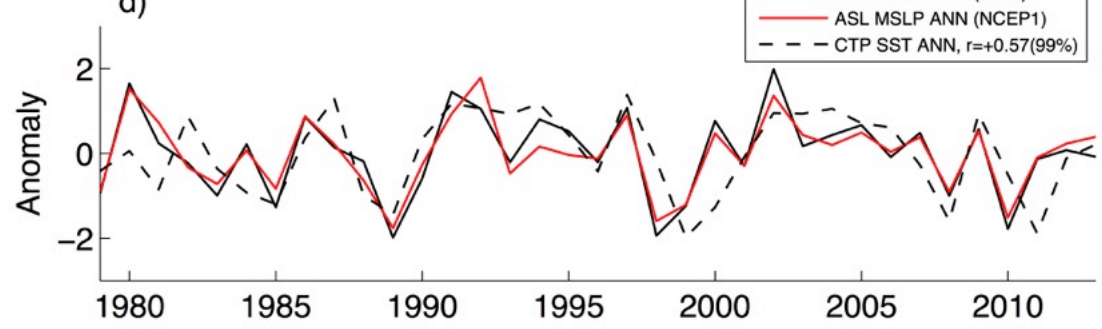

Figure 12. Normalized timeseries of detrended 1979-2013 mean annual minimum latitude of 5-day forward trajectories, compared with detrended seasonal ERA-Interim Amundsen Sea Low (ASL) mean sea level pressure (MSLP, $60^{\circ}-75^{\circ} \mathrm{S}, 170^{\circ}-290^{\circ} \mathrm{E}$; as in Hosking et al., 2013) and central tropical Pacific $\left(20^{\circ}-20^{\circ} \mathrm{S}, 180^{\circ}-240^{\circ} \mathrm{E}\right)$ sea surface temperature (CTP SST). NZ versus DJF ASL MSLP (a), PAT versus SON ASL MSLP (b), AUS versus MAM and annual CTPSST (c) and ASL MSLP from both ERA-Interim and NCEP/NCAR reanalyses versus ERA-Interim CTP SST (d). 
a)

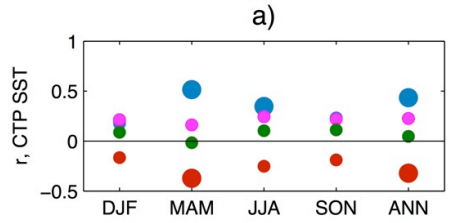

c)

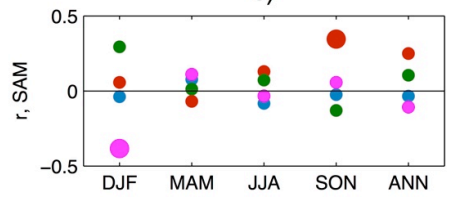

e)

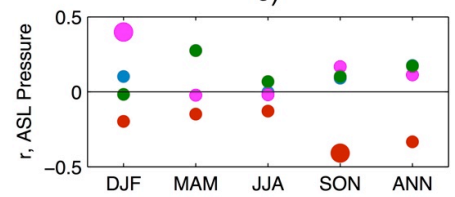

g)

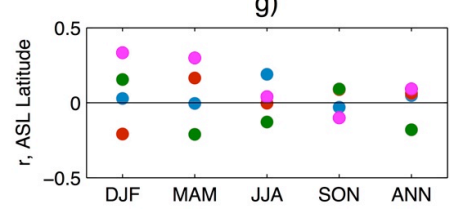

i)

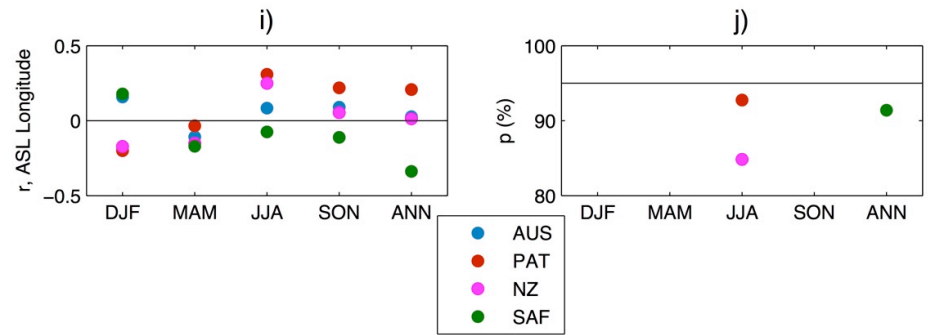

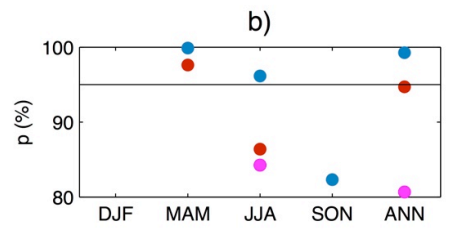

d)

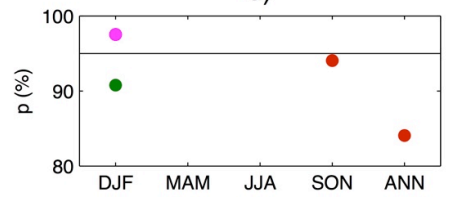

f)

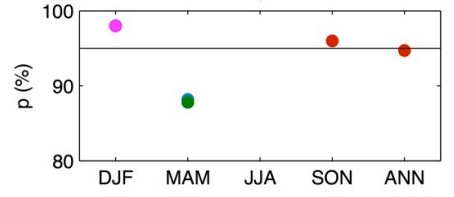

h)

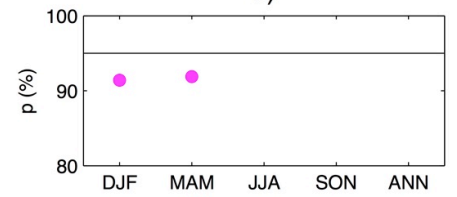$$
\text { . }
$$

Figure 13. Correlation statistics for annual 1979-2013 5-day trajectory minimum latitude (southward extent) versus annnual and seasonal averages of central tropical Pacific seasurface temperature (CTP SST, a, b), the Marshall Southern Annular Mode index (SAM, c, d), and the Amundsen Sea Low (ASL) region mean sea level pressure (ASL Pressure, e, f), mean ASL latitude (ASL Latitude, $g, h$ ) and mean ASL longitude (ASL Longitude, $i, j$ ). Larger circles mark $r$ values with high significance $(\sim p<0.05)$. ASL pressure and latitudinal and longitudinal position are taken from Hosking et al. [2013].

For annual values, as well as during all seasons except DJF (Figure 11), tropical Pacific teleconnections in the SH are confined primarily to the South Pacific basin with some extension into the South Atlantic. During DJF there is a zonally-symmetric anti-correlation between CTP SST and mid-latitude SH circulation. This zonal symmetry is reminiscent of the SAM (Figure S6), which exhibits particularly significant relationships with CTP SST during DJF [Ding et al., 2012; L'Hereux and Thompson, 2006]. This likely explains the positive correlation between NZ southward trajectories and ASL MSLP during DJF (lower 
ASL MSLP, more southerly mean trajectory latitude, Figure 12). Indeed, NZ southward trajectories anti-correlate with the Marshall SAM index during DJF (1979-2012, $r=-0.38, p$ $<0.05$, Figure 13), with NZ trajectories extending further south in the positive SAM phase when the circumpolar westerly winds contract towards Antarctica. SAF southward trajectories also correlate with the SAM during DJF, although with low significance $(\mathrm{r}=$ $0.29, \mathrm{p}<0.1$, Figure 13), indicating possible southward extension of SAF trajectories during SAM negative conditions when westerly winds reach further into the mid-latitudes.

During SON, southward trajectories from PAT are significantly anti-correlated with ASL MSLP (lower ASL MSLP, more northerly mean trajectory latitude, Figure 12, Figure 13). Tropical Pacific teleconnections are strong across the south Pacific basin during SON, and are particularly focused in the ASL region (Figure 11), which is one extreme of a regional dipole in the relationship between CTP SST and atmospheric circulation. Positive correlations between CTP SST and $500 \mathrm{hPa}$ geopotential height in SON center over the ASL region (Figure 11e), with negative correlations to the East, over the Weddell Sea and Atlantic Southern Ocean (described as the Antarctic Oscillation with respect to its influence on seaice [Renwick and Revell, 1999; Yuan and Martinson, 2000]). This arrangement results in positive correlation between CTP SST and northward meridional winds in the region between this dipole (Figure S5), from the Bellingshausen Sea east across the Antarctic Peninsula to the western Weddell Sea, suggesting that southward transport of PAT trajectories in this region weakens during warm CTP SST conditions. PAT southward trajectory extent also positively correlates with the Marshall SAM index during SON, with significance slightly below 95\%: $\mathrm{r}=0.35, \mathrm{p}<0.06$ (Figure 13). This suggests that PAT trajectories reach further south during negative SAM conditions, when circumpolar westerlies expand further into the mid-latitudes.

Southward transport of AUS trajectories is positively correlated with CTP SST as an annual average, strongly positively correlated during austral autumn (MAM), and shows additional correlation in winter (JJA, Figure 12c, Figure 13). We argue that the weak positive correlation between AUS southward trajectories and ASL MSLP during MAM is consistent with the relationship between CTP SST and ASL circulation (i.e. wave train seen in correlation between CTP SST and atmospheric circulation over both Australia and the ASL region, Figure 11c). The correlation with CTP SST likely reflects the large role that tropical variability plays in atmospheric circulation over Australia, seen in strong positive correlations with $500 \mathrm{hPa}$ geopotential height over the continent (Figure 11). 
These relationships between southward dust PSA trajectory extent and both tropical and high-latitude climate variability suggest that variability in atmospheric transport with respect to dust should be carefully considered in future model experiments. Additionally, these results can inform hypotheses with respect to past changes in dust transport, and thus atmospheric circulation, developed from ice core proxy records. For instance, Koffman et al. [2014] suggest poleward contraction of the circumpolar westerly winds from 1050 to 1400 Common Era (CE), based on a dust particle size record developed from the WAIS Divide ice core which demonstrates correlation with cyclonic activity in the ASL region. Although independent of deposition processes, our trajectory results suggest a possible mechanism explaining such a change in southward dust transport, and hence changing particle size observed in ice core records, with links to both tropical and high-latitude climate variability. This process warrants further study.

\subsection{Conclusions}

The dust flux to Antarctica and the SO is dependent on both the strength of the dust source and the competing mechanisms of transport and deposition. Here we focus strictly on the atmospheric transport component and investigate drivers behind observed spatial and temporal variability of SH dust distribution. Examination of modern atmospheric transport from four SH dust PSA to areas of the SO and Antarctica, based on thirty-five years of daily HySPLIT forward trajectories, highlights important features of modern atmospheric transport. Transport from both Patagonian and New Zealand dust sources to the southern high-latitudes is highly efficient with $>40 \%$ of trajectories passing over the SO within the first four days of transport, and $>8 \%$ of trajectories arriving in Antarctica after eight days. Transport from lower-latitude sources in Australia and southern Africa is both less efficient and slower: $<20 \%$ of trajectories from these PSA move over the SO and a maximum of $\sim 2 \%$ arrive in Antarctica within ten days.

Poorly-quantified glaciogenic dust emissions from New Zealand, which were especially active during the LGM, are thus strongly connected to the southern high-latitudes and may play a significant role in fertilization of the SO and uptake of carbon on glacialinterglacial timescales. Linear dust-emission weighting of PSA trajectories provides estimates of SH dust deposition which compare well with independent estimates. This approach suggests that even with very modest dust emissions of $10 \mathrm{Tg} \mathrm{a}^{-1}$, New Zealand may comprise $8.5 \%$ of dust from SH sources distributed over the SO, and $13.7 \%$ of dust 
transported to Antarctica. Efforts should be made to better quantify New Zealand and other glaciogenic dust contributions to atmospheric dust loading and deposition across the SH.

Regional contributions from dust PSA are remarkably distinct over the SO and at individual Antarctic ice core sites. The Pacific SO is dominated by New Zealand and Australian airmasses, while the Atlantic and Indian Ocean sectors of the SO are largely dominated by Patagonian trajectories with southern Africa playing a more limited role. Remote East Antarctic ice core sites show variable source contributions, with Patagonian trajectories playing a larger role nearer the Atlantic sector (EDML), limited and highly mixed contributions across the interior plateau of East Antarctica (Dome F, Vostok, South Pole, Taylor Dome), and Australian trajectories becoming more common in Wilkes and Victoria Land (EDC, Law Dome, Talos Dome). Trajectory distribution over West Antarctica is divided between dominance of the highly-efficient transport from New Zealand and Patagonia, followed by Australian trajectories. Considerable New Zealand contributions span the Ross Ice Shelf and Marie Byrd Land (RICE, Siple Dome, Byrd, WAIS Divide) while clear prevalence of Patagonian trajectories exists over Ellsworth Land, the Antarctic Peninsula and the Weddell Sea (Fletcher Promontory, James Ross Island, Berkner Island).

With respect to the RICE ice core from Roosevelt Island, an ice rise at the northern margin of the Ross Ice Shelf, direct transport from New Zealand is as much as five-times more efficient than transport from any other SH mid-latitude continental source of dust or other aerosol emissions. Source-weighted dust PSA trajectory contributions from Australia and Patagonia are essentially equal at RICE, suggesting that geochemical dust provenance studies undertaken on this core should expect mixed contributions from these large dust sources with some material supplied from yet unquantified New Zealand dust emissions. Dust emissions from Antarctic ice-free areas such as the McMurdo Dry Valleys are not accounted for here. While emissions from these sites are orders of magnitude lower than extra-Antarctic dust sources, transport distances are much shorter and may allow for local ice-free areas to supply significant amounts of dust to ice core sites [Dunbar et al., 2009; Rhodes et al., 2012; Winton et al., 2014].

Finally, we find that the southward extension of trajectories from dust PSA fluctuates in association with both low- and high-latitude climate variability. To understand dust records preserved in ice cores or to quantify the potential near-future influence on the carbon cycle via the biological pump, it is important to identify contributing dust sources, transport pathways and deposition processes to take into account their sensitivity to particular climate drivers. Strengthening of the circumpolar westerly winds (trend towards positive SAM) has 
been observed in recent decades, likely forced by anthropogenic changes in atmospheric ozone and greenhouse gas concentrations [Arblaster and Meehl, 2006; Thompson and Solomon, 2002]. Concomitant tropical warming will combine to alter high-latitude SH circulation [Bracegirdle et al., 2008; Timmermann et al., 1999], with impacts on dust transport to the SO and Antarctica that may affect the global carbon cycle. In addition to providing a mechanism possibly responsible for past dust particle size changes in Antarctic ice cores, this finding may also aid in anticipating future changes in high-latitude $\mathrm{SH}$ circulation and dust distribution over the SO.

Our analysis suggests that a strengthening of the ASL leads to southward extension of New Zealand trajectories during austral summer - when sea ice is reduced and phytoplankton blooms occur-while Patagonian trajectories remain further north when the ASL is strong during austral spring, reducing the transport efficiency of dust to the Atlantic sector of the SO at this time. Moreover, it is well known that the strength of the ASL is coupled with central tropical Pacific SST, promoting a deeper low (decreased pressure) during periods of cooler tropical SST. Southward extent of trajectories originating from Australia are positively correlated with central tropical Pacific SST, with cooler tropical SST and a deepening ASL coinciding with enhanced southward trajectories. This suggests that atmospheric transport affecting dust deposition in three known areas of Antarctic Bottom Water formation (Ross Sea, Weddell Sea, and Mertz Polynya, Orsi et al. [1999]) may be sensitive to distinct dust sources and potentially experience independent fluctuations in dust transport and deposition.

\section{Acknowledgements}

PSA trajectory datasets are available from the corresponding author upon request. The authors appreciate free access to software and data: HySPLIT software was retrieved from the NOAA Air Resources Laboratory (http://ready.arl.noaa.gov/HYSPLIT.php), NCEP1 data were downloaded from the NOAA Earth System Research Laboratory - Physical Sciences Division (http://www.esrl.noaa.gov/psd/data/gridded/data.ncep.reanalysis.html), and ERAi data from the ECMWF (http://apps.ecmwf.int/datasets/data/interim_full_daily/). We thank E. Steig and P. Vallelonga for fruitful discussion of the manuscript. This work is a contribution to the Roosevelt Island Climate Evolution (RICE) Programme, funded by national contributions from New Zealand, Australia, Denmark, Germany, Italy, the People's Republic of China, Sweden, United Kingdom, and the United States of America. P.D.N and N.A.N.B were funded by the New Zealand Ministry of Business, Innovation, and Employment Grants 
through Victoria University of Wellington (RDF-VUW-1103) and GNS Science (540GCT32).

\subsection{References}

Adams, J. (1980), Contemporary uplift and erosion of the Southern Alps, New Zealand, Geological Society of America Bulletin, 91(1 Part II), 1-114, doi:10.1130/GSAB-P2-91-1.

Albani, S., N. M. Mahowald, B. Delmonte, V. Maggi, and G. Winckler (2012), Comparing modeled and observed changes in mineral dust transport and deposition to Antarctica between the Last Glacial Maximum and current climates, Climate dynamics, 38(9-10), 17311755, doi:10.1007/s00382-011-1139-5.

Alloway, B. V., D. J. Lowe, D. J. Barrell, R. M. Newnham, P. C. Almond, P. C. Augustinus, N. A. Bertler, L. Carter, N. J. Litchfield, and M. S. McGlone (2007), Towards a climate event stratigraphy for New Zealand over the past 30000 years (NZ - INTIMATE project), Journal of Quaternary Science, 22(1), 9-35, doi:10.1002/jqs.1079.

Arblaster, J. M., and G. A. Meehl (2006), Contributions of external forcings to southern annular mode trends, Journal of climate, 19(12), 2896-2905, doi:10.1175/JCLI3774.1.

Basile, I., F. E. Grousset, M. Revel, J. R. Petit, P. E. Biscaye, and N. I. Barkov (1997), Patagonian origin of glacial dust deposited in East Antarctica (Vostok and Dome C) during glacial stages 2, 4 and 6, Earth and Planetary Science Letters, 146(3), 573-589, doi: doi:10.1016/S0012-821X(96)00255-5.

Bertler, N., P. Mayewski, and L. Carter (2011), Cold conditions in Antarctica during the Little Ice Age-Implications for abrupt climate change mechanisms, Earth and Planetary Science Letters, 308(1), 41-51, doi:10.1016/j.eps1.2011.05.021. 
Bertler, N., P. A. Mayewski, A. Aristarain, P. Barrett, S. Becagli, R. T. Bernardo, X. Cunde, M. Curran, Q. Dahe, and D. Dixon (2005), Snow Chemistry Across Antarctica, Annals of Glaciology, 41, 167, doi:10.3189/172756405781813320.

Betzer, P., K. Carder, R. Duce, J. Merrill, N. Tindale, M. Uematsu, D. Costello, R. Young, R. Feely, and J. Breland (1988), Long-range transport of giant mineral aerosol particles, Nature, 336, 568-571, doi:10.1038/336568a0.

Bory, A., E. Wolff, R. Mulvaney, E. Jagoutz, A. Wegner, U. Ruth, and H. Elderfield (2010), Multiple sources supply eolian mineral dust to the Atlantic sector of coastal Antarctica: Evidence from recent snow layers at the top of Berkner Island ice sheet, Earth and Planetary Science Letters, 291(1), 138-148, doi:10.1016/j.eps1.2010.01.006.

Bowler, J. (1976), Aridity in Australia: age, origins and expression in aeolian landforms and sediments, Earth-Science Reviews, 12(2), 279-310, doi:Bowler, J. (1976). "Aridity in Australia: age, origins and expression in aeolian landforms and sediments." Earth-Science Reviews 12(2): 279-310.

Bracegirdle, T. J. (2013), Climatology and recent increase of westerly winds over the Amundsen Sea derived from six reanalyses, International Journal of Climatology, 33(4), 843-851, doi:10.1002/joc.3473.

Bracegirdle, T. J., W. M. Connolley, and J. Turner (2008), Antarctic climate change over the twenty first century, Journal of Geophysical Research: Atmospheres (1984-2012), 113(D3), doi:10.1029/2007JD008933.

Bromwich, D. H., and R. L. Fogt (2004), Strong Trends in the Skill of the ERA-40 and NCEP-NCAR Reanalyses in the High and Midlatitudes of the Southern Hemisphere, 19582001*, Journal of Climate, 17(23), 4603-4619, doi:10.1175/3241.1.

Bromwich, D. H., R. L. Fogt, K. I. Hodges, and J. E. Walsh (2007), A tropospheric assessment of the ERA - 40, NCEP, and JRA - 25 global reanalyses in the polar regions, 
Journal of Geophysical Research: Atmospheres (1984 - 2012), 112(D10), doi:10.1029/2006JD007859.

Bromwich, D. H., A. J. Monaghan, and Z. Guo (2004), Modeling the ENSO Modulation of Antarctic Climate in the Late 1990s with the Polar MM5*, Journal of climate, 17(1), 109132, doi:10.1175/1520-0442(2004)017<0109:MTEMOA>2.0.CO;2.

Bullard, J. E. (2013), Contemporary glacigenic inputs to the dust cycle, Earth Surface Processes and Landforms, 38(1), 71-89, doi:10.1002/esp.3315.

Carter, L., H. Neil, and I. McCave (2000), Glacial to interglacial changes in non-carbonate and carbonate accumulation in the SW Pacific Ocean, New Zealand, Palaeogeography, Palaeoclimatology, Palaeoecology, 162(3), 333-356, doi:10.1016/S0031-0182(00)00137-1.

Creamean, J. M., J. R. Spackman, S. M. Davis, and A. B. White (2014), Climatology of long - range transported Asian dust along the West Coast of the United States, Journal of Geophysical Research: Atmospheres, 119(21), 12,171-112,185, doi:10.1002/2014JD021694.

De Deckker, P., M. Norman, I. D. Goodwin, A. Wain, and F. X. Gingele (2010), Lead isotopic evidence for an Australian source of aeolian dust to Antarctica at times over the last 170,000 years, Palaeogeography, Palaeoclimatology, Palaeoecology, 285(3), 205-223, doi:10.1016/j.palaeo.2009.11.013.

Dee, D., S. Uppala, A. Simmons, P. Berrisford, P. Poli, S. Kobayashi, U. Andrae, M. Balmaseda, G. Balsamo, and P. Bauer (2011), The ERA - Interim reanalysis: Configuration and performance of the data assimilation system, Quarterly Journal of the Royal Meteorological Society, 137(656), 553-597, doi:10.1002/qj.828.

Delmonte, B., P. Andersson, M. Hansson, H. Schöberg, J. R. Petit, I. Basile - Doelsch, and V. Maggi (2008), Aeolian dust in East Antarctica (EPICA - Dome C and Vostok): Provenance during glacial ages over the last 800 kyr, Geophysical Research Letters, 35(7), doi:10.1029/2008GL033382. 
Delmonte, B., C. Baroni, P. S. Andersson, H. Schoberg, M. Hansson, S. Aciego, J. R. Petit, S. Albani, C. Mazzola, and V. Maggi (2010), Aeolian dust in the Talos Dome ice core (East Antarctica, Pacific/Ross Sea sector): Victoria Land versus remote sources over the last two climate cycles, Journal of Quaternary Science, 25(8), 1327-1337, doi:10.1002/jqs.1418.

Delmonte, B., I. Basile-Doelsch, J.-R. Petit, V. Maggi, M. Revel-Rolland, A. Michard, E. Jagoutz, and F. Grousset (2004a), Comparing the Epica and Vostok dust records during the last 220,000 years: stratigraphical correlation and provenance in glacial periods, EarthScience Reviews, 66(1), 63-87, doi:10.1016/j.earscirev.2003.10.004.

Delmonte, B., J. Petit, K. K. Andersen, I. Basile-Doelsch, V. Maggi, and V. Y. Lipenkov (2004b), Dust size evidence for opposite regional atmospheric circulation changes over east Antarctica during the last climatic transition, Climate Dynamics, 23(3-4), 427-438, doi:10.1007/s00382-004-0450-9.

Ding, Q., E. J. Steig, D. S. Battisti, and J. M. Wallace (2012), Influence of the tropics on the Southern Annular Mode, Journal of Climate, 25(18), 6330-6348, doi:10.1175/JCLI-D-1100523.1.

Draxler, R. R., and G. Hess (1998), An overview of the HYSPLIT_4 modelling system for trajectories, Australian Meteorological Magazine, 47(4), 295-308.

Dunbar, G., N. Bertler, and R. McKay (2009), Sediment flux through the McMurdo Ice Shelf in Windless Bight, Antarctica, Global and Planetary Change, 69(3), 87-93, doi:10.1016/j.gloplacha.2009.05.007.

Eden, D. N., and A. P. Hammond (2003), Dust accumulation in the New Zealand region since the last glacial maximum, Quaternary Science Reviews, 22(18), 2037-2052, doi:10.1016/S0277-3791(03)00168-9. 
Freidenreich, S. M., S. T. Garner, R. G. Gudgel, C. Gordon, and I. M. Held (2004), The new GFDL global atmosphere and land model AM2-LM2: Evaluation with prescribed SST simulations, Journal of Climate, 17(24), 4641-4673, doi:10.1175/JCLI-3223.1.

Gabrielli, P., A. Wegner, J. R. Petit, B. Delmonte, P. De Deckker, V. Gaspari, H. Fischer, U. Ruth, M. Kriews, and C. Boutron (2010), A major glacial-interglacial change in aeolian dust composition inferred from Rare Earth Elements in Antarctic ice, Quaternary Science Reviews, 29(1), 265-273, doi:10.1016/j.quascirev.2009.09.002.

Gaiero, D. M. (2007), Dust provenance in Antarctic ice during glacial periods: From where in southern South America?, Geophysical Research Letters, 34(17), doi:10.1029/2007GL030520.

Gassó, S., and A. F. Stein (2007), Does dust from Patagonia reach the sub - Antarctic Atlantic Ocean?, Geophysical Research Letters, 34(1), doi:10.1029/2006GL027693.

Ginoux, P., J. M. Prospero, T. E. Gill, N. C. Hsu, and M. Zhao (2012), Global - scale attribution of anthropogenic and natural dust sources and their emission rates based on MODIS Deep Blue aerosol products, Reviews of Geophysics, 50(3), doi:10.1029/2012RG000388.

Hallet, B., L. Hunter, and J. Bogen (1996), Rates of erosion and sediment evacuation by glaciers: a review of field data and their implications, Global and Planetary Change, 12(1), 213-235, doi:10.1016/0921-8181(95)00021-6.

Hosking, J. S., A. Orr, G. J. Marshall, J. Turner, and T. Phillips (2013), The influence of the Amundsen-Bellingshausen Seas low on the climate of West Antarctica and its representation in coupled climate model simulations, Journal of Climate, 26(17), 6633-6648, doi:10.1175/JCLI-D-12-00813.1.

Hoskins, B. J., and K. I. Hodges (2005), A new perspective on Southern Hemisphere storm tracks, Journal of Climate, 18(20), 4108-4129, doi:10.1175/JCLI3570.1. 
Kalnay, E., M. Kanamitsu, R. Kistler, W. Collins, D. Deaven, L. Gandin, M. Iredell, S. Saha, G. White, and J. Woollen (1996), The NCEP/NCAR 40-year reanalysis project, Bulletin of the American meteorological Society, 77(3), 437-471, doi:10.1175/15200477(1996)077<0437:TNYRP>2.0.CO;2.

Karoly, D. J. (1989), Southern hemisphere circulation features associated with El NiñoSouthern Oscillation events, Journal of Climate, 2(11), 1239-1252, doi:10.1175/15200442(1989)002<1239:SHCFAW>2.0.CO;2.

Kidson, J. W. (1988), Indices of the Southern Hemisphere zonal wind, Journal of Climate, l(2), 183-194, doi:10.1175/1520-0442(1988)001<0183:IOTSHZ>2.0.CO;2.

Koffman, B., K. Kreutz, D. Breton, E. Kane, D. Winski, S. Birkel, A. Kurbatov, and M. Handley (2014), Centennial-scale variability of the Southern Hemisphere westerly wind belt in the eastern Pacific over the past two millennia, Climate of the Past, 10(3), 1125-1144, doi:10.5194/cp-10-1125-2014.

Koons, P. (1990), Two-sided orogen: collision and erosion from the sandbox to the Southern Alps, New Zealand, Geology, 18(8), 679-682, doi:10.1130/0091-7613(1990) 018<0679:TSOCAE $>2.3 . \mathrm{CO} ; 2$

Küttel, M., E. J. Steig, Q. Ding, A. J. Monaghan, and D. S. Battisti (2012), Seasonal climate information preserved in West Antarctic ice core water isotopes: Relationships to temperature, large-scale circulation, and sea ice, Climate Dynamics, 39(7-8), 1841-1857, doi:10.1007/s00382-012-1460-7.

Lachlan - Cope, T., and W. Connolley (2006), Teleconnections between the tropical Pacific and the Amundsen - Bellinghausens Sea: Role of the El Niño/Southern Oscillation, Journal of Geophysical Research: Atmospheres (1984-2012), 111(D23), doi:10.1029/2005JD006386.

Lamy, F., R. Gersonde, G. Winckler, O. Esper, A. Jaeschke, G. Kuhn, J. Ullermann, A. Martínez-Garcia, F. Lambert, and R. Kilian (2014), Increased dust deposition in the Pacific 
Southern Ocean during glacial periods, Science, 343(6169), 403-407, doi:10.1126/science.1245424.

L'Heureux, M. L. and D. W. Thompson (2006), Observed relationships between the El NiñoSouthern Oscillation and the extratropical zonal-mean circulation, Journal of Climate, 19(2), 276-287.

Li, F., P. Ginoux, and V. Ramaswamy (2008), Distribution, transport, and deposition of mineral dust in the Southern Ocean and Antarctica: Contribution of major sources, Journal of Geophysical Research: Atmospheres (1984-2012), 113(D10), doi:10.1029/2007JD009190.

Li, F., P. Ginoux, and V. Ramaswamy (2010), Transport of Patagonian dust to Antarctica, Journal of Geophysical Research: Atmospheres (1984-2012), 115(D18), doi:10.1029/2009JD012356.

Lunt, D. J., and P. J. Valdes (2001), Dust transport to Dome C, Antarctica, at the Last Glacial Maximum and present day, Geophysical research letters, 28(2), 295-298, doi:10.1029/2000GL012170.

Luo, C., N. M. Mahowald, and J. Del Corral (2003), Sensitivity study of meteorological parameters on mineral aerosol mobilization, transport, and distribution, Journal of Geophysical Research: Atmospheres (1984-2012), 108(D15), doi:10.1029/2003JD003483.

Maher, B., J. Prospero, D. Mackie, D. Gaiero, P. Hesse, and Y. Balkanski (2010), Global connections between aeolian dust, climate and ocean biogeochemistry at the present day and at the last glacial maximum, Earth-Science Reviews, 99(1), 61-97, doi:10.1016/j.earscirev.2009.12.001.

Mahowald, N., S. Engelstaedter, C. Luo, A. Sealy, P. Artaxo, C. Benitez-Nelson, S. Bonnet, Y. Chen, P. Y. Chuang, and D. D. Cohen (2009), Atmospheric iron deposition: Global distribution, variability, and human perturbations*, Marine Science, 1, 245-278, doi:10.1146/annurev.marine.010908.163727. 
Mahowald, N., K. Kohfeld, M. Hansson, Y. Balkanski, S. P. Harrison, I. C. Prentice, M. Schulz, and H. Rodhe (1999), Dust sources and deposition during the last glacial maximum and current climate: A comparison of model results with paleodata from ice cores and marine sediments, Journal of Geophysical Research: Atmospheres (1984-2012), 104(D13), 1589515916, doi:10.1029/1999JD900084.

Markle, B., N. Bertler, K. Sinclair, and S. Sneed (2012), Synoptic variability in the Ross Sea region, Antarctica, as seen from back - trajectory modeling and ice core analysis, Journal of Geophysical Research: Atmospheres (1984-2012), 117(D2), doi:10.1029/2011JD016437.

Marshall, G. J. (2003), Trends in the Southern Annular Mode from observations and reanalyses, Journal of Climate, 16(24), 4134-4143, doi:10.1175/15200442(2003)016<4134:TITSAM>2.0.CO;2.

Martin, J. H., R. M. Gordon, and S. E. Fitzwater (1990), Iron in Antarctic waters, Nature, $345,156-158$.

Martínez-Garcia, A., A. Rosell-Melé, S. L. Jaccard, W. Geibert, D. M. Sigman, and G. H. Haug (2011), Southern Ocean dust-climate coupling over the past four million years, Nature, 476(7360), 312-315, doi:10.1038/nature10310.

McGowan, H. A., and A. Clark (2008), Identification of dust transport pathways from Lake Eyre, Australia using Hysplit, Atmospheric Environment, 42(29), 6915-6925, doi:10.1016/j.atmosenv.2008.05.053.

McGowan, H. A., A. P. Sturman, and I. F. Owens (1996), Aeolian dust transport and deposition by foehn winds in an alpine environment, Lake Tekapo, New Zealand, Geomorphology, 15(2), 135-146, doi:10.1016/0169-555X(95)00123-M.

Miller, R., and I. Tegen (1998), Climate response to soil dust aerosols, Journal of climate, 11(12), 3247-3267, doi:10.1175/1520-0442(1998)011<3247:CRTSDA>2.0.CO;2. 
Miller, R., I. Tegen, and J. Perlwitz (2004), Surface radiative forcing by soil dust aerosols and the hydrologic cycle, Journal of Geophysical Research: Atmospheres (1984-2012), 109(D4), doi:10.1029/2003JD004085.

Mo, K. C., and J. N. Paegle (2001), The Pacific-South American modes and their downstream effects, International Journal of Climatology, 21(10), 1211-1229, doi:10.1002/joc. 685 .

Nicolas, J. P., and D. H. Bromwich (2011), Climate of West Antarctica and influence of marine air intrusions*, Journal of Climate, 24(1), 49-67, doi:10.1175/2010JCLI3522.1.

Orsi, A., G. Johnson, and J. Bullister (1999), Circulation, mixing, and production of Antarctic Bottom Water, Progress in Oceanography, 43(1), 55-109, doi:10.1016/S00796611(99)00004-X.

Petit, J.-R., J. Jouzel, D. Raynaud, N. I. Barkov, J.-M. Barnola, I. Basile, M. Bender, J. Chappellaz, M. Davis, and G. Delaygue (1999), Climate and atmospheric history of the past 420,000 years from the Vostok ice core, Antarctica, Nature, 399(6735), 429-436, doi:10.1038/20859.

Renwick, J. A. (2004), Trends in the Southern Hemisphere polar vortex in NCEP and ECMWF reanalyses, Geophysical Research Letters, 31(7), L07209, doi:10.1029/2003GL019302.

Renwick, J. A. and M. J. Revell (1999), Blocking over the South Pacific and Rossby wave propagation, Monthly Weather Review, 127(10), 2233-2247.

Revel-Rolland, M., P. De Deckker, B. Delmonte, P. Hesse, J. Magee, I. Basile-Doelsch, F. Grousset, and D. Bosch (2006), Eastern Australia: a possible source of dust in East Antarctica interglacial ice, Earth and Planetary Science Letters, 249(1), 1-13, doi:10.1016/j.eps1.2006.06.028. 
Rhodes, R., N. Bertler, J. Baker, H. C. Steen-Larsen, S. Sneed, U. Morgenstern, and S. J. Johnsen (2012), Little Ice Age climate and oceanic conditions of the Ross Sea, Antarctica from a coastal ice core record, Climate of the Past, 8(4), 1223-1238, doi:10.5194/cp-8-12232012.

Sugden, D. E., R. D. McCulloch, A. J.-M. Bory, and A. S. Hein (2009), Influence of Patagonian glaciers on Antarctic dust deposition during the last glacial period, Nature Geoscience, 2(4), 281-285, doi:10.1038/NGEO474.

Tanaka, T. Y., and M. Chiba (2006), A numerical study of the contributions of dust source regions to the global dust budget, Global and Planetary Change, 52(1), 88-104, doi:10.1016/j.gloplacha.2006.02.002.

Tegen, I., and I. Fung (1994), Modeling of mineral dust in the atmosphere: Sources, transport, and optical thickness, Journal of Geophysical Research: Atmospheres (19842012), 99(D11), 22897-22914.

Thompson, D. W., and S. Solomon (2002), Interpretation of recent Southern Hemisphere climate change, Science, 296(5569), 895-899, doi:10.1126/science.1069270.

Thompson, D. W., and J. M. Wallace (2000), Annular modes in the extratropical circulation. Part I: month-to-month variability*, Journal of Climate, 13(5), 1000-1016, doi:10.1175/1520-0442(2000)013<1000:AMITEC>2.0.CO;2.

Timmermann, A., J. Oberhuber, A. Bacher, M. Esch, M. Latif, and E. Roeckner (1999), Increased El Niño frequency in a climate model forced by future greenhouse warming, Nature, 398(6729), 694-697, doi:10.1038/19505.

Torres, O., P. Bhartia, J. Herman, A. Sinyuk, P. Ginoux, and B. Holben (2002), A long-term record of aerosol optical depth from TOMS observations and comparison to AERONET measurements, Journal of the atmospheric sciences, 59(3), 398-413, doi:10.1175/15200469(2002)059<0398:ALTROA>2.0.CO;2. 
Turner, J. (2004), The El Niño-Southern Oscillation and Antarctica, International Journal of Climatology, 24(1), 1-31, doi:10.1002/joc.965.

Uno, I., K. Eguchi, K. Yumimoto, T. Takemura, A. Shimizu, M. Uematsu, Z. Liu, Z. Wang, Y. Hara, and N. Sugimoto (2009), Asian dust transported one full circuit around the globe, Nature Geoscience, 2(8), 557-560, doi:10.1038/ngeo583.

Vallelonga, P. (2015), the enigma of dust provenance: where else does Antarctic dust come from?, DUST, 24, 74 .

Vallelonga, P., P. Gabrielli, E. Balliana, A. Wegner, B. Delmonte, C. Turetta, G. Burton, F. Vanhaecke, K. Rosman, and S. Hong (2010), Lead isotopic compositions in the EPICA Dome C ice core and Southern Hemisphere Potential Source Areas, Quaternary Science Reviews, 29(1), 247-255, doi:10.1016/j.quascirev.2009.06.019.

Vallelonga, P., P. Gabrielli, K. Rosman, C. Barbante, and C. Boutron (2005), A 220 kyr record of $\mathrm{Pb}$ isotopes at Dome $\mathrm{C}$ Antarctica from analyses of the EPICA ice core, Geophysical research letters, 32(1), doi:10.1029/2004GL021449.

Vallelonga, P., K. Van de Velde, J.-P. Candelone, V. Morgan, C. Boutron, and K. Rosman (2002), The lead pollution history of Law Dome, Antarctica, from isotopic measurements on ice cores: 1500 AD to 1989 AD, Earth and Planetary Science Letters, 204(1), 291-306, doi:10.1016/S0012-821X(02)00983-4.

Wang, Y., A. F. Stein, R. R. Draxler, D. Jesús, and X. Zhang (2011), Global sand and dust storms in 2008: Observation and HYSPLIT model verification, Atmospheric Environment, 45(35), 6368-6381, doi:10.1016/j.atmosenv.2011.08.035.

Wegner, A., P. Gabrielli, D. Wilhelms-Dick, U. Ruth, M. Kriews, P. De Deckker, C. Barbante, G. Cozzi, B. Delmonte, and H. Fischer (2012), Change in dust variability in the Atlantic sector of Antarctica at the end of the last deglaciation, Climate of the Past, 8, 135147, doi:10.5194/cp-8-135-2012. 
Winckler, G., R. F. Anderson, M. Q. Fleisher, D. McGee, and N. Mahowald (2008), Covariant glacial-interglacial dust fluxes in the equatorial Pacific and Antarctica, Science, 320(5872), 93-96, doi:10.1126/science.1150595.

Winton, V., G. Dunbar, N. Bertler, M. A. Millet, B. Delmonte, C. Atkins, J. Chewings, and P. Andersson (2014), The contribution of aeolian sand and dust to iron fertilization of phytoplankton blooms in southwestern Ross Sea, Antarctica, Global Biogeochemical Cycles, 28(4), 423-436, doi:10.1002/2013GB004574.

Wolff, E. W., H. Fischer, F. Fundel, U. Ruth, B. Twarloh, G. C. Littot, R. Mulvaney, R. Röthlisberger, M. De Angelis, and C. F. Boutron (2006), Southern Ocean sea-ice extent, productivity and iron flux over the past eight glacial cycles, Nature, 440(7083), 491-496, doi:10.1038/nature04614.

Yuan, X., and D. G. Martinson (2000), Antarctic sea ice extent variability and its global connectivity*, Journal of Climate, 13(10), 1697-1717, doi:10.1175/15200442(2000)013<1697:ASIEVA>2.0.CO;2.

Zender, C. S., H. Bian, and D. Newman (2003), Mineral Dust Entrainment and Deposition (DEAD) model: Description and 1990s dust climatology, Journal of Geophysical Research: Atmospheres (1984-2012), 108(D14), doi:10.1029/2002JD002775. 


\subsection{Supporting Figures}
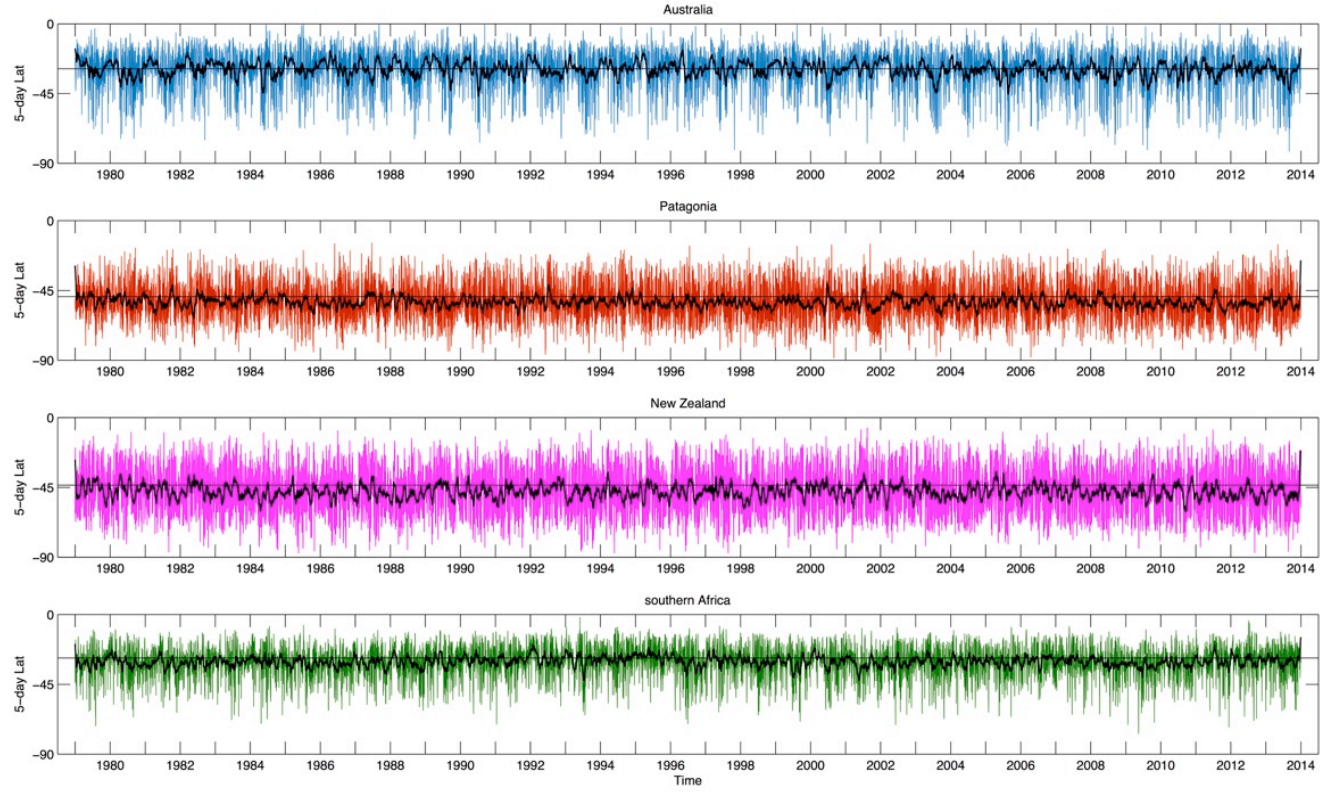

Figure S1. 5-day forward trajectory latitude for Australia (blue), Patagonia (orange), New Zealand (magenta) and southern Africa (green) dust PSA initiation points. Daily data is colored, solid black lines are a 30-point smooth, horizontal lines indicate latitude of trajectory initiation.
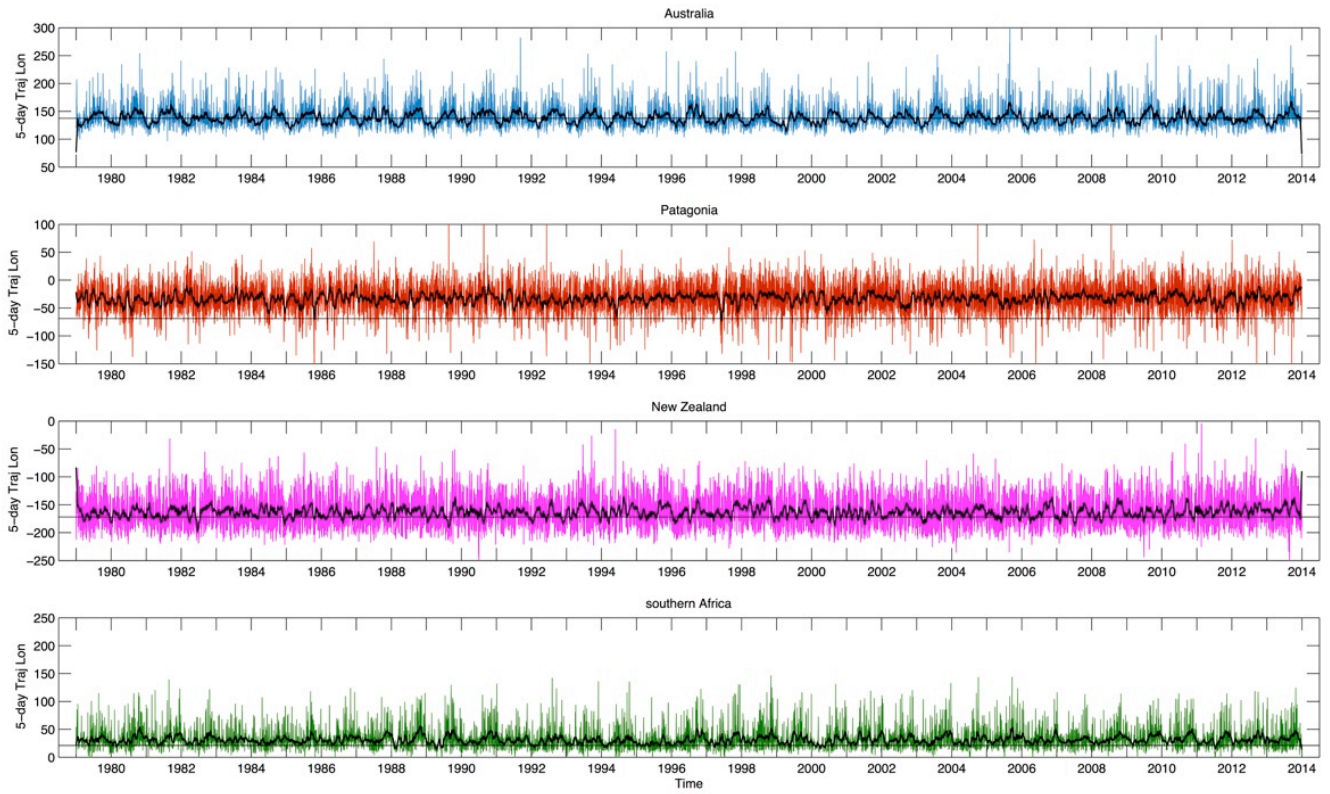

Figure S2. 5-day forward trajectory longitude for Australia (blue), Patagonia (orange), New Zealand (magenta) and southern Africa (green) dust PSA initiation points. Daily data is 
colored, solid black lines are a 30-point smooth, horizontal lines indicate longitude of trajectory initiation.
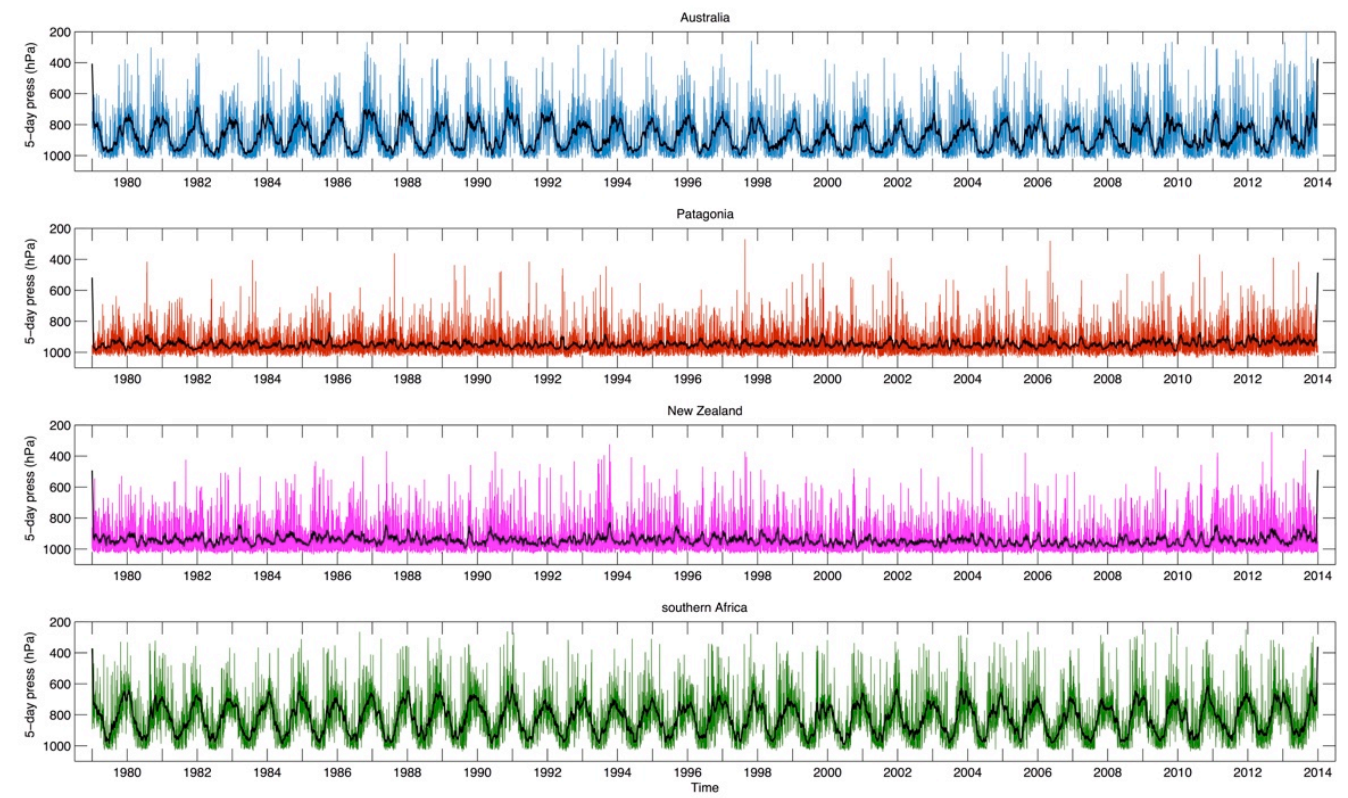

Figure S3. 5-day forward trajectory pressure (hPa) for Australia (blue), Patagonia (orange), New Zealand (magenta) and southern Africa (green) dust PSA initiation points. Daily data is colored, solid black lines are a 30-point smooth, horizontal lines indicate latitude of trajectory initiation. 
a) ANN ERAi CTP SST vs Uwind

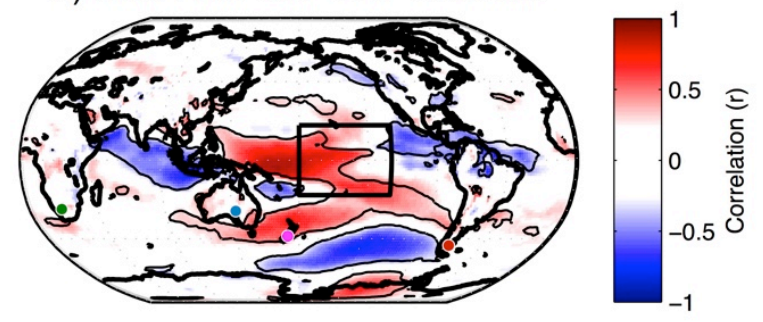

b) DJF ERAi CTP SST vs Uwind

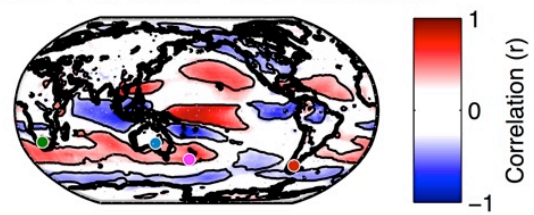

d) JJA ERAi CTP SST vs Uwind

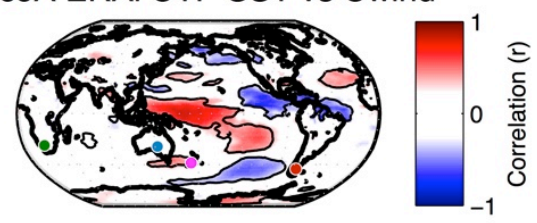

c) MAM ERAi CTP SST vs Uwind

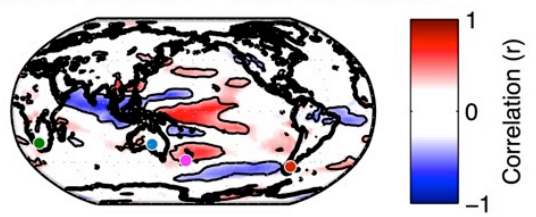

e) SON ERAi CTP SST vs Uwind

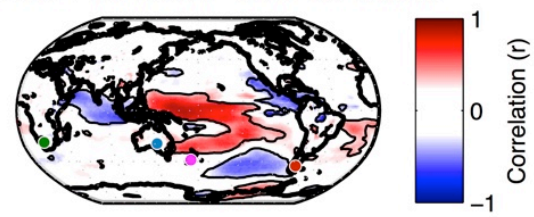

Figure S4. Spatial correlation of 1979-2013 ERA-Interim reanalysis central tropical Pacific sea-surface temperature (CTP SST, $\left.20^{\circ} \mathrm{N}-20^{\circ} \mathrm{S}, 180^{\circ} \mathrm{E}-240^{\circ} \mathrm{E}\right)$ versus $10 \mathrm{~m}$ eastward zonal (U) wind. Mean annual relationsip (ANN, a), December-January-February (DJF, b), MarchApril-May (MAM, c), June-July-August (JJA, d), and September-October-November (SON, e). Dust PSA are marked by colored circles, New Zealand (magenta), Patagonia (orange), southern Africa (green) and Australia (cyan). Black contour indicates $>95 \%$ significance. 
a) ANN ERAi CTP SST vs Vwind

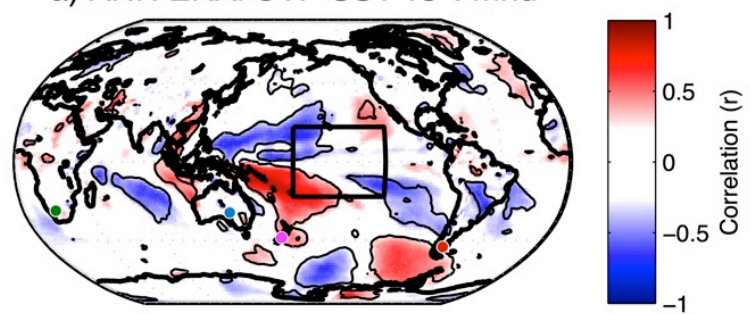

b) DJF ERAi CTP SST vs Vwind

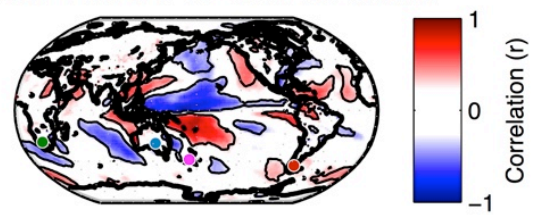

d) JJA ERAi CTP SST vs Vwind

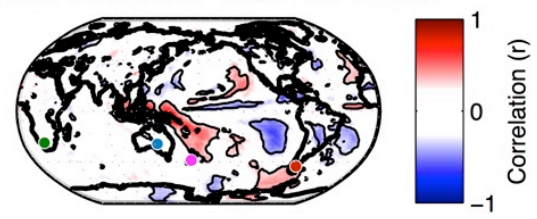

c) MAM ERAi CTP SST vs Vwind

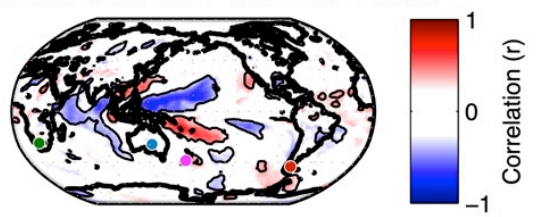

e) SON ERAi CTP SST vs Vwind

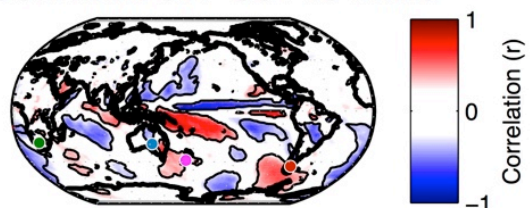

Figure S5. Spatial correlation of 1979-2013 ERA-Interim reanalysis central tropical Pacific sea-surface temperature (CTP SST, $\left.20^{\circ} \mathrm{N}-20^{\circ} \mathrm{S}, 180^{\circ} \mathrm{E}-240^{\circ} \mathrm{E}\right)$ versus $10 \mathrm{~m}$ northward meridional $(V)$ wind. Mean annual relationsip (ANN, a), December-January-February (DJF, b), March-April-May (MAM, c), June-July-August (JJA, d), and September-OctoberNovember (SON, e). Dust PSA are marked by colored circles, New Zealand (magenta), Patagonia (orange), southern Africa (green) and Australia (cyan). Black contour indicates $>95 \%$ significance. 
a) ANN Marshall SAM vs ERAi $z 500$

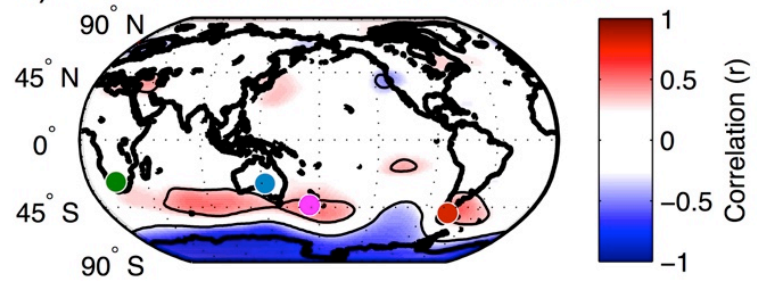

b) DJF Marshall SAM vs ERAi z500

c) MAM Marshall SAM vs ERAi z500
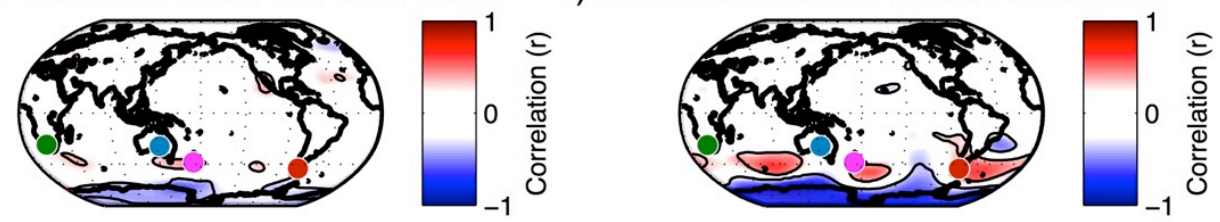

d) JJA Marshall SAM vs ERAi z500

e) SON Marshall SAM vs ERAi z500
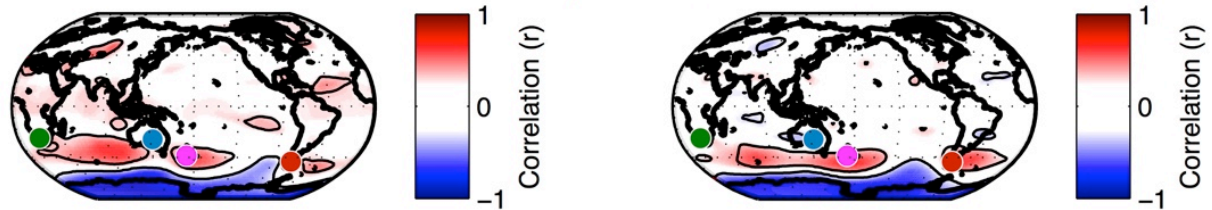

Figure S6. Spatial correlation of the Marshall SAM index (difference between observed zonal mean sea level pressures at $40^{\circ} \mathrm{S}$ and $65^{\circ} \mathrm{S}$, Marshall, 2003) versus $500 \mathrm{hPa}$ geopotential height, plotted as in Figure 11. Mean annual relationsip (ANN, a), DecemberJanuary-February (DJF, b), March-April-May (MAM, c), June-July-August (JJA, d), and September-October-November (SON, e). Dust PSA are marked by colored circles, New Zealand (magenta), Patagonia (orange), southern Africa (green) and Australia (cyan). Black contour indicates $>95 \%$ significance. 


\section{Chapter 3: Low-Femtogram Elemental Analysis of Antarctic Ice Cores without Preconcentration}

\section{Abstract}

The Antarctic ice sheet preserves minute quantities of atmospheric material in a chronological sequence, providing an important historical record for bounding future changes in climate and atmospheric composition. Many chemical species in the ice are only present at the femtogram (fg $\mathrm{g}^{-1}, 10^{-15} \mathrm{~g}$ ) level, and analysis of these species has accordingly required preconcentration and large sample volumes difficult to obtain from deep within the ice sheet. We report the elemental analysis of Antarctic ice at the low $\mathrm{fg}^{-1}$ level using a sector-field inductively coupled plasma mass spectrometer enhanced with a jet interface (Jet-SF-ICPMS) and desolvation nebulizer without preconcentration. The study investigates rare earth elements (REE), transition and post-transition metals, actinide, metalloid, alkali and alkaline earth elements, presenting extremely low detection limits $\left(<10 \mathrm{fg} \mathrm{g}^{-1}\right)$ determined for many elements. Analytical background concentrations are essentially equal to these detection limits, suggesting that sample preparation methods and contamination levels are of primary importance in the pursuit of ultra-trace geochemical proxy information from polar ice cores.

\subsection{Introduction}

Polar ice cores provide records of past atmospheric composition and proxies of polar climate and that of teleconnected regions. ${ }^{1,2}$ Chemical information preserved in layers of snow and ice takes the form of soluble and insoluble aerosols, gas phase species and the isotopic composition of both the ice and its impurities. Many of the impurities in Antarctic ice (e.g. mineral dust, ${ }^{3,4}$ black carbon aerosols ${ }^{5}$ ) have few local sources and reflect transcontinental emissions and transport. Other species derive from regional marine emissions and reflect wind strength, sea-ice extent and biological productivity. ${ }^{6-7}$ Large transient events such as volcanic eruptions, ${ }^{8,9}$ and long-term changes in atmospheric pollution ${ }^{10}$ are captured and allow a remote gauge of atmospheric change. Hence, well-dated glaciochemical time series can constrain the behavior of these processes on a range of spatial and temporal scales. Higher-order information from the records can be obtained through the disaggregation of chemical sources. The analysis of $\mathrm{Pb}^{11,12}$ and $\mathrm{Sr} / \mathrm{Nd}^{13}$ isotope ratios and rare earth element (REE) abundance ${ }^{14-15}$ has been used to identify major sources of mineral dust and anthropogenic pollutants.

Many of the chemical species in the Antarctic ice core record are present at extremely low concentrations ranging from a few femtograms $\left(\mathrm{fg}^{-1}, 10^{-15} \mathrm{~g}\right)$ to the low picogram $\left(\mathrm{pg} \mathrm{g}^{-}\right.$ $1,10^{-12} \mathrm{~g}$ ) level. While seemingly insignificant, measurements of REE concentration at the fg 
$\mathrm{g}^{-1}$ level in Antarctic ice core samples provide insight into major climate and environmental changes. For example, at the Dome $\mathrm{C}^{16}$ and Drønning Maud Land ${ }^{15}$ sites in East Antarctica, a major shift in REE signatures suggests increased dust source variability beginning $\sim 15 \mathrm{ka}$ before present, during the transition from the last glacial period to the present interglacial. This work represents some of the lowest-concentration measurements of glaciochemical species, using sector-field inductively coupled plasma mass spectrometry (SF-ICPMS) for elemental analysis. ${ }^{14}$ These instruments can detect multiple elements across a large range of concentrations, typically nanograms $\left(\mathrm{ng} \mathrm{g}^{-1}, 10^{-9} \mathrm{~g}\right.$ ) to low $\mathrm{pg} \mathrm{g}^{-1}$, with high-sensitivity and small sample volumes $(<5 \mathrm{~mL})$. While the sensitivity of SF-ICPMS is already high, it can be increased further through the use of high-efficiency sample introduction systems ${ }^{17}$ and by increasing ion transport into the mass analyser using a jet interface - a high capacity pump and large orifice cones. ${ }^{18}$ Appropriate acid digestion and sample preparation schemes are also essential for reliable measurements of ice samples. ${ }^{19-20}$ Acid leaching of mineral particles in these samples results in a rapid increase in lithogenic element concentration in the first hours after acidification, followed by continued increases for several weeks after acidification. The variability introduced by acidification schemes requires the establishment and reporting of consistent methodologies for interpreting ice core ICPMS trace-element data.

Here we report the analysis of ice core samples from Antarctica, collected as part of the Roosevelt Island Climate Evolution (RICE) project. Concentrations are quantified to the low $\mathrm{fg}^{-1}$ level using a sector-field inductively coupled plasma mass spectrometer enhanced with a jet interface (Jet-SF-ICPMS) and desolvation nebulizer. This high transport-efficiency sample inlet system achieves reduced instrument backgrounds and improved instrument sensitivity and signal stability. This study focuses on thirty species, including REE, transition and post-transition metals, actinide, metalloid, alkali and alkaline earth elements - all at subng concentrations. Extremely low detection limits $\left(<10 \mathrm{fg} \mathrm{g}^{-1}\right)$ are achieved for many elements without preconcentration, at or below levels of background contamination in the laboratory environment. To assess data quality, details of acidified sample stability, background contamination and instrumental limits are presented.

\subsection{Experimental}

\subsubsection{Materials, Reagents and Standards}

Optima ${ }^{\mathrm{TM}}$ (Fisher Scientific) $\mathrm{HNO}_{3}$ and ultra-clean water $(>18 \mathrm{M} \Omega$ ) were used in cleaning of laboratory materials and acidification of samples at Victoria University of Wellington and GNS Science in New Zealand. Vials for ice core sampling were cleaned in a series of acid baths $\left(1 \% \mathrm{HNO}_{3} \mathrm{v} / \mathrm{v}\right)$ of increasing purity. Sub-boiled double-distilled $\mathrm{HNO}_{3}$ 
prepared in the Curtin University TRACE facility was used to clean vials and acidify blanks and standards used during ICPMS analysis. Standards, including quality control (QC) samples, were made from certified single- and multi-element stock solutions (Elemental Scientific).

\subsubsection{Ice Core Sampling}

The 763 m-long RICE ice core was drilled at Roosevelt Island, Antarctica (79.364 ${ }^{\circ} \mathrm{S}$, $161.706^{\circ} \mathrm{W}$ ), a coastal ice dome at the margin of the Ross Ice Shelf. The core was cut into one-meter sections, packed into polyethylene bags and shipped frozen to New Zealand for sampling. Sticks of ice $(\sim 3.4 \mathrm{~cm} \times 3.4 \mathrm{~cm} \times 100 \mathrm{~cm})$ were prepared and placed on a heated gold-plated copper melt-head, sectioned to isolate pristine interior ice and remove contaminated outer ice surfaces (Continuous Flow Analysis, CFA ${ }^{21,22}$ ). Water from the inner section of the melt-head was pumped to fraction collectors, located inside HEPA-filtered hoods, filling $10 \mathrm{~mL}$ sample vials with $\sim 4 \mathrm{~mL}$ of water. Discussed here are 784 samples from the RICE ice core spanning $9 \mathrm{~m}$ to $40 \mathrm{~m}$ depth (dated using annual chemistry to approximately 1900 - 1990 CE). Procedural blanks were collected throughout ice core processing and at all stages of sample preparation to assess maximum contamination during preparatory stages. Sticks of frozen ultra-clean $(>18 \mathrm{M} \Omega$ ) water were prepared in the same way as ice core samples and passed through the CFA system. Measured concentrations in these blanks were in all instances significantly higher than any measured ice core sample concentrations, likely due to ultra-clean melt water scavenging trace material from CFA tubing walls. Because of this, these blanks are not considered further (i.e. are not subtracted from measured sample concentrations). All samples were stored frozen until acidification, and acidified samples were subsequently frozen only during shipment from New Zealand to Curtin University, Perth, Australia to prevent agitation and contact with vial caps known to contain barium $\left({ }^{137} \mathrm{Ba}\right.$ is quantified here).

\subsubsection{Sample Acidification}

Aerosols contained in ice core samples exist in water-soluble and -insoluble mineralogical matrices. To recover total aerosol concentrations, the sample has to be acidified with the aim of complete digestion of particulates into a leachate. Ice core trace element analysis in an online CFA arrangement, where the sample is melted and water is immediately pumped away, acidified and injected directly into an ICPMS, ${ }^{23}$ results in trace element concentrations that are representative of the water-soluble fraction (plus occasional mineral particles vaporized and ionized in the plasma). Ice core ICPMS analyses, as here, are also commonly performed on discrete samples taken in vials during ice core continuous flow 
sampling, ${ }^{21}$ which are then acidified prior to analysis. Unless leaching rates are observed and quantified, comparison of ice core trace-element concentrations collected from online continuous flow analysis (water-soluble trace element fraction) and those from discrete samples (water-soluble plus partial digestion of particulate trace elements) proves challenging. For instance, Edwards and Sedwick $(2001)^{24}$ and Edwards et al. (2006) ${ }^{19}$ reported that an extended leaching time (up to three months) was required for the analysis of lithogenic iron $(\mathrm{Fe})$ in Antarctic ice and snow using a $0.1 \%$ hydrochloric acid acidification scheme.

Rhodes et al. $(2011)^{25}$ and Koffman et al. $(2014 \mathrm{~b})^{20}$ clearly demonstrate that acidification time and strength affect trace-element concentrations in ice core samples. Lithology and particle size also affect measured concentrations of many elements, suggesting that similar tests are required at individual ice core sites undergoing different aerosol transport regimes. In polar snow and ice, concentration changes over three months are limited for water-soluble elements such as $\mathrm{Mg}, \mathrm{S}, \mathrm{K}, \mathrm{Ca}$ and $\mathrm{Na}$, while elements associated with particulates, such as $\mathrm{Al}, \mathrm{Mn}, \mathrm{Fe}, \mathrm{La}$ and $\mathrm{Pb}$, change substantially. Koffman et al. $(2014 \mathrm{~b})^{20}$ note similar leaching behavior of $\mathrm{Fe}$ and $\mathrm{Al}$, which continue to increase in concentration while most other particulate-associated elements cease changing significantly after one month. Both the Rhodes ${ }^{25}$ and Koffman ${ }^{20}$ studies conclude that ice core samples should be acidified (to $1 \% \mathrm{HNO}_{3}$ ) for at least one month prior to analysis to minimize these leaching effects.

To verify this behavior and determine acidification procedures for RICE ice core samples, we replicated the experiment of Rhodes et al. $(2011)^{25}$ using surface snow from Roosevelt Island. Solutions were prepared and the experiment undertaken in the same class 100 laboratory facilities as the original study. Snow from Roosevelt Island was collected during the 2010-2011 austral summer, placing freshly fallen snow into $\mathrm{HNO}_{3}$-rinsed Nalgene bottles. These solutions were acidified to $1 \% \mathrm{HNO}_{3} \mathrm{v} / \mathrm{v}$ and sampled at set times to allow for examination of changes in trace element concentration. Sampling was undertaken for eight weeks. The samples were analysed for a routine suite of trace elements using an Element 2 SF-ICPMS (Thermo Scientific) at Victoria University of Wellington. An SC-2 FAST autosampler (Elemental Scientific) coupled to a peristaltic pump was used for sample introduction, connected to a micro-flow Teflon nebuliser and a cooled double-bypass quartz spray chamber. Standard nickel sample and skimmer cones were used. Calibration was achieved using a set of eight dilutions of a certified multi-element standard (Inorganic Ventures). A run blank of ultra-pure water acidified to $1 \% \mathrm{HNO}_{3} \mathrm{v} / \mathrm{v}$ and an external 
standard (SLRS-4 riverine water) bracketed every 9 samples, and were used to provide instrument background correction and to assess accuracy and reproducibility of analyses. Measured values of SLRS-4 for most analytes were within 5\% of accepted values (i.e. GeoReM, http://georem.mpch-mainz.gwdg.de/). Considered below are well-quantified measurements of Fe (0.5\% SLRS-4 accuracy), Mn (2.7\%) and La (3\%), representative of metal and REE acid-leaching behavior.

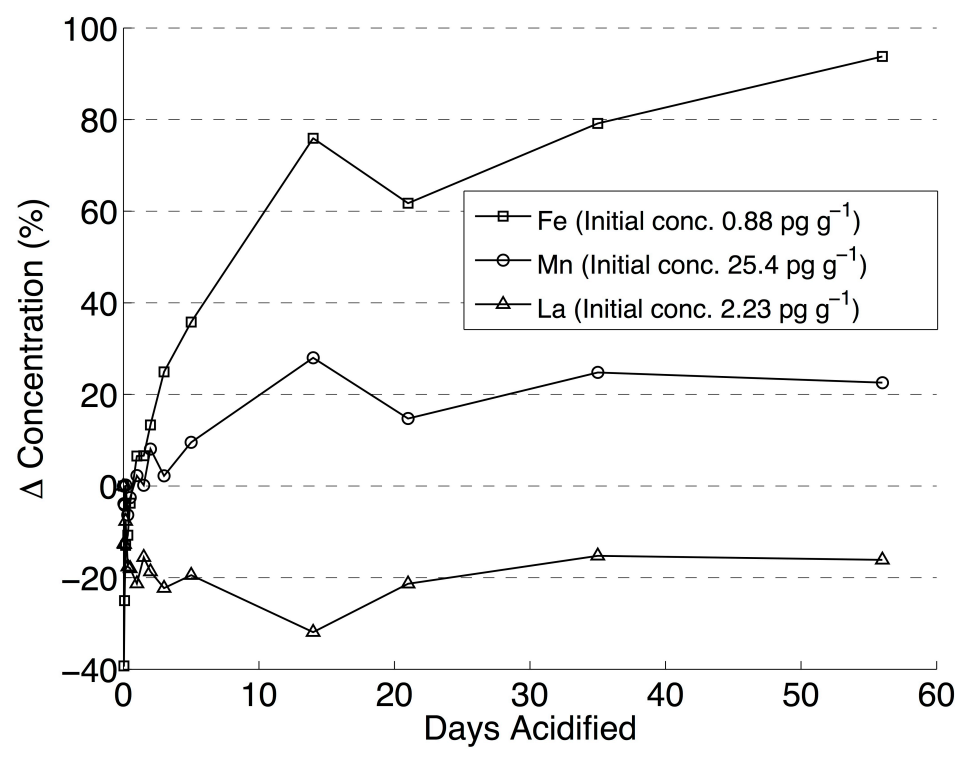

Figure 1. Eight-week percent concentration change in acidified $\left(1 \% \mathrm{HNO}_{3} \mathrm{v} / \mathrm{v}\right) \mathrm{RICE}$ Antarctic snow sample, for Fe, Mn and La.

In the RICE snow samples, these elements show significant concentration change over the 8-week sampling period (Figure 1), with rapid changes during the first 24 hours following acidification and continued large changes during the ensuing two weeks. Fe and $\mathrm{Mn}$ show the same pattern of concentration increase over time as the $1 \% \mathrm{HNO}_{3} \mathrm{v} / \mathrm{v}$ test in Koffman et al. (2014b), ${ }^{20}$ rising by $20-80 \%$ in the first two weeks after acidification. La, in contrast, shows a small decrease in concentration. While other elements stabilize after 3 to 5 weeks, $\mathrm{Fe}$ continues to increase in concentration through the eighth week following acidification (Figure 1). This confirms that an acidification time longer than two months is necessary to allow all elements to stabilize to a point where leaching effects on measured sample concentration become negligible. RICE samples were acidified at the Victoria University of Wellington three months prior to analysis, in a class 100 clean room under laminar-flow hoods. Open vials of $1 \% \mathrm{HNO}_{3} \mathrm{v} / \mathrm{v}$ were placed in hoods for several hours 
during this process, and are presented below as procedural blanks quantifying maximum background contamination.

\subsubsection{Analytical Environment}

Ice core sample analysis and standard preparation was performed in the John de Laeter Centre Trace Research Advanced Clean Environment facility (TRACE) at Curtin University, Western Australia. The TRACE Facility is a unique, purpose-built, clean air environment designed for measuring extremely-low concentrations of chemical species. The laboratory consists of a large, class 100 clean air containment area, provided with air that has been passed through three stages of particulate filtration. The containment space houses five individual laboratory modules that provide an additional level of air filtration (class 10) and separation of activities. All cleaning procedures, sample and reagent preparation activities occurred in the laboratory modules. Analysis by SF-ICPMS occurred in the containment space.

\subsubsection{Instrument Setup}

Ice core sample analysis was performed using an Element XR (Thermo Scientific) SF-ICPMS with a jet interface (a high-capacity jet interface pump with nickel X-Skimmer and Jet-Sampler cones, Jet-SF-ICPMS). The ICPMS torch, auto-sampler and nebulizer desolvation system were all from Elemental Scientific Inc. (ESI). These included an enclosed (acrylic sample enclosure) seaFAST S2 high-purity syringe-pump auto-sampler (configured for direct injection), connected to an APEX-Q desolvation system $\left(100^{\circ} \mathrm{C} /\right.$ $+2{ }^{\circ} \mathrm{C}$ ) fitted with a PFA-ST nebuliser. An additional gas (high purity nitrogen) was introduced to the APEX and adjusted for optimal response. The desolvation system was coupled to the ICPMS torch using a PFA aerosol focusing connector with an additional argon gas (Ar) of $0.350 \mathrm{~L} \mathrm{~min}^{-1}$. The ICP torch Ar gas flow rates were: $\operatorname{cool}$ gas $=16 \mathrm{~L} \mathrm{~min}^{-1}$; auxiliary gas $0.7 \mathrm{~L} \mathrm{~min}^{-1}$, and sample gas flow $\sim 0.8 \mathrm{~L} \mathrm{~min}^{-1}$ (tuned after every run $\sim 32$ hours). Instrument forward power was set $1248 \mathrm{~W}$.

Ice core samples were introduced to the system at a flow rate of $200 \mu \mathrm{L} \mathrm{min}{ }^{-1}$ using a $2 \mathrm{~mL}$ sample loop on the seaFAST2 injection valve and a syringe pumped carrier solution $(1 \% \mathrm{HNO} 3 \mathrm{v} / \mathrm{v})$. Internal standard (1.5 $\mathrm{ng} \mathrm{g}^{-1}$ Indium, $\left.1 \% \mathrm{HNO} 3 \mathrm{v} / \mathrm{v}, 100 \mu \mathrm{L} \mathrm{min}{ }^{-1}\right)$ was mixed inline with the sample and carrier solutions using an internal tee built into the autosampler injection valve. In between samples, the sample probe was rinsed with ultrapure $1 \% \mathrm{HNO} 3 \mathrm{v} / \mathrm{v}$. The total flow rate into the APEX-Q was $300 \mu \mathrm{L} \mathrm{min}^{-1}$, resulting in a diluted internal standard concentration of $0.5 \mathrm{ng} \mathrm{g}^{-1}{ }^{115}$ In which gave a response of $\sim 7 \times 10^{6}$ counts 
per second (equivalent to $14 \times 10^{6}$ counts per second for $1 \mathrm{ng} \mathrm{g}^{-1}{ }^{115} \mathrm{In}$ ) at low mass resolution. This high sensitivity was maintained throughout the analysis period.

\subsubsection{Run Structure}

Samples were analyzed in approximately 32 hour runs, structured with three calibrations of ten multi-element standards placed at the beginning, middle and end of the analytical sequence. Between calibrations, groups of ten samples were bracketed by an instrumental "run" blank and a QC sample (taken from middle-concentration standard; elemental concentrations detailed in Table 1). After every second group of ten samples an additional QC was analyzed as a duplicate to assess repeatability. A typical run consisted of 210 samples, with 59 additional analytes including standards, run blanks, QCs and duplicates.

\subsubsection{Calibration}

All ion intensities were normalized to the ${ }^{115}$ In internal standard, with values calculated for a desired isotope, $I$, where:

$$
I=I_{\text {meas }} \times \frac{c_{\mathrm{IS}}}{I_{\mathrm{IS}}} .
$$

$I_{\text {meas }}$ is the measured intensity of the desired isotope, $c_{I S}$ is the concentration of the internal standard, and $I_{I S}$ is the measured intensity of the internal standard. Normalized intensities were calibrated using ten external standards prepared from NIST traceable elemental standards (diluted in $1 \% \mathrm{HNO}_{3} \mathrm{v} / \mathrm{v}$ ). Blank corrections were determined from the instrumental run blank concentrations. The run blank (average of 10 per $\sim 32$ hour run) was subtracted from all samples and calibration standards. Procedural blanks were determined and used to assess contamination of the samples from the acidification procedure. Linear equations were determined for the external calibrations using bi-square weighted robust linear regression ${ }^{26}$. The regression method was chosen to minimize the effect of outliers on the linear fit (i.e. points near the line get greater weight). A small number of outliers $(>3 \sigma)$ were manually removed from standard calibrations and a new regression calculated.

\subsection{Results and Discussion}

\subsubsection{Quality Control Recoveries and Stability at the Low $\mathrm{Pg} \mathrm{g}^{-1}$ to $\mathrm{Fg} \mathrm{g}^{-1} \mathrm{Level}$}

Elemental recoveries and instrument stability were assessed using the QC standards (run after every 10 samples). Statistics for the QCs determined over four individual $\sim 32$ hour run periods are shown in Table 1 . Recoveries are between $95 \%$ and $100 \%$ for most elements analyzed. QC stability for selected elements is presented in Figure 2 for a 60-hour period of near-continuous analysis. QC stability and replication is excellent across this time period, with no evidence for significant memory effects, suggesting autosampler washout procedures 
are effective. Accuracy is $>95 \%$ for all transition- and post-transition metals, and measurements are precise to within 5\% (Table 1). Additionally, measurements of actinides are excellent with a mean concentration of $100 \%$ for ${ }^{232} \mathrm{Th}$, precise to within $4 \%$, and a mean concentration of ${ }^{238} \mathrm{U}$ only $1 \%$ greater than the known QC concentration suggesting only limited ${ }^{238} \mathrm{U}^{16} \mathrm{O}$ formation - and this at a very low concentration of $0.02 \mathrm{pg} \mathrm{g}^{-1} \cdot{ }^{52} \mathrm{Cr}$ and ${ }^{75} \mathrm{As}$ (Figure $2 \mathrm{~b}$ ) show $80 \%$ and $98 \%$ recovery of expected QC concentration, with $10 \%$ standard deviation at concentrations less than $5 \mathrm{pg} \mathrm{g}^{-1}$.

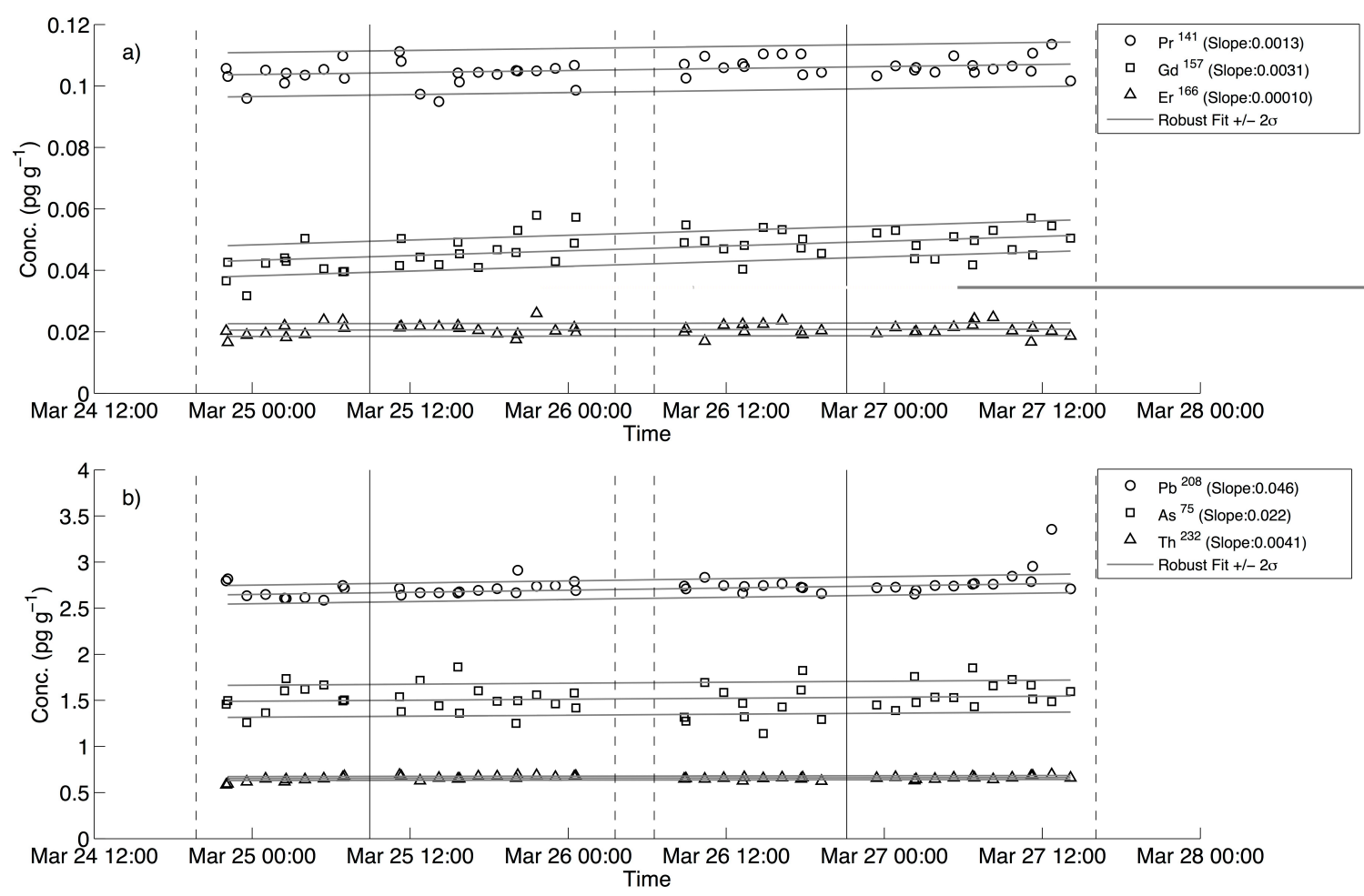

Figure 2. Low-concentration $Q C$ stability through a $\sim 60$-hour analysis period for a) REE (Pr, Gd, Er) and b) Pb, As and Th. Robust linear fits (grey line) are plotted through QCs, with $\pm 2 \sigma$ (dashed). Solid vertical lines mark standard calibrations used in final concentration calculations, dashed vertical lines mark additional calibrations.

Measurements of REE, present in the QC at $1 \mathrm{pg} \mathrm{g}^{-1}$ and below-similar to levels in RICE Antarctic ice core samples-are excellent for the light REE ( $\mathrm{La}, \mathrm{Ce}, \mathrm{Pr}, \mathrm{Nd}$ ) with measured QC concentrations averaging essentially 100\% of known concentrations and standard deviation $\leq 4 \%$. The lower-concentration medium REE ( $\mathrm{Sm}, \mathrm{Eu}, \mathrm{Gd}, \mathrm{Tb}, \mathrm{Dy}, \mathrm{Ho}$ ) and heavy REE (Er, Tm, Yb, Lu) also accurately recover QC concentrations ( $>90 \%)$, with even the lowest mean QC concentration of $0.005 \mathrm{pg} \mathrm{g}^{-1}{ }^{175} \mathrm{Lu}$ being $84 \%$ accurate, to within $\sim 1 \mathrm{fg} \mathrm{g}^{-1}$. Figure $2 \mathrm{a}$ demonstrates QC stability across the REE, showing results over $\sim 60$ 
hours for Pr, Gd and Er QCs. Measurements of medium and heavy REE are all precise to within $\sim 5 \mathrm{fg} \mathrm{g}^{-1}$ or less.

\subsubsection{Oxide formation}

The instrument was set each run to minimize oxide formation, tuned for ${ }^{238} \mathrm{U}^{16} \mathrm{O}$ production $<5 \%$ and including standard REE oxide corrections ${ }^{27}$. None of the REE exhibits appreciable additional recovery beyond the expected concentration of the QCs. As an additional test, REE-specific standards were prepared and measured in isolation, to observe whether oxide formation in mixed-element standards and QCs (which included ${ }^{137} \mathrm{Ba}$ ) increased recovery of REE. No significant difference was observed.

\subsubsection{Limits of Quantification and Concentration in Antarctic Ice Samples}

Many ice core trace element studies report estimates of instrumental limits of detection as three times the standard deviation of limited measurements of an ultrapure acid solution. ${ }^{14,20}$ While this is a critical measure, we provide a broader assessment to include all effects during analysis. Procedural and analytical background concentrations have the potential to limit quantification. Limits of detection for sector-field ICPMS instruments are expected in most cases to be well below blank concentrations due to background contamination during sampling procedures and laboratory analysis. ${ }^{28}$ Means of analytical "run" blanks $(n=86)$ and procedural blanks $(n=13)$ are plotted in Figure 3a, as well as mean RICE Antarctic ice core sample concentration $(n=784)$ for comparison. Values are detailed in Table 2, including $3 \sigma$ limits of detection. These values represent the long-term backgrounds associated with this analytical campaign. Within individual runs samples were corrected for the analytical blank of that run-that is, the mean value of 10 measured run blanks (excluding $3 \sigma$ outliers). Mean sample relative standard deviation (RSD, sample standard deviation divided by mean concentration) for all isotopes is presented in Figure $3 \mathrm{~b}$ as a measure of signal stability during analysis. RSD should not be confused with standard deviation of sample concentrations displayed in Table 2, which are included to demonstrate natural variability of concentrations in Antarctic ice samples.

Determinations of transition metals ${ }^{55} \mathrm{Mn}$ and ${ }^{56} \mathrm{Fe}$ are excellent (Figure 3a), with high accuracy and precision, low analytical and procedural blanks compared to concentrations found in ice core samples and sample RSD across all runs $<5 \%$ (Figure $3 \mathrm{~b}$ ). Both procedural and analytical blanks for ${ }^{59} \mathrm{Co}$, however, are nearly identical to mean ice core sample concentration, and sample RSD is $11-13 \%$. Although ${ }^{52} \mathrm{Cr}$ is well-determined, with low sample RSD $(<5 \%)$, blank concentrations are several times higher than mean ice core sample values (Figure $3 \mathrm{a}$ ). ${ }^{63} \mathrm{Cu}$ procedural blanks are high due to the gold-plated copper melt-head 
used to sample ice cores. Barring this procedural contamination, determination of ${ }^{63} \mathrm{Cu}$ sampled in a different manner would be excellent using this ICPMS instrumentation, as sample RSD across all runs is only $2-3 \%$ and measurements are very accurate and precise (Table 1).
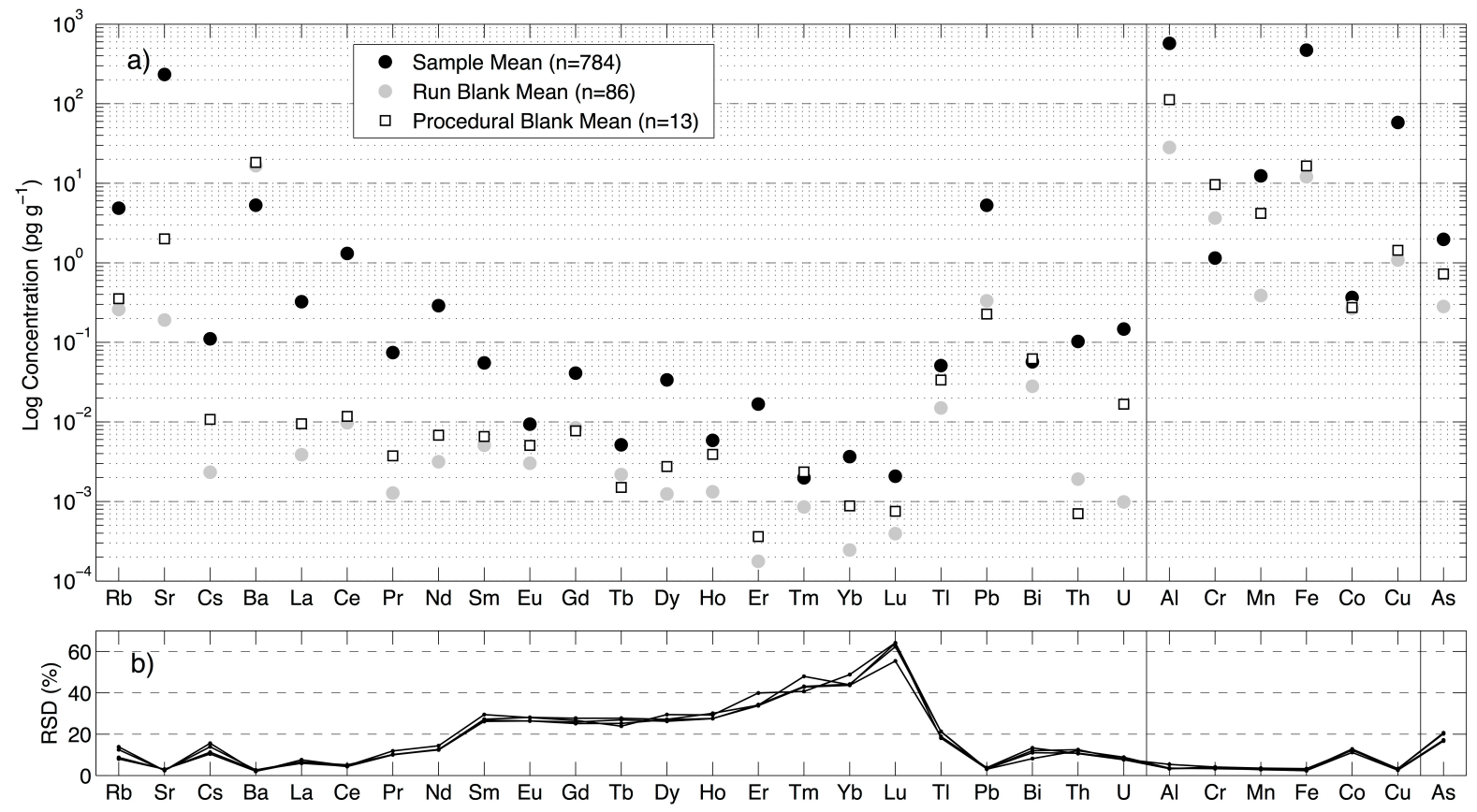

Figure 3. (a) Sample (black circle), run blank (grey circle) and procedural blank (white square) mean concentrations (logarithmic scale) for all isotopes. Vertical lines separate isotopes analyzed at low, medium and high instrument resolution from left to right. (b) Sample relative standard deviation (RSD, \%) for all isotopes, as an average of individual analytical runs; each run plotted as a black line.

Post-transition metals ${ }^{205} \mathrm{Tl}$ and ${ }^{209} \mathrm{Bi}$ (Figure 3a) are quantifiable to concentrations as low as tens of $\mathrm{fg} \mathrm{g}^{-1}$ (i.e. parts per quadrillion), with RICE ice core sample concentrations only slightly above these levels. Sample RSD are $\sim 20 \%$ and $\sim 10 \%$ across all runs for ${ }^{205} \mathrm{Tl}$ and ${ }^{209} \mathrm{Bi}$, respectively (Figure $3 \mathrm{~b}$ ). However, ${ }^{209} \mathrm{Bi}$ procedural blanks are higher than mean ice core concentrations. ${ }^{208} \mathrm{~Pb}$ and ${ }^{27} \mathrm{Al}$ have higher background concentrations due to greater natural abundances, but mean ice core sample concentrations remain well above both analytical and procedural blanks and sample RSD are also low. Actinides ${ }^{232} \mathrm{Th}$ and ${ }^{238} \mathrm{U}$ have very low background contamination, ${ }^{232} \mathrm{Th}$ at the single fg g ${ }^{-1}$ level and ${ }^{238} \mathrm{U}$ at tens of $\mathrm{fg} \mathrm{g}^{-1}$. Mean ice core sample values are well above blank levels for these analytes (Table 2). ${ }^{75}$ As concentrations in ice core samples are on average only twice the concentration of procedural 
blanks, with sample RSD as high as $20 \%$, while analytical blanks are approximately half again as low as procedural blanks.

REE, while present at low concentrations in Antarctic ice core samples, are similarly present at extremely low levels in the laboratory environment, as evidenced by the procedural and analytical blanks here (Figure 3a, Table 2). Analytical blank concentrations for light REE ( $\mathrm{La}, \mathrm{Ce}, \mathrm{Pr}, \mathrm{Nd}$ ) are less than $2 \%$ of mean concentrations found in ice core samples, with procedural blanks concentrations less than $8 \%$ of the sample mean. Sample RSD for light REE are 5-13\% (Figure 3b). Medium and heavy REE show significantly higher blank concentrations relative to single digit part per quadrillion concentrations in ice core samples, especially the alternating abundance of medium REE ( $\mathrm{Sm}, \mathrm{Eu}, \mathrm{Gd}, \mathrm{Tb}, \mathrm{Dy})$ and heavy REE (Ho, Er, Tm, Yb, Lu). At such low concentrations (single $\mathrm{fg}^{-1}$ ), sample RSD are relatively high, approximately $25 \%$ across the medium REE and rising in a linear fashion across the heavy REE to a maximum RSD of $\sim 60 \%$ (Figure $3 \mathrm{~b}$ ). Tm is the only REE which shows a higher mean concentration in procedural blanks (Figure 3a), suggesting that laboratory contamination may render this element of limited use.

Our results suggest that detection limits of Jet-SF-ICPMS instrumentation are not the primary barrier to measuring low-fg $\mathrm{g}^{-1}$ concentration species in polar snow and ice. Instead, methodological contamination and associated uncertainties - for instance type and length of sample acidification - have the largest effect on the utility of trace element data for exploring paleoclimate information preserved in Antarctic snow and ice. International coordination and inter-laboratory comparisons, as called for by others, ${ }^{20}$ would be of great utility to minimize methodological uncertainty and facilitate further development of trace-element ice core proxies, which contain higher-order information clarifying key aspects of climatic and environmental processes affecting myriad aspects of the earth system. 


\section{Tables}

Table 1. QC known concentration, mean of 96 QC measurements and standard deviation of 96 QC measurements.

\begin{tabular}{|c|c|c|c|}
\hline $\begin{array}{l}\text { Isotope } \\
\text { (resolution) }\end{array}$ & $\begin{array}{l}\text { QC Concentration } \\
\left(\mathrm{pg} \mathrm{g}^{-1}\right)\end{array}$ & $\begin{array}{c}\text { Mean of } 96 \mathrm{QC} \text { measurements } \\
(\% \text { of known conc.) }\end{array}$ & $\begin{array}{c}\text { RSD of } 96 \text { QC } \\
\text { measurements (\%) }\end{array}$ \\
\hline $\mathrm{Rb} 85$ (LR) & 526.7 & 99 & 2 \\
\hline Sr 88 (LR) & 105.3 & 99 & 2 \\
\hline Cs 133 (LR) & 0.198 & 99 & 2 \\
\hline Ba 137 (LR) & 26.3 & 95 & 9 \\
\hline La 139 (LR) & 0.527 & 100 & 3 \\
\hline Ce 140 (LR) & 1.053 & 100 & 4 \\
\hline Pr 141 (LR) & 0.105 & 101 & 3 \\
\hline Nd 146 (LR) & 0.527 & 101 & 3 \\
\hline Sm 147 (LR) & 0.105 & 101 & 7 \\
\hline Eu 153 (LR) & 0.021 & 96 & 8 \\
\hline Gd 157 (LR) & 0.053 & 93 & 10 \\
\hline Tb 159 (LR) & 0.011 & 93 & 13 \\
\hline Dy 163 (LR) & 0.053 & 98 & 7 \\
\hline Ho 165 (LR) & 0.011 & 94 & 8 \\
\hline Er 166 (LR) & 0.021 & 98 & 7 \\
\hline Tm 169 (LR) & 0.005 & 90 & 13 \\
\hline Yb 172 (LR) & 0.021 & 101 & 6 \\
\hline Lu 175 (LR) & 0.005 & 84 & 29 \\
\hline Tl 205 (LR) & 0.658 & 99 & 2 \\
\hline $\mathrm{Pb} 208$ (LR) & 2.634 & 102 & 5 \\
\hline Bi 209 (LR) & 0.237 & 97 & 6 \\
\hline Th 232 (LR) & 0.658 & 100 & 3 \\
\hline U 238 (LR) & 0.020 & 101 & 10 \\
\hline Al 27 (MR) & 526.7 & 98 & 4 \\
\hline Cr 52 (MR) & 3.292 & 80 & 10 \\
\hline Mn 55 (MR) & 9.877 & 98 & 2 \\
\hline Fe 56 (MR) & 526.7 & 98 & 2 \\
\hline Co 59 (MR) & 1.053 & 96 & 5 \\
\hline $\mathrm{Cu} 63$ (MR) & 65.8 & 99 & 2 \\
\hline As 75 (HR) & 1.646 & 89 & 10 \\
\hline
\end{tabular}


Table 2. Sample, analytical and procedural blanks $\left(p g g^{-1}\right)$.

\begin{tabular}{|c|c|c|c|c|c|}
\hline $\begin{array}{c}\text { Isotope } \\
\text { (Resolution) }\end{array}$ & $\begin{array}{c}\text { Sample mean, } \\
\text { blank subtracted } \\
(\mathrm{n}=784)\end{array}$ & $\begin{array}{c}\text { Sample SD } \\
(\mathrm{n}=784)\end{array}$ & $\begin{array}{c}\text { Analytical Blank } \\
\text { mean }(\mathrm{n}=86)\end{array}$ & $\begin{array}{c}\text { Procedural Blank } \\
\text { mean }(\mathrm{n}=13)\end{array}$ & $\begin{array}{c}\text { LOD } \\
(3 * \text { SD Analytical } \\
\text { Blank })\end{array}$ \\
\hline Rb 85 (LR) & 4.864 & 3.031 & 0.259 & 0.354 & 0.239 \\
\hline Sr 88 (LR) & 232 & 150 & 0.191 & 2.000 & 0.244 \\
\hline Cs 133 (LR) & 0.111 & 0.115 & 0.002 & 0.011 & 0.002 \\
\hline Ba 137 (LR) & 5.314 & 5.356 & 16.630 & 18.275 & 7.286 \\
\hline La 139 (LR) & 0.324 & 0.385 & 0.004 & 0.009 & 0.004 \\
\hline Ce 140 (LR) & 1.313 & 3.148 & 0.010 & 0.012 & 0.036 \\
\hline Pr 141 (LR) & 0.074 & 0.090 & 0.001 & 0.004 & 0.001 \\
\hline Nd 146 (LR) & 0.289 & 0.354 & 0.003 & 0.007 & 0.006 \\
\hline Sm 147 (LR) & 0.055 & 0.066 & 0.005 & 0.007 & 0.007 \\
\hline Eu 153 (LR) & 0.009 & 0.011 & 0.003 & 0.005 & 0.003 \\
\hline Gd 157 (LR) & 0.041 & 0.050 & 0.008 & 0.008 & 0.012 \\
\hline Tb 159 (LR) & 0.005 & 0.006 & 0.002 & 0.002 & 0.003 \\
\hline Dy 163 (LR) & 0.034 & 0.034 & 0.001 & 0.003 & 0.003 \\
\hline Ho 165 (LR) & 0.006 & 0.006 & 0.001 & 0.004 & 0.001 \\
\hline Er $166(\mathrm{LR})$ & 0.017 & 0.016 & $<0.001$ & $<0.001$ & 0.001 \\
\hline Tm 169 (LR) & 0.002 & 0.002 & 0.001 & 0.002 & 0.002 \\
\hline Yb 172 (LR) & 0.004 & 0.003 & $<0.001$ & 0.001 & $<0.001$ \\
\hline Lu 175 (LR) & 0.002 & 0.006 & $<0.001$ & 0.001 & 0.001 \\
\hline T1 205 (LR) & 0.051 & 0.047 & 0.015 & 0.034 & 0.007 \\
\hline $\mathrm{Pb} 208$ (LR) & 5.297 & 5.647 & 0.333 & 0.227 & 1.670 \\
\hline Bi 209 (LR) & 0.057 & 0.093 & 0.028 & 0.062 & 0.051 \\
\hline Th 232 (LR) & 0.103 & 0.192 & 0.002 & 0.001 & 0.008 \\
\hline U 238 (LR) & 0.147 & 0.067 & 0.001 & 0.017 & 0.003 \\
\hline Al 27 (MR) & 573 & 804 & 28.26 & 112 & 37.21 \\
\hline Cr 52 (MR) & 1.147 & 3.8 & 3.652 & 9.654 & 2.157 \\
\hline Mn 55 (MR) & 12.37 & 15.36 & 0.388 & 4.196 & 0.354 \\
\hline Fe $56(\mathrm{MR})$ & 472 & 1022 & 12.102 & 16.547 & 7.679 \\
\hline Co 59 (MR) & 0.367 & 1.26 & 0.268 & 0.274 & 0.102 \\
\hline $\mathrm{Cu} 63$ (MR) & 58.23 & 92.87 & 1.084 & 1.436 & 0.959 \\
\hline As 75 (HR) & 1.975 & 1.230 & 0.282 & 0.725 & 0.252 \\
\hline
\end{tabular}

\section{Author Contributions}

The manuscript was written through contributions of all authors. PDN, AT, RE and NANB produced samples from the RICE ice core. PDN and AT conducted acidification experiments and prepared samples for analysis. PDN, AT and RE conducted ICPMS analysis, performed data calibration and assessed quality. All authors have given approval to the final version of the manuscript.

\section{Acknowledgements}

The authors are thankful for laboratory assistance at the National Ice Core Research Facility at GNS Science (R. Pyne) and the TRACE laboratory (A. Ellis, K. Jarrett, B. Proemse, H. Winton). This work is a contribution to the Roosevelt Island Climate Evolution (RICE) Program, funded by national contributions from New Zealand, Australia, Denmark, Germany, Italy, the People's Republic of China, Sweden, United Kingdom, and the United States of America. Logistic support for RICE was provided by Antarctica New Zealand and the United States Antarctic Program. 


\subsection{REFERENCES}

1. Augustin, L.; Barbante, C.; Barnes, P. R.; Barnola, J. M.; Bigler, M.; Castellano, E.; Cattani, O.; Chappellaz, J.; Dahl-Jensen, D.; Delmonte, B., Eight glacial cycles from an Antarctic ice core. Nature 2004, 429, (6992), 623-628.

2. Wolff, E.; Barbante, C.; Becagli, S.; Bigler, M.; Boutron, C.; Castellano, E.; De Angelis, M.; Federer, U.; Fischer, H.; Fundel, F., Changes in environment over the last 800,000 years from chemical analysis of the EPICA Dome C ice core. Quaternary Science Reviews 2010, 29, (1), 285-295.

3. Dixon, D. A.; Mayewski, P. A.; Goodwin, I. D.; Marshall, G. J.; Freeman, R.; Maasch, K. A.; Sneed, S. B., An ice-core proxy for northerly air mass incursions into West Antarctica. International Journal of Climatology 2012, 32, (10), 1455-1465.

4. Koffman, B.; Kreutz, K.; Breton, D.; Kane, E.; Winski, D.; Birkel, S.; Kurbatov, A.; Handley, M., Centennial-scale variability of the Southern Hemisphere westerly wind belt in the eastern Pacific over the past two millennia. Climate of the Past 2014, 10, (3), 1125-1144.

5. Bisiaux, M.; Edwards, R.; McConnell, J.; Curran, M.; Van Ommen, T.; Smith, A.; Neumann, T.; Pasteris, D.; Penner, J.; Taylor, K., Changes in black carbon deposition to Antarctica from two high-resolution ice core records, 1850-2000 AD. Atmospheric Chemistry and Physics 2012, 12, (9), 4107-4115.

6. Curran, M. A.; van Ommen, T. D.; Morgan, V. I.; Phillips, K. L.; Palmer, A. S., Ice core evidence for Antarctic sea ice decline since the 1950s. Science 2003, 302, (5648), 1203 1206.

7. Criscitiello, A. S.; Das, S. B.; Evans, M. J.; Frey, K. E.; Conway, H.; Joughin, I.; Medley, B.; Steig, E. J., Ice sheet record of recent sea-ice behavior and polynya variability in the Amundsen Sea, West Antarctica. Journal of Geophysical Research: Oceans 2013, 118, (1), 118-130.

8. Sigl, M.; McConnell, J. R.; Layman, L.; Maselli, O.; McGwire, K.; Pasteris, D.; DahlJensen, D.; Steffensen, J. P.; Vinther, B.; Edwards, R., A new bipolar ice core record of volcanism from WAIS Divide and NEEM and implications for climate forcing of the last 2000 years. Journal of Geophysical Research: Atmospheres 2013, 118, (3), 1151-1169.

9. Sigl, M.; McConnell, J. R.; Toohey, M.; Curran, M.; Das, S. B.; Edwards, R.; Isaksson, E.; Kawamura, K.; Kipfstuhl, S.; Krüger, K., Insights from Antarctica on volcanic forcing during the Common Era. Nature Climate Change 2014, 4, (8), 693-697. 
10. McConnell, J. R.; Maselli, O. J.; Sigl, M.; Vallelonga, P.; Neumann, T.; Anschütz, H.; Bales, R.; Curran, M.; Das, S. B.; Edwards, R., Antarctic-wide array of high-resolution ice core records reveals pervasive lead pollution began in 1889 and persists today. Scientific Reports 2014, 4.

11. Barbante, C.; Bellomi, T.; Mezzadri, G.; Cescon, P.; Scarponi, G.; Morel, C.; Jay, S.; van de Velde, K.; Ferrari, C.; Boutron, C. F., Direct determination of heavy metals at picogram per gram levels in Greenland and Antarctic snow by double focusing inductively coupled plasma mass spectrometry. Journal of Analytical Atomic Spectrometry 1997, 12, (9), 925-931.

12. Vallelonga, P.; Gabrielli, P.; Balliana, E.; Wegner, A.; Delmonte, B.; Turetta, C.; Burton, G.; Vanhaecke, F.; Rosman, K.; Hong, S., Lead isotopic compositions in the EPICA Dome C ice core and Southern Hemisphere Potential Source Areas. Quaternary Science Reviews 2010, 29, (1), 247-255.

13. Delmonte, B.; Andersson, P.; Hansson, M.; Schöberg, H.; Petit, J. R.; Basile-Doelsch, I.; Maggi, V., Aeolian dust in East Antarctica (EPICA-Dome C and Vostok): Provenance during glacial ages over the last 800 kyr. Geophysical Research Letters 2008, 35, (7).

14. Gabrielli, P.; Barbante, C.; Turetta, C.; Marteel, A.; Boutron, C.; Cozzi, G.; Cairns, W.; Ferrari, C.; Cescon, P., Direct determination of rare earth elements at the subpicogram per gram level in antarctic ice by ICP-SFMS using a desolvation system. Analytical Chemistry 2006, 78, (6), 1883-1889.

15. Wegner, A.; Gabrielli, P.; Wilhelms-Dick, D.; Ruth, U.; Kriews, M.; De Deckker, P.; Barbante, C.; Cozzi, G.; Delmonte, B.; Fischer, H., Change in dust variability in the Atlantic sector of Antarctica at the end of the last deglaciation. Climate of the Past 2012, 8, 135-147.

16. Gabrielli, P.; Wegner, A.; Petit, J. R.; Delmonte, B.; De Deckker, P.; Gaspari, V.; Fischer, H.; Ruth, U.; Kriews, M.; Boutron, C., A major glacial-interglacial change in aeolian dust composition inferred from Rare Earth Elements in Antarctic ice. Quaternary Science Reviews 2010, 29, (1), 265-273.

17. Todolí, J. L.; Mermet, J. M., Sample introduction systems for the analysis of liquid microsamples by ICP-AES and ICP-MS. Spectrochimica Acta Part B: Atomic Spectroscopy 2006, 61, (3), 239-283.

18. Russell, B. C.; Croudace, I. W.; Warwick, P. E.; Milton, J. A., Determination of Precise 135Cs/137Cs Ratio in Environmental Samples Using Sector Field Inductively Coupled Plasma Mass Spectrometry. Analytical Chemistry 2014, 86, (17), 8719-8726. 
19. Edwards, R.; Sedwick, P.; Morgan, V.; Boutron, C., Iron in ice cores from Law Dome: A record of atmospheric iron deposition for maritime East Antarctica during the Holocene and Last Glacial Maximum. Geochemistry, Geophysics, Geosystems 2006, 7, (12). 20. Koffman, B. G.; Handley, M. J.; Osterberg, E. C.; Wells, M. L.; Kreutz, K. J., Dependence of ice-core relative trace-element concentration on acidification. Journal of Glaciology 2014, 60, (219), 103-112.

21. Breton, D.; Koffman, B.; Kurbatov, A.; Kreutz, K.; Hamilton, G., Quantifying signal dispersion in a hybrid ice core melting system for geochemical and microparticle analysis, Environmental Science \& Technology 2012, 46, (21), 11,922-11,928.

22. Bigler, M.; Svensson, A.; Kettner, E.; Vallelonga, P.; Nielsen, M. E.; Steffensen, J. P., Optimization of high-resolution continuous flow analysis for transient climate signals in ice cores. Environmental Science \& Technology 2011, 45, (10), 4483-4489.

23. McConnell, J. R.; Lamorey, G. W.; Lambert, S. W.; Taylor, K. C., Continuous icecore chemical analyses using inductively coupled plasma mass spectrometry. Environmental Science \& Technology, 2002, 36, (1), 7-11.

24. Edwards, R.; Sedwick, P., Iron in East Antarctic snow: Implications for atmospheric iron deposition and algal production in Antarctic waters. Geophysical Research Letters 2001, 28, (20), 3907-3910.

25. Rhodes, R. H.; Baker, J. A.; Millet, M.-A.; Bertler, N. A., Experimental investigation of the effects of mineral dust on the reproducibility and accuracy of ice core trace element analyses. Chemical Geology 2011, 286, (3), 207-221.

26. Huber, P. J., Robust Statistics. Springer: 2011.

27. Aries, S.; Valladon, M.; Polvé, M.; Dupré, B., A Routine Method for Oxide and Hydroxide Interference Corrections in ICP-MS Chemical Analysis of Environmental and Geological Samples. Geostandards Newsletter 2000, 24, (1), 19-31.

28. Rodushkin, I.; Engström, E.; Baxter, D. C., Sources of contamination and remedial strategies in the multi-elemental trace analysis laboratory. Analytical and Bioanalytical Chemistry 2010, 396, (1), 365-377. 
Chapter 4: Rare earth element dust signatures over the past two thousand years in the RICE ice core, Pacific sector, West Antarctica

\begin{abstract}
Concentrations of the Rare Earth Elements (REE) have been measured in the Roosevelt Island Climate Evolution (RICE) ice core, the first such measurements from the Pacific sector of Antarctica and the only REE data spanning the last two thousand years before present (ka BP). We find high variability in crustal-normalized REE measured as low as single fg $\mathrm{g}^{-1}$, with persistent enrichment in the light REE and depletion in heavy REE. These data suggest 1) high variability in crustal-normalized REE signatures over the last $2 \mathrm{ka} \mathrm{BP}$, similar to that seen in Holocene samples from the Drønning Maud Land and Dome C ice cores, 2) only 5\% of all RICE samples indicate possible REE signatures of South American dust, and 3) suggest contributions from local Antarctic dust sources in $\sim 40 \%$ of RICE samples showing strong negative trends across REE. These results are supported by trajectory modeling, which suggests that the RICE ice core site receives strongest transport from limited New Zealand dust sources, with lesser contributions and longer transport times from Patagonian and Australian dust sources.
\end{abstract}

\title{
4.1 Introduction
}

Terrestrial mineral aerosols (dust) have significant climatic effects, as a result of direct and indirect impacts on radiative forcing during atmospheric suspension [Tegen et al., 1996], and through biogeochemical mechanisms when deposited over nutrient-rich, irondeficient ocean areas [Martínez-Garcia et al., 2011]. Records of dust deposition are preserved in glaciers and ice sheets, and have been used to infer past changes in regional and global dust regimes over the last 800,000 years [EPICA, 2004; Fischer et al., 2007; Wolff et al., 2010]. Dust flux in the European Project for Ice Coring in Antarctica (EPICA) Dome C, Antarctica ice core is 25-times greater during glacial periods than warmer interglacials [Lambert et al., 2008], similar to other ice cores across the remote East Antarctic plateau [Petit et al., 1999]. These fluctuations are the result of a complex mixture of environmental change in dust source regions [Sugden et al., 2009], changing precipitation amounts and patterns affecting aerosol atmospheric lifetime [Mahowald et al., 1999], and changing wind patterns and wind strength. Identifying which of these processes (or the combination of which) controls dust composition at ice core sites will allow for more accurate interpretation of these paleoclimate and paleoenvironmental records. 
GCM results [Li et al., 2008; Mahowald et al., 2011] and ice core dust geochemical studies [Delmonte et al., 2008; Vallelonga et al., 2010] show some agreement that southern South American dust sources are the most dominant contributors to the Antarctic, particularly during glacial periods, with Australian dust emissions becoming of greater importance during interglacials and since the onset of the Holocene. Additional Southern Hemisphere dust sources exist in southern Africa and New Zealand, the latter of which may play a large role in dust deposition over and fertilization of the South Pacific Ocean during interglacial periods [Lamy et al., 2014]. Ice core provenance studies, however, are restricted to the Atlantic and Indian Ocean sectors of the East Antarctic Ice Sheet (EAIS) and biased towards samples from dusty glacial periods, which contain enough material to allow for robust geochemical analysis.

The rare earth elements (REE, lanthanide elements Lanthanum to Lutetium) have been suggested as tracers to identify signatures of individual dust potential source areas (PSA) in small $\left(<5 \mathrm{~mL}\right.$ ), low-concentration (sub-pg g $\mathrm{g}^{-1}$ to single $\mathrm{fg} \mathrm{g}^{-1}$ ) Antarctic ice core samples [Gabrielli et al., 2010; Wegner et al., 2012]. REE analysis requires no preconcentration or other laborious sample preparation, and although low concentrations in Holocene samples approach instrumental limits of detection this is mitigated by the large number of samples that can quickly be measured (e.g. Gabrielli et al. [2006] and Neff et al. [in review]). The REE are lithophilic elements abundant in the terrestrial crust [Wedepohl, 1995], and they are chemically conservative with low solubility and restricted mobility in terrestrial systems. They are not unlike isotopes, exhibiting slight differences in how they are included in crystal structures due to a small decrease in atomic radii with increasing atomic number (lanthanide contraction) [Henderson, 1984]. Because of their sedimentary conservatism, the relative amount of the fourteen REE measured in aeolian dust is thought to remain relatively stable and thus reflect the signature of their source. This may allow for dust provenance identification, or a reduction of possible sources, in Antarctic ice provided that the parent material has a unique, well-characterized REE signature, and that this signature is retained through atmospheric transport and deposition. However, analytical uncertainties including irregular dissolution of REE after sample acidification (e.g. Rhodes et al. [2011] and Koffman et al. [2014a]) and increased measurement uncertainty in low-concentration interglacial ice samples remain to be comprehensively addressed in consideration of REE as a paleoclimate tool. 


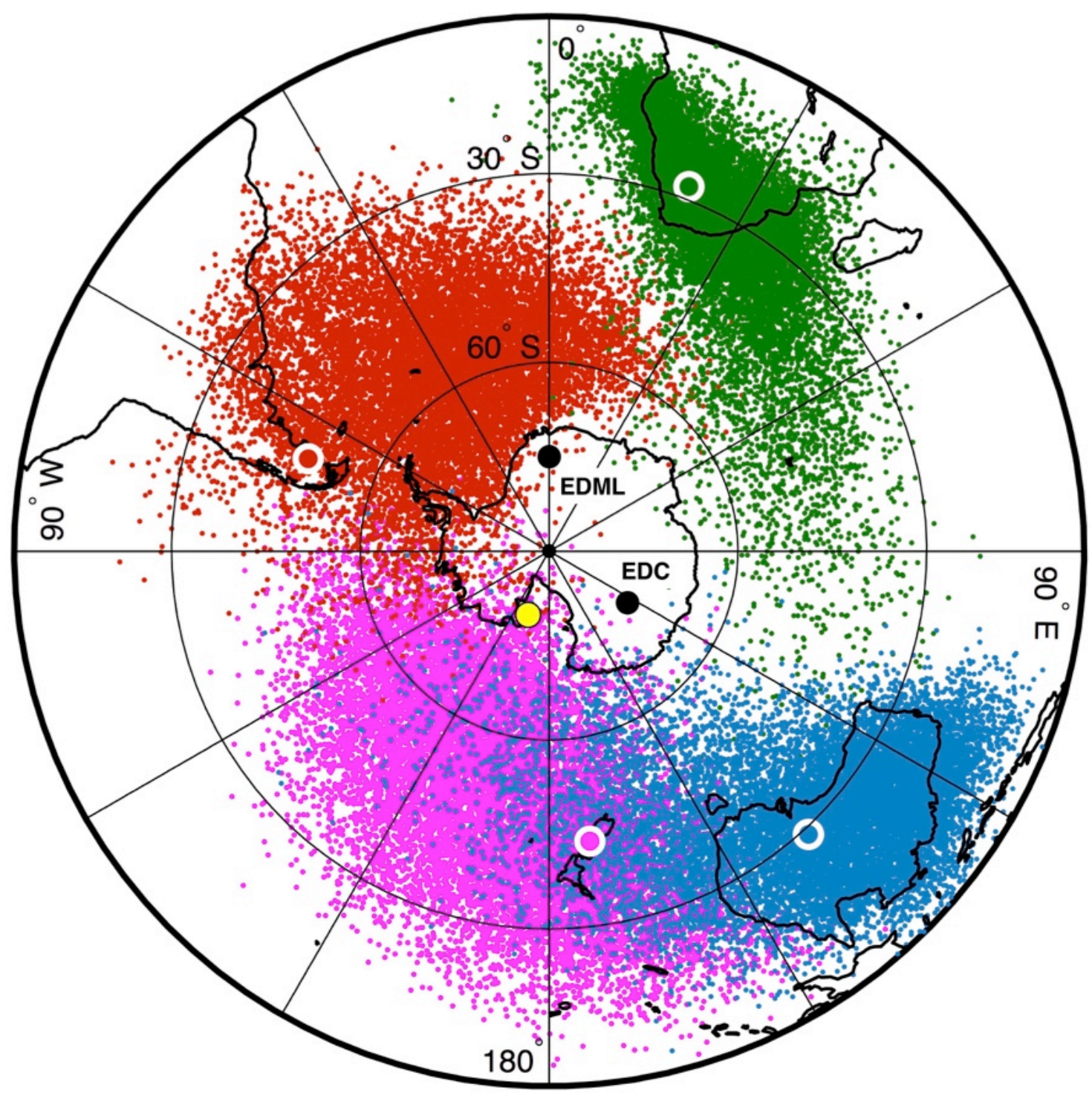

Figure 1. RICE ice core site (yellow circle) relative to EDC and EDML (black circles) where other REE datasets are located. Small colored circles mark 5-day trajectory endpoints, initiated daily at dust potential source areas (PSA) from 1979-2013 (HySPLIT model, data from Neff and Bertler, in review). This outlines immediate transport pathways from extraAntarctic dust PSA. PSA trajectory initiation points are indicated by large colored circles: New Zealand (magenta), Patagonia (orange), southern Africa (green) and Australia (blue).

We present here the first ice core REE data from the Pacific Ocean sector of Antarctica. The Roosevelt Island Climate Evolution (RICE) ice core was drilled to bedrock (764 m) on Roosevelt Island, Antarctica (79.364 ${ }^{\circ} \mathrm{S}, 161.706{ }^{\circ} \mathrm{W}$, Figure 1), located at the northern margin of the Ross Ice Shelf. REE measured in the RICE ice core are the only data spanning the $20^{\text {th }}$ Century and the last two thousand years, and with higher-resolution than 
previous studies (sub-annual to three-year resolution). At this low-elevation ( $\sim 550 \mathrm{~m}$ a.s.l.) site on the Ross Sea coast of the West Antarctic Ice Sheet (WAIS), trajectory modeling suggests strongest direct atmospheric transport from New Zealand, with lesser influence from potential dust-carrying Australian and Patagonian air masses [see data in Figure 1, from Neff and Bertler, in review]. RICE REE data are compared to the two existing ice core REE datasets from the EPICA Dome C (EDC, $75.1^{\circ} \mathrm{S}, 123.4^{\circ} \mathrm{E}, 3233 \mathrm{~m}$ a.s.1.) and EPICA Drønning Maud Land (EDML, $75^{\circ} \mathrm{S}, 0^{\circ} \mathrm{E}, 2892 \mathrm{~m}$ a.s.1.) ice cores.

In Section 2, we discuss sample preparation of RICE ice core samples and analytical methods employed to measure REE concentrations as low as single femtogram $\left(10^{-15} \mathrm{~g} \mathrm{~g}^{-1}\right)$. Section 3 details the result of these analytical efforts, with comparison to measurements on the EDC and EDML ice cores. The discussion in Section 4 considers procedural and analytical challenges of this and previous work using REE to explore dust provenance, before commenting on possible advances in understanding of Antarctic dust gained from this new REE data from the RICE ice core. Conclusions are provided in Section 5, and suggestions are made for future steps to develop the REE as dust provenance indicators in polar ice core studies.

\subsection{Methods}

The detailed methodology for sample treatment and analysis is discussed at length in Neff et al. [in review], but is summarized here with additional details specific to REEs. Discrete samples were taken from the RICE ice core during a continuous flow analysis (CFA, e.g. Bigler et al. [2011]) campaign, melting in sequence $1 \mathrm{~m}$-long rods cut from the interior of ice cores ( $\sim 34 \mathrm{~mm}$ by $34 \mathrm{~mm}$ wide). Samples from the RICE ice core discussed here span depths from $8 \mathrm{~m}$ to $320 \mathrm{~m}$ below the 2011 snow surface (an $8 \mathrm{~m}$ deep trench was required to accommodate drill infrastructure). From $8 \mathrm{~m}$ to $40 \mathrm{~m}$, mean sample depth-resolution is $4 \mathrm{~cm}$ ( $\sim 4 \mathrm{~mL}$ liquid), with a total of 784 samples. Annual layer counting of sulfate and water stable isotopes in shallow firn cores and the RICE deep ice core dates ice at $8 \mathrm{~m}$ depth to $1993 \mathrm{CE}$ ( \pm 0.5 years) and $40 \mathrm{~m}$ depth to $1901 \mathrm{CE}$ ( \pm 1 year). Due to high loading of marine salts in the coastal RICE ice core, identification of known volcanic events has proven difficult and is ongoing. This agescale results in a mean sample age-resolution of $\sim 0.13$ years for $8 \mathrm{~m}-40 \mathrm{~m}$ samples spanning the $20^{\text {th }}$ Century (linear interpolation between annual layer determinations).

Below $40 \mathrm{~m}$, individual samples were combined into approximately 3-year averages, estimated using a preliminary depth-age scale (Dansgaard and Johnsen [1969] ice flow model, T.J. Fudge, personal communication, 2014). Sampling was stopped at $320 \mathrm{~m}$ depth, determined to be approximately $2 \mathrm{ka}$ BP using this initial age model. Aliquots were taken 
from every other sample (alternate samples were reserved for additional analyses) and pipetted into a single vial, combining samples spanning $\sim 1 \mathrm{~m}$ depth at $40 \mathrm{~m}$ (14 individual samples combined into one), reducing to a $\sim 0.2 \mathrm{~m}$ interval (4-5 samples into one) at $320 \mathrm{~m}$ for a total of 580 combined samples. Refinement of the RICE agescale since samples were prepared includes matching to high-resolution methane gas measurements from the RICE, WAIS Divide, and Law Dome ice cores, assuming a constant 150 year gas-age ice-age difference ( $\triangle$ age) at RICE. A volcanic tie point to the $1257 \mathrm{CE}$ "unknown" eruption [Sigl et al., 2013] also provides age control at $165 \mathrm{~m}$ depth (A. Kurbatov, personal communication 2015). The ice age at $320 \mathrm{~m}$ is approximately $2.3 \mathrm{ka} \mathrm{BP}$. This increases mean sample age resolution for $40 \mathrm{~m}$ to $320 \mathrm{~m}$ combined samples to 3.6 years.

Preparatory work was conducted in a class-100 clean room under laminar flow hoods, and procedural blanks of ultrapure water $(>18 \mathrm{M} \Omega)$ and $1 \% \mathrm{HNO}_{3} \mathrm{v} / \mathrm{v}\left(\mathrm{Optima}^{\mathrm{TM}}\right)$ were placed under hoods during this process to constrain maximum contamination levels (procedural blanks, mean concentrations in Table 1). All ice core samples were acidified to $1 \% \mathrm{HNO}_{3} \mathrm{v} / \mathrm{v}$ at least three months prior to analysis, allowing for extended solid-particle leaching and stable elemental concentrations (e.g. Rhodes et al. [2011], Koffman et al. [2014a]). Incongruent dissolution in acidified samples has considerable implications for elemental ratios with respect to crustal abundance, which is particularly important for REE dust provenance studies, and is discussed below. Trace element analysis was undertaken in the John de Laeter Centre Trace Research Advanced Clean Environment (TRACE) facility at Curtin University, Perth, Australia using a jet-interface sector-field inductively coupled plasma mass spectrometer (Jet-SF-ICPMS, Element XR, e.g. Russell et al. [2014]). A seaFAST S2 syringe-pump auto-sampler was coupled to a PFA-ST nebulizer and APEX-Q desolvation system (all Elemental Scientific, Inc.), with an additional flow of high-purity nitrogen to tune response. A $500 \mathrm{pg} \mathrm{g}^{-1}$ Indium (In) was mixed inline as an internal standard to correct for instrumental drift, with sensitivity of $14 \times 10^{6}$ counts per second per $n g \mathrm{~g}^{-1}$ maintained through instrument tuning after every $\sim 32$ hour analytical session. Analytical blanks $\left(1 \% \mathrm{HNO}_{3} \mathrm{v} / \mathrm{v}\right.$ Optima $\left.{ }^{\mathrm{TM}}\right)$ and quality control samples (made from certified singleand multi-element stock solutions, Elemental Scientific, Inc.) were placed after every ten samples with duplicate quality controls run in every second grouping. Indium-normalized ion intensities were calibrated to ten external standards prepared from National Institute of Standards and Technology traceable elemental standards. Analytical blanks, an average of at least ten per $\sim 32$ hour analytical session, were subtracted from ice core sample concentrations (Table 1). 


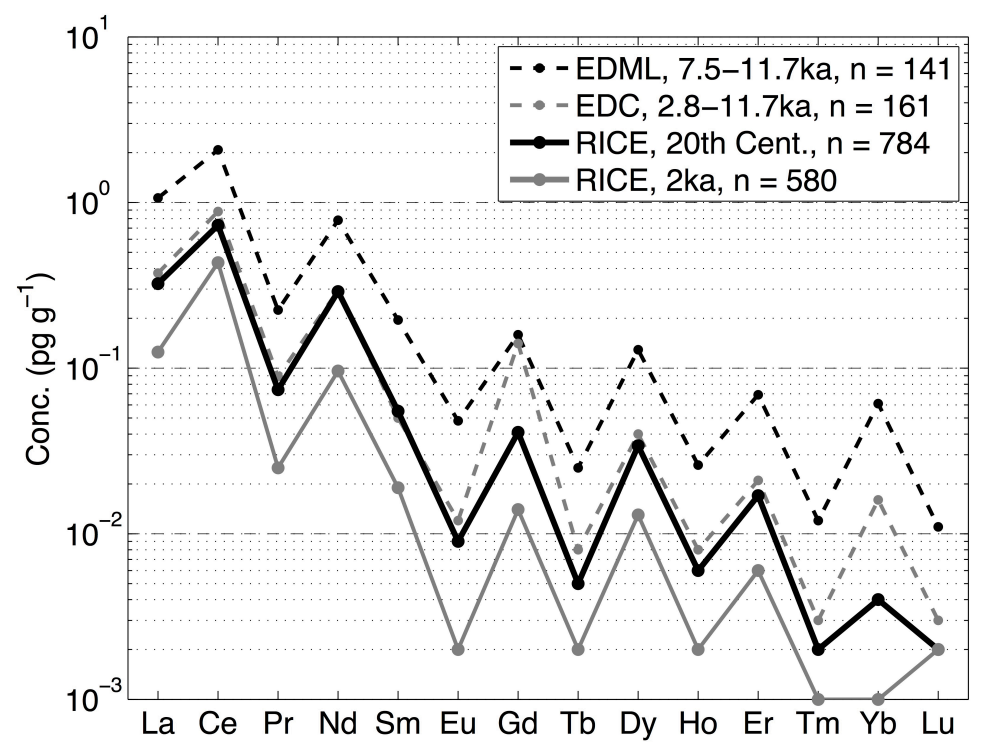

Figure 2. Log concentration ( $\mathrm{g} \mathrm{g}^{-1}$ ) of mean REE in RICE ice core samples (20 ${ }^{\text {th }}$ Century, solid black; 2 ka BP, solid gray), and mean EDML (dashed black) and EDC (dashed gray) samples. EDML and EDC samples span the Holocene (beginning $11.7 \mathrm{ka} \mathrm{BP}$ ) and extend to youngest measured samples (7.5 $\mathrm{ka} \mathrm{BP}$ and $2.9 \mathrm{ka} \mathrm{BP}$, respectively).

\subsection{Results}

Mean RICE ice core REE concentrations, analytical and procedural blanks and limits of detection (LOD, three standard deviations, $3 \sigma$, of the analytical blank) are listed in Table 1. Modern RICE REE compare well to Holocene (beginning $11.7 \mathrm{ka} \mathrm{BP}$ ) samples from EDC and EDML (Figure 2). Expected REE features are observed in RICE data: decreasing abundance with increasing atomic number (lanthanide contraction), a drop in concentration from $\mathrm{Sm}$ to $\mathrm{Eu}$ (Europium anomaly), and greater abundance of elements with even atomic numbers (Oddo-Harkins rule: paired protons of even atomic numbered elements enhance stability and hence natural abundance). Observed departures from expectations are as follows.

All RICE samples show low concentrations of Yb (Figure 2), which are not normallydistributed (see Figure S1 and S2) and thus excluded from further analysis. RICE samples also have very high concentrations of Ce near all breaks in the ice core (at least every $1 \mathrm{~m}$ ), with concentrations $>10 \mathrm{pg} \mathrm{g}^{-1}$. This is removed by excluding all Ce values $>1 \sigma\left(3.2 \mathrm{pg} \mathrm{g}^{-1}\right.$, 49 samples), and the corrected mean is plotted in Figure 2. Despite this correction values for Ce remain anomalously high (especially in crustal ratios, see below), thus Ce is removed from calculations for all RICE samples and is interpreted with caution. RICE $40 \mathrm{~m}-320 \mathrm{~m}$ 
combined samples have lower concentrations for all REE than $8 \mathrm{~m}-40 \mathrm{~m}$ samples, particularly for Eu and Tm (see Table 1). This is likely due to particulate settling, as vials were not agitated prior to combination into 3-year averages. Tm is excluded from calculation of REE means for these samples. Certain REE are also excluded from consideration for EDC and EDML. Maximum Gd concentrations are reported for EDC samples due to spectral interferences during analysis, explaining anomalously high mean EDC Gd concentrations in Figure 1 [Gabrielli et al., 2010]. Gd is not used further in calculations of means or consideration of REE patterns in EDC samples. High concentrations are observed in EDML samples for all REE, likely due to these data not being blank subtracted (see discussion in Wegner et al. [2012]). Tm was not considered by Wegner et al. [2012] due to likely spectral interferences and is similarly excluded here for EDML samples.

Mean REE concentrations for $8 \mathrm{~m}-40 \mathrm{~m}$ samples are displayed in Table 1 both with and without samples below the LOD removed. We proceed with data analysis including all samples, bearing in mind this analytical limitation for very low-concentration HREE. Mean sample relative standard deviation (RSD) at sub-pg $\mathrm{g}^{-1}$ concentration is $\sim 5-15 \%$ for light REE (LREE: La, Ce, Pr, Nd), 25-30\% for medium REE (MREE: Sm, Eu, Gd, Tb, Dy) and rising from $30 \%$ to $60 \%$ for lowest-concentration heavy REE (HREE: Ho, Er, Tm, Yb, Lu). RICE REE measurement uncertainty at sub-pg $\mathrm{g}^{-1}$ (sub part per trillion) concentration compares favorably to that of EDC samples in Gabrielli et al. [2010], with consistent relationships between concentration and sample RSD (Figure 3). Wegner et al. [2012] did not publish RSD for EDML data, however since the same analytical method was used as Gabrielli et al. [2010], we assume similar sample RSD as for EDC samples. RICE $8 \mathrm{~m}$ to $40 \mathrm{~m}$ samples have similar concentration versus RSD trends to those of EDC measurements. One ICPMS analytical session, including combined samples from $40 \mathrm{~m}-180 \mathrm{~m}$, had reduced stability and high RSD and sample variability; this anomalous analytical performance is not included in Figure 3. The final ICPMS analytical session, samples spanning $180 \mathrm{~m}-320 \mathrm{~m}$, was very stable and showed limited increase in RSD even at single $\mathrm{fg}^{-1}$ concentrations suggesting that with further optimization the method of Neff et al. (in review) may significantly reduce uncertainty in measurements of REE at these ultra-low concentrations (black x's, Figure 3).

All sample concentrations are normalized to upper continental crust (UCC) values as in Wegner et al. [2012]:

$$
L a^{*}=\frac{L a_{i c e}}{L a_{U C C}},
$$


where $\mathrm{La}_{\text {ice }}$ is the La concentration in the ice sample ( $\mathrm{La}$ used as an example), and $\mathrm{La}_{\mathrm{UCC}}$ is the mean La concentration in the UCC [Wedepohl, 1995]. A further normalization step is made to remove the mean concentration of all REE from the ratio:

$$
L a_{n o r m}=\frac{L a^{*}}{R E E^{*}},
$$

where REE ${ }^{*}$ is the mean normalized value of all REE as in Eq. 1 (excluding Ce and $\mathrm{Yb}$ for reasons stated above). Mean UCC-normalized REE concentrations ( $\left.\mathrm{REE}_{\text {norm}}\right)$ are presented in Table 2. $\mathrm{LREE}_{\text {norm}}, \mathrm{MREE}_{\text {norm }}$ and $\mathrm{HREE}_{\text {norm }}$ are plotted in Figure 4 for RICE samples from $8 \mathrm{~m}$ to $40 \mathrm{~m}$ and $40 \mathrm{~m}$ to $320 \mathrm{~m}$. LREE $E_{\text {norm }}$ are consistently enriched by $\sim 30 \%$, with mean $\mathrm{MREE}_{n o r m}$ enrichment of $\sim 10 \%$ and $\mathrm{HREE}_{\text {norm }}$ depletion of $\sim 10 \%$. Similar characteristics are observed in 3.6-year combined samples spanning $2 \mathrm{ka} \mathrm{BP}$, although MREE are slightly less enriched due to anomalously low Eu concentration (with respect to sub-annual $8 \mathrm{~m}-40 \mathrm{~m}$ samples). However, mean $\mathrm{REE}_{\text {norm }}$ values remain constant through samples measured during the unstable analytical session (40 m to $180 \mathrm{~m}$ samples, Figure 4), as do diagnostics discussed below, with some additional variability. No persistent shifts are observed in relative enrichment between REE groupings. Figure 4 illustrates the impact of increased sample resolution on variability in $\mathrm{REE}_{\text {norm }}$ groupings, which suggests caution in interpreting increased variability observed in Holocene REE trends relative to the LGS (Last Glacial Stage) as in Gabrielli et al. [2010] and Wegner et al. [2012]. Holocene samples from EDC and EDML are spaced more closely and span less time, reducing signal averaging as ice flow thinning effects progressively lessen and snow accumulation rates increase from LGS minima (e.g. Cuffey and Paterson [2010]). This is additionally complicated by the fact that EDC samples represent 2-3 to 4-5 years per samples (with large and inconsistent sample spacing), while EDML samples are 20 to 45 year averages (with samples more consistently spaced). 
a) LREE (La, $\mathrm{Pr}, \mathrm{Nd})$

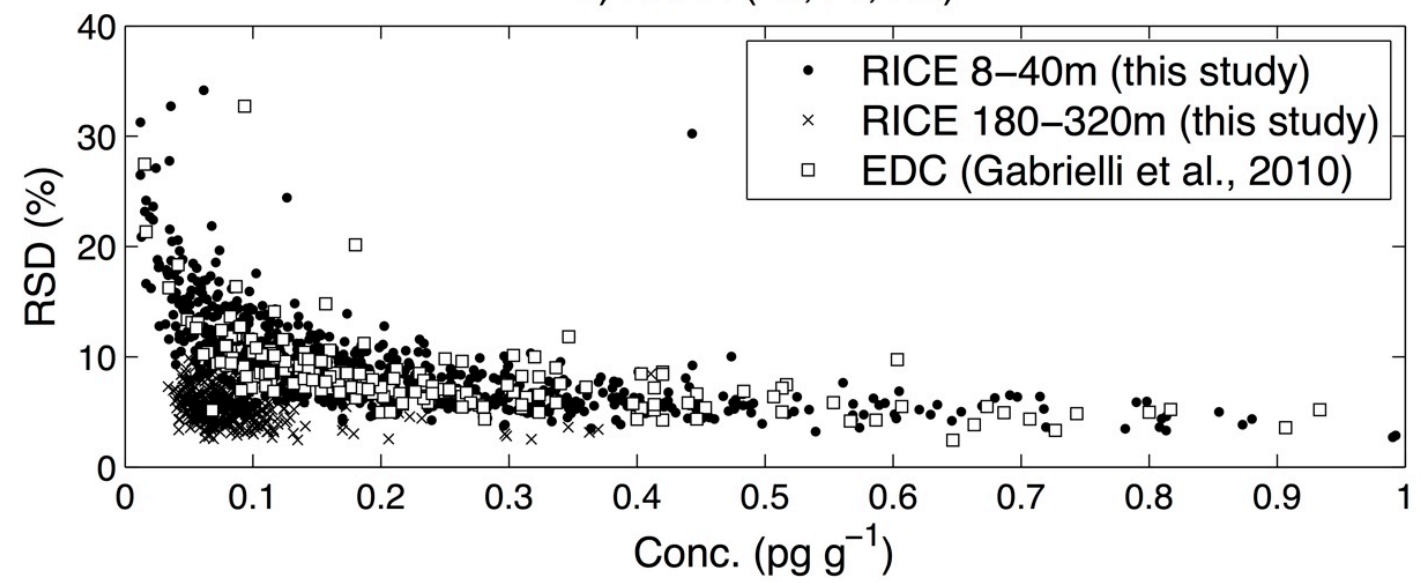

b) MREE (Sm, Eu, Tb, Dy)

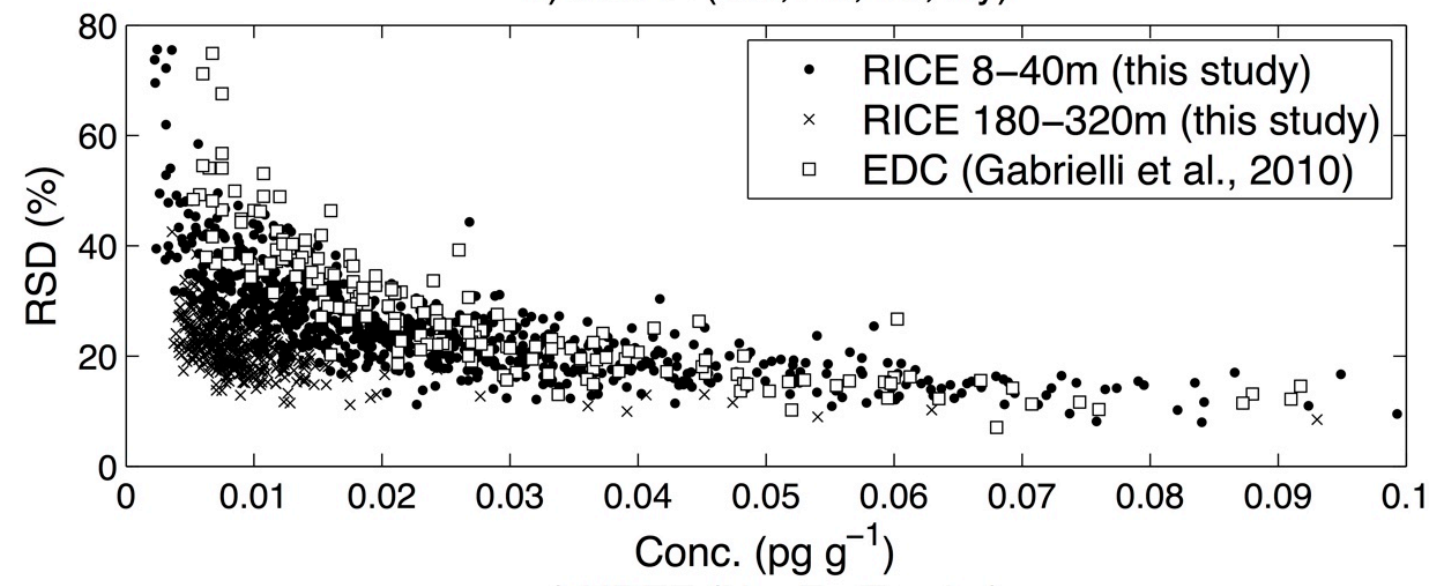

c) HREE (Ho, Er, Tm, Lu)

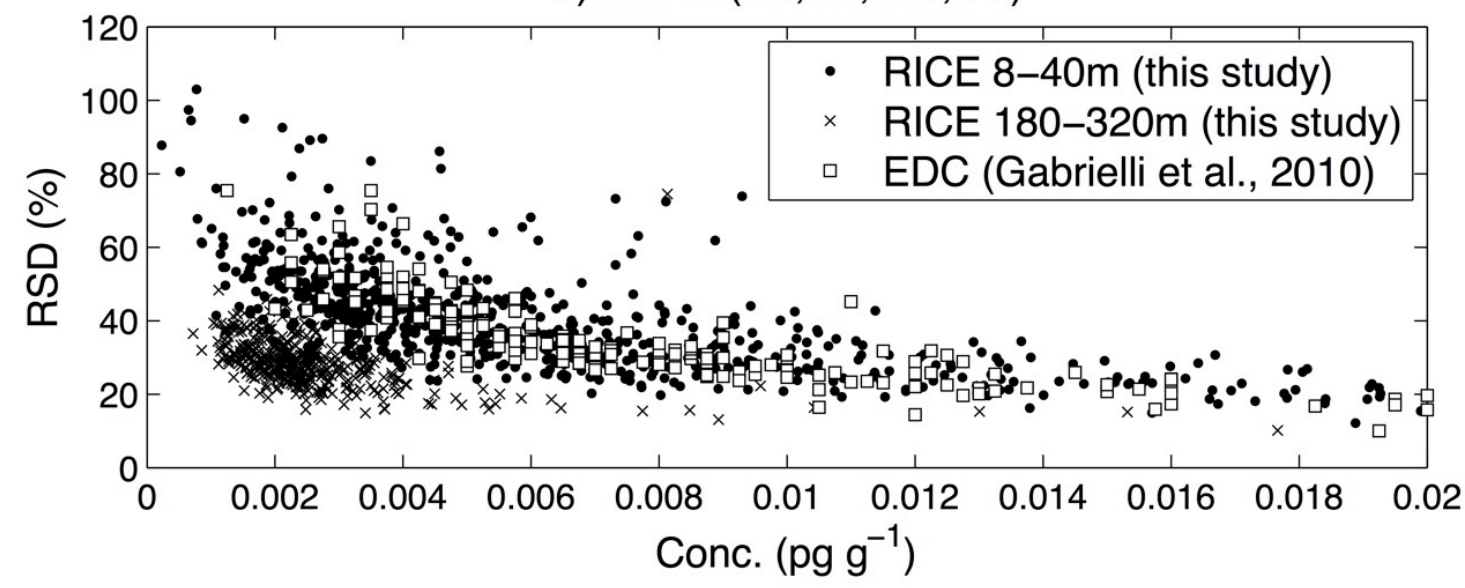

Figure 3. Sub-pg $g^{-1}$ concentration relative standard deviation (RSD, \%) for a) LREE (excluding $C e$ ), b) MREE (excluding $G d$ ), and c) HREE (excluding Yb) in RICE (black circle and $x$ ) and EDC (white square) samples. RSD from unstable analytical session, samples from $40 \mathrm{~m}$ to $180 \mathrm{~m}$, are not included. 
Table 1. Concentration $\left(p g g^{-1}\right)$ of 20th Century RICE REE sample mean, analytical blank mean, procedural blank mean and Limit of Detection (LOD)

\begin{tabular}{|c|c|c|c|c|c|c|}
\hline Isotope & $\begin{array}{c}8 \mathrm{~m}-40 \mathrm{~m} \\
\text { mean conc. } \\
\text { (analytical blank } \\
\text { subtracted, } \\
\mathrm{n}=784^{*} \text { ) }\end{array}$ & $\begin{array}{c}8 \mathrm{~m}-40 \mathrm{~m} \\
\text { mean conc. } \\
\text { (analytical blank } \\
\text { subtracted, } \\
<\text { LOD removed) }\end{array}$ & $\begin{array}{c}40 \mathrm{~m}-320 \mathrm{~m} \\
\text { mean conc. } \\
\text { (analytical blank } \\
\text { subtracted, } \mathrm{n}= \\
580 \text { ) }\end{array}$ & $\begin{array}{c}\text { Analytical } \\
\text { blank mean } \\
(\mathrm{n}=86)\end{array}$ & $\begin{array}{c}\text { Procedural } \\
\text { blank mean } \\
(\mathrm{n}=13)\end{array}$ & 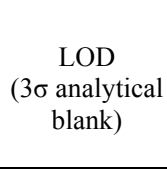 \\
\hline${ }^{139} \mathrm{La}$ & 0.324 & 0.324 & 0.125 & 0.004 & 0.009 & 0.004 \\
\hline${ }^{140} \mathrm{Ce}$ & 0.730 & 0.737 & 0.433 & 0.010 & 0.012 & 0.036 \\
\hline${ }^{141} \mathrm{Pr}$ & 0.074 & 0.074 & 0.025 & 0.001 & 0.004 & 0.001 \\
\hline${ }^{146} \mathrm{Nd}$ & 0.290 & 0.290 & 0.096 & 0.003 & 0.007 & 0.006 \\
\hline${ }^{147} \mathrm{Sm}$ & 0.055 & 0.057 & 0.019 & 0.005 & 0.007 & 0.007 \\
\hline${ }^{153} \mathrm{Eu}$ & 0.009 & 0.011 & 0.002 & 0.003 & 0.005 & 0.003 \\
\hline${ }^{157} \mathrm{Gd}$ & 0.041 & 0.047 & 0.014 & 0.008 & 0.008 & 0.012 \\
\hline${ }^{159} \mathrm{~Tb}$ & 0.005 & 0.008 & 0.002 & 0.002 & 0.002 & 0.003 \\
\hline${ }^{163}$ Dy & 0.034 & 0.034 & 0.013 & 0.001 & 0.003 & 0.003 \\
\hline${ }^{165} \mathrm{Ho}$ & 0.006 & 0.006 & 0.002 & 0.001 & 0.004 & 0.001 \\
\hline${ }^{166} \mathrm{Er}$ & 0.017 & 0.017 & 0.007 & $<0.001$ & $<0.001$ & 0.001 \\
\hline${ }^{169} \mathrm{Tm}$ & 0.002 & 0.004 & 0.001 & 0.001 & 0.002 & 0.002 \\
\hline${ }^{172} \mathrm{Yb}$ & 0.004 & 0.004 & 0.001 & $<0.001$ & 0.001 & $<0.001$ \\
\hline${ }^{175} \mathrm{Lu}$ & 0.002 & 0.003 & 0.002 & $<0.001$ & 0.001 & 0.001 \\
\hline
\end{tabular}
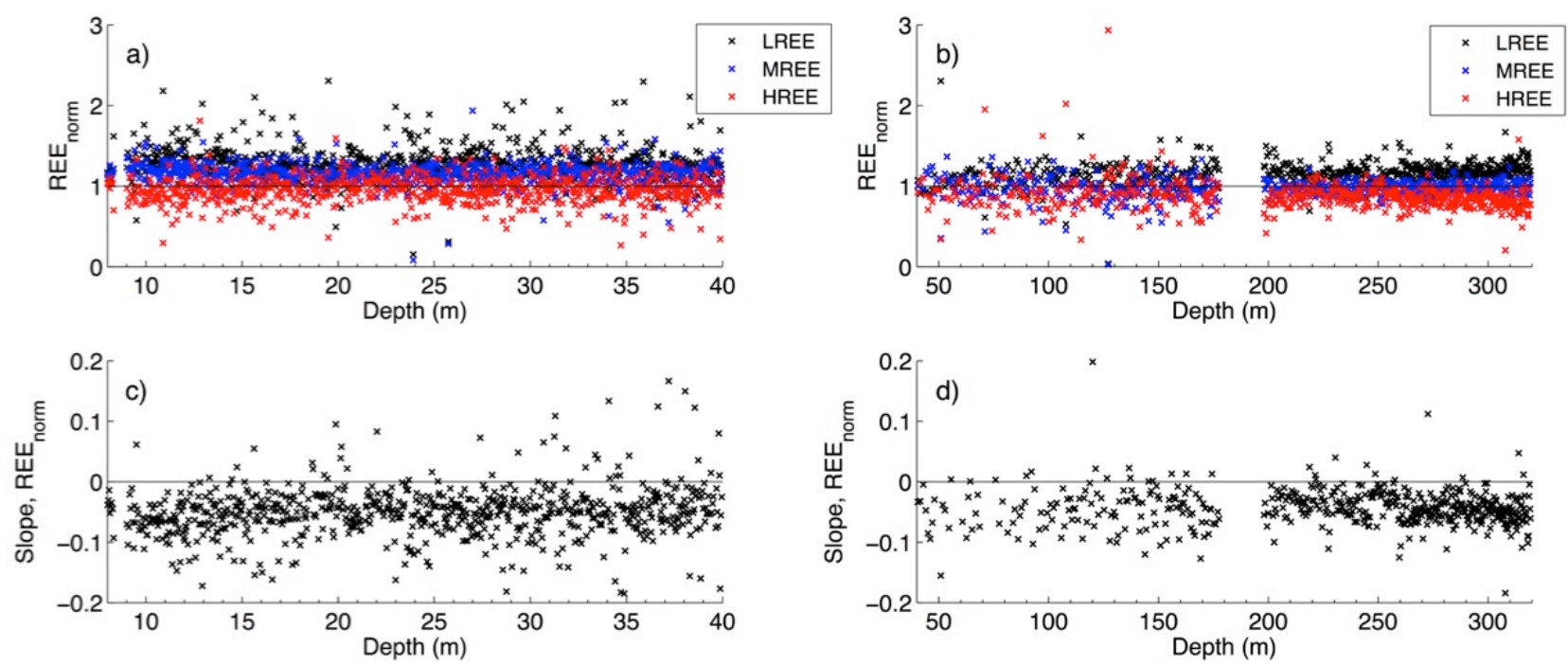

Figure 4. $R E E_{\text {norm }}$ for light (LREE, black), medium (MREE, blue) and heavy REE (HREE, red), a) $8 \mathrm{~m}$ to $40 \mathrm{~m}$ samples and b) $40 \mathrm{~m}$ to $320 \mathrm{~m}$ combined samples and corresponding $R E E_{\text {norm }}$ slope in c) and d). The analytical run for samples from $40 \mathrm{~m}$ to $180 \mathrm{~m}$ depth (b) had reduced stability, explaining increased variability of these data. 


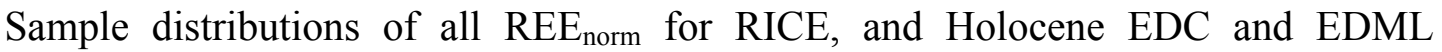
datasets (all normalized as in Eq. 1 and 2) are displayed in Figures S1-S4. We classify $\mathrm{REE}_{\text {norm }}$ patterns in samples by calculating the linear slope across all REE $\mathrm{norm}_{\text {concentrations }}$ to indicate relative enrichment of heavier REE (positive slope) versus enrichment of lighter REE (negative slope). This diagnostic has the advantage of taking into account all measured LREE and HREE isotopes, and not biasing interpretations towards individual elements or REE groupings (Figure 5). Although $\mathrm{REE}_{\text {norm }}$ slope is insensitive to less-variable MREE, this measure clearly captures strong trends across $\mathrm{REE}_{\text {norm }}$ (significant enrichment or depletion of the LREE and HREE), which are present in the most distinct and identifiable dust PSA signatures (see further discussion, Section 4.4). $\mathrm{Ce}$ and $\mathrm{Yb}$ are not considered in samples from the RICE ice core, Gd is excluded from consideration in EDC samples and Tm excluded in EDML samples, as above. $\mathrm{REE}_{\text {norm }}$ slope was not calculated for many samples from $40 \mathrm{~m}$ to $180 \mathrm{~m}$ depth, as many HREE concentrations were below blank levels; more variable but consistent slope values are maintained for calibrated samples through this analytical session (Figure 4d).

The slope from light to heavy elements across $\mathrm{REE}_{\text {norm }}$ in the RICE ice core is compared to existing data from the EDC and EDML ice cores in Figure 6 (mean and standard deviation detailed in Table 3). There is agreement between the two sample types from the RICE ice core, with a mean slope of $-0.050 \pm 0.049(1 \sigma)$ in $20^{\text {th }}$ Century sub-annual samples from $8 \mathrm{~m}-40 \mathrm{~m}$ and a slope of $-0.043 \pm 0.030$ in 3.6-year combined samples from $40 \mathrm{~m}-$ $320 \mathrm{~m}$ extending from the late $19^{\text {th }}$ Century to $\sim 2 \mathrm{ka}$ BP. Similar enrichment is seen in Holocene samples from EDC, while EDML $\mathrm{REE}_{\text {norm }}$ is essentially crustal in its mean signature (Figure 6, Table 3). Mean $\mathrm{REE}_{\text {norm }}$ slope and standard deviation for RICE samples and Holocene / Last Glacial Stage (LGS) EDC and EDML samples are presented in Table 3. 

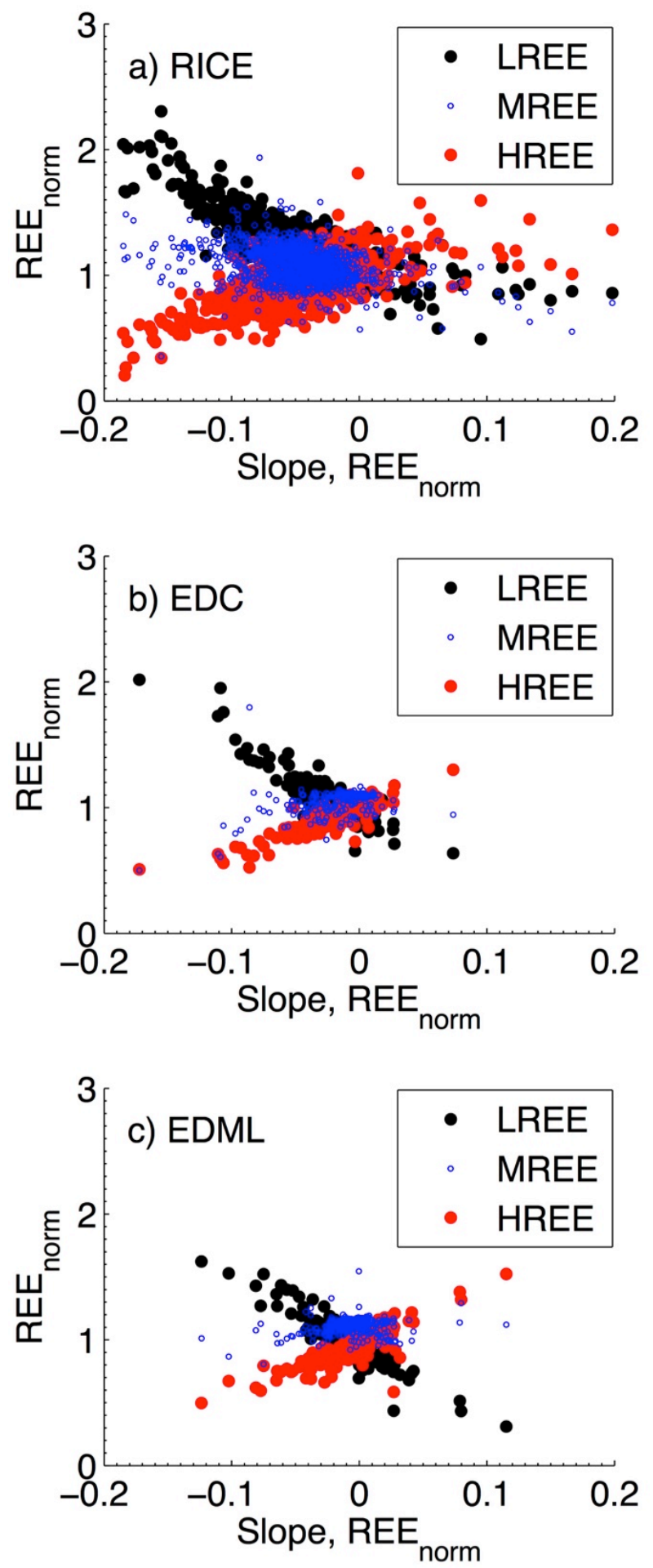

Figure 5. $R E E_{\text {norm }}$ slope sensitivity to $L R E E_{\text {norm }}, M R E E_{\text {norm }}$ and $H R E E_{\text {norm }}$ in a) RICE, b) EDC and c) EDML samples. 
Table 2. Mean and standard deviation of UCC-normalized REE concentrations $\left(R E E_{\text {norm }}\right)$ in RICE samples and Holocene EDML and EDC ice core samples.

\begin{tabular}{|c|c|c|c|c|c|c|c|c|c|}
\hline Isotope & $\begin{array}{c}\text { RICE } \\
8-40 \mathrm{~m} \\
\text { REE }_{\text {norm }}\end{array}$ & $\begin{array}{c}\text { RICE } \\
8-40 \mathrm{~m} \\
\text { REE }_{\text {norm }} \\
\left(<\text { LOD rem. }^{2}\right) \\
\end{array}$ & $\begin{array}{c}\text { RICE } \\
8-40 \mathrm{~m} \\
\text { STD }\end{array}$ & $\begin{array}{c}\text { RICE } \\
40-320 \mathrm{~m} \\
\text { REE }_{\text {norm }}\end{array}$ & $\begin{array}{c}\text { RICE } \\
40-320 \mathrm{~m} \\
\text { STD }\end{array}$ & $\begin{array}{c}\text { EDC } \\
\text { Holo. } \\
\text { REE }_{\text {norm }}\end{array}$ & $\begin{array}{l}\text { EDC } \\
\text { Holo. } \\
\text { STD }\end{array}$ & $\begin{array}{l}\text { EDML } \\
\text { Holo. } \\
\text { REE }_{\text {norm }}\end{array}$ & $\begin{array}{c}\text { EDML } \\
\text { Holo. } \\
\text { STD }\end{array}$ \\
\hline${ }^{139} \mathrm{La}$ & 1.29 & 1.29 & 0.26 & 1.37 & 0.19 & 1.11 & 0.34 & 1.01 & 0.20 \\
\hline${ }^{140} \mathrm{Ce}$ & 1.78 & 1.55 & 1.21 & 1.87 & 0.50 & 1.23 & 0.45 & 1.01 & 0.25 \\
\hline${ }^{141} \mathrm{Pr}$ & 1.32 & 1.31 & 0.22 & 1.23 & 0.19 & 1.19 & 0.26 & 0.96 & 0.15 \\
\hline${ }^{146} \mathrm{Nd}$ & 1.27 & 1.27 & 0.19 & 1.13 & 0.27 & 0.99 & 0.16 & 0.84 & 0.12 \\
\hline${ }^{147} \mathrm{Sm}$ & 1.25 & 1.24 & 0.27 & 1.15 & 0.26 & 0.90 & 0.18 & 1.10 & 0.15 \\
\hline${ }^{153} \mathrm{Eu}$ & 0.88 & 0.88 & 0.23 & 0.47 & 0.26 & 0.82 & 0.22 & 1.10 & 0.55 \\
\hline${ }^{157} \mathrm{Gd}$ & 1.21 & 1.24 & 0.25 & 1.09 & 0.25 & 3.30 & 2.77 & 1.15 & 0.11 \\
\hline${ }^{159} \mathrm{~Tb}$ & 0.94 & 0.98 & 0.26 & 0.92 & 0.28 & 1.20 & 0.19 & 1.13 & 0.10 \\
\hline${ }^{163}$ Dy & 1.12 & 1.09 & 0.20 & 1.08 & 0.21 & 1.08 & 0.16 & 0.96 & 0.12 \\
\hline${ }^{165} \mathrm{Ho}$ & 0.90 & 0.92 & 0.21 & 0.79 & 0.31 & 0.97 & 0.16 & 0.93 & 0.12 \\
\hline${ }^{166} \mathrm{Er}$ & 1.03 & 0.99 & 0.23 & 1.03 & 0.23 & 1.01 & 0.17 & 0.92 & 0.13 \\
\hline${ }^{169} \mathrm{Tm}$ & 0.84 & 0.91 & 0.33 & 0.90 & 0.37 & 0.98 & 0.20 & 1.17 & 0.19 \\
\hline${ }^{172} \mathrm{Yb}$ & 0.24 & 0.23 & 0.07 & 0.21 & 0.08 & 0.73 & 0.19 & 0.86 & 0.13 \\
\hline${ }^{175} \mathrm{Lu}$ & 0.72 & 0.65 & 0.76 & 0.74 & 0.62 & 0.77 & 0.17 & 0.87 & 0.18 \\
\hline
\end{tabular}
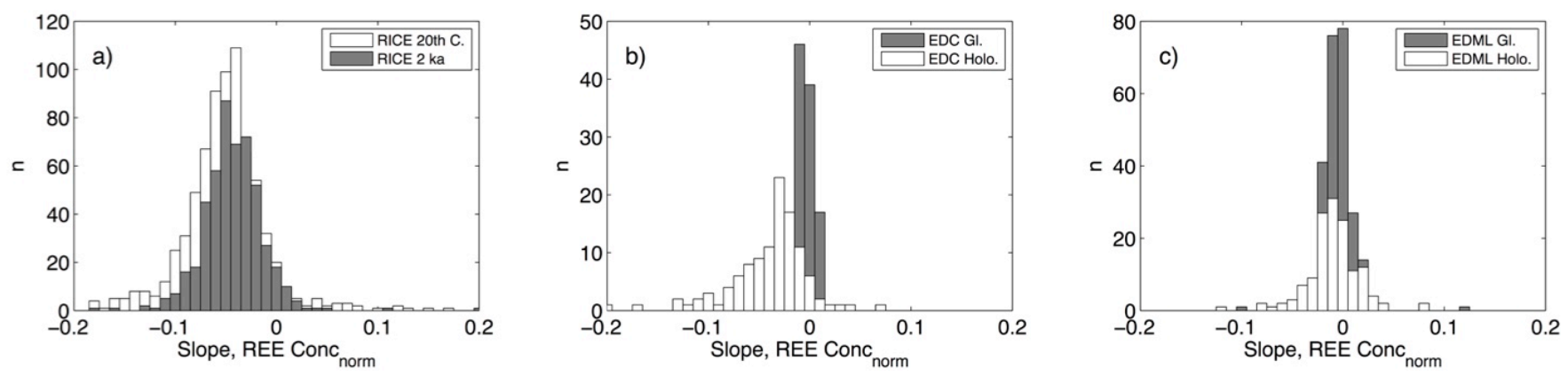

Figure 6. Distribution (number of samples, $n$ ) of REE $E_{\text {norm }}$ slope in samples from a) RICE $\left(20^{\text {th }}\right.$ Century and $\left.2 \mathrm{ka} \mathrm{BP}\right)$, b) EDC (LGS, $33.7 \mathrm{ka} \mathrm{BP}$ to $11.7 \mathrm{ka} \mathrm{BP,} n=134$; Holocene, $11.7 \mathrm{ka} \mathrm{BP}$ to $2.9 \mathrm{ka} \mathrm{BP,} n=161)$ and c) EDML (LGS, $26.6 \mathrm{ka} \mathrm{BP}$ to $11.7 \mathrm{ka} \mathrm{BP,} n=258$; Holocene, $11.7 \mathrm{ka} \mathrm{BP}$ to $7.5 \mathrm{ka} \mathrm{BP}, n=141$ ). Positive slope indicates relative enrichment in $H R E E_{\text {norm }}$ (depletion in LREE), negative slope indicates relative enrichment in LREE $E_{\text {norm }}$ (depletion in HREE). 
Table 3. Mean REE $E_{\text {norm }}$ slope and standard deviation in RICE, EDC and EDML samples spanning the Holocene and Last Glacial Stage

\begin{tabular}{c|cc|cc|cc} 
Age & $\begin{array}{c}\text { Mean RICE } \\
\text { REE }_{\text {norm }} \text { slope }\end{array}$ & $1 \sigma$ & \multicolumn{2}{c|}{$\begin{array}{c}\text { Mean EDC } \\
\text { REE }_{\text {norm }} \text { slope }\end{array}$} & $1 \sigma$ & \multicolumn{2}{c}{ Mean EDML } \\
REE $_{\text {norm }}$ slope & $1 \sigma$ \\
\hline Holocene* & -0.050 & 0.049 & -0.042 & 0.047 & -0.010 & 0.026 \\
LGS & - & - & -0.005 & 0.011 & -0.006 & 0.022 \\
\hline * RICE samples are 8-40m (20th Century) samples
\end{tabular}

\subsection{Discussion}

\subsubsection{Sample acidification biases towards LREE enrichment}

Precaution must be taken during sample preparation in REE dust provenance studies, due to preferential leaching of lighter REE and incongruent leaching with respect to crustal values in acidified samples (required for ICPMS analysis). RICE samples show persistent

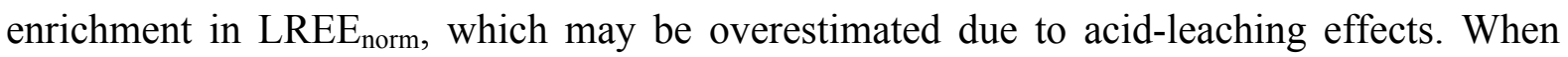
comparing lightly-acidified $\left(1 \% \mathrm{HNO}_{3}\right.$, as here) ice core sample REE recovery with that from a full acid digestion ( $\mathrm{HF}$ and $\mathrm{HNO}_{3}$ ), Gabrielli et al. [2010] found preferential enrichment of LREE- $20 \%$ to $30 \%$ additional recovery relative to the HREE. An additional LREE bias was also observed in un-filtered samples with particle sizes larger than $0.2 \mu \mathrm{m}$, suggesting that larger particle sizes release more LREE after acidification. Preliminary particle size data from RICE surface snow (summer 2012) suggest a mode diameter of $\sim 2$ $\mu \mathrm{m}$, but also indicate that particles $>5 \mu \mathrm{m}$ diameter are present $(H$. Winton and B. Delmonte, unpublished data). In the WAIS Divide ice core $\left(79.5^{\circ} \mathrm{S}, 112.1^{\circ} \mathrm{W}\right)$, located at the highestelevation ice divide of the WAIS (1766 m a.s.1.), large mode particle diameters of $\sim 5 \mu \mathrm{m}$ are observed in Holocene samples [Koffman et al., 2014b], compared to $\sim 2 \mu \mathrm{m}$ in EDC samples [Delmonte et al., 2004]. Similar results suggesting incongruent REE dissolution were found by Rhodes et al. [2011], in acidification tests of rock standards diluted to approximate ice core dust concentrations. While we did not perform a similar experiment specifically for REE in RICE ice core samples, we assume that some preferential LREE enrichment may affect our samples. We suggest that a proportional correction to enriched RICE LREE norm $_{\text {data does }}$ not negate this observation and cannot explain $\mathrm{HREE}_{\text {norm }}$ depletion prevalent in RICE samples.

\subsubsection{RICE REE comparison to EDC and EDML}

Two observations have resulted from previous REE dust provenance studies in ice cores. Firstly, REE in both the EDC and EDML ice cores display a persistent, approximately crustal-average $\mathrm{REE}_{\text {norm }}$ pattern in samples from the LGS [Gabrielli et al., 2010; Wegner et 
al., 2012]. Interpretation has been equivocal, suggesting that this stable signature either represents one dominant dust source or a consistent mix of many. The second observation is that $\mathrm{REE}_{\text {norm }}$ variability increases beginning $\sim 15 \mathrm{ka}$ BP. However, we caution that this change coincides with a twenty- to thirty-fold reduction in REE concentrations and dust mass, which continues through youngest available late-Holocene samples. This increase in variability is most pronounced in EDC samples, seen as a broadening of the Holocene normalized REE slope distribution in Figure $6 \mathrm{~b}$ and Figure 7 , with the mean $\mathrm{REE}_{\text {norm }}$ slope also shifting toward greater LREE enrichment (more negative $\mathrm{REE}_{\text {norm }}$ slope). EDML mean $\mathrm{REE}_{\text {norm }}$ trends do not change significantly, but show a small $(\sim 20 \%)$ increase in $R E E_{\text {norm }}$ slope variability from LGS to Holocene samples (Figure 6c, Table 3; this result is similar if data are partitioned at $15 \mathrm{ka} \mathrm{BP}$ as in Wegner et al. [2012]). Increased EDML REE ${ }_{\text {norm }}$ variably during the Holocene is not as well captured by our $\mathrm{REE}_{\text {norm }}$ slope diagnostic, as this measure is insensitive to fluctuations in $\mathrm{MREE}_{\text {norm }}$ (Figure 5).

The role of increased measurement uncertainty in more variable Holocene $\mathrm{REE}_{\text {norm }}$ patterns must be carefully considered to evaluate REE as a tool to explore dust provenance during less dusty periods when the utility of other geochemical techniques are limited (e.g. $\mathrm{Pb}$ and $\mathrm{Sr} / \mathrm{Nd}$ isotopes [Delmonte et al., 2008; Vallelonga et al., 2010]). Low REE concentrations during the Holocene incur greater relative measurement uncertainty, especially for MREE and HREE, which approach instrumental LODs. In EDC samples, RSD increases from $<20 \%$ in LGS samples to $30-60 \%$ during the Holocene when many MREE and HREE concentrations are only several times greater than reported $3 \sigma$ LODs (Figure 7, data from Gabrielli et al. [2010]). Holocene mean concentrations and LODs are presented in Table 4 for RICE, EDC and EDML. RICE REE have similar measurement uncertainty to EDC samples, as shown in Figure 3, but show slightly higher average errors due to lower concentrations especially in combined samples from $40 \mathrm{~m}$ to $320 \mathrm{~m}$ depth (Figure 7). While RSD representing uncertainties as small as single $\mathrm{fg} \mathrm{g}^{-1}$ may seem insignificant, these relative uncertainties are propagated through crustal normalization, resulting in large uncertainties for $\mathrm{MREE}_{\text {norm }}$ and $\mathrm{HREE}_{\text {norm }}$ (uncertainties for $\mathrm{LREE}_{\text {norm }}$ remain lower). 
Table 4. Mean Holocene REE concentrations ( $\mathrm{pg}^{-1}$ ) and Limits of Detection (LOD) in RICE, EDC and EDML ice core samples

\begin{tabular}{|c|c|c|c|c|c|c|c|c|c|}
\hline & $\begin{array}{r}\text { RICE 8- } \\
40 \mathrm{~m} \text { conc. }\end{array}$ & $\begin{array}{l}\text { RICE } \\
\text { LOD } \\
\end{array}$ & $\begin{array}{c}\text { RICE } \\
\text { conc./LOD }\end{array}$ & $\begin{array}{l}\text { EDC } \\
\text { Holo. } \\
\text { conc. }\end{array}$ & $\begin{array}{l}\text { EDC } \\
\text { LOD } \\
\end{array}$ & $\begin{array}{c}\begin{array}{c}\text { EDC } \\
\text { conc./LOD }\end{array} \\
\end{array}$ & $\begin{array}{c}\text { EDML } \\
\text { Holo. } \\
\text { conc. }\end{array}$ & $\begin{array}{l}\text { EDML } \\
\text { LOD }\end{array}$ & $\begin{array}{c}\text { EDML } \\
\text { conc./LOD* }\end{array}$ \\
\hline${ }^{139} \mathrm{La}$ & 0.324 & 0.004 & 81 & 0.375 & 0.004 & 94 & 1.066 & 0.027 & 39 \\
\hline${ }^{140} \mathrm{Ce}$ & 0.730 & 0.036 & 20 & 0.882 & 0.004 & 221 & 2.078 & 0.160 & 13 \\
\hline${ }^{141} \mathrm{Pr}$ & 0.074 & 0.001 & 74 & 0.089 & 0.002 & 45 & 0.224 & 0.050 & 4.5 \\
\hline${ }^{146} \mathrm{Nd}$ & 0.290 & 0.006 & 48 & 0.294 & 0.008 & 37 & 0.781 & 0.010 & 78 \\
\hline $\begin{array}{l}\text { LREE } \\
\text { mean }\end{array}$ & 0.355 & 0.012 & 56 & 0.410 & 0.005 & 99 & 1.037 & 0.062 & 34 \\
\hline${ }^{147} \mathrm{Sm}$ & 0.055 & 0.007 & 7.9 & 0.050 & 0.008 & 6.3 & 0.195 & 0.012 & 16 \\
\hline${ }^{153} \mathrm{Eu}$ & 0.009 & 0.003 & 3.1 & 0.012 & 0.003 & 4.0 & 0.048 & 0.005 & 9.6 \\
\hline${ }^{157} \mathrm{Gd}$ & 0.041 & 0.012 & 3.4 & 0.141 & 0.030 & 4.7 & 0.159 & 0.003 & 53 \\
\hline${ }^{159} \mathrm{~Tb}$ & 0.005 & 0.003 & 1.8 & 0.008 & 0.002 & 3.9 & 0.025 & 0.002 & 13 \\
\hline${ }^{163}$ Dy & 0.034 & 0.003 & 11 & 0.040 & 0.003 & 13 & 0.129 & 0.002 & 65 \\
\hline $\begin{array}{l}\text { MREE } \\
\text { mean }\end{array}$ & 0.029 & 0.006 & 5.5 & 0.050 & 0.009 & 6.5 & 0.111 & 0.005 & 31 \\
\hline${ }^{165} \mathrm{Ho}$ & 0.006 & 0.001 & 5.9 & 0.008 & 0.001 & 7.7 & 0.026 & 0.001 & 26 \\
\hline${ }^{166} \mathrm{Er}$ & 0.017 & 0.001 & 17 & 0.021 & 0.002 & 11 & 0.069 & 0.002 & 35 \\
\hline${ }^{169} \mathrm{Tm}$ & 0.002 & 0.002 & 1.0 & 0.003 & 0.001 & 3.0 & 0.012 & 0.001 & 12 \\
\hline${ }^{172} \mathrm{Yb}$ & 0.004 & 0.001 & 3.7 & 0.016 & 0.002 & 8.0 & 0.061 & 0.002 & 30 \\
\hline${ }^{175} \mathrm{Lu}$ & 0.002 & 0.001 & 2.1 & 0.003 & 0.001 & 2.7 & 0.011 & 0.002 & 5.3 \\
\hline $\begin{array}{c}\text { HREE } \\
\text { mean }\end{array}$ & 0.006 & 0.001 & 5.9 & 0.010 & 0.001 & 6.4 & 0.036 & 0.002 & 22 \\
\hline
\end{tabular}

Comparing observed trends across all REE (i.e. $\mathrm{REE}_{\text {norm }}$ slope) in all ice core samples is the simplest method to reduce measurement uncertainty in Holocene samples, taking advantage of the large sample sizes achievable with REE analysis. In both RICE and Holocene EDC samples, $\mathrm{REE}_{\text {norm }}$ slope is persistently negative, enriched in LREE and depleted in HREE relative to UCC (Figures 6 and 7, Table 3). The majority of EDML samples show limited change in $\mathrm{REE}_{\text {norm }}$ slope from the LGS to the Holocene, exhibiting crustal $\mathrm{LREE}_{\text {norm }}$ values, $10-15 \%$ enrichment in $\mathrm{MREE}_{\text {norm }}$ and 10\% depletion in $\mathrm{HREE}_{\text {norm }}$ (Table 2). We proceed with an interpretation of this observed LREE norm $_{\text {enrichment and }}$ HREE $_{\text {norm }}$ depletion observed in Holocene ice from RICE and EDC, and a mean crustal $\mathrm{REE}_{\text {norm }}$ signature at EDML. Yet, we do not treat these data as timeseries, acknowledging that understanding of signal-noise relationships has not been confidently demonstrated.

Figure 7. (Following page) Characteristics of RICE and EDC ice core REE samples mean concentration $\left(\mathrm{pg} \mathrm{g}^{-1}\right)$ of LREE, MREE and HREE ( $(a, b)$, REE slope (c, $\left.d\right)$, and mean relative standard deviation (RSD; e, f). Vertical line marks the $15 \mathrm{ka}$ BP transition discussed by Gabrielli et al. [2010] and Wegner et al. [2012]. 


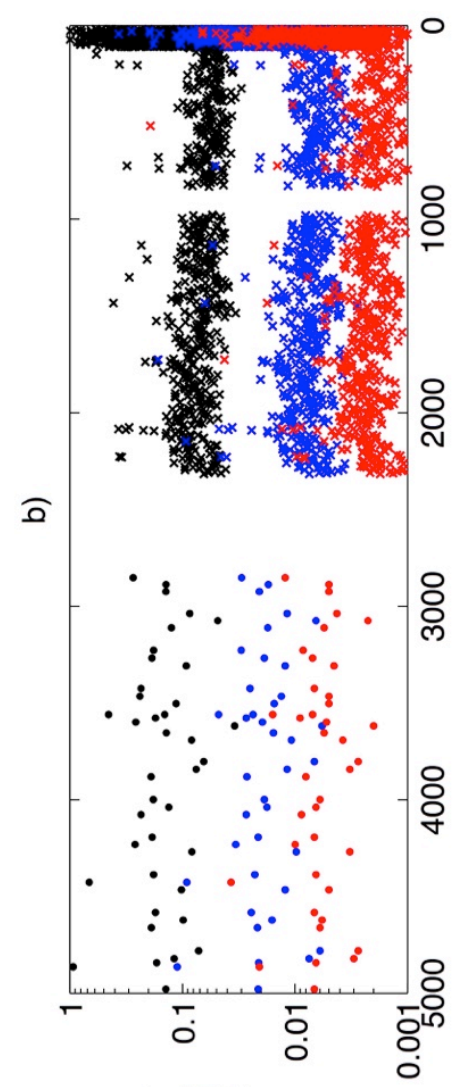

(_- 6 6d) · गuoว
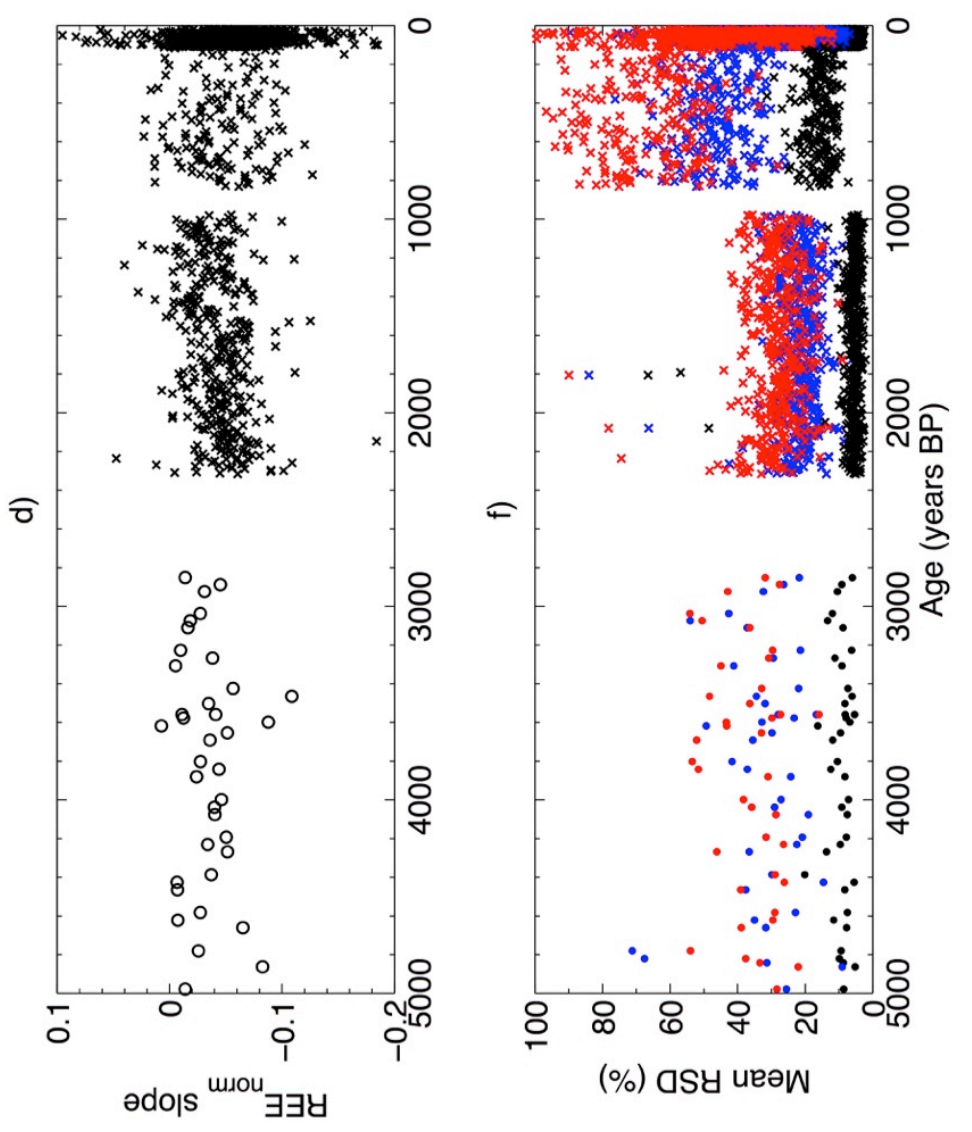

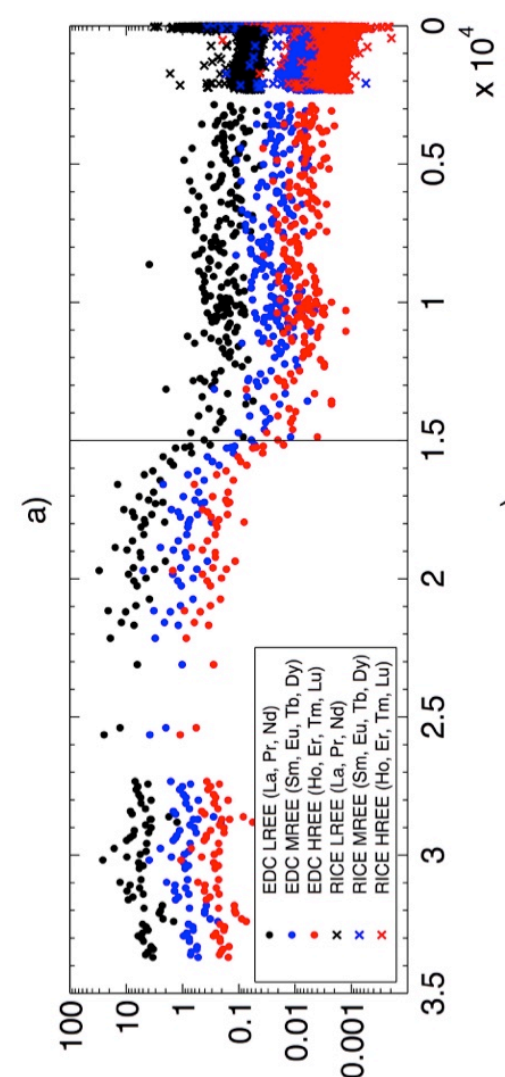

( $\_$- 6 6d) 'suoว
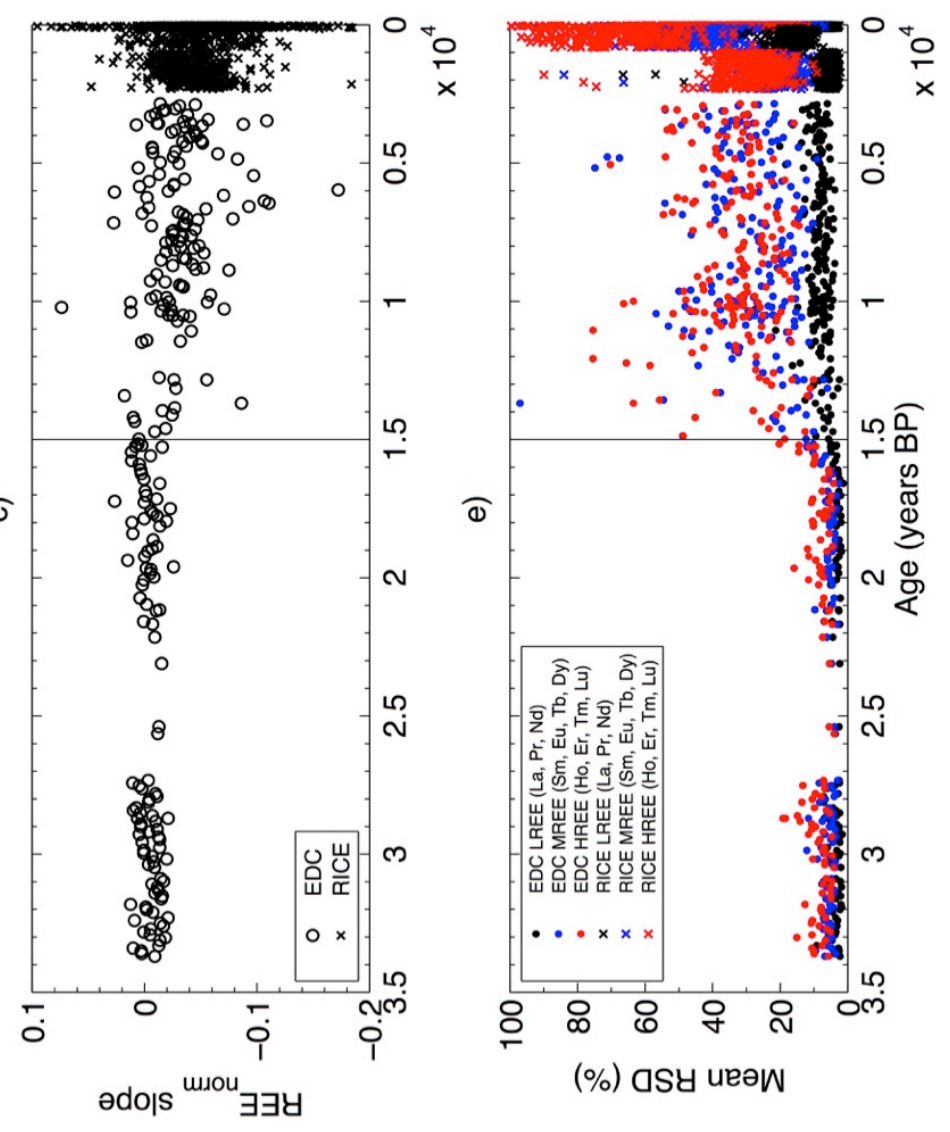


\subsubsection{Modern/Holocene dust PSA contributions to ice core sites}

Prior to attributing the origin of REE signatures in ice core samples, likely PSA supplying dust to ice core sites are identified. We use the forward-trajectory data of Neff and Bertler (in review) to consider the modern atmospheric transport regimes at these sites (Figure 9), with additional consideration of independent local/regional geochemical and atmospheric model studies constraining dust sources for these sites. Neff and Bertler use the Hybrid Single Particle Lagrangian Integrated Trajectory model (HySPLIT, http://ready.arl.noaa.gov/HYSPLIT.php, National Oceanic and Atmospheric Administration Air Resources Laboratory, Silver Spring, MD, USA; [Draxler and Hess, 1998]) to explore atmospheric transport pathways from Southern Hemisphere dust PSA to Antarctica, calculating daily forward trajectories from 1979-2013 with a 10-day runtime. Daily trajectory endpoints (12,775 total) for each dust PSA are presented after 5 and 10 days, with an additional 15-day run time, in Figure S5. Trajectories become well-mixed after 15 days; this represents longer transport time than the average particle lifetime in either present or LGS model studies (e.g. Mahowald et al. [1999]) but is presented for reference.

\subsubsection{RICE}

RICE is a low-elevation, coastal site in the Pacific sector of Antarctica that is most directly downwind of Australian and New Zealand dust sources (Figure 1, Figure S5, Neff and Bertler, in review). This site and the WAIS is strongly influenced by synoptic storm activity associated with the Amundsen Sea Low [Hosking et al., 2013; Nicolas and Bromwich, 2011], which brings airmasses from the Pacific sector of the Southern Ocean up the relatively shallow coastal gradient of the WAIS. Backward trajectories generated using the HySPLIT model demonstrate that in the 48-hours before arriving at Roosevelt Island, most daily trajectories over the four year period from 2010 to 2013 pass over the WAIS and specifically Marie Byrd Land (Figure 8). 


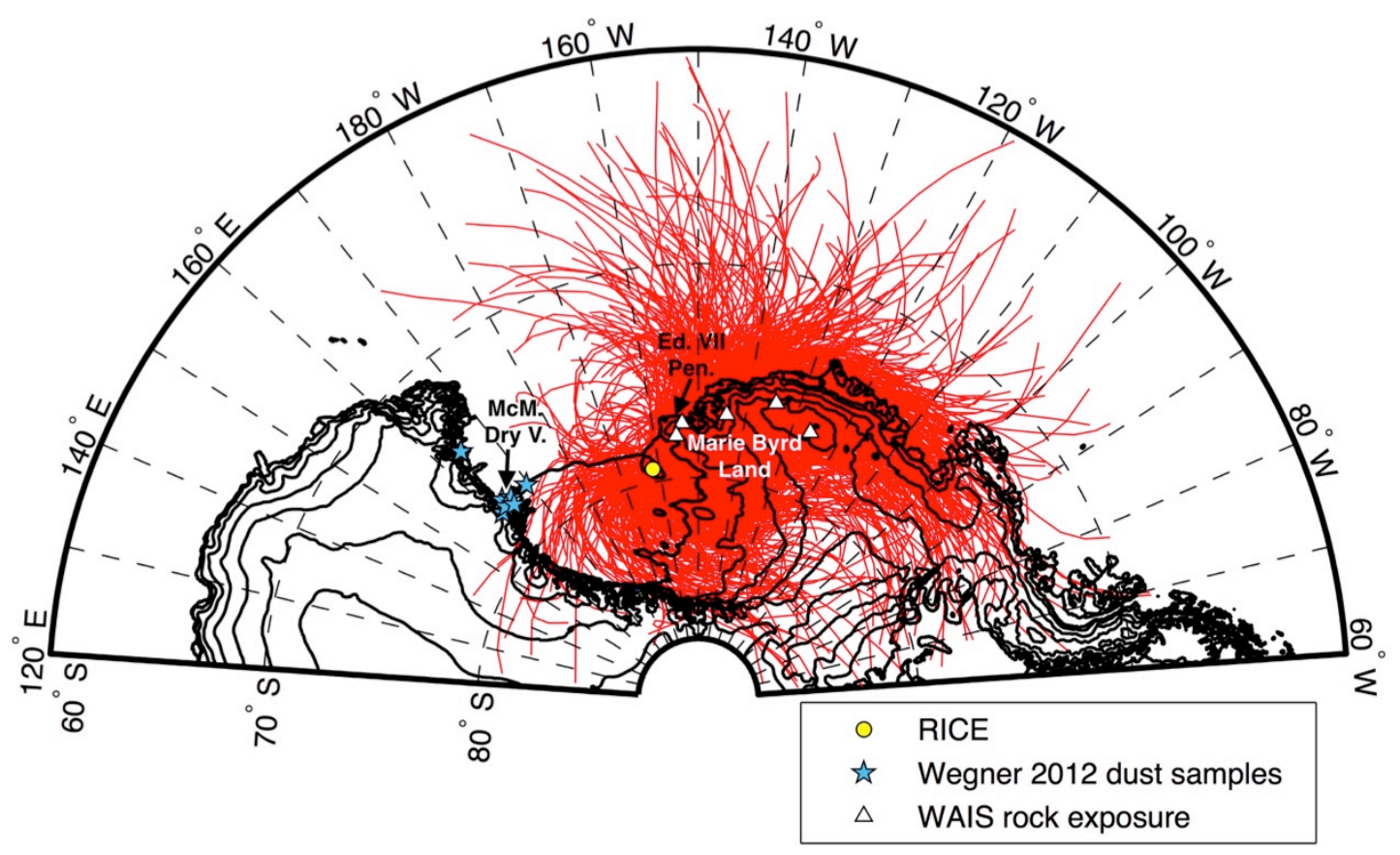

Figure 8. 2010-2013 daily 48-hour HySPLIT backward trajectories, initiated at the RICE ice core site (yellow circle), $100 \mathrm{~m}$ above ground level. The large ice-free McMurdo Dry Valleys are indicated, with dust samples from Wegner et al. [2012] marked (blue stars). Outcropping Marie Byrd Land mountain ranges, not sampled for REE, are marked (white triangles) and the location of King Edward VII Peninsula (Ed. VII Pen.) is indicated.

Few high-order geochemical studies have been previously undertaken on West Antarctic ice cores, but large dust particle size distributions $(5-8 \mu \mathrm{m}$ mode diameter) in the WAIS Divide ice core, spanning the last $2.4 \mathrm{ka} \mathrm{BP}$, suggest a possible local West Antarctic dust source in addition to extra-Antarctic PSA [Koffman et al., 2014b]. While ice-free areas are not extensive cross the Marie Byrd land and the WAIS, a number of granitic, metamorphic and volcanic rock outcrops may contribute to local dust loading, indicated in Figure 8, including the Rockefeller and Alexandra Mountains (Edward VII Peninsula), Ford Ranges, Flood Range and Executive Committee Range in addition to regional volcanoes [Luyendyk et al., 1996].

Neff and Bertler (in review) demonstrate that this sector of Antarctica, and the RICE ice core site, is subject to strong, direct atmospheric transport from New Zealand dust sources (Figure 9a, b). Over the last thirty-five years, fewer than of $12 \%$ of daily trajectories initiated at any Southern Hemisphere dust PSA reach the Antarctic continent (defined as areas south of $70^{\circ} \mathrm{S}$ latitude). The number of New Zealand trajectories passing over the RICE ice core site within ten days is three to four times more than those from the Patagonian dust PSA (0.6 
$-0.8 \%$ of all New Zealand trajectories pass over RICE, compared to $0.2 \%$ of all Patagonian trajectories). Half as many Australian dust PSA trajectories $(0.1 \%)$ as those from Patagonia arrive in the vicinity of RICE within 10 days of transport time, and essentially no southern African trajectories arrive near RICE. While the differing trajectory contributions from these dust PSA trajectories seems small, the relative differences are significant as the represents a 35-year average of daily trajectory calculations. When trajectories are weighted by modeled dust emission rates from $\mathrm{Li}$ et al. [2008], contributions appear more mixed due to small but poorly quantified New Zealand dust emissions and large weighting given to Australian trajectories. Several independent GCM results also suggest that coastal Wilkes Land, Victoria Land and Marie Byrd Land are the most likely areas to be influenced by long-range midtropospheric transport of Australian dust [Albani et al., 2012; Krinner et al., 2010; Li et al., 2008].

\subsubsection{EDC}

Isolated in the high interior of the EAIS plateau, EDC is removed from all dust sources. Katabatic airflow is persistent across Antarctica [Parish and Bromwich, 2007], restricting access of low-level airflow to interior areas of the continent-especially cutting off the high EAIS plateau and the EDC ice core site from extra-Antarctic atmospheric transport. As discussed above, geochemical studies from EDC and other EAIS ice cores favor South America as a dominant dust source (e.g. Delmonte et al. [2008]), especially during glacial periods when glaciogenic dust sources in Patagonia abruptly activate [Sugden et al., 2009]. Transport of pollutants $(\mathrm{Pb})$ from Australia is clearly observed in modern ice core samples from the coastal East Antarctic Law Dome ice core $\left(66.8^{\circ} \mathrm{S}, 112.8^{\circ} \mathrm{E}\right)$ [Vallelonga et al., 2002], confirming that Australian atmospheric transport is linked to this sector of the Antarctic and may also be an identifiable contributor to dust across coastal Wilkes Land and the EAIS during interglacial periods [De Deckker et al., 2010; Revel-Rolland et al., 2006]. Figure 9 (c, d) suggests highly mixed dust PSA contributions to the remote interior of the EAIS plateau, with very few trajectories initiated at dust PSA arriving over EDC in the thirtyfive years considered by Neff and Bertler (in review). When weighted for dust PSA emissions, however, Australian dust contribution to EDC appears to be significantly greater than other PSA (Figure 9d).

\subsubsection{EDML}

EDML, located on the Atlantic margin of the EAIS plateau, is directly downwind of the significant Patagonian dust source (Figure 9). It is clearly subject to strong influence of this dust PSA, both at present and during the LGS, as indicated by model studies [Albani et 
al., 2012; Krinner and Genthon, 2003; Krinner et al., 2010; Li et al., 2008; Li et al., 2010b], and dust transport over the South Atlantic has been observed using remote sensing techniques [Gassó and Stein, 2007; Li et al., 2010a]. The results of Neff and Bertler (in review) at EDML similarly suggest dominance of trajectories initiated near Patagonian dust sources (Figure 9e), followed by trajectories originating in New Zealand, although this dust source is clearly less influential as evidenced by dust emission-weighted trajectories (Figure 9f). Very little contribution from distant Australian and upwind southern African sources are seen in trajectory or other model results. Mineralogy of dust in LGS ice from EDML is similar to that of EDC, linking the strong $\mathrm{Sr} / \mathrm{Nd}$ isotopic evidence for South American glacial dust composition at EDC to the dust budget of EDML [Marino et al., 2009].

Figure 9. (Following page) Percent of 1979-2013 daily forward-trajectories initiated at dust $P S A$, both unweighted (\%, a, c, e) and terrestrial dust emission-weighted (\% Tg $\left.a^{-1}, e-h\right)$, passing over Antarctic ice core sites at daily increments for all Southern Hemisphere dust PSA. Map of trajectory endpoints after 5 days $(g)$ detail areas surrounding ice core sites considered in trajectory percentages $\left( \pm 2.5^{\circ}\right.$ latitude for all sites; $\pm 10^{\circ}$ longitude, EDC, EDML; $\pm 14^{\circ}$ longitude, RICE; total area $\sim 3.2 \times 10^{5} \mathrm{~km}^{2}$ for all sites). Emission estimates are taken from Li et al. (2008), with Patagonia emitting $38 \mathrm{Tg} \mathrm{a}^{-1}$, Australia $120 \mathrm{Tg} \mathrm{a}^{-1}$, southern Africa $34 \mathrm{Tg} \mathrm{a}^{-1}$ and a 10-30 $\mathrm{Tg} \mathrm{a}^{-1}$ range of emission rates for unquantified New Zealand dust sources. 

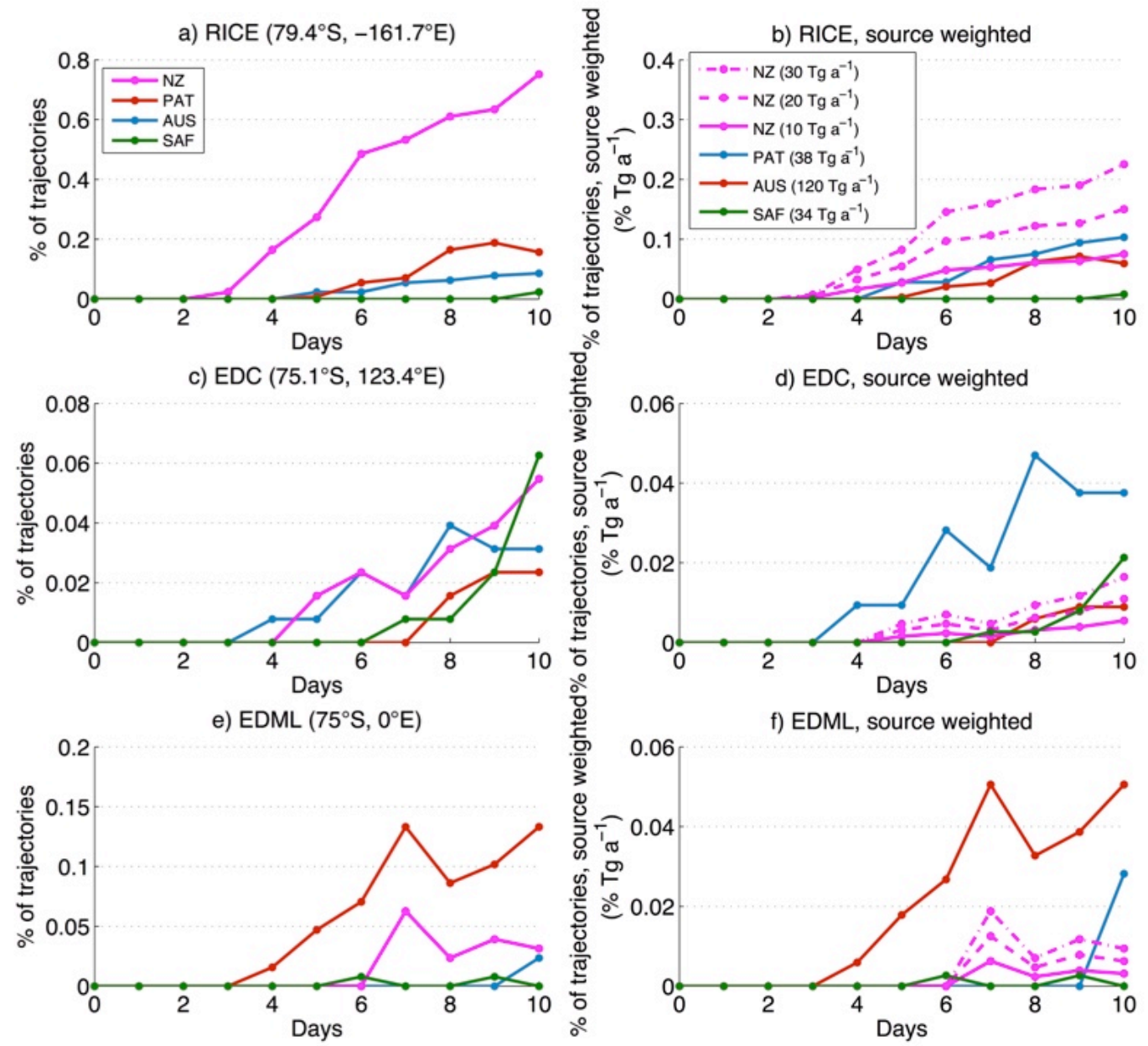

g) Day 5 snapshot

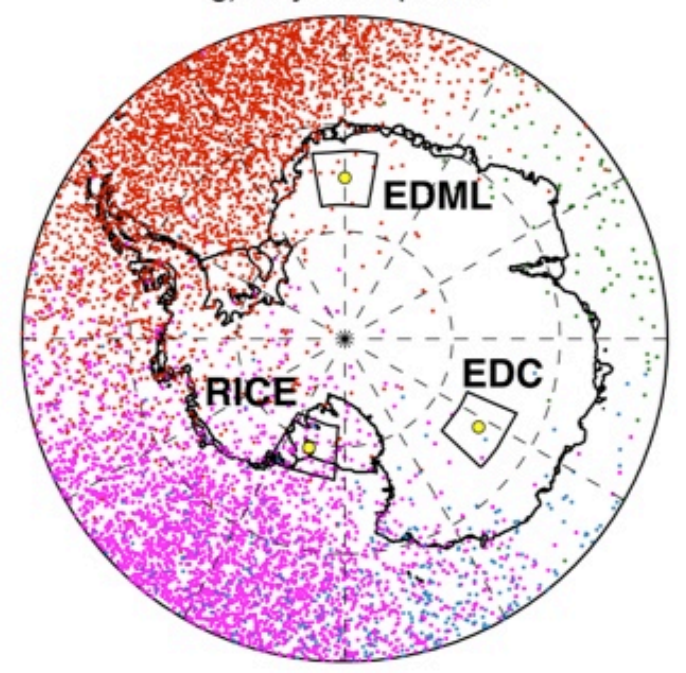




\subsubsection{PSA REE signatures}

The utility of the REE as a tool to identify dust provenance relies on thorough characterization of signatures in PSA dust, and that source REE signatures have unique distinguishing features. There is limited analytical uncertainty in determining REE signatures in highly concentrated dust samples, although $\mathrm{REE}_{\text {norm }}$ signatures are dependent on the dust size-fraction analyzed (e.g. Gaiero et al. [2004]; Wegner et al. [2012]). The compilation and measurement of REE in PSA samples by Wegner et al. [2012] is a significant advancement of this effort, however they note that these samples only "spotlight" regional REE patterns. We reproduce this compilation for reference in Figure 10. Australian PSA dust samples are primarily from the southeastern Murray-Darling region [Marx et al., 2005] with few from the Lake Eyre region for which transport of dust emissions has been modeled [McGowan and Clark, 2008]. Five samples from southern Africa show large variability in REE signature, with three samples showing significant $\mathrm{MREE}_{\text {norm }}$ enrichment and $\mathrm{HREE}_{\text {norm }}$ depletion (Figure 10). Samples from New Zealand rivers and beaches show approximately crustal $\mathrm{REE}_{\text {norm }}$ except for two samples, which are depleted in $\mathrm{LREE}_{\text {norm }}$ and have a large Eu anomaly.

Antarctic dust samples analyzed by Wegner et al. [2012] (locations marked in Figure 8) show distinct negative trends across $R E_{n o r m}$ with strong enrichment in $L_{R E E}$ norm and depletion in $\mathrm{HREE}_{\text {norm. }}$. While these few samples are primarily from the McMurdo Dry Valleys, the negative trend in $\mathrm{REE}_{\text {norm }}$ is consistent across all samples. The $\mathrm{REE}_{\text {norm }}$ signature of South American sediments and aeolian dust is particularly well characterized and $\mathrm{REE}_{\text {norm }}$ patterns are also quite distinct: South American $\mathrm{REE}_{\text {norm }}$ signatures show consistent depletion in $\mathrm{LREE}_{\text {norm }}$ and enrichment in $\mathrm{HREE}_{\text {norm }}$ across many samples (see Gaiero et al. [2004], Smith et al. [2003], data included in Figure 10). Southern African dust is highly unlikely to arrive at the RICE site in identifiable quantities, based on trajectory results and atmospheric modeling studies suggesting that southern African dust represents $<5 \%$ of the total Antarctic dust budget [ $\mathrm{Li}$ et al., 2008]. At this time, the dust PSA samples from Antarctica (Dry Valleys) and South America (Patagonia) show the most distinct REE signatures: both are easily distinguishable from the crustal mean and from each other. As with our examination of RICE REE data above, we choose to not rest conclusions on single elemental anomalies in dust PSA samples especially if anomalies are not consistent across many samples. For the RICE site, this unfortunately precludes consideration of New Zealand dust samples until they 
are better characterized and it is determined whether observed Europium anomalies present several New Zealand dust samples are truly representative of this PSA.
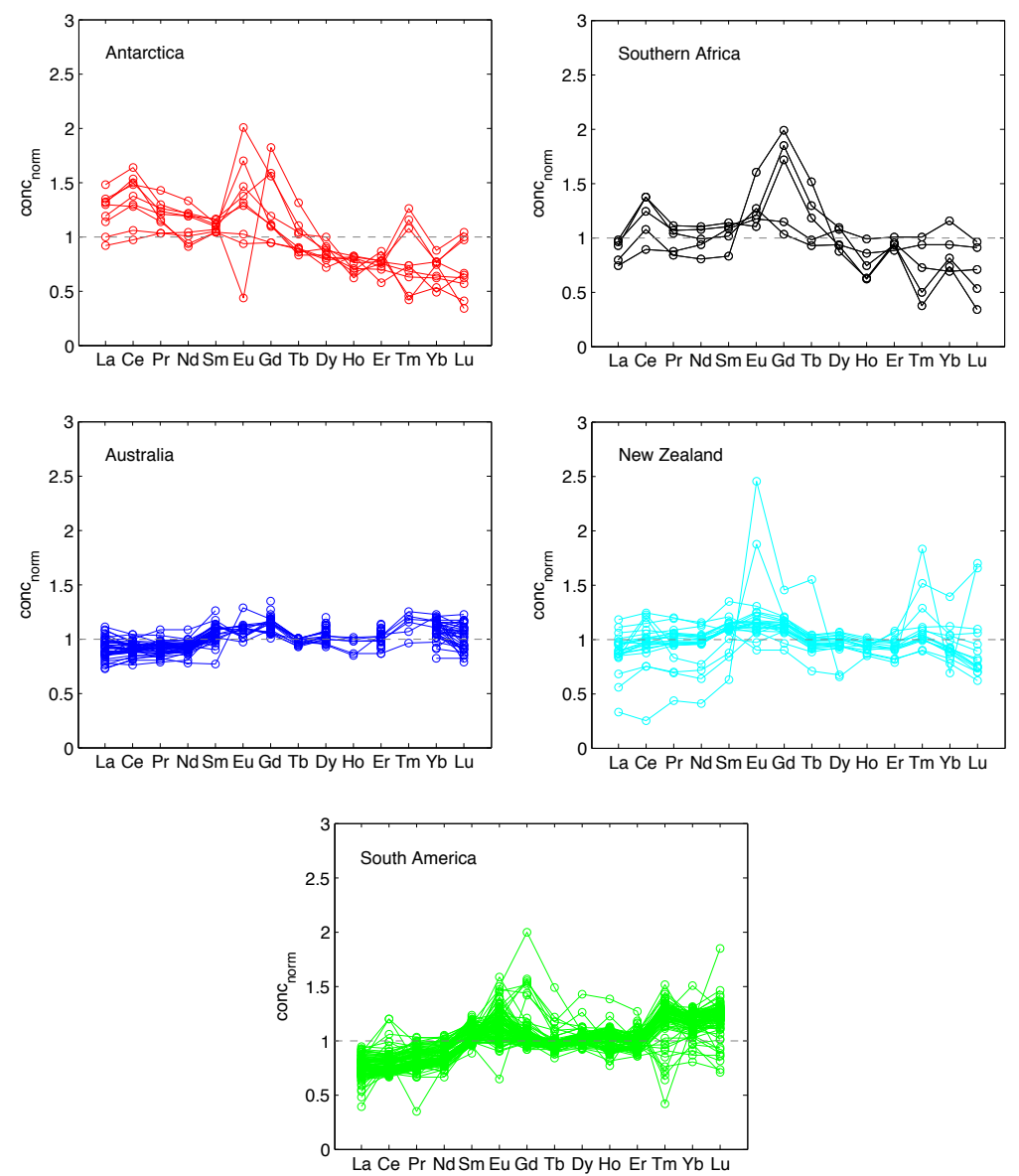

Figure 10. $R E E_{\text {norm }}$ patterns in dust PSA samples, from Wegner et al. [2012].

\subsubsection{RICE ice core REE indications of dust provenance}

RICE ice core samples show a consistent enrichment of LREE $_{\text {norm }}$ and depletion of $\mathrm{HREE}_{\text {norm }}$ over the past $2.3 \mathrm{ka} \mathrm{BP}$. Although REE characterization of Antarctic dust PSA is in early stages, we find it difficult to explain this negative $\mathrm{REE}_{\text {norm }}$ trend without a background dust source that is highly depleted in HREE. Several southern African samples show significant depletion in HREE, but these can be ruled out as a significant source of dust to the RICE ice core site, located on the opposite side of Antarctica from the African continent and shown to only weakly contribute to Antarctic dust loading. Considering the mean $\mathrm{REE}_{\text {norm }}$ slope of all RICE ice core samples spanning the last $2.3 \mathrm{ka} \mathrm{BP}$, it also is difficult to explain such strong trends by invoking a mix of multiple dust sources, as this would likely result in a more closely crustal REE signature-as seen in glacial samples from both EDC and EDML. 
South American dust samples show trends opposite to those most common in RICE samples; nearly all South American PSA samples have a positive REE $_{\text {norm }}$ slope (Figure 11). While the South American dust sources are likely not the primary contributor of dust to the RICE ice core site, smaller contributions cannot be ruled out. Indeed, 71 samples measured here exhibit positive $\mathrm{REE}_{\text {norm }}$ slope (Figure 4, Figure 6a), suggesting by the most generous terms that South American REE signatures are represented in no more than 5\% of all RICE samples spanning the last $2.3 \mathrm{ka}$. In contrast, strong negative $\mathrm{REE}_{\text {norm }}$ slope $(<-0.05)$ is seen in 563 samples, $41 \%$ of those measured. As acknowledged previously, some of this tendency towards negative $\mathrm{REE}_{\text {norm }}$ slope may be due to preferential acid leaching of LREE during sample preparation, but this cannot explain the observed HREE $_{\text {norm }}$ depletion.

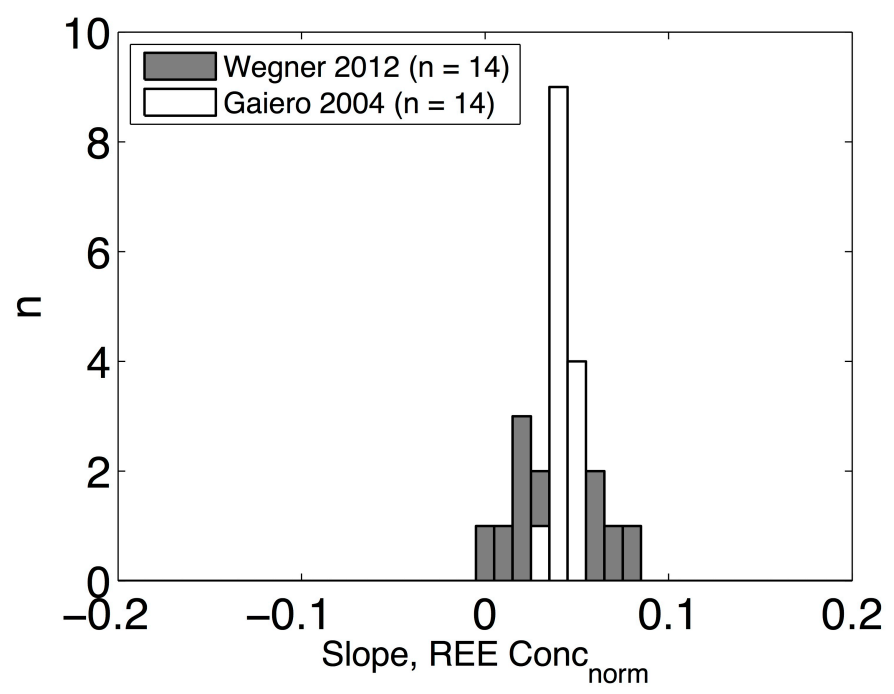

Figure 11. REE norm slope of dust samples taken from PSA in South America, from data published in Wegner et al. [2012] (all new South American samples) and Gaiero et al. [2004] (aeolian samples).

If the Antarctic dust samples of Wegner et al. [2012] are representative of wider REE signatures present in dust originating in the Transantarctic Mountains and ranges in West Antarctica, data from the RICE ice core suggest a large overprinting of local dust onto extraAntarctic REE signatures. Additional evidence for local dust contributions comes from preliminary characterization of RICE surface snow (summer 2012), which has ${ }^{87} \mathrm{Sr} /{ }^{86} \mathrm{Sr}$ ratios similar to those seen in low-grade metamorphic rocks from Mt. Nilsen located on King Edward VII Peninsula (indicated in Figure 8) [Adams et al., 1995], one of several small outcropping peaks located only $\sim 200 \mathrm{~km}$ in the upwind direction of the RICE site (see backward trajectories, Fig 8). Surface snow samples also include dust particles $>5 \mu \mathrm{m}$ 
diameter which are unlikely to originate from extra-Antarctic dust PSA ( $H$. Winton and B. Delmonte, personal communication 2015). While information about local dust could provide useful constraints on modern dust and wind activity within Antarctica, it likely obscures some REE signatures that would otherwise reveal details of wider Southern Hemisphere dust transport.

REE data from the East Antarctic EDC ice core become highly variable and trend towards negative $\mathrm{REE}_{\text {norm }}$ slope following the $15 \mathrm{ka} \mathrm{BP}$ transition from dusty LGS conditions into the Holocene (Figure 7). RICE data fill the gap from $2.5 \mathrm{ka} \mathrm{BP}$ to the present for which no previous REE data exist, and share the negative REE $_{\text {norm }}$ slope of Holocene EDC samples. Although these sites experience very different climatological regimes - one is located on the Pacific margin of WAIS, the other on the central EAIS plateau-they are similarly removed geographically from South American dust PSA and likely only receive contributions from this source after extended periods of transport. Only 52 of 294 EDC samples, spanning 33.7 ka BP to $2.5 \mathrm{ka} \mathrm{BP}$, have positive $\mathrm{REE}_{\text {norm }}$ slope (18\%) and only 11 of those occur during the Holocene. The EDML ice core is more proximal to South America, causing Holocene REE at this site to be more influenced by the characteristic South American positive REE $E_{\text {norm }}$ trends. Samples with positive $\mathrm{REE}_{\text {norm }}$ slope represent $29 \%$ of those measured from EDML (representing $26.6 \mathrm{ka}$ BP to $7.5 \mathrm{ka} \mathrm{BP}$ ), rising slightly to $31 \%$ of Holocene samples. Although Holocene emissions of South American dust are lower than during the LGS, REE signatures confirm that this PSA represents a significant contributor to the dust loading observed in the EDML ice core.

\subsection{Conclusions}

REE patterns in the RICE ice core, located at the northeastern margin of the Ross Ice Shelf on the Pacific Ocean / Ross Sea margin of the WAIS, suggest a persistent local Antarctic dust contribution in both 3.6-year resolution and sub-annual samples spanning the last $2.3 \mathrm{ka}$ BP. REE patterns suggest that the distinct South American dust source signature is present in fewer than $5 \%$ of all measured RICE ice core samples. Our diagnostic, $\mathrm{REE}_{\text {norm }}$ slope, and treatment of data as long-term averages also suggests that REE measured in Holocene samples from both RICE and the East Antarctic EDC ice core tend towards LREE enrichment and HREE depletion - a signature seen in dust samples from the largest ice-free area in Antarctica (McMurdo Dry Valleys). Although this treatment is conservative relative to the large number of elements (14 REE) and samples analyzed (minimum of 294, EDC, 31.2 ka total, Gabrielli et al. [2010]; maximum of 1364, $2.3 \mathrm{ka}$ total; this study), we argue that this is the most constructive approach to interpret existing data and incorporate new 
information provided by the RICE ice core. RICE REE data are both the first from the Pacific sector of Antarctica, and the only existing REE data measured in samples younger than 2.5 ka BP, adding significantly to the spatial characterization of these signals in the Antarctic.

These data suggest that although South America is a dominant source of dust during the LGS, as evidenced by other dust provenance measures, at present its contribution varies regionally. Proximal EDML exhibits REE signatures with limited trends, possibly reflecting greater input of South American dust, which has characteristically positive REE trends. EDC is strongly isolated on the high EAIS plateau, and the RICE ice core site is located on the far side of the WAIS ice divide from South America. REE data from these sites suggests that local dust sources may have significant influence at these locations, although additional sources for which REE signatures are poorly characterized cannot be ruled out (e.g. Australia, New Zealand, southern Africa).

Future work developing the REE should focus on the following points, progressing through sample preparation, analysis and data interpretation.

1) Comprehensive evaluation of acid leaching effects on all REE for the particular matrix and insoluble particle characteristics at individual ice core sites, as previously recommended by Rhodes et al. [2011], with specific consideration of how the preferential LREE recovery observed by Gabrielli et al. [2010] affects REE crustal ratios.

2) Analysis of measurement uncertainty (e.g. RSD) effects on crust-normalized REE values, especially spanning the transition from the LGS to the Holocene. Consideration should also be given to changing sample resolution across measured time periods.

3) Development of a Southern Hemisphere dust PSA sample database, targeting samples from areas of known dust emission, spanning a range of particle sizes and measuring the $\mathrm{REE}, \mathrm{Pb}$ - and $\mathrm{Sr} / \mathrm{Nd}$ isotopic signatures and other parameters of relevance to dust provenance work. This work is highly relevant to international efforts, particularly several working groups of the Past Global Changes (PAGES) project (e.g. Dust Impact on Climate and Environment, Ocean Circulation and Carbon Cycling, International Partnerships in Ice Core Sciences).

4) Investigation into existing samples from Marie Byrd Land ice-free areas, which could be used to characterize small particle size fraction for $\mathrm{Sr}, \mathrm{Nd}, \mathrm{Pb}$ isotope ratios and REE concentrations. 


\section{Acknowledgements}

We wish to thank P. Gabrielli and A. Wegner for making their ice core REE data easily accessible (EDC: doi:10.1016/j.quascirev.2009.09.002, EDML: doi:10.1594/PANGAEA.756834). EDC insoluble dust data was accessed from the US NOAA Paleoclimate Database (www.ncdc.noaa.gov/paleo, B. Delmonte, Data Contribution Series \# 2004-040). The authors are thankful for assistance at the New Zealand National Ice Core Research Facility at GNS Science (R. Pyne), the TRACE laboratory (A. Ellis, K. Jarrett, B. Proemse, H. Winton), and VUW geochemistry laboratory (M. Handler, S. Lange, D. Sinclair). We thank all members of the RICE Community for their cooperation and support of this study. This work has been funded through the New Zealand Ministry for Business, Innovation, and Employment through contracts with Victoria University of Wellington (RDF-VUW-1103) and GNS Science (540-GCT-32). This work is a contribution to the Roosevelt Island Climate Evolution (RICE) Program, funded by national contributions from New Zealand, Australia, Denmark, Germany, Italy, the People's Republic of China, Sweden, United Kingdom, and the United States of America. Logistic support for RICE was provided by Antarctica New Zealand and the United States Antarctic Program.

\subsection{References}

Neff, P. D., and N. A. N. Bertler (2015, in review), Trajectory modeling of modern dust transport to the Southern Ocean and Antarctica, Journal of Geophysical Research: Atmospheres.

Neff, P. D., A. Tuohy, R. Edwards, and N. A. N. Bertler (2015, in review), Low-femtogram elemental analysis of Antarctic ice cores without preconcentration, Environmental Science \& Technology.

Adams, C., D. Seward, and S. Weaver (1995), Geochronology of Cretaceous granites and metasedimentary basement on Edward VII Peninsula, Marie Byrd Land, West Antarctica, Antarctic science, 7(03), 265-276.

Albani, S., N. M. Mahowald, B. Delmonte, V. Maggi, and G. Winckler (2012), Comparing modeled and observed changes in mineral dust transport and deposition to Antarctica between the Last Glacial Maximum and current climates, Climate dynamics, 38(9-10), 17311755, doi:10.1007/s00382-011-1139-5. 
Bigler, M., A. Svensson, E. Kettner, P. Vallelonga, M. E. Nielsen, and J. P. Steffensen (2011), Optimization of high-resolution continuous flow analysis for transient climate signals in ice cores, Environmental science \& technology, 45(10), 4483-4489, doi:10.1021/es200118j.

Cuffey, K. M., and W. S. B. Paterson (2010), The physics of glaciers, Academic Press.

Dansgaard, W., and S. Johnsen (1969), A flow model and a time scale for the ice core from Camp Century, Greenland, Journal of Glaciology, 8, 215-223.

De Deckker, P., M. Norman, I. D. Goodwin, A. Wain, and F. X. Gingele (2010), Lead isotopic evidence for an Australian source of aeolian dust to Antarctica at times over the last 170,000 years, Palaeogeography, Palaeoclimatology, Palaeoecology, 285(3), 205-223, doi:10.1016/j.palaeo.2009.11.013.

Delmonte, B., P. Andersson, M. Hansson, H. Schöberg, J. R. Petit, I. Basile-Doelsch, and V. Maggi (2008), Aeolian dust in East Antarctica (EPICA-Dome C and Vostok): Provenance during glacial ages over the last 800 kyr, Geophysical Research Letters, 35(7), doi:10.1029/2008GL033382.

Delmonte, B., J. Petit, K. K. Andersen, I. Basile-Doelsch, V. Maggi, and V. Y. Lipenkov (2004), Dust size evidence for opposite regional atmospheric circulation changes over east Antarctica during the last climatic transition, Climate Dynamics, 23(3-4), 427-438, doi:10.1007/s00382-004-0450-9.

Draxler, R. R., and G. Hess (1998), An overview of the HYSPLIT_4 modelling system for trajectories, Australian Meteorological Magazine, 47(4), 295-308.

EPICA (2004), Eight glacial cycles from an Antarctic ice core, Nature, 429(6992), 623-628, doi:10.1038/nature02599.

Fischer, H., M. L. Siggaard-Andersen, U. Ruth, R. Röthlisberger, and E. Wolff (2007), Glacial/interglacial changes in mineral dust and sea-salt records in polar ice cores: Sources, transport, and deposition, Reviews of Geophysics, 45(1), doi:10.1029/2005RG000192.

Gabrielli, P., C. Barbante, C. Turetta, A. Marteel, C. Boutron, G. Cozzi, W. Cairns, C. Ferrari, and P. Cescon (2006), Direct determination of rare earth elements at the subpicogram 
per gram level in antarctic ice by ICP-SFMS using a desolvation system, Analytical chemistry, 78(6), 1883-1889, doi:10.1021/ac0518957.

Gabrielli, P., A. Wegner, J. R. Petit, B. Delmonte, P. De Deckker, V. Gaspari, H. Fischer, U. Ruth, M. Kriews, and C. Boutron (2010), A major glacial-interglacial change in aeolian dust composition inferred from Rare Earth Elements in Antarctic ice, Quaternary Science Reviews, 29(1), 265-273, doi:10.1016/j.quascirev.2009.09.002.

Gaiero, D. M., P. J. Depetris, J.-L. Probst, S. M. Bidart, and L. Leleyter (2004), The signature of river-and wind-borne materials exported from Patagonia to the southern latitudes: a view from REEs and implications for paleoclimatic interpretations, Earth and Planetary Science Letters, 219(3), 357-376.

Gassó, S., and A. F. Stein (2007), Does dust from Patagonia reach the sub-Antarctic Atlantic Ocean?, Geophysical Research Letters, 34(1), doi:10.1029/2006GL027693.

Henderson, P. (1984), Rare earth element geochemistry, Elsevier.

Hosking, J. S., A. Orr, G. J. Marshall, J. Turner, and T. Phillips (2013), The influence of the Amundsen-Bellingshausen Seas low on the climate of West Antarctica and its representation in coupled climate model simulations, Journal of Climate, 26(17), 6633-6648, doi:10.1175/JCLI-D-12-00813.1.

Koffman, B. G., M. J. Handley, E. C. Osterberg, M. L. Wells, and K. J. Kreutz (2014a), Dependence of ice-core relative trace-element concentration on acidification, Journal of Glaciology, 60(219), 103-112, doi:10.3189/2014JoG13J137.

Koffman, B. G., K. Kreutz, D. Breton, E. Kane, D. Winski, S. Birkel, A. Kurbatov, and M. Handley (2014b), Centennial-scale variability of the Southern Hemisphere westerly wind belt in the eastern Pacific over the past two millennia, Climate of the Past, 10(3), 1125-1144, doi:10.5194/cp-10-1125-2014.

Krinner, G., and C. Genthon (2003), Tropospheric transport of continental tracers towards Antarctica under varying climatic conditions, Tellus B, 55(1), 54-70. 
Krinner, G., J.-R. Petit, and B. Delmonte (2010), Altitude of atmospheric tracer transport towards Antarctica inpresent and glacial climate, Quaternary science reviews, 29(1), 274284.

Lambert, F., B. Delmonte, J.-R. Petit, M. Bigler, P. R. Kaufmann, M. A. Hutterli, T. F. Stocker, U. Ruth, J. P. Steffensen, and V. Maggi (2008), Dust-climate couplings over the past 800,000 years from the EPICA Dome C ice core, Nature, 452(7187), 616-619, doi:10.1038/nature06763.

Lamy, F., R. Gersonde, G. Winckler, O. Esper, A. Jaeschke, G. Kuhn, J. Ullermann, A. Martínez-Garcia, F. Lambert, and R. Kilian (2014), Increased dust deposition in the Pacific Southern Ocean during glacial periods, Science, 343(6169), 403-407, doi:10.1126/science.1245424.

Li, F., P. Ginoux, and V. Ramaswamy (2008), Distribution, transport, and deposition of mineral dust in the Southern Ocean and Antarctica: Contribution of major sources, Journal of Geophysical Research: Atmospheres (1984-2012), 113(D10), doi:10.1029/2007JD009190.

Li, F., P. Ginoux, and V. Ramaswamy (2010a), Transport of Patagonian dust to Antarctica, Journal of Geophysical Research: Atmospheres (1984-2012), 115(D18), doi:10.1029/2009JD012356.

Li, F., V. Ramaswamy, P. Ginoux, A. J. Broccoli, T. Delworth, and F. Zeng (2010b), Toward understanding the dust deposition in Antarctica during the Last Glacial Maximum: Sensitivity studies on plausible causes, Journal of Geophysical Research: Atmospheres (1984-2012), 115(D24), doi:10.1029/2010JD014791.

Luyendyk, B., S. Cisowski, C. Smith, S. Richard, and D. Kimbrough (1996), Paleomagnetic study of the northern Ford Ranges, western Marie Byrd Land, West Antarctica: Motion between West and East Antarctica, Tectonics, 15(1), 122-141.

Mahowald, N., S. Albani, S. Engelstaedter, G. Winckler, and M. Goman (2011), Model insight into glacial-interglacial paleodust records, Quaternary Science Reviews, 30(7), 832854, doi:10.1016/j.quascirev.2010.09.007.

Mahowald, N., K. Kohfeld, M. Hansson, Y. Balkanski, S. P. Harrison, I. C. Prentice, M. Schulz, and H. Rodhe (1999), Dust sources and deposition during the last glacial maximum 
and current climate: A comparison of model results with paleodata from ice cores and marine sediments, Journal of Geophysical Research: Atmospheres (1984-2012), 104(D13), 1589515916, doi:10.1029/1999JD900084.

Marino, F., E. Castellano, S. Nava, M. Chiari, U. Ruth, A. Wegner, F. Lucarelli, R. Udisti, B. Delmonte, and V. Maggi (2009), Coherent composition of glacial dust on opposite sides of the East Antarctic Plateau inferred from the deep EPICA ice cores, Geophysical research letters, 36(23).

Martínez-Garcia, A., A. Rosell-Melé, S. L. Jaccard, W. Geibert, D. M. Sigman, and G. H. Haug (2011), Southern Ocean dust-climate coupling over the past four million years, Nature, 476(7360), 312-315, doi:10.1038/nature10310.

Marx, S. K., B. S. Kamber, and H. A. McGowan (2005), Provenance of long-travelled dust determined with ultra-trace-element composition: a pilot study with samples from New Zealand glaciers, Earth Surface Processes and Landforms, 30(6), 699-716.

McGowan, H. A., and A. Clark (2008), Identification of dust transport pathways from Lake Eyre, Australia using Hysplit, Atmospheric Environment, 42(29), 6915-6925, doi:10.1016/j.atmosenv.2008.05.053.

Nicolas, J. P., and D. H. Bromwich (2011), Climate of West Antarctica and influence of marine air intrusions, Journal of Climate, 24(1), 49-67, doi:10.1175/2010JCLI3522.1.

Parish, T. R., and D. H. Bromwich (2007), Reexamination of the near-surface airflow over the Antarctic continent and implications on atmospheric circulations at high southern latitudes*, Monthly Weather Review, 135(5), 1961-1973, doi:10.1175/MWR3374.1.

Petit, J.-R., J. Jouzel, D. Raynaud, N. I. Barkov, J.-M. Barnola, I. Basile, M. Bender, J. Chappellaz, M. Davis, and G. Delaygue (1999), Climate and atmospheric history of the past 420,000 years from the Vostok ice core, Antarctica, Nature, 399(6735), 429-436, doi:10.1038/20859.

Revel-Rolland, M., P. De Deckker, B. Delmonte, P. Hesse, J. Magee, I. Basile-Doelsch, F. Grousset, and D. Bosch (2006), Eastern Australia: a possible source of dust in East Antarctica interglacial ice, Earth and Planetary Science Letters, 249(1), 1-13, doi:10.1016/j.eps1.2006.06.028. 
Rhodes, R. H., J. A. Baker, M.-A. Millet, and N. A. Bertler (2011), Experimental investigation of the effects of mineral dust on the reproducibility and accuracy of ice core trace element analyses, Chemical Geology, 286(3), 207-221, doi:10.1016/j.chemgeo.2011.05.006.

Russell, B. C., I. W. Croudace, P. E. Warwick, and J. A. Milton (2014), Determination of Precise 135Cs/137Cs Ratio in Environmental Samples Using Sector Field Inductively Coupled Plasma Mass Spectrometry, Analytical chemistry, 86(17), 8719-8726, doi:10.1021/ac501894a.

Sigl, M., J. R. McConnell, L. Layman, O. Maselli, K. McGwire, D. Pasteris, D. Dahl-Jensen, J. P. Steffensen, B. Vinther, and R. Edwards (2013), A new bipolar ice core record of volcanism from WAIS Divide and NEEM and implications for climate forcing of the last 2000 years, Journal of Geophysical Research: Atmospheres, 118(3), 1151-1169, doi:10.1029/2012JD018603.

Smith, J., D. Vance, R. A. Kemp, C. Archer, P. Toms, M. King, and M. Zárate (2003), Isotopic constraints on the source of Argentinian loess-with implications for atmospheric circulation and the provenance of Antarctic dust during recent glacial maxima, Earth and Planetary Science Letters, 212(1), 181-196.

Sugden, D. E., R. D. McCulloch, A. J.-M. Bory, and A. S. Hein (2009), Influence of Patagonian glaciers on Antarctic dust deposition during the last glacial period, Nature Geoscience, 2(4), 281-285, doi:10.1038/NGEO474.

Tegen, I., A. A. Lacis, and I. Fung (1996), The influence on climate forcing of mineral aerosols from disturbed soils, Nature, 380(6573), 419-422, doi:10.1038/380419a0.

Vallelonga, P., P. Gabrielli, E. Balliana, A. Wegner, B. Delmonte, C. Turetta, G. Burton, F. Vanhaecke, K. Rosman, and S. Hong (2010), Lead isotopic compositions in the EPICA Dome C ice core and Southern Hemisphere Potential Source Areas, Quaternary Science Reviews, 29(1), 247-255, doi:10.1016/j.quascirev.2009.06.019.

Vallelonga, P., K. Van de Velde, J.-P. Candelone, V. Morgan, C. Boutron, and K. Rosman (2002), The lead pollution history of Law Dome, Antarctica, from isotopic measurements on 
ice cores: 1500 AD to 1989 AD, Earth and Planetary Science Letters, 204(1), 291-306, doi:10.1016/S0012-821X(02)00983-4.

Wedepohl, K. H. (1995), The composition of the continental crust, Geochimica et cosmochimica Acta, 59(7), 1217-1232, doi:10.1016/0016-7037(95)00038-2.

Wegner, A., P. Gabrielli, D. Wilhelms-Dick, U. Ruth, M. Kriews, P. De Deckker, C. Barbante, G. Cozzi, B. Delmonte, and H. Fischer (2012), Change in dust variability in the Atlantic sector of Antarctica at the end of the last deglaciation, Climate of the Past, 8, 135147, doi:10.5194/cp-8-135-2012.

Wolff, E., C. Barbante, S. Becagli, M. Bigler, C. Boutron, E. Castellano, M. De Angelis, U. Federer, H. Fischer, and F. Fundel (2010), Changes in environment over the last 800,000 years from chemical analysis of the EPICA Dome C ice core, Quaternary Science Reviews, 29(1), 285-295, doi:10.1016/j.quascirev.20 09.06.013. 


\subsection{Supplementary Figures}

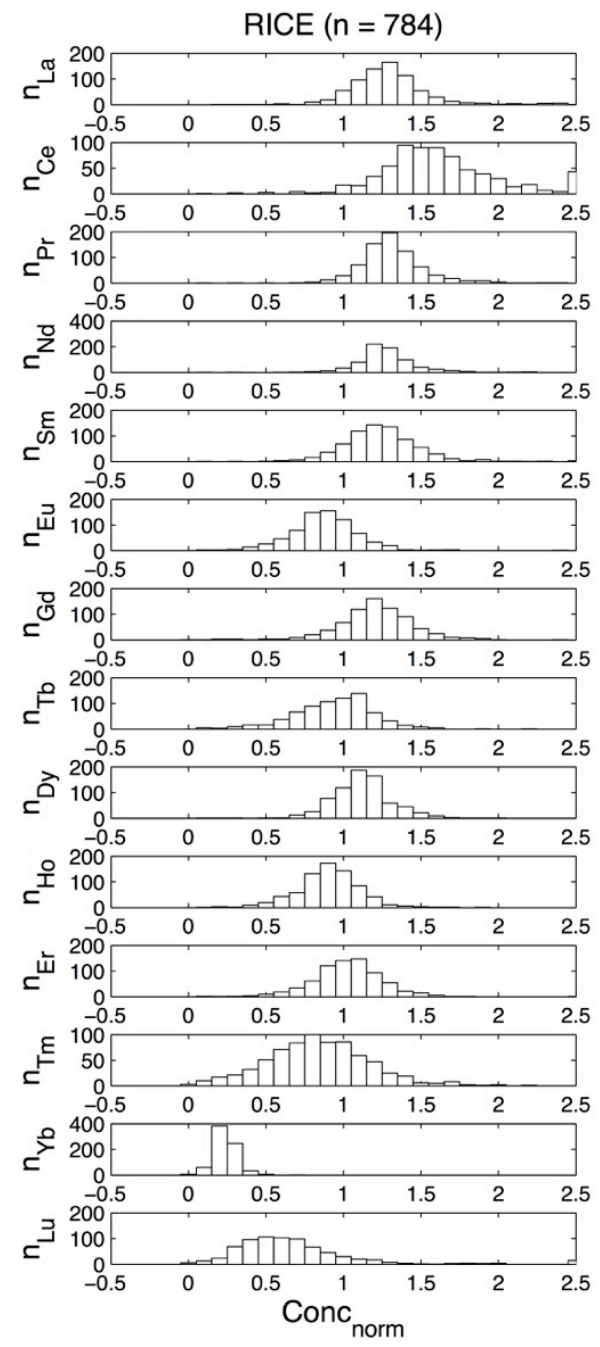

Figure S1. UCC-normalized concentrations for all REE in $8 m-40 m$ RICE ice core samples $(n=784)$. 


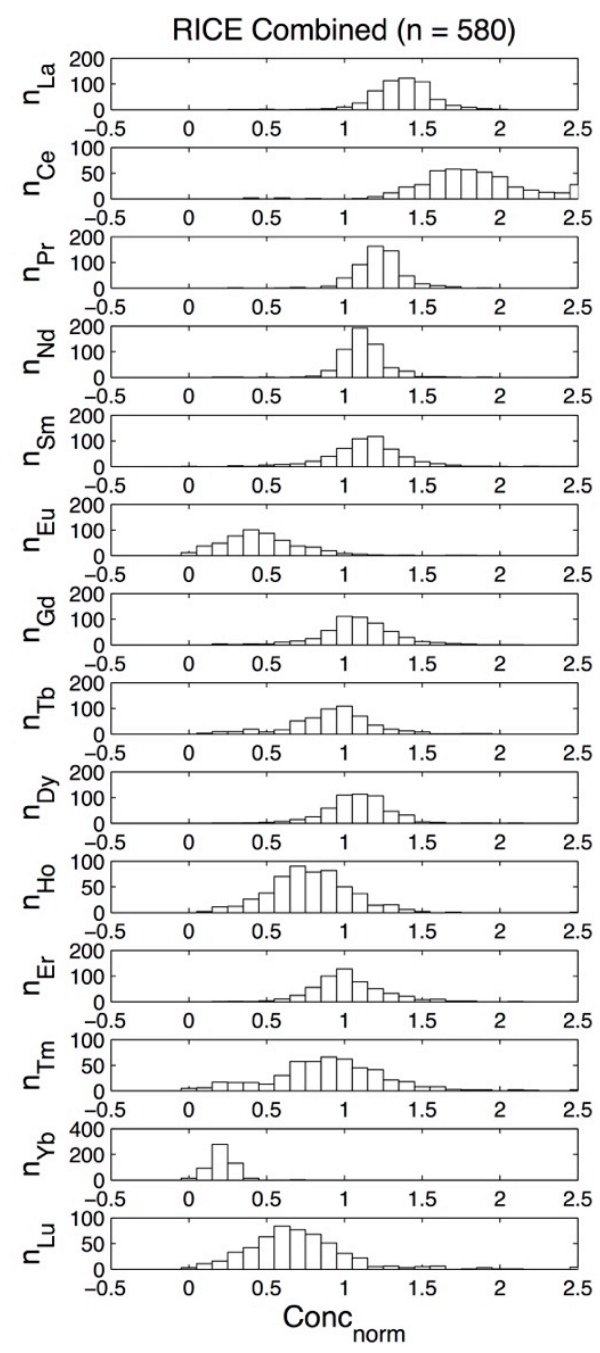

Figure S2. UCC-normalized concentrations for all REE in $40 \mathrm{~m}-320 \mathrm{~m}$ RICE ice core samples $(n=580)$. 


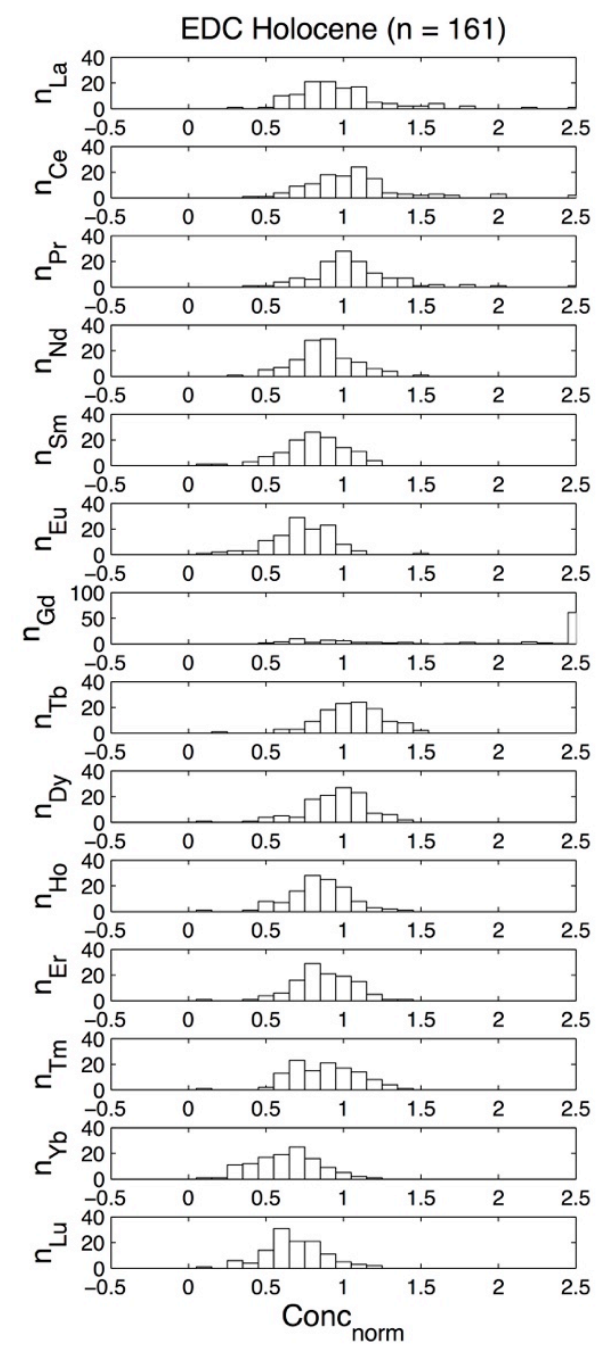

Figure S3. UCC-normalized concentrations for all REE in Holocene EDC ice core samples $(n=161)$. 


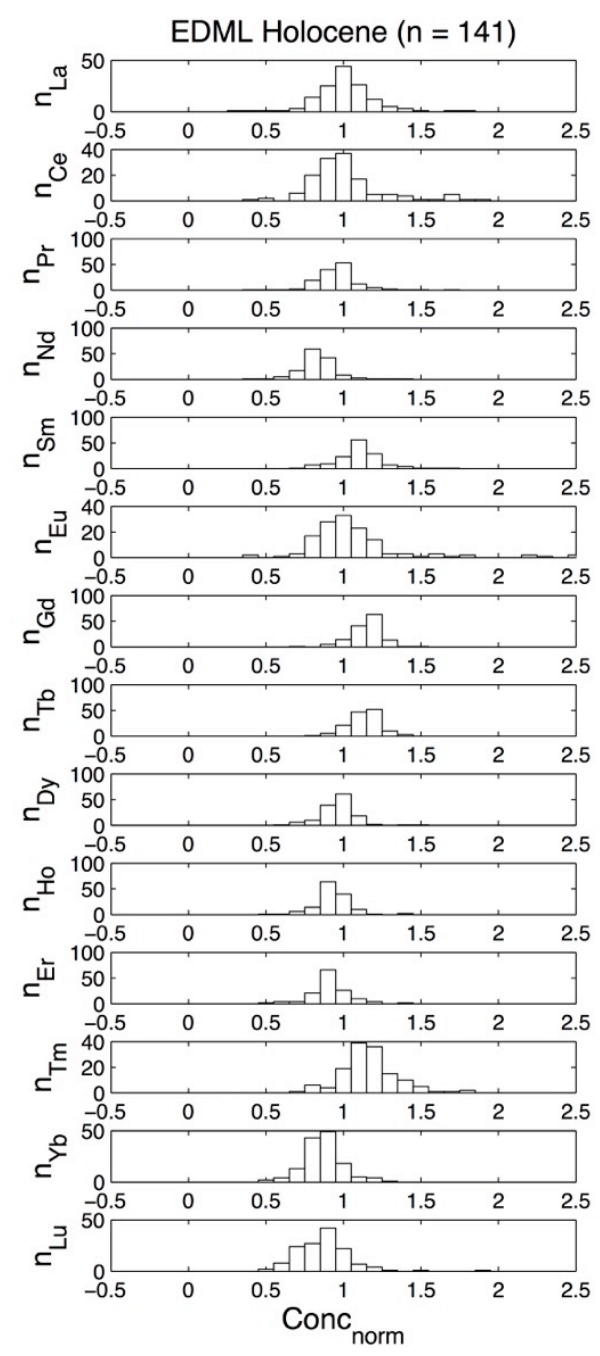

Figure S4. UCC-normalized concentrations for all REE in Holocene EDML ice core samples $(n=141)$. 
a) New Zealand, 5 Day

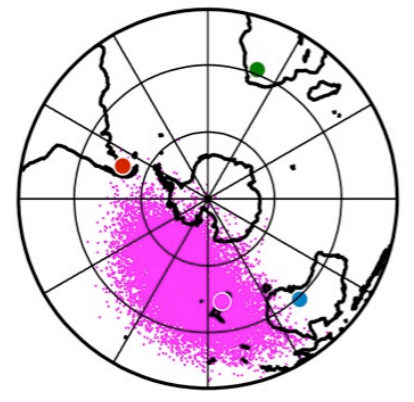

d) Patagonia, 5 Day

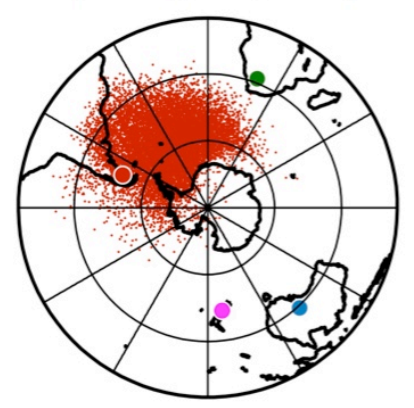

g) southern Africa, 5 Day

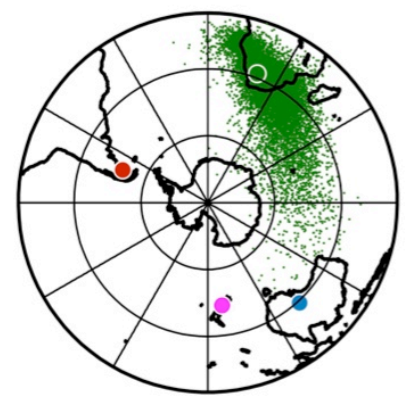

j) Australia, 5 Day

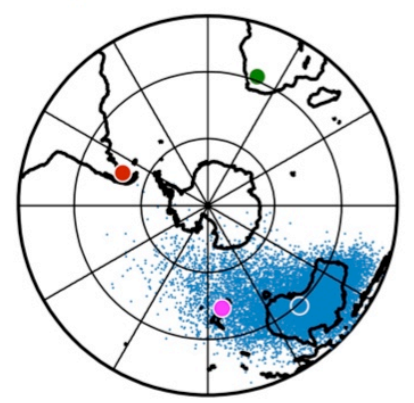

b) 10 Day

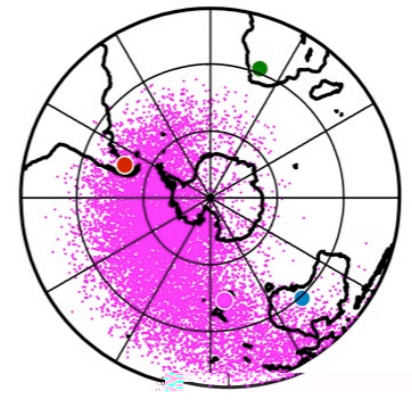

e) 10 Day

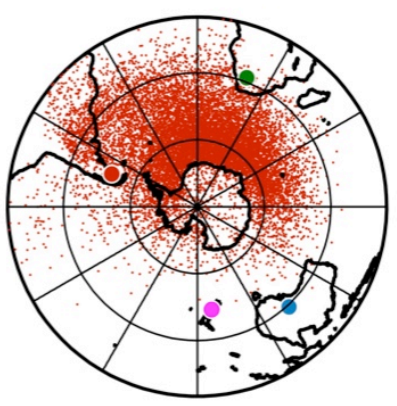

h) 10 Day

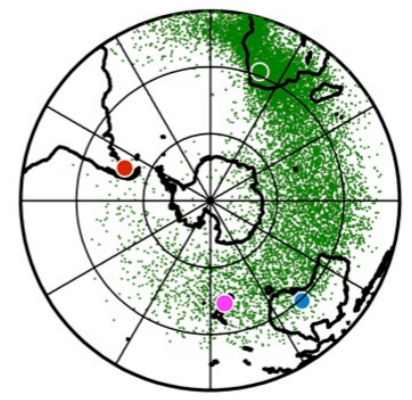

k) 10 Day

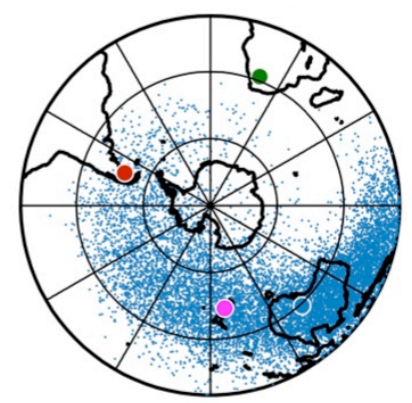

c) 15 Day

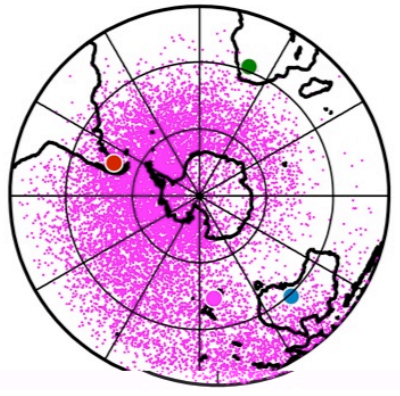

f) 15 Day

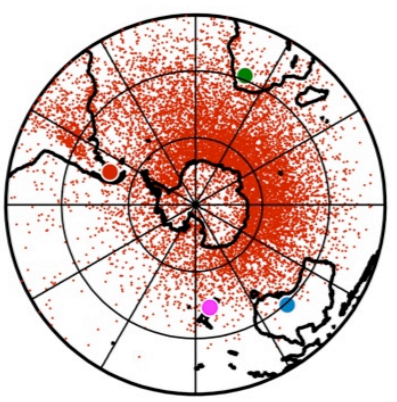

i) 15 Day

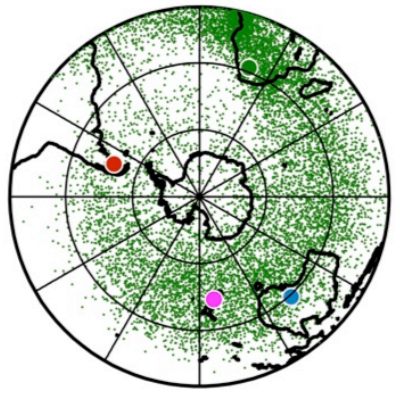

I) 15 Day

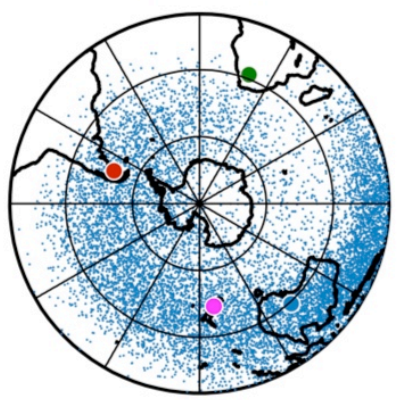

Figure S5. Forward-trajectory endpoints from Neff and Bertler (in review), with 1979-2013 daily HySPLIT forward-trajectory endpoints displayed after 5, 10 and 15 days of runtime. Trajectories were initiated near New Zealand, Patagonia, southern Africa and Australia dust PSA. 


\section{Chapter 5: Summary and future work}

\subsection{Project summary}

The objective of this thesis was to develop better understanding of dust transport from Southern Hemisphere sources to the Antarctic, and ultimately explore the rare earth elements (REE) as an indicator of dust provenance in modern Antarctic ice. In working to achieve this objective, work progressed through three stages:

1) Trajectory analysis to determine likely distribution of extra-Antarctic dust potential source areas (PSA) across the Southern Ocean and at Antarctic ice core sites, while also exploring variability in atmospheric transport strength with respect to high- and low-latitude climate forcing.

2) Demonstration of analytical capability to quantify REE as low as single fg $\mathrm{g}^{-1}\left(10^{-15} \mathrm{~g}\right.$ $\mathrm{g}^{-1}$ ) concentrations, and measurement of RICE samples dating to $\sim 2 \mathrm{ka} \mathrm{BP}$.

3) Characterization and interpretation of REE signatures observed in the RICE ice core, combining dust PSA trajectory constraints with analytical understanding to reduce uncertainty associated with ice core and dust PSA REE data.

Conclusions made through these stages are as follows:

\section{1) Trajectory modeling of Southern Hemisphere dust transport (Chapter 2)}

Thirty-five year averages of daily forward trajectories from dust PSA, in the place of computationally expensive GCM simulations, demonstrate persistent, strong transport from Patagonia and New Zealand to the Southern Ocean and Antarctica. Even with New Zealand dust emission rates only one-third the size of any other dust PSA, this dust PSA may contribute more than $10 \%$ of the Antarctic dust budget. Seasonality, mode of atmospheric transport (e.g. altitude) and dust PSA trajectory distribution using this method agree well with previous studies, and reveal new associations between atmospheric transport strength and variability of both central Tropical Pacific sea surface temperature and state of the Southern Annular Mode.

\section{2) Preparation and ICPMS analysis of REE in ice core samples (Chapter 3)}

Examination of sample preparation methods and analytical performance suggests that Jet-SF-ICPMS instrumentation can ably measure a large number of analytes across a range of concentrations in ice core samples, with sensitivity not seen in other analytical arrangements. 
Stability across extended analysis campaigns using this system allowed for accurate determination of $>35$ elements in $>1400$ samples from the RICE ice core. For many elements, limits of detection are below procedural blank concentrations, suggesting that sample preparation and contamination in the laboratory environment are the primary barriers to accurate determination of sub $\mathrm{pg} \mathrm{g}^{-1}$ species.

\section{3) REE as paleoclimate tools to identify dust provenance (Chapter 4)}

RICE ice core REE measurements are both the first from the Pacific sector of Antarctica and the first spanning the last $2.3 \mathrm{ka} \mathrm{BP}$. These measurements show strong trends across the REE (enrichment in light REE and depletion in heavy REE). This pattern is consistent through time, and is similar only to REE trends (slope) seen regularly in dust samples collected from Antarctic ice-free areas. Although the REE characterization of Antarctic dust is incomplete, this suggests significant contribution of local dust sources to RICE. REE signatures associated with South American dust, which is reliably enriched in heavy REE, are observed in less than $5 \%$ of RICE samples. Applying this same REE characterization method to the EPICA Dome $\mathrm{C}$ ice core suggests Holocene REE patterns similar to those of RICE, while the EPICA Drønning Maud Land site-closer to South American dust sources - exhibits a mean Holocene REE pattern likely more influenced by heavy REE enrichment seen in Patagonian dust samples. These results suggested significant overprinting of local Antarctic dust in Holocene ice core records, obscuring information about long range atmospheric transport from and environmental change at mid-latitude Southern Hemisphere dust sources.

\subsection{Future work}

When investigating any line of scientific inquiry, one undoubtedly produces as many questions as answers. Guided by the results of this thesis, we suggest the following points for further investigation.

\section{1) Trajectory modeling}

- Modern and last glacial stage emissions from New Zealand should be quantified, as strong connectivity between New Zealand and Antarctica (Chapter 2) suggests this dust PSA may influence dust records in West Antarctic ice cores and South Pacific marine sediment cores [e.g. Lamy et al., 2014].

- These trajectory data can easily be adapted to consider transport of other aerosols to the Antarctic, including black carbon from fires and anthropogenic toxic heavy metal emissions [e.g. Bisiaux et al., 2012; McConnell et al., 2014]. 


\section{2) Trace element sample preparation and analysis}

- Strategies should be developed to use matrix-matched bulk waters (e.g. Antarctic snow-melt) to quantify trace element contamination from continuous flow analysis (CFA) systems, as $>18 \mathrm{M} \Omega$ laboratory water blanks scour contaminants from CFA plumbing and are not representative of true background concentrations of trace elements (noted in Chapter 2 and mentioned by Wegner et al. [2012]).

- Prior to interpretation of REE dust provenance in ice cores, uncertainties associated with sample acidification, highlighted by Rhodes et al. [2011] and Koffman et al. [2014] and discussed in Chapters 3 and 4, must be constrained for individual ice core sites to account for any incongruent and artificial enrichment.

\section{3) REE ice core dust provenance}

- Across the last glacial transition, the effects of reduced REE concentrations, increased measurement uncertainty and decreased sample resolution on crustal-normalized REE trends must be quantified. Until this is done, interpretations of increased REE variability indicating changing dust sources across this period remain incomplete. To this end, detailed preparation and measurement methodologies quantifying uncertainties also must be reported to facilitate comparison of results produced by international laboratory facilities.

- Dust REE signatures of Southern Hemisphere dust potential source areas (PSA) are currently poorly characterized (with the possible exception of South America). Local expertise and existing samples should be utilized to build a database of measurements useful for Antarctic dust provenance work (e.g. Sr, $\mathrm{Nd}, \mathrm{Pb}$ isotopes, $\mathrm{REE}$ ).

- This work develops an array of Antarctic ice core REE records. Further REE measurements from ice cores at sites with dust regimes dominated by a single source could aid in evaluating the REE as a dust provenance tool. For instance, trajectory analysis (Chapter 2) suggests that the James Ross Island ice core is strongly influenced by South American atmospheric transport, while Law Dome is the only site possibly showing significant connection with southern Africa. REE measurements at these sites might more clearly reflect the signatures of these respective dust source areas and could further elucidate the fidelity of REE dust provenance identification. 


\subsection{References}

Bisiaux, M., R. Edwards, J. McConnell, M. Curran, T. Van Ommen, A. Smith, T. Neumann, D. Pasteris, J. Penner, and K. Taylor (2012), Changes in black carbon deposition to Antarctica from two high-resolution ice core records, 1850-2000 AD, Atmospheric Chemistry and Physics, 12(9), 4107-4115, doi:10.5194/acp-12-4107-2012.

Koffman, B. G., M. J. Handley, E. C. Osterberg, M. L. Wells, and K. J. Kreutz (2014), Dependence of ice-core relative trace-element concentration on acidification, Journal of Glaciology, 60(219), 103-112, doi:10.3189/2014JoG13J137.

Lamy, F., R. Gersonde, G. Winckler, O. Esper, A. Jaeschke, G. Kuhn, J. Ullermann, A. Martínez-Garcia, F. Lambert, and R. Kilian (2014), Increased dust deposition in the Pacific Southern Ocean during glacial periods, Science, 343(6169), 403-407, doi:10.1126/science. 1245424 .

McConnell, J. R., O. J. Maselli, M. Sigl, P. Vallelonga, T. Neumann, H. Anschütz, R. Bales, M. Curran, S. B. Das, and R. Edwards (2014), Antarctic-wide array of high-resolution ice core records reveals pervasive lead pollution began in 1889 and persists today, Scientific reports, 4, doi:10.1038/srep05848.

Rhodes, R. H., J. A. Baker, M.-A. Millet, and N. A. Bertler (2011), Experimental investigation of the effects of mineral dust on the reproducibility and accuracy of ice core trace element analyses, Chemical Geology, 286(3), 207-221, doi:10.1016/j.chemgeo.2011.05.006.

Wegner, A., P. Gabrielli, D. Wilhelms-Dick, U. Ruth, M. Kriews, P. De Deckker, C. Barbante, G. Cozzi, B. Delmonte, and H. Fischer (2012), Change in dust variability in the Atlantic sector of Antarctica at the end of the last deglaciation, Climate of the Past, 8, 135147, doi:10.5194/cp-8-135-2012. 


\title{
Appendix A: A review of the brittle ice zone in polar ice cores
}

This appendix represents a published work:

Neff, P.D. (2014). A review of the brittle ice zone in polar ice cores, Annals of Glaciology, 55(68), 72-82, doi: 10.3189/2014AoG68A023.

\begin{abstract}
Maintaining ice core quality through the brittle ice zone (BIZ) remains challenging for polar ice core studies. At depth, increasing ice overburden pressurizes trapped air bubbles, causing fracture of cores upon exposure to atmospheric pressure. Fractured ice cores degrade analyses, reducing resolution and causing contamination. BIZ encounters at eighteen sites across the Greenland, West and East Antarctic ice sheets are documented. The BIZ begins at a mean depth of $545 \pm 162 \mathrm{~m}$ (1 standard deviation), extending to depths where ductile clathrate-ice is reached: an average of $1132 \pm 178 \mathrm{~m}$ depth. Ice ages in this zone vary with snow accumulation rate and ice thickness, beginning as young as $2 \mathrm{ka}$ before present (BP) at Dye 3, Greenland, affecting ice $>160 \mathrm{ka} \mathrm{BP}$ in age at Taylor Dome, Antarctica and compromising up to $90 \%$ of retrieved samples at intermediate-depth sites. Effects of pressure and temperature on the BIZ are explored using modeled firn-column overburden pressure and borehole temperatures, revealing complex associations between firn densification and BIZ depth, and qualitatively supporting expected thinning of the BIZ at low ice temperatures due to shallower clathrate stability. Mitigating techniques for drilling, transport, sampling and analysis of brittle ice cores are also discussed.
\end{abstract}

\section{Introduction}

Deep ice drilling at both poles reveals valuable climate records extending up to 800,000 years into the past (EPICA Community Members, 2004), in addition to unveiling much about the physical structure of the Greenland, West and East Antarctic ice sheets. In recent years, ice core drilling, transport, sampling, and analytical procedures have continually improved, spurred by the goal of providing continuous, high-resolution records of atmospheric greenhouse gases and climate and environmental proxies.

However, poor ice core quality in the so-called brittle ice zone (BIZ), where extensive fracturing of core samples is caused by rapid relaxation (decompression) of the ice (e.g. Gow, 1971), remains a technical challenge at all phases of intermediate-depth and deep ice core studies. At the drill site, mechanical stresses from drilling and logging the core can degrade initial core quality in this zone. Sampling at freezer facilities often induces further fracturing 
as individual brittle ice core samples are cut with bandsaws. Finally, brittle ice samples prove challenging for laboratory procedures such as continuous-flow analysis (e.g. Osterberg and others, 2006; Bigler and others, 2011), with fractures allowing drilling fluid required for deep ice drilling to penetrate into samples, contaminating major-ion chemistry, trace chemistry and gas measurements.

While at relatively high snow accumulation deep drill sites ice ages in the BIZ represent several thousand years of the Holocene, high snow accumulation intermediatedepth drill sites and low snow accumulation deep drill sites may place many thousands of years of transitional and/or glacial ice within this zone of compromised core quality. In the case of drill sites with intermediate ice-thickness, a large fraction ( $90 \%$ or more) of the dated ice core record will likely be placed within the BIZ. Brittle ice core quality, through recovery, transport, sampling and analysis, is one of the technical challenges identified by the International Partnerships in Ice Core Sciences (IPICS), with implications both for the " $40 \mathrm{k}$ array" initiative to gather a spatially-distributed, bi-polar network of $40 \mathrm{ka}$ ice core records, and any Antarctic "oldest ice" site chosen to retrieve a continuous 1.5 Ma record (IPICS, 2005; Brook and others, 2006).

The term "brittle ice" with respect to ice drilling originates in the description by Gow and others (1968) of highly fractured ice from depths between $400 \mathrm{~m}$ and $900 \mathrm{~m}$ in the Byrd Station ice core - the first drilled to bedrock in Antarctica. Investigation of ice relaxation by Gow (1968, 1971), also in the Byrd Station ice core, indicates that the linear increase in overburden pressure with depth accordingly increases the in situ pressure within air bubbles in the ice; once removed from this high-pressure environment, bubble pressure exceeds the tensile strength of the confining ice, causing cracking between bubbles and initiating widespread fracturing in ice cores (Uchida and others, 1994; IPICS, 2005). Immediately upon exposure at the surface, fracturing begins explosively, propagating across- and alongcore on decimeter scales. Slower relaxation of ice cores over periods of months to years after drilling (also explored by Gow, 1971) may alleviate some or all remaining brittleness, however ice cores from Siple Dome, Antarctica remain brittle more than a decade after cores were retrieved (M. Twickler, personal communication). Brittle fracture in ice cores only fully diminishes at depths where air bubbles are absorbed into the ice, transitioning to airhydrate crystals (clathrates). Here, the ice is more ductile as dissociation pressure and temperature is reached, incorporating gases into the crystal lattice (e.g. Miller, 1969; Shoji and Langway, 1982; Pauer and others, 1995; Kuhs and others, 2000; Lipenkov, 2000). This transition occurs gradually as bubble number-densities decrease and clathrates become 
dominant (e.g. Uchida and others, 1994; Kipfstuhl and others, 2001; Ueltzhöffer and others, 2010). It is expected that clathrate formation - and thus onset of ductile ice and improved ice core quality_occurs at shallower depths as ice temperature decreases (Miller, 1969).

The BIZ, though observed at all deep drilling sites, has seldom been specifically examined and is only approximately defined as a zone beginning several-hundred meters below the ice surface and extending to depths between $1000 \mathrm{~m}$ and $1500 \mathrm{~m}$. This is in part due to the inherently qualitative definition of brittle ice, wide-ranging metrics for ice core quality, rounding of reported depths, and the entangled effects of ice physical properties and stresses (mechanical and thermal) induced during drilling, on-site handling and transport. BIZ depths collated here are likely accurate to $\pm 50 \mathrm{~m}$. The first sustained decline in ice core quality should be reported - and is considered here - as the top depth of the BIZ, with the bottom depth marked by a return to consistently excellent ice core quality (e.g. Fig. 10 of Souney and others, this issue). This paper compiles reported information regarding the BIZ for eighteen deep $(>1500 \mathrm{~m})$ and intermediate-depth $(500 \mathrm{~m}$ to $1500 \mathrm{~m})$ polar ice drilling projects (Figure 1a, b). Two effects are explored with possible controls on brittle ice onset and relief. First, the effect of varying firn-column thickness on overburden pressure at depth is considered using modeled firn-column densities at all sites. Second, reported brittle ice depths are examined with respect to clathrate stability using in-situ ice temperature from borehole measurements and modelled overburden pressures. Techniques are detailed that have been or could be employed in order to reduce brittle fracture in ice cores during drilling, transport and sampling, and challenges pertaining to analysis of brittle ice samples are also discussed.

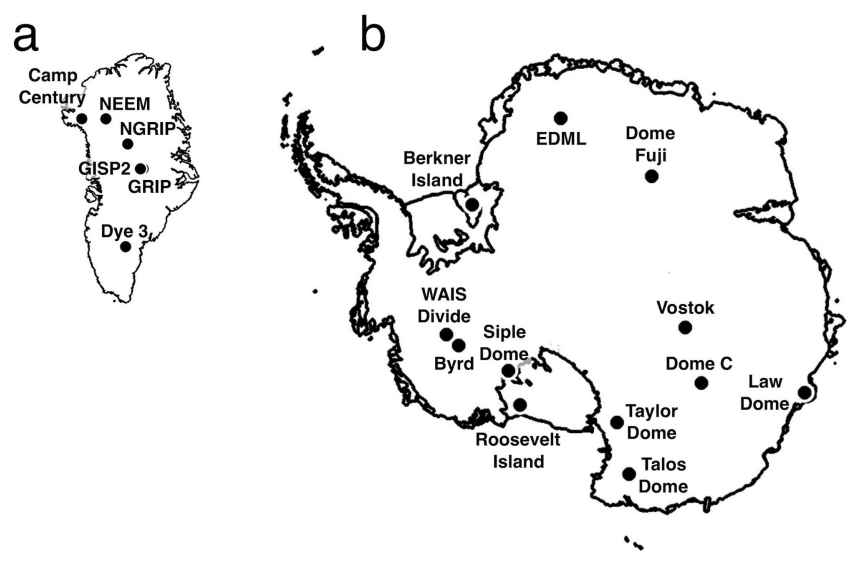

Figure 1. Locations of polar drill sites in a) Greenland and b) Antarctica discussed in text. Map data from Timmerman and others (2011). 
Table 1: Site information, brittle ice zone (BIZ) depths, mean annual snow accumulation ( $m$ $a^{-1}$ ice), mean surface air temperature $\left({ }^{\circ} \mathrm{C}\right)$, firn-ice transition depth (density $830 \mathrm{~kg} \mathrm{~m}^{-3}$ reached) and BIZ ice ages for Greenland Ice Sheet ice drilling sites.

\begin{tabular}{|c|c|c|c|c|c|c|}
\hline & Camp Century & Dye-3 & GRIP & GISP2 & NGRIP & NEEM \\
\hline Coordinates & $\begin{array}{l}77.17^{\circ} \mathrm{N} \\
61.13^{\circ} \mathrm{W}\end{array}$ & $\begin{array}{l}65.18^{\circ} \mathrm{N} \\
43.82^{\circ} \mathrm{W}\end{array}$ & $\begin{array}{l}72.58^{\circ} \mathrm{N} \\
37.63^{\circ} \mathrm{W}\end{array}$ & $\begin{array}{l}72.60^{\circ} \mathrm{N} \\
38.50^{\circ} \mathrm{W}\end{array}$ & $\begin{array}{l}75.10^{\circ} \mathrm{N} \\
42.32^{\circ} \mathrm{W}\end{array}$ & $\begin{array}{l}77.45^{\circ} \mathrm{N} \\
51.60^{\circ} \mathrm{W}\end{array}$ \\
\hline Years drilled & $1963-66^{1}$ & $1979-81^{7}$ & $1989-92^{9}$ & $1989-93^{14}$ & $1996-2004^{9}$ & $2008-12^{19}$ \\
\hline Surface elevation (m) & $1887^{2}$ & $2490^{7}$ & $3238^{11}$ & $3200^{14}$ & $2917^{9}$ & $2450^{19}$ \\
\hline Drill depth $(m)$ & $1387^{1}$ & $2037^{7}$ & $3029^{11}$ & $3053^{14}$ & $3090^{9}$ & $2540^{19}$ \\
\hline Ice thickness (m) & $1387^{1}$ & $2037^{7}$ & $3029^{11}$ & $3053^{14}$ & $3090^{9}$ & $2540^{19}$ \\
\hline $\mathrm{BIZ}$ top $(\mathrm{m})$ & $600^{3}$ & $\mathbf{8 0 0}^{8,9}$ & $\mathbf{8 0 0}^{11}$ & $\mathbf{6 5 0}^{15,16}$ & $790^{9}$ & $609^{20}$ \\
\hline BIZ bottom (m) & $1150^{3}$ & $\mathbf{1 2 0 0}^{8,9}$ & $\mathbf{1 3 0 0}^{11,12}$ & $\mathbf{1 4 0 0}^{15,16}$ & $1200^{9}$ & $1281^{20}$ \\
\hline BIZ thickness $(\mathrm{m})$ & 550 & 400 & 500 & 750 & 410 & 671 \\
\hline Snow accumulation $\left(\mathrm{mice}^{-1}\right)$ & $0.33^{2}$ & $0.56^{9}$ & $0.23^{9}$ & $0.22^{9}$ & $0.19^{9}$ & $0.22^{19}$ \\
\hline Mean air temperature $\left({ }^{\circ} \mathrm{C}\right)$ & $-24^{4}$ & $-20^{9}$ & $-32^{9}$ & $-32^{4}$ & $-32^{9}$ & $-29^{19}$ \\
\hline Firn/ice transition $(\mathrm{m})$ & $72^{5}$ & $67.5^{4}$ & $78^{13}$ & $77^{4}$ & $78^{18}$ & $78.8^{21}$ \\
\hline BIZ top age (ka BP) & $2.3^{6}$ & $2^{10}$ & $4^{9}$ & $3^{15,17}$ & $4.7^{9}$ & $3^{22}$ \\
\hline BIZ bottom age (ka BP) & $10^{6}$ & $3.8^{10}$ & $7.1^{9}$ & $8.3^{15,17}$ & $8^{9}$ & $9^{22}$ \\
\hline
\end{tabular}

${ }^{1}$ Ueda and Garfield (1968); ${ }^{2}$ Drinkwater and others (2001); ${ }^{3}$ Shoji and Langway (1987); ${ }^{4}$ Cuffey and Paterson $(2010) ;{ }^{5}$ Kovacs and others $(1969) ;{ }^{6}$ Dansgaard and others (1969); ${ }^{7}$ Gundestrup and Hansen (1984); ${ }^{8}$ Shoji and Langway (1982); ${ }^{9}$ Vinther and others (2006); ${ }^{10}$ Langway and others (1985); ${ }^{11}$ Dansgaard and others (1993); ${ }^{12}$ Pauer and others (1995); ${ }^{13}$ Schwander and others (1993); ${ }^{14}$ Alley and others (1993); ${ }^{15}$ Gow and others (1997); ${ }^{16} \mathrm{M}$. Twickler (personal communication, 2013); ${ }^{17}$ The Greenland Summit Ice Cores CD-ROM (1997); ${ }^{18}$ Martinerie and others (2009); ${ }^{19}$ NEEM Community Members (2013); ${ }^{20}$ Warming and others (2013); ${ }^{21}$ Buizert and others (2012); ${ }^{22}$ Rasmussen and others (2013).

\section{Brittle ice zone depth}

Reported BIZ depths and drill site conditions_-snow accumulation rate, mean annual surface air temperature and firn-ice transition depth-are summarized in Tables 1,2 and 3 for sites across the Greenland Ice Sheet (GIS), West Antarctic Ice Sheet (WAIS) and East Antarctic Ice Sheet (EAIS), respectively. BIZ top and bottom depths, as well as firn-ice transition (FIT) depth (assuming a density of $830 \mathrm{~kg} \mathrm{~m}^{-3}$ ), are displayed for all sites in Figure 2. While intermediate-depth drilling projects at Siple Dome, Berkner Island, Roosevelt Island, Law Dome and Taylor Dome experienced brittle ice conditions, the ice-bed interface was encountered before reaching pressures and temperatures suitable for clathrate formation and the transition to ductile ice. Some ice core quality improvement was anecdotally observed in the final several meters of the Siple Dome, Berkner Island and Roosevelt Island ice cores, possibly due to warmer temperatures near the bed (Gow and Meese, 2007; Mulvaney and others, 2007; N. Bertler, personal communication).

\section{Pressure and temperature effects I: brittle zone onset}

Snow accumulation rate and surface air temperature are primary controls on the densification of polar firn (e.g. Herron and Langway, 1980; Ligtenberg and others, 2011), although the firnification process is not fully understood (Hörhold and others, 2011). Firn densification is relevant here for its role in isolating air bubbles from porous firn and because the thickness and density of the firn column controls the exact overburden pressure imposed 
on ice and air bubbles at depth. Overburden pressure may affect where brittle fracture of ice cores commences, as thin firn columns at warmer, higher snow accumulation sites should reach full ice density $\left(920 \mathrm{~kg} \mathrm{~m}^{-3}\right)$ more rapidly and thus exert more overburden pressure on ice and air bubbles at depth, and vice versa. Additionally, overburden pressure and in-situ ice temperature control clathrate stability and are expected to affect the depth of the transition out of the bubbly, BIZ and into the bubble-free, ductile clathrate-ice zone below-with clathrates stabilizing at lower pressures when temperatures are low, and vice versa (e.g. Miller, 1969).

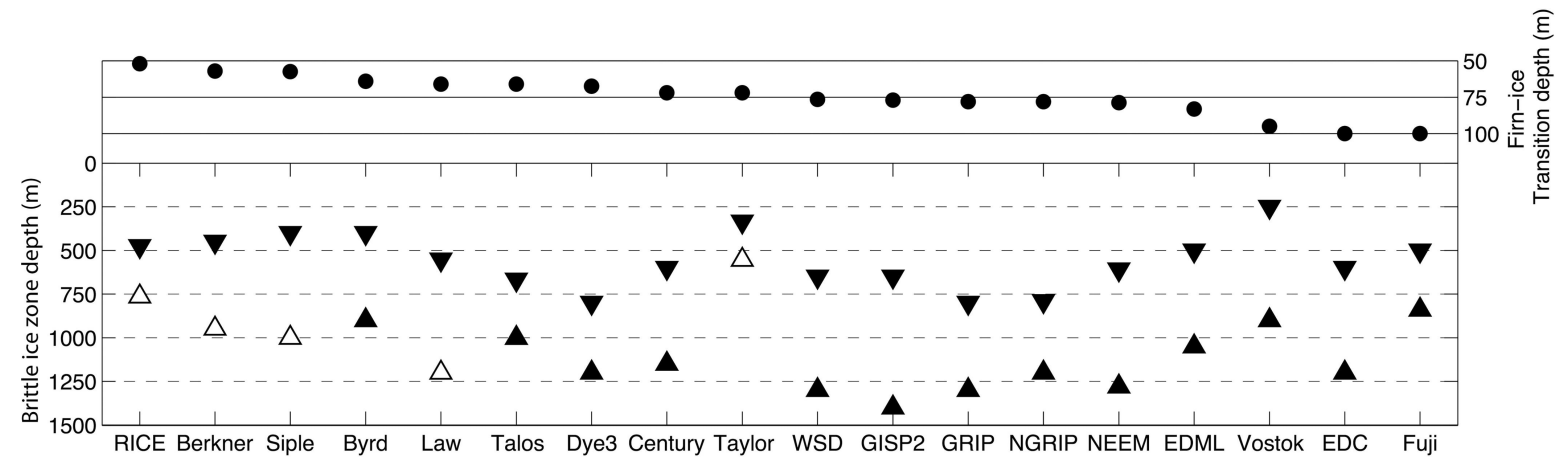

Figure 2. Firn-ice transition (FIT, depth where density $830 \mathrm{~kg} \mathrm{~m}^{-3}$ reached, circles), BIZ top depths (inverted triangles) and BIZ bottom depths (triangles) at ice drilling sites, ordered by increasing FIT depth. Open triangles denote BIZ bottom depths which represent the ice-bed interface, rather than transition to the bubble-free, ductile ice zone. Abbreviated: WSD (WAIS Divide), RICE (Roosevelt Island Climate Evolution), EDC (EPICA Dome C), EDML (EPICA Drønning Maud Land).

Table 2: Site information, brittle ice zone (BIZ) depths, mean annual snow accumulation ( $m$ $a^{-1}$ ice), mean surface air temperature $\left({ }^{\circ} \mathrm{C}\right.$ ), firn-ice transition depth (density $830 \mathrm{~kg} \mathrm{~m}^{-3}$ reached) and BIZ ice ages for West Antarctic Ice Sheet ice drilling sites.

\begin{tabular}{|c|c|c|c|c|c|}
\hline & Byrd Station & Siple Dome & Berkner Island & WAIS Divide & Roosevelt Island \\
\hline Coordinates & $80.02^{\circ} \mathrm{S}, 119.52^{\circ} \mathrm{W}$ & $81.65^{\circ} \mathrm{S}, 148.81^{\circ} \mathrm{W}$ & $79.55^{\circ} \mathrm{S}, 45.68^{\circ} \mathrm{W}$ & $79.47^{\circ} \mathrm{S}, 112.09^{\circ} \mathrm{W}$ & $79.36^{\circ} \mathrm{S}, 161.71^{\circ} \mathrm{W}$ \\
\hline Years drilled & $1966-68^{1}$ & $1997-99^{5}$ & $2003-05^{7}$ & $2006-11^{10}$ & 2011-12 \\
\hline Surface elevation $(\mathrm{m})$ & $1530^{1}$ & $620^{5}$ & $890^{7}$ & $1766^{10}$ & 550 \\
\hline Drill depth $(\mathrm{m})$ & $2164^{1}$ & $1004^{5}$ & $948^{7}$ & $3405^{10}$ & 764 \\
\hline Ice thickness (m) & $2164^{1}$ & $1004^{5}$ & $948^{7}$ & $3455^{10}$ & 764 \\
\hline $\mathrm{BIZ}$ top $(\mathrm{m})$ & $\mathbf{4 0 0}^{1,2}$ & $400^{5}$ & $450^{7}$ & $650^{11}$ & 475 \\
\hline BIZ bottom (m) & $900^{1,2}$ & $1000^{5}$ & $948^{7}$ & $1300^{11}$ & 764 \\
\hline BIZ thickness $(\mathrm{m})$ & 500 & 600 & 498 & 650 & 289 \\
\hline Snow accumulation $\left(\mathrm{m} \mathrm{ice}^{-1}\right.$ ) & $0.14^{3}$ & $0.11^{3}$ & $0.13^{7}$ & $0.22^{10}$ & $0.23^{13}$ \\
\hline Mean air temperature $\left({ }^{\circ} \mathrm{C}\right)$ & $-28^{3}$ & $-25^{3}$ & $-26.5^{7}$ & $-30^{10}$ & $-23^{13}$ \\
\hline Firn/ice transition $(\mathrm{m})$ & $64^{3}$ & $57.5^{3}$ & $57^{8}$ & $76.5^{12}$ & $52^{13}$ \\
\hline $\mathrm{BIZ}$ top age (ka BP) & $3.5^{4}$ & $5^{6}$ & $4.5^{9}$ & $2.7^{10}$ & $4^{13}$ \\
\hline BIZ bottom age (ka BP) & $9.5^{4}$ & $57^{6}$ & $95^{9}$ & $6^{10}$ & $>40^{13}$ \\
\hline
\end{tabular}

${ }^{1}$ Gow (1968); ${ }^{2}$ Gow (1971); ${ }^{3}$ Cuffey and Paterson (2010); ${ }^{4}$ Blunier and Brook (2001); ${ }^{5}$ Gow and Meese (2007); ${ }^{6}$ Brook and others (2005); ${ }^{7}$ Mulvaney and others (2007); ${ }^{8}$ Gerland and others (1999); ${ }^{9}$ R. Mulvaney (personal communication (2014); ${ }^{10}$ WAIS Divide Project Members (2013); ${ }^{11}$ Souney and others (2014); ${ }^{12}$ Kreutz and others (2011); ${ }^{13}$ N. Bertler (unpublished information). 
Table 3: Site information, brittle ice zone (BIZ) depths, mean annual snow accumulation (m $a^{-1}$ ice), mean surface air temperature $\left({ }^{\circ} \mathrm{C}\right)$, firn-ice transition depth (density $830 \mathrm{~kg} \mathrm{~m}^{-3}$ reached) and BIZ ice ages for East Antarctic Ice Sheet ice drilling sites.

\begin{tabular}{|c|c|c|c|c|c|c|c|}
\hline & Law Dome & Taylor Dome & Vostok station & EPICA Dome C & Dome Fuji & $\begin{array}{l}\text { EPICA Dronning } \\
\text { Maud Land }\end{array}$ & Talos Dome \\
\hline Coordinates & $\begin{array}{l}66.77^{\circ} \mathrm{S} \\
112.80^{\circ} \mathrm{E}\end{array}$ & $\begin{array}{l}77.70^{\circ} \mathrm{S} \\
159.07^{\circ} \mathrm{E}\end{array}$ & $\begin{array}{l}78.47^{\circ} \mathrm{S} \\
106.87^{\circ} \mathrm{E}\end{array}$ & $\begin{array}{l}75.10^{\circ} \mathrm{S} \\
123.35^{\circ} \mathrm{E}\end{array}$ & $\begin{array}{l}77.32^{\circ} \mathrm{S} \\
39.70^{\circ} \mathrm{E}\end{array}$ & $75^{\circ} \mathrm{S}, 0^{\circ} \mathrm{E}$ & $\begin{array}{l}72.78^{\circ} \mathrm{S} \\
159.07^{\circ} \mathrm{E}\end{array}$ \\
\hline Years drilled & $1991-93^{1}$ & $1993-94^{4}$ & $\begin{array}{l}1990-98 \\
2005-12^{7}\end{array}$ & $1999-2004^{12}$ & $\begin{array}{l}1993-96,^{15} \\
2003-07^{16}\end{array}$ & $2000-06^{20}$ & $2005-07^{25}$ \\
\hline Surface elevation (m) & $1370^{1}$ & $2375^{5}$ & $3488^{8}$ & $3233^{13}$ & $3810^{15}$ & $2892^{21}$ & $2318^{26}$ \\
\hline Drill depth $(m)$ & $1200^{1}$ & $554^{4}$ & $3769^{9}$ & $3260^{12}$ & $3035^{16}$ & $2774^{20}$ & $1620^{26}$ \\
\hline Ice thickness (m) & $1220^{1}$ & $554^{4}$ & $3769^{9}$ & $3275^{12}$ & $3035^{16}$ & $2774^{20}$ & $1795^{26}$ \\
\hline $\mathrm{BIZ}$ top $(\mathrm{m})$ & $552^{2}$ & $335^{4}$ & $\mathbf{2 5 0} \mathbf{0}^{10}$ & $600^{14}$ & $\mathbf{5 0 0}^{17}$ & $500^{22}$ & $667^{27,28}$ \\
\hline BIZ bottom (m) & $1200^{2}$ & $554^{4}$ & $900^{10}$ & $1200^{14}$ & $\mathbf{8 4 0}^{17}$ & $1050^{22}$ & $1002^{27,28}$ \\
\hline BIZ thickness $(\mathrm{m})$ & 648 & 291 & 650 & 600 & 340 & 550 & 334 \\
\hline Snow accumulation $\left(\mathrm{m} \mathrm{ice}^{-1}\right)$ & $0.7^{1}$ & $0.06^{5}$ & $0.022^{11}$ & $0.036^{11}$ & $0.03^{15}$ & $0.064^{21}$ & $0.08^{26}$ \\
\hline Mean air temperature $\left({ }^{\circ} \mathrm{C}\right)$ & $-22^{1}$ & $-43^{5}$ & $-55^{8}$ & $-54^{11}$ & $-58^{15}$ & $-44^{21}$ & $-41^{26}$ \\
\hline Firn/ice transition $(\mathrm{m})$ & $66^{3}$ & $72^{4}$ & $95^{11}$ & $100^{11}$ & $100^{18}$ & $83^{23}$ & $66^{27}$ \\
\hline BIZ top age (ka BP) & $0.9^{1}$ & $10^{6}$ & $10.5^{8}$ & $29^{13}$ & $19.3^{19}$ & $7.7^{24}$ & $11^{26}$ \\
\hline BIZ bottom age (ka BP) & $20^{1}$ & $>160^{6}$ & $61.5^{8}$ & $80.5^{13}$ & $46^{19}$ & $24.3^{24}$ & $30^{26}$ \\
\hline
\end{tabular}

${ }^{1}$ Morgan and others (1997); ${ }^{2}$ Morgan and others (1994); ${ }^{3}$ Etheridge and others (1996); ${ }^{4}$ Fitzpatrick (1994); ${ }^{5}$ Morse and others (1999); ${ }^{6}$ Steig and others (2000); ${ }^{7}$ Vasiliev and others (2011); ${ }^{8}$ Petit and others (1999); ${ }^{9}$ Jouzel (2013); ${ }^{10}$ Uchida and others (1994); ${ }^{11}$ Cuffey and Paterson (2010); ${ }^{12}$ Parrenin and others (2007); ${ }^{13}$ EPICA Community Members (2004); ${ }^{14}$ Parrenin and others (2012); ${ }^{15}$ Watanabe and others (1999); ${ }^{16}$ Motoyama $(2007) ;{ }^{17}$ Fujii and others (2002); ${ }^{18}$ Hondoh and others (1999); ${ }^{19}$ Kawamura and others (2007); ${ }^{20}$ Severi and others (2007); ${ }^{21}$ Ueltzhöffer and others (2010); ${ }^{22} \mathrm{~F}$. Wilhelms (personal communication, 2014); ${ }^{23}$ Oerter and others (2004); ${ }^{24}$ EPICA Community Members (2010); ${ }^{25}$ TALDICE (Talos Dome Site Information; http://www.taldice.org/project/site/index. php); ${ }^{26}$ Stenni and others (2011); ${ }^{27}$ TALDICE, 2006/07 field season (http://www.taldice.org/site/0607/index.php); ${ }^{28}$ Schilt and others (2010); ${ }^{29}$ Frezzotti and others (2004).

To quantify the influence of firn column thickness on overburden pressure at depth, while also converting BIZ depths to equivalent overburden pressures, firn-column density is modeled using the University of Washington Firn Model Intercomparison Experiment online Herron and Langway (1980) model (FirnMICE, http://firny.ess.washington.edu/communityfirnmodel/). A surface snow density of $390 \mathrm{~kg} \mathrm{~m}^{-3}$ is assumed for all sites, and mean annual surface air temperature and snow accumulation rate (ice-equivalent) are input into the model to construct one-meter resolution depth-density profiles from the surface to $300 \mathrm{~m}$ for each site (Figure 3a). Constant ice density of $920 \mathrm{~kg}$ $\mathrm{m}^{-3}$ is assumed below $300 \mathrm{~m}$, although for bubbly ice this may be an overestimate of several kilograms per cubic meter. Snow density measurements from Taylor Dome, Berkner Island and WAIS Divide agree well with model data generated for these sites (density measurements provided with the FirnMICE online model, not shown). Overburden pressure at a given depth is calculated as the sum of overlying snow and ice with density prescribed by the FirnMICE model output. One cubic meter of ice (density $920 \mathrm{~kg} \mathrm{~m}^{-3}$ ) exerts $9.02 \times 10^{-3}$ MPa overburden pressure (Figure 3b). Modeled overburden pressure at $300 \mathrm{~m}$ - the depth at which the thickest modeled firn column (Dome Fuji) reaches ice density of $920 \mathrm{~kg} \mathrm{~m}^{-3}$-is presented in Figure 3c for all sites, plotted against modelled and observed FIT depths $(830 \mathrm{~kg}$ $\mathrm{m}^{-3}$ density). The mean misfit between observed and modeled FIT depth is $-4 \%$, with 
minimum misfits of $+1 \%$ and $-2 \%$ (EPICA Dome $\mathrm{C}$ and WAIS Divide, respectively) and a maximum misfit of $-25 \%$ (Siple Dome).

Across the 18 drill sites, $300 \mathrm{~m}$ overburden pressure varies from $2.36 \mathrm{MPa}$ at Dome Fuji (modeled FIT depth $114 \mathrm{~m},+12 \%$ misfit) to $2.56 \mathrm{MPa}$ at Siple Dome (modeled FIT depth 46 m, -25\% misfit; Figure 3b, c). Poor FIT depth reproduction for these end-member sites (Figure 3c) suggests an overestimate of the possible range of overburden pressuresmore conservative is $2.4 \mathrm{MPa}$ at EPICA Dome $\mathrm{C}$ (modeled FIT depth $101 \mathrm{~m},+1 \%$ misfit) to 2.55 $\mathrm{MPa}$ at Berkner Island (modeled FIT depth $52 \mathrm{~m},-10 \%$ misfit). This overburden pressure fluctuation at depth, a maximum difference of approximately $0.15 \mathrm{MPa}$ to $0.2 \mathrm{MPa}$ between the thickest firn column (slower firnification, lower overburden pressure at depth) to the thinnest (faster firnification, higher overburden pressure at depth), is equivalent to $16.5 \mathrm{~m}$ to $22.2 \mathrm{~m}$ of ice overburden. If the firn column is ignored and full ice density is assumed from the surface, overburden pressure at depth $(2.7 \mathrm{MPa}$ at $300 \mathrm{~m})$ is overestimated by 0.14 $\mathrm{MPa}$ to $0.34 \mathrm{MPa}$ or $\sim 15.5 \mathrm{~m}$ to $37.7 \mathrm{~m}$ of ice (dashed line, Figure $3 \mathrm{a}, \mathrm{b}$ ). This results in an under-estimation of the depth for theoretical clathrate stability. The BIZ does generally occur at shallower depths where the firn-ice transition is shallower (e.g. Figure 2) and exerts greater overburden pressure at depth. This is most clearly observed at GIS and WAIS drill sitesalthough with low significance, as is expected due to low precision of reported BIZ depths and complex temperature and accumulation effects on firnification and clathrate formation processes. Reported BIZ top depths begin $\sim 10 \mathrm{~m}$ deeper per $1 \mathrm{~m}$ thickening of the FIT at the eleven GIS and WAIS drill sites (regression of GIS and WAIS FIT depths and BIZ top depths gives $\mathrm{R}^{2}=0.54$, not shown). As overburden pressure alone cannot explain such a deepening, this suggests that unidentified firnification processes likely exert significant control on BIZ onset depth. Proportional deepening of BIZ onset is not observed at all EAIS drill sites, especially not those on the EAIS plateau, perhaps because of increasing tensile strength of ice at smaller grain sizes and lower temperatures (e.g. Butkovich, 1954; Petrovic, 2003), as well as other unknown effects associated with extreme low-temperature and lowaccumulation firn densification, grain growth and air-bubble formation. 

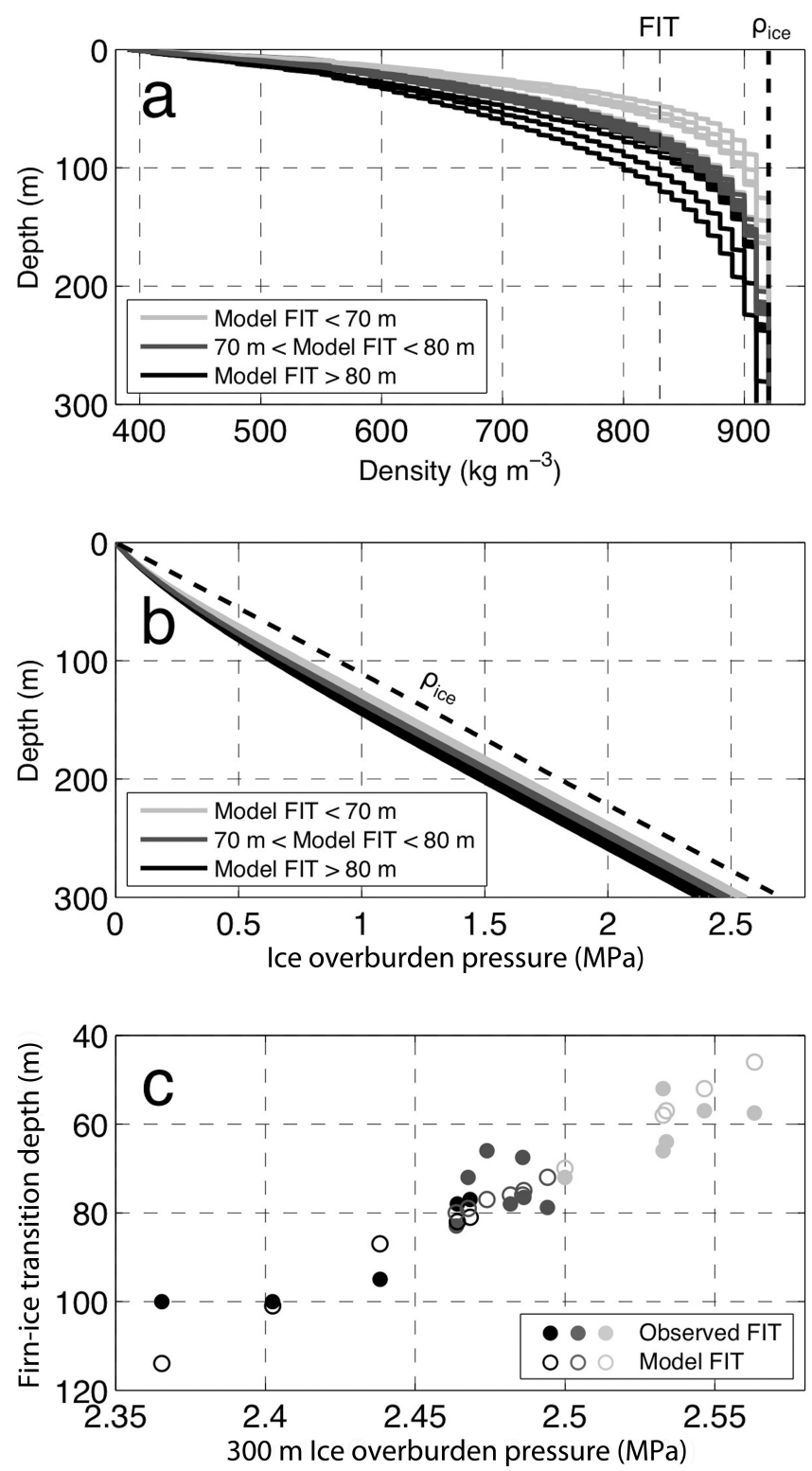

Figure 3. Results of FirnMICE firn column density modeling (Herron and Langway, 1980 model) and overburden pressure calculations. a) Density-depth profiles generated for the 18 drill site temperature and snow accumulation regimes, shaded according to modeled firn-ice transition (FIT) depth (light grey, model FIT $<70 \mathrm{~m}$; grey, $70 \mathrm{~m}<$ model FIT $<80 \mathrm{~m}$; black, model FIT $>80 \mathrm{~m})$; bold dashed line indicates ice density $\left(920 \mathrm{~kg} \mathrm{~m}^{-3}\right)$. b) Ice overburden pressure versus depth in the firn column $(0-300 \mathrm{~m})$ for the 18 drill sites (light grey, model FIT < $70 \mathrm{~m}$; grey, $70 \mathrm{~m}<$ model FIT $<80 \mathrm{~m}$; black, model FIT $>80 \mathrm{~m}$ ); bold dashed line indicates overburden pressure assuming constant ice density from the surface. c) $300 \mathrm{~m}$ depth overburden pressure versus firn-ice transition (FIT) depth from modeled (open circles) and measured (filled circles) firn-column density data. 


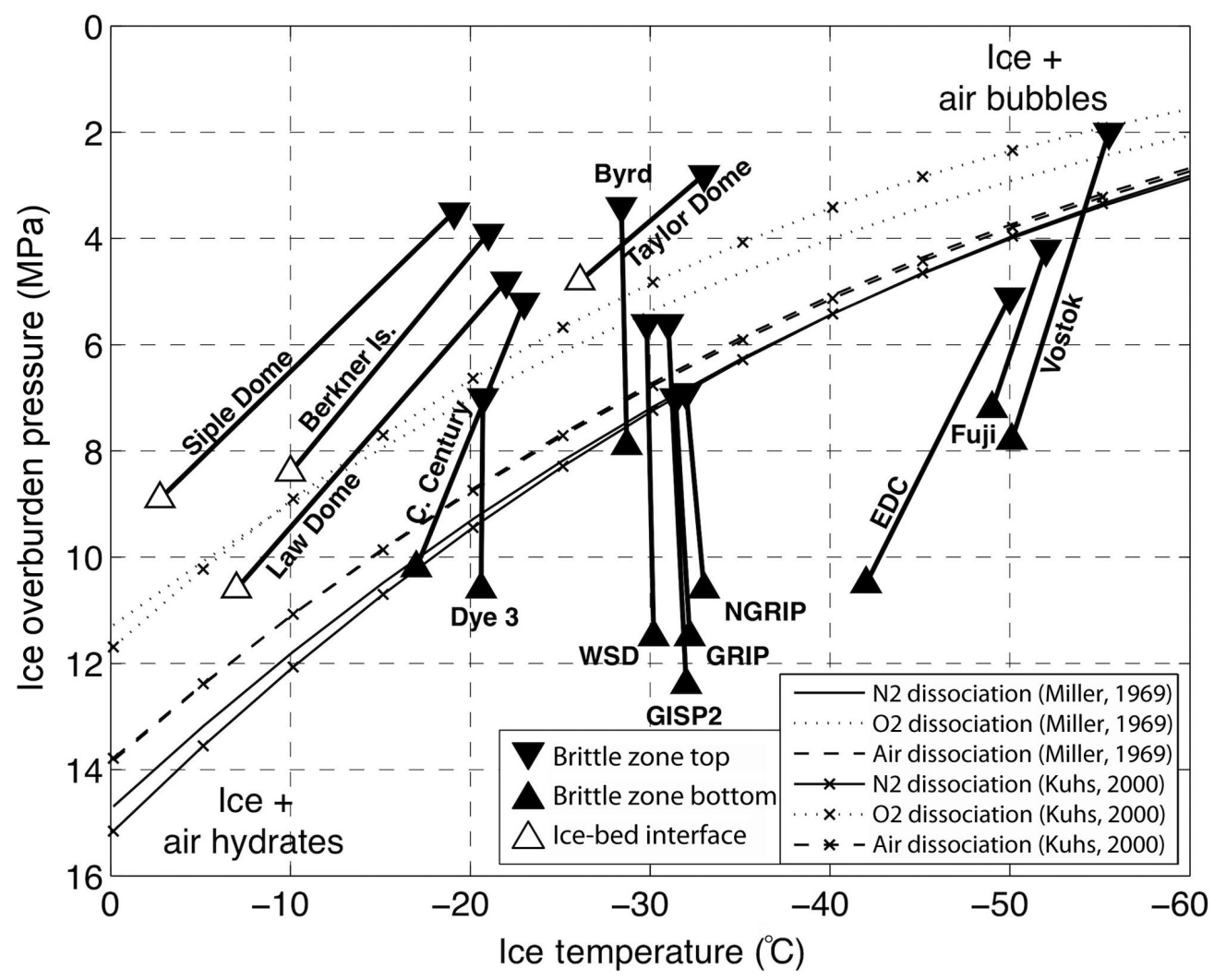

Figure 4. BIZ top (inverted triangles) and bottom pressures (triangles) plotted at respective in-situ ice temperature from borehole temperature measurements (detailed in Table 4). Theoretical clathrate stability curves are plotted for $\mathrm{N}_{2}$ (solid), $\mathrm{O}_{2}$ (dotted), and air (dashed) hydrates (Miller, 1969; Kuhs and others, 2000). The stability curve of Kuhs and others (2000) is indicated with ' $x$ '. Open triangles denote BIZ bottom pressures at the ice-bed interface, thus not the full transition from the bubbly, brittle-ice zone to the bubble-free, ductile ice zone below. Abbreviated: WSD (WAIS Divide), EDC (EPICA Dome C).

\section{Pressure and temperature effects II: brittle zone relief}

In-situ ice temperature determines the depth (pressure) of clathrate stability and thus should affect the depth of the transition from bubbly, brittle ice to bubble-free, ductile ice. This is supported by observations of shallower appearance of clathrates and disappearance of air bubbles in ice cores at low-temperature sites (e.g. observations from Dye 3 and GRIP versus Vostok and Dome Fuji, Ikeda-Fukuzawa and others, 2001). While temperature effects controlling BIZ onset are less clear, it is expected that the BIZ will be relieved at shallower depths (lower pressures) where ice temperatures are lower. Using overburden pressure as calculated above, and borehole temperature data from selected drill sites (Table 4), the BIZ can be evaluated with respect to temperature and pressure and thus compared more 
accurately with theoretical clathrate stability (Figure 4). BIZ onset in many cases begins at pressures (depths) where clathrates should already begin to stabilize, but brittle fracture is not relieved until ductile conditions are reached as bubble number-densities become sufficiently low and clathrates dominate, strengthening ice cores. While it is tempting to suggest that BIZ bottom pressure indeed decreases with lower ice temperatures, this is not a statistically significant feature including all reported BIZ data (excluding intermediate-depth sites where clathrates do not stabilize before the ice-bed interface is reached). Certainly the BIZ in the Greenland summit ice cores and at WAIS Divide (1200 m to $1400 \mathrm{~m}$ BIZ bottom depths, $\sim 5.5 \mathrm{MPa}$ to $12.5 \mathrm{MPa}$ ) extends several hundred meters deeper than that of Dome Fuji, Vostok, EPICA Drønning Maud Land and Talos Dome (840 m to $1050 \mathrm{~m}$ BIZ bottom depths, 8.2 $\mathrm{MPa}$ to 9.2 $\mathrm{MPa}$ ), but the EPICA Dome $\mathrm{C}$ ice core remained highly fractured to $1200 \mathrm{~m}$ depth (10.5 MPa). Additionally, the BIZ at Camp Century, Dye 3 and Byrd Station transitions to ductile ice at shallow depths-with pressures only $1 \mathrm{MPa}$ to $2 \mathrm{MPa}$ greater than that required for initial clathrate stability-while most sites transition out of the BIZ at pressures $3 \mathrm{MPa}$ to $5 \mathrm{MPa}$ in excess of requirements for theoretical onset of clathrate stability (Figure 4). This raises the interesting prospect that ice-flow advection of cold ice towards the surface at flank sites could encourage shallower formation of clathrates (e.g. Camp Century, Byrd Station; Shoji and Langway, 1987). However, without disentangling the effects of imprecise BIZ records, drill performance and ice core handling/transport, it is difficult to use reported brittle ice depths to further evaluate this correlation between clathrate stability and the bottom of the BIZ.

To improve understanding of the mechanisms involved in BIZ onset and relief, it may prove useful to investigate ice physical properties including bubble number-density, bubble size, micro-bubbles and ice fabric (e.g. grain size, crystal anisotropy). Take the anomalously shallow BIZ at Vostok, for example: Uchida and others (1994) observed a reduction of core quality caused by fractures as shallow as $100 \mathrm{~m}$ (likely linked to thermal drilling at Vostok), becoming heavily fractured from $250 \mathrm{~m}$ to $750 \mathrm{~m}$ with progressive improvement to $900 \mathrm{~m}$ where core quality again became excellent. This shallowest occurrence of the BIZ may be related to a rapid increase in bubble number-density (bubbles $\mathrm{cm}^{-3}$ ) observed in the Vostok ice core beginning at approximately $300 \mathrm{~m}$ depth (increasing from $\sim 400$ to $\sim 800$ bubbles $\mathrm{cm}^{-}$ 3; Uchida and others, 1994; Ueltzhöffer and others, 2010). Such an increase in bubble number-density may effectively reduce bubble pressures required for fracture propagation by narrowing interstitial ice between bubble cavities. Bubble number-densities reported in the BIZ at Byrd Station and WAIS Divide were relatively more constant at $\sim 200$ and $\sim 450$ 
bubbles $\mathrm{cm}^{-3}$, respectively (Gow, 1971; Fitzpatrick et al., in press). Micro-bubbles formed through sublimation-condensation processes may also play a role at Vostok (e.g. Lipenkov, 2000), and are observed in the EPICA Dome C and Drønning Maud Land ice cores (Ueltzhöffer and others, 2010). The second shallowest occurrence of the BIZ, $335 \mathrm{~m}$ at Taylor Dome, may be anomalously shallow due to high strain rates at this site-elongated bubbles were observed from 360 to 390 m (Fitzpatrick, 1994).

Table 4: In-situ ice temperature (borehole temperature) at brittle ice zone (BIZ) top and bottom depths (see Tables 1-3) for selected sites. Temperatures are $\pm 0.5{ }^{\circ} \mathrm{C}$, estimated from published graphical data where original datasets could not be accessed. Temperature data for Berkner Island is modeled.

\begin{tabular}{|c|c|c|c|}
\hline \multirow[t]{2}{*}{ Drill site } & \multicolumn{2}{|c|}{ Temperature } & \multirow[t]{2}{*}{ Source } \\
\hline & $\begin{array}{l}\text { BIZ } \\
\text { top depth }\end{array}$ & $\begin{array}{c}\text { BIZ } \\
\text { bottom depth }\end{array}$ & \\
\hline Camp Century & -23 & -17 & Shoji and Langway (1987) \\
\hline Dye-3 & -20.7 & -20.6 & Shoji and Langway (1987) \\
\hline GRIP & -31.4 & -32.2 & $\begin{array}{c}\text { The Greenland Summit Ice } \\
\text { Cores CD-ROM (1997) }\end{array}$ \\
\hline GISP2 & -31 & -32 & $\begin{array}{c}\text { The Greenland Summit Ice } \\
\text { Cores CD-ROM (1997) }\end{array}$ \\
\hline NorthGRIP & -32 & -33 & $\begin{array}{c}\text { Dahl-Jensen and others } \\
\text { (2003) }\end{array}$ \\
\hline Byrd Station & -28.4 & -28.7 & $\begin{array}{l}\text { Ueda and Garfield (1969), } \\
\text { T.J. Fudge (personal } \\
\text { communication, 2014) }\end{array}$ \\
\hline Siple Dome & -19.1 & -2.75 & $\begin{array}{l}\text { G. Clow (personal } \\
\text { communication (2014) }\end{array}$ \\
\hline Berkner Island & -21 & -10 & $\begin{array}{c}\text { Mulvaney and others } \\
\text { (2007) }\end{array}$ \\
\hline WAIS Divide & -29.8 & -30.2 & Cuffey and Clow (2014) \\
\hline Law Dome & -22 & -7 & $\begin{array}{l}\text { Van Ommen and others } \\
(1999)\end{array}$ \\
\hline Taylor Dome & -33 & -26.1 & $\begin{array}{c}\text { G. Clow (personal } \\
\text { communication, 2014) }\end{array}$ \\
\hline Vostok station & -55.5 & -50.1 & $\begin{array}{l}\text { Salamatin and others } \\
\text { (1994) }\end{array}$ \\
\hline EPICA Dome C & -50 & -42 & Pol and others (2010) \\
\hline Dome Fuji & -52 & -49 & $\begin{array}{l}\text { Ikeda-Fukuzawa and } \\
\text { others (2001) }\end{array}$ \\
\hline
\end{tabular}

\section{Brittle ice zone age}

Figure 5 displays observed BIZ top and bottom ages from published agescales developed for the eighteen drill sites discussed above (detailed ages in Tables 1, 2 and 3). At deep ice core sites where snow accumulation rates are relatively high (e.g. GIS and inland WAIS sites), the age of ice within the BIZ is relatively young, dating from the as few as $2 \mathrm{ka}$ BP (Dye-3; Langway and others, 1985) to 9500 years BP (Byrd Station; Blunier and Brook, 
2001). These ages represent approximately $10 \%$ or less of the age of dated ice core records developed from these sites. While the Holocene marks the beginning of relatively stable global climate, with the exception of the $8.2 \mathrm{ka} \mathrm{BP}$ event (e.g. Alley and others, 1997), continued emphasis on understanding natural climate variability precludes classifying ice of this age as scientifically less interesting than older transitional and glacial ice (e.g. Mayewski and others, 2004; Marcott and others, 2013; Steig and others, 2013).

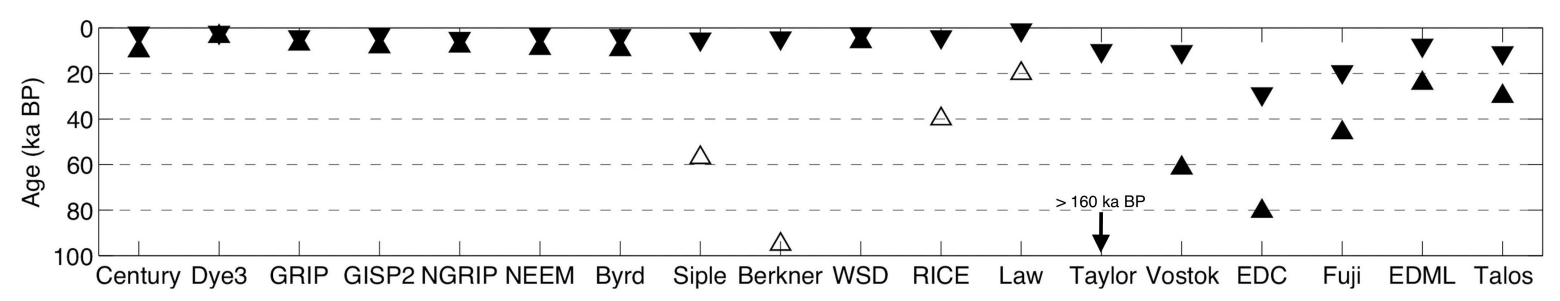

Figure 5. BIZ top (inverted triangles) and bottom (triangles) age (kiloannum before present, $B P)$ at drill sites, ordered by region and date of drilling. Open triangles denote BIZ bottom ages which represent the maximum dated age ( ice-bed interface) at these sites. Abbreviated: WSD (WAIS Divide), RICE (Roosevelt Island Climate Evolution), EDC (EPICA Dome C), EDML (EPICA Drønning Maud Land).

A wide range of ice ages are found within the BIZ at deep ice core sites with low snow accumulation rates (e.g. EAIS plateau sites: Taylor Dome, Vostok, Dome C, Drønning Maud Land, Dome Fuji, Talos Dome), and intermediate-depth ice core sites with higher snow accumulation rates (e.g. coastal Antarctic sites: Siple Dome, Berkner Island, Roosevelt Island, Law Dome). In intermediate-depth ice core records (all at intermediate ice-thickness coastal Antarctic locations), ice at the top of the BIZ dates to between approximately $4 \mathrm{ka}$ BP at Roosevelt Island (N. Bertler, personal communication) and 9 ka BP at Law Dome (Morgan and others, 1997). Ice at these coastal Antarctic sites remains brittle to the bed, dating to a minimum of $\sim 40$ ka BP (Roosevelt Island; N. Bertler, personal communication) and in all cases placing at least $90 \%$ of the dated ice core record within the BIZ. Brittle ice at EPICA Dome C dates from $29 \mathrm{ka}$ BP to $80.5 \mathrm{ka}$ BP (EPICA Community Members, 2004). While not a large fraction of the entire ice core record ( $\sim 6 \%$ of the $800 \mathrm{ka}$ record), this section of the Dome $\mathrm{C}$ ice core is highly detailed when compared to deeper ice where ice-flow thinning impairs resolution at this extremely low-accumulation site. From the surface to $\sim 2000 \mathrm{~m}$ depth, $55 \mathrm{~cm}$-long sections of the Dome $\mathrm{C}$ ice core exhibit temporal resolution of 50-100 years or less, while below $2000 \mathrm{~m}$ similar sections contain between 200-1000 years or more (Pol and others, 2010). Taylor Dome, a very shallow site, became brittle from a depth of 335 
$\mathrm{m}$, dated to $10 \mathrm{ka} \mathrm{BP}$, remaining brittle to the bed and spanning ice ages in excess of $160 \mathrm{ka}$ BP (Steig and others, 2000). Ice within the BIZ at these coastal Antarctic and EAIS plateau sites spans ages of fundamental interest to paleoclimate research, relevant to investigations into regional timing of the onset of deglaciation during the late-Pleistocene and rapid climate anomalies occurring during this transition (e.g. Younger Dryas, Antarctic Cold Reversal; Alley and others, 1993; WAIS Divide Project Members, 2013).

\section{Mitigating brittle ice impacts}

\section{Drilling techniques}

Currently, drilling through the BIZ produces ice core sections with several to many breaks, fractures and hairline cracks, commonly affecting more than half of recovered ice in the middle of this zone. Drilling fluid required at these depths pervades all cracks and fractures, contaminating many chemical analyses. At WAIS Divide, where BIZ core quality was the best of any recent United States led drilling project, $1 \mathrm{~m}$-long core sections from 900 $\mathrm{m}$ to $1200 \mathrm{~m}$ were on average between "good" (containing zero to three breaks or $50 \%$ unfractured) and "fair" quality (containing more than $10 \mathrm{~cm}$ of core length without fractures; Souney and others, this issue).

As the only step performed at in situ pressures within the ice sheet (minimum of 2.0 $\mathrm{MPa}$, maximum 12.4 MPa in the BIZ), with the added benefit of damping effects associated with a liquid-filled borehole, the drilling process provides important opportunities to reduce the major component of brittle fracture in ice cores by performing mechanically severe steps that might damage cores if performed at surface pressures $(\sim 700 \mathrm{hPa}, 0.07 \mathrm{MPa})$. For example, drilling at WAIS Divide employed a unique strategy specifically for brittle ice, performing three core-breaks per $\sim 2.5 \mathrm{~m}$ drill run before returning the drill sonde to the surface (detailed in Souney and others, this issue). This technique of performing several core breaks per run at in situ pressure results in ice core sections that are ready to ship, without subjecting brittle ice cores at surface pressure to the vibration and high-stresses of making circular-saw section cuts. A similar down-hole technical innovation suggested by Ueda (2002) is the development of a drill sonde that captures and seals cores in a vessel at in situ pressures, potentially allowing for a more gradual transition to atmospheric pressure than the usual minutes- to hours-long transition as the drill sonde is brought to the surface. Slowing the pressure and temperature transition by hoisting brittle ice drill runs slowly to the surface, reducing drill penetration rate, and considering drill fluid pressure balance have also been proposed (see the discussion by J. Schwander and others in IPICS, 2005). 
Maintaining temperatures within drilling and on-site storage structures similar to those at depth in the borehole is a commonly-practiced technique in ice drilling (e.g. Souney and others, this issue). At Roosevelt Island, an actively-cooled storage cave kept ice at -23 ${ }^{\circ} \mathrm{C}$ despite surface temperatures reaching as much as $-5{ }^{\circ} \mathrm{C}$ (D. Mandeno, personal communication). Temperature gradients may reach several tens of degrees between in-situ ice temperature and surface drill structure temperatures, which will cause differential heating of ice cores brought to the surface, inducing temperature and stress gradients as the ice core surface warms (and expands) more quickly than the interior. However, it is difficult to overstate the primary impact of the pressure gradient between the BIZ and the surface, which, as a ratio, is a minimum of 30:1 at the shallowest observed BIZ onset (Vostok: 2.0 MPa at $250 \mathrm{~m}, \sim 0.07 \mathrm{MPa}$ surface air pressure) and grows to more than a 100:1 ratio at most ice core drill sites (reaching a maximum BIZ bottom to surface pressure ratio of 177:1 at the bottom of the GISP2 BIZ: $1400 \mathrm{~m}$ depth, $12.4 \mathrm{MPa}$ ).

\section{Transport techniques}

Reduction of mechanical shock during core transport from the drill site to laboratories has been achieved primarily by sheathing brittle ice cores in tight-fitting nylon netting immediately upon removal from the drill, and delaying shipment of brittle ice for as long as logistically possible to allow for maximum relaxation. Use of netting was innovated at Berkner Island (Mulvaney and others, 2007), and the same was used successfully at WAIS Divide (Souney and others, this issue) and Roosevelt Island (N. Bertler, personal communication). While itself not preventing initial fracture of brittle ice cores, nylon netting holds badly fragmented sections in place, preventing any loss of stratigraphic order, and protects cores from further damage due to vibration during shipment.

Relaxation of ice cores after drilling is examined thoroughly by Gow (1971), measuring significant post-drilling volume expansion (density reduction) at all depths in the Byrd Station ice core. Cores from the BIZ around $800 \mathrm{~m}$ depth exhibit greatest expansion: $\sim 0.2 \%\left(0.002 \mathrm{~kg} \mathrm{~m}^{-3}\right.$ density decrease $)$ after 8 months, $\sim 0.4 \%\left(0.004 \mathrm{~kg} \mathrm{~m}^{-3}\right.$ decrease $)$ after 16 months, and up to $\sim 0.6 \%\left(0.006 \mathrm{~kg} \mathrm{~m}^{-3}\right.$ decrease) after 27 months (see Fig. 2 of Gow, 1971). Cores from other depths expanded by an average of $\sim 0.2 \%\left(0.002 \mathrm{~kg} \mathrm{~m}^{-3}\right.$ decrease $)$ after 27 months. Nearly identical relaxation characteristics were observed in the GISP2 ice core (Gow and others, 1997). Ice cores retrieved using a hot-water drill at Siple Dome relaxed very quickly, likely due to the thermal drilling technique but cores were also stored at relatively warm surface temperatures after drilling (Engelhardt and others, 2000; Gow and Meese, 2007). Ice cores retrieved by PICO (Polar Ice Coring Office) mechanical drilling at 
Siple Dome showed very little relaxation, and remain brittle to date (Gow and Meese, 2007; M. Twickler, personal communication).

Much of this relaxation in brittle ice is attributed to slow dilation of highlypressurized bubbles abundant in this zone. This lends support to the practice of overwintering brittle ice, most recently performed at WAIS Divide (Souney and others, this issue). At Roosevelt Island, $\sim 2 \mathrm{~m}$ long drill runs were sheathed in netting and stored in a refrigerated snow cave for up to 14 days before making $1 \mathrm{~m}$ section cuts for shipment. Improvements were noted in band saw cuts after even this short period of relaxation, although some propensity for fracturing remained (N. Bertler, personal communication). It is important to note that over-wintering or long-term storage of brittle ice cores delays sampling and analysis of this section of ice. While this delay is less significant on the timeframe of a multi-year deep drilling project, for smaller endeavors, especially at intermediate-depth coastal sites where a significant portion of the dated ice core record lies within the BIZ, delaying shipment and/or sampling of ice cores is more challenging.

\section{Sampling techniques}

Ice core sampling is commonly performed at -20 to $-25^{\circ} \mathrm{C}$, making preliminary longitudinal cuts using a horizontal band saw and subsequent sampling with common vertical band saws. While a simple tool, the band saw applies consistent force at the cutting teeth, especially if tracking of the saw along-core is automated to steadily move the saw blade through the ice. After sufficient relaxation-allowing for slow dilation of air bubbles long after initial violent cracking and fracturing observed immediately after drilling - brittle ice may feed through a band saw with little additional fracturing. Brittle ice below depths of 475 $\mathrm{m}$ from Roosevelt Island proved prohibitively brittle after 6 months stored at $-30{ }^{\circ} \mathrm{C}$, with several instances of near-catastrophic fracturing during horizontal cutting due to vibration from the saw blade. At this depth, a conventional vertical band saw used to make $\sim 0.035 \mathrm{x}$ $0.035 \times 1.0 \mathrm{~m}$ rods of ice also began to add many fractures to previously flawless ice core samples, which had immediately prior been cut into $\sim 0.1 \times 0.035 \times 1.0 \mathrm{~m}$ slabs without damage. Core sampling was halted at $500 \mathrm{~m}$ and the remaining ice stored at $-18{ }^{\circ} \mathrm{C}$ for an additional year, after which cutting proceeded without significant challenges.

Other cutting instruments may prove more conducive to processing brittle ice core samples. Tison (1994) describes the use of a diamond wire-saw for preparing thin sections of debris-rich or brittle ice, an option attractive for its reduced vibration levels. However, with slow cutting rates and high cost of diamond wires, this option may require significant development before being applicable to high-volume ice core sample processing. 


\section{Analytical techniques}

Many analyses performed in polar ice core studies depend on relatively unbroken samples to prevent contaminants altering original paleoclimate or paleoenvironmental signals. Measurements of atmospheric gases preserved in bubbles ideally require avoidance of section cuts and other breaks present in ice core samples, in order to exclude modern atmospheric gases from analysis. Major-ion and trace chemistry, analyzed in longitudinal samples from the center of ice cores in order to avoid modern contaminants imparted during drilling, shipment and sampling, requires removal of outer sample surfaces and cleaning of any exposed surfaces including section cuts and fractures. Drilling fluid pervades all fractures in ice core samples - especially fluids with low volatility, such as Estisol-240 (Dow Haltermann, Germany) coconut oil extract used at NEEM and Roosevelt Island-rendering chemical analyses extremely difficult, especially in ice from the BIZ.

Continuous-flow analysis (CFA) systems gravity-feed longitudinal ice samples through a sectioned heating plate, pumping meltwater directly into on-line instruments and/or fraction collectors to create discrete sub-samples (e.g. Osterberg and others, 2006; Bigler and others, 2011). When analyzing highly-fractured samples in CFA systems, contamination does not only affect fractured core sections, but also subsequent ice as relatively highconcentration contaminants wash out of sample lines and instruments. Additionally, vertical guide systems for gravity-feeding samples struggle to accommodate ice samples containing fractures, especially high-angle longitudinal fractures, which commonly wedge against plastic guides, disrupting sample flow and accurate depth logging.

Fractured sample sections are commonly removed entirely from CFA campaigns, such that continuous-flow analysis for major-ion chemistry of brittle ice from the WAIS Divide ice core only processed $\sim 62 \%$ of ice from the depths of $577 \mathrm{~m}$ to $1300 \mathrm{~m}$ (D. Ferris, personal communication). An optical drill fluid detection system identified 27 instances of drill fluid contamination in CFA tubing while analyzing $175 \mathrm{~m}$ of brittle ice from the NEEM ice core (Warming and others, 2013). Using this detection system, particular negative impacts were noted for dust, conductivity, ammonium, hydrogen peroxide and sulfate datasets in brittle ice from the NEEM ice core. While technically challenging, feasible solutions have been developed for analyzing brittle ice core samples with little sample loss, such as the high-resolution CFA water stable-isotope analysis of $13 \mathrm{~mm} \times 13 \mathrm{~mm} \times 1.0 \mathrm{~m}$ rods of ice from the WAIS Divide ice core (B. Vaughn, V. Morris, T. Jones and J. White, unpublished). This approach used tightly fitting square acrylic tubes to protect the fragile ice rods during shipment, and also support them vertically in a sample rack during analysis- 
while light vibration successfully prevented wedging against the acrylic tubing during melting, even in highly-fractured brittle ice (B. Vaughn, personal communication).

\section{Conclusion}

At eighteen intermediate-depth and deep polar ice core drilling sites across the Greenland Ice Sheet and West and East Antarctic ice sheets, the brittle ice zone of poorquality, highly-fractured ice cores extends from a mean top depth of $545 \pm 162 \mathrm{~m}$ to a mean bottom depth of $1132 \pm 178 \mathrm{~m}$ (excluding intermediate-depth sites where the ice-bed interface is reached before the transition to ductile ice).

Firn-column thickness, controlled primarily by site temperature and snow accumulation rate, determines the precise overburden pressure at depth, quantified here to demonstrate that thicker firn columns apply less pressure at depth and vice versa. Both reported BIZ top and bottom depths at GIS and WAIS sites are in fact deeper where FIT depth is similarly deep, as could expected due to fluctuating overburden pressure, however the deepening of the BIZ is greater than can be explained from overburden pressure alone. Additionally, the absence of this relationship at extremely cold, dry EAIS plateau sites suggests that other factors associated with firn densification and grain growth, affecting eventual clathrate formation and stability, are likely involved. While it is expected, due to pressure and temperature controls on clathrate stability, that the BIZ should transition to ductile, bubble-free ice at lower pressures (shallower depths) when ice temperatures are lower, this is not a quantitative feature of reported BIZ bottom depths including all deep drill sites. Although shallower stability of clathrates and shallower disappearance of air bubbles is observed in ice cores from colder sites, BIZ bottom depths do not clearly behave similarly. This is likely due to imprecision in reported BIZ depths, as well as the convolution of ice core fracture caused purely by physical properties during relaxation and fracture due to additional stresses induced during retrieval (e.g. drill performance, handling techniques).

Consideration of this $531 \pm 138 \mathrm{~m}$ thick zone (mean BIZ top minus bottom depth excluding intermediate-depth sites), where pressurized air bubbles and ice relaxation upon retrieval of cores causes extensive and sometimes explosive fracturing, is pertinent to all projects developing records from ice cores recovered at depths greater than approximately $400 \mathrm{~m}$ (i.e. mean BIZ top depth, $545 \mathrm{~m}$, less one standard deviation, $162 \mathrm{~m}$, gives $383 \mathrm{~m}$ ). Relatively high snow accumulation rates and thick ice ensures that ice from the BIZ at inland GIS and WAIS sites is restricted to Holocene ages, and spans less than $10 \%$ of the completed ice core records. EAIS plateau and coastal Antarctic drill sites, however, place a considerably larger amount of dated ice core records in the BIZ. Low snow accumulation 
rates and large ice thicknesses at EAIS plateau sites place 20,000 to 50,000 years of glacial ice from these ice core records in the BIZ, affecting the resolution of these valuable records which are already challenged by low snow accumulation rates. Conversely, high snow accumulation rates and limited ice thickness at coastal Antarctic drill sites place the majority of recovered ice and dated ice core records within the BIZ - at least $90 \%$ of the records at all coastal Antarctic drill sites.

Innovative drilling and transport strategies have had recent successes in minimizing fracturing in ice cores from the BIZ, including the WAIS Divide brittle-ice drilling technique, netting core after removing from the drill, and relaxing ice prior to shipment and/or sampling. However, comparatively little has been done to develop better sampling methods and techniques for analyzing highly fractured ice core samples. Consideration of mitigating strategies at any stage can have beneficial impacts on downstream work phases, most importantly potentially improving final scientific results. Targeting of ice core sites is increasingly focused by refined scientific questions, specific research interests, and desire to infill areas of sparse geographical coverage. Advancing understanding of the physical mechanisms controlling the BIZ has the potential to significantly improve the continuous recovery and development of ice core paleoclimate and environmental records, as this zone affects samples of ages spanning periods of fundamental scientific interest at many potential drill sites.

\section{Acknowledgements}

The author thanks R. Dadic and N. Bertler for thoughtful discussion of the manuscript. Thorough critique, discussion and encouragement from two anonymous reviewers significantly improved on the original text. The online University of Washington FirnMICE model (http://firny.ess.washington.edu/communityfirnmodel/) was used to model firn density and estimate overburden pressures. The author has been funded by the New Zealand Ministry of Business, Innovation, and Employment Grants (RDF-VUW-1103, CO5X0202), Victoria University and GNS Science. This work is a contribution to the Roosevelt Island Climate Evolution (RICE) Programme, funded by national contributions from New Zealand, Australia, Denmark, Germany, Italy, the People's Republic of China, Sweden, United Kingdom, and the United States of America. The main logistic support for RICE was provided by Antarctica New Zealand (K049) and the US Antarctic Program (I209M). 


\section{References}

Alley RB, Meese DA, Shuman CA and 8 others (1993). Abrupt increase in Greenland snow accumulation at the end of the Younger Dryas event. Nature, 362, 527-529.

Alley RB, Mayewski PA, Sowers T and 3 others (1997). Holocene climate instability: A prominent, widespread event 8200 yr ago. Geology, 25(6), 483.

Bigler M, Svensson A, Kettner E and 3 others (2011). Optimization of high-resolution continuous flow analysis for transient climate signals in ice cores. Environ. Sci. Technol., 45, 4483-4489.

Blunier T and Brook E (2001). Timing of millennial-scale climate change in Antarctica and Greenland during the last glacial period. Science, 291, 109-112.

Brook EJ, White JWC, Schilla ASM and 6 others (2005). Timing of millennial-scale climate change at Siple Dome, West Antarctica, during the last glacial period. Quaternary Sci. Rev., Vol. 24, pp. 1333-1343. doi:10.1016/j.quascirev.2005.02.002.

Brook EJ, Wolff E, Dahl-Jensen D, Fischer H, Steig EJ (2006). The future of ice coring: International Partnerships in Ice Core Sciences (IPICS), PAGES News, Volume 14(1), 6-9.

Buizert C, Martinerie P, Petrenko VV and 23 others (2012). Gas transport in firn: multipletracer characterization and model intercomparison for NEEM, Northern Greenland. Atmos. Chem. Phys., 12, 4259-4277, doi:10.5194/acp-12-4259-2012.

Butkovich TR (1954). Ultimate strength of ice. Snow Ice and Permafrost Research Establishment Research Paper 11, U.S. Army Corps of Engineers.

Cuffey KM and Clow G (2014). Temperature Profile of the West Antarctic Ice Sheet Divide Deep Borehole. Boulder, Colorado USA: National Snow and Ice Data Center. http://dx.doi.org/10.7265/N5V69GJW.

Cuffey KM and Paterson WSB (2010). The Physics of Glaciers, $4^{\text {th }}$ edn. Elsevier, Oxford. 
Dahl-Jensen D, Gundestrup N, Gogineni SP and Miller H (2003). Basal melt at NorthGRIP modeled from borehole, ice-core and radio-echo sounder observations. Ann. Glaciol., 37, 207-212.

Dansgaard W, Johnsen SJ, Møller J and Langway CC Jr (1969). One thousand centuries of climate record from Camp Century on the Greenland Ice Sheet. Science, Vol. 166(3903), 377-381.

Dansgaard W, Johnsen SJ, Clausen HB and 8 others (1993). Evidence for general instability of past climate from a 250-kyr ice-core record. Nature, 364, 218-220.

Drinkwater MR, Long DG and Bingham AW (2001). Greenland snow accumulation estimates from satellite radar scatterometer data. J. Geophys. Res., 101(D24), 33,935-33,950.

EPICA community members (2004). Eight glacial cycles from an Antarctic ice core. Nature, $429,623-628$.

EPICA Community Members (2010). Stable oxygen isotopes of ice core EDML. doi:10.1594/PANGAEA.754444

Engelhardt H, Kamb B and Bolsey R (2000). A hot-water ice-coring drill. J. Glaciol., 46(153), 341-345.

Etheridge DM, Steele LP, Langenfelds RL and 3 others (1996). Natural and anthropogenic changes in atmospheric $\mathrm{CO}_{2}$ over the last 1000 years from air in Antarctic ice and firn. $J$. Geophys. Res., 101(D2), 4115-4128.

Fitzpatrick JJ (1994). Preliminary report on the physical and stratigraphic properties of the Taylor Dome ice core. Antarctic Journal of the United States, 29(5), 84-86.

Fitzpatrick JJ, Voigt DE, Fegyveresi JM and 9 others (in press). Physical properties of the WAIS Divide ice core. J. Glaciol.

Frezzotti M, Bitelli G, De Michelis P and 10 others (2004). Geophysical survey at Talos Dome, East Antarctica: the search for a new deep-drilling site. Ann. Glaciol., 39, 423-432. 
Fujii Y, Azuma N, Tanaka Y and 23 others (2002). Deep ice core drilling to $2503 \mathrm{~m}$ depth at Dome Fuji, Antarctica. Memoirs of National Institute of Polar Research, Special Issue No. 56.

Gerland S, Oerter H, Kipfstuhl J and 6 others (1999). Density log of a $181 \mathrm{~m}$ long ice core from Berkner Island, Antarctica. Ann. Glaciol., 29, 215-219.

Gow AJ, Ueda HT and Garfield DE (1968). Antarctic Ice Sheet: preliminary results of the first core hole to bedrock. Science, v. 161, p. 1011-1013.

Gow AJ (1968). Bubbles and bubble pressures in Antarctic glacier ice. J. Glaciol., 7(50), 167-182.

Gow AJ (1971). Relaxation of ice in deep drill cores from Antarctica. J. Geophys. Res., Vol. $76,2533-2541$.

Gow AJ, Meese DA, Alley RB and 4 others (1997). Physical and structural properties of the Greenland Ice Sheet Project 2 ice core: A review. J. Geophys. Res., 102(C12), 26,55926,575 .

Gow AJ and Meese DA (2007). Physical properties, crystalline textures and $c$-axis fabrics of the Siple Dome (Antarctica) ice core. J. Glaciol., 53(183), 573-584.

Gundestrup NS and Hansen BL (1984). Bore-hole survey at Dye 3, South Greenland. J. Glaciol., 30(106), 282-288.

Herron MM and Langway CC Jr (1980). Firn densification: and empirical model. J. Glaciol., 25(93), 373-385.

Hörhold MW, Kipfstuhl S, Wilhelms F and 2 others (2011). The densification of layered polar firn. J. Geophys. Res., 116, F01001, doi:10.1029/2009JF001630.

Hondoh T, Narita H, Hori A and 13 others (1999). Basic analyses of Dome Fuji deep ice core Part 2: physical properties. Polar Meterol. Glaciol., 13, 90-98. 
Ikeda-Fukazawa, T., T. Hondoh, T. Fukumura, H. Fukazawa, and S. Mae (2001). Variation in N2/O2 ratio of occluded air in Dome Fuji antarctic ice, J. Geophys. Res., 106(D16), 1779917810, doi:10.1029/2000JD000104.

International Partnerships in Ice Core Sciences (2005). IPICS 2004 Workshop Report. http://www.icedrill.org/documents/view.shtml?id=38, accessed 30 July, 2014.

Kawamura K, Parrenin F, Lisiecki L and 15 others (2007). Northern Hemisphere forcing of climatic cycles in Antarctica over the past 360,000 years. Nature, 448, 912-916. doi:10.1038/nature06015.

Kipfstuhl S, Pauer F, Kuhs WH and Shoji H (2001). Air bubbles and clathrate hydrates in the transition zone of the NGRIP deep ice core. Geophys. Res. Lett., Vol. 28, No. 4, 591-594.

Kovacs A, Weeks WF and Michitti, F (1969). Variation of some mechanical properties of polar snow, Camp Century, Greenland. U.S. Army Cold Regions Research and Engineering Laboratory, Research Rep. 276.

Kreutz K, Koffman B, Breton D and Hamilton G (2011). Microparticle, Conductivity, and Density Measurements from the WAIS Divide Deep Ice Core, Antarctica. Boulder, Colorado USA: National Snow and Ice Data Center. http://dx.doi.org/10.7265/N5K07264.

Kuhs WF, Klapproth A and Chazallon B (2000). Chemical physics of air clathrate hydrates. In "Physics of Ice Core Records," T. Hondoh (ed.), Hokkaido Univ. Press, 2000, Sapporo.

Langway CC Jr, Oeschger H and Dansgaard W eds. (1985). Greenland ice core: Geophysics, geochemistry and environment: Geophysical Monographs, v. 33, American Geophysical Union, Washington D.C.

Ligtenberg SRM, Helsen MM and van den Broeke MR (2011). An improved semi-empirical model for the densification of Antarctic firn. The Cryosphere, 5, 809-819. doi:10.5194/tc-5809-2011. 
Lipenkov V (2000). Air bubbles and air-hydrate cyrstals in the Vostok ice core. In "Physics of Ice Core Records,” T. Hondoh (ed.), Hokkaido Univ. Press, 2000, Sapporo.

Lipenkov V, Vasiliev N, Ekaykin A and 2 others (2013). What have we learned from the first unsealing of Lake Vostok? $7^{\text {th }}$ International Workshop on Ice Drilling Technology, September 9-13, 2013, Madison, WI, USA.

Marcott SA, Shakun JD, Clark PU and Mix AC (2013). A reconstruction of regional and global temperature for the past 11,300 years. Science, 339, 1198-1201.

Martinerie P, Nourtier-Mazaurie E, Barnola J-M and 6 others (2009). Long-lived halocarbon trends and budgets from atmospheric chemistry modelling constrained with measurements in polar firn. Atmos. Chem. Phys., 9, 3911-3934.

Mayewski PA, Rohling EE, Stager JC and 12 others (2004). Holocene climate variability. Quaternary Res., 62(3), 243-255.

Miller SL (1969). Clathrate hydrates of air in Antarctic ice. Science, Vol. 165, 489-490.

Morgan V, Wehrle E, Fleming A and 3 others (1994). Technical aspects of deep ice drilling on Law Dome, Memoirs of National Institute of Polar Research, Special Issue No. 49, Pages 78-86.

Morgan VI, Wookey CW, van Ommen T and 2 others (1997). Site information and initial results from deep ice drilling on Law Dome, Antarctica. J. Glaciol., 43(143), 3-10.

Morse DL, Waddington ED, Marshall H-P and 5 others (1999). Accumulation rate measurements at Taylor Dome, East Antarctica: techniques and strategies for mass balance measurements in polar environments. Geog. Ann., 81A, 683-694.

Motoyama H (2007). The second deep ice coring project at Dome Fuji, Antarctica. Scientific Drilling, 5, 41-43.

Mulvaney R, Alemany O and Possenti P (2007). The Berkner Island (Antarctica) ice-core drilling project. Ann. Glaciol., 47 (1), 115-124. 
NEEM community members (2013). Eemian interglacial reconstructed from a Greenland folded ice core, Nature, 493, 489-494, doi:10.1038/nature11789.

Oerter H, Graf W, Meyer H and Wilhelms F (2004). The EPICA ice core from Drønning Maud Land: first results from stable-isotope measurements. Ann. Glaciol., 39(1), 307-312. van Ommen TD, Morgan VI, Jacka TH and 2 others (1999). Near-surface temperatures in the Dome Summit South (Law Dome, East Antarctica) borehole. Ann. Glaciol., 29(1), 141-144.

Osterberg EC, Handley MJ, Sneed SB, Mayewski PA and Kreutz KJ (2006). Continuous ice core melter system with discrete sampling for major ion, trace element, and stable isotope analysis. Environ. Sci. Technol., 40, 3355-3361.

Parrenin F, Barnola J-M, Beer J and 24 others (2007). The EDC3 chronology for the EPICA Dome C ice core. Clim. Past, 3, 485-597.

Parrenin F, Petit J-R, Masson-Delmotte V and 10 others (2012). Volcanic synchronization between the EPICA Dome C and Vostok ice cores (Antarctica) 0-145 kyr BP. Climate of the Past, 8, 1031-1045.

Pauer F, Kipfstuhl J and Kuhs WF (1995). Raman spectroscopic study on the nitrogen/oxygen ratio in natural ice clathrates in the GRIP ice core. Geophys. Res. Lett., 22(8), 969-971.

Petit JR, Jouzel J, Raynaud D and 16 others (1999). Climate and atmospheric history of the past 420,000 years from the Vostok ice core, Antarctica. Nature 399: 429-436.

Petrovic JJ (2003). Review: mechanical properties of ice and snow. J. Materials Sci., 38, 1-6.

Pol K, Masson-Delmotte V, Johnsen S and 10 others (2010). New MIS 19 EPICA Dome C high resolution deuterium data: hints for a problematic preservation of climate variability at sub-millennial scale in the "oldest ice." Earth and Planetary Sci. Lett., 298, 95-103. 
Rasmussen SO, Abbott P, Blunier T and 21 others (2013). A first chronology for the NEEM ice core. Clim. Past Discuss., 9, 2967-3013.

Salamatin AN, Lipenkov Vya and Blinov KV (1994). Vostok (Antarctica) climate record time-scale deduced from the analysis of a borehole-temperature profile. Ann. Glaciol., 20, $207-214$

Schilt A, Baumgartner M, Schwander J and 8 others (2010). Atmospheric nitrous oxide during the last 140,000 years. Earth and Planetary Sci. Lett., 300, 33-43, doi:10.1016/j.eps1.2010.09.027.

Schwander J, Barnola JM, Andrié C and 4 others (1993). The age of the air in the firn and the ice at Summit, Greenland. J. Geophys. Res., 98(D2), 2831-2838.

Severi M, Becagli S, Castellano E and 11 others (2007). Syncronization of the EDML and EDC ice cores for the last 52 kyr by volcanic signature matching. Clim. Past., 3, 367-374.

Shoji H and Langway CC Jr (1982). Air hydrate inclusions in fresh ice core. Nature, 298, 548-550.

Shoji H and Langway CC Jr (1987). Microscopic observations of the air hydrate-bubble transformation process in glacier ice. Journal de Physique, 48(C1), 551-556.

Souney JM, Twickler MS, Hargreaves GM and 13 others (in press). Core handling and processing for the WAIS Divide ice-core project. Ann. Glaciol., 55(68).

Steig EJ, Ding Q, White JWC and 19 others (2013). Recent climate and ice-sheet change in West Antarctica compared to the past 2000 years. Nature Geoscience, 6, 372-375.

Steig EJ, Morse DL, Waddington ED and 5 others (2000). Wisconsinan and Holocene climate history from an ice core at Taylor Dome, western Ross Embayment, Antarctica. Geog. Ann., 82A, 213-235. 
Stenni B, Buiron D, Frezzotti M and 37 others (2010). Expression of the bipolar see-saw in Antarctic climate records during the last deglaciation. Nature Geoscience, Vol. 4, No. 1, 4649, doi: 10.1038/NGEO1026.

TALDICE, 2006-2007 Field season, http://www.taldice.org/site/0607/index.php, accessed 13 November, 2013.

TALDICE, Talos Dome Site Information, http://www.taldice.org/project/site/index.php, accessed 13 November 2013.

The Greenland Summit Ice Cores CD-ROM (1997). Available from the National Snow and Ice Data Center, University of Colorado at Boulder, and the World Data Center-A for Paleoclimatology, National Geophysical Data Center, Boulder, Colorado.

Timmerman R, LeBrocq AM, Deen TJ and 17 others (2011). A consistent dataset of Antarctic ice sheet topography, cavity geometry, and global bathymetry. Earth System Science Data, 2(2), 261-273, doi:10.5194/essd-2-261-2010.

Tison J-L (1994). Diamond wire-saw cutting technique for investigating textures and fabrics of debris-laden and brittle ice. J. Glaciol., 40(135), 410-414.

Uchida T, Duval P, Lipenkov V and 3 others (1994). Brittle zone and air-hydrate formation in polar ice sheets. Memoirs of the National Institute of Polar Research, Special Issue No. 49. Ueda HT and Garfield DE (1968). Drilling through the Greenland Ice Sheet. U.S. Army Cold Region Research and Engineering Laboratory (CRREL) Spec. Rep. 126.

Ueda HT and Garfield DE (1969). Drilling through the Antarctic Ice Sheet. U.S. Army Cold Region Research and Engineering Laboratory (CRREL) Tech. Rep. 231.

Ueda HT (2002). Some thoughts on deep core drilling systems design. Mem. National Institute of Polar Res., Special Issue No. 56, 126-135. 
Ueltzhöffer KJ, Bendel V, Freitag J and 4 others (2010). Distribution of air bubbles in the EDML and EDC (Antarctica) ice cores, using a new method of automatic image analysis. $J$. Glaciol., 56(196), 339-348.

Vasiliev N, Talalay P, and Vostok Deep Ice Core Drilling Parties (2011). Twenty years of drilling the deepest hole in ice. Scientific Drilling, 11, 41-45, doi:10.2204/iodp.sd.11.05.2011.

Vinther BM, Clausen HB, Johnsen SJ and 10 others (2006). A synchronized dating of three Greenland ice cores throughout the Holocene. J. Geophys. Res., 111(D13), D13102.

WAIS Divide Project Members (2013). Onset of deglacial warming in West Antarctica driven by local orbital forcing, Nature, 500, 440-444,doi: 10.1038/nature12376.

Warming E, Svensson A, Vallelonga P and Bigler M (2013). A technique for continuous detection of drill liquid in ice cores. J. Glaciol., 59(215), 503-506.

Watanabe O, Kamiyama K, Motoyama H and 3 others (1999). The paleoclimate record in the ice core at Dome Fuji station, East Antarctica. Ann. Glaciol., 29(1), 176. 


\section{Appendix B: RICE REE data}

RICE deep core $8 \mathrm{~m}$ to $40 \mathrm{~m}$ samples, from the 2013 core processing campaign. Recalibrated using MATLAB 'robustfit' (bisquare) method; analytical blank corrected. All concentrations in $\mathrm{pg} \mathrm{g}^{-1}$.

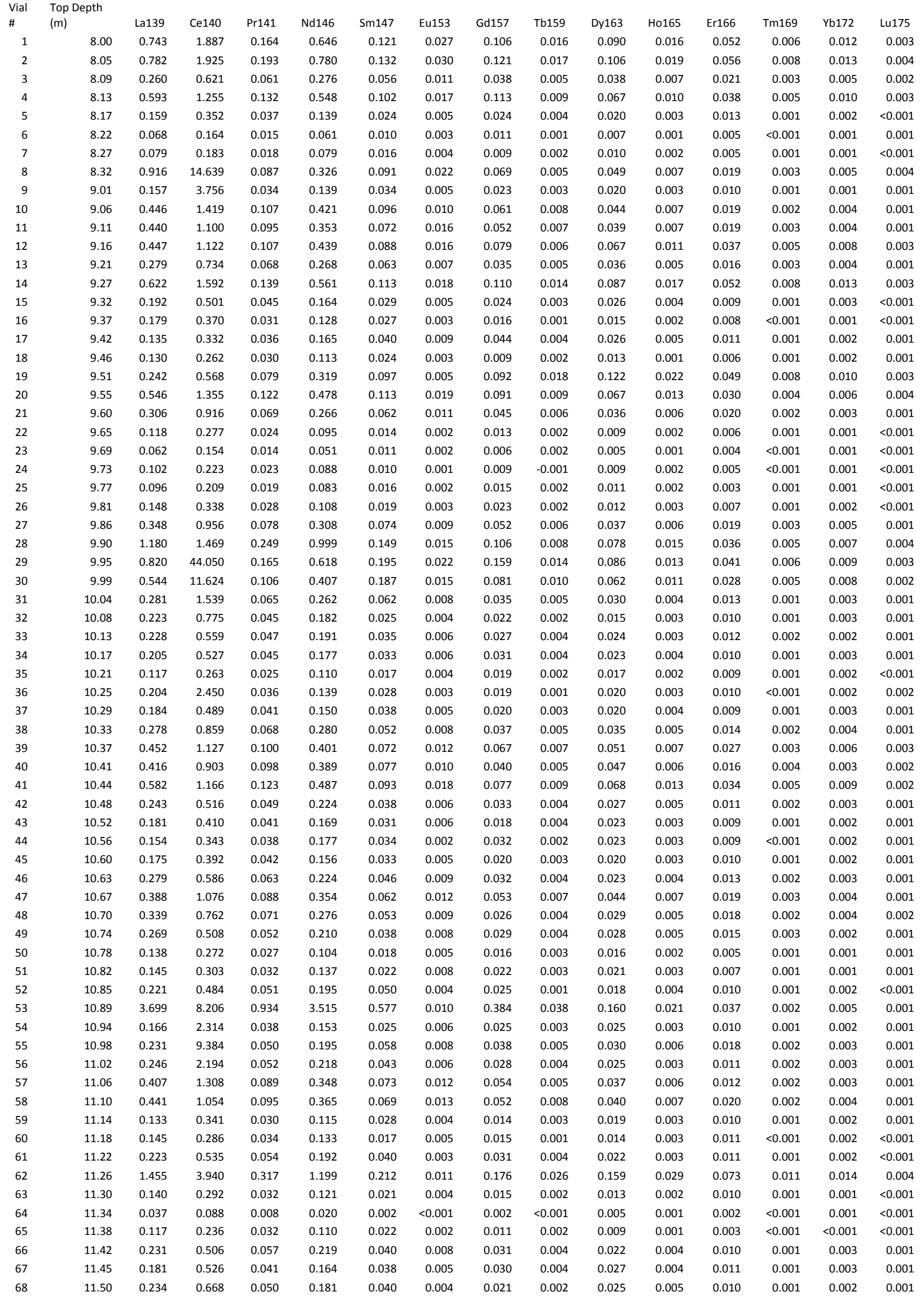




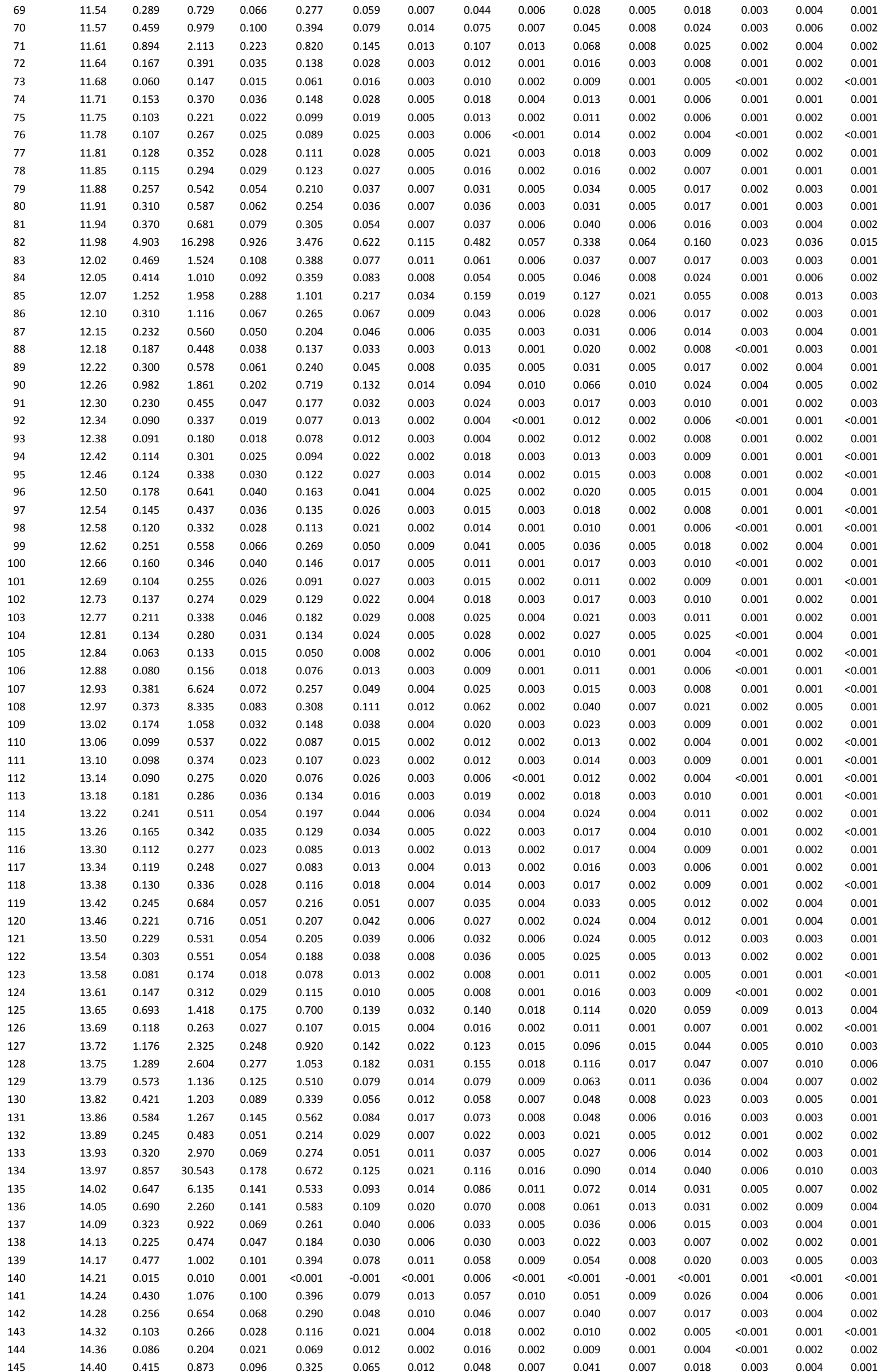




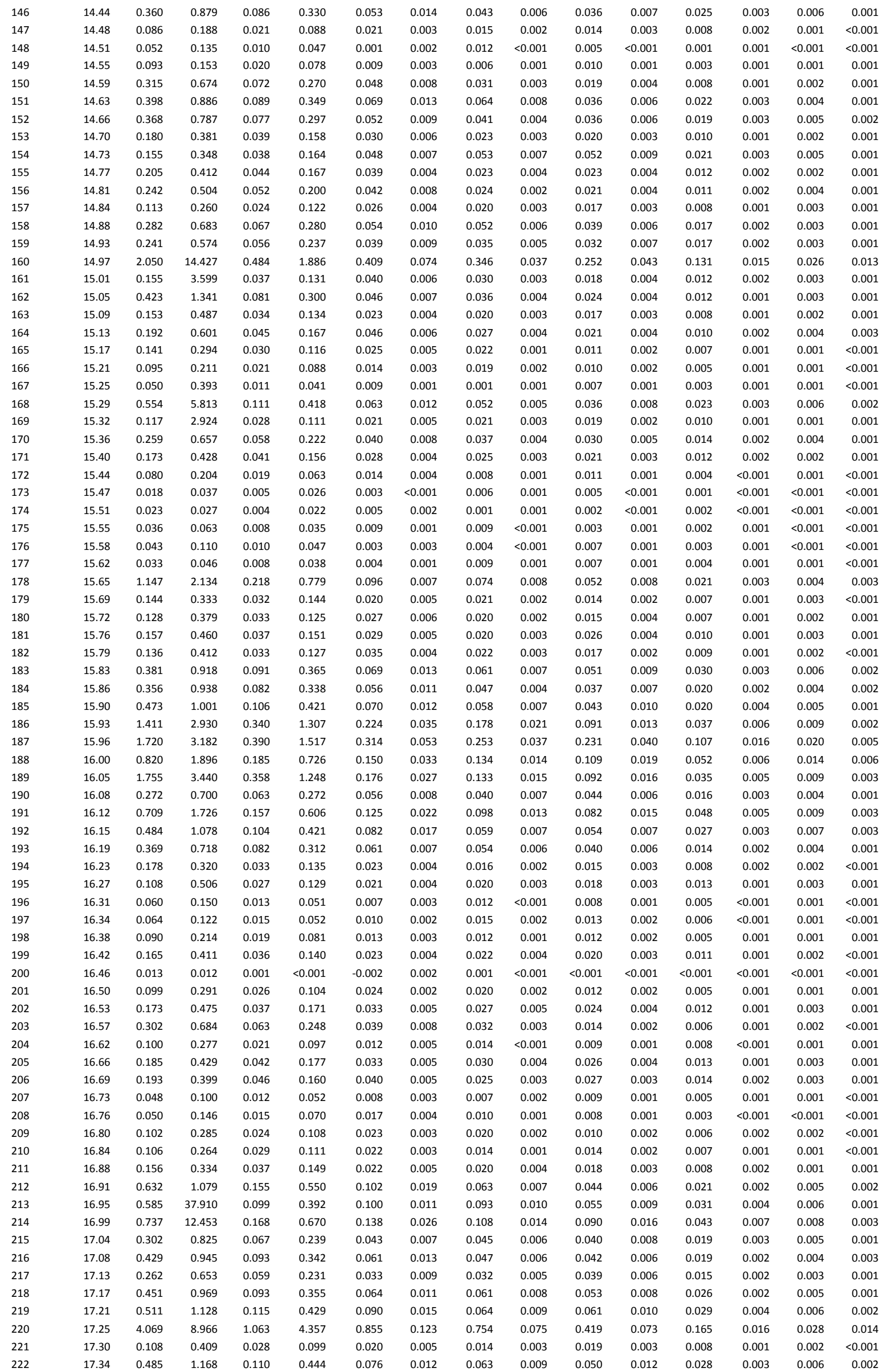




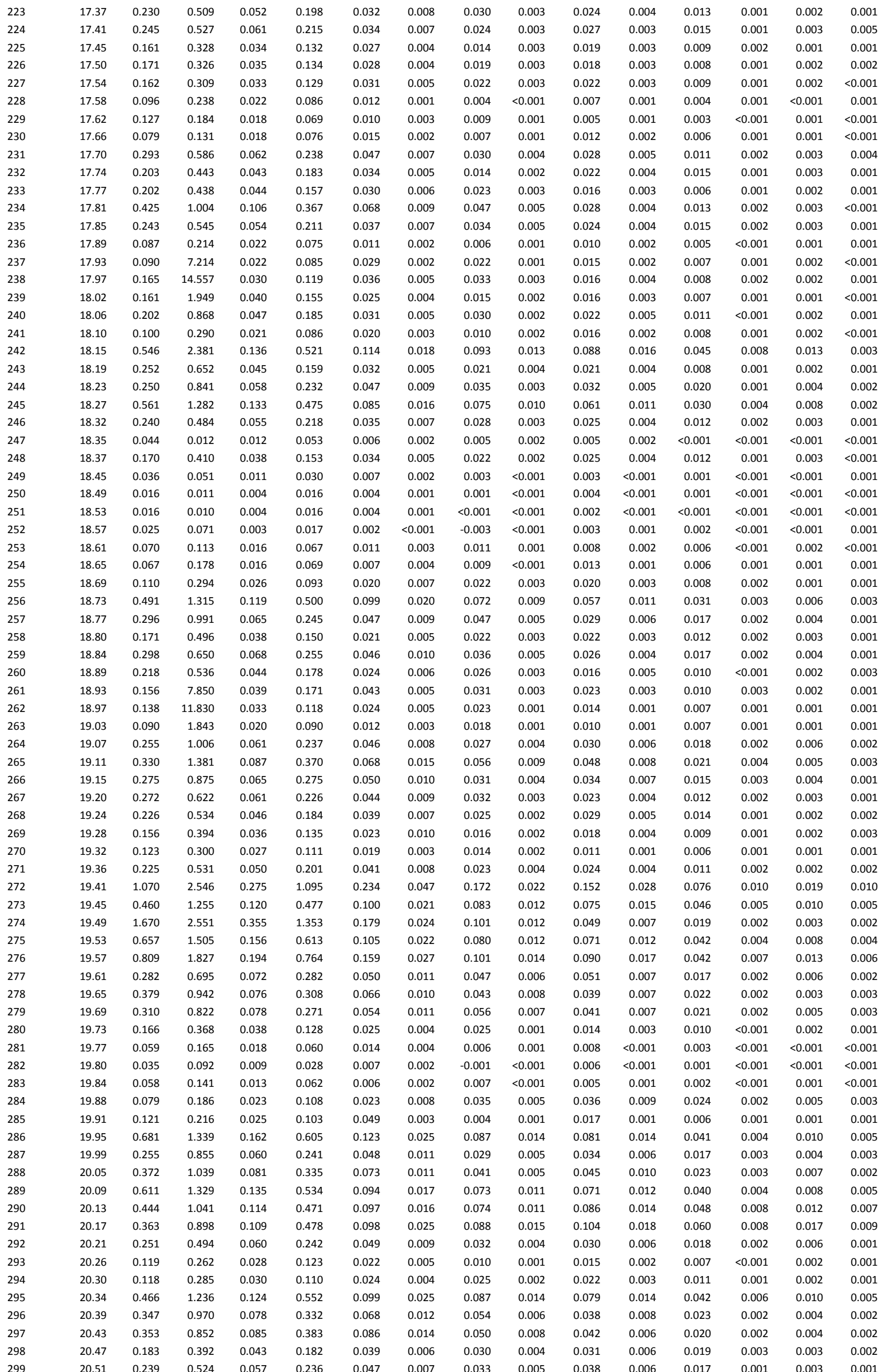




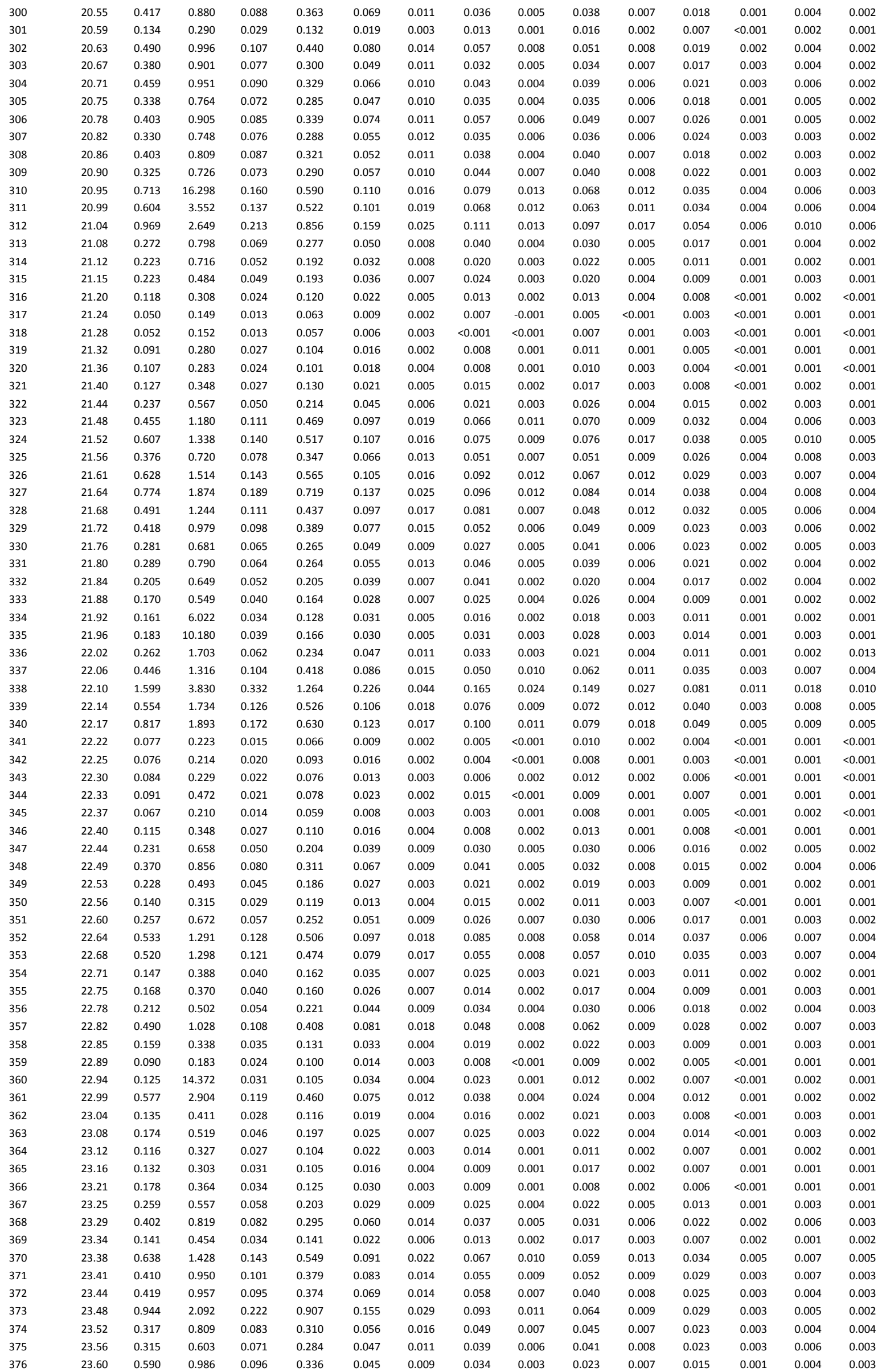




\begin{tabular}{|c|c|c|c|c|c|c|c|c|c|c|c|c|c|c|c|}
\hline 377 & 23.64 & 0.185 & 0.419 & 0.043 & 0.173 & 0.028 & 0.007 & 0.024 & 0.003 & 0.028 & 0.004 & 0.016 & 0.001 & 0.006 & 0.002 \\
\hline 378 & 23.68 & 0.721 & 1.763 & 0.196 & 0.886 & 0.178 & 0.032 & 0.154 & 0.022 & 0.147 & 0.026 & 0.083 & 0.009 & 0.015 & 0.008 \\
\hline 380 & 23.77 & 0.511 & 1.278 & 0.109 & 0.374 & 0.067 & 0.008 & 0.041 & 0.005 & 0.033 & 0.008 & 0.023 & 0.001 & 0.004 & 0.002 \\
\hline 382 & 23.84 & 0.534 & 1.116 & 0.123 & 0.496 & 0.093 & 0.014 & 0.059 & 0.009 & 0.058 & 0.010 & 0.028 & 0.004 & 0.006 & 0.003 \\
\hline 383 & 23.87 & 0.127 & 0.319 & 0.036 & 0.146 & 0.026 & 0.005 & 0.014 & 0.001 & 0.019 & 0.003 & 0.007 & 0.001 & 0.002 & $<0.001$ \\
\hline 384 & 23.91 & 0.157 & 0.534 & 0.029 & 0.109 & 0.018 & 0.003 & 0.008 & 0.002 & 0.007 & 0.002 & 0.005 & $<0.001$ & 0.001 & 0.127 \\
\hline 387 & 24.06 & 0.112 & 0.363 & 0.026 & 0.112 & 0.014 & 0.004 & 0.015 & 0.002 & 0.016 & 0.002 & 0.010 & 0.001 & 0.001 & 0.001 \\
\hline 388 & 24.10 & 0.257 & 0.529 & 0.054 & 0.207 & 0.040 & 0.006 & 0.028 & 0.003 & 0.022 & 0.006 & 0.014 & 0.002 & 0.004 & 0.003 \\
\hline 389 & 24.14 & 0.133 & 0.360 & 0.030 & 0.125 & 0.023 & 0.005 & 0.013 & 0.002 & 0.016 & 0.002 & 0.007 & 0.001 & 0.001 & 0.001 \\
\hline 390 & 24.18 & 0.658 & 1.461 & 0.156 & 0.653 & 0.104 & 0.015 & 0.067 & 0.012 & 0.052 & 0.008 & 0.019 & 0.002 & 0.004 & 0.002 \\
\hline 391 & 24.21 & 0.265 & 0.631 & 0.060 & 0.229 & 0.046 & 0.007 & 0.028 & 0.003 & 0.026 & 0.005 & 0.015 & 0.001 & 0.004 & 0.002 \\
\hline 392 & 24.25 & 0.117 & 2.699 & 0.026 & 0.109 & 0.023 & 0.003 & 0.015 & 0.002 & 0.012 & 0.004 & 0.009 & $<0.001$ & 0.002 & 0.001 \\
\hline 397 & 24.45 & 0.256 & 0.554 & 0.061 & 0.256 & 0.052 & 0.009 & 0.036 & 0.006 & 0.032 & 0.006 & 0.012 & 0.001 & 0.003 & 0.002 \\
\hline 398 & 24.49 & 0.253 & 0.592 & 0.066 & 0.260 & 0.041 & 0.008 & 0.033 & 0.005 & 0.029 & 0.005 & 0.015 & 0.001 & 0.002 & 0.002 \\
\hline 399 & 24.53 & 0.119 & 0.273 & 0.029 & 0.117 & 0.015 & 0.004 & 0.011 & 0.002 & 0.014 & 0.003 & 0.009 & $<0.001$ & 0.002 & 0.001 \\
\hline 400 & 24.56 & 0.141 & 0.311 & 0.030 & 0.128 & 0.036 & 0.004 & 0.010 & 0.002 & 0.010 & 0.003 & 0.007 & $<0.001$ & 0.002 & 0.001 \\
\hline 401 & 24.60 & 0.118 & 0.352 & 0.028 & 0.116 & 0.028 & 0.003 & 0.008 & 0.002 & 0.017 & 0.001 & 0.010 & 0.001 & 0.002 & 0.001 \\
\hline 402 & 24.64 & 0.963 & 1.240 & 0.241 & 0.949 & 0.168 & 0.024 & 0.095 & 0.011 & 0.071 & 0.011 & 0.028 & 0.003 & 0.005 & 0.003 \\
\hline 403 & 24.67 & 0.464 & 1.126 & 0.115 & 0.457 & 0.088 & 0.017 & 0.061 & 0.007 & 0.049 & 0.010 & 0.033 & 0.002 & 0.006 & 0.003 \\
\hline 404 & 24.71 & 0.329 & 0.596 & 0.070 & 0.259 & 0.043 & 0.008 & 0.032 & 0.004 & 0.027 & 0.006 & 0.017 & 0.002 & 0.004 & 0.004 \\
\hline 405 & 24.74 & 0.264 & 0.529 & 0.051 & 0.184 & 0.034 & 0.004 & 0.017 & 0.001 & 0.017 & 0.002 & 0.010 & 0.001 & 0.001 & $<0.001$ \\
\hline 406 & 24.78 & 0.053 & 0.167 & 0.012 & 0.043 & 0.020 & 0.002 & $<0.001$ & 0.001 & 0.006 & 0.001 & 0.003 & 0.001 & 0.001 & $<0.001$ \\
\hline 407 & 24.81 & 0.114 & 0.249 & 0.024 & 0.115 & 0.020 & 0.006 & 0.014 & 0.003 & 0.020 & 0.001 & 0.009 & 0.001 & 0.002 & 0.001 \\
\hline 416 & 25.20 & 0.132 & 0.317 & 0.030 & 0.108 & 0.023 & 0.004 & 0.016 & 0.002 & 0.014 & 0.003 & 0.012 & 0.001 & 0.002 & 0.002 \\
\hline 417 & 25.23 & 0.180 & 0.364 & 0.044 & 0.174 & 0.030 & 0.006 & 0.030 & 0.003 & 0.024 & 0.004 & 0.013 & 0.001 & 0.003 & 0.002 \\
\hline 418 & 25.27 & 0.090 & 0.183 & 0.017 & 0.084 & 0.011 & 0.003 & 0.011 & 0.002 & 0.011 & 0.002 & 0.006 & 0.001 & 0.001 & $<0.001$ \\
\hline 419 & 25.31 & 0.030 & 0.078 & 0.007 & 0.021 & 0.009 & 0.002 & 0.001 & $<0.001$ & 0.003 & $<0.001$ & 0.002 & 0.001 & 0.001 & $<0.001$ \\
\hline 420 & 25.35 & 0.078 & 0.160 & 0.019 & 0.079 & 0.018 & 0.004 & 0.007 & 0.001 & 0.009 & 0.001 & 0.006 & $<0.001$ & 0.001 & 0.001 \\
\hline 421 & 25.39 & 0.140 & 0.339 & 0.037 & 0.152 & 0.030 & 0.005 & 0.018 & 0.003 & 0.019 & 0.002 & 0.008 & 0.001 & 0.003 & 0.002 \\
\hline 422 & 25.43 & 0.471 & 1.072 & 0.106 & 0.450 & 0.067 & 0.011 & 0.049 & 0.005 & 0.041 & 0.009 & 0.016 & 0.002 & 0.002 & 0.002 \\
\hline 423 & 25.48 & 0.193 & 0.409 & 0.036 & 0.121 & 0.027 & 0.003 & 0.013 & 0.002 & 0.020 & 0.003 & 0.007 & 0.002 & 0.002 & 0.002 \\
\hline 424 & 25.52 & 0.491 & 1.368 & 0.103 & 0.403 & 0.071 & 0.015 & 0.055 & 0.006 & 0.050 & 0.009 & 0.025 & 0.003 & 0.004 & 0.004 \\
\hline 425 & 25.55 & 0.131 & 0.355 & 0.030 & 0.132 & 0.019 & 0.005 & 0.015 & 0.001 & 0.014 & 0.002 & 0.007 & $<0.001$ & 0.002 & 0.001 \\
\hline 426 & 25.58 & 0.340 & 0.753 & 0.074 & 0.273 & 0.057 & 0.009 & 0.034 & 0.003 & 0.028 & 0.005 & 0.013 & 0.002 & 0.004 & 0.002 \\
\hline 427 & 25.62 & 0.330 & 0.867 & 0.076 & 0.300 & 0.056 & 0.009 & 0.045 & 0.006 & 0.032 & 0.005 & 0.017 & 0.002 & 0.005 & 0.002 \\
\hline 428 & 25.66 & 0.284 & 4.758 & 0.058 & 0.258 & 0.046 & 0.010 & 0.036 & 0.003 & 0.028 & 0.006 & 0.011 & 0.001 & 0.003 & 0.002 \\
\hline 429 & 25.70 & 0.795 & 1.796 & 0.187 & 0.800 & 0.158 & 0.023 & 0.116 & 0.018 & 0.094 & 0.018 & 0.041 & 0.007 & 0.010 & 0.005 \\
\hline 430 & 25.74 & 0.226 & 0.486 & 0.056 & 0.217 & 0.045 & 0.008 & 0.030 & 0.003 & 0.021 & 0.004 & 0.013 & 0.001 & 0.002 & 0.089 \\
\hline 431 & 25.77 & 0.399 & 0.956 & 0.098 & 0.432 & 0.095 & 0.012 & 0.060 & 0.009 & 0.049 & 0.008 & 0.020 & 0.003 & 0.004 & 0.003 \\
\hline 432 & 25.80 & 0.143 & 0.281 & 0.033 & 0.128 & 0.020 & 0.003 & 0.014 & 0.001 & 0.009 & 0.002 & 0.008 & 0.001 & 0.002 & 0.001 \\
\hline 433 & 25.83 & 0.047 & 0.118 & 0.010 & 0.047 & 0.007 & 0.002 & 0.005 & 0.001 & 0.006 & 0.001 & 0.002 & 0.001 & $<0.001$ & $<0.001$ \\
\hline 434 & 25.87 & 0.196 & 0.441 & 0.044 & 0.160 & 0.025 & 0.007 & 0.019 & 0.002 & 0.022 & 0.002 & 0.012 & 0.002 & 0.003 & 0.001 \\
\hline 435 & 25.91 & 0.190 & 0.476 & 0.042 & 0.174 & 0.031 & 0.009 & 0.023 & 0.004 & 0.030 & 0.005 & 0.014 & 0.001 & 0.003 & 0.001 \\
\hline 436 & 25.95 & 0.504 & 1.835 & 0.114 & 0.403 & 0.068 & 0.014 & 0.058 & 0.006 & 0.051 & 0.010 & 0.023 & 0.002 & 0.007 & 0.004 \\
\hline 437 & 26.00 & 0.619 & 25.324 & 0.146 & 0.637 & 0.132 & 0.021 & 0.111 & 0.013 & 0.061 & 0.012 & 0.032 & 0.003 & 0.006 & 0.003 \\
\hline 438 & 26.05 & 0.252 & 0.820 & 0.062 & 0.263 & 0.062 & 0.011 & 0.037 & 0.005 & 0.034 & 0.006 & 0.015 & 0.003 & 0.003 & 0.001 \\
\hline 439 & 26.08 & 0.182 & 0.816 & 0.042 & 0.178 & 0.031 & 0.008 & 0.025 & 0.003 & 0.029 & 0.005 & 0.012 & 0.001 & 0.003 & 0.001 \\
\hline
\end{tabular}




\begin{tabular}{|c|c|c|c|c|c|c|c|c|c|c|c|c|c|c|c|}
\hline 454 & 26.65 & 0.419 & 0.796 & 0.094 & 0.362 & 0.060 & 0.007 & 0.039 & 0.005 & 0.026 & 0.006 & 0.013 & 0.002 & 0.004 & 0.002 \\
\hline 455 & 26.69 & 0.202 & 0.542 & 0.043 & 0.166 & 0.026 & 0.005 & 0.021 & 0.003 & 0.026 & 0.004 & 0.013 & 0.001 & 0.003 & 0.001 \\
\hline 457 & 26.77 & 0.280 & 1.004 & 0.060 & 0.278 & 0.053 & 0.010 & 0.041 & 0.007 & 0.034 & 0.007 & 0.015 & 0.002 & 0.003 & 0.003 \\
\hline 459 & 26.84 & 0.456 & 1.099 & 0.110 & 0.432 & 0.061 & 0.012 & 0.054 & 0.009 & 0.047 & 0.007 & 0.023 & 0.002 & 0.004 & 0.002 \\
\hline 460 & 26.88 & 0.179 & 0.465 & 0.041 & 0.152 & 0.028 & 0.006 & 0.019 & 0.002 & 0.014 & 0.004 & 0.015 & 0.001 & 0.003 & 0.001 \\
\hline 461 & 26.91 & 0.212 & 0.500 & 0.047 & 0.185 & 0.026 & 0.005 & 0.027 & 0.004 & 0.019 & 0.003 & 0.011 & 0.001 & 0.002 & $<0.001$ \\
\hline 464 & 27.04 & 0.279 & 1.353 & 0.057 & 0.225 & 0.050 & 0.008 & 0.024 & 0.003 & 0.020 & 0.004 & 0.013 & 0.001 & 0.003 & 0.001 \\
\hline 465 & 27.08 & 0.174 & 0.578 & 0.038 & 0.152 & 0.027 & 0.005 & 0.030 & 0.002 & 0.026 & 0.004 & 0.011 & $<0.001$ & 0.003 & 0.002 \\
\hline 466 & 27.13 & 0.241 & 0.732 & 0.052 & 0.222 & 0.041 & 0.009 & 0.037 & 0.003 & 0.022 & 0.004 & 0.013 & 0.001 & 0.004 & 0.001 \\
\hline 467 & 27.17 & 0.187 & 0.569 & 0.043 & 0.175 & 0.044 & 0.007 & 0.027 & 0.004 & 0.026 & 0.005 & 0.016 & 0.001 & 0.002 & 0.001 \\
\hline 468 & 27.21 & 0.284 & 0.710 & 0.059 & 0.262 & 0.048 & 0.007 & 0.031 & 0.003 & 0.031 & 0.006 & 0.017 & 0.001 & 0.004 & 0.002 \\
\hline 469 & 27.25 & 0.243 & 0.645 & 0.063 & 0.244 & 0.039 & 0.009 & 0.027 & 0.002 & 0.027 & 0.004 & 0.011 & 0.001 & 0.003 & 0.001 \\
\hline 474 & 27.43 & 0.251 & 0.760 & 0.063 & 0.229 & 0.046 & 0.006 & 0.020 & 0.003 & 0.024 & 0.003 & 0.010 & 0.001 & 0.002 & 0.002 \\
\hline 475 & 27.47 & 0.446 & 1.063 & 0.099 & 0.352 & 0.076 & 0.014 & 0.053 & 0.007 & 0.043 & 0.009 & 0.022 & 0.003 & 0.005 & 0.002 \\
\hline 476 & 27.50 & 0.592 & 1.311 & 0.125 & 0.434 & 0.069 & 0.015 & 0.054 & 0.005 & 0.039 & 0.010 & 0.025 & 0.003 & 0.007 & 0.004 \\
\hline 477 & 27.54 & 0.325 & 0.874 & 0.084 & 0.353 & 0.068 & 0.012 & 0.054 & 0.010 & 0.043 & 0.010 & 0.024 & 0.004 & 0.006 & 0.004 \\
\hline 478 & 27.57 & 0.283 & 0.738 & 0.073 & 0.324 & 0.066 & 0.014 & 0.047 & 0.007 & 0.045 & 0.006 & 0.020 & 0.002 & 0.003 & 0.002 \\
\hline 479 & 27.61 & 0.136 & 0.474 & 0.036 & 0.135 & 0.029 & 0.005 & 0.014 & 0.002 & 0.015 & 0.002 & 0.007 & 0.001 & 0.002 & 0.001 \\
\hline 480 & 27.65 & 0.130 & 0.355 & 0.034 & 0.118 & 0.022 & 0.004 & 0.018 & 0.003 & 0.015 & 0.004 & 0.011 & 0.001 & 0.002 & 0.001 \\
\hline 481 & 27.68 & 0.431 & 1.076 & 0.120 & 0.515 & 0.114 & 0.017 & 0.062 & 0.007 & 0.042 & 0.005 & 0.016 & 0.002 & 0.003 & 0.001 \\
\hline 482 & 27.71 & 0.388 & 0.943 & 0.087 & 0.342 & 0.063 & 0.009 & 0.048 & 0.007 & 0.041 & 0.006 & 0.027 & 0.003 & 0.004 & 0.003 \\
\hline 483 & 27.74 & 0.351 & 0.816 & 0.077 & 0.313 & 0.067 & 0.010 & 0.047 & 0.007 & 0.041 & 0.006 & 0.015 & 0.004 & 0.004 & 0.001 \\
\hline 484 & 27.77 & 0.145 & 0.315 & 0.028 & 0.127 & 0.028 & 0.005 & 0.012 & 0.001 & 0.013 & 0.002 & 0.008 & 0.001 & 0.001 & 0.001 \\
\hline 493 & 28.10 & 0.152 & 0.600 & 0.039 & 0.166 & 0.038 & 0.005 & 0.021 & 0.004 & 0.019 & 0.005 & 0.011 & 0.001 & 0.002 & 0.001 \\
\hline 494 & 28.14 & 0.097 & 0.318 & 0.021 & 0.083 & 0.014 & 0.003 & 0.013 & 0.001 & 0.013 & 0.003 & 0.009 & 0.001 & 0.001 & 0.001 \\
\hline 495 & 28.17 & 0.205 & 0.461 & 0.042 & 0.156 & 0.021 & 0.004 & 0.013 & 0.002 & 0.012 & 0.002 & 0.008 & 0.001 & 0.002 & 0.001 \\
\hline 496 & 28.21 & 0.207 & 0.474 & 0.045 & 0.158 & 0.027 & 0.004 & 0.016 & 0.003 & 0.016 & 0.004 & 0.013 & 0.001 & 0.002 & 0.002 \\
\hline 497 & 28.25 & 0.298 & 0.710 & 0.065 & 0.246 & 0.048 & 0.008 & 0.034 & 0.004 & 0.031 & 0.006 & 0.011 & 0.001 & 0.003 & 0.002 \\
\hline 498 & 28.29 & 2.196 & 4.335 & 0.460 & 1.809 & 0.383 & 0.056 & 0.241 & 0.036 & 0.232 & 0.039 & 0.110 & 0.013 & 0.027 & 0.012 \\
\hline 499 & 28.33 & 0.953 & 1.970 & 0.212 & 0.844 & 0.169 & 0.033 & 0.121 & 0.017 & 0.118 & 0.017 & 0.053 & 0.008 & 0.011 & 0.007 \\
\hline 500 & 28.37 & 0.348 & 0.813 & 0.079 & 0.292 & 0.049 & 0.013 & 0.038 & 0.004 & 0.034 & 0.006 & 0.021 & 0.002 & 0.004 & 0.002 \\
\hline 501 & 28.41 & 0.424 & 1.073 & 0.104 & 0.394 & 0.078 & 0.014 & 0.052 & 0.008 & 0.045 & 0.008 & 0.027 & 0.002 & 0.006 & 0.003 \\
\hline 502 & 28.45 & 0.112 & 0.259 & 0.026 & 0.086 & 0.022 & 0.004 & 0.016 & 0.002 & 0.012 & 0.002 & 0.008 & 0.001 & 0.001 & 0.001 \\
\hline 503 & 28.49 & 0.360 & 0.790 & 0.073 & 0.331 & 0.059 & 0.015 & 0.047 & 0.006 & 0.042 & 0.007 & 0.023 & 0.002 & 0.006 & 0.002 \\
\hline 504 & 28.53 & 0.969 & 1.941 & 0.205 & 0.786 & 0.130 & 0.030 & 0.109 & 0.011 & 0.080 & 0.018 & 0.056 & 0.006 & 0.013 & 0.008 \\
\hline 505 & 28.57 & 0.434 & 1.128 & 0.108 & 0.440 & 0.073 & 0.010 & 0.048 & 0.006 & 0.027 & 0.006 & 0.010 & 0.001 & 0.002 & 0.001 \\
\hline 506 & 28.60 & 0.116 & 0.301 & 0.027 & 0.119 & 0.013 & 0.006 & 0.009 & 0.001 & 0.015 & 0.002 & 0.008 & 0.002 & 0.002 & 0.001 \\
\hline 507 & 28.64 & 0.204 & 0.788 & 0.055 & 0.223 & 0.045 & 0.008 & 0.029 & 0.006 & 0.030 & 0.005 & 0.015 & 0.001 & 0.003 & 0.002 \\
\hline 508 & 28.68 & 0.740 & 1.697 & 0.211 & 0.856 & 0.164 & 0.033 & 0.134 & 0.013 & 0.108 & 0.025 & 0.062 & 0.006 & 0.015 & 0.006 \\
\hline 509 & 28.72 & 0.137 & 0.364 & 0.035 & 0.130 & 0.019 & 0.004 & 0.021 & 0.002 & 0.019 & 0.004 & 0.007 & $<0.001$ & 0.001 & $<0.001$ \\
\hline 510 & 28.76 & 2.223 & 5.197 & 0.515 & 1.620 & 0.264 & 0.019 & 0.170 & 0.022 & 0.110 & 0.015 & 0.034 & 0.004 & 0.006 & 0.003 \\
\hline 511 & 28.80 & 0.359 & 0.803 & 0.076 & 0.284 & 0.062 & 0.009 & 0.054 & 0.006 & 0.033 & 0.005 & 0.018 & 0.002 & 0.004 & 0.002 \\
\hline 512 & 28.84 & 0.235 & 0.559 & 0.055 & 0.200 & 0.042 & 0.008 & 0.034 & 0.002 & 0.021 & 0.005 & 0.015 & 0.001 & 0.004 & 0.002 \\
\hline 513 & 28.88 & 0.450 & 1.006 & 0.107 & 0.390 & 0.070 & 0.011 & 0.047 & 0.006 & 0.046 & 0.007 & 0.021 & 0.003 & 0.005 & 0.003 \\
\hline 514 & 28.91 & 0.456 & 0.406 & 0.109 & 0.417 & 0.073 & 0.008 & 0.046 & 0.006 & 0.042 & 0.006 & 0.017 & 0.002 & 0.003 & 0.001 \\
\hline 515 & 28.95 & 0.233 & 2.358 & 0.059 & 0.228 & 0.065 & 0.012 & 0.054 & 0.008 & 0.055 & 0.009 & 0.022 & 0.003 & 0.004 & 0.002 \\
\hline 516 & 29.00 & 0.377 & 1.186 & 0.076 & 0.303 & 0.070 & 0.013 & 0.039 & 0.004 & 0.035 & 0.008 & 0.019 & 0.003 & 0.005 & 0.002 \\
\hline
\end{tabular}




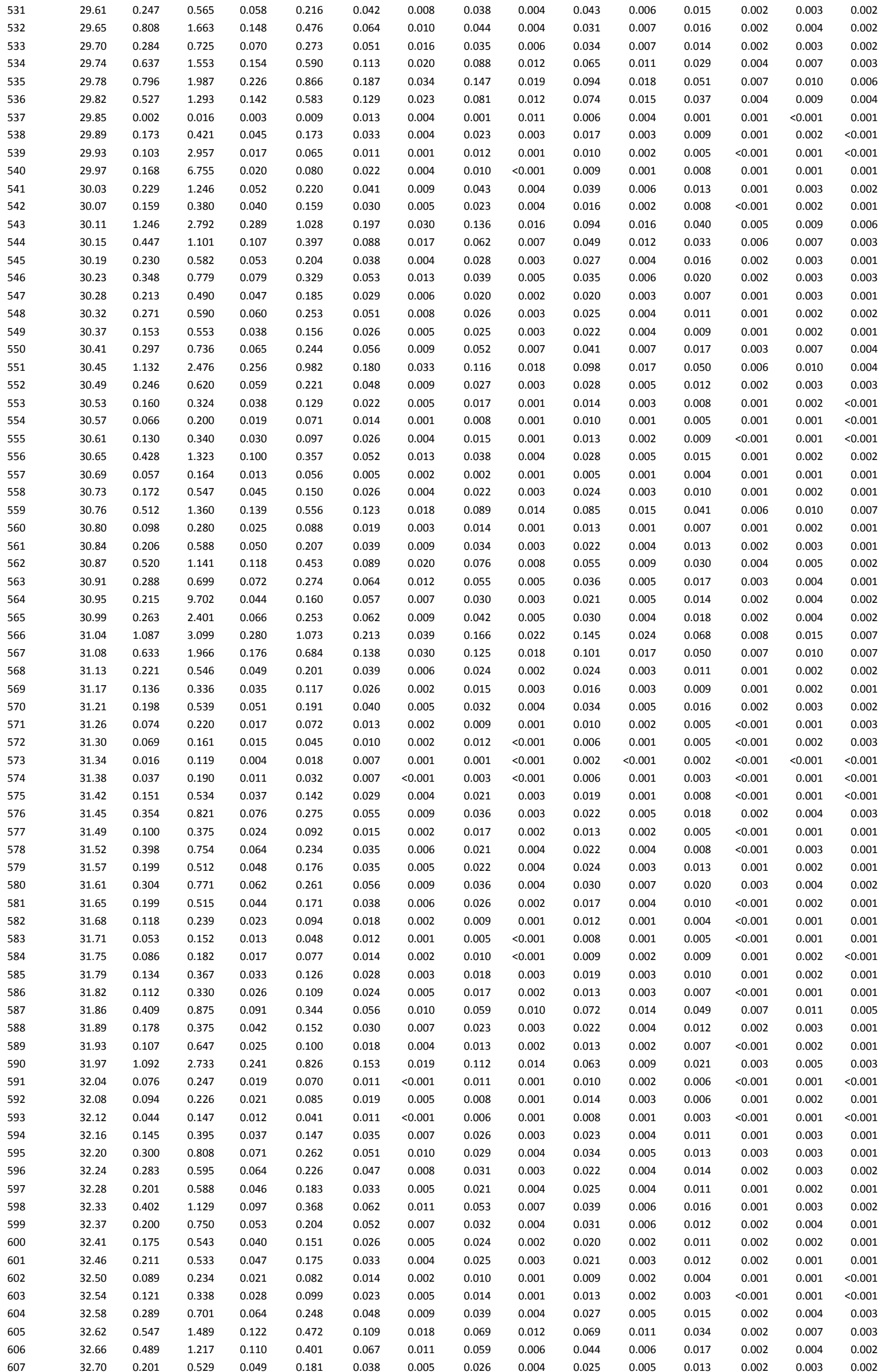




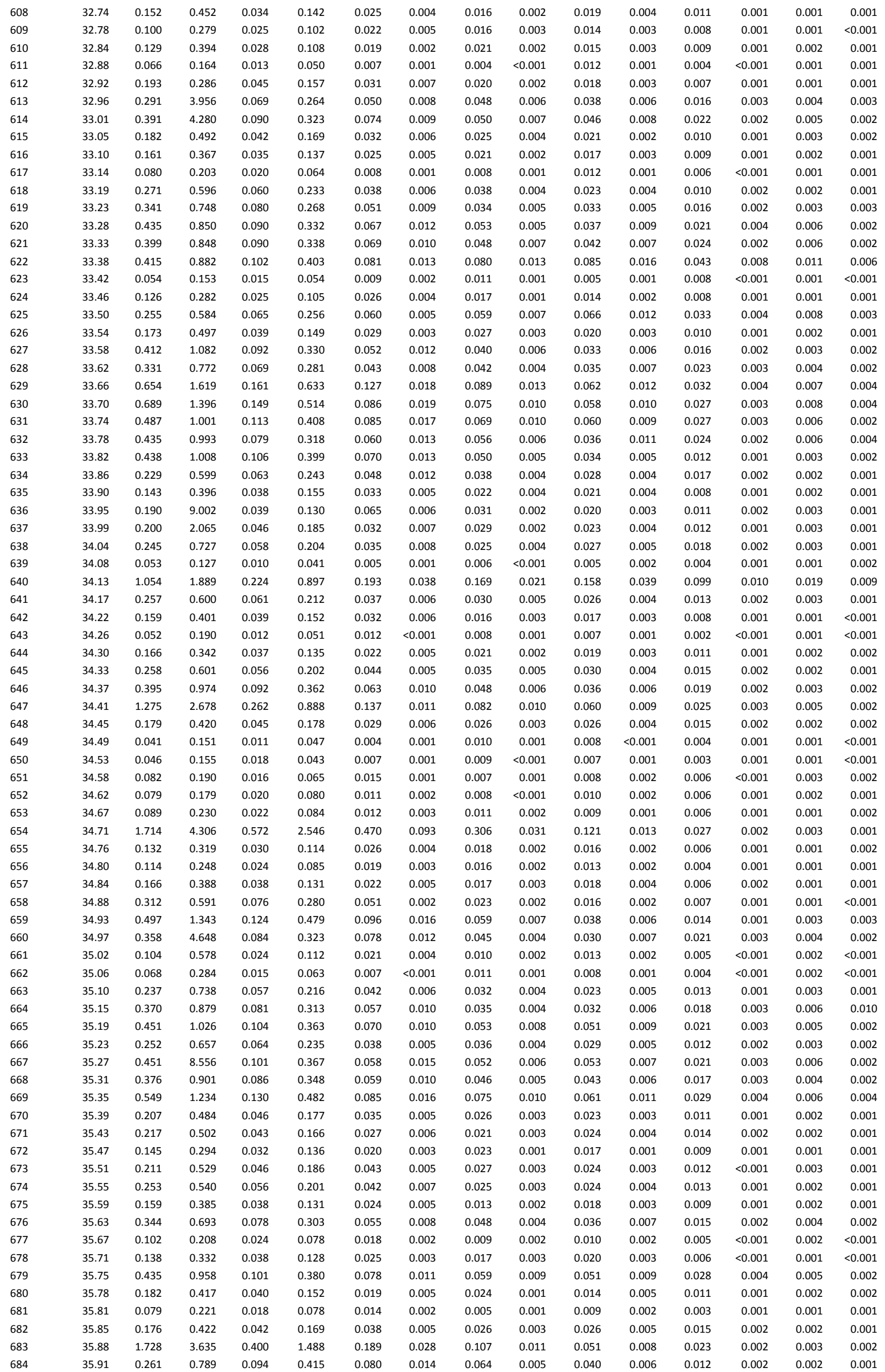




\begin{tabular}{|c|c|c|c|c|c|c|c|c|c|c|c|c|c|c|c|}
\hline 685 & 35.95 & 0.123 & 0.285 & 0.031 & 0.119 & 0.024 & 0.003 & 0.011 & 0.002 & 0.016 & 0.002 & 0.007 & $<0.001$ & 0.001 & 0.001 \\
\hline 686 & 35.98 & 0.415 & 0.997 & 0.093 & 0.328 & 0.055 & 0.013 & 0.037 & 0.006 & 0.041 & 0.007 & 0.014 & 0.002 & 0.005 & 0.001 \\
\hline 688 & 36.08 & 0.257 & 0.597 & 0.061 & 0.239 & 0.048 & 0.009 & 0.027 & 0.004 & 0.032 & 0.006 & 0.013 & 0.004 & 0.003 & 0.002 \\
\hline 690 & 36.16 & 0.201 & 0.498 & 0.041 & 0.151 & 0.026 & 0.002 & 0.020 & 0.003 & 0.017 & 0.004 & 0.009 & $<0.001$ & 0.002 & 0.002 \\
\hline 691 & 36.21 & 0.272 & 0.672 & 0.055 & 0.227 & 0.041 & 0.005 & 0.032 & 0.005 & 0.028 & 0.007 & 0.016 & 0.002 & 0.004 & 0.002 \\
\hline 692 & 36.25 & 0.245 & 0.562 & 0.053 & 0.193 & 0.035 & 0.007 & 0.030 & 0.003 & 0.019 & 0.004 & 0.012 & 0.002 & 0.003 & 0.001 \\
\hline 695 & 36.37 & 0.206 & 0.491 & 0.048 & 0.175 & 0.027 & 0.004 & 0.021 & 0.004 & 0.020 & 0.002 & 0.008 & 0.001 & 0.002 & 0.001 \\
\hline 696 & 36.41 & 0.157 & 0.331 & 0.033 & 0.145 & 0.023 & 0.004 & 0.017 & 0.002 & 0.013 & 0.004 & 0.010 & 0.002 & 0.002 & 0.001 \\
\hline 697 & 36.45 & 0.065 & 0.235 & 0.015 & 0.066 & 0.015 & 0.003 & 0.005 & 0.002 & 0.015 & 0.002 & 0.007 & $<0.001$ & 0.001 & $<0.001$ \\
\hline 698 & 36.49 & 0.059 & 0.197 & 0.017 & 0.077 & 0.024 & 0.006 & 0.031 & 0.003 & 0.014 & 0.002 & 0.008 & $<0.001$ & $<0.001$ & 0.001 \\
\hline 699 & 36.52 & 0.093 & 0.248 & 0.025 & 0.088 & 0.025 & 0.002 & 0.012 & 0.003 & 0.015 & 0.002 & 0.006 & 0.001 & 0.002 & $<0.001$ \\
\hline 700 & 36.56 & 0.288 & 0.515 & 0.063 & 0.248 & 0.042 & 0.008 & 0.029 & 0.005 & 0.027 & 0.007 & 0.018 & 0.002 & 0.004 & 0.002 \\
\hline 705 & 36.76 & 0.211 & 0.662 & 0.053 & 0.210 & 0.040 & 0.008 & 0.037 & 0.003 & 0.025 & 0.006 & 0.013 & 0.001 & 0.004 & 0.001 \\
\hline 706 & 36.79 & 0.148 & 0.486 & 0.039 & 0.141 & 0.030 & 0.006 & 0.024 & 0.003 & 0.022 & 0.003 & 0.008 & 0.001 & 0.002 & 0.001 \\
\hline 707 & 36.83 & 0.280 & 0.716 & 0.065 & 0.251 & 0.051 & 0.010 & 0.044 & 0.006 & 0.032 & 0.005 & 0.015 & 0.001 & 0.003 & 0.002 \\
\hline 708 & 36.87 & 0.243 & 0.557 & 0.058 & 0.232 & 0.040 & 0.007 & 0.028 & 0.003 & 0.024 & 0.004 & 0.012 & 0.002 & 0.002 & 0.001 \\
\hline 709 & 36.91 & 0.342 & 0.461 & 0.076 & 0.296 & 0.056 & 0.012 & 0.041 & 0.006 & 0.029 & 0.005 & 0.012 & 0.001 & 0.003 & 0.003 \\
\hline 710 & 36.95 & 0.267 & 2.751 & 0.068 & 0.241 & 0.066 & 0.010 & 0.038 & 0.005 & 0.033 & 0.006 & 0.018 & 0.002 & 0.004 & 0.002 \\
\hline 711 & 37.00 & 0.642 & 2.120 & 0.142 & 0.536 & 0.115 & 0.019 & 0.083 & 0.012 & 0.066 & 0.013 & 0.029 & 0.003 & 0.007 & 0.004 \\
\hline 712 & 37.04 & 0.281 & 0.644 & 0.068 & 0.269 & 0.044 & 0.011 & 0.038 & 0.005 & 0.037 & 0.009 & 0.021 & 0.003 & 0.006 & 0.003 \\
\hline 713 & 37.08 & 0.239 & 0.630 & 0.058 & 0.244 & 0.050 & 0.008 & 0.041 & 0.007 & 0.034 & 0.006 & 0.018 & 0.002 & 0.004 & 0.003 \\
\hline 714 & 37.13 & 0.442 & 0.922 & 0.124 & 0.480 & 0.100 & 0.013 & 0.075 & 0.011 & 0.058 & 0.009 & 0.027 & 0.003 & 0.004 & 0.002 \\
\hline 715 & 37.16 & 0.165 & 0.466 & 0.041 & 0.158 & 0.035 & 0.005 & 0.031 & 0.004 & 0.028 & 0.005 & 0.010 & 0.001 & 0.002 & 0.002 \\
\hline 724 & 37.50 & 0.627 & 1.355 & 0.145 & 0.575 & 0.123 & 0.025 & 0.111 & 0.014 & 0.100 & 0.019 & 0.054 & 0.006 & 0.013 & 0.005 \\
\hline 725 & 37.54 & 0.543 & 1.228 & 0.136 & 0.499 & 0.102 & 0.009 & 0.077 & 0.010 & 0.056 & 0.009 & 0.027 & 0.003 & 0.005 & 0.002 \\
\hline 726 & 37.58 & 0.080 & 0.215 & 0.019 & 0.072 & 0.016 & 0.002 & 0.016 & 0.002 & 0.010 & 0.002 & 0.006 & $<0.001$ & 0.001 & $<0.001$ \\
\hline 727 & 37.61 & 0.063 & 0.194 & 0.014 & 0.061 & 0.014 & 0.002 & 0.008 & 0.001 & 0.007 & 0.002 & 0.006 & 0.001 & 0.001 & $<0.001$ \\
\hline 728 & 37.65 & 0.431 & 0.962 & 0.105 & 0.391 & 0.072 & 0.017 & 0.059 & 0.006 & 0.049 & 0.007 & 0.025 & 0.003 & 0.004 & 0.002 \\
\hline 729 & 37.69 & 0.446 & 1.069 & 0.111 & 0.420 & 0.078 & 0.013 & 0.055 & 0.009 & 0.046 & 0.008 & 0.023 & 0.002 & 0.005 & 0.002 \\
\hline 730 & 37.72 & 0.796 & 1.725 & 0.196 & 0.714 & 0.157 & 0.024 & 0.118 & 0.020 & 0.096 & 0.018 & 0.041 & 0.005 & 0.009 & 0.003 \\
\hline 731 & 37.76 & 0.356 & 1.057 & 0.102 & 0.376 & 0.072 & 0.016 & 0.063 & 0.009 & 0.050 & 0.010 & 0.026 & 0.002 & 0.005 & 0.003 \\
\hline 732 & 37.80 & 0.091 & 0.202 & 0.023 & 0.084 & 0.016 & 0.004 & 0.010 & 0.001 & 0.009 & 0.001 & 0.006 & 0.001 & 0.001 & 0.001 \\
\hline 733 & 37.85 & 0.055 & 0.147 & 0.014 & 0.049 & 0.016 & 0.002 & 0.005 & 0.001 & 0.007 & 0.001 & 0.005 & 0.001 & 0.001 & 0.001 \\
\hline 734 & 37.89 & 0.088 & 0.239 & 0.020 & 0.079 & 0.012 & 0.002 & 0.012 & 0.002 & 0.010 & 0.001 & 0.005 & 0.001 & 0.001 & $<0.001$ \\
\hline 735 & 37.93 & 0.188 & 0.462 & 0.047 & 0.163 & 0.034 & 0.006 & 0.025 & 0.002 & 0.018 & 0.002 & 0.009 & 0.001 & 0.002 & 0.001 \\
\hline 736 & 37.97 & 0.418 & 16.994 & 0.094 & 0.382 & 0.095 & 0.017 & 0.069 & 0.007 & 0.049 & 0.012 & 0.030 & 0.002 & 0.007 & 0.002 \\
\hline 737 & 38.01 & 0.149 & 0.739 & 0.040 & 0.152 & 0.025 & 0.004 & 0.018 & 0.003 & 0.018 & 0.003 & 0.009 & 0.002 & 0.002 & 0.001 \\
\hline 738 & 38.05 & 0.207 & 0.515 & 0.048 & 0.175 & 0.026 & 0.005 & 0.030 & 0.004 & 0.025 & 0.004 & 0.012 & 0.002 & 0.002 & 0.014 \\
\hline 739 & 38.09 & 0.214 & 0.543 & 0.047 & 0.177 & 0.026 & 0.004 & 0.024 & 0.005 & 0.021 & 0.004 & 0.010 & 0.002 & 0.003 & 0.001 \\
\hline 740 & 38.13 & 0.141 & 0.315 & 0.034 & 0.126 & 0.017 & 0.007 & 0.021 & 0.001 & 0.014 & 0.002 & 0.006 & 0.001 & 0.001 & 0.002 \\
\hline 741 & 38.17 & 0.082 & 0.242 & 0.020 & 0.069 & 0.011 & 0.003 & 0.008 & 0.001 & 0.014 & 0.001 & 0.005 & $<0.001$ & 0.001 & $<0.001$ \\
\hline 742 & 38.21 & 0.355 & 0.736 & 0.076 & 0.274 & 0.058 & 0.009 & 0.042 & 0.006 & 0.036 & 0.006 & 0.013 & 0.001 & 0.003 & 0.004 \\
\hline 743 & 38.25 & 0.310 & 0.790 & 0.081 & 0.306 & 0.056 & 0.011 & 0.046 & 0.006 & 0.037 & 0.005 & 0.018 & 0.002 & 0.005 & 0.002 \\
\hline 744 & 38.29 & 1.291 & 0.854 & 0.233 & 0.871 & 0.105 & 0.020 & 0.071 & 0.006 & 0.051 & 0.009 & 0.026 & 0.003 & 0.006 & 0.004 \\
\hline 745 & 38.33 & 1.137 & 1.569 & 0.132 & 0.452 & 0.078 & 0.015 & 0.066 & 0.010 & 0.055 & 0.009 & 0.037 & 0.003 & 0.006 & 0.004 \\
\hline 746 & 38.37 & 0.633 & 1.403 & 0.148 & 0.640 & 0.116 & 0.022 & 0.106 & 0.014 & 0.083 & 0.015 & 0.048 & 0.005 & 0.009 & 0.005 \\
\hline 747 & 38.40 & 0.538 & 1.180 & 0.127 & 0.482 & 0.108 & 0.017 & 0.082 & 0.012 & 0.065 & 0.015 & 0.036 & 0.006 & 0.008 & 0.005 \\
\hline
\end{tabular}




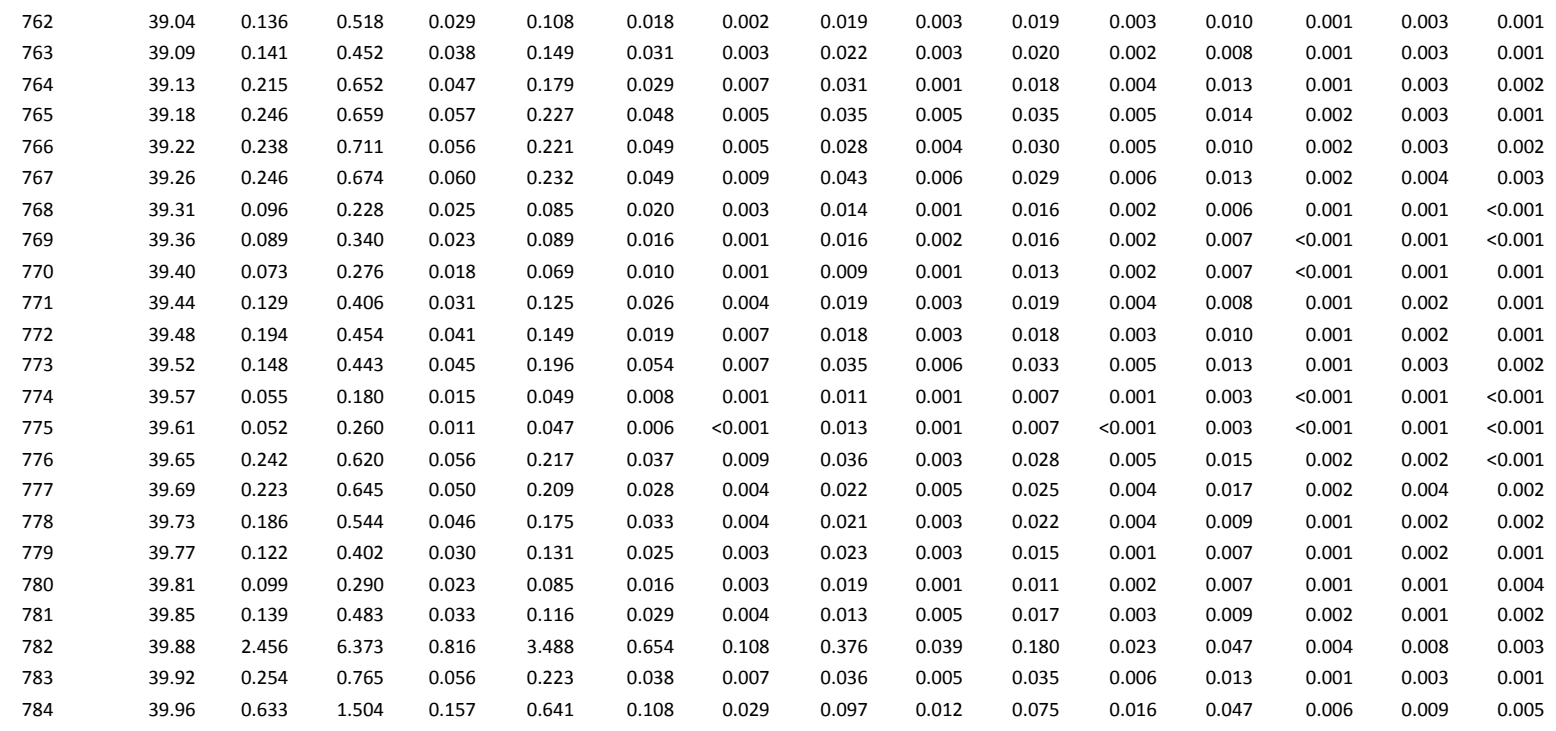

RICE deep core $8 \mathrm{~m}$ to $40 \mathrm{~m}$ samples, relative standard deviation (RSD, \%).

\begin{tabular}{|c|c|c|c|c|c|c|c|c|c|c|c|c|c|c|c|}
\hline $\begin{array}{l}\text { Vial } \\
\#\end{array}$ & (m) & La139 & Ce140 & Pr141 & Nd146 & Sm147 & Eu153 & Gd157 & Tb159 & Dy163 & Ho165 & Er166 & $\operatorname{Tm} 169$ & Yb172 & Lu175 \\
\hline 1 & 8.00 & 2.9 & 3.3 & 5.1 & 6.5 & 17.4 & 14.9 & 15.7 & 7.9 & 16.2 & 10.5 & 15.9 & 27.0 & 15.9 & 33.5 \\
\hline 2 & 8.05 & 4.8 & 4.4 & 8.2 & 5.7 & 6.6 & 15.2 & 15.6 & 9.6 & 13.4 & 6.7 & 13.8 & 24.2 & 26.4 & 17.5 \\
\hline 3 & 8.09 & 7.4 & 3.1 & 11.1 & 9.4 & 11.5 & 27.1 & 28.8 & 19.9 & 28.8 & 18.4 & 10.3 & 27.0 & 17.5 & 53.2 \\
\hline 4 & 8.13 & 2.8 & 2.7 & 6.9 & 8.4 & 23.4 & 19.3 & 18.7 & 15.6 & 24.5 & 16.8 & 10.2 & 29.4 & 23.8 & 22.4 \\
\hline 5 & 8.17 & 4.5 & 2.6 & 11.6 & 6.7 & 33.4 & 38.1 & 42.2 & 13.9 & 21.1 & 24.7 & 48.6 & 53.0 & 24.8 & 50.5 \\
\hline 6 & 8.22 & 4.5 & 4.8 & 10.6 & 26.4 & 42.6 & 42.3 & 18.0 & 30.8 & 57.7 & 43.0 & 30.5 & 47.6 & 89.0 & 104.4 \\
\hline 7 & 8.27 & 5.2 & 5.6 & 10.6 & 10.9 & 43.4 & 20.2 & 25.2 & 43.3 & 23.4 & 26.1 & 37.7 & 51.1 & 56.8 & 121.5 \\
\hline 8 & 8.32 & 76.4 & 3.2 & 6.1 & 8.3 & 19.2 & 64.0 & 25.1 & 21.2 & 17.1 & 16.2 & 45.6 & 69.9 & 38.9 & 45.1 \\
\hline 9 & 9.01 & 5.6 & 2.2 & 6.4 & 7.3 & 18.5 & 24.4 & 8.1 & 18.8 & 22.6 & 34.0 & 13.7 & 53.5 & 55.7 & 37.6 \\
\hline 10 & 9.06 & 4.8 & 3.6 & 6.1 & 6.3 & 16.0 & 17.8 & 16.0 & 20.5 & 15.1 & 19.6 & 31.5 & 33.9 & 31.5 & 61.2 \\
\hline 11 & 9.11 & 2.3 & 1.9 & 5.5 & 3.5 & 16.6 & 14.1 & 25.6 & 22.9 & 19.4 & 12.6 & 20.5 & 42.5 & 41.8 & 48.3 \\
\hline 12 & 9.16 & 3.4 & 3.1 & 10.9 & 9.1 & 16.5 & 17.2 & 15.8 & 14.1 & 9.8 & 10.9 & 20.2 & 19.8 & 28.5 & 13.8 \\
\hline 13 & 9.21 & 4.3 & 3.2 & 5.8 & 8.0 & 28.1 & 25.0 & 13.6 & 15.1 & 12.1 & 21.9 & 35.6 & 41.9 & 37.2 & 33.2 \\
\hline 14 & 9.27 & 3.6 & 2.2 & 4.6 & 8.6 & 12.7 & 14.8 & 9.3 & 10.8 & 7.7 & 10.6 & 10.7 & 28.9 & 6.0 & 11.6 \\
\hline 15 & 9.32 & 8.8 & 3.3 & 8.0 & 13.1 & 27.4 & 14.5 & 51.6 & 20.0 & 18.6 & 20.4 & 30.1 & 49.8 & 49.1 & 65.0 \\
\hline 16 & 9.37 & 9.1 & 3.8 & 10.5 & 8.6 & 39.0 & 30.4 & 44.3 & 27.6 & 38.0 & 26.2 & 26.8 & 34.8 & 57.1 & 80.2 \\
\hline 17 & 9.42 & 5.9 & 3.6 & 8.7 & 9.7 & 21.1 & 35.3 & 14.9 & 35.2 & 13.4 & 35.3 & 13.1 & 54.4 & 29.8 & 67.4 \\
\hline 18 & 9.46 & 4.5 & 2.6 & 7.8 & 11.3 & 19.4 & 22.9 & 18.2 & 34.1 & 36.7 & 39.9 & 77.8 & 42.6 & 54.2 & 51.2 \\
\hline 19 & 9.51 & 2.5 & 3.3 & 4.3 & 8.3 & 17.5 & 25.3 & 9.5 & 16.9 & 14.9 & 18.9 & 19.5 & 15.8 & 28.9 & 19.5 \\
\hline 20 & 9.55 & 7.0 & 2.1 & 8.4 & 7.9 & 16.9 & 28.1 & 21.2 & 20.3 & 11.8 & 17.0 & 26.7 & 37.8 & 35.2 & 31.5 \\
\hline 21 & 9.60 & 4.2 & 1.4 & 6.8 & 8.5 & 10.2 & 18.7 & 19.6 & 25.4 & 18.8 & 25.8 & 25.9 & 36.0 & 46.1 & 48.8 \\
\hline 22 & 9.65 & 6.0 & 7.0 & 8.8 & 12.0 & 36.1 & 26.3 & 34.1 & 23.2 & 37.9 & 18.5 & 54.6 & 70.6 & 71.1 & 74.1 \\
\hline 23 & 9.69 & 8.0 & 6.3 & 6.7 & 20.2 & 59.3 & 38.8 & 15.5 & 29.6 & 55.7 & 32.4 & 22.6 & 126.2 & 112.3 & 98.8 \\
\hline 24 & 9.73 & 9.2 & 6.2 & 25.6 & 20.9 & 31.0 & 36.0 & 30.5 & 38.7 & 46.8 & 15.3 & 50.7 & 61.2 & 106.4 & 112.4 \\
\hline 25 & 9.77 & 2.7 & 5.8 & 8.6 & 14.6 & 36.6 & 43.4 & 32.5 & 23.9 & 26.9 & 41.4 & 38.2 & 55.2 & 9.2 & 72.6 \\
\hline 26 & 9.81 & 5.8 & 3.3 & 11.2 & 12.4 & 38.6 & 23.8 & 42.7 & 21.0 & 34.7 & 25.3 & 68.4 & 50.2 & 46.3 & 69.6 \\
\hline 27 & 9.86 & 4.7 & 1.4 & 6.3 & 6.3 & 12.5 & 30.5 & 14.7 & 17.6 & 22.7 & 15.7 & 15.7 & 45.3 & 34.5 & 40.0 \\
\hline 28 & 9.90 & 3.6 & 3.6 & 3.4 & 6.2 & 8.9 & 23.4 & 20.6 & 20.3 & 9.9 & 10.3 & 18.7 & 24.3 & 43.0 & 34.3 \\
\hline 29 & 9.95 & 3.7 & 2.7 & 6.6 & 5.4 & 13.8 & 16.2 & 15.2 & 20.5 & 11.3 & 18.1 & 17.5 & 18.2 & 20.6 & 39.0 \\
\hline 30 & 9.99 & 4.1 & 1.8 & 4.8 & 6.9 & 11.8 & 17.0 & 20.6 & 7.7 & 8.4 & 14.7 & 20.9 & 22.4 & 17.4 & 45.7 \\
\hline 31 & 10.04 & 4.5 & 3.2 & 6.0 & 11.9 & 17.2 & 32.0 & 21.7 & 30.3 & 17.9 & 16.2 & 29.6 & 36.6 & 38.0 & 54.2 \\
\hline 32 & 10.08 & 4.2 & 5.6 & 13.2 & 7.5 & 42.4 & 46.5 & 32.3 & 29.7 & 29.3 & 29.4 & 21.5 & 75.8 & 50.2 & 42.3 \\
\hline 33 & 10.13 & 4.6 & 6.9 & 4.6 & 8.4 & 21.4 & 20.2 & 24.2 & 35.4 & 29.7 & 35.3 & 34.5 & 49.4 & 38.7 & 19.4 \\
\hline 34 & 10.17 & 7.1 & 3.1 & 8.2 & 9.9 & 13.0 & 33.7 & 42.7 & 23.0 & 23.4 & 19.4 & 20.7 & 44.8 & 24.1 & 24.1 \\
\hline 35 & 10.21 & 4.7 & 3.5 & 12.7 & 20.5 & 32.4 & 26.1 & 28.3 & 26.4 & 25.3 & 19.7 & 32.1 & 64.7 & 19.6 & 80.2 \\
\hline 36 & 10.25 & 48.5 & 9.3 & 10.1 & 14.7 & 33.4 & 50.8 & 39.1 & 26.5 & 35.9 & 20.7 & 61.6 & 73.6 & 64.0 & 89.8 \\
\hline 37 & 10.29 & 3.0 & 2.8 & 8.9 & 6.2 & 25.2 & 33.2 & 41.4 & 36.0 & 20.1 & 16.3 & 38.5 & 38.0 & 38.3 & 57.5 \\
\hline 38 & 10.33 & 8.0 & 2.8 & 5.0 & 12.1 & 14.8 & 28.9 & 16.2 & 16.0 & 17.8 & 23.0 & 19.5 & 42.5 & 20.1 & 27.5 \\
\hline 39 & 10.37 & 4.5 & 3.8 & 10.0 & 5.7 & 13.3 & 23.5 & 23.7 & 12.2 & 18.6 & 22.8 & 16.3 & 22.3 & 11.8 & 108.5 \\
\hline 40 & 10.41 & 4.5 & 2.9 & 8.2 & 11.5 & 21.8 & 18.5 & 17.4 & 20.7 & 25.4 & 19.7 & 24.0 & 17.6 & 34.4 & 51.3 \\
\hline 41 & 10.44 & 3.5 & 2.2 & 7.5 & 8.0 & 21.5 & 20.0 & 23.4 & 22.0 & 16.5 & 12.3 & 21.2 & 28.8 & 16.0 & 31.1 \\
\hline 42 & 10.48 & 7.7 & 4.0 & 9.9 & 9.6 & 30.4 & 37.8 & 40.5 & 28.2 & 24.8 & 30.2 & 36.0 & 38.4 & 28.0 & 42.5 \\
\hline 43 & 10.52 & 5.5 & 3.3 & 9.7 & 12.7 & 27.5 & 15.6 & 42.7 & 11.2 & 25.1 & 35.0 & 39.8 & 46.4 & 58.6 & 89.9 \\
\hline 44 & 10.56 & 6.9 & 3.6 & 8.0 & 13.7 & 28.2 & 28.6 & 23.8 & 22.5 & 22.7 & 27.7 & 47.3 & 65.8 & 60.3 & 49.0 \\
\hline 45 & 10.60 & 3.8 & 3.0 & 10.6 & 11.0 & 20.4 & 29.0 & 31.6 & 28.5 & 40.1 & 21.4 & 27.9 & 53.9 & 13.0 & 74.3 \\
\hline 46 & 10.63 & 5.5 & 3.4 & 7.0 & 8.1 & 23.0 & 21.0 & 20.9 & 26.1 & 19.4 & 24.2 & 25.8 & 34.9 & 19.6 & 36.8 \\
\hline 47 & 10.67 & 2.8 & 3.7 & 3.8 & 10.1 & 14.3 & 23.5 & 22.5 & 17.7 & 9.8 & 11.9 & 18.9 & 36.4 & 39.8 & 34.2 \\
\hline 48 & 10.70 & 5.7 & 3.7 & 6.1 & 11.5 & 32.3 & 27.3 & 29.5 & 28.3 & 17.4 & 35.3 & 36.9 & 17.4 & 33.1 & 33.7 \\
\hline 49 & 10.74 & 10.8 & 3.2 & 4.3 & 8.0 & 12.1 & 25.8 & 44.1 & 41.1 & 21.3 & 31.7 & 23.0 & 44.6 & 43.6 & 162.5 \\
\hline
\end{tabular}




\begin{tabular}{|c|c|c|c|c|c|c|c|c|c|c|c|c|c|c|c|}
\hline 50 & 10.78 & 9.9 & 2.0 & 11.7 & 17.6 & 35.7 & 31.2 & 29.3 & 19.8 & 26.5 & 43.3 & 46.1 & 31.2 & 61.7 & 94.9 \\
\hline 51 & 10.82 & 4.8 & 3.0 & 12.0 & 15.9 & 39.7 & 12.8 & 19.9 & 22.4 & 14.3 & 29.3 & 45.1 & 46.4 & 79.7 & 79.1 \\
\hline 52 & 10.85 & 4.4 & 2.0 & 9.7 & 17.5 & 19.9 & 37.5 & 25.9 & 24.4 & 39.6 & 20.1 & 33.4 & 56.2 & 37.6 & 93.2 \\
\hline 53 & 10.89 & 3.1 & 2.4 & 2.1 & 2.4 & 7.3 & 10.9 & 11.0 & 7.7 & 11.6 & 19.9 & 8.0 & 33.9 & 32.1 & 29.2 \\
\hline 54 & 10.94 & 4.2 & 2.7 & 5.3 & 8.6 & 25.2 & 15.7 & 48.3 & 27.6 & 30.6 & 50.4 & 25.1 & 85.0 & 50.0 & 23.7 \\
\hline 55 & 10.98 & 2.9 & 2.9 & 10.5 & 15.2 & 16.3 & 21.7 & 17.2 & 17.0 & 16.4 & 26.4 & 31.9 & 44.7 & 14.9 & 21.0 \\
\hline 56 & 11.02 & 2.3 & 2.0 & 6.8 & 19.7 & 27.9 & 30.6 & 21.3 & 25.9 & 24.9 & 38.6 & 23.1 & 60.8 & 35.5 & 60.9 \\
\hline 57 & 11.06 & 2.7 & 3.0 & 8.7 & 7.7 & 30.1 & 23.2 & 22.8 & 32.0 & 23.3 & 17.7 & 34.2 & 37.5 & 34.5 & 45.4 \\
\hline 58 & 11.10 & 6.0 & 6.5 & 2.9 & 6.5 & 18.5 & 14.0 & 18.7 & 19.4 & 20.2 & 19.1 & 32.6 & 33.0 & 27.5 & 34.4 \\
\hline 59 & 11.14 & 8.4 & 4.9 & 13.9 & 18.5 & 25.6 & 22.0 & 20.4 & 16.0 & 22.5 & 20.2 & 44.0 & 57.2 & 35.3 & 42.6 \\
\hline 60 & 11.18 & 5.9 & 5.4 & 11.8 & 16.4 & 39.1 & 31.2 & 24.2 & 28.7 & 41.1 & 15.7 & 13.4 & 38.2 & 50.7 & 120.0 \\
\hline 61 & 11.22 & 7.5 & 3.6 & 8.1 & 11.2 & 26.9 & 31.3 & 25.3 & 33.1 & 25.8 & 22.2 & 26.6 & 51.7 & 38.2 & 78.6 \\
\hline 62 & 11.26 & 2.5 & 2.9 & 2.0 & 3.6 & 13.2 & 6.6 & 10.9 & 8.9 & 4.9 & 13.4 & 4.9 & 26.6 & 25.9 & 34.4 \\
\hline 63 & 11.30 & 4.5 & 3.3 & 3.8 & 12.2 & 17.7 & 9.5 & 35.1 & 36.9 & 18.1 & 32.0 & 34.5 & 33.9 & 59.9 & 56.2 \\
\hline 64 & 11.34 & 15.1 & 7.0 & 27.5 & 28.3 & 61.1 & 48.1 & 62.2 & 28.9 & 54.2 & 73.3 & 91.5 & 30.9 & 59.0 & 138.5 \\
\hline 65 & 11.38 & 5.3 & 7.0 & 8.1 & 8.4 & 37.7 & 48.4 & 36.9 & 33.4 & 69.8 & 44.6 & 48.0 & 83.8 & 89.0 & 56.2 \\
\hline 66 & 11.42 & 6.4 & 5.3 & 11.1 & 11.0 & 22.2 & 24.0 & 26.6 & 40.5 & 31.7 & 45.4 & 28.3 & 48.6 & 48.2 & 60.3 \\
\hline 67 & 11.45 & 5.5 & 4.6 & 11.4 & 6.9 & 22.3 & 33.5 & 31.6 & 32.8 & 19.7 & 22.1 & 26.8 & 33.7 & 16.3 & 69.4 \\
\hline 68 & 11.50 & 5.8 & 3.2 & 12.6 & 13.3 & 25.2 & 42.1 & 21.8 & 26.8 & 20.2 & 42.2 & 49.3 & 29.6 & 65.3 & 50.3 \\
\hline 69 & 11.54 & 6.0 & 4.0 & 4.6 & 11.4 & 24.0 & 30.9 & 20.2 & 14.1 & 27.7 & 18.9 & 24.0 & 41.5 & 43.9 & 72.1 \\
\hline 70 & 11.57 & 4.0 & 5.0 & 6.7 & 6.2 & 12.2 & 30.9 & 19.2 & 24.8 & 19.6 & 29.3 & 37.3 & 28.6 & 14.1 & 43.1 \\
\hline 71 & 11.61 & 2.8 & 1.2 & 4.3 & 5.5 & 9.2 & 19.1 & 11.4 & 14.1 & 14.1 & 20.1 & 32.3 & 25.9 & 16.9 & 77.8 \\
\hline 72 & 11.64 & 4.6 & 3.1 & 7.5 & 27.1 & 46.5 & 52.4 & 43.7 & 28.8 & 44.3 & 32.1 & 75.9 & 48.0 & 49.0 & 35.3 \\
\hline 73 & 11.68 & 6.2 & 7.4 & 15.7 & 21.4 & 20.3 & 31.9 & 37.4 & 43.8 & 34.8 & 45.9 & 34.2 & 90.8 & 66.3 & 64.7 \\
\hline 74 & 11.71 & 10.7 & 3.1 & 10.7 & 16.7 & 15.4 & 23.2 & 26.3 & 24.2 & 49.5 & 68.8 & 51.5 & 84.0 & 58.5 & 143.3 \\
\hline 75 & 11.75 & 8.8 & 3.6 & 16.8 & 17.2 & 48.2 & 11.9 & 39.3 & 15.7 & 29.3 & 61.6 & 43.2 & 58.5 & 57.4 & 50.5 \\
\hline 76 & 11.78 & 7.5 & 5.3 & 22.3 & 29.1 & 23.8 & 37.4 & 50.8 & 43.2 & 35.8 & 34.8 & 43.7 & 63.1 & 85.5 & 64.6 \\
\hline 77 & 11.81 & 8.4 & 1.9 & 11.9 & 18.0 & 29.1 & 38.8 & 41.2 & 43.9 & 48.1 & 23.1 & 33.6 & 23.2 & 45.7 & 55.8 \\
\hline 78 & 11.85 & 3.7 & 2.4 & 8.2 & 16.2 & 27.4 & 38.2 & 35.2 & 36.6 & 45.7 & 27.6 & 19.0 & 22.8 & 31.1 & 67.2 \\
\hline 79 & 11.88 & 3.4 & 2.0 & 6.3 & 11.5 & 18.3 & 28.9 & 29.3 & 22.0 & 25.8 & 25.3 & 16.7 & 38.8 & 40.1 & 26.0 \\
\hline 80 & 11.91 & 5.6 & 5.4 & 9.7 & 14.3 & 33.6 & 16.9 & 21.3 & 19.1 & 27.8 & 41.9 & 16.7 & 40.6 & 39.6 & 73.1 \\
\hline 81 & 11.94 & 8.3 & 2.5 & 5.0 & 6.0 & 21.9 & 22.7 & 31.5 & 25.6 & 30.4 & 40.6 & 19.8 & 18.6 & 49.9 & 121.9 \\
\hline 82 & 11.98 & 2.5 & 2.1 & 2.4 & 4.6 & 7.2 & 8.3 & 3.6 & 6.8 & 11.6 & 8.3 & 8.3 & 15.9 & 6.5 & 91.5 \\
\hline 83 & 12.02 & 5.5 & 2.9 & 5.8 & 8.8 & 23.0 & 23.7 & 14.4 & 24.8 & 18.2 & 31.9 & 23.2 & 23.4 & 36.6 & 20.2 \\
\hline 84 & 12.05 & 3.2 & 2.6 & 6.6 & 8.7 & 17.6 & 19.5 & 15.3 & 25.2 & 17.0 & 18.8 & 36.2 & 36.8 & 29.9 & 29.1 \\
\hline 85 & 12.07 & 4.7 & 5.0 & 4.4 & 4.0 & 8.3 & 9.9 & 8.0 & 9.7 & 10.2 & 15.7 & 9.3 & 19.9 & 8.3 & 17.5 \\
\hline 86 & 12.10 & 4.4 & 2.1 & 6.6 & 8.7 & 20.6 & 16.9 & 9.7 & 27.6 & 13.5 & 17.7 & 21.4 & 40.1 & 39.4 & 21.0 \\
\hline 87 & 12.15 & 3.8 & 2.1 & 6.2 & 9.1 & 18.2 & 23.3 & 23.4 & 17.3 & 29.9 & 24.9 & 24.5 & 47.7 & 33.5 & 57.1 \\
\hline 88 & 12.18 & 3.3 & 4.3 & 9.6 & 13.9 & 25.2 & 23.4 & 41.4 & 18.0 & 20.7 & 36.3 & 49.6 & 41.7 & 49.3 & 51.4 \\
\hline 89 & 12.22 & 4.0 & 3.7 & 3.4 & 14.7 & 23.1 & 16.1 & 20.5 & 24.1 & 38.4 & 24.3 & 22.1 & 34.7 & 40.9 & 67.0 \\
\hline 90 & 12.26 & 7.8 & 3.4 & 5.1 & 4.2 & 13.8 & 10.5 & 10.6 & 14.9 & 15.6 & 20.6 & 23.2 & 32.2 & 18.5 & 84.0 \\
\hline 91 & 12.30 & 4.9 & 6.6 & 5.4 & 8.2 & 31.3 & 23.1 & 27.4 & 18.6 & 16.8 & 36.9 & 49.7 & 50.4 & 34.0 & 207.3 \\
\hline 92 & 12.34 & 10.0 & 5.8 & 12.0 & 15.7 & 51.8 & 29.6 & 37.1 & 16.2 & 31.6 & 36.1 & 49.2 & 57.7 & 73.7 & 90.5 \\
\hline 93 & 12.38 & 15.1 & 7.2 & 8.3 & 12.9 & 42.9 & 54.1 & 51.8 & 60.5 & 40.6 & 21.2 & 44.9 & 78.1 & 72.3 & 76.4 \\
\hline 94 & 12.42 & 9.6 & 6.2 & 7.2 & 7.0 & 22.8 & 37.3 & 30.4 & 18.3 & 47.8 & 42.0 & 36.8 & 63.3 & 76.8 & 73.7 \\
\hline 95 & 12.46 & 6.5 & 2.9 & 15.9 & 17.2 & 22.6 & 34.8 & 33.9 & 33.1 & 17.6 & 51.5 & 29.5 & 28.6 & 18.9 & 55.7 \\
\hline 96 & 12.50 & 5.1 & 3.5 & 12.8 & 20.2 & 38.4 & 22.4 & 24.8 & 32.4 & 12.0 & 52.7 & 28.0 & 30.9 & 53.3 & 71.8 \\
\hline 97 & 12.54 & 7.5 & 5.3 & 12.4 & 10.5 & 31.8 & 30.0 & 34.7 & 23.6 & 17.3 & 55.5 & 26.4 & 56.3 & 48.0 & 53.8 \\
\hline 98 & 12.58 & 6.4 & 4.3 & 5.3 & 18.0 & 42.6 & 28.2 & 28.3 & 42.4 & 39.2 & 23.0 & 63.0 & 29.8 & 20.4 & 70.1 \\
\hline 99 & 12.62 & 5.7 & 5.0 & 6.6 & 11.2 & 17.7 & 25.2 & 30.1 & 14.8 & 31.7 & 22.5 & 18.6 & 45.5 & 34.0 & 52.8 \\
\hline 100 & 12.66 & 3.5 & 2.1 & 14.4 & 12.3 & 18.8 & 44.7 & 36.2 & 38.9 & 30.9 & 32.8 & 43.1 & 48.1 & 94.9 & 85.5 \\
\hline 101 & 12.69 & 3.7 & 2.6 & 12.3 & 12.0 & 33.4 & 34.8 & 33.4 & 47.2 & 34.9 & 41.0 & 49.7 & 71.0 & 75.5 & 82.6 \\
\hline 102 & 12.73 & 7.8 & 6.0 & 13.1 & 7.9 & 31.3 & 56.1 & 26.2 & 27.3 & 23.2 & 29.9 & 34.2 & 47.3 & 27.4 & 46.9 \\
\hline 103 & 12.77 & 4.8 & 3.8 & 12.8 & 12.0 & 14.9 & 26.9 & 24.0 & 33.1 & 13.0 & 13.2 & 33.6 & 40.3 & 50.4 & 44.8 \\
\hline 104 & 12.81 & 6.9 & 4.8 & 9.6 & 16.0 & 25.6 & 34.9 & 26.4 & 30.9 & 35.7 & 36.9 & 104.9 & 10.3 & 41.8 & 100.3 \\
\hline 105 & 12.84 & 7.5 & 9.9 & 16.3 & 12.2 & 44.6 & 24.4 & 39.7 & 27.9 & 23.2 & 40.7 & 43.7 & 27.4 & 50.4 & 63.5 \\
\hline 106 & 12.88 & 5.3 & 8.6 & 21.4 & 14.1 & 23.6 & 33.2 & 23.3 & 59.1 & 57.0 & 36.2 & 34.2 & 81.8 & 69.4 & 91.1 \\
\hline 107 & 12.93 & 3.5 & 1.2 & 5.9 & 6.4 & 29.2 & 33.3 & 21.4 & 23.6 & 14.8 & 45.0 & 22.6 & 45.5 & 51.3 & 53.3 \\
\hline 108 & 12.97 & 6.1 & 2.5 & 7.3 & 6.2 & 26.3 & 21.1 & 18.6 & 21.5 & 25.0 & 17.5 & 19.3 & 51.3 & 41.4 & 48.1 \\
\hline 109 & 13.02 & 5.4 & 1.7 & 10.7 & 20.4 & 40.3 & 26.5 & 29.5 & 37.4 & 28.2 & 51.1 & 37.3 & 45.2 & 22.0 & 21.0 \\
\hline 110 & 13.06 & 6.8 & 5.0 & 15.1 & 15.3 & 43.3 & 25.5 & 32.0 & 26.4 & 37.4 & 28.1 & 45.1 & 74.2 & 35.8 & 79.9 \\
\hline 111 & 13.10 & 7.3 & 3.1 & 16.2 & 8.2 & 31.7 & 49.3 & 35.6 & 40.2 & 51.5 & 24.7 & 54.6 & 68.9 & 36.0 & 79.8 \\
\hline 112 & 13.14 & 8.8 & 5.1 & 10.2 & 23.2 & 38.7 & 43.4 & 37.0 & 21.3 & 18.9 & 54.8 & 80.2 & 98.5 & 92.7 & 132.1 \\
\hline 113 & 13.18 & 11.3 & 2.3 & 10.1 & 21.6 & 28.9 & 35.6 & 31.9 & 38.2 & 24.8 & 37.4 & 35.2 & 39.2 & 56.5 & 70.5 \\
\hline 114 & 13.22 & 2.7 & 4.4 & 8.3 & 10.0 & 28.8 & 25.1 & 27.4 & 19.3 & 19.9 & 40.7 & 25.5 & 62.5 & 34.0 & 42.7 \\
\hline 115 & 13.26 & 5.8 & 4.7 & 13.1 & 13.3 & 35.3 & 43.1 & 19.9 & 23.7 & 21.0 & 31.2 & 35.7 & 38.0 & 48.4 & 59.4 \\
\hline 116 & 13.30 & 9.9 & 4.0 & 19.7 & 20.9 & 36.9 & 32.7 & 27.2 & 19.8 & 20.7 & 33.1 & 40.2 & 45.8 & 61.1 & 59.7 \\
\hline 117 & 13.34 & 8.2 & 6.1 & 12.3 & 16.7 & 54.8 & 40.7 & 23.1 & 45.0 & 35.9 & 21.5 & 39.5 & 40.0 & 63.7 & 112.0 \\
\hline 118 & 13.38 & 2.6 & 4.0 & 7.4 & 10.5 & 46.0 & 19.9 & 24.3 & 20.9 & 19.2 & 18.0 & 26.8 & 46.4 & 56.2 & 53.9 \\
\hline 119 & 13.42 & 7.6 & 4.8 & 5.7 & 6.1 & 33.0 & 24.5 & 28.9 & 27.4 & 12.4 & 30.3 & 44.1 & 41.1 & 28.9 & 34.6 \\
\hline 120 & 13.46 & 7.6 & 3.9 & 12.9 & 15.0 & 28.6 & 34.1 & 23.6 & 35.8 & 25.9 & 39.0 & 19.2 & 103.6 & 38.9 & 91.1 \\
\hline 121 & 13.50 & 4.9 & 3.0 & 9.7 & 7.7 & 31.4 & 42.9 & 19.6 & 16.6 & 28.9 & 21.0 & 19.4 & 31.6 & 51.6 & 48.2 \\
\hline 122 & 13.54 & 6.5 & 4.3 & 9.3 & 8.4 & 20.1 & 27.0 & 16.5 & 12.5 & 12.3 & 25.2 & 28.3 & 62.9 & 35.9 & 63.3 \\
\hline 123 & 13.58 & 8.9 & 6.6 & 16.7 & 23.9 & 48.4 & 9.6 & 43.7 & 33.9 & 39.7 & 42.7 & 54.9 & 39.5 & 55.9 & 75.8 \\
\hline 124 & 13.61 & 10.5 & 2.6 & 14.6 & 14.0 & 42.8 & 33.7 & 31.8 & 13.6 & 38.1 & 19.3 & 48.3 & 61.9 & 73.4 & 37.3 \\
\hline 125 & 13.65 & 3.9 & 2.6 & 6.1 & 5.2 & 14.9 & 4.2 & 12.0 & 9.6 & 4.0 & 21.1 & 16.1 & 29.3 & 20.9 & 25.8 \\
\hline 126 & 13.69 & 6.7 & 5.6 & 8.7 & 16.5 & 37.0 & 32.4 & 18.6 & 28.1 & 39.5 & 53.4 & 45.1 & 84.2 & 43.4 & 91.8 \\
\hline
\end{tabular}




\begin{tabular}{|c|c|c|c|c|c|c|c|c|c|c|c|c|c|c|c|}
\hline 127 & 13.72 & 4.4 & 2.3 & 3.3 & 2.7 & 14.5 & 22.7 & 16.2 & 14.9 & 9.0 & 14.7 & 14.0 & 16.6 & 32.5 & 24.0 \\
\hline 128 & 13.75 & 4.0 & 1.7 & 3.6 & 3.9 & 15.6 & 9.5 & 16.5 & 21.1 & 21.7 & 10.0 & 18.8 & 34.3 & 25.4 & 24.1 \\
\hline 129 & 13.79 & 3.1 & 2.2 & 5.8 & 8.5 & 23.1 & 10.4 & 13.8 & 22.8 & 24.8 & 15.9 & 16.4 & 28.9 & 22.6 & 24.0 \\
\hline 130 & 13.82 & 2.9 & 2.9 & 4.8 & 5.6 & 23.4 & 20.3 & 23.7 & 19.4 & 13.6 & 11.5 & 35.0 & 25.9 & 30.9 & 35.2 \\
\hline 131 & 13.86 & 3.7 & 3.2 & 8.8 & 2.3 & 6.2 & 15.5 & 12.0 & 24.3 & 11.5 & 17.0 & 17.3 & 43.1 & 16.9 & 48.0 \\
\hline 132 & 13.89 & 5.3 & 6.0 & 12.8 & 12.2 & 41.4 & 39.0 & 58.7 & 34.5 & 52.7 & 32.6 & 44.7 & 59.1 & 58.5 & 57.1 \\
\hline 133 & 13.93 & 4.1 & 2.9 & 11.9 & 7.2 & 25.3 & 24.0 & 17.8 & 38.8 & 21.0 & 17.4 & 29.9 & 48.9 & 32.3 & 39.4 \\
\hline 134 & 13.97 & 4.0 & 2.4 & 4.6 & 4.1 & 11.2 & 21.5 & 17.9 & 8.5 & 10.3 & 14.9 & 10.8 & 18.2 & 24.9 & 16.1 \\
\hline 135 & 14.02 & 3.5 & 2.1 & 8.1 & 10.3 & 13.9 & 15.3 & 24.5 & 21.7 & 17.7 & 44.7 & 30.9 & 23.7 & 18.6 & 37.5 \\
\hline 136 & 14.05 & 2.8 & 3.9 & 7.2 & 5.2 & 6.7 & 18.5 & 15.6 & 26.9 & 22.0 & 20.0 & 21.7 & 34.8 & 24.5 & 32.1 \\
\hline 137 & 14.09 & 2.7 & 2.2 & 11.4 & 11.3 & 14.2 & 46.4 & 29.7 & 22.5 & 16.3 & 13.4 & 18.4 & 53.8 & 25.8 & 43.4 \\
\hline 138 & 14.13 & 4.6 & 4.7 & 7.2 & 20.7 & 13.0 & 32.5 & 23.7 & 30.9 & 21.8 & 37.4 & 38.6 & 49.6 & 23.5 & 83.8 \\
\hline 139 & 14.17 & 5.5 & 3.1 & 6.4 & 7.8 & 9.8 & 23.2 & 17.1 & 15.0 & 22.4 & 15.3 & 33.7 & 28.3 & 24.8 & 75.3 \\
\hline 140 & 14.21 & 17.6 & 17.4 & 61.7 & 40.1 & 133.6 & 48.0 & 49.8 & 36.2 & 140.8 & 43.2 & 182.5 & 34.3 & 94.7 & 88.3 \\
\hline 141 & 14.24 & 4.2 & 2.9 & 7.5 & 10.6 & 28.2 & 28.3 & 18.6 & 11.6 & 21.1 & 9.0 & 22.1 & 24.1 & 16.2 & 39.8 \\
\hline 142 & 14.28 & 3.5 & 2.6 & 7.0 & 8.4 & 20.8 & 13.2 & 29.4 & 18.4 & 9.9 & 18.6 & 26.4 & 35.4 & 44.1 & 79.0 \\
\hline 143 & 14.32 & 9.0 & 5.9 & 18.0 & 10.8 & 18.9 & 19.1 & 26.7 & 42.7 & 45.5 & 36.8 & 24.6 & 68.1 & 64.2 & 73.8 \\
\hline 144 & 14.36 & 8.2 & 7.7 & 15.9 & 13.7 & 19.8 & 26.2 & 42.5 & 23.8 & 45.1 & 33.0 & 66.4 & 54.0 & 55.4 & 73.1 \\
\hline 145 & 14.40 & 4.1 & 2.2 & 4.5 & 7.6 & 11.8 & 27.1 & 13.3 & 35.4 & 21.1 & 31.7 & 19.1 & 33.9 & 20.3 & 52.3 \\
\hline 146 & 14.44 & 5.0 & 2.6 & 7.4 & 7.1 & 35.7 & 32.8 & 19.0 & 19.3 & 20.8 & 31.4 & 19.4 & 33.2 & 17.2 & 61.4 \\
\hline 147 & 14.48 & 5.7 & 3.0 & 12.6 & 7.1 & 32.4 & 29.7 & 36.1 & 28.6 & 26.3 & 16.7 & 28.5 & 33.7 & 93.4 & 66.9 \\
\hline 148 & 14.51 & 10.6 & 6.0 & 18.5 & 16.6 & 38.9 & 18.8 & 33.5 & 36.7 & 21.1 & 17.2 & 68.9 & 34.9 & 54.2 & 124.6 \\
\hline 149 & 14.55 & 10.7 & 4.1 & 14.4 & 16.3 & 30.0 & 21.3 & 37.3 & 32.1 & 37.8 & 61.5 & 57.0 & 52.4 & 65.3 & 208.9 \\
\hline 150 & 14.59 & 6.4 & 4.0 & 10.5 & 9.5 & 21.8 & 21.0 & 16.6 & 21.7 & 36.5 & 26.2 & 42.5 & 80.8 & 81.6 & 33.0 \\
\hline 151 & 14.63 & 2.9 & 1.2 & 5.2 & 10.5 & 23.3 & 10.4 & 22.0 & 46.2 & 24.6 & 22.1 & 68.9 & 50.9 & 41.6 & 25.1 \\
\hline 152 & 14.66 & 4.1 & 2.1 & 6.0 & 7.1 & 23.9 & 17.0 & 15.3 & 15.1 & 25.0 & 27.0 & 24.4 & 10.6 & 37.2 & 27.7 \\
\hline 153 & 14.70 & 6.5 & 2.5 & 7.5 & 10.3 & 13.1 & 16.1 & 22.4 & 32.3 & 40.7 & 33.2 & 29.9 & 27.5 & 30.0 & 37.4 \\
\hline 154 & 14.73 & 6.0 & 5.3 & 3.6 & 10.4 & 24.5 & 24.1 & 21.6 & 17.0 & 19.2 & 19.4 & 30.9 & 42.9 & 50.1 & 31.7 \\
\hline 155 & 14.77 & 4.8 & 3.3 & 11.1 & 12.4 & 27.6 & 11.2 & 15.4 & 34.8 & 42.1 & 21.6 & 25.2 & 22.2 & 77.1 & 52.5 \\
\hline 156 & 14.81 & 5.5 & 5.0 & 8.3 & 17.0 & 25.3 & 32.7 & 25.4 & 22.2 & 39.8 & 22.0 & 35.4 & 47.4 & 74.4 & 36.6 \\
\hline 157 & 14.84 & 5.2 & 3.4 & 7.1 & 16.4 & 33.7 & 24.7 & 22.5 & 44.2 & 22.1 & 40.8 & 48.5 & 93.6 & 26.6 & 63.4 \\
\hline 158 & 14.88 & 3.9 & 3.6 & 11.2 & 16.1 & 36.2 & 25.4 & 27.4 & 35.8 & 26.2 & 24.7 & 21.7 & 41.4 & 39.0 & 40.2 \\
\hline 159 & 14.93 & 4.3 & 4.8 & 10.0 & 7.3 & 27.4 & 28.9 & 18.2 & 22.2 & 37.3 & 21.9 & 23.8 & 33.0 & 46.4 & 58.7 \\
\hline 160 & 14.97 & 1.7 & 1.8 & 3.4 & 5.6 & 12.2 & 9.7 & 6.8 & 7.7 & 5.8 & 13.0 & 7.3 & 12.5 & 14.6 & 22.3 \\
\hline 161 & 15.01 & 3.8 & 2.4 & 13.4 & 26.6 & 31.6 & 32.0 & 31.8 & 15.6 & 24.0 & 12.2 & 13.5 & 76.8 & 46.9 & 54.7 \\
\hline 162 & 15.05 & 3.1 & 2.9 & 8.4 & 4.9 & 15.8 & 21.6 & 32.8 & 22.7 & 12.5 & 17.7 & 46.0 & 39.1 & 39.8 & 62.2 \\
\hline 163 & 15.09 & 5.0 & 3.6 & 6.8 & 12.1 & 35.3 & 49.9 & 15.9 & 37.3 & 34.5 & 39.6 & 44.3 & 63.0 & 25.4 & 61.4 \\
\hline 164 & 15.13 & 6.5 & 4.1 & 8.0 & 11.3 & 15.0 & 28.2 & 20.0 & 26.2 & 17.3 & 48.3 & 34.3 & 43.7 & 40.7 & 131.1 \\
\hline 165 & 15.17 & 5.8 & 3.9 & 6.2 & 23.5 & 32.7 & 26.9 & 28.3 & 19.8 & 35.3 & 52.4 & 58.2 & 50.6 & 63.0 & 77.9 \\
\hline 166 & 15.21 & 6.5 & 2.8 & 16.6 & 20.8 & 47.2 & 84.2 & 44.3 & 21.3 & 27.4 & 27.9 & 27.6 & 44.0 & 68.8 & 115.0 \\
\hline 167 & 15.25 & 5.5 & 3.8 & 16.5 & 31.0 & 59.2 & 22.3 & 60.8 & 44.0 & 66.4 & 24.5 & 54.4 & 54.5 & 68.1 & 84.9 \\
\hline 168 & 15.29 & 3.4 & 1.4 & 8.0 & 8.1 & 19.0 & 44.6 & 15.8 & 28.3 & 31.8 & 33.4 & 29.8 & 49.6 & 30.3 & 51.3 \\
\hline 169 & 15.32 & 5.1 & 2.9 & 13.1 & 18.1 & 39.0 & 34.2 & 34.2 & 43.3 & 34.9 & 63.7 & 42.4 & 37.8 & 81.6 & 59.3 \\
\hline 170 & 15.36 & 3.3 & 2.3 & 10.0 & 15.2 & 16.2 & 26.2 & 9.4 & 29.0 & 15.5 & 24.0 & 32.0 & 41.1 & 47.8 & 50.4 \\
\hline 171 & 15.40 & 8.2 & 2.0 & 13.7 & 12.4 & 21.1 & 36.7 & 41.8 & 40.9 & 16.0 & 25.4 & 45.3 & 33.3 & 35.6 & 43.1 \\
\hline 172 & 15.44 & 8.3 & 9.8 & 16.9 & 11.4 & 29.6 & 24.4 & 25.0 & 24.9 & 20.4 & 60.5 & 31.2 & 31.0 & 76.1 & 75.6 \\
\hline 173 & 15.47 & 14.5 & 9.1 & 35.2 & 22.9 & 69.0 & 82.2 & 79.0 & 63.6 & 63.4 & 83.2 & 100.5 & 82.3 & 101.2 & 245.0 \\
\hline 174 & 15.51 & 19.5 & 7.7 & 13.0 & 17.4 & 69.7 & 31.6 & 70.5 & 100.1 & 101.0 & 65.2 & 84.1 & 126.0 & 81.9 & 114.2 \\
\hline 175 & 15.55 & 4.4 & 3.3 & 12.2 & 38.5 & 95.8 & 64.7 & 39.0 & 59.7 & 68.7 & 51.5 & 70.4 & 95.6 & 147.4 & 180.8 \\
\hline 176 & 15.58 & 13.9 & 7.5 & 16.1 & 22.3 & 32.7 & 43.2 & 19.3 & 30.1 & 27.0 & 44.8 & 55.7 & 58.7 & 61.2 & 144.5 \\
\hline 177 & 15.62 & 10.7 & 4.2 & 21.8 & 21.8 & 54.5 & 42.3 & 40.7 & 43.2 & 51.4 & 39.6 & 45.6 & 54.0 & 120.0 & 77.3 \\
\hline 178 & 15.65 & 5.1 & 2.1 & 4.2 & 10.0 & 25.9 & 22.8 & 17.7 & 12.9 & 13.6 & 25.2 & 17.4 & 38.5 & 31.8 & 166.2 \\
\hline 179 & 15.69 & 8.6 & 4.7 & 17.4 & 8.3 & 28.4 & 27.5 & 26.0 & 32.2 & 53.9 & 49.4 & 56.2 & 40.2 & 61.9 & 62.4 \\
\hline 180 & 15.72 & 6.4 & 5.7 & 14.5 & 12.5 & 29.4 & 21.7 & 41.2 & 33.4 & 36.9 & 29.4 & 25.3 & 41.8 & 48.4 & 25.7 \\
\hline 181 & 15.76 & 4.4 & 1.6 & 12.1 & 13.9 & 39.1 & 29.0 & 40.3 & 24.9 & 19.8 & 34.7 & 26.6 & 66.8 & 41.6 & 43.1 \\
\hline 182 & 15.79 & 6.5 & 5.3 & 4.9 & 12.9 & 13.6 & 26.1 & 17.9 & 19.3 & 33.7 & 39.3 & 30.6 & 38.0 & 59.2 & 84.4 \\
\hline 183 & 15.83 & 6.0 & 2.8 & 2.7 & 4.9 & 22.6 & 24.0 & 13.0 & 25.6 & 12.4 & 20.8 & 25.3 & 18.4 & 19.6 & 33.1 \\
\hline 184 & 15.86 & 3.2 & 3.8 & 6.2 & 6.7 & 20.3 & 15.3 & 12.0 & 23.0 & 11.0 & 34.7 & 6.4 & 37.6 & 41.6 & 37.8 \\
\hline 185 & 15.90 & 2.5 & 2.0 & 6.3 & 3.6 & 17.0 & 14.8 & 20.6 & 25.3 & 21.2 & 17.2 & 31.1 & 31.7 & 31.3 & 24.3 \\
\hline 186 & 15.93 & 2.3 & 2.4 & 6.0 & 7.2 & 7.6 & 12.8 & 8.1 & 11.3 & 12.3 & 24.1 & 17.5 & 33.6 & 19.6 & 38.0 \\
\hline 187 & 15.96 & 2.8 & 2.8 & 4.7 & 4.2 & 10.2 & 7.3 & 11.0 & 8.2 & 11.2 & 14.3 & 10.9 & 15.2 & 10.2 & 9.5 \\
\hline 188 & 16.00 & 2.6 & 2.3 & 6.2 & 5.4 & 14.1 & 12.8 & 13.3 & 12.3 & 16.7 & 14.1 & 14.3 & 15.0 & 15.9 & 20.1 \\
\hline 189 & 16.05 & 2.0 & 1.1 & 2.8 & 3.6 & 10.8 & 16.9 & 8.7 & 17.6 & 11.4 & 13.3 & 22.6 & 21.5 & 20.4 & 34.0 \\
\hline 190 & 16.08 & 5.5 & 3.1 & 9.2 & 9.0 & 25.8 & 30.3 & 24.2 & 20.6 & 14.3 & 24.5 & 19.8 & 30.9 & 49.1 & 42.6 \\
\hline 191 & 16.12 & 3.0 & 3.7 & 8.1 & 6.2 & 16.1 & 25.9 & 15.2 & 16.8 & 8.6 & 22.8 & 11.9 & 17.9 & 22.8 & 23.3 \\
\hline 192 & 16.15 & 4.5 & 4.0 & 4.4 & 12.2 & 7.3 & 13.2 & 21.3 & 16.5 & 15.6 & 14.0 & 14.7 & 29.7 & 40.5 & 24.7 \\
\hline 193 & 16.19 & 7.7 & 6.7 & 6.0 & 13.1 & 25.8 & 35.1 & 31.3 & 21.4 & 21.1 & 19.3 & 17.9 & 31.8 & 32.0 & 62.6 \\
\hline 194 & 16.23 & 4.9 & 5.5 & 7.2 & 8.2 & 21.2 & 24.7 & 21.3 & 32.5 & 20.1 & 40.4 & 35.8 & 55.5 & 47.0 & 78.6 \\
\hline 195 & 16.27 & 4.0 & 2.2 & 17.6 & 14.5 & 29.3 & 34.7 & 32.2 & 36.9 & 30.7 & 34.1 & 20.8 & 42.2 & 30.6 & 82.3 \\
\hline 196 & 16.31 & 6.9 & 4.1 & 12.3 & 42.5 & 74.8 & 46.7 & 21.6 & 29.2 & 45.5 & 24.6 & 59.6 & 63.7 & 94.3 & 61.0 \\
\hline 197 & 16.34 & 9.7 & 8.6 & 13.2 & 8.6 & 41.5 & 34.1 & 54.4 & 20.0 & 16.9 & 49.5 & 33.7 & 54.9 & 31.4 & 70.2 \\
\hline 198 & 16.38 & 5.4 & 3.8 & 10.0 & 18.2 & 50.1 & 39.1 & 32.7 & 43.6 & 21.9 & 17.4 & 29.6 & 35.1 & 61.6 & 112.9 \\
\hline 199 & 16.42 & 7.3 & 4.2 & 9.2 & 7.8 & 31.7 & 55.3 & 37.6 & 21.6 & 25.3 & 32.0 & 29.6 & 66.2 & 36.2 & 91.4 \\
\hline 200 & 16.46 & 11.0 & 41.6 & 53.5 & 69.9 & 56.6 & 48.1 & 72.7 & 32.8 & 118.6 & 39.5 & 170.0 & 34.0 & 102.5 & 107.3 \\
\hline 201 & 16.50 & 6.1 & 2.8 & 13.3 & 9.8 & 62.0 & 43.7 & 12.2 & 24.6 & 37.6 & 56.5 & 39.2 & 57.7 & 62.2 & 44.8 \\
\hline 202 & 16.53 & 2.8 & 3.3 & 9.2 & 8.5 & 39.4 & 30.7 & 15.2 & 12.6 & 39.1 & 28.7 & 30.7 & 56.2 & 48.4 & 75.7 \\
\hline 203 & 16.57 & 6.1 & 2.2 & 9.0 & 8.2 & 29.5 & 29.1 & 31.1 & 29.8 & 34.8 & 35.3 & 69.7 & 59.7 & 28.4 & 54.7 \\
\hline
\end{tabular}




\begin{tabular}{|c|c|c|c|c|c|c|c|c|c|c|c|c|c|c|c|}
\hline 204 & 16.62 & 8.4 & 4.1 & 12.2 & 26.5 & 71.3 & 42.1 & 25.1 & 14.2 & 38.8 & 44.4 & 57.6 & 20.2 & 46.7 & 51.5 \\
\hline 205 & 16.66 & 6.4 & 3.3 & 9.1 & 7.8 & 30.8 & 20.7 & 27.3 & 17.3 & 18.4 & 33.1 & 30.6 & 35.0 & 59.4 & 80.2 \\
\hline 206 & 16.69 & 11.8 & 5.0 & 12.1 & 20.6 & 24.2 & 24.2 & 35.3 & 23.3 & 24.3 & 38.5 & 35.9 & 46.5 & 46.4 & 84.2 \\
\hline 207 & 16.73 & 10.4 & 10.2 & 22.3 & 15.2 & 24.2 & 48.6 & 51.2 & 39.2 & 28.2 & 23.6 & 28.0 & 56.4 & 70.4 & 84.1 \\
\hline 208 & 16.76 & 12.1 & 8.8 & 31.4 & 13.0 & 25.2 & 32.4 & 42.3 & 39.9 & 39.5 & 35.2 & 86.0 & 74.2 & 91.8 & 144.7 \\
\hline 209 & 16.80 & 8.6 & 3.9 & 13.2 & 9.6 & 39.1 & 36.2 & 37.3 & 32.8 & 22.7 & 60.9 & 44.2 & 41.6 & 34.2 & 54.7 \\
\hline 210 & 16.84 & 6.3 & 4.3 & 11.5 & 13.4 & 28.6 & 30.5 & 20.2 & 15.0 & 33.5 & 43.7 & 35.2 & 48.8 & 70.0 & 26.4 \\
\hline 211 & 16.88 & 3.8 & 4.2 & 14.0 & 21.8 & 31.2 & 20.1 & 42.3 & 38.4 & 27.6 & 40.7 & 36.6 & 47.7 & 38.5 & 57.3 \\
\hline 212 & 16.91 & 5.1 & 1.9 & 4.3 & 8.2 & 14.1 & 24.6 & 15.3 & 27.1 & 30.3 & 41.4 & 37.4 & 26.9 & 35.7 & 58.9 \\
\hline 213 & 16.95 & 3.0 & 1.5 & 6.3 & 5.8 & 15.5 & 8.9 & 14.6 & 22.9 & 13.7 & 21.2 & 23.5 & 41.8 & 26.0 & 46.9 \\
\hline 214 & 16.99 & 2.0 & 1.6 & 7.1 & 10.0 & 18.0 & 13.2 & 10.6 & 12.9 & 13.2 & 9.9 & 19.2 & 16.2 & 16.1 & 27.0 \\
\hline 215 & 17.04 & 2.4 & 2.9 & 2.8 & 11.8 & 30.2 & 24.7 & 17.6 & 19.3 & 15.1 & 35.7 & 27.0 & 23.8 & 28.0 & 23.2 \\
\hline 216 & 17.08 & 5.6 & 2.8 & 9.4 & 9.3 & 16.4 & 17.2 & 7.4 & 10.6 & 20.5 & 21.0 & 11.2 & 25.0 & 30.9 & 77.3 \\
\hline 217 & 17.13 & 2.8 & 2.3 & 15.7 & 12.3 & 23.7 & 17.9 & 28.1 & 16.9 & 11.0 & 10.1 & 29.6 & 38.9 & 51.5 & 19.4 \\
\hline 218 & 17.17 & 4.6 & 2.4 & 11.1 & 11.9 & 15.4 & 17.5 & 20.3 & 7.8 & 17.3 & 16.9 & 9.9 & 72.8 & 24.4 & 47.0 \\
\hline 219 & 17.21 & 2.6 & 1.4 & 4.8 & 8.8 & 25.1 & 21.7 & 15.2 & 7.6 & 12.8 & 14.5 & 21.5 & 33.7 & 22.0 & 25.3 \\
\hline 220 & 17.25 & 2.3 & 2.9 & 3.6 & 3.5 & 5.7 & 9.4 & 7.2 & 6.1 & 6.0 & 8.8 & 6.9 & 20.6 & 12.6 & 10.7 \\
\hline 221 & 17.30 & 16.0 & 8.7 & 10.9 & 16.9 & 28.7 & 46.9 & 47.4 & 52.1 & 47.0 & 29.9 & 31.2 & 49.1 & 40.7 & 35.9 \\
\hline 222 & 17.34 & 2.1 & 2.8 & 5.5 & 8.4 & 13.8 & 10.8 & 22.4 & 19.1 & 14.1 & 20.7 & 18.5 & 26.3 & 41.6 & 35.4 \\
\hline 223 & 17.37 & 5.7 & 4.5 & 5.8 & 6.1 & 32.6 & 13.8 & 11.7 & 28.4 & 17.5 & 28.6 & 31.4 & 92.3 & 35.5 & 35.6 \\
\hline 224 & 17.41 & 4.4 & 3.4 & 10.4 & 14.1 & 21.4 & 25.0 & 32.7 & 13.1 & 12.4 & 32.7 & 36.1 & 50.3 & 8.4 & 128.4 \\
\hline 225 & 17.45 & 5.2 & 4.8 & 12.0 & 11.1 & 16.5 & 26.2 & 25.6 & 47.5 & 21.1 & 44.3 & 53.8 & 63.1 & 71.5 & 64.6 \\
\hline 226 & 17.50 & 8.5 & 3.8 & 6.5 & 10.3 & 23.8 & 43.2 & 30.2 & 40.0 & 29.1 & 27.9 & 52.5 & 98.8 & 44.9 & 90.7 \\
\hline 227 & 17.54 & 3.8 & 7.6 & 10.7 & 7.2 & 27.6 & 29.0 & 31.3 & 19.3 & 26.0 & 24.7 & 19.6 & 42.0 & 34.1 & 59.5 \\
\hline 228 & 17.58 & 7.5 & 8.5 & 10.2 & 18.2 & 44.5 & 39.5 & 43.2 & 20.8 & 37.9 & 44.0 & 49.4 & 23.3 & 122.9 & 50.6 \\
\hline 229 & 17.62 & 4.8 & 4.4 & 23.4 & 18.2 & 44.2 & 40.1 & 48.3 & 44.9 & 63.2 & 21.8 & 43.9 & 93.9 & 72.9 & 100.5 \\
\hline 230 & 17.66 & 9.1 & 7.9 & 13.4 & 25.5 & 25.7 & 37.5 & 39.2 & 41.9 & 34.2 & 48.1 & 57.5 & 62.1 & 50.8 & 98.6 \\
\hline 231 & 17.70 & 2.2 & 1.9 & 7.5 & 4.8 & 10.0 & 30.1 & 21.1 & 31.8 & 22.8 & 15.7 & 12.6 & 46.6 & 39.0 & 181.5 \\
\hline 232 & 17.74 & 5.9 & 3.4 & 14.4 & 18.3 & 26.9 & 29.5 & 15.5 & 16.6 & 23.5 & 32.6 & 24.7 & 27.3 & 18.8 & 33.6 \\
\hline 233 & 17.77 & 5.0 & 1.1 & 7.2 & 12.1 & 23.5 & 38.6 & 29.2 & 15.3 & 29.7 & 24.9 & 28.5 & 40.6 & 73.7 & 38.3 \\
\hline 234 & 17.81 & 2.4 & 2.8 & 5.8 & 10.6 & 9.3 & 18.6 & 16.7 & 30.0 & 23.7 & 32.4 & 24.8 & 57.1 & 40.5 & 78.4 \\
\hline 235 & 17.85 & 6.1 & 2.6 & 10.8 & 9.4 & 46.9 & 33.3 & 36.1 & 20.6 & 27.0 & 37.0 & 44.7 & 26.0 & 52.6 & 31.1 \\
\hline 236 & 17.89 & 11.0 & 3.8 & 12.4 & 14.6 & 28.5 & 32.0 & 16.2 & 34.4 & 39.0 & 48.9 & 51.0 & 57.6 & 42.7 & 75.6 \\
\hline 237 & 17.93 & 10.5 & 1.6 & 9.0 & 13.4 & 21.5 & 53.1 & 30.1 & 28.4 & 25.5 & 29.3 & 36.6 & 110.8 & 64.0 & 78.6 \\
\hline 238 & 17.97 & 4.7 & 3.4 & 14.4 & 15.0 & 34.6 & 29.7 & 39.4 & 49.3 & 46.3 & 30.1 & 12.8 & 47.9 & 55.8 & 53.5 \\
\hline 239 & 18.02 & 4.9 & 3.5 & 11.7 & 9.7 & 21.3 & 50.8 & 60.1 & 22.6 & 15.7 & 16.3 & 51.4 & 74.1 & 56.5 & 59.2 \\
\hline 240 & 18.06 & 5.3 & 2.5 & 17.3 & 13.4 & 30.5 & 26.5 & 19.5 & 16.2 & 50.6 & 25.5 & 50.2 & 58.1 & 52.4 & 53.9 \\
\hline 241 & 18.10 & 7.5 & 6.0 & 3.3 & 16.6 & 39.3 & 41.7 & 31.1 & 32.0 & 25.0 & 24.7 & 37.0 & 72.6 & 32.2 & 76.8 \\
\hline 242 & 18.15 & 20.1 & 1.7 & 3.5 & 2.3 & 22.3 & 30.3 & 18.1 & 38.2 & 10.9 & 10.8 & 24.5 & 24.4 & 25.7 & 44.5 \\
\hline 243 & 18.19 & 5.5 & 3.4 & 8.9 & 10.0 & 24.4 & 14.9 & 25.3 & 45.3 & 14.5 & 50.8 & 19.1 & 64.3 & 82.6 & 54.0 \\
\hline 244 & 18.23 & 3.0 & 3.4 & 10.3 & 8.9 & 17.6 & 24.8 & 23.6 & 29.5 & 29.0 & 21.9 & 27.4 & 33.7 & 33.7 & 16.3 \\
\hline 245 & 18.27 & 4.1 & 2.0 & 6.3 & 9.9 & 11.4 & 9.8 & 24.9 & 6.4 & 18.1 & 8.6 & 17.9 & 23.6 & 35.6 & 35.2 \\
\hline 246 & 18.32 & 8.0 & 3.7 & 9.0 & 13.7 & 20.4 & 19.8 & 32.1 & 30.6 & 11.2 & 26.2 & 27.4 & 36.1 & 27.8 & 59.9 \\
\hline 247 & 18.35 & 132.1 & 108.7 & 118.8 & 128.5 & 65.0 & 52.1 & 67.6 & 97.2 & 87.8 & 79.6 & 114.2 & 107.7 & 87.8 & 110.6 \\
\hline 248 & 18.37 & 5.4 & 5.1 & 11.8 & 14.4 & 41.5 & 40.1 & 33.5 & 25.8 & 31.8 & 37.6 & 27.2 & 36.7 & 36.6 & 71.4 \\
\hline 249 & 18.45 & 7.6 & 4.4 & 13.0 & 35.8 & 79.6 & 43.0 & 75.8 & 50.3 & 75.0 & 81.2 & 44.0 & 89.4 & 109.5 & 163.5 \\
\hline 250 & 18.49 & 13.0 & 7.7 & 35.7 & 45.1 & 64.8 & 70.5 & 42.3 & 71.2 & 88.6 & 134.9 & 91.0 & 111.5 & 159.0 & 117.0 \\
\hline 251 & 18.53 & 12.1 & 9.2 & 33.6 & 33.8 & 49.6 & 59.5 & 115.1 & 58.8 & 84.2 & 76.4 & 245.0 & 166.4 & 84.3 & 159.3 \\
\hline 252 & 18.57 & 18.4 & 12.0 & 25.0 & 26.2 & 46.4 & 30.8 & 46.2 & 27.9 & 79.3 & 44.8 & 124.5 & 68.2 & 127.7 & 147.6 \\
\hline 253 & 18.61 & 8.5 & 6.4 & 6.0 & 27.1 & 34.7 & 56.7 & 46.1 & 38.7 & 51.2 & 30.5 & 75.2 & 95.4 & 19.5 & 162.3 \\
\hline 254 & 18.65 & 9.0 & 4.5 & 10.4 & 24.8 & 23.3 & 21.5 & 31.9 & 52.7 & 42.7 & 15.8 & 33.6 & 49.1 & 32.9 & 11.5 \\
\hline 255 & 18.69 & 5.9 & 5.3 & 13.2 & 15.6 & 37.3 & 38.8 & 17.6 & 12.6 & 14.8 & 48.7 & 58.5 & 26.7 & 25.9 & 44.2 \\
\hline 256 & 18.73 & 3.9 & 2.5 & 8.5 & 10.7 & 13.4 & 16.0 & 3.5 & 23.8 & 11.3 & 9.5 & 27.6 & 24.0 & 28.2 & 26.8 \\
\hline 257 & 18.77 & 4.5 & 3.4 & 8.2 & 11.6 & 31.6 & 27.6 & 17.1 & 25.5 & 15.6 & 25.9 & 24.8 & 49.1 & 34.3 & 55.2 \\
\hline 258 & 18.80 & 8.1 & 3.4 & 8.9 & 22.1 & 27.3 & 27.1 & 36.9 & 21.9 & 23.0 & 16.9 & 24.7 & 32.1 & 42.7 & 36.1 \\
\hline 259 & 18.84 & 2.5 & 2.4 & 15.4 & 9.1 & 24.8 & 29.6 & 16.5 & 24.6 & 29.3 & 20.4 & 22.7 & 40.9 & 26.4 & 34.8 \\
\hline 260 & 18.89 & 2.9 & 1.6 & 11.6 & 12.4 & 37.5 & 6.2 & 25.5 & 20.8 & 15.7 & 24.9 & 25.7 & 29.0 & 47.1 & 160.8 \\
\hline 261 & 18.93 & 4.7 & 3.2 & 9.3 & 15.7 & 31.8 & 34.7 & 27.4 & 31.2 & 26.0 & 29.3 & 29.2 & 17.8 & 39.4 & 70.2 \\
\hline 262 & 18.97 & 4.2 & 1.8 & 6.9 & 18.7 & 38.6 & 13.3 & 13.7 & 24.2 & 41.3 & 44.4 & 26.3 & 33.2 & 72.2 & 54.0 \\
\hline 263 & 19.03 & 7.2 & 65.7 & 8.1 & 22.1 & 39.0 & 37.2 & 31.0 & 21.7 & 34.2 & 24.4 & 41.4 & 51.7 & 82.5 & 68.7 \\
\hline 264 & 19.07 & 6.1 & 2.6 & 10.6 & 11.9 & 27.6 & 22.3 & 17.2 & 21.3 & 21.0 & 41.9 & 48.3 & 39.0 & 22.2 & 47.7 \\
\hline 265 & 19.11 & 3.0 & 2.1 & 6.9 & 10.9 & 19.5 & 13.7 & 18.5 & 16.3 & 18.5 & 21.8 & 24.8 & 27.7 & 27.5 & 25.1 \\
\hline 266 & 19.15 & 5.6 & 4.3 & 5.3 & 11.4 & 14.8 & 33.2 & 23.0 & 32.9 & 14.0 & 17.5 & 32.2 & 48.6 & 23.5 & 36.7 \\
\hline 267 & 19.20 & 5.0 & 3.6 & 8.8 & 10.8 & 18.5 & 39.9 & 19.9 & 19.8 & 22.1 & 25.5 & 29.7 & 18.8 & 30.3 & 63.4 \\
\hline 268 & 19.24 & 7.4 & 4.0 & 8.3 & 20.6 & 27.5 & 22.7 & 32.6 & 34.9 & 34.2 & 20.8 & 28.5 & 51.3 & 41.0 & 81.3 \\
\hline 269 & 19.28 & 17.6 & 3.1 & 9.7 & 14.0 & 27.7 & 43.0 & 29.8 & 20.4 & 17.5 & 29.6 & 25.8 & 37.9 & 76.2 & 79.3 \\
\hline 270 & 19.32 & 3.7 & 2.1 & 13.2 & 11.2 & 38.2 & 27.2 & 43.4 & 13.8 & 24.8 & 16.5 & 51.9 & 38.0 & 74.0 & 60.7 \\
\hline 271 & 19.36 & 4.1 & 3.8 & 8.5 & 9.7 & 23.9 & 15.8 & 28.8 & 26.6 & 13.4 & 34.4 & 37.2 & 24.0 & 47.4 & 54.1 \\
\hline 272 & 19.41 & 1.1 & 1.9 & 5.0 & 3.9 & 15.0 & 6.2 & 8.0 & 6.4 & 10.9 & 12.1 & 9.9 & 13.7 & 11.9 & 40.6 \\
\hline 273 & 19.45 & 3.2 & 2.9 & 7.4 & 7.3 & 15.9 & 18.4 & 11.5 & 19.3 & 19.7 & 9.1 & 16.1 & 10.6 & 17.8 & 49.0 \\
\hline 274 & 19.49 & 3.3 & 2.0 & 2.6 & 5.1 & 12.2 & 16.2 & 28.3 & 14.7 & 18.5 & 30.8 & 40.8 & 30.7 & 35.0 & 35.4 \\
\hline 275 & 19.53 & 3.3 & 3.0 & 5.9 & 8.3 & 21.4 & 17.0 & 17.9 & 7.5 & 14.5 & 23.7 & 10.9 & 18.9 & 22.0 & 38.4 \\
\hline 276 & 19.57 & 2.8 & 1.8 & 4.4 & 9.7 & 13.4 & 11.4 & 18.8 & 21.4 & 10.6 & 13.5 & 17.1 & 24.6 & 17.0 & 25.6 \\
\hline 277 & 19.61 & 6.2 & 4.1 & 12.2 & 10.8 & 27.6 & 16.7 & 9.1 & 21.3 & 19.9 & 36.4 & 28.2 & 38.6 & 15.9 & 41.9 \\
\hline 278 & 19.65 & 3.8 & 3.3 & 11.1 & 9.7 & 11.3 & 26.4 & 13.7 & 23.8 & 14.7 & 18.8 & 19.9 & 26.3 & 23.6 & 68.1 \\
\hline 279 & 19.69 & 5.3 & 2.0 & 5.9 & 8.8 & 15.7 & 15.5 & 19.6 & 15.8 & 9.3 & 24.3 & 29.0 & 16.9 & 35.9 & 102.8 \\
\hline 280 & 19.73 & 9.5 & 4.3 & 10.4 & 13.7 & 26.7 & 16.1 & 35.6 & 34.5 & 30.0 & 31.9 & 26.7 & 39.1 & 20.6 & 71.8 \\
\hline
\end{tabular}




\begin{tabular}{|c|c|c|c|c|c|c|c|c|c|c|c|c|c|c|c|}
\hline 281 & 19.77 & 11.0 & 5.7 & 12.2 & 19.5 & 37.7 & 27.4 & 40.9 & 23.7 & 39.8 & 16.6 & 61.2 & 26.6 & 97.7 & 61.4 \\
\hline 282 & 19.80 & 17.9 & 9.0 & 17.7 & 45.7 & 28.9 & 34.2 & 47.4 & 21.1 & 50.8 & 66.1 & 86.4 & 53.0 & 72.1 & 120.5 \\
\hline 283 & 19.84 & 2.4 & 5.8 & 23.2 & 30.7 & 24.8 & 33.8 & 32.2 & 36.0 & 65.3 & 37.8 & 47.0 & 44.2 & 69.4 & 36.8 \\
\hline 284 & 19.88 & 4.9 & 4.3 & 6.5 & 8.5 & 27.8 & 27.9 & 10.3 & 17.0 & 22.2 & 39.8 & 13.2 & 24.8 & 36.2 & 52.0 \\
\hline 285 & 19.91 & 4.0 & 3.5 & 11.9 & 12.5 & 23.8 & 33.1 & 12.4 & 30.4 & 23.9 & 25.4 & 46.1 & 40.9 & 54.8 & 55.9 \\
\hline 286 & 19.95 & 3.5 & 2.8 & 9.0 & 7.3 & 6.7 & 20.7 & 13.3 & 16.0 & 16.0 & 21.0 & 6.9 & 48.7 & 24.5 & 33.8 \\
\hline 287 & 19.99 & 5.1 & 2.5 & 8.1 & 6.7 & 21.8 & 19.1 & 21.7 & 21.7 & 21.3 & 28.1 & 50.1 & 16.8 & 34.1 & 32.5 \\
\hline 288 & 20.05 & 2.1 & 2.7 & 12.7 & 10.3 & 31.4 & 25.5 & 34.8 & 18.2 & 16.2 & 26.8 & 29.1 & 21.2 & 20.5 & 38.9 \\
\hline 289 & 20.09 & 3.0 & 3.7 & 7.7 & 5.4 & 20.8 & 13.8 & 23.8 & 11.1 & 10.7 & 9.9 & 25.9 & 24.0 & 36.7 & 32.2 \\
\hline 290 & 20.13 & 8.6 & 3.8 & 5.6 & 8.8 & 22.3 & 14.0 & 12.4 & 17.0 & 15.3 & 18.5 & 19.8 & 17.6 & 28.1 & 21.3 \\
\hline 291 & 20.17 & 4.6 & 2.5 & 3.5 & 9.2 & 15.0 & 16.7 & 20.8 & 14.7 & 4.5 & 14.4 & 23.4 & 20.7 & 16.0 & 17.0 \\
\hline 292 & 20.21 & 4.4 & 4.0 & 5.7 & 9.0 & 30.1 & 29.0 & 27.4 & 29.2 & 33.9 & 30.7 & 15.6 & 21.7 & 25.6 & 67.6 \\
\hline 293 & 20.26 & 5.9 & 6.7 & 8.5 & 7.4 & 42.2 & 30.7 & 19.5 & 21.2 & 52.4 & 32.3 & 51.2 & 54.3 & 63.4 & 71.4 \\
\hline 294 & 20.30 & 10.5 & 3.5 & 9.1 & 22.8 & 12.4 & 32.2 & 22.0 & 17.0 & 32.8 & 18.9 & 24.1 & 45.2 & 40.1 & 37.2 \\
\hline 295 & 20.34 & 3.8 & 4.0 & 9.0 & 8.7 & 23.1 & 23.7 & 16.2 & 21.1 & 26.8 & 21.3 & 8.1 & 15.7 & 24.8 & 29.6 \\
\hline 296 & 20.39 & 5.8 & 5.8 & 6.4 & 3.9 & 15.8 & 28.9 & 18.3 & 17.6 & 17.5 & 16.1 & 21.4 & 33.3 & 40.9 & 39.4 \\
\hline 297 & 20.43 & 7.8 & 7.7 & 6.5 & 7.0 & 21.3 & 24.9 & 23.7 & 15.6 & 20.0 & 10.7 & 20.7 & 27.3 & 36.3 & 35.9 \\
\hline 298 & 20.47 & 3.9 & 6.4 & 7.8 & 15.3 & 13.3 & 22.7 & 20.3 & 23.3 & 18.2 & 31.6 & 18.5 & 24.1 & 37.9 & 30.6 \\
\hline 299 & 20.51 & 5.0 & 6.4 & 7.0 & 10.8 & 16.5 & 14.0 & 8.9 & 21.1 & 19.8 & 17.2 & 31.7 & 20.3 & 43.6 & 44.5 \\
\hline 300 & 20.55 & 3.9 & 3.5 & 5.2 & 7.9 & 31.9 & 11.7 & 12.3 & 20.3 & 20.3 & 25.5 & 22.3 & 31.3 & 38.5 & 40.0 \\
\hline 301 & 20.59 & 10.3 & 5.4 & 11.8 & 7.8 & 40.3 & 36.9 & 21.0 & 22.7 & 24.3 & 46.6 & 61.7 & 29.4 & 39.0 & 78.8 \\
\hline 302 & 20.63 & 2.3 & 3.1 & 4.3 & 6.9 & 13.4 & 16.7 & 14.0 & 16.9 & 19.8 & 17.3 & 17.0 & 23.4 & 39.1 & 21.5 \\
\hline 303 & 20.67 & 2.9 & 2.9 & 3.8 & 11.7 & 30.5 & 16.8 & 24.9 & 20.6 & 13.7 & 32.1 & 18.8 & 25.3 & 39.0 & 43.0 \\
\hline 304 & 20.71 & 4.2 & 3.2 & 9.4 & 6.7 & 13.9 & 12.5 & 23.3 & 7.0 & 16.2 & 24.7 & 25.8 & 22.4 & 23.9 & 85.1 \\
\hline 305 & 20.75 & 3.5 & 3.7 & 7.5 & 8.9 & 22.7 & 20.7 & 16.4 & 21.1 & 10.9 & 16.7 & 35.0 & 47.9 & 27.6 & 60.6 \\
\hline 306 & 20.78 & 5.1 & 3.7 & 10.6 & 8.7 & 23.2 & 19.5 & 21.4 & 32.6 & 16.4 & 16.5 & 27.2 & 39.8 & 15.4 & 48.1 \\
\hline 307 & 20.82 & 7.1 & 2.0 & 10.5 & 6.8 & 19.7 & 18.2 & 19.6 & 10.1 & 21.8 & 10.8 & 21.9 & 53.6 & 18.3 & 33.1 \\
\hline 308 & 20.86 & 3.8 & 3.3 & 6.0 & 9.3 & 10.3 & 15.3 & 33.9 & 11.1 & 25.6 & 24.7 & 18.3 & 37.1 & 41.1 & 56.5 \\
\hline 309 & 20.90 & 6.9 & 6.8 & 11.1 & 13.3 & 21.0 & 17.2 & 25.3 & 11.7 & 35.2 & 12.0 & 24.3 & 33.0 & 41.8 & 28.3 \\
\hline 310 & 20.95 & 2.9 & 2.6 & 4.9 & 9.0 & 16.9 & 23.8 & 23.0 & 7.0 & 19.7 & 16.3 & 31.2 & 17.5 & 13.7 & 31.4 \\
\hline 311 & 20.99 & 3.8 & 0.9 & 6.3 & 6.3 & 20.2 & 27.6 & 12.5 & 8.0 & 24.3 & 21.1 & 16.6 & 25.6 & 19.5 & 51.7 \\
\hline 312 & 21.04 & 3.8 & 2.2 & 5.8 & 9.2 & 8.2 & 4.6 & 13.6 & 14.5 & 10.9 & 19.3 & 17.7 & 17.3 & 31.0 & 22.9 \\
\hline 313 & 21.08 & 6.3 & 5.7 & 7.6 & 8.6 & 23.5 & 39.3 & 17.1 & 16.3 & 34.0 & 30.7 & 21.6 & 36.4 & 30.9 & 43.6 \\
\hline 314 & 21.12 & 3.8 & 3.4 & 9.9 & 7.0 & 13.4 & 46.6 & 38.9 & 21.8 & 24.1 & 24.5 & 23.3 & 61.9 & 53.6 & 102.1 \\
\hline 315 & 21.15 & 5.0 & 4.2 & 9.8 & 7.8 & 15.3 & 18.1 & 18.8 & 32.8 & 25.3 & 22.3 & 29.9 & 47.2 & 19.4 & 26.8 \\
\hline 316 & 21.20 & 4.1 & 3.8 & 19.5 & 14.5 & 43.2 & 36.7 & 22.8 & 39.5 & 11.8 & 30.1 & 31.7 & 32.6 & 52.3 & 67.5 \\
\hline 317 & 21.24 & 10.1 & 6.9 & 20.1 & 20.5 & 59.1 & 50.1 & 42.0 & 38.3 & 45.5 & 53.2 & 59.7 & 67.5 & 52.7 & 29.3 \\
\hline 318 & 21.28 & 13.7 & 5.5 & 16.8 & 15.3 & 49.3 & 34.5 & 36.1 & 29.3 & 38.3 & 40.8 & 74.2 & 64.2 & 39.7 & 115.3 \\
\hline 319 & 21.32 & 5.7 & 5.0 & 16.1 & 15.5 & 45.9 & 54.7 & 38.5 & 17.9 & 49.1 & 59.5 & 81.0 & 74.8 & 59.4 & 76.8 \\
\hline 320 & 21.36 & 7.3 & 2.0 & 5.9 & 15.0 & 39.1 & 31.4 & 33.9 & 24.0 & 41.1 & 27.5 & 59.2 & 60.5 & 109.0 & 87.9 \\
\hline 321 & 21.40 & 7.2 & 6.3 & 9.7 & 14.7 & 45.1 & 28.8 & 42.8 & 32.4 & 38.7 & 32.8 & 20.5 & 22.0 & 32.5 & 51.5 \\
\hline 322 & 21.44 & 6.2 & 4.7 & 9.6 & 11.3 & 21.7 & 45.0 & 16.2 & 21.8 & 9.9 & 29.2 & 22.6 & 22.7 & 49.4 & 64.8 \\
\hline 323 & 21.48 & 3.8 & 2.7 & 5.9 & 13.3 & 20.5 & 7.4 & 16.4 & 22.0 & 18.5 & 11.2 & 17.9 & 24.0 & 34.6 & 29.9 \\
\hline 324 & 21.52 & 5.1 & 5.6 & 7.8 & 4.6 & 14.6 & 11.8 & 11.8 & 19.0 & 14.8 & 21.3 & 20.9 & 13.7 & 35.3 & 36.3 \\
\hline 325 & 21.56 & 5.6 & 3.6 & 10.1 & 4.9 & 21.0 & 11.5 & 29.3 & 27.1 & 12.2 & 13.8 & 29.2 & 29.6 & 23.3 & 41.8 \\
\hline 326 & 21.61 & 3.4 & 2.2 & 5.4 & 7.1 & 12.1 & 21.2 & 8.1 & 8.4 & 20.4 & 18.1 & 17.7 & 43.6 & 27.2 & 25.8 \\
\hline 327 & 21.64 & 4.7 & 6.3 & 8.1 & 10.2 & 13.7 & 13.2 & 13.7 & 16.2 & 16.1 & 5.3 & 18.0 & 45.4 & 21.4 & 30.0 \\
\hline 328 & 21.68 & 3.2 & 3.2 & 6.9 & 8.0 & 24.0 & 23.6 & 17.7 & 9.2 & 25.6 & 23.8 & 19.2 & 20.6 & 46.4 & 55.9 \\
\hline 329 & 21.72 & 6.4 & 3.0 & 5.9 & 8.0 & 14.5 & 23.5 & 14.1 & 15.7 & 21.4 & 24.5 & 11.6 & 18.7 & 41.9 & 42.1 \\
\hline 330 & 21.76 & 6.7 & 5.6 & 9.8 & 8.0 & 37.7 & 27.1 & 24.9 & 27.9 & 17.2 & 25.3 & 19.3 & 37.2 & 23.5 & 18.6 \\
\hline 331 & 21.80 & 6.4 & 1.9 & 5.7 & 17.6 & 16.0 & 26.8 & 20.7 & 15.4 & 18.2 & 29.8 & 25.6 & 37.4 & 37.7 & 52.1 \\
\hline 332 & 21.84 & 2.0 & 3.6 & 10.2 & 8.9 & 27.0 & 27.6 & 17.8 & 17.2 & 27.8 & 22.0 & 17.5 & 15.9 & 46.7 & 47.4 \\
\hline 333 & 21.88 & 4.0 & 5.0 & 12.9 & 13.0 & 39.6 & 13.3 & 26.6 & 43.6 & 19.6 & 35.3 & 17.9 & 63.4 & 37.4 & 58.7 \\
\hline 334 & 21.92 & 9.8 & 2.0 & 10.6 & 10.2 & 44.4 & 17.4 & 13.8 & 31.3 & 33.9 & 36.2 & 36.3 & 37.2 & 63.0 & 34.7 \\
\hline 335 & 21.96 & 6.2 & 2.9 & 5.4 & 11.5 & 36.9 & 30.7 & 22.3 & 33.9 & 19.0 & 18.4 & 26.5 & 54.7 & 43.4 & 42.7 \\
\hline 336 & 22.02 & 4.0 & 2.5 & 6.2 & 8.4 & 13.0 & 16.5 & 30.6 & 14.4 & 9.6 & 17.9 & 33.5 & 38.1 & 67.2 & 203.5 \\
\hline 337 & 22.06 & 4.6 & 3.3 & 4.4 & 6.7 & 12.0 & 7.2 & 21.8 & 14.1 & 25.8 & 18.6 & 15.5 & 16.5 & 32.6 & 50.8 \\
\hline 338 & 22.10 & 2.3 & 2.2 & 4.8 & 7.1 & 16.5 & 9.5 & 14.6 & 15.6 & 10.5 & 14.8 & 16.9 & 21.2 & 24.5 & 24.2 \\
\hline 339 & 22.14 & 6.7 & 3.4 & 5.9 & 6.2 & 12.4 & 35.1 & 6.1 & 17.3 & 12.9 & 19.4 & 12.3 & 29.4 & 22.6 & 31.8 \\
\hline 340 & 22.17 & 3.3 & 2.7 & 3.1 & 3.3 & 26.5 & 12.7 & 10.5 & 12.5 & 15.5 & 22.1 & 12.5 & 23.2 & 12.6 & 33.3 \\
\hline 341 & 22.22 & 7.3 & 7.3 & 21.8 & 22.5 & 33.9 & 51.9 & 28.0 & 21.9 & 33.1 & 24.8 & 74.4 & 53.5 & 83.9 & 93.3 \\
\hline 342 & 22.25 & 9.6 & 5.3 & 18.3 & 23.0 & 40.5 & 62.5 & 56.2 & 44.6 & 69.8 & 29.6 & 101.4 & 98.3 & 47.3 & 82.0 \\
\hline 343 & 22.30 & 12.3 & 7.2 & 13.5 & 21.5 & 47.0 & 27.8 & 43.2 & 19.9 & 44.0 & 45.0 & 32.3 & 29.4 & 71.2 & 44.2 \\
\hline 344 & 22.33 & 5.8 & 2.7 & 16.6 & 19.9 & 27.1 & 26.2 & 29.9 & 30.2 & 24.1 & 29.0 & 47.7 & 41.4 & 42.9 & 39.0 \\
\hline 345 & 22.37 & 6.7 & 8.8 & 17.2 & 21.7 & 42.2 & 27.2 & 23.7 & 45.3 & 47.3 & 42.2 & 53.2 & 89.1 & 55.5 & 94.1 \\
\hline 346 & 22.40 & 2.7 & 5.3 & 14.9 & 26.2 & 24.3 & 49.4 & 16.0 & 15.0 & 50.2 & 28.2 & 36.9 & 57.5 & 66.9 & 64.2 \\
\hline 347 & 22.44 & 2.7 & 5.4 & 10.5 & 3.4 & 24.1 & 32.3 & 28.6 & 46.4 & 27.2 & 18.3 & 20.2 & 37.9 & 49.9 & 62.1 \\
\hline 348 & 22.49 & 7.7 & 2.1 & 7.2 & 7.5 & 22.2 & 34.0 & 25.8 & 29.0 & 21.8 & 38.2 & 42.1 & 38.5 & 24.6 & 114.6 \\
\hline 349 & 22.53 & 10.0 & 8.5 & 7.1 & 18.8 & 27.2 & 43.5 & 36.6 & 28.8 & 29.5 & 35.8 & 41.3 & 34.5 & 46.8 & 65.5 \\
\hline 350 & 22.56 & 7.3 & 6.7 & 7.0 & 19.4 & 41.0 & 38.4 & 29.1 & 8.7 & 21.8 & 30.3 & 36.5 & 55.7 & 41.0 & 48.9 \\
\hline 351 & 22.60 & 5.5 & 6.6 & 15.6 & 10.4 & 21.0 & 21.7 & 38.3 & 20.1 & 18.6 & 32.6 & 22.5 & 36.9 & 49.9 & 36.9 \\
\hline 352 & 22.64 & 4.0 & 3.9 & 8.2 & 5.8 & 23.3 & 18.8 & 19.4 & 10.6 & 9.3 & 20.7 & 15.2 & 22.6 & 25.3 & 57.7 \\
\hline 353 & 22.68 & 6.6 & 5.7 & 6.3 & 11.6 & 13.5 & 25.9 & 14.3 & 11.6 & 22.5 & 15.4 & 6.8 & 28.6 & 31.2 & 27.9 \\
\hline 354 & 22.71 & 6.7 & 3.7 & 9.7 & 8.1 & 22.8 & 27.0 & 24.8 & 15.3 & 38.2 & 25.6 & 48.3 & 40.5 & 50.1 & 68.9 \\
\hline 355 & 22.75 & 9.3 & 6.2 & 7.6 & 10.9 & 26.4 & 36.0 & 40.5 & 25.3 & 28.6 & 24.9 & 39.2 & 69.7 & 48.5 & 55.0 \\
\hline 356 & 22.78 & 4.4 & 3.2 & 9.2 & 5.7 & 31.8 & 28.0 & 22.1 & 15.4 & 18.6 & 21.3 & 23.0 & 29.1 & 34.6 & 55.0 \\
\hline 357 & 22.82 & 8.4 & 6.7 & 6.0 & 8.6 & 15.7 & 22.1 & 19.1 & 20.9 & 17.1 & 12.2 & 29.8 & 51.9 & 25.6 & 58.2 \\
\hline
\end{tabular}




\begin{tabular}{|c|c|c|c|c|c|c|c|c|c|c|c|c|c|c|c|}
\hline 358 & 22.85 & 6.1 & 1.2 & 9.1 & 17.1 & 32.3 & 25.5 & 41.9 & 29.8 & 19.6 & 36.5 & 24.6 & 58.6 & 38.9 & 70.3 \\
\hline 359 & 22.89 & 7.4 & 6.0 & 5.7 & 19.4 & 40.8 & 44.2 & 51.9 & 33.3 & 60.5 & 17.1 & 56.7 & 35.1 & 67.5 & 138.5 \\
\hline 360 & 22.94 & 7.9 & 2.0 & 17.1 & 14.4 & 34.6 & 34.4 & 19.7 & 30.9 & 31.5 & 33.5 & 37.5 & 74.4 & 38.8 & 50.9 \\
\hline 361 & 22.99 & 5.7 & 2.2 & 10.4 & 6.9 & 20.2 & 5.5 & 30.9 & 24.6 & 34.8 & 33.6 & 34.1 & 60.9 & 29.5 & 43.1 \\
\hline 362 & 23.04 & 5.3 & 4.5 & 11.5 & 12.2 & 20.9 & 54.5 & 31.5 & 23.4 & 29.3 & 30.6 & 48.0 & 57.3 & 25.8 & 58.8 \\
\hline 363 & 23.08 & 4.4 & 4.9 & 7.8 & 11.2 & 19.8 & 27.3 & 31.4 & 23.8 & 25.8 & 23.5 & 41.8 & 49.7 & 31.3 & 88.8 \\
\hline 364 & 23.12 & 6.8 & 3.9 & 7.2 & 8.3 & 33.8 & 34.1 & 23.5 & 18.6 & 35.9 & 53.4 & 33.0 & 41.0 & 67.0 & 45.9 \\
\hline 365 & 23.16 & 7.8 & 6.8 & 13.1 & 5.6 & 39.4 & 30.5 & 40.3 & 40.6 & 42.4 & 40.6 & 45.0 & 50.6 & 57.7 & 68.0 \\
\hline 366 & 23.21 & 7.1 & 1.5 & 12.9 & 8.2 & 48.9 & 24.3 & 46.2 & 31.5 & 60.5 & 24.0 & 54.2 & 69.3 & 45.0 & 89.6 \\
\hline 367 & 23.25 & 9.1 & 7.1 & 14.3 & 18.3 & 23.0 & 20.6 & 28.7 & 25.5 & 26.5 & 22.0 & 56.1 & 49.5 & 69.9 & 63.4 \\
\hline 368 & 23.29 & 4.4 & 3.0 & 9.2 & 7.8 & 29.4 & 20.0 & 23.2 & 33.8 & 11.3 & 39.6 & 37.0 & 34.4 & 33.5 & 49.1 \\
\hline 369 & 23.34 & 6.2 & 6.6 & 14.2 & 20.8 & 26.2 & 20.7 & 22.0 & 28.0 & 24.9 & 17.0 & 54.1 & 37.7 & 93.1 & 38.2 \\
\hline 370 & 23.38 & 7.2 & 4.4 & 14.4 & 6.0 & 18.7 & 14.5 & 21.8 & 18.3 & 15.8 & 27.6 & 33.2 & 15.2 & 24.6 & 43.9 \\
\hline 371 & 23.41 & 3.2 & 3.5 & 3.6 & 4.8 & 22.5 & 31.3 & 26.9 & 27.4 & 19.1 & 15.3 & 19.1 & 27.4 & 26.4 & 15.3 \\
\hline 372 & 23.44 & 6.4 & 2.9 & 11.8 & 12.0 & 16.0 & 16.0 & 19.1 & 20.2 & 13.4 & 27.6 & 21.9 & 18.3 & 43.0 & 37.5 \\
\hline 373 & 23.48 & 7.3 & 1.7 & 4.2 & 8.2 & 12.2 & 9.8 & 8.7 & 13.5 & 14.0 & 16.9 & 15.6 & 27.6 & 41.6 & 43.8 \\
\hline 374 & 23.52 & 7.8 & 5.5 & 8.3 & 4.3 & 33.6 & 21.3 & 22.1 & 32.6 & 24.0 & 44.0 & 27.2 & 19.1 & 26.6 & 85.6 \\
\hline 375 & 23.56 & 5.1 & 3.5 & 11.6 & 7.1 & 17.7 & 30.1 & 20.0 & 27.4 & 15.1 & 28.2 & 25.3 & 46.2 & 34.8 & 25.8 \\
\hline 376 & 23.60 & 2.7 & 2.1 & 8.5 & 5.9 & 30.3 & 15.7 & 14.4 & 27.1 & 29.0 & 28.5 & 21.0 & 14.3 & 24.1 & 33.0 \\
\hline 377 & 23.64 & 6.3 & 7.6 & 6.5 & 13.7 & 29.5 & 36.8 & 46.0 & 39.9 & 19.8 & 10.6 & 29.3 & 30.7 & 29.6 & 38.8 \\
\hline 378 & 23.68 & 2.9 & 3.4 & 4.6 & 7.0 & 14.7 & 17.6 & 14.4 & 17.5 & 16.9 & 18.4 & 11.4 & 24.6 & 11.6 & 19.6 \\
\hline 379 & 23.73 & 4.8 & 4.1 & 12.0 & 8.4 & 10.6 & 19.0 & 9.2 & 20.5 & 29.6 & 25.0 & 30.7 & 33.7 & 72.0 & 75.2 \\
\hline 380 & 23.77 & 3.8 & 1.4 & 6.7 & 4.5 & 9.8 & 27.7 & 6.7 & 22.2 & 16.2 & 16.6 & 21.5 & 51.3 & 44.3 & 44.2 \\
\hline 381 & 23.81 & 3.8 & 5.1 & 10.1 & 5.2 & 13.3 & 13.7 & 8.1 & 16.4 & 26.6 & 35.6 & 26.9 & 42.6 & 15.1 & 20.6 \\
\hline 382 & 23.84 & 5.9 & 1.3 & 8.0 & 5.1 & 15.5 & 11.4 & 10.2 & 18.2 & 14.2 & 17.1 & 33.3 & 46.7 & 47.6 & 40.7 \\
\hline 383 & 23.87 & 4.3 & 4.2 & 8.9 & 4.3 & 38.5 & 44.7 & 16.6 & 45.9 & 43.8 & 36.6 & 44.1 & 46.1 & 24.9 & 51.1 \\
\hline 384 & 23.91 & 4.0 & 4.6 & 17.3 & 13.7 & 18.2 & 31.6 & 26.9 & 11.6 & 32.8 & 25.4 & 47.1 & 35.6 & 95.6 & 243.0 \\
\hline 385 & 23.95 & 5.3 & 3.2 & 3.5 & 6.8 & 9.2 & 15.2 & 6.5 & 6.9 & 21.9 & 21.7 & 36.6 & 24.9 & 44.2 & 37.5 \\
\hline 386 & 24.02 & 8.1 & 2.0 & 13.8 & 21.2 & 26.9 & 34.3 & 40.5 & 26.4 & 35.4 & 35.6 & 36.1 & 53.8 & 44.7 & 103.0 \\
\hline 387 & 24.06 & 10.3 & 1.9 & 21.8 & 16.5 & 50.8 & 34.8 & 54.8 & 39.0 & 29.4 & 41.8 & 33.7 & 69.5 & 43.8 & 60.5 \\
\hline 388 & 24.10 & 5.7 & 4.7 & 11.6 & 10.2 & 17.5 & 15.5 & 24.8 & 22.8 & 24.6 & 18.9 & 18.5 & 42.6 & 31.2 & 47.4 \\
\hline 389 & 24.14 & 4.4 & 3.7 & 10.8 & 11.1 & 29.9 & 20.8 & 29.2 & 45.3 & 51.6 & 36.4 & 38.4 & 53.6 & 98.5 & 62.0 \\
\hline 390 & 24.18 & 6.2 & 4.5 & 3.5 & 5.1 & 15.4 & 19.3 & 21.2 & 25.4 & 12.6 & 18.0 & 23.2 & 13.1 & 57.4 & 33.0 \\
\hline 391 & 24.21 & 7.4 & 6.0 & 8.5 & 17.2 & 17.8 & 20.7 & 34.2 & 53.8 & 40.3 & 40.2 & 28.0 & 68.0 & 30.4 & 47.4 \\
\hline 392 & 24.25 & 8.1 & 1.8 & 14.7 & 10.6 & 25.8 & 30.0 & 28.9 & 14.0 & 34.2 & 24.6 & 48.0 & 35.6 & 56.9 & 55.2 \\
\hline 393 & 24.30 & 2.3 & 2.1 & 6.6 & 6.7 & 28.1 & 15.6 & 19.9 & 24.5 & 16.8 & 16.9 & 23.9 & 36.5 & 32.8 & 27.2 \\
\hline 394 & 24.34 & 1.7 & 4.0 & 7.3 & 8.1 & 17.7 & 22.0 & 12.4 & 23.8 & 10.7 & 24.8 & 24.1 & 49.2 & 23.2 & 39.3 \\
\hline 395 & 24.37 & 3.6 & 2.7 & 3.7 & 6.2 & 14.9 & 16.9 & 20.7 & 26.3 & 11.5 & 17.3 & 11.7 & 38.2 & 18.0 & 44.6 \\
\hline 396 & 24.41 & 4.4 & 1.1 & 4.0 & 6.5 & 13.8 & 11.8 & 16.8 & 20.7 & 7.5 & 14.9 & 23.2 & 32.4 & 29.9 & 43.5 \\
\hline 397 & 24.45 & 7.3 & 3.3 & 12.3 & 7.1 & 11.3 & 14.3 & 14.1 & 33.1 & 24.3 & 18.4 & 45.3 & 46.0 & 37.1 & 54.7 \\
\hline 398 & 24.49 & 2.7 & 5.3 & 8.6 & 5.2 & 33.6 & 26.1 & 27.0 & 10.0 & 20.3 & 17.2 & 27.1 & 54.5 & 19.8 & 42.0 \\
\hline 399 & 24.53 & 6.0 & 2.9 & 17.8 & 10.5 & 46.4 & 41.9 & 21.9 & 32.7 & 35.5 & 22.5 & 28.6 & 60.3 & 31.9 & 84.4 \\
\hline 400 & 24.56 & 4.7 & 5.5 & 9.1 & 21.6 & 22.4 & 15.9 & 36.3 & 24.0 & 16.8 & 20.5 & 21.2 & 37.5 & 50.7 & 54.2 \\
\hline 401 & 24.60 & 4.3 & 5.2 & 12.3 & 9.7 & 22.6 & 36.6 & 40.4 & 28.1 & 34.8 & 24.1 & 32.2 & 45.6 & 73.0 & 54.2 \\
\hline 402 & 24.64 & 4.4 & 3.2 & 3.0 & 8.4 & 9.6 & 20.9 & 22.1 & 12.1 & 20.7 & 9.9 & 28.2 & 40.4 & 19.5 & 43.9 \\
\hline 403 & 24.67 & 5.4 & 2.6 & 9.0 & 4.6 & 17.9 & 17.5 & 14.2 & 15.1 & 21.9 & 26.1 & 27.2 & 28.6 & 41.7 & 41.2 \\
\hline 404 & 24.71 & 7.5 & 2.3 & 13.7 & 10.5 & 31.3 & 17.7 & 20.7 & 29.5 & 20.5 & 33.3 & 15.2 & 19.2 & 36.5 & 92.4 \\
\hline 405 & 24.74 & 4.1 & 3.2 & 9.0 & 11.9 & 36.9 & 12.6 & 17.9 & 40.4 & 24.0 & 58.5 & 33.7 & 51.5 & 41.1 & 59.8 \\
\hline 406 & 24.78 & 12.0 & 3.9 & 20.8 & 23.4 & 25.9 & 19.8 & 53.9 & 43.4 & 49.5 & 29.5 & 56.0 & 65.6 & 164.1 & 90.7 \\
\hline 407 & 24.81 & 9.9 & 1.9 & 8.3 & 16.3 & 25.5 & 23.3 & 34.9 & 13.1 & 13.6 & 38.6 & 19.4 & 58.7 & 91.1 & 43.6 \\
\hline 408 & 24.85 & 5.6 & 6.2 & 10.8 & 14.6 & 72.9 & 33.8 & 46.3 & 38.7 & 41.1 & 18.3 & 32.3 & 63.5 & 56.3 & 66.7 \\
\hline 409 & 24.88 & 13.5 & 4.8 & 15.0 & 14.5 & 17.2 & 38.9 & 40.5 & 37.2 & 30.5 & 37.1 & 24.6 & 36.2 & 43.8 & 78.8 \\
\hline 410 & 24.92 & 6.2 & 3.3 & 12.7 & 9.5 & 33.0 & 49.8 & 15.0 & 18.1 & 44.0 & 30.4 & 35.8 & 52.2 & 50.7 & 69.1 \\
\hline 411 & 24.97 & 2.8 & 3.9 & 12.2 & 10.3 & 19.0 & 12.8 & 25.9 & 22.2 & 22.2 & 18.3 & 21.0 & 49.4 & 22.4 & 27.0 \\
\hline 412 & 25.03 & 1.7 & 3.0 & 5.5 & 9.6 & 39.6 & 21.3 & 21.4 & 17.6 & 15.4 & 32.4 & 21.4 & 23.1 & 24.9 & 38.1 \\
\hline 413 & 25.07 & 4.9 & 1.9 & 11.9 & 7.6 & 24.9 & 29.0 & 19.3 & 23.4 & 29.8 & 12.2 & 32.2 & 38.2 & 52.2 & 44.1 \\
\hline 414 & 25.11 & 3.1 & 3.5 & 5.0 & 7.7 & 15.2 & 20.3 & 10.4 & 9.9 & 20.0 & 13.3 & 12.7 & 30.8 & 35.7 & 26.9 \\
\hline 415 & 25.16 & 6.6 & 6.5 & 10.7 & 13.3 & 28.9 & 36.6 & 44.4 & 12.2 & 50.4 & 93.7 & 41.4 & 83.7 & 18.3 & 69.8 \\
\hline 416 & 25.20 & 8.0 & 7.3 & 10.3 & 9.0 & 37.4 & 46.8 & 12.8 & 28.2 & 29.1 & 42.2 & 16.0 & 24.4 & 65.2 & 52.8 \\
\hline 417 & 25.23 & 3.4 & 3.1 & 8.5 & 11.1 & 11.9 & 39.3 & 16.9 & 56.7 & 23.5 & 25.5 & 33.8 & 30.2 & 34.1 & 46.5 \\
\hline 418 & 25.27 & 8.8 & 4.6 & 17.5 & 19.3 & 38.3 & 23.3 & 41.4 & 37.2 & 50.7 & 43.6 & 61.0 & 37.6 & 81.4 & 60.2 \\
\hline 419 & 25.31 & 15.9 & 11.0 & 24.2 & 28.0 & 51.9 & 32.9 & 51.1 & 34.8 & 45.2 & 39.6 & 30.4 & 56.8 & 38.9 & 144.2 \\
\hline 420 & 25.35 & 11.5 & 10.2 & 9.5 & 12.0 & 28.9 & 17.5 & 34.3 & 30.9 & 39.4 & 56.5 & 39.9 & 81.4 & 72.7 & 72.0 \\
\hline 421 & 25.39 & 7.1 & 8.0 & 18.9 & 12.4 & 38.4 & 26.7 & 31.4 & 16.7 & 54.9 & 59.3 & 51.5 & 44.5 & 19.8 & 62.9 \\
\hline 422 & 25.43 & 4.9 & 3.7 & 11.7 & 7.2 & 21.2 & 11.9 & 29.0 & 27.3 & 22.3 & 33.3 & 54.4 & 61.9 & 30.9 & 71.2 \\
\hline 423 & 25.48 & 9.5 & 4.0 & 5.2 & 18.5 & 33.4 & 35.6 & 28.3 & 28.7 & 29.6 & 62.0 & 50.1 & 44.6 & 51.8 & 47.1 \\
\hline 424 & 25.52 & 4.9 & 4.3 & 5.2 & 6.0 & 11.3 & 19.9 & 22.1 & 24.5 & 15.3 & 9.8 & 25.0 & 20.2 & 49.4 & 53.3 \\
\hline 425 & 25.55 & 6.2 & 3.9 & 9.4 & 27.8 & 17.5 & 56.0 & 34.8 & 36.0 & 39.8 & 51.8 & 63.6 & 78.2 & 81.8 & 37.3 \\
\hline 426 & 25.58 & 5.2 & 6.1 & 7.0 & 10.5 & 24.7 & 29.6 & 18.0 & 27.8 & 32.8 & 41.9 & 28.9 & 43.3 & 10.5 & 68.0 \\
\hline 427 & 25.62 & 4.1 & 3.9 & 9.6 & 17.3 & 22.5 & 21.4 & 19.0 & 33.2 & 27.5 & 21.9 & 24.8 & 16.5 & 35.8 & 36.5 \\
\hline 428 & 25.66 & 1.6 & 2.6 & 15.5 & 10.6 & 25.2 & 14.6 & 26.1 & 20.5 & 25.3 & 34.3 & 30.9 & 37.0 & 66.8 & 54.1 \\
\hline 429 & 25.70 & 3.3 & 4.7 & 5.2 & 8.9 & 18.1 & 22.9 & 11.2 & 15.4 & 9.4 & 20.7 & 19.0 & 32.4 & 17.8 & 34.5 \\
\hline 430 & 25.74 & 2.9 & 4.9 & 11.8 & 15.2 & 25.3 & 27.9 & 31.4 & 25.0 & 41.3 & 22.8 & 44.0 & 91.0 & 54.8 & 240.1 \\
\hline 431 & 25.77 & 3.0 & 6.5 & 5.1 & 7.2 & 21.0 & 21.7 & 10.9 & 20.7 & 10.5 & 25.8 & 16.2 & 22.6 & 25.7 & 24.0 \\
\hline 432 & 25.80 & 5.1 & 2.2 & 8.3 & 11.7 & 17.7 & 26.5 & 28.5 & 16.7 & 30.3 & 34.9 & 53.2 & 60.1 & 56.4 & 76.0 \\
\hline 433 & 25.83 & 15.6 & 4.7 & 29.7 & 19.5 & 58.1 & 34.8 & 26.7 & 44.7 & 59.0 & 28.7 & 64.3 & 55.9 & 97.7 & 95.4 \\
\hline 434 & 25.87 & 5.4 & 1.6 & 7.4 & 15.3 & 39.7 & 25.1 & 19.7 & 31.4 & 30.9 & 20.8 & 34.3 & 46.3 & 49.0 & 128.9 \\
\hline
\end{tabular}




\begin{tabular}{|c|c|c|c|c|c|c|c|c|c|c|c|c|c|c|c|}
\hline 435 & 25.91 & 6.2 & 3.3 & 14.7 & 20.0 & 24.7 & 14.4 & 11.3 & 20.0 & 30.9 & 32.0 & 38.2 & 19.6 & 61.7 & 79.4 \\
\hline 436 & 25.95 & 15.1 & 2.1 & 8.9 & 4.7 & 18.6 & 35.3 & 18.8 & 17.7 & 16.8 & 21.1 & 22.4 & 23.5 & 33.9 & 42.5 \\
\hline 437 & 26.00 & 3.3 & 3.0 & 5.3 & 10.7 & 19.3 & 24.9 & 11.8 & 24.2 & 14.5 & 15.7 & 27.2 & 41.0 & 49.3 & 17.3 \\
\hline 438 & 26.05 & 7.9 & 3.8 & 8.4 & 5.1 & 13.7 & 38.7 & 23.1 & 17.2 & 26.8 & 33.1 & 30.2 & 36.9 & 41.1 & 50.0 \\
\hline 439 & 26.08 & 6.5 & 6.3 & 10.9 & 16.3 & 35.4 & 27.5 & 21.8 & 25.7 & 18.2 & 28.8 & 18.0 & 45.4 & 78.2 & 69.7 \\
\hline 440 & 26.12 & 7.4 & 4.3 & 8.8 & 13.0 & 46.6 & 25.3 & 34.3 & 28.1 & 40.1 & 47.5 & 24.2 & 62.7 & 31.9 & 21.8 \\
\hline 441 & 26.16 & 4.1 & 5.5 & 7.6 & 21.1 & 30.1 & 26.9 & 11.9 & 22.1 & 22.2 & 29.5 & 37.8 & 73.6 & 40.8 & 32.2 \\
\hline 442 & 26.21 & 15.4 & 2.6 & 11.8 & 6.4 & 42.3 & 24.8 & 19.9 & 27.7 & 6.1 & 45.0 & 32.6 & 33.5 & 29.2 & 52.2 \\
\hline 443 & 26.26 & 4.5 & 3.3 & 8.3 & 4.6 & 7.7 & 16.8 & 31.8 & 28.7 & 20.4 & 41.9 & 34.1 & 26.5 & 41.6 & 53.6 \\
\hline 444 & 26.30 & 12.3 & 4.2 & 8.4 & 7.8 & 12.8 & 33.9 & 16.7 & 17.0 & 29.2 & 28.9 & 30.3 & 32.4 & 22.4 & 70.8 \\
\hline 445 & 26.32 & 4.5 & 5.4 & 9.0 & 5.5 & 42.6 & 14.7 & 12.8 & 51.8 & 21.7 & 21.8 & 35.5 & 51.2 & 47.2 & 96.2 \\
\hline 446 & 26.36 & 1.4 & 4.8 & 18.1 & 18.2 & 16.3 & 29.4 & 33.5 & 36.0 & 26.8 & 18.0 & 62.9 & 60.2 & 77.1 & 50.2 \\
\hline 447 & 26.39 & 10.5 & 3.0 & 7.7 & 11.4 & 33.8 & 38.6 & 39.1 & 13.0 & 56.0 & 59.1 & 39.0 & 37.3 & 50.6 & 63.3 \\
\hline 448 & 26.43 & 4.7 & 3.1 & 7.2 & 5.7 & 28.2 & 34.3 & 14.0 & 31.2 & 30.1 & 52.7 & 34.9 & 45.1 & 67.6 & 38.3 \\
\hline 449 & 26.47 & 2.3 & 6.1 & 13.8 & 10.4 & 28.1 & 45.5 & 28.5 & 19.0 & 17.9 & 17.5 & 19.0 & 71.9 & 33.3 & 41.6 \\
\hline 450 & 26.51 & 2.4 & 3.3 & 6.7 & 9.5 & 24.6 & 14.0 & 18.2 & 27.6 & 29.6 & 22.5 & 18.6 & 56.6 & 29.4 & 24.1 \\
\hline 451 & 26.55 & 5.9 & 2.9 & 8.9 & 15.3 & 33.4 & 46.7 & 19.5 & 27.5 & 21.6 & 31.1 & 59.3 & 45.4 & 44.7 & 71.1 \\
\hline 452 & 26.58 & 3.6 & 5.0 & 4.5 & 6.8 & 8.0 & 21.9 & 14.3 & 11.1 & 21.4 & 22.2 & 25.4 & 29.9 & 38.0 & 30.7 \\
\hline 453 & 26.62 & 6.5 & 3.8 & 5.6 & 8.1 & 21.2 & 17.0 & 29.6 & 25.2 & 18.7 & 17.4 & 26.8 & 41.5 & 21.0 & 55.0 \\
\hline 454 & 26.65 & 2.6 & 3.2 & 10.0 & 11.1 & 19.0 & 42.3 & 28.7 & 13.5 & 30.3 & 16.3 & 37.7 & 31.8 & 26.2 & 32.2 \\
\hline 455 & 26.69 & 5.7 & 4.0 & 14.8 & 13.0 & 36.8 & 42.4 & 23.4 & 24.7 & 23.3 & 40.9 & 39.2 & 100.1 & 51.0 & 71.0 \\
\hline 456 & 26.73 & 2.3 & 3.0 & 3.9 & 2.5 & 9.5 & 14.3 & 17.7 & 13.6 & 18.7 & 14.2 & 12.7 & 17.7 & 15.0 & 30.2 \\
\hline 457 & 26.77 & 6.7 & 4.2 & 12.8 & 6.2 & 25.3 & 27.3 & 37.6 & 25.7 & 14.9 & 23.5 & 23.4 & 36.3 & 37.8 & 47.4 \\
\hline 458 & 26.81 & 5.2 & 4.4 & 11.3 & 11.2 & 15.1 & 30.8 & 20.5 & 40.0 & 31.9 & 23.6 & 51.3 & 63.7 & 33.3 & 36.6 \\
\hline 459 & 26.84 & 3.0 & 5.7 & 8.5 & 9.0 & 25.7 & 14.0 & 17.4 & 18.2 & 28.8 & 28.3 & 21.7 & 56.1 & 44.6 & 34.9 \\
\hline 460 & 26.88 & 3.6 & 4.0 & 12.0 & 12.5 & 34.9 & 38.5 & 13.9 & 23.3 & 14.9 & 22.0 & 17.2 & 32.6 & 67.3 & 52.1 \\
\hline 461 & 26.91 & 7.7 & 3.5 & 10.1 & 18.0 & 42.0 & 39.4 & 32.2 & 25.9 & 13.0 & 50.8 & 41.2 & 36.6 & 63.8 & 115.6 \\
\hline 462 & 26.95 & 1.8 & 1.8 & 11.1 & 12.6 & 12.4 & 18.8 & 21.8 & 37.4 & 32.0 & 23.0 & 25.5 & 44.9 & 38.5 & 41.8 \\
\hline 463 & 26.99 & 5.7 & 2.7 & 20.9 & 27.5 & 25.3 & 16.6 & 32.7 & 29.1 & 53.8 & 32.8 & 35.1 & 28.7 & 99.5 & 87.3 \\
\hline 464 & 27.04 & 4.6 & 3.7 & 11.0 & 11.4 & 11.8 & 29.2 & 16.5 & 32.5 & 40.3 & 32.3 & 33.7 & 52.3 & 57.5 & 51.1 \\
\hline 465 & 27.08 & 5.1 & 4.1 & 10.3 & 16.3 & 22.9 & 29.7 & 29.2 & 33.8 & 37.9 & 41.7 & 53.7 & 37.4 & 74.7 & 50.3 \\
\hline 466 & 27.13 & 6.0 & 2.7 & 11.3 & 16.9 & 28.3 & 28.5 & 24.7 & 34.8 & 19.9 & 63.8 & 31.5 & 29.6 & 23.2 & 39.3 \\
\hline 467 & 27.17 & 3.8 & 3.7 & 13.9 & 21.0 & 26.3 & 18.2 & 32.8 & 19.7 & 33.0 & 22.5 & 28.7 & 72.0 & 43.5 & 61.7 \\
\hline 468 & 27.21 & 5.9 & 3.0 & 11.9 & 15.6 & 25.2 & 6.9 & 18.2 & 16.5 & 19.2 & 29.0 & 25.2 & 33.3 & 34.5 & 25.0 \\
\hline 469 & 27.25 & 2.0 & 3.2 & 6.6 & 8.9 & 39.3 & 24.8 & 23.0 & 31.8 & 24.4 & 22.8 & 41.9 & 56.7 & 44.9 & 46.9 \\
\hline 470 & 27.28 & 3.7 & 4.5 & 20.1 & 18.7 & 30.8 & 15.8 & 12.9 & 17.6 & 23.8 & 15.8 & 69.6 & 52.2 & 61.8 & 64.0 \\
\hline 471 & 27.31 & 5.4 & 4.9 & 10.5 & 12.7 & 35.1 & 46.4 & 26.1 & 23.8 & 55.2 & 41.6 & 19.0 & 26.9 & 44.4 & 41.3 \\
\hline 472 & 27.35 & 2.9 & 0.8 & 11.0 & 10.8 & 41.6 & 37.9 & 38.6 & 17.2 & 23.7 & 27.7 & 24.0 & 45.2 & 45.3 & 43.2 \\
\hline 473 & 27.39 & 5.4 & 3.4 & 12.2 & 22.7 & 64.1 & 31.5 & 47.0 & 42.8 & 44.2 & 22.8 & 41.8 & 54.9 & 120.5 & 214.2 \\
\hline 474 & 27.43 & 6.8 & 5.7 & 9.4 & 15.5 & 19.1 & 26.5 & 31.7 & 34.3 & 16.2 & 32.2 & 42.2 & 55.1 & 60.9 & 53.7 \\
\hline 475 & 27.47 & 3.9 & 4.7 & 9.4 & 14.0 & 12.5 & 18.4 & 19.7 & 18.5 & 21.6 & 16.7 & 47.2 & 48.9 & 34.7 & 36.0 \\
\hline 476 & 27.50 & 1.4 & 4.1 & 3.8 & 7.5 & 28.4 & 20.3 & 19.0 & 25.0 & 19.5 & 30.3 & 42.5 & 39.0 & 32.4 & 35.1 \\
\hline 477 & 27.54 & 3.7 & 3.3 & 8.6 & 5.2 & 19.5 & 16.6 & 22.4 & 20.1 & 4.2 & 18.5 & 15.5 & 37.7 & 23.1 & 35.2 \\
\hline 478 & 27.57 & 6.7 & 5.2 & 10.8 & 7.7 & 31.7 & 14.3 & 37.6 & 17.1 & 16.5 & 45.7 & 28.8 & 54.0 & 39.4 & 60.2 \\
\hline 479 & 27.61 & 12.9 & 3.4 & 21.0 & 18.8 & 28.2 & 28.9 & 32.8 & 27.9 & 50.9 & 43.6 & 17.9 & 50.4 & 29.6 & 135.5 \\
\hline 480 & 27.65 & 3.7 & 5.8 & 13.9 & 13.5 & 53.4 & 31.0 & 23.8 & 30.2 & 21.6 & 32.2 & 20.8 & 36.2 & 32.0 & 73.3 \\
\hline 481 & 27.68 & 4.2 & 2.3 & 6.8 & 10.2 & 22.3 & 26.2 & 17.2 & 29.3 & 22.8 & 25.0 & 35.8 & 37.6 & 31.6 & 65.8 \\
\hline 482 & 27.71 & 4.8 & 4.1 & 10.5 & 11.2 & 14.4 & 18.5 & 33.7 & 12.7 & 31.2 & 12.4 & 25.6 & 53.5 & 18.3 & 42.2 \\
\hline 483 & 27.74 & 5.2 & 3.1 & 10.7 & 8.6 & 17.7 & 12.8 & 25.1 & 12.9 & 30.5 & 16.6 & 21.9 & 34.6 & 51.8 & 71.1 \\
\hline 484 & 27.77 & 6.4 & 3.4 & 18.8 & 17.6 & 42.6 & 28.1 & 18.2 & 32.7 & 27.0 & 24.9 & 22.7 & 57.5 & 79.0 & 90.7 \\
\hline 485 & 27.80 & 3.7 & 8.5 & 13.0 & 18.9 & 33.7 & 44.4 & 36.6 & 38.6 & 23.6 & 20.0 & 28.4 & 45.2 & 59.0 & 49.6 \\
\hline 486 & 27.83 & 3.0 & 6.8 & 18.3 & 10.3 & 59.3 & 36.0 & 24.4 & 44.5 & 27.3 & 31.7 & 61.3 & 82.9 & 63.8 & 50.4 \\
\hline 487 & 27.86 & 5.6 & 3.0 & 3.5 & 3.8 & 12.3 & 29.3 & 26.1 & 16.0 & 26.3 & 23.1 & 30.2 & 41.3 & 27.4 & 37.7 \\
\hline 488 & 27.89 & 4.5 & 2.6 & 5.2 & 11.0 & 25.9 & 18.9 & 19.9 & 17.0 & 16.6 & 12.4 & 21.0 & 23.4 & 32.8 & 40.2 \\
\hline 489 & 27.93 & 4.2 & 2.6 & 11.3 & 12.9 & 13.8 & 14.7 & 18.3 & 15.9 & 15.0 & 18.2 & 34.0 & 28.4 & 19.7 & 53.2 \\
\hline 490 & 27.97 & 4.7 & 2.9 & 11.5 & 8.0 & 29.5 & 8.6 & 12.4 & 31.9 & 19.8 & 13.0 & 23.3 & 40.4 & 15.3 & 33.6 \\
\hline 491 & 28.02 & 7.2 & 2.5 & 14.1 & 9.1 & 22.5 & 17.5 & 30.9 & 26.1 & 9.4 & 14.1 & 27.9 & 29.7 & 42.2 & 99.1 \\
\hline 492 & 28.06 & 2.4 & 4.2 & 6.8 & 6.4 & 7.5 & 20.6 & 11.2 & 22.9 & 18.4 & 25.6 & 18.1 & 20.2 & 38.5 & 25.1 \\
\hline 493 & 28.10 & 5.5 & 2.1 & 7.3 & 15.7 & 52.6 & 34.2 & 22.3 & 31.4 & 34.8 & 18.4 & 38.7 & 23.3 & 40.7 & 48.9 \\
\hline 494 & 28.14 & 7.0 & 5.4 & 14.9 & 30.1 & 54.8 & 32.9 & 14.6 & 36.7 & 41.1 & 23.0 & 23.9 & 44.9 & 90.1 & 51.4 \\
\hline 495 & 28.17 & 9.9 & 3.9 & 10.4 & 11.7 & 38.8 & 32.2 & 33.8 & 43.7 & 22.7 & 60.9 & 52.8 & 79.1 & 22.7 & 41.0 \\
\hline 496 & 28.21 & 5.3 & 3.4 & 13.6 & 11.0 & 27.5 & 30.2 & 33.2 & 25.9 & 37.0 & 37.5 & 33.2 & 36.1 & 39.8 & 55.9 \\
\hline 497 & 28.25 & 4.0 & 4.7 & 6.2 & 7.5 & 28.0 & 23.8 & 23.0 & 26.8 & 24.8 & 12.3 & 46.3 & 54.9 & 46.2 & 53.1 \\
\hline 498 & 28.29 & 2.7 & 2.0 & 4.6 & 8.1 & 8.0 & 9.2 & 6.2 & 10.7 & 7.9 & 9.3 & 12.2 & 11.9 & 25.2 & 38.4 \\
\hline 499 & 28.33 & 2.0 & 1.6 & 3.1 & 11.5 & 11.3 & 9.3 & 15.9 & 15.5 & 10.5 & 22.9 & 7.7 & 25.4 & 23.4 & 35.2 \\
\hline 500 & 28.37 & 4.8 & 4.9 & 7.6 & 8.8 & 24.1 & 39.4 & 13.2 & 12.4 & 18.9 & 22.3 & 24.5 & 35.0 & 43.3 & 39.4 \\
\hline 501 & 28.41 & 6.2 & 2.7 & 6.4 & 9.1 & 21.7 & 20.5 & 24.5 & 14.5 & 33.0 & 29.4 & 26.6 & 25.7 & 33.5 & 23.0 \\
\hline 502 & 28.45 & 9.7 & 5.5 & 13.4 & 13.9 & 53.1 & 37.2 & 55.8 & 54.5 & 31.5 & 43.2 & 78.6 & 70.4 & 119.3 & 88.6 \\
\hline 503 & 28.49 & 5.0 & 8.5 & 14.3 & 7.4 & 25.2 & 34.0 & 11.8 & 12.9 & 26.8 & 15.3 & 33.5 & 50.6 & 34.6 & 35.3 \\
\hline 504 & 28.53 & 4.1 & 2.6 & 4.5 & 6.6 & 12.2 & 12.4 & 14.7 & 14.9 & 16.3 & 20.7 & 15.8 & 18.0 & 21.5 & 25.7 \\
\hline 505 & 28.57 & 2.3 & 4.1 & 5.7 & 13.0 & 26.7 & 18.8 & 22.5 & 31.6 & 47.6 & 35.3 & 44.4 & 101.2 & 70.1 & 65.9 \\
\hline 506 & 28.60 & 9.4 & 4.5 & 15.0 & 20.8 & 9.2 & 38.0 & 62.1 & 59.6 & 31.7 & 35.4 & 47.2 & 39.1 & 80.9 & 91.5 \\
\hline 507 & 28.64 & 3.4 & 73.1 & 11.6 & 10.3 & 25.9 & 20.3 & 13.0 & 13.2 & 22.6 & 14.8 & 36.2 & 65.5 & 38.7 & 61.1 \\
\hline 508 & 28.68 & 3.9 & 1.4 & 4.7 & 4.6 & 13.1 & 17.0 & 9.4 & 20.4 & 8.5 & 11.2 & 16.5 & 35.0 & 28.2 & 23.6 \\
\hline 509 & 28.72 & 3.8 & 2.0 & 9.3 & 10.2 & 41.2 & 20.9 & 24.9 & 31.1 & 13.8 & 33.1 & 32.2 & 54.2 & 34.6 & 50.0 \\
\hline 510 & 28.76 & 2.5 & 2.1 & 3.3 & 3.4 & 7.2 & 8.7 & 9.7 & 11.6 & 13.2 & 15.1 & 16.2 & 17.6 & 31.6 & 45.1 \\
\hline 511 & 28.80 & 2.2 & 1.8 & 5.5 & 5.0 & 23.6 & 17.3 & 20.9 & 10.1 & 17.4 & 33.7 & 22.2 & 25.8 & 23.1 & 25.3 \\
\hline
\end{tabular}




\begin{tabular}{|c|c|c|c|c|c|c|c|c|c|c|c|c|c|c|c|}
\hline 512 & 28.84 & 6.0 & 4.7 & 10.8 & 15.3 & 36.4 & 23.5 & 11.3 & 28.1 & 12.9 & 24.6 & 27.3 & 66.3 & 29.5 & 58.6 \\
\hline 513 & 28.88 & 4.1 & 2.6 & 4.0 & 8.0 & 10.7 & 12.9 & 5.5 & 19.9 & 19.3 & 8.1 & 21.7 & 39.1 & 28.8 & 23.9 \\
\hline 514 & 28.91 & 5.0 & 3.9 & 8.5 & 6.9 & 21.9 & 24.9 & 17.5 & 19.7 & 14.5 & 43.1 & 18.1 & 32.1 & 49.9 & 53.3 \\
\hline 515 & 28.95 & 3.2 & 1.3 & 7.3 & 14.4 & 22.6 & 25.3 & 20.1 & 20.0 & 10.3 & 17.7 & 16.4 & 31.7 & 17.8 & 42.0 \\
\hline 516 & 29.00 & 2.7 & 3.4 & 2.7 & 14.2 & 16.8 & 21.1 & 29.2 & 12.0 & 16.2 & 43.3 & 30.4 & 40.7 & 40.5 & 55.1 \\
\hline 517 & 29.04 & 5.0 & 64.3 & 3.5 & 16.1 & 26.8 & 30.8 & 24.8 & 26.8 & 34.7 & 27.8 & 16.7 & 18.0 & 41.3 & 75.5 \\
\hline 518 & 29.09 & 7.7 & 2.5 & 17.0 & 12.3 & 32.6 & 19.2 & 20.1 & 33.9 & 29.0 & 30.7 & 67.9 & 29.2 & 40.9 & 45.4 \\
\hline 519 & 29.13 & 2.2 & 2.5 & 2.6 & 7.7 & 20.0 & 41.9 & 14.4 & 21.1 & 20.5 & 15.6 & 27.6 & 36.9 & 26.8 & 17.2 \\
\hline 520 & 29.17 & 5.7 & 4.8 & 7.7 & 7.9 & 12.2 & 16.1 & 19.9 & 26.0 & 14.1 & 19.2 & 21.3 & 51.6 & 44.5 & 30.6 \\
\hline 521 & 29.21 & 22.6 & 4.6 & 4.9 & 11.8 & 52.7 & 27.5 & 17.3 & 21.1 & 25.6 & 12.7 & 34.5 & 61.5 & 50.0 & 77.4 \\
\hline 522 & 29.24 & 4.1 & 3.4 & 7.2 & 14.2 & 28.6 & 31.2 & 19.0 & 36.9 & 33.8 & 23.4 & 27.5 & 54.7 & 35.0 & 48.0 \\
\hline 523 & 29.28 & 5.6 & 2.7 & 6.5 & 4.5 & 14.8 & 16.1 & 23.1 & 8.2 & 5.7 & 22.7 & 32.0 & 43.0 & 32.6 & 24.1 \\
\hline 524 & 29.32 & 3.1 & 3.7 & 6.7 & 13.0 & 38.4 & 22.5 & 27.5 & 26.6 & 38.0 & 29.5 & 33.4 & 43.4 & 44.8 & 34.7 \\
\hline 525 & 29.36 & 10.3 & 2.9 & 11.7 & 12.9 & 9.2 & 32.4 & 38.5 & 26.8 & 21.2 & 39.0 & 13.4 & 44.9 & 42.5 & 175.1 \\
\hline 526 & 29.42 & 4.9 & 3.2 & 7.5 & 8.3 & 11.4 & 19.8 & 15.2 & 21.3 & 24.6 & 21.1 & 25.5 & 40.6 & 31.2 & 34.3 \\
\hline 527 & 29.46 & 4.1 & 5.9 & 10.7 & 15.4 & 26.8 & 23.9 & 19.9 & 28.5 & 13.2 & 46.1 & 23.7 & 37.0 & 54.6 & 65.2 \\
\hline 528 & 29.50 & 8.8 & 1.9 & 16.3 & 9.6 & 32.3 & 33.3 & 37.5 & 38.1 & 35.8 & 31.7 & 17.4 & 36.0 & 30.0 & 91.7 \\
\hline 529 & 29.54 & 3.1 & 3.8 & 4.3 & 10.0 & 26.3 & 18.9 & 13.2 & 28.2 & 20.2 & 20.4 & 21.7 & 23.4 & 33.8 & 28.4 \\
\hline 530 & 29.58 & 4.9 & 3.8 & 8.0 & 7.9 & 39.3 & 35.3 & 24.3 & 23.7 & 11.8 & 37.5 & 30.8 & 26.0 & 58.7 & 25.5 \\
\hline 531 & 29.61 & 4.0 & 2.0 & 7.3 & 12.1 & 10.6 & 32.4 & 5.8 & 23.1 & 15.2 & 34.5 & 32.4 & 21.4 & 41.6 & 29.1 \\
\hline 532 & 29.65 & 3.9 & 2.8 & 5.3 & 8.1 & 20.6 & 9.0 & 11.2 & 31.2 & 26.0 & 21.7 & 15.9 & 32.1 & 40.3 & 50.9 \\
\hline 533 & 29.70 & 3.6 & 3.0 & 11.9 & 7.6 & 32.1 & 106.9 & 10.7 & 16.9 & 21.4 & 19.2 & 21.3 & 46.7 & 44.0 & 36.5 \\
\hline 534 & 29.74 & 3.7 & 1.8 & 2.1 & 7.3 & 12.2 & 13.7 & 9.9 & 17.0 & 20.7 & 23.8 & 12.3 & 28.4 & 16.2 & 40.6 \\
\hline 535 & 29.78 & 3.2 & 4.0 & 4.1 & 7.0 & 18.6 & 19.1 & 15.4 & 13.5 & 9.4 & 12.6 & 16.0 & 23.8 & 25.0 & 22.6 \\
\hline 536 & 29.82 & 3.3 & 2.9 & 7.4 & 5.8 & 15.7 & 24.4 & 16.4 & 22.8 & 12.3 & 10.8 & 23.7 & 26.5 & 28.6 & 32.1 \\
\hline 537 & 29.85 & 105.1 & 33.3 & 82.4 & 141.6 & 89.7 & 97.8 & 56.7 & 99.6 & 140.3 & 112.9 & 245.0 & 118.9 & 245.0 & 128.4 \\
\hline 538 & 29.89 & 5.5 & 5.6 & 6.2 & 12.2 & 20.5 & 15.1 & 47.3 & 31.3 & 23.6 & 29.0 & 22.7 & 31.7 & 67.5 & 51.0 \\
\hline 539 & 29.93 & 70.2 & 2.3 & 15.1 & 17.2 & 40.4 & 43.3 & 26.6 & 35.5 & 35.3 & 45.3 & 42.1 & 96.1 & 48.3 & 62.6 \\
\hline 540 & 29.97 & 106.7 & 2.3 & 12.7 & 18.3 & 54.0 & 29.6 & 27.2 & 31.3 & 43.8 & 22.8 & 46.6 & 38.6 & 51.0 & 144.8 \\
\hline 541 & 30.03 & 5.2 & 2.7 & 13.0 & 10.4 & 11.5 & 15.9 & 23.7 & 13.1 & 14.7 & 19.0 & 39.5 & 50.8 & 45.0 & 38.5 \\
\hline 542 & 30.07 & 6.3 & 3.5 & 6.5 & 14.2 & 39.7 & 8.3 & 26.2 & 32.3 & 61.9 & 43.1 & 49.5 & 52.1 & 22.6 & 98.6 \\
\hline 543 & 30.11 & 1.8 & 0.8 & 8.7 & 4.5 & 6.5 & 11.9 & 11.0 & 4.8 & 8.8 & 14.1 & 13.9 & 31.6 & 21.2 & 24.8 \\
\hline 544 & 30.15 & 8.9 & 2.7 & 8.2 & 14.0 & 17.6 & 18.8 & 27.2 & 20.9 & 16.7 & 17.5 & 16.6 & 18.9 & 18.2 & 31.4 \\
\hline 545 & 30.19 & 3.5 & 2.7 & 12.8 & 7.4 & 23.2 & 19.9 & 17.1 & 39.2 & 21.6 & 28.4 & 19.4 & 59.8 & 24.4 & 32.0 \\
\hline 546 & 30.23 & 2.9 & 2.3 & 8.9 & 8.2 & 22.4 & 26.8 & 23.4 & 14.5 & 25.7 & 15.9 & 28.0 & 23.7 & 38.6 & 32.1 \\
\hline 547 & 30.28 & 3.0 & 3.2 & 11.1 & 14.3 & 19.8 & 26.2 & 15.6 & 24.1 & 21.7 & 20.3 & 26.6 & 57.1 & 35.8 & 51.9 \\
\hline 548 & 30.32 & 5.1 & 5.0 & 5.4 & 10.0 & 17.0 & 27.3 & 27.8 & 18.2 & 40.4 & 16.7 & 47.0 & 7.1 & 38.5 & 25.0 \\
\hline 549 & 30.37 & 6.3 & 2.4 & 13.1 & 7.4 & 22.9 & 23.6 & 37.3 & 28.2 & 33.1 & 29.6 & 48.4 & 38.7 & 24.9 & 74.4 \\
\hline 550 & 30.41 & 14.4 & 2.6 & 11.6 & 12.3 & 21.1 & 13.5 & 16.1 & 27.2 & 16.1 & 21.8 & 27.0 & 13.8 & 28.4 & 51.9 \\
\hline 551 & 30.45 & 3.8 & 3.4 & 6.9 & 6.9 & 7.6 & 16.3 & 8.3 & 10.4 & 6.8 & 17.6 & 17.7 & 17.0 & 11.8 & 28.3 \\
\hline 552 & 30.49 & 5.9 & 5.2 & 9.1 & 11.3 & 32.1 & 24.4 & 34.1 & 21.1 & 10.0 & 19.3 & 16.3 & 58.5 & 54.3 & 92.1 \\
\hline 553 & 30.53 & 4.8 & 4.7 & 6.5 & 20.0 & 22.2 & 17.6 & 38.3 & 28.9 & 16.7 & 49.3 & 42.3 & 53.1 & 39.9 & 61.7 \\
\hline 554 & 30.57 & 14.8 & 5.6 & 13.8 & 19.5 & 25.3 & 33.4 & 22.5 & 21.9 & 21.4 & 21.3 & 42.7 & 27.5 & 72.9 & 59.0 \\
\hline 555 & 30.61 & 5.5 & 2.3 & 14.0 & 18.1 & 26.6 & 22.3 & 67.2 & 26.6 & 15.1 & 34.4 & 33.7 & 62.8 & 57.6 & 84.8 \\
\hline 556 & 30.65 & 5.7 & 2.4 & 4.2 & 8.0 & 13.2 & 25.5 & 6.7 & 14.6 & 18.9 & 42.2 & 30.0 & 37.6 & 54.8 & 67.3 \\
\hline 557 & 30.69 & 6.7 & 5.4 & 22.3 & 15.4 & 31.0 & 30.5 & 56.4 & 34.1 & 54.5 & 52.9 & 50.7 & 28.9 & 58.7 & 91.8 \\
\hline 558 & 30.73 & 4.6 & 9.1 & 12.7 & 13.5 & 36.2 & 8.4 & 18.0 & 23.9 & 23.1 & 40.3 & 31.3 & 29.5 & 73.2 & 60.7 \\
\hline 559 & 30.76 & 7.3 & 2.5 & 3.4 & 6.0 & 13.5 & 13.2 & 14.4 & 10.3 & 11.5 & 19.2 & 18.1 & 25.4 & 17.8 & 29.0 \\
\hline 560 & 30.80 & 6.5 & 8.6 & 7.9 & 17.2 & 36.3 & 49.1 & 23.5 & 28.7 & 38.2 & 42.7 & 46.2 & 70.5 & 42.0 & 45.7 \\
\hline 561 & 30.84 & 6.9 & 2.4 & 6.7 & 7.7 & 25.4 & 30.4 & 29.3 & 25.7 & 49.0 & 15.9 & 25.0 & 47.6 & 15.5 & 44.2 \\
\hline 562 & 30.87 & 2.2 & 2.7 & 2.4 & 6.0 & 25.4 & 21.0 & 20.1 & 19.2 & 13.6 & 10.1 & 5.1 & 30.4 & 25.8 & 52.3 \\
\hline 563 & 30.91 & 3.1 & 3.3 & 5.3 & 5.8 & 11.0 & 21.8 & 14.2 & 11.6 & 17.7 & 49.6 & 28.2 & 29.4 & 44.9 & 70.5 \\
\hline 564 & 30.95 & 1.9 & 0.8 & 12.0 & 12.8 & 22.6 & 27.2 & 15.7 & 20.5 & 36.9 & 14.8 & 19.9 & 33.1 & 30.9 & 82.8 \\
\hline 565 & 30.99 & 1.2 & 2.5 & 6.3 & 6.7 & 8.3 & 29.1 & 22.6 & 19.1 & 27.9 & 32.2 & 18.6 & 60.8 & 11.4 & 27.2 \\
\hline 566 & 31.04 & 3.4 & 2.3 & 3.2 & 7.3 & 14.2 & 10.4 & 16.2 & 8.4 & 6.9 & 10.1 & 15.6 & 19.6 & 12.8 & 12.4 \\
\hline 567 & 31.08 & 2.8 & 1.4 & 5.6 & 3.3 & 14.8 & 16.1 & 12.2 & 9.1 & 11.6 & 8.9 & 17.4 & 12.1 & 17.5 & 37.8 \\
\hline 568 & 31.13 & 5.4 & 3.2 & 5.7 & 7.1 & 20.7 & 22.3 & 33.3 & 27.6 & 21.6 & 34.2 & 15.0 & 32.2 & 42.2 & 31.1 \\
\hline 569 & 31.17 & 3.7 & 3.5 & 6.0 & 13.3 & 51.1 & 44.7 & 22.8 & 38.8 & 37.7 & 28.0 & 36.8 & 29.8 & 50.7 & 36.1 \\
\hline 570 & 31.21 & 3.4 & 2.7 & 10.5 & 17.1 & 23.4 & 36.9 & 21.5 & 14.2 & 11.4 & 15.9 & 32.3 & 38.3 & 33.6 & 58.7 \\
\hline 571 & 31.26 & 10.7 & 4.9 & 12.3 & 12.8 & 20.9 & 32.1 & 32.6 & 33.4 & 34.4 & 49.3 & 34.8 & 65.5 & 103.6 & 124.0 \\
\hline 572 & 31.30 & 7.1 & 5.4 & 19.8 & 31.9 & 26.1 & 51.4 & 35.3 & 42.7 & 37.8 & 32.0 & 54.6 & 82.1 & 71.8 & 187.9 \\
\hline 573 & 31.34 & 7.6 & 7.4 & 20.2 & 34.8 & 34.3 & 44.7 & 60.3 & 43.9 & 72.5 & 70.3 & 41.5 & 62.3 & 55.3 & 161.8 \\
\hline 574 & 31.38 & 5.8 & 6.0 & 21.0 & 11.6 & 27.4 & 51.2 & 32.1 & 71.2 & 59.8 & 23.6 & 84.4 & 31.2 & 55.0 & 65.4 \\
\hline 575 & 31.42 & 5.2 & 3.0 & 3.4 & 10.9 & 47.2 & 18.0 & 24.5 & 24.1 & 16.1 & 26.8 & 43.0 & 64.2 & 46.1 & 53.1 \\
\hline 576 & 31.45 & 11.3 & 4.2 & 5.8 & 10.6 & 18.8 & 35.4 & 9.2 & 18.2 & 26.6 & 18.2 & 24.6 & 10.4 & 54.2 & 67.5 \\
\hline 577 & 31.49 & 17.6 & 4.2 & 8.3 & 15.4 & 60.7 & 29.8 & 45.4 & 29.4 & 32.8 & 22.7 & 33.1 & 43.2 & 59.4 & 79.8 \\
\hline 578 & 31.52 & 2.2 & 3.0 & 7.2 & 14.3 & 19.7 & 28.2 & 25.6 & 15.3 & 15.7 & 21.9 & 34.7 & 67.2 & 39.1 & 38.2 \\
\hline 579 & 31.57 & 2.4 & 1.8 & 11.1 & 15.3 & 25.4 & 24.7 & 7.9 & 23.2 & 39.1 & 25.6 & 32.3 & 52.2 & 33.1 & 41.9 \\
\hline 580 & 31.61 & 2.8 & 3.8 & 7.3 & 16.1 & 15.1 & 30.4 & 16.8 & 15.4 & 34.8 & 18.9 & 27.5 & 11.3 & 31.1 & 62.8 \\
\hline 581 & 31.65 & 7.6 & 2.5 & 6.6 & 12.9 & 20.4 & 21.1 & 21.1 & 36.8 & 33.0 & 27.7 & 13.5 & 25.9 & 56.0 & 56.1 \\
\hline 582 & 31.68 & 2.9 & 1.6 & 11.6 & 12.6 & 44.2 & 34.5 & 32.8 & 25.6 & 27.8 & 67.1 & 27.7 & 63.7 & 65.4 & 69.8 \\
\hline 583 & 31.71 & 4.0 & 5.1 & 16.2 & 21.2 & 49.8 & 38.7 & 38.6 & 45.1 & 47.0 & 41.6 & 52.0 & 39.2 & 55.3 & 44.8 \\
\hline 584 & 31.75 & 3.9 & 4.0 & 8.3 & 14.1 & 26.8 & 38.8 & 21.4 & 23.1 & 26.5 & 45.1 & 50.3 & 31.0 & 48.0 & 99.8 \\
\hline 585 & 31.79 & 7.5 & 5.5 & 23.7 & 16.5 & 23.2 & 28.2 & 29.7 & 16.1 & 36.1 & 27.7 & 18.4 & 47.4 & 34.6 & 69.3 \\
\hline 586 & 31.82 & 3.3 & 4.5 & 17.3 & 13.2 & 38.1 & 22.5 & 35.4 & 35.3 & 35.8 & 20.9 & 44.8 & 59.1 & 33.3 & 54.1 \\
\hline 587 & 31.86 & 3.4 & 1.3 & 8.1 & 4.0 & 15.4 & 27.4 & 23.8 & 10.9 & 14.3 & 16.1 & 12.0 & 7.0 & 22.8 & 13.4 \\
\hline 588 & 31.89 & 1.8 & 6.5 & 11.2 & 15.4 & 24.6 & 37.2 & 20.9 & 16.6 & 34.3 & 20.7 & 44.1 & 48.5 & 55.8 & 33.5 \\
\hline
\end{tabular}




\begin{tabular}{|c|c|c|c|c|c|c|c|c|c|c|c|c|c|c|c|}
\hline 589 & 31.93 & 3.7 & 3.0 & 8.1 & 12.6 & 45.2 & 23.5 & 35.9 & 19.7 & 29.4 & 36.2 & 33.1 & 88.0 & 41.4 & 48.8 \\
\hline 590 & 31.97 & 2.6 & 2.7 & 3.9 & 4.3 & 16.7 & 12.7 & 8.7 & 18.8 & 12.0 & 16.8 & 37.2 & 21.2 & 40.1 & 40.4 \\
\hline 591 & 32.04 & 5.2 & 3.1 & 3.4 & 8.5 & 73.1 & 61.8 & 43.8 & 34.4 & 64.5 & 25.0 & 44.5 & 57.0 & 45.5 & 54.4 \\
\hline 592 & 32.08 & 6.0 & 4.5 & 13.0 & 16.8 & 23.7 & 27.1 & 57.7 & 34.6 & 35.7 & 42.4 & 48.0 & 24.1 & 48.7 & 113.0 \\
\hline 593 & 32.12 & 6.0 & 3.9 & 18.8 & 28.8 & 18.9 & 35.8 & 29.5 & 43.6 & 25.8 & 54.5 & 35.6 & 44.9 & 40.1 & 83.3 \\
\hline 594 & 32.16 & 5.0 & 2.2 & 7.8 & 16.4 & 20.2 & 15.9 & 19.6 & 18.3 & 20.8 & 20.0 & 23.4 & 42.8 & 67.0 & 45.3 \\
\hline 595 & 32.20 & 2.6 & 2.3 & 8.8 & 13.9 & 14.3 & 25.4 & 26.4 & 27.2 & 17.3 & 14.9 & 23.9 & 25.1 & 18.2 & 46.5 \\
\hline 596 & 32.24 & 6.4 & 4.3 & 10.9 & 7.2 & 20.1 & 25.0 & 26.5 & 18.4 & 17.9 & 23.8 & 19.4 & 53.3 & 39.4 & 50.4 \\
\hline 597 & 32.28 & 4.1 & 2.5 & 6.6 & 13.8 & 20.4 & 12.5 & 29.4 & 18.9 & 15.5 & 24.6 & 52.0 & 42.9 & 39.5 & 116.8 \\
\hline 598 & 32.33 & 2.6 & 2.7 & 8.5 & 7.7 & 18.8 & 26.7 & 19.1 & 12.9 & 12.3 & 11.5 & 19.4 & 23.7 & 25.9 & 47.1 \\
\hline 599 & 32.37 & 5.4 & 4.3 & 10.9 & 13.5 & 13.3 & 22.9 & 22.7 & 17.1 & 21.1 & 25.2 & 31.1 & 56.0 & 26.6 & 52.9 \\
\hline 600 & 32.41 & 6.6 & 4.1 & 10.0 & 5.1 & 33.0 & 26.8 & 21.7 & 26.1 & 27.2 & 37.1 & 28.2 & 27.8 & 52.5 & 58.4 \\
\hline 601 & 32.46 & 5.4 & 2.4 & 11.1 & 13.6 & 21.2 & 32.2 & 21.8 & 42.9 & 10.9 & 27.1 & 29.3 & 16.4 & 78.6 & 21.7 \\
\hline 602 & 32.50 & 7.2 & 4.2 & 13.4 & 12.6 & 29.6 & 25.8 & 34.3 & 39.7 & 22.0 & 29.5 & 64.7 & 52.8 & 59.8 & 64.9 \\
\hline 603 & 32.54 & 1.5 & 3.3 & 6.7 & 15.3 & 40.9 & 26.5 & 30.1 & 30.4 & 28.9 & 33.1 & 34.7 & 53.2 & 84.8 & 50.4 \\
\hline 604 & 32.58 & 4.2 & 2.4 & 8.2 & 8.6 & 11.6 & 7.9 & 33.4 & 26.8 & 26.1 & 23.0 & 56.5 & 44.5 & 17.1 & 67.3 \\
\hline 605 & 32.62 & 5.0 & 3.1 & 6.6 & 7.3 & 10.8 & 11.1 & 21.0 & 17.4 & 13.1 & 21.0 & 13.2 & 41.1 & 25.7 & 22.7 \\
\hline 606 & 32.66 & 2.4 & 2.3 & 3.0 & 7.1 & 20.9 & 13.2 & 22.7 & 30.7 & 16.0 & 15.1 & 49.6 & 38.3 & 29.2 & 30.7 \\
\hline 607 & 32.70 & 4.2 & 3.0 & 11.9 & 18.7 & 34.0 & 29.9 & 33.4 & 39.9 & 26.9 & 22.7 & 20.8 & 53.4 & 45.1 & 29.8 \\
\hline 608 & 32.74 & 7.3 & 2.1 & 9.1 & 10.0 & 32.1 & 11.8 & 30.6 & 13.6 & 27.2 & 18.9 & 50.9 & 46.9 & 48.3 & 51.6 \\
\hline 609 & 32.78 & 5.7 & 3.0 & 11.5 & 7.2 & 33.2 & 31.8 & 41.1 & 15.8 & 22.4 & 34.9 & 29.8 & 46.0 & 47.6 & 61.8 \\
\hline 610 & 32.84 & 5.7 & 4.5 & 16.2 & 12.6 & 36.5 & 21.8 & 15.1 & 19.9 & 39.3 & 31.7 & 36.1 & 45.9 & 47.5 & 47.9 \\
\hline 611 & 32.88 & 9.3 & 2.8 & 9.3 & 17.1 & 32.6 & 29.1 & 36.2 & 37.4 & 24.4 & 44.5 & 37.7 & 40.7 & 61.5 & 99.1 \\
\hline 612 & 32.92 & 5.5 & 4.1 & 2.7 & 15.2 & 24.2 & 52.3 & 16.8 & 36.0 & 43.3 & 36.8 & 33.5 & 45.4 & 64.0 & 57.6 \\
\hline 613 & 32.96 & 3.1 & 1.9 & 7.3 & 7.3 & 13.9 & 31.1 & 25.1 & 10.4 & 22.5 & 20.5 & 12.2 & 27.3 & 35.5 & 46.5 \\
\hline 614 & 33.01 & 2.4 & 1.8 & 9.2 & 11.1 & 12.4 & 39.1 & 20.8 & 32.5 & 25.1 & 11.2 & 14.4 & 45.4 & 33.3 & 41.1 \\
\hline 615 & 33.05 & 3.8 & 5.0 & 14.3 & 10.7 & 27.1 & 31.2 & 32.0 & 22.8 & 20.9 & 51.4 & 26.8 & 78.1 & 55.8 & 72.3 \\
\hline 616 & 33.10 & 5.6 & 2.1 & 14.2 & 11.9 & 31.0 & 25.2 & 17.6 & 29.7 & 29.9 & 34.4 & 58.9 & 79.8 & 47.7 & 63.4 \\
\hline 617 & 33.14 & 9.1 & 5.6 & 8.6 & 11.0 & 43.3 & 33.4 & 39.2 & 34.0 & 26.9 & 39.3 & 46.1 & 26.7 & 46.0 & 65.0 \\
\hline 618 & 33.19 & 4.7 & 4.0 & 4.8 & 14.5 & 32.2 & 23.2 & 25.3 & 10.8 & 35.3 & 41.3 & 24.6 & 34.7 & 25.4 & 23.9 \\
\hline 619 & 33.23 & 6.6 & 4.1 & 8.3 & 9.7 & 34.2 & 14.3 & 11.8 & 7.5 & 18.0 & 20.9 & 33.6 & 24.9 & 28.0 & 111.0 \\
\hline 620 & 33.28 & 2.7 & 3.9 & 5.5 & 9.2 & 23.0 & 19.9 & 12.8 & 17.5 & 31.9 & 31.7 & 27.8 & 28.9 & 29.0 & 20.3 \\
\hline 621 & 33.33 & 3.9 & 2.1 & 9.1 & 6.3 & 7.2 & 12.1 & 21.3 & 21.0 & 8.3 & 7.3 & 17.2 & 21.6 & 34.1 & 39.6 \\
\hline 622 & 33.38 & 5.0 & 4.3 & 4.0 & 12.3 & 26.2 & 24.9 & 18.0 & 26.2 & 12.0 & 23.2 & 13.2 & 31.5 & 14.9 & 6.9 \\
\hline 623 & 33.42 & 8.2 & 6.8 & 20.0 & 25.6 & 42.9 & 37.2 & 23.2 & 16.9 & 65.0 & 43.2 & 153.5 & 50.6 & 48.1 & 53.0 \\
\hline 624 & 33.46 & 4.3 & 4.2 & 17.3 & 7.1 & 37.1 & 27.8 & 30.3 & 28.5 & 23.9 & 17.4 & 43.7 & 66.3 & 56.6 & 51.9 \\
\hline 625 & 33.50 & 3.9 & 4.0 & 5.8 & 4.2 & 17.1 & 26.1 & 24.5 & 10.2 & 6.7 & 13.9 & 16.3 & 37.2 & 36.6 & 21.9 \\
\hline 626 & 33.54 & 6.4 & 4.5 & 14.7 & 11.9 & 18.7 & 10.6 & 28.3 & 29.0 & 36.7 & 16.2 & 29.0 & 21.2 & 65.7 & 48.6 \\
\hline 627 & 33.58 & 2.3 & 0.8 & 10.0 & 3.1 & 13.1 & 23.8 & 18.7 & 26.0 & 15.9 & 26.8 & 17.5 & 18.6 & 34.4 & 42.8 \\
\hline 628 & 33.62 & 4.7 & 3.5 & 7.2 & 11.2 & 22.9 & 28.9 & 22.4 & 19.8 & 23.8 & 23.1 & 31.5 & 21.2 & 30.5 & 25.7 \\
\hline 629 & 33.66 & 2.8 & 3.2 & 7.1 & 6.9 & 15.6 & 4.5 & 18.8 & 16.1 & 7.5 & 16.0 & 22.4 & 20.5 & 22.2 & 22.3 \\
\hline 630 & 33.70 & 2.2 & 2.9 & 4.1 & 6.9 & 20.3 & 18.0 & 14.3 & 18.8 & 5.0 & 27.0 & 19.2 & 29.7 & 25.4 & 41.9 \\
\hline 631 & 33.74 & 3.0 & 4.3 & 6.8 & 12.7 & 13.7 & 27.3 & 23.1 & 16.0 & 6.8 & 14.6 & 14.1 & 31.0 & 27.2 & 49.6 \\
\hline 632 & 33.78 & 13.5 & 4.2 & 7.3 & 8.9 & 10.5 & 33.1 & 27.5 & 26.2 & 34.5 & 8.6 & 31.0 & 35.7 & 26.7 & 54.7 \\
\hline 633 & 33.82 & 4.4 & 1.6 & 4.3 & 6.0 & 14.9 & 17.3 & 20.6 & 12.2 & 27.2 & 17.6 & 16.6 & 50.3 & 14.7 & 104.9 \\
\hline 634 & 33.86 & 5.3 & 2.8 & 11.5 & 9.1 & 22.2 & 23.5 & 12.4 & 29.8 & 27.8 & 17.1 & 30.2 & 28.4 & 61.8 & 73.3 \\
\hline 635 & 33.90 & 5.4 & 4.2 & 6.5 & 9.8 & 36.8 & 24.9 & 21.6 & 36.0 & 29.3 & 19.4 & 20.1 & 21.1 & 51.0 & 78.8 \\
\hline 636 & 33.95 & 7.3 & 2.3 & 8.6 & 17.0 & 32.1 & 23.5 & 15.5 & 27.2 & 35.9 & 38.8 & 19.2 & 31.2 & 53.0 & 71.7 \\
\hline 637 & 33.99 & 8.8 & 4.3 & 8.7 & 9.3 & 30.6 & 30.8 & 22.5 & 28.5 & 35.7 & 29.9 & 44.2 & 66.0 & 33.7 & 34.5 \\
\hline 638 & 34.04 & 3.2 & 2.3 & 6.2 & 8.7 & 31.1 & 16.7 & 24.6 & 22.9 & 16.7 & 36.4 & 27.3 & 40.4 & 36.9 & 42.9 \\
\hline 639 & 34.08 & 17.4 & 21.0 & 29.5 & 36.4 & 68.5 & 33.9 & 58.6 & 60.5 & 35.1 & 29.6 & 73.2 & 56.9 & 55.4 & 157.6 \\
\hline 640 & 34.13 & 2.3 & 2.7 & 4.1 & 3.4 & 18.3 & 9.1 & 7.1 & 11.9 & 3.4 & 9.0 & 12.8 & 20.1 & 21.4 & 30.6 \\
\hline 641 & 34.17 & 3.6 & 2.7 & 7.7 & 11.6 & 24.9 & 41.9 & 19.5 & 14.2 & 14.2 & 41.5 & 43.5 & 51.4 & 20.0 & 56.1 \\
\hline 642 & 34.22 & 5.1 & 3.4 & 6.2 & 13.5 & 39.6 & 8.1 & 40.3 & 18.0 & 35.4 & 26.4 & 18.9 & 35.9 & 48.5 & 100.1 \\
\hline 643 & 34.26 & 3.8 & 5.1 & 20.9 & 27.6 & 62.9 & 44.4 & 48.8 & 35.7 & 49.2 & 39.1 & 45.8 & 49.3 & 47.3 & 152.7 \\
\hline 644 & 34.30 & 2.3 & 4.1 & 19.9 & 18.8 & 39.1 & 25.6 & 22.1 & 17.4 & 25.8 & 40.2 & 45.0 & 30.2 & 38.9 & 70.2 \\
\hline 645 & 34.33 & 7.8 & 3.8 & 4.4 & 9.9 & 8.7 & 17.0 & 9.8 & 24.3 & 19.9 & 23.6 & 40.2 & 43.8 & 34.6 & 22.7 \\
\hline 646 & 34.37 & 1.2 & 2.1 & 5.3 & 9.8 & 19.5 & 15.0 & 27.9 & 17.3 & 21.0 & 27.2 & 13.2 & 27.0 & 21.5 & 28.0 \\
\hline 647 & 34.41 & 3.4 & 1.5 & 1.8 & 5.7 & 9.8 & 15.7 & 10.4 & 18.2 & 23.5 & 21.6 & 30.8 & 36.1 & 12.7 & 32.0 \\
\hline 648 & 34.45 & 2.9 & 2.6 & 6.6 & 12.1 & 48.2 & 30.6 & 42.1 & 17.5 & 36.1 & 38.9 & 19.8 & 46.1 & 56.6 & 30.5 \\
\hline 649 & 34.49 & 11.1 & 7.4 & 16.6 & 25.1 & 53.3 & 56.3 & 19.1 & 45.4 & 61.1 & 43.9 & 66.4 & 58.4 & 62.6 & 106.2 \\
\hline 650 & 34.53 & 6.9 & 7.6 & 75.7 & 15.6 & 47.1 & 34.2 & 32.5 & 22.3 & 23.8 & 27.6 & 45.4 & 41.4 & 96.1 & 99.2 \\
\hline 651 & 34.58 & 13.6 & 5.8 & 14.7 & 11.7 & 51.2 & 27.2 & 53.4 & 47.5 & 43.0 & 26.5 & 50.4 & 25.9 & 53.2 & 100.1 \\
\hline 652 & 34.62 & 10.3 & 8.6 & 9.8 & 28.7 & 37.1 & 53.1 & 32.9 & 40.0 & 36.8 & 54.4 & 27.3 & 53.4 & 62.9 & 66.4 \\
\hline 653 & 34.67 & 5.1 & 3.1 & 10.7 & 12.5 & 45.1 & 34.5 & 41.5 & 24.4 & 44.2 & 29.1 & 50.6 & 63.8 & 45.3 & 82.5 \\
\hline 654 & 34.71 & 2.7 & 1.2 & 2.6 & 3.1 & 7.7 & 9.5 & 8.3 & 8.1 & 11.8 & 17.7 & 32.9 & 48.5 & 38.3 & 41.2 \\
\hline 655 & 34.76 & 8.2 & 4.1 & 10.7 & 20.7 & 19.3 & 26.3 & 36.0 & 18.1 & 24.4 & 35.8 & 8.9 & 39.7 & 17.4 & 108.2 \\
\hline 656 & 34.80 & 6.9 & 3.0 & 13.9 & 12.6 & 45.5 & 63.4 & 29.8 & 28.1 & 19.5 & 33.0 & 50.7 & 51.9 & 74.4 & 40.9 \\
\hline 657 & 34.84 & 6.7 & 4.7 & 18.3 & 12.8 & 33.4 & 21.3 & 21.5 & 22.4 & 38.7 & 29.8 & 36.7 & 46.2 & 70.1 & 63.5 \\
\hline 658 & 34.88 & 4.0 & 3.3 & 10.6 & 7.4 & 25.0 & 26.7 & 32.3 & 36.2 & 21.0 & 25.2 & 35.5 & 31.6 & 65.5 & 92.3 \\
\hline 659 & 34.93 & 3.1 & 2.3 & 5.3 & 8.4 & 13.7 & 23.4 & 22.8 & 9.7 & 23.7 & 31.7 & 28.1 & 47.0 & 33.2 & 38.2 \\
\hline 660 & 34.97 & 5.9 & 2.1 & 7.4 & 9.2 & 13.6 & 23.1 & 21.3 & 30.0 & 20.9 & 22.8 & 20.9 & 18.0 & 14.9 & 47.8 \\
\hline 661 & 35.02 & 5.5 & 3.6 & 11.5 & 11.1 & 18.9 & 14.7 & 16.5 & 30.4 & 24.6 & 25.0 & 32.8 & 27.3 & 88.2 & 83.4 \\
\hline 662 & 35.06 & 4.6 & 2.6 & 23.2 & 16.9 & 38.6 & 57.5 & 30.3 & 35.3 & 42.0 & 23.2 & 41.3 & 85.7 & 76.7 & 94.5 \\
\hline 663 & 35.10 & 3.6 & 2.7 & 6.4 & 6.8 & 17.4 & 35.5 & 17.7 & 19.6 & 29.3 & 29.6 & 33.1 & 33.0 & 58.7 & 30.8 \\
\hline 664 & 35.15 & 5.5 & 4.2 & 6.0 & 7.8 & 20.5 & 29.6 & 8.7 & 22.0 & 14.9 & 28.4 & 44.7 & 30.8 & 15.2 & 191.7 \\
\hline 665 & 35.19 & 4.7 & 3.9 & 7.3 & 9.8 & 16.1 & 22.5 & 14.3 & 19.7 & 10.3 & 21.8 & 17.2 & 34.0 & 39.8 & 36.7 \\
\hline
\end{tabular}




\begin{tabular}{|c|c|c|c|c|c|c|c|c|c|c|c|c|c|c|c|}
\hline 666 & 35.23 & 6.6 & 2.4 & 7.1 & 11.6 & 18.6 & 23.9 & 19.0 & 18.8 & 13.8 & 17.4 & 35.1 & 33.0 & 43.3 & 55.3 \\
\hline 667 & 35.27 & 4.7 & 6.2 & 6.2 & 9.4 & 19.4 & 24.2 & 12.2 & 21.7 & 13.4 & 8.7 & 17.6 & 38.5 & 31.6 & 50.0 \\
\hline 668 & 35.31 & 2.4 & 4.0 & 6.8 & 14.8 & 18.3 & 25.5 & 23.2 & 33.5 & 16.1 & 25.4 & 16.9 & 32.7 & 35.9 & 30.1 \\
\hline 669 & 35.35 & 2.5 & 1.7 & 5.0 & 4.1 & 16.3 & 17.7 & 7.6 & 20.3 & 18.4 & 21.8 & 27.7 & 29.4 & 18.7 & 32.6 \\
\hline 670 & 35.39 & 4.6 & 4.9 & 5.9 & 13.6 & 35.8 & 39.5 & 30.5 & 28.0 & 25.7 & 29.3 & 12.7 & 46.7 & 25.8 & 64.4 \\
\hline 671 & 35.43 & 5.4 & 3.7 & 4.5 & 9.8 & 25.3 & 17.6 & 25.8 & 23.4 & 22.6 & 8.8 & 31.0 & 54.5 & 38.0 & 74.3 \\
\hline 672 & 35.47 & 2.3 & 3.1 & 17.1 & 8.1 & 46.7 & 55.3 & 21.8 & 39.9 & 33.0 & 42.2 & 36.6 & 36.8 & 80.4 & 51.9 \\
\hline 673 & 35.51 & 6.7 & 4.3 & 7.8 & 16.1 & 17.2 & 25.6 & 31.7 & 13.9 & 28.3 & 33.3 & 27.1 & 61.7 & 13.3 & 32.5 \\
\hline 674 & 35.55 & 3.7 & 2.5 & 6.1 & 3.5 & 11.0 & 15.1 & 30.4 & 28.1 & 25.7 & 24.0 & 23.3 & 58.8 & 31.4 & 33.2 \\
\hline 675 & 35.59 & 4.0 & 3.5 & 7.6 & 11.9 & 19.0 & 24.7 & 33.1 & 25.1 & 18.0 & 24.1 & 48.7 & 54.9 & 37.8 & 82.2 \\
\hline 676 & 35.63 & 4.0 & 4.6 & 8.8 & 8.6 & 18.6 & 38.3 & 14.9 & 12.9 & 27.4 & 16.5 & 18.1 & 35.4 & 35.3 & 31.7 \\
\hline 677 & 35.67 & 5.9 & 4.9 & 10.7 & 16.9 & 24.9 & 26.6 & 52.9 & 39.6 & 44.0 & 20.0 & 67.8 & 39.3 & 49.7 & 52.4 \\
\hline 678 & 35.71 & 4.1 & 4.8 & 9.2 & 4.3 & 11.2 & 21.1 & 28.3 & 19.8 & 36.2 & 16.2 & 25.0 & 45.0 & 33.7 & 84.4 \\
\hline 679 & 35.75 & 5.2 & 3.6 & 3.6 & 11.1 & 20.5 & 11.9 & 14.7 & 17.1 & 18.2 & 19.8 & 13.2 & 32.6 & 35.8 & 17.8 \\
\hline 680 & 35.78 & 7.2 & 4.4 & 10.3 & 11.5 & 27.1 & 27.5 & 21.7 & 46.6 & 27.8 & 76.0 & 17.1 & 59.0 & 51.1 & 75.1 \\
\hline 681 & 35.81 & 6.1 & 4.3 & 23.2 & 9.3 & 26.6 & 43.6 & 30.0 & 67.7 & 28.9 & 30.4 & 80.4 & 60.6 & 81.6 & 109.3 \\
\hline 682 & 35.85 & 3.2 & 3.7 & 11.4 & 14.5 & 33.8 & 28.3 & 28.7 & 20.2 & 13.3 & 24.5 & 21.3 & 41.5 & 69.6 & 41.4 \\
\hline 683 & 35.88 & 2.2 & 2.6 & 2.4 & 6.4 & 13.6 & 5.7 & 9.3 & 18.0 & 15.8 & 16.6 & 32.6 & 39.5 & 50.6 & 31.9 \\
\hline 684 & 35.91 & 3.8 & 3.7 & 3.6 & 10.1 & 12.4 & 17.7 & 25.8 & 4.8 & 14.4 & 23.4 & 38.6 & 25.5 & 27.7 & 62.9 \\
\hline 685 & 35.95 & 3.5 & 5.4 & 5.7 & 6.2 & 28.0 & 8.0 & 14.4 & 34.7 & 29.4 & 30.0 & 38.2 & 69.8 & 76.1 & 41.4 \\
\hline 686 & 35.98 & 3.2 & 1.6 & 5.5 & 9.9 & 10.9 & 19.4 & 20.8 & 25.5 & 20.3 & 21.0 & 26.0 & 29.9 & 53.6 & 58.7 \\
\hline 687 & 36.05 & 5.2 & 3.5 & 12.4 & 12.4 & 17.5 & 35.1 & 43.0 & 22.5 & 27.4 & 26.7 & 26.3 & 27.6 & 74.7 & 45.4 \\
\hline 688 & 36.08 & 7.4 & 3.5 & 3.2 & 8.6 & 14.9 & 30.4 & 25.4 & 21.4 & 31.2 & 18.8 & 56.4 & 28.1 & 41.9 & 42.3 \\
\hline 689 & 36.12 & 3.9 & 3.8 & 10.7 & 15.8 & 19.2 & 31.2 & 38.9 & 27.0 & 43.6 & 21.1 & 24.5 & 42.1 & 54.1 & 54.4 \\
\hline 690 & 36.16 & 6.6 & 3.5 & 4.9 & 7.5 & 31.4 & 22.7 & 19.9 & 9.4 & 23.9 & 36.1 & 34.7 & 47.7 & 60.3 & 137.2 \\
\hline 691 & 36.21 & 5.0 & 4.3 & 9.1 & 13.6 & 23.4 & 30.1 & 20.0 & 22.8 & 16.1 & 15.1 & 17.3 & 68.0 & 42.0 & 19.0 \\
\hline 692 & 36.25 & 3.7 & 4.2 & 5.5 & 8.6 & 13.9 & 20.1 & 27.5 & 16.1 & 18.9 & 26.4 & 23.4 & 65.0 & 53.8 & 39.4 \\
\hline 693 & 36.29 & 3.4 & 3.7 & 6.5 & 4.8 & 12.0 & 37.5 & 14.4 & 22.9 & 13.7 & 12.0 & 13.4 & 27.9 & 35.3 & 31.6 \\
\hline 694 & 36.33 & 10.9 & 5.9 & 7.3 & 13.5 & 30.5 & 28.2 & 46.5 & 40.9 & 27.7 & 14.9 & 41.8 & 38.6 & 37.4 & 91.5 \\
\hline 695 & 36.37 & 10.9 & 3.9 & 2.1 & 10.1 & 34.9 & 27.1 & 14.6 & 26.7 & 30.8 & 39.9 & 32.2 & 35.2 & 16.3 & 50.2 \\
\hline 696 & 36.41 & 6.0 & 1.9 & 7.8 & 11.9 & 13.8 & 35.5 & 21.3 & 12.6 & 33.4 & 15.3 & 45.8 & 37.7 & 55.6 & 62.4 \\
\hline 697 & 36.45 & 6.5 & 5.5 & 14.5 & 15.9 & 39.9 & 33.2 & 42.9 & 44.8 & 44.7 & 37.9 & 44.3 & 43.3 & 76.6 & 89.6 \\
\hline 698 & 36.49 & 6.2 & 3.8 & 9.5 & 19.6 & 18.2 & 28.2 & 34.8 & 38.8 & 47.0 & 17.2 & 58.8 & 42.9 & 55.7 & 90.2 \\
\hline 699 & 36.52 & 5.6 & 3.1 & 13.9 & 9.8 & 19.9 & 37.1 & 21.6 & 30.0 & 29.7 & 14.2 & 36.6 & 53.7 & 51.3 & 82.2 \\
\hline 700 & 36.56 & 4.4 & 3.3 & 8.4 & 5.7 & 18.9 & 43.3 & 48.9 & 16.8 & 15.5 & 18.5 & 17.8 & 22.1 & 38.9 & 38.2 \\
\hline 701 & 36.60 & 6.4 & 5.1 & 12.6 & 8.9 & 30.4 & 51.3 & 38.4 & 22.0 & 36.0 & 29.4 & 30.7 & 70.5 & 80.2 & 109.4 \\
\hline 702 & 36.64 & 10.1 & 2.0 & 11.3 & 26.1 & 64.9 & 35.6 & 34.1 & 28.5 & 37.4 & 21.0 & 76.1 & 91.3 & 77.1 & 181.8 \\
\hline 703 & 36.67 & 9.2 & 5.2 & 14.9 & 10.7 & 21.5 & 40.6 & 60.1 & 31.9 & 32.6 & 41.3 & 82.0 & 56.0 & 58.2 & 71.6 \\
\hline 704 & 36.71 & 4.5 & 5.0 & 11.4 & 13.3 & 29.9 & 41.8 & 33.4 & 23.0 & 35.2 & 19.7 & 45.6 & 60.9 & 40.7 & 82.9 \\
\hline 705 & 36.76 & 5.5 & 3.1 & 10.5 & 14.9 & 16.0 & 29.8 & 33.4 & 41.7 & 29.4 & 22.1 & 36.0 & 42.0 & 41.9 & 35.5 \\
\hline 706 & 36.79 & 3.8 & 3.5 & 9.6 & 16.5 & 29.9 & 30.3 & 11.5 & 36.4 & 34.3 & 21.4 & 52.2 & 53.4 & 26.7 & 80.3 \\
\hline 707 & 36.83 & 8.3 & 3.8 & 11.3 & 12.9 & 12.4 & 21.1 & 18.8 & 31.2 & 20.4 & 21.1 & 22.6 & 50.3 & 24.3 & 78.9 \\
\hline 708 & 36.87 & 1.8 & 3.4 & 9.5 & 8.0 & 22.6 & 23.7 & 35.4 & 16.1 & 24.9 & 24.2 & 24.6 & 25.6 & 53.1 & 48.4 \\
\hline 709 & 36.91 & 8.3 & 3.9 & 8.7 & 10.0 & 28.8 & 20.2 & 21.1 & 28.2 & 17.9 & 33.4 & 44.5 & 75.5 & 36.6 & 71.2 \\
\hline 710 & 36.95 & 2.6 & 4.0 & 7.3 & 9.2 & 28.1 & 24.4 & 27.7 & 27.0 & 30.2 & 24.6 & 25.7 & 37.5 & 38.6 & 45.7 \\
\hline 711 & 37.00 & 3.9 & 3.4 & 5.5 & 3.9 & 12.7 & 23.2 & 12.2 & 18.8 & 20.6 & 14.8 & 8.1 & 36.8 & 8.7 & 35.0 \\
\hline 712 & 37.04 & 5.3 & 2.8 & 11.3 & 8.0 & 11.2 & 7.3 & 25.6 & 12.5 & 27.5 & 20.1 & 27.2 & 31.9 & 32.6 & 50.8 \\
\hline 713 & 37.08 & 3.5 & 3.2 & 8.9 & 11.6 & 14.5 & 26.2 & 20.6 & 22.9 & 28.9 & 24.1 & 11.7 & 54.8 & 24.4 & 28.2 \\
\hline 714 & 37.13 & 1.5 & 3.2 & 7.7 & 5.5 & 16.2 & 31.7 & 14.1 & 16.3 & 18.3 & 14.4 & 14.9 & 38.0 & 8.7 & 38.8 \\
\hline 715 & 37.16 & 3.1 & 3.3 & 9.5 & 8.9 & 27.3 & 22.5 & 23.4 & 16.6 & 15.2 & 29.1 & 53.5 & 39.2 & 27.8 & 149.4 \\
\hline 716 & 37.20 & 11.6 & 8.1 & 16.0 & 22.9 & 22.1 & 41.3 & 34.6 & 23.3 & 83.3 & 29.1 & 41.6 & 70.2 & 114.0 & 217.3 \\
\hline 717 & 37.24 & 22.0 & 9.5 & 26.1 & 19.2 & 46.2 & 38.0 & 56.9 & 63.0 & 64.3 & 29.6 & 60.4 & 62.6 & 92.9 & 89.3 \\
\hline 718 & 37.28 & 10.5 & 7.1 & 15.7 & 22.5 & 40.7 & 29.8 & 50.4 & 43.4 & 44.0 & 88.8 & 56.3 & 116.2 & 100.9 & 91.9 \\
\hline 719 & 37.32 & 10.5 & 150.6 & 17.9 & 10.5 & 60.1 & 18.2 & 57.3 & 44.7 & 42.2 & 28.4 & 137.9 & 38.0 & 47.6 & 118.0 \\
\hline 720 & 37.35 & 4.8 & 3.2 & 10.0 & 17.6 & 23.7 & 31.3 & 34.1 & 18.8 & 38.7 & 22.2 & 20.1 & 53.5 & 50.7 & 54.6 \\
\hline 721 & 37.39 & 14.0 & 6.2 & 9.6 & 11.2 & 32.7 & 21.8 & 20.1 & 18.0 & 27.4 & 15.3 & 49.0 & 30.7 & 26.7 & 22.1 \\
\hline 722 & 37.43 & 15.4 & 3.8 & 6.9 & 6.9 & 23.6 & 5.1 & 13.5 & 20.7 & 16.3 & 18.7 & 19.0 & 35.7 & 31.7 & 50.4 \\
\hline 723 & 37.46 & 6.0 & 5.3 & 4.5 & 7.0 & 21.5 & 23.5 & 37.3 & 13.5 & 18.3 & 18.2 & 15.9 & 26.0 & 45.7 & 20.7 \\
\hline 724 & 37.50 & 4.6 & 2.8 & 5.2 & 7.3 & 19.1 & 11.1 & 9.9 & 18.1 & 12.0 & 17.7 & 21.0 & 16.4 & 19.6 & 33.5 \\
\hline 725 & 37.54 & 5.8 & 2.7 & 5.2 & 5.6 & 20.1 & 24.9 & 23.9 & 20.0 & 23.3 & 18.6 & 26.5 & 33.2 & 30.1 & 71.3 \\
\hline 726 & 37.58 & 4.0 & 3.7 & 9.2 & 11.5 & 21.7 & 26.1 & 41.1 & 50.0 & 43.6 & 48.6 & 24.0 & 58.7 & 86.3 & 82.8 \\
\hline 727 & 37.61 & 6.2 & 2.9 & 8.7 & 19.3 & 74.2 & 39.4 & 52.8 & 18.1 & 13.4 & 45.2 & 51.6 & 60.0 & 43.0 & 53.2 \\
\hline 728 & 37.65 & 5.9 & 2.7 & 6.4 & 6.2 & 23.4 & 25.6 & 15.0 & 33.9 & 22.0 & 18.8 & 18.8 & 38.5 & 44.1 & 41.0 \\
\hline 729 & 37.69 & 3.9 & 4.3 & 5.8 & 6.1 & 10.0 & 7.2 & 19.7 & 15.4 & 18.9 & 14.9 & 21.4 & 49.1 & 31.7 & 49.2 \\
\hline 730 & 37.72 & 5.0 & 1.8 & 6.4 & 2.8 & 18.8 & 15.2 & 13.6 & 15.5 & 11.1 & 17.4 & 22.8 & 27.8 & 33.6 & 54.6 \\
\hline 731 & 37.76 & 2.9 & 2.4 & 8.0 & 5.5 & 14.0 & 12.5 & 17.0 & 18.7 & 7.2 & 16.2 & 14.2 & 49.8 & 16.4 & 43.0 \\
\hline 732 & 37.80 & 3.9 & 6.8 & 16.4 & 15.9 & 50.1 & 31.2 & 39.1 & 30.9 & 56.7 & 19.6 & 45.9 & 69.1 & 69.7 & 121.2 \\
\hline 733 & 37.85 & 7.9 & 7.5 & 5.4 & 17.3 & 35.3 & 34.7 & 51.9 & 33.7 & 27.5 & 39.5 & 32.7 & 55.5 & 44.6 & 77.7 \\
\hline 734 & 37.89 & 6.1 & 6.6 & 7.1 & 18.5 & 18.3 & 40.0 & 39.1 & 40.8 & 47.9 & 27.4 & 72.5 & 65.9 & 72.1 & 103.6 \\
\hline 735 & 37.93 & 2.6 & 2.9 & 11.1 & 11.4 & 23.2 & 15.7 & 18.8 & 22.7 & 49.5 & 26.6 & 28.9 & 25.1 & 78.8 & 40.6 \\
\hline 736 & 37.97 & 3.4 & 1.3 & 4.2 & 8.2 & 15.3 & 10.4 & 19.4 & 21.2 & 18.4 & 7.1 & 15.4 & 31.5 & 24.5 & 22.9 \\
\hline 737 & 38.01 & 5.1 & 2.8 & 10.3 & 14.5 & 21.5 & 32.1 & 30.0 & 16.2 & 36.6 & 13.2 & 45.7 & 48.3 & 41.5 & 86.5 \\
\hline 738 & 38.05 & 7.8 & 4.0 & 7.6 & 8.2 & 16.1 & 14.8 & 18.6 & 26.0 & 18.5 & 16.1 & 24.4 & 39.7 & 34.7 & 209.5 \\
\hline 739 & 38.09 & 5.4 & 6.4 & 9.1 & 13.6 & 39.5 & 31.9 & 20.4 & 31.2 & 20.9 & 35.5 & 30.1 & 42.6 & 39.5 & 67.7 \\
\hline 740 & 38.13 & 5.1 & 3.4 & 10.3 & 12.7 & 31.1 & 17.4 & 39.6 & 18.6 & 35.0 & 27.0 & 53.2 & 21.5 & 39.7 & 133.1 \\
\hline 741 & 38.17 & 6.3 & 6.6 & 19.8 & 18.8 & 43.6 & 26.1 & 30.9 & 35.4 & 14.5 & 22.0 & 33.8 & 54.7 & 63.6 & 51.0 \\
\hline 742 & 38.21 & 4.9 & 2.2 & 6.0 & 8.9 & 36.3 & 30.2 & 28.2 & 21.6 & 21.1 & 30.7 & 29.2 & 39.2 & 17.8 & 87.5 \\
\hline
\end{tabular}




\begin{tabular}{|c|c|c|c|c|c|c|c|c|c|c|c|c|c|c|c|}
\hline 743 & 38.25 & 2.3 & 3.5 & 7.8 & 12.9 & 7.7 & 27.1 & 17.5 & 18.0 & 11.6 & 29.3 & 35.2 & 44.0 & 32.7 & 21.3 \\
\hline 744 & 38.29 & 4.7 & 3.4 & 4.5 & 8.7 & 14.6 & 11.0 & 18.2 & 17.8 & 17.3 & 29.2 & 24.8 & 26.9 & 17.6 & 55.4 \\
\hline 745 & 38.33 & 2.1 & 2.0 & 2.5 & 6.1 & 20.9 & 12.2 & 4.8 & 21.2 & 16.6 & 15.4 & 17.3 & 25.4 & 33.4 & 43.6 \\
\hline 746 & 38.37 & 3.1 & 1.9 & 5.3 & 21.7 & 10.7 & 23.2 & 14.8 & 11.7 & 6.8 & 17.8 & 10.1 & 32.2 & 13.2 & 47.4 \\
\hline 747 & 38.40 & 4.0 & 3.8 & 5.9 & 7.1 & 21.6 & 22.3 & 13.3 & 16.8 & 15.5 & 10.7 & 26.7 & 29.8 & 25.7 & 32.0 \\
\hline 748 & 38.44 & 6.1 & 5.8 & 4.6 & 6.7 & 11.6 & 25.1 & 19.2 & 16.3 & 20.7 & 20.7 & 24.7 & 43.1 & 26.3 & 31.8 \\
\hline 749 & 38.48 & 6.3 & 4.6 & 4.4 & 8.4 & 30.5 & 22.4 & 25.3 & 39.3 & 30.7 & 25.4 & 37.9 & 34.9 & 37.3 & 94.2 \\
\hline 750 & 38.52 & 4.6 & 3.8 & 10.2 & 11.2 & 54.4 & 25.4 & 37.3 & 21.1 & 17.0 & 35.5 & 34.6 & 51.0 & 35.8 & 53.2 \\
\hline 751 & 38.55 & 20.4 & 4.8 & 17.0 & 28.3 & 28.6 & 33.4 & 36.3 & 32.8 & 23.3 & 30.4 & 37.4 & 24.3 & 59.7 & 190.6 \\
\hline 752 & 38.59 & 4.5 & 4.6 & 7.4 & 9.5 & 39.2 & 19.7 & 38.4 & 26.6 & 13.4 & 22.3 & 38.6 & 48.5 & 56.5 & 37.4 \\
\hline 753 & 38.64 & 4.3 & 2.2 & 6.8 & 9.3 & 17.2 & 16.5 & 20.8 & 32.4 & 29.4 & 35.1 & 35.3 & 52.8 & 53.8 & 54.9 \\
\hline 754 & 38.69 & 11.8 & 4.4 & 16.7 & 22.2 & 48.8 & 39.5 & 52.1 & 58.0 & 30.4 & 16.8 & 30.0 & 41.5 & 16.2 & 66.0 \\
\hline 755 & 38.74 & 9.5 & 4.5 & 12.9 & 15.7 & 35.5 & 25.9 & 23.6 & 15.1 & 37.5 & 48.5 & 59.4 & 40.0 & 73.5 & 155.8 \\
\hline 756 & 38.79 & 5.2 & 4.4 & 9.0 & 17.4 & 33.1 & 47.5 & 56.2 & 26.4 & 26.9 & 40.6 & 55.8 & 57.2 & 49.3 & 30.1 \\
\hline 757 & 38.83 & 6.1 & 5.4 & 10.1 & 9.8 & 28.5 & 22.6 & 13.5 & 31.7 & 10.0 & 32.6 & 42.1 & 20.0 & 62.6 & 41.3 \\
\hline 758 & 38.86 & 4.7 & 3.5 & 7.9 & 7.7 & 8.6 & 30.9 & 18.7 & 30.4 & 14.4 & 42.7 & 38.9 & 44.7 & 48.6 & 199.1 \\
\hline 759 & 38.91 & 10.6 & 4.1 & 14.6 & 21.3 & 72.1 & 27.4 & 32.5 & 37.0 & 39.4 & 26.6 & 49.0 & 51.6 & 97.5 & 45.7 \\
\hline 760 & 38.95 & 4.3 & 1.6 & 13.1 & 8.6 & 28.4 & 43.6 & 23.9 & 28.3 & 29.2 & 32.0 & 18.0 & 65.3 & 52.4 & 99.2 \\
\hline 761 & 38.99 & 8.2 & 2.3 & 7.4 & 18.7 & 36.3 & 27.2 & 14.0 & 32.0 & 39.5 & 47.8 & 36.9 & 45.9 & 49.3 & 70.4 \\
\hline 762 & 39.04 & 6.7 & 2.3 & 7.2 & 8.5 & 32.9 & 35.8 & 33.9 & 51.2 & 22.8 & 41.7 & 36.5 & 23.2 & 66.7 & 68.2 \\
\hline 763 & 39.09 & 6.6 & 4.4 & 6.6 & 13.2 & 29.7 & 17.4 & 32.8 & 31.0 & 29.5 & 22.0 & 43.5 & 70.3 & 32.8 & 42.5 \\
\hline 764 & 39.13 & 4.8 & 4.5 & 14.4 & 6.8 & 32.7 & 35.8 & 35.7 & 31.3 & 35.2 & 19.1 & 27.7 & 94.6 & 54.7 & 35.5 \\
\hline 765 & 39.18 & 3.8 & 4.0 & 7.9 & 7.3 & 13.4 & 29.3 & 11.5 & 42.0 & 28.7 & 36.1 & 16.0 & 36.8 & 37.5 & 63.2 \\
\hline 766 & 39.22 & 3.8 & 2.4 & 4.6 & 13.8 & 21.5 & 28.8 & 23.7 & 20.4 & 34.5 & 43.6 & 28.0 & 65.6 & 55.6 & 38.3 \\
\hline 767 & 39.26 & 7.0 & 2.5 & 10.6 & 13.3 & 15.8 & 18.7 & 16.9 & 34.5 & 27.9 & 26.1 & 21.1 & 52.8 & 35.5 & 89.7 \\
\hline 768 & 39.31 & 5.9 & 6.5 & 15.0 & 13.6 & 49.3 & 37.5 & 15.7 & 20.1 & 48.8 & 28.6 & 41.3 & 61.2 & 41.7 & 101.1 \\
\hline 769 & 39.36 & 9.1 & 4.5 & 10.0 & 15.7 & 28.5 & 44.0 & 31.3 & 70.5 & 23.3 & 35.3 & 62.4 & 32.9 & 26.8 & 83.2 \\
\hline 770 & 39.40 & 8.3 & 5.1 & 26.7 & 20.4 & 34.3 & 35.3 & 26.7 & 34.0 & 21.7 & 30.7 & 32.0 & 46.3 & 56.4 & 22.4 \\
\hline 771 & 39.44 & 19.5 & 3.7 & 10.3 & 13.4 & 47.4 & 37.4 & 14.4 & 36.8 & 48.6 & 24.9 & 41.0 & 26.4 & 44.1 & 78.1 \\
\hline 772 & 39.48 & 7.0 & 3.5 & 10.2 & 18.1 & 34.8 & 15.3 & 21.7 & 20.0 & 39.5 & 34.6 & 42.7 & 73.9 & 48.0 & 38.0 \\
\hline 773 & 39.52 & 5.8 & 3.8 & 13.7 & 8.4 & 12.1 & 17.3 & 19.9 & 20.5 & 21.3 & 10.1 & 22.0 & 20.8 & 36.3 & 43.6 \\
\hline 774 & 39.57 & 4.3 & 5.0 & 13.4 & 20.6 & 26.2 & 45.4 & 45.8 & 70.3 & 49.3 & 49.4 & 34.1 & 71.8 & 78.2 & 116.6 \\
\hline 775 & 39.61 & 9.9 & 1.8 & 16.5 & 35.0 & 52.8 & 20.0 & 19.8 & 56.2 & 24.5 & 55.4 & 41.6 & 50.9 & 14.2 & 140.1 \\
\hline 776 & 39.65 & 3.9 & 3.0 & 9.8 & 7.0 & 13.2 & 30.8 & 20.6 & 30.7 & 16.3 & 16.1 & 27.0 & 41.3 & 47.2 & 60.9 \\
\hline 777 & 39.69 & 4.3 & 5.0 & 11.4 & 10.2 & 28.9 & 27.0 & 32.0 & 18.0 & 33.4 & 27.2 & 15.3 & 60.3 & 40.6 & 26.9 \\
\hline 778 & 39.73 & 3.6 & 1.3 & 8.9 & 6.8 & 31.9 & 26.3 & 35.1 & 30.4 & 29.8 & 26.1 & 54.5 & 53.5 & 57.6 & 52.9 \\
\hline 779 & 39.77 & 11.6 & 3.6 & 8.1 & 17.6 & 26.9 & 34.9 & 24.6 & 34.8 & 44.2 & 23.2 & 31.6 & 72.3 & 46.9 & 68.7 \\
\hline 780 & 39.81 & 9.0 & 4.6 & 14.2 & 17.6 & 38.5 & 42.8 & 23.4 & 26.1 & 45.1 & 24.8 & 18.3 & 41.4 & 64.7 & 178.4 \\
\hline 781 & 39.85 & 12.2 & 3.1 & 6.1 & 17.1 & 18.6 & 17.6 & 42.9 & 42.0 & 27.5 & 37.6 & 37.4 & 29.4 & 84.9 & 66.8 \\
\hline 782 & 39.88 & 3.7 & 2.7 & 4.0 & 3.5 & 7.4 & 7.2 & 11.2 & 11.0 & 8.5 & 20.6 & 14.6 & 14.4 & 21.1 & 24.9 \\
\hline 783 & 39.92 & 6.3 & 2.8 & 12.7 & 9.4 & 18.5 & 34.3 & 15.6 & 21.9 & 17.0 & 12.9 & 23.6 & 37.0 & 46.1 & 39.0 \\
\hline 784 & 39.96 & 3.1 & 3.7 & 5.7 & 9.6 & 11.8 & 10.6 & 16.7 & 10.4 & 17.4 & 15.1 & 10.5 & 20.2 & 24.4 & 24.3 \\
\hline
\end{tabular}

RICE deep core combined 40m to $320 \mathrm{~m}$ samples, from the 2013 core processing campaign. Recalibrated using MATLAB 'robustfit' (bisquare) method; analytical blank corrected. All concentrations in $\mathrm{pg} \mathrm{g}^{-1}$.

\begin{tabular}{|c|c|c|c|c|c|c|c|c|c|c|c|c|c|c|c|}
\hline (m) & Sample ID & La139 & Ce140 & Pr141 & Nd146 & Sm147 & Eu153 & Gd157 & Tb159 & Dy163 & Ho165 & Er166 & Tm169 & Yb172 & Lu175 \\
\hline 40.00 & RICE_3yr_1 & 0.228 & 0.612 & 0.051 & 0.200 & 0.039 & 0.007 & 0.032 & 0.004 & 0.024 & 0.005 & 0.016 & 0.003 & 0.004 & 0.001 \\
\hline 40.95 & RICE_3yr_2 & 0.129 & 0.352 & 0.026 & 0.113 & 0.028 & 0.005 & 0.022 & 0.002 & 0.016 & 0.003 & 0.012 & 0.001 & 0.001 & $<0.001$ \\
\hline 42.27 & RICE_3yr_3 & 0.123 & 0.325 & 0.029 & 0.107 & 0.021 & 0.004 & 0.020 & 0.002 & 0.016 & 0.004 & 0.011 & 0.001 & 0.001 & 0.001 \\
\hline 43.64 & RICE_3yr_4 & 0.068 & 0.198 & 0.015 & 0.064 & 0.019 & 0.003 & 0.010 & 0.002 & 0.012 & 0.002 & 0.005 & $<0.001$ & 0.001 & $<0.001$ \\
\hline 44.68 & RICE_3yr_5 & 0.091 & 0.214 & 0.016 & 0.066 & 0.012 & 0.001 & 0.018 & 0.002 & 0.008 & 0.001 & 0.004 & $<0.001$ & 0.001 & $<0.001$ \\
\hline 45.61 & RICE_3yr_6 & 0.099 & 0.254 & 0.020 & 0.063 & 0.035 & 0.003 & 0.009 & 0.002 & 0.009 & 0.001 & 0.007 & $<0.001$ & 0.001 & $<0.001$ \\
\hline 46.60 & RICE_3yr_7 & 0.091 & 0.221 & 0.021 & 0.079 & 0.021 & 0.003 & 0.021 & 0.001 & 0.013 & 0.002 & 0.006 & $<0.001$ & 0.001 & $<0.001$ \\
\hline 47.59 & RICE_3yr_8 & 0.119 & 0.259 & 0.022 & 0.085 & 0.020 & 0.003 & 0.010 & 0.001 & 0.008 & 0.002 & 0.006 & $<0.001$ & 0.001 & 0.002 \\
\hline 48.56 & RICE_3yr_9 & 0.092 & 0.190 & 0.017 & 0.065 & 0.020 & 0.001 & 0.012 & 0.002 & 0.009 & 0.001 & 0.007 & $<0.001$ & $<0.001$ & $<0.001$ \\
\hline 49.58 & RICE_3yr_10 & 0.069 & 0.153 & 0.012 & 0.058 & 0.025 & 0.001 & 0.007 & 0.001 & 0.003 & 0.001 & 0.005 & $<0.001$ & 0.001 & $<0.001$ \\
\hline 50.50 & RICE_3yr_11 & 0.137 & 0.308 & 0.034 & 1.575 & 0.024 & 0.005 & 0.014 & 0.003 & 0.018 & 0.003 & 0.009 & 0.001 & 0.003 & 0.001 \\
\hline 51.41 & RICE_3yr_12 & 0.098 & 0.202 & 0.021 & 0.074 & 0.012 & 0.002 & 0.010 & $<0.001$ & 0.013 & 0.003 & 0.006 & 0.001 & 0.001 & $<0.001$ \\
\hline 52.34 & RICE_3yr_13 & 0.078 & 0.192 & 0.015 & 0.048 & 0.015 & 0.002 & 0.017 & 0.001 & 0.004 & 0.001 & 0.005 & 0.001 & 0.001 & $<0.001$ \\
\hline 53.31 & RICE_3yr_14 & 0.088 & 1.347 & 0.016 & 0.059 & 0.023 & 0.003 & 0.016 & $<0.001$ & 0.007 & 0.002 & 0.003 & $<0.001$ & $<0.001$ & $<0.001$ \\
\hline 54.19 & RICE_3yr_15 & 0.084 & 0.257 & 0.020 & 0.058 & 0.020 & 0.003 & 0.008 & 0.001 & 0.007 & 0.001 & 0.006 & 0.001 & $<0.001$ & $<0.001$ \\
\hline 55.17 & RICE_3yr_16 & 0.069 & 0.148 & 0.015 & 0.046 & 0.012 & $<0.001$ & 0.010 & 0.001 & 0.006 & 0.001 & 0.003 & 0.001 & $<0.001$ & 0.001 \\
\hline 56.02 & RICE_3yr_17 & 0.104 & 0.235 & 0.020 & 0.070 & 0.015 & 0.002 & 0.016 & 0.001 & 0.010 & 0.002 & 0.008 & $<0.001$ & 0.001 & $<0.001$ \\
\hline 56.89 & RICE_3yr_18 & 0.068 & 0.176 & 0.015 & 0.059 & 0.008 & 0.002 & 0.007 & 0.002 & 0.008 & 0.001 & 0.005 & -0.001 & 0.001 & $<0.001$ \\
\hline 57.77 & RICE_3yr_19 & 0.068 & 0.183 & 0.012 & 0.045 & 0.011 & 0.002 & 0.013 & $<0.001$ & 0.005 & 0.002 & 0.004 & $<0.001$ & $<0.001$ & $<0.001$ \\
\hline 58.69 & RICE_3yr_20 & 0.073 & 0.192 & 0.014 & 0.055 & 0.012 & 0.001 & 0.011 & $<0.001$ & 0.005 & 0.002 & 0.006 & $<0.001$ & 0.001 & $<0.001$ \\
\hline 59.52 & RICE_3yr_21 & 0.086 & 0.210 & 0.017 & 0.068 & 0.007 & 0.001 & 0.009 & 0.003 & 0.009 & 0.001 & 0.007 & $<0.001$ & 0.001 & $<0.001$ \\
\hline 60.40 & RICE_3yr_22 & 0.095 & 0.267 & 0.015 & 0.074 & 0.015 & 0.001 & 0.012 & 0.001 & 0.008 & 0.002 & 0.006 & $<0.001$ & $<0.001$ & $<0.001$ \\
\hline
\end{tabular}




\begin{tabular}{|c|c|c|c|c|c|c|c|c|c|c|c|c|c|c|c|}
\hline 61.36 & RICE_3yr_23 & 0.072 & 0.195 & 0.014 & 0.063 & 0.008 & 0.003 & 0.017 & $<0.001$ & 0.008 & $<0.001$ & 0.005 & $<0.001$ & $<0.001$ & $<0.001$ \\
\hline 62.17 & RICE_3yr_24 & 0.103 & 0.258 & 0.020 & 0.078 & 0.015 & 0.002 & 0.017 & 0.002 & 0.007 & 0.002 & 0.005 & $<0.001$ & 0.001 & $<0.001$ \\
\hline 63.08 & RICE_3yr_25 & 0.537 & 1.032 & 0.116 & 0.436 & 0.064 & 0.011 & 0.062 & 0.009 & 0.054 & 0.008 & 0.023 & 0.001 & 0.004 & 0.008 \\
\hline 63.92 & RICE_3yr_26 & 0.428 & 0.766 & 0.073 & 0.256 & 0.045 & 0.006 & 0.041 & 0.004 & 0.027 & 0.006 & 0.020 & 0.002 & 0.002 & 0.007 \\
\hline 64.76 & RICE_3yr_27 & 0.101 & 0.217 & 0.018 & 0.065 & 0.012 & 0.002 & 0.009 & 0.001 & 0.008 & 0.002 & 0.004 & $<0.001$ & $<0.001$ & $<0.001$ \\
\hline 65.61 & RICE_3yr_28 & 0.131 & 0.272 & 0.022 & 0.090 & 0.023 & 0.003 & 0.013 & 0.002 & 0.014 & 0.001 & 0.007 & $<0.001$ & $<0.001$ & 0.001 \\
\hline 66.45 & RICE_3yr_29 & 0.082 & 0.180 & 0.016 & 0.063 & 0.012 & 0.001 & 0.009 & 0.002 & 0.005 & 0.001 & 0.006 & 0.001 & $<0.001$ & $<0.001$ \\
\hline 67.32 & RICE_3yr_30 & 0.079 & 0.160 & 0.015 & 0.055 & 0.011 & 0.002 & 0.014 & $<0.001$ & 0.010 & 0.001 & 0.005 & $<0.001$ & 0.001 & 0.001 \\
\hline 68.14 & RICE_3yr_31 & 0.057 & 0.130 & 0.013 & 0.043 & 0.007 & 0.002 & 0.009 & 0.001 & 0.004 & $<0.001$ & 0.003 & $<0.001$ & $<0.001$ & 0.001 \\
\hline 68.97 & RICE_3yr_32 & 0.107 & 0.378 & 0.021 & 0.084 & 0.007 & 0.003 & 0.013 & 0.001 & 0.010 & $<0.001$ & 0.006 & $<0.001$ & 0.001 & $<0.001$ \\
\hline 69.80 & RICE_3yr_33 & 0.073 & 0.160 & 0.014 & 0.053 & 0.017 & 0.002 & 0.006 & 0.001 & 0.008 & 0.002 & 0.007 & $<0.001$ & $<0.001$ & $<0.001$ \\
\hline 70.65 & RICE_3yr_34 & 0.058 & 0.168 & 0.009 & 0.040 & 0.008 & 0.001 & 0.003 & 0.001 & 0.005 & 0.001 & 0.004 & $<0.001$ & $<0.001$ & 0.012 \\
\hline 71.46 & RICE_3yr_35 & 0.064 & 0.161 & 0.015 & 0.058 & 0.011 & 0.001 & 0.006 & 0.001 & 0.010 & 0.001 & 0.005 & $<0.001$ & $<0.001$ & 0.001 \\
\hline 72.30 & RICE_3yr_36 & 0.060 & 0.141 & 0.012 & 0.036 & 0.016 & $<0.001$ & 0.011 & $<0.001$ & 0.006 & $<0.001$ & 0.003 & $<0.001$ & $<0.001$ & $<0.001$ \\
\hline 73.15 & RICE_3yr_37 & 0.073 & 0.162 & 0.015 & 0.061 & 0.008 & 0.001 & 0.006 & 0.002 & 0.008 & 0.001 & 0.004 & $<0.001$ & $<0.001$ & $<0.001$ \\
\hline 73.93 & RICE_3yr_38 & 0.084 & 0.338 & 0.019 & 0.065 & 0.022 & 0.001 & 0.012 & 0.001 & 0.010 & 0.001 & 0.003 & $<0.001$ & 0.001 & $<0.001$ \\
\hline 74.75 & RICE_3yr_39 & 0.072 & 0.467 & 0.013 & 0.053 & 0.012 & 0.001 & 0.006 & $<0.001$ & 0.005 & 0.002 & 0.004 & $<0.001$ & $<0.001$ & 0.001 \\
\hline 75.54 & RICE_3yr_40 & 0.129 & 0.383 & 0.028 & 0.113 & 0.018 & 0.002 & 0.016 & 0.002 & 0.018 & 0.004 & 0.011 & 0.001 & 0.001 & 0.001 \\
\hline 76.31 & RICE_3yr_41 & 0.112 & 0.276 & 0.020 & 0.084 & 0.022 & 0.002 & 0.013 & 0.001 & 0.013 & 0.002 & 0.007 & 0.002 & 0.001 & $<0.001$ \\
\hline 77.14 & RICE_3yr_42 & 0.076 & 0.183 & 0.014 & 0.056 & 0.014 & $<0.001$ & 0.011 & 0.001 & 0.010 & 0.002 & 0.002 & $<0.001$ & $<0.001$ & $<0.001$ \\
\hline 77.94 & RICE_3yr_43 & 0.122 & 0.320 & 0.018 & 0.073 & 0.021 & 0.001 & 0.010 & 0.001 & 0.014 & 0.002 & 0.005 & $<0.001$ & 0.001 & 0.001 \\
\hline 78.75 & RICE_3yr_44 & 0.080 & 0.381 & 0.015 & 0.061 & 0.008 & 0.002 & 0.009 & $<0.001$ & 0.007 & 0.002 & 0.005 & $<0.001$ & 0.001 & 0.001 \\
\hline 79.51 & RICE_3yr_45 & 0.077 & 0.413 & 0.017 & 0.055 & 0.015 & $<0.001$ & 0.009 & 0.001 & 0.009 & 0.003 & 0.006 & $<0.001$ & 0.001 & $<0.001$ \\
\hline 80.32 & RICE_3yr_46 & 0.094 & 0.329 & 0.018 & 0.066 & 0.018 & 0.001 & 0.015 & 0.001 & 0.006 & 0.001 & 0.003 & $<0.001$ & 0.002 & 0.001 \\
\hline 81.06 & RICE_3yr_47 & 0.075 & 0.256 & 0.014 & 0.050 & 0.007 & 0.002 & 0.008 & $<0.001$ & 0.009 & 0.001 & 0.003 & $<0.001$ & $<0.001$ & $<0.001$ \\
\hline 81.86 & RICE_3yr_48 & 0.107 & 0.401 & 0.020 & 0.070 & 0.023 & 0.001 & 0.008 & 0.001 & 0.011 & 0.001 & 0.007 & $<0.001$ & 0.001 & $<0.001$ \\
\hline 82.64 & RICE_3yr_49 & 0.103 & 0.242 & 0.019 & 0.089 & 0.014 & 0.004 & 0.017 & 0.002 & 0.010 & 0.002 & 0.006 & 0.001 & 0.001 & $<0.001$ \\
\hline 83.51 & RICE_3yr_50 & 0.099 & 0.285 & 0.019 & 0.065 & 0.012 & 0.001 & 0.009 & 0.001 & 0.010 & 0.002 & 0.005 & $<0.001$ & 0.001 & $<0.001$ \\
\hline 84.29 & RICE_3yr_51 & 0.112 & 0.289 & 0.020 & 0.079 & 0.024 & 0.004 & 0.011 & 0.002 & 0.012 & 0.001 & 0.009 & $<0.001$ & 0.001 & 0.001 \\
\hline 85.01 & RICE_3yr_52 & 0.080 & 0.215 & 0.015 & 0.051 & 0.008 & $<0.001$ & 0.011 & 0.001 & 0.006 & 0.002 & 0.002 & 0.001 & $<0.001$ & $<0.001$ \\
\hline 85.80 & RICE_3yr_53 & 0.131 & 0.235 & 0.028 & 0.114 & 0.019 & 0.003 & 0.016 & $<0.001$ & 0.015 & 0.001 & 0.006 & $<0.001$ & 0.001 & 0.001 \\
\hline 86.57 & RICE_3yr_54 & 0.091 & 0.533 & 0.019 & 0.065 & 0.023 & 0.002 & 0.015 & 0.002 & 0.012 & 0.002 & 0.008 & $<0.001$ & $<0.001$ & $<0.001$ \\
\hline 87.32 & RICE_3yr_55 & 0.096 & 1.030 & 0.018 & 0.059 & 0.024 & 0.002 & 0.008 & 0.001 & 0.005 & 0.001 & 0.005 & 0.001 & $<0.001$ & 0.001 \\
\hline 88.09 & RICE_3yr_56 & 0.083 & 0.889 & 0.016 & 0.054 & 0.009 & 0.001 & 0.010 & $<0.001$ & 0.008 & 0.001 & 0.004 & -0.001 & $<0.001$ & 0.001 \\
\hline 88.84 & RICE_3yr_57 & 0.118 & 0.320 & 0.025 & 0.095 & 0.022 & 0.003 & 0.015 & 0.003 & 0.016 & 0.002 & 0.007 & 0.001 & 0.002 & $<0.001$ \\
\hline 89.57 & RICE_3yr_58 & 0.132 & 0.321 & 0.031 & 0.105 & 0.023 & 0.002 & 0.020 & 0.003 & 0.019 & 0.004 & 0.012 & 0.001 & 0.002 & 0.001 \\
\hline 90.30 & RICE_3yr_59 & 0.049 & 0.438 & 0.010 & 0.031 & 0.013 & 0.001 & 0.011 & $<0.001$ & 0.007 & 0.001 & 0.004 & $<0.001$ & $<0.001$ & $<0.001$ \\
\hline 91.05 & RICE_3yr_60 & 0.079 & 0.211 & 0.016 & 0.057 & 0.007 & 0.002 & 0.006 & $<0.001$ & 0.009 & 0.001 & 0.006 & $<0.001$ & $<0.001$ & 0.001 \\
\hline 91.80 & RICE_3yr_61 & 0.111 & 0.236 & 0.021 & 0.089 & 0.016 & 0.002 & 0.014 & 0.001 & 0.012 & 0.002 & 0.005 & 0.001 & 0.001 & 0.002 \\
\hline 92.56 & RICE_3yr_62 & 0.129 & 0.391 & 0.026 & 0.097 & 0.019 & 0.002 & 0.020 & 0.001 & 0.013 & 0.002 & 0.005 & $<0.001$ & 0.002 & $<0.001$ \\
\hline 93.30 & RICE_3yr_63 & 0.067 & 0.182 & 0.014 & 0.058 & 0.012 & 0.002 & 0.008 & $<0.001$ & 0.009 & 0.001 & 0.004 & 0.001 & 0.001 & 0.001 \\
\hline 93.99 & RICE_3yr_64 & 0.055 & 0.225 & 0.011 & 0.045 & 0.010 & 0.001 & 0.005 & 0.001 & 0.002 & $<0.001$ & 0.003 & $<0.001$ & $<0.001$ & $<0.001$ \\
\hline 94.75 & RICE_3yr_65 & 0.065 & 0.186 & 0.014 & 0.052 & 0.013 & 0.002 & 0.007 & $<0.001$ & 0.008 & 0.001 & 0.004 & $<0.001$ & $<0.001$ & 0.001 \\
\hline 95.50 & RICE_3yr_66 & 0.072 & 0.185 & 0.017 & 0.058 & 0.009 & 0.001 & 0.003 & 0.001 & 0.005 & 0.001 & 0.004 & $<0.001$ & 0.001 & $<0.001$ \\
\hline 96.21 & RICE_3yr_67 & 0.069 & 0.160 & 0.012 & 0.055 & 0.011 & 0.001 & 0.009 & $<0.001$ & 0.007 & 0.001 & 0.005 & $<0.001$ & $<0.001$ & $<0.001$ \\
\hline 96.92 & RICE_3yr_68 & 0.078 & 0.212 & 0.016 & 0.066 & 0.006 & 0.003 & 0.009 & $<0.001$ & 0.007 & 0.001 & 0.015 & $<0.001$ & $<0.001$ & $<0.001$ \\
\hline 97.67 & RICE_3yr_69 & 0.087 & 0.205 & 0.018 & 0.070 & 0.009 & 0.002 & 0.009 & 0.001 & 0.013 & 0.002 & 0.005 & $<0.001$ & 0.001 & $<0.001$ \\
\hline 98.40 & RICE_3yr_70 & 0.072 & 0.155 & 0.016 & 0.061 & 0.008 & 0.001 & 0.002 & 0.001 & 0.011 & 0.001 & 0.003 & $<0.001$ & $<0.001$ & $<0.001$ \\
\hline 99.09 & RICE_3yr_71 & 0.070 & 0.150 & 0.015 & 0.059 & 0.010 & 0.001 & 0.013 & 0.001 & 0.004 & 0.001 & 0.003 & $<0.001$ & 0.001 & 0.001 \\
\hline 99.78 & RICE_3yr_72 & 0.055 & 0.293 & 0.010 & 0.036 & 0.008 & $<0.001$ & 0.004 & 0.001 & 0.008 & 0.001 & 0.001 & 0.001 & $<0.001$ & $<0.001$ \\
\hline 100.51 & RICE_3yr_73 & 0.092 & 0.254 & 0.020 & 0.070 & 0.017 & 0.002 & 0.012 & 0.002 & 0.010 & 0.001 & 0.003 & 0.001 & $<0.001$ & 0.001 \\
\hline 101.23 & RICE_3yr_74 & 0.073 & 0.167 & 0.015 & 0.055 & 0.015 & 0.001 & 0.009 & 0.001 & 0.010 & 0.001 & 0.005 & $<0.001$ & 0.001 & 0.001 \\
\hline 101.92 & RICE_3yr_75 & 0.070 & 0.147 & 0.014 & 0.053 & 0.013 & 0.002 & 0.010 & 0.001 & 0.013 & 0.001 & 0.003 & 0.001 & $<0.001$ & $<0.001$ \\
\hline 102.67 & RICE_3yr_76 & 0.055 & 0.198 & 0.010 & 0.046 & 0.014 & 0.001 & 0.001 & $<0.001$ & 0.006 & $<0.001$ & 0.003 & $<0.001$ & $<0.001$ & $<0.001$ \\
\hline 103.36 & RICE_3yr_77 & 0.067 & 0.273 & 0.014 & 0.057 & 0.007 & 0.001 & 0.008 & 0.001 & 0.008 & 0.001 & 0.005 & $<0.001$ & $<0.001$ & 0.001 \\
\hline 104.04 & RICE_3yr_78 & 0.070 & 0.168 & 0.014 & 0.047 & 0.012 & 0.001 & 0.009 & 0.001 & 0.011 & $<0.001$ & 0.005 & $<0.001$ & $<0.001$ & $<0.001$ \\
\hline 104.77 & RICE_3yr_79 & 0.077 & 0.184 & 0.016 & 0.090 & 0.013 & 0.002 & 0.008 & 0.002 & 0.006 & 0.001 & 0.005 & $<0.001$ & $<0.001$ & $<0.001$ \\
\hline 105.47 & RICE_3yr_80 & 0.151 & 0.873 & 0.031 & 0.114 & 0.028 & 0.004 & 0.015 & 0.001 & 0.009 & 0.001 & 0.008 & $<0.001$ & 0.002 & 0.001 \\
\hline 106.18 & RICE_3yr_81 & 0.115 & 0.290 & 0.025 & 0.096 & 0.014 & 0.003 & 0.014 & 0.001 & 0.009 & 0.002 & 0.008 & 0.001 & 0.002 & 0.001 \\
\hline 106.91 & RICE_3yr_82 & 0.088 & 0.727 & 0.018 & 0.074 & 0.026 & 0.003 & 0.012 & 0.001 & 0.008 & 0.002 & 0.005 & $<0.001$ & 0.001 & $<0.001$ \\
\hline 107.56 & RICE_3yr_83 & 0.117 & 0.279 & 0.023 & 0.076 & 0.019 & 0.003 & 0.009 & 0.002 & 0.010 & 0.002 & 0.007 & $<0.001$ & 0.001 & 0.034 \\
\hline 108.25 & RICE_3yr_84 & 0.146 & 0.306 & 0.031 & 0.094 & 0.021 & 0.003 & 0.023 & 0.001 & 0.016 & 0.003 & 0.009 & 0.001 & 0.002 & 0.001 \\
\hline 108.96 & RICE_3yr_85 & 0.119 & 0.806 & 0.021 & 0.085 & 0.024 & 0.004 & 0.018 & 0.001 & 0.011 & 0.001 & 0.009 & $<0.001$ & 0.002 & 0.001 \\
\hline
\end{tabular}




\begin{tabular}{|c|c|c|c|c|c|c|c|c|c|c|c|c|c|c|c|}
\hline 109.62 & RICE_3yr_86 & 0.108 & 0.823 & 0.022 & 0.088 & 0.018 & 0.004 & 0.013 & 0.002 & 0.011 & 0.003 & 0.008 & 0.001 & 0.001 & $<0.001$ \\
\hline 110.31 & RICE_3yr_87 & 0.165 & 0.391 & 0.037 & 0.129 & 0.018 & 0.005 & 0.031 & 0.002 & 0.017 & 0.001 & 0.009 & 0.001 & 0.001 & 0.001 \\
\hline 111.04 & RICE_3yr_88 & 0.082 & 0.192 & 0.016 & 0.071 & 0.019 & 0.003 & 0.007 & 0.001 & 0.012 & $<0.001$ & 0.004 & 0.001 & 0.001 & 0.001 \\
\hline 111.71 & RICE_3yr_89 & 0.096 & 0.233 & 0.018 & 0.060 & 0.014 & 0.003 & 0.001 & 0.001 & 0.007 & 0.001 & 0.007 & 0.001 & 0.001 & $<0.001$ \\
\hline 112.38 & RICE_3yr_90 & 0.098 & 0.214 & 0.019 & 0.066 & 0.009 & 0.002 & 0.011 & 0.001 & 0.007 & 0.001 & 0.007 & $<0.001$ & $<0.001$ & $<0.001$ \\
\hline 113.06 & RICE_3yr_91 & 0.140 & 0.322 & 0.028 & 0.105 & 0.020 & 0.003 & 0.018 & 0.003 & 0.013 & 0.002 & 0.007 & $<0.001$ & 0.001 & 0.001 \\
\hline 113.73 & RICE_3yr_92 & 0.077 & 0.196 & 0.015 & 0.054 & 0.010 & 0.001 & 0.010 & $<0.001$ & 0.010 & 0.001 & 0.004 & $<0.001$ & $<0.001$ & 0.001 \\
\hline 114.39 & RICE_3yr_93 & 0.074 & 0.329 & 0.014 & 0.045 & 0.008 & $<0.001$ & 0.005 & 0.001 & 0.006 & $<0.001$ & 0.001 & -0.001 & $<0.001$ & $<0.001$ \\
\hline 115.11 & RICE_3yr_94 & 0.120 & 0.334 & 0.025 & 0.097 & 0.020 & 0.001 & 0.011 & 0.001 & 0.010 & 0.002 & 0.005 & $<0.001$ & 0.002 & 0.001 \\
\hline 115.78 & RICE_3yr_95 & 0.121 & 0.392 & 0.024 & 0.095 & 0.024 & 0.002 & 0.014 & 0.002 & 0.013 & 0.002 & 0.006 & 0.001 & 0.001 & 0.002 \\
\hline 116.44 & RICE_3yr_96 & 0.141 & 0.331 & 0.023 & 0.099 & 0.012 & 0.003 & 0.014 & 0.002 & 0.015 & 0.001 & 0.008 & $<0.001$ & 0.002 & 0.002 \\
\hline 117.12 & RICE_3yr_97 & 0.080 & 0.207 & 0.017 & 0.070 & 0.011 & 0.002 & 0.005 & $<0.001$ & 0.009 & 0.001 & 0.004 & $<0.001$ & 0.001 & $<0.001$ \\
\hline 117.76 & RICE_3yr_98 & 0.054 & 0.170 & 0.011 & 0.045 & 0.010 & 0.001 & 0.006 & $<0.001$ & 0.007 & 0.001 & 0.004 & 0.001 & $<0.001$ & 0.001 \\
\hline 118.41 & RICE_3yr_99 & 0.093 & 0.552 & 0.019 & 0.079 & 0.011 & 0.001 & 0.008 & 0.001 & 0.013 & 0.001 & 0.007 & 0.001 & 0.001 & 0.001 \\
\hline 119.08 & RICE_3yr_100 & 0.090 & 0.233 & 0.020 & 0.076 & 0.016 & 0.002 & 0.011 & 0.001 & 0.012 & 0.001 & 0.007 & $<0.001$ & 0.001 & 0.001 \\
\hline 119.75 & RICE_3yr_101 & 0.088 & 0.214 & 0.020 & 0.057 & 0.016 & $<0.001$ & 0.010 & 0.002 & 0.007 & 0.001 & 0.004 & 0.001 & 0.002 & 0.009 \\
\hline 120.44 & RICE_3yr_102 & 0.057 & 0.202 & 0.014 & 0.051 & 0.006 & 0.001 & 0.008 & 0.001 & 0.006 & 0.001 & 0.003 & $<0.001$ & $<0.001$ & $<0.001$ \\
\hline 121.05 & RICE_3yr_103 & 0.065 & 0.164 & 0.013 & 0.052 & 0.012 & 0.001 & 0.007 & $<0.001$ & 0.005 & 0.001 & 0.002 & 0.001 & $<0.001$ & 0.001 \\
\hline 121.74 & RICE_3yr_104 & 0.084 & 0.233 & 0.018 & 0.074 & 0.023 & 0.002 & 0.012 & 0.002 & 0.011 & 0.001 & 0.005 & 0.001 & 0.001 & 0.001 \\
\hline 122.37 & RICE_3yr_105 & 0.084 & 0.189 & 0.017 & 0.059 & 0.018 & $<0.001$ & 0.007 & 0.001 & 0.007 & 0.002 & 0.003 & 0.001 & 0.001 & $<0.001$ \\
\hline 123.04 & RICE_3yr_106 & 0.069 & 0.142 & 0.013 & 0.041 & 0.007 & $<0.001$ & 0.007 & 0.001 & 0.004 & $<0.001$ & 0.004 & $<0.001$ & $<0.001$ & 0.001 \\
\hline 123.69 & RICE_3yr_107 & 0.066 & 0.237 & 0.012 & 0.049 & 0.014 & 0.002 & 0.004 & $<0.001$ & 0.008 & 0.001 & 0.005 & $<0.001$ & $<0.001$ & 0.001 \\
\hline 124.33 & RICE_3yr_108 & 0.071 & 0.168 & 0.015 & 0.051 & 0.016 & 0.001 & 0.003 & $<0.001$ & 0.004 & 0.001 & 0.003 & $<0.001$ & $<0.001$ & 0.001 \\
\hline 124.94 & RICE_3yr_109 & 0.089 & 0.487 & 0.017 & 0.074 & 0.014 & 0.002 & 0.008 & $<0.001$ & 0.007 & 0.001 & 0.004 & $<0.001$ & $<0.001$ & 0.001 \\
\hline 125.59 & RICE_3yr_110 & 0.060 & 0.161 & 0.011 & 0.047 & 0.005 & 0.002 & 0.003 & 0.001 & 0.006 & 0.001 & 0.005 & $<0.001$ & $<0.001$ & $<0.001$ \\
\hline 126.25 & RICE_3yr_111 & 0.075 & 0.175 & 0.014 & 0.059 & 0.005 & 0.001 & 0.008 & 0.002 & 0.009 & 0.001 & 0.006 & 0.001 & $<0.001$ & 0.001 \\
\hline 126.89 & RICE_3yr_112 & 0.102 & 0.702 & 0.020 & 0.082 & 0.015 & $<0.001$ & 0.008 & 0.001 & 0.008 & 0.001 & 0.005 & 0.001 & 0.001 & 0.764 \\
\hline 127.53 & RICE_3yr_113 & 0.123 & 0.331 & 0.022 & 0.077 & 0.011 & $<0.001$ & 0.013 & 0.002 & 0.007 & 0.002 & 0.006 & $<0.001$ & 0.001 & $<0.001$ \\
\hline 128.17 & RICE_3yr_114 & 0.068 & 0.173 & 0.014 & 0.058 & 0.004 & 0.001 & 0.007 & 0.001 & 0.005 & 0.001 & 0.007 & $<0.001$ & 0.001 & $<0.001$ \\
\hline 128.81 & RICE_3yr_115 & 0.088 & 0.835 & 0.021 & 0.064 & 0.009 & 0.002 & 0.008 & 0.002 & 0.012 & 0.003 & 0.006 & $<0.001$ & 0.002 & 0.001 \\
\hline 129.45 & RICE_3yr_116 & 0.084 & 0.276 & 0.016 & 0.058 & 0.017 & 0.003 & 0.009 & 0.001 & 0.008 & 0.001 & 0.008 & $<0.001$ & 0.001 & $<0.001$ \\
\hline 130.06 & RICE_3yr_117 & 0.088 & 0.234 & 0.018 & 0.075 & 0.018 & 0.003 & 0.004 & 0.001 & 0.005 & 0.001 & 0.005 & $<0.001$ & 0.001 & 0.001 \\
\hline 130.71 & RICE_3yr_118 & 0.101 & 0.298 & 0.024 & 0.077 & 0.016 & 0.002 & 0.011 & 0.002 & 0.007 & 0.002 & 0.004 & $<0.001$ & 0.001 & $<0.001$ \\
\hline 131.32 & RICE_3yr_119 & 0.115 & 0.265 & 0.023 & 0.082 & 0.018 & 0.003 & 0.014 & 0.001 & 0.009 & 0.002 & 0.006 & $<0.001$ & 0.001 & $<0.001$ \\
\hline 131.95 & RICE_3yr_120 & 0.109 & 0.926 & 0.023 & 0.073 & 0.016 & 0.003 & 0.012 & 0.001 & 0.006 & 0.002 & 0.006 & 0.001 & 0.001 & 0.001 \\
\hline 132.61 & RICE_3yr_121 & 0.090 & 0.381 & 0.016 & 0.049 & 0.014 & 0.002 & 0.006 & 0.001 & 0.006 & 0.001 & 0.008 & $<0.001$ & 0.001 & 0.001 \\
\hline 133.20 & RICE_3yr_122 & 0.077 & 0.194 & 0.013 & 0.055 & 0.008 & 0.001 & 0.010 & 0.001 & 0.007 & $<0.001$ & 0.004 & $<0.001$ & $<0.001$ & $<0.001$ \\
\hline 133.83 & RICE_3yr_123 & 0.066 & 0.186 & 0.014 & 0.044 & 0.011 & 0.002 & 0.003 & $<0.001$ & 0.006 & 0.001 & 0.006 & $<0.001$ & $<0.001$ & 0.001 \\
\hline 134.45 & RICE_3yr_124 & 0.073 & 0.209 & 0.016 & 0.054 & 0.006 & 0.001 & 0.009 & 0.001 & 0.006 & $<0.001$ & 0.005 & $<0.001$ & 0.001 & $<0.001$ \\
\hline 135.10 & RICE_3yr_125 & 0.102 & 0.250 & 0.020 & 0.082 & 0.006 & 0.001 & 0.007 & 0.002 & 0.010 & 0.001 & 0.005 & 0.001 & 0.001 & 0.001 \\
\hline 135.69 & RICE_3yr_126 & 0.092 & 1.034 & 0.022 & 0.072 & 0.015 & $<0.001$ & 0.015 & 0.002 & 0.010 & 0.002 & 0.007 & $<0.001$ & 0.001 & 0.001 \\
\hline 136.33 & RICE_3yr_127 & 0.065 & 0.224 & 0.012 & 0.053 & 0.013 & 0.001 & 0.006 & 0.001 & 0.004 & 0.001 & 0.004 & 0.001 & $<0.001$ & 0.001 \\
\hline 136.92 & RICE_3yr_128 & 0.077 & 0.244 & 0.016 & 0.067 & 0.010 & 0.002 & 0.014 & 0.002 & 0.015 & 0.002 & 0.008 & $<0.001$ & 0.001 & 0.001 \\
\hline 137.52 & RICE_3yr_129 & 0.073 & 0.287 & 0.014 & 0.064 & 0.015 & 0.001 & 0.011 & $<0.001$ & 0.007 & 0.002 & 0.005 & 0.001 & 0.001 & $<0.001$ \\
\hline 138.15 & RICE_3yr_130 & 0.072 & 0.205 & 0.016 & 0.065 & 0.009 & 0.002 & 0.013 & 0.001 & 0.009 & 0.001 & 0.003 & $<0.001$ & 0.001 & $<0.001$ \\
\hline 138.77 & RICE_3yr_131 & 0.083 & 0.634 & 0.016 & 0.057 & 0.016 & 0.001 & 0.010 & 0.002 & 0.008 & 0.002 & 0.004 & 0.001 & $<0.001$ & $<0.001$ \\
\hline 139.36 & RICE_3yr_132 & 0.063 & 0.179 & 0.013 & 0.049 & 0.002 & 0.001 & 0.006 & 0.002 & 0.008 & $<0.001$ & 0.006 & $<0.001$ & 0.001 & 0.001 \\
\hline 139.97 & RICE_3yr_133 & 0.089 & 0.228 & 0.017 & 0.068 & 0.012 & 0.004 & 0.013 & 0.001 & 0.007 & 0.001 & 0.006 & $<0.001$ & 0.001 & 0.001 \\
\hline 140.59 & RICE_3yr_134 & 0.081 & 0.240 & 0.015 & 0.056 & 0.014 & 0.002 & 0.005 & 0.001 & 0.009 & 0.001 & 0.006 & $<0.001$ & 0.001 & 0.001 \\
\hline 141.18 & RICE_3yr_135 & 0.090 & 0.230 & 0.020 & 0.066 & 0.013 & 0.002 & 0.015 & 0.002 & 0.007 & $<0.001$ & 0.003 & 0.001 & 0.001 & $<0.001$ \\
\hline 141.78 & RICE_3yr_136 & 0.072 & 1.457 & 0.013 & 0.057 & 0.016 & 0.001 & 0.010 & 0.002 & 0.012 & $<0.001$ & 0.004 & $<0.001$ & 0.001 & 0.001 \\
\hline 142.37 & RICE_3yr_137 & 0.079 & 0.229 & 0.018 & 0.053 & 0.020 & 0.001 & 0.007 & $<0.001$ & 0.007 & 0.001 & 0.006 & $<0.001$ & 0.001 & 0.001 \\
\hline 142.97 & RICE_3yr_138 & 0.075 & 0.198 & 0.015 & 0.061 & 0.011 & 0.002 & 0.012 & 0.001 & 0.007 & 0.001 & 0.005 & $<0.001$ & 0.001 & 0.001 \\
\hline 143.59 & RICE_3yr_139 & 0.082 & 0.651 & 0.014 & 0.048 & 0.019 & $<0.001$ & 0.007 & 0.001 & 0.006 & 0.001 & 0.004 & $<0.001$ & 0.001 & $<0.001$ \\
\hline 144.19 & RICE_3yr_140 & 0.111 & 0.255 & 0.024 & 0.091 & 0.017 & 0.003 & 0.013 & 0.001 & 0.011 & 0.001 & 0.005 & $<0.001$ & 0.002 & 0.001 \\
\hline 144.76 & RICE_3yr_141 & 0.087 & 1.209 & 0.020 & 0.063 & 0.016 & 0.002 & 0.012 & 0.002 & 0.010 & $<0.001$ & 0.006 & 0.001 & 0.001 & $<0.001$ \\
\hline 145.32 & RICE_3yr_142 & 0.062 & 0.186 & 0.012 & 0.052 & $<0.001$ & 0.002 & 0.005 & $<0.001$ & 0.007 & 0.001 & 0.005 & 0.001 & 0.001 & $<0.001$ \\
\hline 145.91 & RICE_3yr_143 & 0.076 & 0.220 & 0.014 & 0.059 & 0.014 & $<0.001$ & 0.011 & 0.001 & 0.007 & 0.002 & 0.008 & $<0.001$ & 0.001 & $<0.001$ \\
\hline 146.48 & RICE_3yr_144 & 0.142 & 2.322 & 0.031 & 0.097 & 0.025 & 0.004 & 0.009 & 0.002 & 0.017 & 0.001 & 0.011 & 0.001 & 0.002 & 0.002 \\
\hline 147.08 & RICE_3yr_145 & 0.098 & 0.301 & 0.021 & 0.080 & 0.008 & 0.003 & 0.011 & 0.002 & 0.008 & 0.001 & 0.007 & 0.001 & 0.001 & 0.001 \\
\hline 147.67 & RICE_3yr_146 & 0.114 & 0.333 & 0.021 & 0.067 & 0.015 & 0.003 & 0.012 & 0.003 & 0.010 & 0.001 & 0.007 & 0.001 & $<0.001$ & $<0.001$ \\
\hline 148.28 & RICE_3yr_147 & 0.105 & 0.282 & 0.019 & 0.092 & 0.016 & 0.002 & 0.006 & 0.002 & 0.013 & 0.001 & 0.007 & $<0.001$ & 0.002 & $<0.001$ \\
\hline 148.84 & RICE_3yr_148 & 0.079 & 0.252 & 0.014 & 0.059 & 0.008 & 0.002 & 0.009 & $<0.001$ & 0.006 & 0.001 & 0.004 & 0.001 & 0.001 & 0.001 \\
\hline
\end{tabular}




\begin{tabular}{|c|c|c|c|c|c|c|c|c|c|c|c|c|c|c|c|}
\hline 149.44 & RICE_3yr_149 & 0.081 & 0.822 & 0.014 & 0.063 & 0.011 & 0.001 & 0.002 & 0.001 & 0.005 & 0.001 & 0.005 & 0.001 & $<0.001$ & $<0.001$ \\
\hline 150.03 & RICE_3yr_150 & 0.090 & 0.312 & 0.020 & 0.074 & 0.012 & 0.001 & 0.016 & 0.001 & 0.012 & 0.001 & 0.005 & 0.001 & 0.002 & 0.001 \\
\hline 150.61 & RICE_3yr_151 & 0.067 & 0.367 & 0.014 & 0.053 & 0.003 & 0.002 & 0.004 & $<0.001$ & 0.004 & 0.001 & 0.002 & $<0.001$ & $<0.001$ & $<0.001$ \\
\hline 151.20 & RICE_3yr_152 & 0.060 & 0.189 & 0.012 & 0.040 & 0.006 & -0.001 & 0.003 & $<0.001$ & 0.006 & 0.005 & 0.002 & 0.001 & 0.001 & $<0.001$ \\
\hline 151.77 & RICE_3yr_153 & 0.083 & 0.236 & 0.016 & 0.086 & 0.020 & 0.001 & 0.006 & 0.001 & 0.009 & 0.001 & 0.006 & $<0.001$ & 0.001 & $<0.001$ \\
\hline 152.32 & RICE_3yr_154 & 0.080 & 0.209 & 0.015 & 0.049 & 0.011 & 0.001 & 0.005 & $<0.001$ & 0.014 & 0.001 & 0.005 & $<0.001$ & 0.001 & $<0.001$ \\
\hline 152.91 & RICE_3yr_155 & 0.099 & 1.505 & 0.017 & 0.075 & 0.029 & 0.001 & 0.018 & 0.002 & 0.010 & 0.002 & 0.007 & $<0.001$ & 0.001 & $<0.001$ \\
\hline 153.49 & RICE_3yr_156 & 0.138 & 0.530 & 0.023 & 0.101 & 0.021 & 0.004 & 0.017 & 0.002 & 0.009 & 0.001 & 0.006 & 0.001 & 0.001 & $<0.001$ \\
\hline 154.04 & RICE_3yr_157 & 0.139 & 0.362 & 0.025 & 0.090 & 0.017 & 0.003 & 0.017 & 0.003 & 0.013 & 0.002 & 0.009 & $<0.001$ & 0.001 & 0.001 \\
\hline 154.61 & RICE_3yr_158 & 0.227 & 1.002 & 0.049 & 0.215 & 0.043 & 0.007 & 0.027 & 0.006 & 0.025 & 0.004 & 0.014 & 0.002 & 0.003 & 0.002 \\
\hline 155.21 & RICE_3yr_159 & 0.114 & 0.373 & 0.025 & 0.099 & 0.017 & 0.003 & 0.012 & 0.002 & 0.010 & 0.002 & 0.008 & $<0.001$ & 0.001 & 0.001 \\
\hline 155.75 & RICE_3yr_160 & 0.105 & 0.409 & 0.021 & 0.071 & 0.014 & 0.001 & 0.013 & 0.002 & 0.015 & 0.003 & 0.011 & 0.001 & 0.002 & 0.001 \\
\hline 156.34 & RICE_3yr_161 & 0.091 & 0.238 & 0.017 & 0.075 & 0.012 & 0.003 & 0.008 & 0.002 & 0.012 & 0.001 & 0.005 & 0.001 & 0.002 & 0.001 \\
\hline 156.90 & RICE_3yr_162 & 0.092 & 0.360 & 0.019 & 0.066 & 0.017 & 0.002 & 0.017 & 0.002 & 0.014 & 0.001 & 0.005 & $<0.001$ & $<0.001$ & 0.001 \\
\hline 157.45 & RICE_3yr_163 & 0.137 & 0.411 & 0.028 & 0.106 & 0.019 & 0.004 & 0.015 & 0.002 & 0.013 & 0.001 & 0.007 & 0.002 & 0.002 & 0.001 \\
\hline 157.97 & RICE_3yr_164 & 0.109 & 0.320 & 0.023 & 0.071 & 0.015 & 0.002 & 0.009 & 0.003 & 0.009 & 0.002 & 0.009 & $<0.001$ & 0.001 & 0.001 \\
\hline 158.54 & RICE_3yr_165 & 0.091 & 0.417 & 0.018 & 0.073 & 0.013 & 0.005 & 0.007 & 0.002 & 0.009 & 0.001 & 0.007 & 0.001 & 0.001 & 0.001 \\
\hline 159.13 & RICE_3yr_166 & 0.123 & 0.326 & 0.023 & 0.090 & 0.007 & 0.002 & 0.008 & 0.002 & 0.012 & 0.001 & 0.003 & 0.001 & 0.001 & $<0.001$ \\
\hline 159.67 & RICE_3yr_167 & 0.146 & 0.471 & 0.029 & 0.097 & 0.023 & 0.004 & 0.019 & 0.003 & 0.017 & 0.003 & 0.011 & 0.001 & 0.002 & $<0.001$ \\
\hline 160.24 & RICE_3yr_168 & 0.057 & 0.163 & 0.012 & 0.054 & 0.006 & 0.001 & 0.008 & 0.001 & 0.007 & $<0.001$ & 0.004 & 0.001 & $<0.001$ & $<0.001$ \\
\hline 160.79 & RICE_3yr_169 & 0.117 & 0.352 & 0.023 & 0.102 & 0.017 & 0.002 & 0.010 & 0.003 & 0.009 & 0.002 & 0.007 & $<0.001$ & 0.001 & 0.001 \\
\hline 161.32 & RICE_3yr_170 & 0.100 & 0.298 & 0.024 & 0.087 & 0.018 & 0.003 & 0.015 & 0.003 & 0.011 & 0.003 & 0.009 & 0.001 & 0.001 & $<0.001$ \\
\hline 161.87 & RICE_3yr_171 & 0.402 & 2.047 & 0.101 & 0.429 & 0.110 & 0.017 & 0.086 & 0.011 & 0.065 & 0.012 & 0.039 & 0.004 & 0.006 & 0.003 \\
\hline 162.44 & RICE_3yr_172 & 0.079 & 0.223 & 0.016 & 0.067 & 0.007 & 0.003 & 0.007 & 0.002 & 0.009 & 0.002 & 0.004 & 0.001 & 0.001 & 0.001 \\
\hline 162.97 & RICE_3yr_173 & 0.105 & 0.269 & 0.023 & 0.078 & 0.021 & 0.002 & 0.007 & 0.003 & 0.011 & 0.002 & 0.006 & 0.001 & 0.001 & $<0.001$ \\
\hline 163.54 & RICE_3yr_174 & 0.144 & 0.568 & 0.032 & 0.138 & 0.022 & 0.002 & 0.024 & 0.003 & 0.019 & 0.003 & 0.010 & 0.002 & 0.002 & 0.001 \\
\hline 164.06 & RICE_3yr_175 & 0.247 & 0.722 & 0.051 & 0.188 & 0.040 & 0.009 & 0.035 & 0.003 & 0.032 & 0.004 & 0.015 & 0.001 & 0.003 & 0.001 \\
\hline 164.62 & RICE_3yr_176 & 0.161 & 0.495 & 0.035 & 0.103 & 0.022 & 0.003 & 0.015 & 0.002 & 0.014 & 0.003 & 0.007 & 0.001 & 0.003 & $<0.001$ \\
\hline 165.14 & RICE_3yr_177 & 0.069 & 0.187 & 0.014 & 0.050 & 0.010 & 0.003 & 0.005 & 0.002 & 0.011 & 0.001 & 0.002 & $<0.001$ & 0.001 & $<0.001$ \\
\hline 165.68 & RICE_3yr_178 & 0.083 & 0.242 & 0.015 & 0.067 & 0.012 & 0.004 & 0.005 & 0.002 & 0.006 & 0.002 & 0.002 & $<0.001$ & 0.001 & $<0.001$ \\
\hline 166.26 & RICE_3yr_179 & 0.122 & 0.316 & 0.023 & 0.085 & 0.010 & 0.002 & 0.014 & 0.002 & 0.013 & 0.001 & 0.005 & $<0.001$ & $<0.001$ & $<0.001$ \\
\hline 166.80 & RICE_3yr_180 & 0.087 & 0.503 & 0.018 & 0.057 & 0.016 & 0.002 & 0.012 & 0.001 & 0.011 & 0.001 & 0.003 & 0.001 & 0.001 & 0.001 \\
\hline 167.35 & RICE_3yr_181 & 0.063 & 0.162 & 0.013 & 0.055 & 0.008 & 0.001 & 0.003 & 0.001 & 0.007 & 0.001 & 0.002 & $<0.001$ & 0.001 & $<0.001$ \\
\hline 167.88 & RICE_3yr_182 & 0.098 & 0.601 & 0.020 & 0.067 & 0.019 & 0.002 & 0.010 & 0.001 & 0.011 & 0.001 & 0.005 & $<0.001$ & 0.001 & $<0.001$ \\
\hline 168.39 & RICE_3yr_183 & 0.097 & 0.243 & 0.020 & 0.076 & 0.016 & 0.003 & 0.013 & 0.001 & 0.010 & 0.003 & 0.008 & 0.001 & 0.002 & 0.001 \\
\hline 168.94 & RICE_3yr_184 & 0.093 & 0.271 & 0.018 & 0.068 & 0.007 & 0.001 & 0.011 & 0.002 & 0.006 & 0.001 & 0.003 & $<0.001$ & 0.001 & $<0.001$ \\
\hline 169.45 & RICE_3yr_185 & 0.084 & 0.592 & 0.018 & 0.069 & 0.020 & 0.006 & 0.010 & 0.001 & 0.012 & $<0.001$ & 0.003 & 0.001 & $<0.001$ & 0.001 \\
\hline 170.02 & RICE_3yr_186 & 0.083 & 0.566 & 0.017 & 0.057 & 0.007 & 0.002 & 0.017 & 0.001 & 0.009 & 0.001 & 0.007 & 0.001 & $<0.001$ & $<0.001$ \\
\hline 170.55 & RICE_3yr_187 & 0.101 & 0.520 & 0.019 & 0.068 & 0.015 & 0.001 & 0.011 & 0.002 & 0.006 & 0.001 & 0.006 & $<0.001$ & 0.001 & $<0.001$ \\
\hline 171.07 & RICE_3yr_188 & 0.070 & 0.831 & 0.012 & 0.046 & 0.009 & 0.002 & 0.008 & 0.001 & 0.008 & 0.001 & 0.004 & $<0.001$ & 0.001 & $<0.001$ \\
\hline 171.59 & RICE_3yr_189 & 0.079 & 0.260 & 0.014 & 0.078 & 0.008 & 0.001 & 0.009 & $<0.001$ & 0.008 & 0.001 & 0.005 & $<0.001$ & 0.001 & 0.001 \\
\hline 172.10 & RICE_3yr_190 & 0.100 & 0.274 & 0.025 & 0.069 & 0.014 & 0.003 & 0.017 & 0.002 & 0.011 & 0.001 & 0.006 & $<0.001$ & 0.001 & $<0.001$ \\
\hline 172.63 & RICE_3yr_191 & 0.080 & 1.175 & 0.014 & 0.077 & 0.012 & 0.003 & 0.012 & 0.001 & 0.007 & $<0.001$ & 0.005 & $<0.001$ & 0.001 & $<0.001$ \\
\hline 173.16 & RICE_3yr_192 & 0.062 & 0.202 & 0.015 & 0.060 & 0.006 & 0.001 & 0.002 & 0.001 & 0.004 & $<0.001$ & 0.003 & 0.001 & 0.001 & $<0.001$ \\
\hline 173.66 & RICE_3yr_193 & 0.075 & 0.347 & 0.017 & 0.066 & 0.007 & 0.002 & 0.010 & 0.001 & 0.005 & 0.001 & 0.006 & $<0.001$ & 0.001 & $<0.001$ \\
\hline 174.18 & RICE_3yr_194 & 0.105 & 0.317 & 0.023 & 0.098 & 0.005 & 0.002 & 0.009 & 0.001 & 0.013 & 0.003 & 0.004 & 0.002 & 0.001 & 0.001 \\
\hline 174.71 & RICE_3yr_195 & 0.084 & 0.285 & 0.019 & 0.067 & 0.018 & 0.002 & 0.015 & 0.001 & 0.006 & 0.001 & 0.007 & $<0.001$ & 0.001 & $<0.001$ \\
\hline 175.23 & RICE_3yr_196 & 0.089 & 0.265 & 0.019 & 0.085 & 0.006 & 0.001 & 0.013 & 0.001 & 0.010 & 0.002 & 0.006 & $<0.001$ & 0.001 & $<0.001$ \\
\hline 175.76 & RICE_3yr_197 & 0.139 & 0.661 & 0.022 & 0.107 & 0.017 & 0.002 & 0.012 & 0.001 & 0.009 & 0.002 & 0.006 & 0.001 & 0.001 & 0.001 \\
\hline 176.26 & RICE_3yr_198 & 0.067 & 0.190 & 0.016 & 0.047 & 0.012 & 0.001 & 0.003 & 0.001 & 0.007 & $<0.001$ & 0.004 & $<0.001$ & 0.001 & $<0.001$ \\
\hline 176.79 & RICE_3yr_199 & 0.121 & 0.379 & 0.022 & 0.101 & 0.022 & 0.003 & 0.013 & 0.002 & 0.019 & 0.003 & 0.010 & $<0.001$ & 0.002 & $<0.001$ \\
\hline 177.32 & RICE_3yr_200 & 0.092 & 0.403 & 0.019 & 0.062 & 0.008 & 0.001 & 0.013 & 0.001 & 0.006 & 0.001 & 0.006 & $<0.001$ & $<0.001$ & 0.001 \\
\hline 197.84 & RICE_3yr_241 & 0.081 & 0.505 & 0.017 & 0.064 & 0.012 & $<0.001$ & 0.009 & 0.001 & 0.011 & 0.001 & 0.003 & 0.001 & 0.001 & $<0.001$ \\
\hline 198.27 & RICE_3yr_242 & 0.125 & 0.347 & 0.023 & 0.093 & 0.017 & 0.001 & 0.012 & 0.002 & 0.012 & 0.001 & 0.006 & 0.001 & 0.001 & 0.001 \\
\hline 198.78 & RICE_3yr_243 & 0.078 & 0.226 & 0.018 & 0.063 & 0.009 & $<0.001$ & 0.007 & 0.001 & 0.010 & $<0.001$ & 0.001 & 0.001 & 0.001 & $<0.001$ \\
\hline 199.25 & RICE_3yr_244 & 0.065 & 0.200 & 0.014 & 0.060 & 0.010 & $<0.001$ & 0.004 & 0.002 & 0.008 & $<0.001$ & 0.002 & $<0.001$ & 0.001 & $<0.001$ \\
\hline 199.69 & RICE_3yr_245 & 0.095 & 0.717 & 0.020 & 0.070 & 0.019 & 0.001 & 0.009 & 0.002 & 0.008 & 0.001 & 0.005 & 0.001 & 0.001 & 0.001 \\
\hline 200.15 & RICE_3yr_246 & 0.161 & 0.347 & 0.029 & 0.112 & 0.016 & $<0.001$ & 0.012 & 0.002 & 0.011 & 0.002 & 0.006 & 0.001 & 0.001 & 0.001 \\
\hline 200.63 & RICE_3yr_247 & 0.089 & 0.428 & 0.017 & 0.068 & 0.019 & $<0.001$ & 0.008 & 0.001 & 0.010 & 0.001 & 0.004 & 0.001 & 0.001 & 0.001 \\
\hline 201.08 & RICE_3yr_248 & 0.113 & 0.311 & 0.022 & 0.080 & 0.014 & 0.001 & 0.013 & 0.003 & 0.015 & 0.002 & 0.007 & 0.001 & 0.001 & 0.001 \\
\hline 201.56 & RICE_3yr_249 & 0.103 & 0.266 & 0.020 & 0.073 & 0.016 & 0.001 & 0.007 & 0.001 & 0.010 & 0.002 & 0.005 & 0.001 & 0.001 & 0.001 \\
\hline 201.99 & RICE_3yr_250 & 0.068 & 0.185 & 0.015 & 0.053 & 0.008 & $<0.001$ & 0.007 & 0.001 & 0.007 & 0.001 & 0.004 & 0.001 & 0.001 & $<0.001$ \\
\hline 202.45 & RICE_3yr_251 & 0.101 & 0.202 & 0.019 & 0.072 & 0.011 & $<0.001$ & 0.008 & 0.001 & 0.009 & 0.001 & 0.003 & $<0.001$ & 0.001 & $<0.001$ \\
\hline
\end{tabular}




\begin{tabular}{|c|c|c|c|c|c|c|c|c|c|c|c|c|c|c|c|}
\hline 202.89 & RICE_3yr_252 & 0.107 & 0.700 & 0.021 & 0.080 & 0.016 & $<0.001$ & 0.012 & 0.002 & 0.011 & 0.001 & 0.005 & 0.001 & 0.001 & 0.001 \\
\hline 203.34 & RICE_3yr_253 & 0.122 & 0.356 & 0.023 & 0.088 & 0.012 & $<0.001$ & 0.010 & 0.002 & 0.011 & 0.002 & 0.004 & 0.001 & 0.001 & 0.001 \\
\hline 203.80 & RICE_3yr_254 & 0.103 & 0.472 & 0.020 & 0.084 & 0.019 & $<0.001$ & 0.008 & 0.002 & 0.011 & 0.003 & 0.005 & 0.001 & 0.002 & 0.001 \\
\hline 204.29 & RICE_3yr_255 & 0.144 & 0.431 & 0.029 & 0.116 & 0.022 & 0.002 & 0.016 & 0.002 & 0.015 & 0.002 & 0.009 & 0.001 & 0.001 & 0.001 \\
\hline 204.70 & RICE_3yr_256 & 0.094 & 0.257 & 0.019 & 0.074 & 0.012 & 0.001 & 0.008 & 0.002 & 0.013 & 0.002 & 0.004 & 0.001 & 0.001 & 0.001 \\
\hline 205.19 & RICE_3yr_257 & 0.072 & 0.188 & 0.014 & 0.060 & 0.011 & $<0.001$ & 0.006 & 0.001 & 0.008 & 0.001 & 0.004 & 0.001 & 0.001 & $<0.001$ \\
\hline 205.62 & RICE_3yr_258 & 0.116 & 0.311 & 0.024 & 0.094 & 0.014 & 0.001 & 0.013 & 0.002 & 0.014 & 0.002 & 0.006 & 0.001 & 0.002 & 0.001 \\
\hline 206.07 & RICE_3yr_259 & 0.120 & 0.334 & 0.024 & 0.097 & 0.020 & 0.002 & 0.013 & 0.002 & 0.018 & 0.003 & 0.006 & 0.001 & 0.002 & 0.001 \\
\hline 206.50 & RICE_3yr_260 & 0.110 & 0.278 & 0.021 & 0.073 & 0.012 & $<0.001$ & 0.012 & 0.002 & 0.010 & 0.001 & 0.004 & 0.001 & 0.001 & 0.001 \\
\hline 206.95 & RICE_3yr_261 & 0.077 & 0.395 & 0.017 & 0.055 & 0.018 & 0.001 & 0.008 & 0.001 & 0.008 & 0.002 & 0.005 & 0.001 & 0.001 & 0.001 \\
\hline 207.41 & RICE_3yr_262 & 0.138 & 0.323 & 0.027 & 0.097 & 0.017 & 0.001 & 0.012 & 0.002 & 0.014 & 0.002 & 0.005 & 0.001 & 0.001 & 0.001 \\
\hline 207.85 & RICE_3yr_263 & 0.102 & 0.233 & 0.019 & 0.071 & 0.015 & 0.001 & 0.012 & 0.002 & 0.013 & 0.002 & 0.006 & 0.001 & 0.001 & 0.001 \\
\hline 208.30 & RICE_3yr_264 & 0.116 & 0.258 & 0.022 & 0.078 & 0.015 & 0.001 & 0.011 & 0.002 & 0.011 & 0.002 & 0.004 & 0.001 & 0.001 & 0.001 \\
\hline 208.72 & RICE_3yr_265 & 0.138 & 0.370 & 0.026 & 0.104 & 0.020 & 0.002 & 0.014 & 0.002 & 0.015 & 0.003 & 0.007 & 0.002 & 0.002 & 0.001 \\
\hline 209.19 & RICE_3yr_266 & 0.084 & 0.221 & 0.016 & 0.057 & 0.013 & $<0.001$ & 0.007 & 0.001 & 0.009 & 0.001 & 0.003 & 0.001 & 0.001 & 0.001 \\
\hline 209.61 & RICE_3yr_267 & 0.109 & 0.405 & 0.023 & 0.080 & 0.019 & $<0.001$ & 0.010 & 0.002 & 0.008 & 0.003 & 0.006 & 0.001 & 0.001 & 0.001 \\
\hline 210.04 & RICE_3yr_268 & 0.068 & 0.202 & 0.014 & 0.051 & 0.009 & $<0.001$ & 0.006 & 0.001 & 0.008 & 0.001 & 0.003 & $<0.001$ & $<0.001$ & $<0.001$ \\
\hline 210.49 & RICE_3yr_269 & 0.061 & 0.172 & 0.013 & 0.051 & 0.010 & $<0.001$ & 0.006 & 0.001 & 0.007 & 0.001 & 0.003 & 0.001 & 0.001 & $<0.001$ \\
\hline 210.93 & RICE_3yr_270 & 0.124 & 0.381 & 0.027 & 0.098 & 0.020 & 0.002 & 0.012 & 0.002 & 0.011 & 0.002 & 0.006 & 0.001 & 0.002 & 0.001 \\
\hline 211.38 & RICE_3yr_271 & 0.105 & 0.282 & 0.020 & 0.084 & 0.019 & 0.001 & 0.012 & 0.002 & 0.011 & 0.003 & 0.006 & 0.001 & 0.001 & 0.001 \\
\hline 211.80 & RICE_3yr_272 & 0.151 & 0.451 & 0.028 & 0.114 & 0.021 & 0.001 & 0.017 & 0.003 & 0.017 & 0.003 & 0.008 & 0.001 & 0.001 & 0.001 \\
\hline 212.25 & RICE_3yr_273 & 0.127 & 0.325 & 0.025 & 0.088 & 0.020 & $<0.001$ & 0.014 & 0.002 & 0.011 & 0.002 & 0.005 & 0.001 & 0.001 & 0.001 \\
\hline 212.67 & RICE_3yr_274 & 0.084 & 0.428 & 0.017 & 0.065 & 0.017 & $<0.001$ & 0.011 & 0.002 & 0.011 & 0.002 & 0.005 & 0.001 & 0.001 & 0.001 \\
\hline 213.08 & RICE_3yr_275 & 0.111 & 0.298 & 0.022 & 0.083 & 0.017 & 0.001 & 0.011 & 0.002 & 0.009 & 0.002 & 0.005 & 0.001 & 0.002 & 0.001 \\
\hline 213.51 & RICE_3yr_276 & 0.108 & 0.291 & 0.021 & 0.077 & 0.014 & 0.002 & 0.011 & 0.001 & 0.011 & 0.002 & 0.005 & 0.001 & 0.002 & 0.001 \\
\hline 213.94 & RICE_3yr_277 & 0.066 & 0.154 & 0.013 & 0.050 & 0.007 & $<0.001$ & 0.007 & 0.002 & 0.007 & 0.002 & 0.004 & 0.001 & 0.001 & $<0.001$ \\
\hline 214.39 & RICE_3yr_278 & 0.100 & 0.232 & 0.019 & 0.073 & 0.013 & $<0.001$ & 0.009 & 0.001 & 0.009 & 0.002 & 0.003 & 0.001 & 0.001 & 0.001 \\
\hline 214.78 & RICE_3yr_279 & 0.071 & 0.243 & 0.014 & 0.052 & 0.011 & $<0.001$ & 0.006 & 0.001 & 0.009 & 0.001 & 0.003 & $<0.001$ & 0.001 & $<0.001$ \\
\hline 215.23 & RICE_3yr_280 & 0.116 & 0.248 & 0.022 & 0.083 & 0.014 & $<0.001$ & 0.011 & 0.002 & 0.010 & 0.003 & 0.005 & 0.001 & 0.001 & 0.001 \\
\hline 215.66 & RICE_3yr_281 & 0.129 & 0.421 & 0.024 & 0.103 & 0.023 & 0.001 & 0.016 & 0.001 & 0.014 & 0.003 & 0.007 & 0.001 & 0.001 & $<0.001$ \\
\hline 216.07 & RICE_3yr_282 & 0.104 & 0.279 & 0.020 & 0.084 & 0.017 & 0.001 & 0.011 & 0.002 & 0.013 & 0.002 & 0.004 & 0.001 & 0.001 & 0.001 \\
\hline 216.50 & RICE_3yr_283 & 0.113 & 0.272 & 0.023 & 0.082 & 0.019 & 0.001 & 0.013 & 0.002 & 0.012 & 0.003 & 0.005 & 0.001 & 0.001 & 0.001 \\
\hline 216.92 & RICE_3yr_284 & 0.082 & 0.192 & 0.017 & 0.063 & 0.013 & 0.001 & 0.010 & 0.001 & 0.007 & 0.002 & 0.005 & $<0.001$ & 0.001 & $<0.001$ \\
\hline 217.32 & RICE_3yr_285 & 0.108 & 0.267 & 0.021 & 0.079 & 0.018 & 0.001 & 0.012 & 0.002 & 0.011 & 0.002 & 0.006 & 0.001 & 0.001 & 0.001 \\
\hline 217.77 & RICE_3yr_286 & 0.084 & 0.735 & 0.017 & 0.066 & 0.014 & 0.001 & 0.011 & 0.001 & 0.008 & 0.002 & 0.005 & $<0.001$ & 0.001 & $<0.001$ \\
\hline 218.17 & RICE_3yr_287 & 0.079 & 0.217 & 0.015 & 0.055 & 0.011 & $<0.001$ & 0.009 & 0.001 & 0.008 & 0.002 & 0.002 & $<0.001$ & 0.001 & $<0.001$ \\
\hline 218.61 & RICE_3yr_288 & 0.259 & 0.347 & 0.080 & 0.356 & 0.093 & 0.017 & 0.071 & 0.016 & 0.090 & 0.016 & 0.037 & 0.005 & 0.006 & 0.003 \\
\hline 219.00 & RICE_3yr_289 & 0.119 & 0.302 & 0.025 & 0.089 & 0.021 & 0.001 & 0.011 & 0.002 & 0.012 & 0.003 & 0.005 & 0.001 & 0.001 & 0.001 \\
\hline 219.43 & RICE_3yr_290 & 0.095 & 0.266 & 0.019 & 0.075 & 0.015 & $<0.001$ & 0.010 & 0.002 & 0.011 & 0.002 & 0.005 & 0.001 & 0.001 & 0.001 \\
\hline 219.85 & RICE_3yr_291 & 0.161 & 0.406 & 0.030 & 0.116 & 0.026 & 0.002 & 0.015 & 0.003 & 0.015 & 0.003 & 0.008 & 0.001 & 0.002 & 0.001 \\
\hline 220.28 & RICE_3yr_292 & 0.087 & 0.241 & 0.017 & 0.060 & 0.010 & 0.001 & 0.010 & 0.001 & 0.010 & 0.002 & 0.005 & 0.001 & 0.001 & 0.001 \\
\hline 220.66 & RICE_3yr_293 & 0.095 & 0.782 & 0.018 & 0.058 & 0.014 & 0.001 & 0.011 & 0.001 & 0.007 & 0.001 & 0.006 & $<0.001$ & 0.001 & 0.001 \\
\hline 221.11 & RICE_3yr_294 & 0.080 & 0.225 & 0.017 & 0.063 & 0.010 & $<0.001$ & 0.009 & 0.001 & 0.010 & 0.002 & 0.005 & 0.001 & 0.001 & 0.001 \\
\hline 221.52 & RICE_3yr_295 & 0.087 & 0.241 & 0.016 & 0.066 & 0.015 & 0.001 & 0.012 & 0.002 & 0.010 & 0.003 & 0.007 & 0.001 & 0.001 & 0.001 \\
\hline 221.91 & RICE_3yr_296 & 0.128 & 0.340 & 0.025 & 0.095 & 0.026 & 0.002 & 0.012 & 0.003 & 0.012 & 0.003 & 0.007 & 0.001 & 0.002 & 0.001 \\
\hline 222.33 & RICE_3yr_297 & 0.066 & 0.191 & 0.016 & 0.047 & 0.009 & $<0.001$ & 0.008 & 0.001 & 0.009 & 0.002 & 0.005 & 0.001 & 0.001 & 0.001 \\
\hline 222.71 & RICE_3yr_298 & 0.143 & 0.404 & 0.031 & 0.108 & 0.024 & 0.002 & 0.017 & 0.003 & 0.018 & 0.004 & 0.009 & 0.001 & 0.002 & 0.001 \\
\hline 223.16 & RICE_3yr_299 & 0.162 & 0.407 & 0.031 & 0.119 & 0.026 & 0.002 & 0.016 & 0.003 & 0.015 & 0.003 & 0.008 & 0.001 & 0.002 & 0.001 \\
\hline 223.54 & RICE_3yr_300 & 0.113 & 0.289 & 0.022 & 0.091 & 0.017 & 0.001 & 0.012 & 0.002 & 0.010 & 0.003 & 0.006 & 0.001 & 0.002 & 0.001 \\
\hline 223.96 & RICE_3yr_301 & 0.108 & 0.420 & 0.024 & 0.092 & 0.020 & 0.001 & 0.014 & 0.002 & 0.014 & 0.003 & 0.006 & 0.001 & 0.001 & 0.001 \\
\hline 224.35 & RICE_3yr_302 & 0.148 & 0.333 & 0.027 & 0.105 & 0.015 & 0.002 & 0.013 & 0.001 & 0.013 & 0.002 & 0.006 & 0.001 & 0.001 & 0.001 \\
\hline 224.76 & RICE_3yr_303 & 0.114 & 0.286 & 0.024 & 0.085 & 0.021 & 0.001 & 0.013 & 0.002 & 0.011 & 0.002 & 0.005 & 0.001 & 0.001 & 0.001 \\
\hline 225.14 & RICE_3yr_304 & 0.096 & 0.259 & 0.019 & 0.071 & 0.015 & 0.001 & 0.011 & 0.002 & 0.013 & 0.003 & 0.007 & 0.001 & 0.001 & 0.001 \\
\hline 225.54 & RICE_3yr_305 & 0.082 & 0.207 & 0.015 & 0.052 & 0.012 & $<0.001$ & 0.007 & 0.001 & 0.009 & 0.001 & 0.004 & 0.001 & $<0.001$ & 0.001 \\
\hline 225.96 & RICE_3yr_306 & 0.089 & 0.286 & 0.019 & 0.063 & 0.016 & $<0.001$ & 0.009 & 0.001 & 0.009 & 0.002 & 0.005 & 0.001 & 0.001 & $<0.001$ \\
\hline 226.42 & RICE_3yr_307 & 0.111 & 0.253 & 0.021 & 0.085 & 0.014 & 0.002 & 0.011 & 0.002 & 0.009 & 0.002 & 0.005 & 0.001 & 0.001 & 0.001 \\
\hline 226.79 & RICE_3yr_308 & 0.088 & 0.430 & 0.017 & 0.059 & 0.013 & $<0.001$ & 0.007 & 0.001 & 0.008 & 0.002 & 0.004 & $<0.001$ & 0.002 & $<0.001$ \\
\hline 227.22 & RICE_3yr_309 & 0.331 & 0.416 & 0.063 & 0.223 & 0.040 & 0.002 & 0.021 & 0.003 & 0.018 & 0.003 & 0.008 & 0.001 & 0.001 & 0.001 \\
\hline 227.58 & RICE_3yr_310 & 0.184 & 0.279 & 0.033 & 0.115 & 0.019 & 0.001 & 0.010 & 0.002 & 0.012 & 0.002 & 0.006 & 0.001 & 0.001 & 0.001 \\
\hline 228.00 & RICE_3yr_311 & 0.096 & 0.208 & 0.020 & 0.074 & 0.014 & $<0.001$ & 0.010 & 0.002 & 0.008 & 0.002 & 0.004 & $<0.001$ & 0.001 & $<0.001$ \\
\hline 228.41 & RICE_3yr_312 & 0.095 & 0.205 & 0.018 & 0.061 & 0.015 & $<0.001$ & 0.010 & 0.002 & 0.008 & 0.002 & 0.005 & 0.001 & 0.001 & 0.001 \\
\hline 228.77 & RICE_3yr_313 & 0.114 & 3.552 & 0.021 & 0.083 & 0.021 & 0.001 & 0.011 & 0.002 & 0.012 & 0.003 & 0.006 & 0.001 & 0.002 & 0.001 \\
\hline 229.17 & RICE_3yr_314 & 0.134 & 0.359 & 0.027 & 0.102 & 0.021 & 0.002 & 0.014 & 0.002 & 0.013 & 0.002 & 0.007 & 0.001 & 0.002 & 0.001 \\
\hline
\end{tabular}




\begin{tabular}{|c|c|c|c|c|c|c|c|c|c|c|c|c|c|c|c|}
\hline 229.57 & RICE_3yr_315 & 0.100 & 0.266 & 0.019 & 0.072 & 0.015 & $<0.001$ & 0.010 & 0.001 & 0.009 & 0.002 & 0.006 & 0.001 & 0.001 & 0.001 \\
\hline 229.97 & RICE_3yr_316 & 0.165 & 0.957 & 0.031 & 0.108 & 0.031 & 0.001 & 0.012 & 0.002 & 0.016 & 0.004 & 0.008 & 0.002 & 0.002 & 0.001 \\
\hline 230.37 & RICE_3yr_317 & 0.078 & 0.183 & 0.016 & 0.060 & 0.014 & 0.001 & 0.010 & 0.001 & 0.014 & 0.003 & 0.005 & 0.001 & 0.001 & 0.001 \\
\hline 230.76 & RICE_3yr_318 & 0.140 & 0.334 & 0.031 & 0.112 & 0.030 & 0.002 & 0.015 & 0.003 & 0.016 & 0.003 & 0.009 & 0.001 & 0.002 & 0.001 \\
\hline 231.12 & RICE_3yr_319 & 0.085 & 0.213 & 0.017 & 0.067 & 0.018 & 0.001 & 0.010 & 0.002 & 0.012 & 0.002 & 0.006 & 0.001 & 0.002 & 0.001 \\
\hline 231.53 & RICE_3yr_320 & 0.088 & 0.203 & 0.016 & 0.065 & 0.016 & 0.001 & 0.010 & 0.002 & 0.010 & 0.002 & 0.004 & $<0.001$ & 0.001 & 0.001 \\
\hline 231.90 & RICE_3yr_321 & 0.117 & 0.326 & 0.022 & 0.087 & 0.018 & $<0.001$ & 0.012 & 0.002 & 0.013 & 0.002 & 0.006 & 0.001 & 0.001 & 0.001 \\
\hline 232.33 & RICE_3yr_322 & 0.156 & 0.389 & 0.031 & 0.121 & 0.023 & 0.002 & 0.015 & 0.003 & 0.014 & 0.003 & 0.009 & 0.001 & 0.002 & 0.001 \\
\hline 232.71 & RICE_3yr_323 & 0.143 & 0.325 & 0.029 & 0.108 & 0.026 & 0.002 & 0.013 & 0.003 & 0.014 & 0.002 & 0.007 & 0.001 & 0.002 & 0.001 \\
\hline 233.07 & RICE_3yr_324 & 0.125 & 0.277 & 0.023 & 0.091 & 0.017 & 0.001 & 0.012 & 0.002 & 0.012 & 0.003 & 0.006 & 0.001 & 0.001 & 0.001 \\
\hline 233.45 & RICE_3yr_325 & 0.133 & 0.322 & 0.026 & 0.089 & 0.019 & 0.001 & 0.011 & 0.002 & 0.014 & 0.002 & 0.006 & 0.001 & 0.001 & 0.001 \\
\hline 233.85 & RICE_3yr_326 & 0.108 & 0.292 & 0.021 & 0.082 & 0.016 & 0.001 & 0.013 & 0.002 & 0.015 & 0.002 & 0.006 & 0.001 & 0.001 & 0.001 \\
\hline 234.25 & RICE_3yr_327 & 0.117 & 0.266 & 0.024 & 0.083 & 0.019 & 0.002 & 0.013 & 0.002 & 0.013 & 0.003 & 0.007 & 0.001 & 0.002 & 0.001 \\
\hline 234.63 & RICE_3yr_328 & 0.106 & 0.311 & 0.019 & 0.071 & 0.020 & $<0.001$ & 0.009 & 0.001 & 0.012 & 0.002 & 0.004 & 0.001 & 0.001 & 0.001 \\
\hline 235.02 & RICE_3yr_329 & 0.093 & 0.226 & 0.016 & 0.070 & 0.016 & 0.001 & 0.008 & 0.001 & 0.008 & 0.002 & 0.005 & $<0.001$ & 0.001 & $<0.001$ \\
\hline 235.36 & RICE_3yr_330 & 0.119 & 0.282 & 0.022 & 0.084 & 0.014 & 0.001 & 0.010 & 0.002 & 0.010 & 0.002 & 0.006 & $<0.001$ & 0.001 & 0.001 \\
\hline 235.75 & RICE_3yr_331 & 0.077 & 0.225 & 0.016 & 0.060 & 0.017 & $<0.001$ & 0.008 & 0.002 & 0.009 & 0.002 & 0.003 & $<0.001$ & 0.001 & $<0.001$ \\
\hline 236.14 & RICE_3yr_332 & 0.099 & 0.201 & 0.019 & 0.070 & 0.015 & 0.001 & 0.009 & 0.001 & 0.010 & 0.002 & 0.005 & 0.001 & 0.001 & 0.001 \\
\hline 236.49 & RICE_3yr_333 & 0.114 & 0.252 & 0.022 & 0.080 & 0.019 & 0.002 & 0.012 & 0.002 & 0.013 & 0.002 & 0.006 & 0.001 & 0.001 & 0.001 \\
\hline 236.88 & RICE_3yr_334 & 0.469 & 0.946 & 0.088 & 0.333 & 0.054 & 0.013 & 0.034 & 0.006 & 0.037 & 0.007 & 0.019 & 0.002 & 0.005 & 0.003 \\
\hline 237.29 & RICE_3yr_335 & 0.081 & 0.195 & 0.014 & 0.056 & 0.009 & 0.001 & 0.006 & 0.001 & 0.008 & 0.002 & 0.003 & 0.001 & 0.001 & $<0.001$ \\
\hline 237.64 & RICE_3yr_336 & 0.132 & 1.572 & 0.024 & 0.079 & 0.018 & 0.001 & 0.009 & 0.001 & 0.011 & 0.002 & 0.005 & 0.001 & 0.001 & 0.001 \\
\hline 238.03 & RICE_3yr_337 & 0.080 & 0.246 & 0.014 & 0.053 & 0.010 & 0.001 & 0.007 & 0.001 & 0.008 & 0.002 & 0.004 & $<0.001$ & 0.001 & $<0.001$ \\
\hline 238.39 & RICE_3yr_338 & 0.066 & 0.153 & 0.014 & 0.053 & 0.013 & $<0.001$ & 0.007 & 0.001 & 0.006 & 0.001 & 0.003 & $<0.001$ & 0.001 & $<0.001$ \\
\hline 238.78 & RICE_3yr_339 & 0.079 & 0.276 & 0.015 & 0.053 & 0.013 & 0.001 & 0.007 & $<0.001$ & 0.007 & 0.002 & 0.003 & 0.001 & 0.001 & $<0.001$ \\
\hline 239.15 & RICE_3yr_340 & 0.157 & 0.347 & 0.029 & 0.099 & 0.025 & 0.001 & 0.015 & 0.002 & 0.015 & 0.002 & 0.006 & 0.001 & 0.001 & 0.001 \\
\hline 239.51 & RICE_3yr_341 & 0.065 & 0.170 & 0.012 & 0.047 & 0.014 & $<0.001$ & 0.007 & 0.001 & 0.008 & 0.001 & 0.003 & $<0.001$ & 0.001 & $<0.001$ \\
\hline 239.86 & RICE_3yr_342 & 0.104 & 0.240 & 0.020 & 0.064 & 0.015 & 0.001 & 0.009 & 0.002 & 0.010 & 0.002 & 0.005 & 0.001 & 0.001 & 0.001 \\
\hline 240.23 & RICE_3yr_343 & 0.078 & 0.188 & 0.016 & 0.049 & 0.012 & $<0.001$ & 0.008 & 0.001 & 0.006 & 0.001 & 0.003 & $<0.001$ & $<0.001$ & $<0.001$ \\
\hline 240.60 & RICE_3yr_344 & 0.083 & 0.158 & 0.015 & 0.051 & 0.011 & $<0.001$ & 0.005 & 0.001 & 0.007 & 0.002 & 0.004 & 0.001 & 0.001 & $<0.001$ \\
\hline 240.96 & RICE_3yr_345 & 0.170 & 0.568 & 0.034 & 0.126 & 0.030 & 0.004 & 0.018 & 0.003 & 0.021 & 0.004 & 0.010 & 0.002 & 0.002 & 0.002 \\
\hline 241.37 & RICE_3yr_346 & 0.064 & 0.148 & 0.012 & 0.043 & 0.009 & $<0.001$ & 0.005 & 0.001 & 0.007 & 0.001 & 0.003 & $<0.001$ & $<0.001$ & $<0.001$ \\
\hline 241.69 & RICE_3yr_347 & 0.094 & 1.421 & 0.017 & 0.064 & 0.012 & 0.001 & 0.008 & 0.001 & 0.008 & 0.002 & 0.004 & 0.001 & 0.001 & $<0.001$ \\
\hline 242.07 & RICE_3yr_348 & 0.060 & 0.160 & 0.011 & 0.045 & 0.014 & -0.001 & 0.004 & 0.002 & 0.006 & 0.001 & 0.003 & $<0.001$ & 0.001 & $<0.001$ \\
\hline 242.46 & RICE_3yr_349 & 0.110 & 0.255 & 0.022 & 0.088 & 0.019 & 0.002 & 0.009 & 0.002 & 0.015 & 0.003 & 0.008 & 0.001 & 0.002 & 0.001 \\
\hline 242.79 & RICE_3yr_350 & 0.096 & 0.209 & 0.019 & 0.076 & 0.014 & 0.001 & 0.009 & 0.001 & 0.010 & 0.002 & 0.003 & 0.001 & 0.001 & 0.001 \\
\hline 243.15 & RICE_3yr_351 & 0.074 & 0.193 & 0.014 & 0.050 & 0.009 & $<0.001$ & 0.008 & 0.001 & 0.007 & 0.001 & 0.005 & 0.001 & 0.001 & $<0.001$ \\
\hline 243.54 & RICE_3yr_352 & 0.104 & 0.240 & 0.020 & 0.072 & 0.015 & 0.001 & 0.009 & 0.001 & 0.012 & 0.002 & 0.004 & $<0.001$ & 0.002 & $<0.001$ \\
\hline 243.89 & RICE_3yr_353 & 0.113 & 0.351 & 0.026 & 0.097 & 0.022 & 0.002 & 0.010 & 0.002 & 0.014 & 0.002 & 0.006 & 0.001 & 0.001 & 0.001 \\
\hline 244.24 & RICE_3yr_354 & 0.132 & 0.299 & 0.026 & 0.104 & 0.021 & 0.001 & 0.014 & 0.002 & 0.011 & 0.002 & 0.006 & 0.001 & 0.001 & 0.001 \\
\hline 244.63 & RICE_3yr_355 & 0.119 & 0.269 & 0.025 & 0.097 & 0.023 & 0.002 & 0.016 & 0.003 & 0.024 & 0.004 & 0.011 & 0.002 & 0.002 & 0.001 \\
\hline 245.00 & RICE_3yr_356 & 0.096 & 0.300 & 0.017 & 0.069 & 0.015 & 0.001 & 0.009 & 0.002 & 0.009 & 0.002 & 0.004 & $<0.001$ & 0.001 & 0.001 \\
\hline 245.35 & RICE_3yr_357 & 0.081 & 0.208 & 0.014 & 0.054 & 0.009 & $<0.001$ & 0.006 & 0.001 & 0.007 & 0.001 & 0.003 & $<0.001$ & 0.001 & $<0.001$ \\
\hline 245.68 & RICE_3yr_358 & 0.087 & 0.210 & 0.015 & 0.053 & 0.010 & $<0.001$ & 0.007 & 0.001 & 0.007 & 0.001 & 0.003 & $<0.001$ & 0.001 & $<0.001$ \\
\hline 246.07 & RICE_3yr_359 & 0.075 & 0.206 & 0.016 & 0.059 & 0.014 & $<0.001$ & 0.008 & 0.001 & 0.009 & 0.002 & 0.005 & $<0.001$ & 0.001 & $<0.001$ \\
\hline 246.40 & RICE_3yr_360 & 0.161 & 0.425 & 0.038 & 0.133 & 0.022 & 0.004 & 0.018 & 0.002 & 0.021 & 0.003 & 0.010 & 0.002 & 0.002 & 0.001 \\
\hline 246.78 & RICE_3yr_361 & 0.147 & 0.500 & 0.034 & 0.115 & 0.029 & 0.003 & 0.023 & 0.003 & 0.021 & 0.003 & 0.010 & 0.001 & 0.002 & 0.001 \\
\hline 247.14 & RICE_3yr_362 & 0.126 & 0.317 & 0.025 & 0.095 & 0.016 & 0.003 & 0.016 & 0.002 & 0.012 & 0.002 & 0.008 & 0.001 & 0.001 & 0.001 \\
\hline 247.48 & RICE_3yr_363 & 0.164 & 0.415 & 0.035 & 0.122 & 0.024 & 0.003 & 0.022 & 0.003 & 0.018 & 0.004 & 0.009 & 0.001 & 0.002 & 0.001 \\
\hline 247.85 & RICE_3yr_364 & 0.093 & 0.291 & 0.019 & 0.065 & 0.019 & 0.001 & 0.011 & 0.002 & 0.012 & 0.003 & 0.006 & 0.001 & 0.001 & 0.001 \\
\hline 248.17 & RICE_3yr_365 & 0.186 & 0.458 & 0.042 & 0.148 & 0.031 & 0.005 & 0.023 & 0.003 & 0.023 & 0.004 & 0.012 & 0.002 & 0.004 & 0.001 \\
\hline 248.54 & RICE_3yr_366 & 0.165 & 0.439 & 0.034 & 0.131 & 0.027 & 0.003 & 0.025 & 0.003 & 0.023 & 0.003 & 0.014 & 0.002 & 0.002 & 0.002 \\
\hline 248.88 & RICE_3yr_367 & 0.126 & 0.330 & 0.027 & 0.103 & 0.023 & 0.003 & 0.019 & 0.002 & 0.021 & 0.003 & 0.008 & 0.001 & 0.002 & 0.001 \\
\hline 249.25 & RICE_3yr_368 & 0.092 & 0.263 & 0.017 & 0.062 & 0.010 & 0.001 & 0.009 & 0.001 & 0.007 & 0.002 & 0.003 & $<0.001$ & 0.001 & $<0.001$ \\
\hline 249.59 & RICE_3yr_369 & 0.114 & 0.263 & 0.022 & 0.089 & 0.016 & 0.002 & 0.013 & 0.002 & 0.016 & 0.002 & 0.007 & 0.001 & 0.002 & 0.001 \\
\hline 249.97 & RICE_3yr_370 & 0.168 & 0.414 & 0.037 & 0.132 & 0.025 & 0.004 & 0.029 & 0.004 & 0.020 & 0.004 & 0.012 & 0.002 & 0.002 & 0.001 \\
\hline 250.28 & RICE_3yr_371 & 0.589 & 1.401 & 0.137 & 0.506 & 0.120 & 0.046 & 0.058 & 0.017 & 0.069 & 0.017 & 0.042 & 0.006 & 0.007 & 0.005 \\
\hline 250.65 & RICE_3yr_372 & 0.074 & 0.174 & 0.012 & 0.046 & 0.009 & $<0.001$ & 0.004 & 0.001 & 0.006 & 0.001 & 0.004 & $<0.001$ & 0.001 & $<0.001$ \\
\hline 250.97 & RICE_3yr_373 & 0.078 & 0.190 & 0.014 & 0.051 & 0.009 & $<0.001$ & 0.009 & 0.001 & 0.008 & 0.002 & 0.005 & $<0.001$ & 0.001 & $<0.001$ \\
\hline 251.34 & RICE_3yr_374 & 0.070 & 0.347 & 0.013 & 0.048 & 0.010 & $<0.001$ & 0.008 & 0.001 & 0.006 & 0.002 & 0.005 & 0.001 & 0.001 & $<0.001$ \\
\hline 251.66 & RICE_3yr_375 & 0.061 & 0.143 & 0.011 & 0.041 & 0.005 & -0.001 & 0.008 & 0.001 & 0.006 & 0.002 & 0.004 & $<0.001$ & 0.001 & $<0.001$ \\
\hline 252.03 & RICE_3yr_376 & 0.093 & 0.210 & 0.016 & 0.063 & 0.012 & $<0.001$ & 0.012 & 0.001 & 0.009 & 0.001 & 0.005 & 0.001 & 0.001 & $<0.001$ \\
\hline 252.38 & RICE_3yr_377 & 0.099 & 0.267 & 0.021 & 0.071 & 0.013 & 0.002 & 0.010 & 0.002 & 0.010 & 0.001 & 0.006 & 0.001 & 0.002 & 0.001 \\
\hline
\end{tabular}




\begin{tabular}{|c|c|c|c|c|c|c|c|c|c|c|c|c|c|c|c|}
\hline 252.76 & RICE_3yr_378 & 0.079 & 0.598 & 0.018 & 0.065 & 0.015 & 0.002 & 0.009 & 0.001 & 0.009 & 0.001 & 0.006 & 0.001 & 0.001 & 0.001 \\
\hline 253.08 & RICE_3yr_379 & 0.128 & 0.263 & 0.023 & 0.071 & 0.011 & -0.001 & 0.010 & 0.001 & 0.009 & 0.001 & 0.004 & $<0.001$ & 0.001 & $<0.001$ \\
\hline 253.44 & RICE_3yr_380 & 0.077 & 0.182 & 0.015 & 0.051 & 0.011 & 0.001 & 0.009 & 0.002 & 0.007 & 0.001 & 0.004 & 0.001 & 0.001 & 0.001 \\
\hline 253.77 & RICE_3yr_381 & 0.072 & 0.449 & 0.014 & 0.055 & 0.010 & 0.001 & 0.009 & 0.001 & 0.010 & 0.001 & 0.004 & 0.001 & 0.001 & $<0.001$ \\
\hline 254.14 & RICE_3yr_382 & 0.111 & 0.279 & 0.022 & 0.082 & 0.021 & 0.001 & 0.015 & 0.002 & 0.016 & 0.002 & 0.007 & 0.001 & 0.002 & 0.001 \\
\hline 254.46 & RICE_3yr_383 & 0.103 & 0.241 & 0.019 & 0.065 & 0.017 & 0.001 & 0.010 & 0.002 & 0.013 & 0.001 & 0.006 & 0.001 & 0.002 & 0.001 \\
\hline 254.80 & RICE_3yr_384 & 0.153 & 0.300 & 0.030 & 0.104 & 0.023 & 0.002 & 0.016 & 0.002 & 0.017 & 0.002 & 0.006 & 0.001 & 0.001 & 0.001 \\
\hline 255.13 & RICE_3yr_385 & 0.065 & 0.149 & 0.014 & 0.042 & 0.009 & -0.001 & 0.007 & 0.001 & 0.007 & 0.001 & 0.003 & $<0.001$ & 0.001 & $<0.001$ \\
\hline 255.47 & RICE_3yr_386 & 0.053 & 0.129 & 0.012 & 0.037 & 0.008 & $<0.001$ & 0.007 & $<0.001$ & 0.007 & 0.001 & 0.003 & $<0.001$ & 0.001 & $<0.001$ \\
\hline 255.80 & RICE_3yr_387 & 0.104 & 0.668 & 0.023 & 0.080 & 0.018 & 0.002 & 0.013 & 0.001 & 0.013 & 0.002 & 0.006 & 0.001 & 0.001 & 0.001 \\
\hline 256.13 & RICE_3yr_388 & 0.079 & 0.192 & 0.016 & 0.052 & 0.007 & $<0.001$ & 0.010 & 0.001 & 0.008 & 0.001 & 0.004 & 0.001 & 0.001 & 0.001 \\
\hline 256.49 & RICE_3yr_389 & 0.138 & 0.336 & 0.026 & 0.093 & 0.021 & $<0.001$ & 0.012 & 0.002 & 0.015 & 0.002 & 0.006 & 0.001 & 0.001 & 0.001 \\
\hline 256.80 & RICE_3yr_390 & 0.098 & 1.450 & 0.020 & 0.071 & 0.014 & 0.001 & 0.012 & 0.002 & 0.011 & 0.001 & 0.006 & 0.001 & 0.002 & 0.001 \\
\hline 257.15 & RICE_3yr_391 & 0.193 & 0.641 & 0.044 & 0.168 & 0.031 & 0.003 & 0.027 & 0.004 & 0.031 & 0.005 & 0.014 & 0.002 & 0.003 & 0.001 \\
\hline 257.49 & RICE_3yr_392 & 0.062 & 0.203 & 0.013 & 0.050 & 0.008 & $<0.001$ & 0.008 & 0.001 & 0.007 & $<0.001$ & 0.003 & $<0.001$ & $<0.001$ & 0.001 \\
\hline 257.80 & RICE_3yr_393 & 0.094 & 0.309 & 0.020 & 0.073 & 0.015 & $<0.001$ & 0.015 & 0.002 & 0.013 & 0.001 & 0.006 & $<0.001$ & 0.002 & 0.001 \\
\hline 258.14 & RICE_3yr_394 & 0.102 & 0.244 & 0.021 & 0.066 & 0.010 & $<0.001$ & 0.011 & 0.001 & 0.009 & 0.002 & 0.005 & 0.001 & 0.001 & $<0.001$ \\
\hline 258.47 & RICE_3yr_395 & 0.096 & 0.258 & 0.018 & 0.062 & 0.013 & $<0.001$ & 0.009 & 0.002 & 0.008 & 0.002 & 0.005 & 0.001 & 0.001 & $<0.001$ \\
\hline 258.81 & RICE_3yr_396 & 0.101 & 0.732 & 0.020 & 0.069 & 0.015 & 0.001 & 0.012 & 0.002 & 0.010 & 0.002 & 0.004 & 0.001 & 0.002 & 0.001 \\
\hline 259.14 & RICE_3yr_397 & 0.101 & 0.259 & 0.019 & 0.068 & 0.015 & $<0.001$ & 0.010 & 0.001 & 0.009 & 0.002 & 0.006 & $<0.001$ & 0.001 & $<0.001$ \\
\hline 259.47 & RICE_3yr_398 & 0.277 & 0.586 & 0.055 & 0.179 & 0.031 & 0.002 & 0.019 & 0.003 & 0.014 & 0.002 & 0.007 & 0.001 & 0.001 & 0.001 \\
\hline 259.82 & RICE_3yr_399 & 0.109 & 0.998 & 0.021 & 0.067 & 0.017 & 0.001 & 0.011 & 0.001 & 0.011 & 0.002 & 0.005 & $<0.001$ & 0.001 & 0.001 \\
\hline 260.13 & RICE_3yr_400 & 0.150 & 0.361 & 0.029 & 0.104 & 0.017 & 0.002 & 0.013 & 0.001 & 0.008 & 0.001 & 0.005 & 0.001 & 0.001 & $<0.001$ \\
\hline 260.44 & RICE_3yr_401 & 0.199 & 0.460 & 0.040 & 0.134 & 0.022 & 0.003 & 0.017 & 0.002 & 0.016 & 0.002 & 0.008 & 0.001 & 0.002 & 0.001 \\
\hline 260.76 & RICE_3yr_402 & 0.109 & 0.271 & 0.023 & 0.085 & 0.015 & 0.002 & 0.017 & 0.001 & 0.013 & 0.001 & 0.005 & 0.001 & 0.001 & 0.001 \\
\hline 261.14 & RICE_3yr_403 & 0.106 & 0.268 & 0.023 & 0.078 & 0.016 & 0.002 & 0.012 & 0.002 & 0.012 & 0.002 & 0.006 & 0.001 & 0.001 & 0.001 \\
\hline 261.47 & RICE_3yr_404 & 0.124 & 0.280 & 0.023 & 0.080 & 0.015 & 0.001 & 0.011 & 0.001 & 0.010 & 0.001 & 0.005 & 0.001 & 0.001 & 0.001 \\
\hline 261.81 & RICE_3yr_405 & 0.193 & 0.957 & 0.042 & 0.159 & 0.032 & 0.003 & 0.027 & 0.003 & 0.024 & 0.005 & 0.013 & 0.002 & 0.003 & 0.002 \\
\hline 262.14 & RICE_3yr_406 & 0.106 & 0.258 & 0.022 & 0.079 & 0.016 & 0.002 & 0.013 & 0.001 & 0.009 & 0.001 & 0.003 & $<0.001$ & 0.001 & 0.001 \\
\hline 262.46 & RICE_3yr_407 & 0.113 & 0.287 & 0.022 & 0.085 & 0.014 & 0.001 & 0.009 & 0.001 & 0.012 & 0.001 & 0.005 & 0.001 & 0.001 & 0.001 \\
\hline 262.77 & RICE_3yr_408 & 0.129 & 0.324 & 0.025 & 0.082 & 0.020 & 0.001 & 0.010 & 0.002 & 0.013 & 0.002 & 0.007 & 0.001 & 0.001 & 0.001 \\
\hline 263.09 & RICE_3yr_409 & 0.177 & 0.412 & 0.032 & 0.114 & 0.022 & 0.002 & 0.018 & 0.002 & 0.014 & 0.002 & 0.008 & 0.001 & 0.002 & 0.001 \\
\hline 263.42 & RICE_3yr_410 & 0.103 & 0.250 & 0.021 & 0.072 & 0.016 & $<0.001$ & 0.010 & 0.002 & 0.011 & 0.001 & 0.005 & 0.001 & 0.001 & 0.001 \\
\hline 263.75 & RICE_3yr_411 & 0.109 & 0.260 & 0.022 & 0.076 & 0.013 & 0.002 & 0.014 & 0.002 & 0.013 & 0.002 & 0.006 & 0.001 & 0.002 & 0.001 \\
\hline 264.08 & RICE_3yr_412 & 0.113 & 0.242 & 0.021 & 0.074 & 0.013 & 0.001 & 0.008 & 0.001 & 0.007 & 0.001 & 0.004 & $<0.001$ & $<0.001$ & $<0.001$ \\
\hline 264.41 & RICE_3yr_413 & 0.077 & 0.382 & 0.016 & 0.054 & 0.014 & 0.001 & 0.009 & 0.001 & 0.006 & 0.001 & 0.002 & 0.001 & 0.001 & $<0.001$ \\
\hline 264.75 & RICE_3yr_414 & 0.109 & 0.268 & 0.023 & 0.075 & 0.016 & 0.001 & 0.011 & 0.002 & 0.012 & 0.002 & 0.005 & $<0.001$ & 0.001 & $<0.001$ \\
\hline 265.04 & RICE_3yr_415 & 0.118 & 0.385 & 0.022 & 0.074 & 0.019 & 0.002 & 0.009 & 0.002 & 0.009 & 0.002 & 0.004 & 0.001 & 0.001 & 0.001 \\
\hline 265.34 & RICE_3yr_416 & 0.086 & 0.213 & 0.018 & 0.068 & 0.015 & 0.001 & 0.008 & 0.001 & 0.008 & 0.001 & 0.004 & 0.001 & 0.001 & $<0.001$ \\
\hline 265.66 & RICE_3yr_417 & 0.093 & 0.219 & 0.019 & 0.063 & 0.013 & 0.001 & 0.010 & 0.001 & 0.010 & 0.002 & 0.005 & 0.001 & 0.001 & $<0.001$ \\
\hline 265.98 & RICE_3yr_418 & 0.111 & 1.148 & 0.023 & 0.079 & 0.017 & 0.002 & 0.013 & 0.002 & 0.013 & 0.002 & 0.006 & 0.001 & 0.001 & 0.001 \\
\hline 266.30 & RICE_3yr_419 & 0.109 & 0.264 & 0.022 & 0.070 & 0.016 & 0.002 & 0.010 & 0.001 & 0.009 & 0.001 & 0.005 & 0.001 & 0.001 & 0.001 \\
\hline 266.58 & RICE_3yr_420 & 0.170 & 0.420 & 0.034 & 0.113 & 0.019 & 0.002 & 0.013 & 0.002 & 0.016 & 0.002 & 0.008 & 0.001 & 0.001 & 0.001 \\
\hline 266.91 & RICE_3yr_421 & 0.180 & 0.494 & 0.034 & 0.130 & 0.030 & 0.002 & 0.019 & 0.003 & 0.015 & 0.003 & 0.008 & 0.001 & 0.001 & 0.001 \\
\hline 267.21 & RICE_3yr_422 & 0.133 & 0.370 & 0.026 & 0.093 & 0.019 & 0.002 & 0.013 & 0.001 & 0.015 & 0.002 & 0.006 & 0.001 & 0.001 & $<0.001$ \\
\hline 267.54 & RICE_3yr_423 & 0.102 & 0.261 & 0.019 & 0.073 & 0.015 & 0.001 & 0.010 & 0.001 & 0.009 & 0.001 & 0.004 & 0.001 & 0.001 & 0.001 \\
\hline 267.84 & RICE_3yr_424 & 0.159 & 0.481 & 0.026 & 0.103 & 0.021 & 0.002 & 0.014 & 0.002 & 0.013 & 0.003 & 0.007 & 0.001 & 0.002 & 0.001 \\
\hline 268.19 & RICE_3yr_425 & 0.075 & 0.187 & 0.015 & 0.048 & 0.011 & $<0.001$ & 0.004 & 0.001 & 0.010 & 0.001 & 0.003 & $<0.001$ & 0.001 & $<0.001$ \\
\hline 268.47 & RICE_3yr_426 & 0.103 & 0.278 & 0.020 & 0.075 & 0.015 & 0.001 & 0.011 & 0.002 & 0.011 & 0.002 & 0.006 & 0.001 & 0.001 & 0.001 \\
\hline 268.79 & RICE_3yr_427 & 0.167 & 0.581 & 0.032 & 0.121 & 0.026 & 0.002 & 0.014 & 0.002 & 0.013 & 0.002 & 0.008 & 0.001 & 0.001 & 0.001 \\
\hline 269.09 & RICE_3yr_428 & 0.087 & 0.242 & 0.019 & 0.061 & 0.014 & $<0.001$ & 0.013 & 0.001 & 0.010 & 0.001 & 0.005 & 0.001 & 0.001 & $<0.001$ \\
\hline 269.40 & RICE_3yr_429 & 0.106 & 0.286 & 0.021 & 0.081 & 0.017 & 0.001 & 0.011 & 0.001 & 0.012 & 0.002 & 0.005 & 0.001 & 0.001 & 0.001 \\
\hline 269.72 & RICE_3yr_430 & 0.148 & 0.347 & 0.029 & 0.102 & 0.019 & 0.002 & 0.013 & 0.002 & 0.011 & 0.002 & 0.007 & 0.001 & 0.001 & 0.001 \\
\hline 270.05 & RICE_3yr_431 & 0.101 & 0.252 & 0.022 & 0.077 & 0.018 & 0.001 & 0.010 & 0.001 & 0.010 & 0.001 & 0.006 & 0.001 & 0.001 & 0.001 \\
\hline 270.34 & RICE_3yr_432 & 0.115 & 0.269 & 0.023 & 0.078 & 0.019 & 0.001 & 0.014 & 0.001 & 0.010 & 0.001 & 0.005 & $<0.001$ & 0.001 & $<0.001$ \\
\hline 270.65 & RICE_3yr_433 & 0.164 & 0.838 & 0.034 & 0.110 & 0.025 & 0.003 & 0.017 & 0.002 & 0.017 & 0.002 & 0.007 & 0.001 & 0.001 & 0.001 \\
\hline 270.96 & RICE_3yr_434 & 0.092 & 0.404 & 0.019 & 0.070 & 0.012 & 0.001 & 0.011 & 0.002 & 0.010 & 0.001 & 0.007 & 0.001 & 0.001 & $<0.001$ \\
\hline 271.27 & RICE_3yr_435 & 0.128 & 0.353 & 0.026 & 0.089 & 0.017 & 0.002 & 0.013 & 0.002 & 0.012 & 0.002 & 0.008 & 0.001 & 0.001 & $<0.001$ \\
\hline 271.56 & RICE_3yr_436 & 0.067 & 0.175 & 0.014 & 0.045 & 0.007 & -0.001 & 0.005 & 0.001 & 0.008 & 0.001 & 0.005 & 0.001 & 0.001 & $<0.001$ \\
\hline 271.86 & RICE_3yr_437 & 0.094 & 0.513 & 0.018 & 0.060 & 0.013 & 0.002 & 0.007 & 0.001 & 0.008 & 0.001 & 0.006 & $<0.001$ & 0.001 & 0.001 \\
\hline 272.20 & RICE_3yr_438 & 0.128 & 0.257 & 0.025 & 0.082 & 0.016 & 0.002 & 0.012 & 0.002 & 0.010 & 0.001 & 0.004 & 0.001 & 0.001 & 0.001 \\
\hline 272.47 & RICE_3yr_439 & 0.121 & 0.309 & 0.023 & 0.084 & 0.014 & 0.002 & 0.012 & 0.001 & 0.011 & 0.002 & 0.005 & 0.001 & 0.001 & 0.006 \\
\hline 272.82 & RICE_3yr_440 & 0.137 & 0.358 & 0.027 & 0.094 & 0.024 & 0.002 & 0.016 & 0.002 & 0.015 & 0.003 & 0.007 & 0.001 & 0.001 & 0.001 \\
\hline
\end{tabular}




\begin{tabular}{|c|c|c|c|c|c|c|c|c|c|c|c|c|c|c|c|}
\hline 273.10 & RICE_3yr_441 & 0.137 & 0.349 & 0.027 & 0.100 & 0.021 & 0.002 & 0.012 & 0.002 & 0.012 & 0.002 & 0.006 & 0.001 & 0.001 & 0.001 \\
\hline 273.39 & RICE_3yr_442 & 0.138 & 0.313 & 0.028 & 0.096 & 0.020 & 0.001 & 0.014 & 0.002 & 0.013 & 0.002 & 0.007 & 0.001 & 0.001 & 0.001 \\
\hline 273.70 & RICE_3yr_443 & 0.121 & 0.783 & 0.025 & 0.096 & 0.035 & 0.002 & 0.017 & 0.003 & 0.016 & 0.003 & 0.009 & 0.001 & 0.001 & 0.001 \\
\hline 274.01 & RICE_3yr_444 & 0.093 & 0.256 & 0.017 & 0.064 & 0.013 & 0.001 & 0.008 & 0.002 & 0.008 & 0.001 & 0.004 & 0.001 & 0.001 & $<0.001$ \\
\hline 274.30 & RICE_3yr_445 & 0.077 & 0.195 & 0.018 & 0.060 & 0.007 & 0.001 & 0.006 & 0.001 & 0.008 & 0.001 & 0.004 & $<0.001$ & 0.001 & 0.001 \\
\hline 274.62 & RICE_3yr_446 & 0.109 & 0.300 & 0.022 & 0.077 & 0.014 & 0.002 & 0.008 & 0.001 & 0.011 & 0.002 & 0.007 & 0.001 & 0.001 & $<0.001$ \\
\hline 274.88 & RICE_3yr_447 & 0.141 & 0.516 & 0.026 & 0.105 & 0.023 & 0.002 & 0.015 & 0.003 & 0.015 & 0.003 & 0.009 & 0.001 & 0.002 & 0.001 \\
\hline 275.19 & RICE_3yr_448 & 0.143 & 0.324 & 0.026 & 0.087 & 0.017 & 0.002 & 0.015 & 0.001 & 0.016 & 0.003 & 0.006 & 0.001 & 0.002 & 0.001 \\
\hline 275.51 & RICE_3yr_449 & 0.196 & 0.440 & 0.037 & 0.125 & 0.029 & 0.003 & 0.024 & 0.003 & 0.018 & 0.003 & 0.009 & 0.002 & 0.003 & 0.001 \\
\hline 275.82 & RICE_3yr_450 & 2.665 & 5.076 & 0.504 & 1.818 & 0.331 & 0.056 & 0.245 & 0.040 & 0.231 & 0.038 & 0.107 & 0.014 & 0.021 & 0.010 \\
\hline 276.12 & RICE_3yr_451 & 0.263 & 0.617 & 0.055 & 0.192 & 0.040 & 0.004 & 0.026 & 0.004 & 0.028 & 0.005 & 0.016 & 0.002 & 0.002 & 0.001 \\
\hline 276.40 & RICE_3yr_452 & 0.205 & 0.460 & 0.040 & 0.141 & 0.026 & 0.004 & 0.019 & 0.003 & 0.023 & 0.004 & 0.011 & 0.001 & 0.002 & 0.001 \\
\hline 276.72 & RICE_3yr_453 & 0.355 & 1.110 & 0.061 & 0.226 & 0.039 & 0.005 & 0.028 & 0.005 & 0.029 & 0.005 & 0.018 & 0.002 & 0.002 & 0.001 \\
\hline 276.98 & RICE_3yr_454 & 0.285 & 1.248 & 0.055 & 0.178 & 0.037 & 0.004 & 0.026 & 0.004 & 0.025 & 0.006 & 0.012 & 0.002 & 0.002 & 0.001 \\
\hline 277.28 & RICE_3yr_455 & 0.133 & 0.283 & 0.023 & 0.088 & 0.018 & 0.001 & 0.013 & 0.002 & 0.011 & 0.002 & 0.005 & 0.001 & 0.001 & 0.001 \\
\hline 277.60 & RICE_3yr_456 & 0.184 & 0.402 & 0.035 & 0.129 & 0.029 & 0.003 & 0.017 & 0.003 & 0.019 & 0.003 & 0.009 & 0.001 & 0.002 & 0.001 \\
\hline 277.89 & RICE_3yr_457 & 0.179 & 0.624 & 0.033 & 0.113 & 0.022 & 0.003 & 0.022 & 0.003 & 0.011 & 0.003 & 0.007 & 0.001 & 0.001 & 0.001 \\
\hline 278.20 & RICE_3yr_458 & 0.126 & 0.287 & 0.025 & 0.093 & 0.017 & 0.002 & 0.013 & 0.002 & 0.013 & 0.002 & 0.005 & 0.001 & 0.001 & 0.001 \\
\hline 278.48 & RICE_3yr_459 & 0.162 & 0.354 & 0.033 & 0.110 & 0.025 & 0.003 & 0.017 & 0.003 & 0.018 & 0.003 & 0.008 & 0.001 & 0.002 & 0.001 \\
\hline 278.76 & RICE_3yr_460 & 0.200 & 0.451 & 0.041 & 0.138 & 0.030 & 0.004 & 0.023 & 0.002 & 0.023 & 0.003 & 0.009 & 0.001 & 0.002 & 0.002 \\
\hline 279.06 & RICE_3yr_461 & 0.170 & 0.424 & 0.036 & 0.129 & 0.027 & 0.003 & 0.019 & 0.003 & 0.017 & 0.002 & 0.009 & 0.001 & 0.002 & 0.001 \\
\hline 279.35 & RICE_3yr_462 & 0.154 & 0.344 & 0.031 & 0.116 & 0.022 & 0.002 & 0.019 & 0.003 & 0.020 & 0.003 & 0.010 & 0.001 & 0.002 & 0.001 \\
\hline 279.63 & RICE_3yr_463 & 0.098 & 0.226 & 0.022 & 0.069 & 0.016 & 0.001 & 0.012 & 0.002 & 0.011 & 0.002 & 0.005 & 0.001 & 0.001 & 0.001 \\
\hline 279.91 & RICE_3yr_464 & 0.178 & 0.611 & 0.036 & 0.135 & 0.031 & 0.003 & 0.019 & 0.003 & 0.018 & 0.003 & 0.010 & 0.001 & 0.002 & 0.001 \\
\hline 280.21 & RICE_3yr_465 & 0.115 & 0.265 & 0.024 & 0.074 & 0.017 & 0.001 & 0.014 & 0.001 & 0.009 & 0.002 & 0.005 & 0.001 & 0.001 & 0.001 \\
\hline 280.51 & RICE_3yr_466 & 0.093 & 0.216 & 0.019 & 0.064 & 0.014 & $<0.001$ & 0.009 & 0.001 & 0.009 & 0.002 & 0.005 & 0.001 & 0.001 & $<0.001$ \\
\hline 280.77 & RICE_3yr_467 & 0.148 & 0.535 & 0.029 & 0.106 & 0.024 & 0.002 & 0.015 & 0.003 & 0.018 & 0.002 & 0.009 & 0.001 & 0.001 & 0.001 \\
\hline 281.06 & RICE_3yr_468 & 0.180 & 0.435 & 0.135 & 0.128 & 0.031 & 0.002 & 0.017 & 0.002 & 0.020 & 0.003 & 0.008 & 0.001 & 0.002 & 0.001 \\
\hline 281.35 & RICE_3yr_469 & 0.137 & 0.307 & 0.028 & 0.101 & 0.018 & 0.001 & 0.011 & 0.002 & 0.015 & 0.002 & 0.007 & 0.001 & 0.001 & 0.001 \\
\hline 281.65 & RICE_3yr_470 & 0.098 & 0.216 & 0.018 & 0.066 & 0.016 & 0.001 & 0.009 & 0.001 & 0.010 & 0.001 & 0.005 & 0.001 & 0.001 & 0.001 \\
\hline 281.91 & RICE_3yr_471 & 0.146 & 0.320 & 0.029 & 0.109 & 0.020 & 0.002 & 0.015 & 0.002 & 0.012 & 0.002 & 0.005 & 0.001 & 0.002 & 0.001 \\
\hline 282.23 & RICE_3yr_472 & 0.076 & 0.167 & 0.015 & 0.055 & 0.009 & 0.001 & 0.007 & $<0.001$ & 0.005 & $<0.001$ & 0.003 & 0.001 & 0.001 & $<0.001$ \\
\hline 282.48 & RICE_3yr_473 & 0.116 & 0.278 & 0.024 & 0.092 & 0.022 & 0.002 & 0.011 & 0.002 & 0.013 & 0.001 & 0.005 & $<0.001$ & 0.002 & 0.001 \\
\hline 282.79 & RICE_3yr_474 & 0.150 & 1.132 & 0.031 & 0.112 & 0.027 & 0.002 & 0.018 & 0.002 & 0.015 & 0.003 & 0.007 & 0.001 & 0.001 & 0.001 \\
\hline 283.05 & RICE_3yr_475 & 0.133 & 0.516 & 0.027 & 0.108 & 0.025 & 0.001 & 0.015 & 0.002 & 0.017 & 0.001 & 0.007 & 0.001 & 0.002 & 0.001 \\
\hline 283.32 & RICE_3yr_476 & 0.144 & 0.437 & 0.029 & 0.105 & 0.018 & 0.002 & 0.018 & 0.002 & 0.013 & 0.002 & 0.007 & 0.001 & 0.001 & 0.001 \\
\hline 283.64 & RICE_3yr_477 & 0.091 & 0.290 & 0.019 & 0.063 & 0.015 & $<0.001$ & 0.009 & 0.001 & 0.010 & 0.001 & 0.005 & 0.001 & 0.001 & $<0.001$ \\
\hline 283.89 & RICE_3yr_478 & 0.161 & 0.678 & 0.039 & 0.160 & 0.044 & 0.004 & 0.028 & 0.004 & 0.029 & 0.003 & 0.012 & 0.001 & 0.003 & 0.002 \\
\hline 284.18 & RICE_3yr_479 & 0.138 & 0.338 & 0.029 & 0.096 & 0.019 & 0.001 & 0.014 & 0.002 & 0.012 & 0.001 & 0.006 & 0.001 & 0.001 & $<0.001$ \\
\hline 284.45 & RICE_3yr_480 & 0.092 & 0.224 & 0.016 & 0.056 & 0.018 & $<0.001$ & 0.010 & 0.001 & 0.010 & 0.001 & 0.003 & 0.001 & 0.001 & $<0.001$ \\
\hline 284.74 & RICE_3yr_481 & 0.105 & 0.267 & 0.020 & 0.079 & 0.015 & 0.001 & 0.013 & 0.002 & 0.012 & 0.001 & 0.005 & 0.001 & 0.001 & 0.001 \\
\hline 285.02 & RICE_3yr_482 & 0.108 & 0.311 & 0.021 & 0.075 & 0.020 & $<0.001$ & 0.011 & 0.002 & 0.010 & 0.001 & 0.007 & 0.001 & 0.001 & 0.001 \\
\hline 285.32 & RICE_3yr_483 & 0.082 & 0.214 & 0.017 & 0.059 & 0.010 & 0.001 & 0.008 & 0.001 & 0.009 & 0.001 & 0.004 & $<0.001$ & 0.001 & $<0.001$ \\
\hline 285.57 & RICE_3yr_484 & 0.119 & 0.345 & 0.025 & 0.103 & 0.018 & 0.003 & 0.017 & 0.001 & 0.012 & 0.002 & 0.008 & 0.001 & 0.001 & 0.001 \\
\hline 285.86 & RICE_3yr_485 & 0.165 & 4.119 & 0.034 & 0.133 & 0.030 & 0.002 & 0.022 & 0.003 & 0.018 & 0.002 & 0.009 & 0.001 & 0.003 & 0.001 \\
\hline 286.15 & RICE_3yr_486 & 0.120 & 0.388 & 0.025 & 0.093 & 0.016 & 0.002 & 0.013 & 0.002 & 0.012 & 0.002 & 0.007 & 0.001 & 0.001 & $<0.001$ \\
\hline 286.41 & RICE_3yr_487 & 0.118 & 0.372 & 0.025 & 0.096 & 0.022 & 0.002 & 0.015 & 0.001 & 0.014 & 0.002 & 0.007 & 0.001 & 0.001 & $<0.001$ \\
\hline 286.68 & RICE_3yr_488 & 0.116 & 0.346 & 0.022 & 0.089 & 0.017 & 0.002 & 0.011 & 0.002 & 0.012 & 0.002 & 0.009 & 0.001 & 0.001 & 0.001 \\
\hline 286.99 & RICE_3yr_489 & 0.143 & 0.837 & 0.033 & 0.113 & 0.021 & 0.003 & 0.020 & 0.003 & 0.016 & 0.003 & 0.010 & 0.001 & 0.002 & 0.001 \\
\hline 287.28 & RICE_3yr_490 & 0.135 & 0.435 & 0.028 & 0.088 & 0.018 & 0.002 & 0.015 & 0.002 & 0.014 & 0.003 & 0.008 & 0.001 & 0.002 & 0.001 \\
\hline 287.55 & RICE_3yr_491 & 0.127 & 0.338 & 0.026 & 0.088 & 0.018 & 0.002 & 0.012 & 0.002 & 0.013 & 0.002 & 0.006 & 0.001 & 0.001 & 0.001 \\
\hline 287.80 & RICE_3yr_492 & 0.144 & 0.383 & 0.029 & 0.111 & 0.023 & 0.001 & 0.015 & 0.003 & 0.014 & 0.002 & 0.008 & 0.001 & 0.002 & 0.001 \\
\hline 288.05 & RICE_3yr_493 & 0.121 & 0.336 & 0.023 & 0.093 & 0.019 & 0.001 & 0.014 & 0.001 & 0.014 & 0.002 & 0.006 & 0.001 & 0.001 & 0.001 \\
\hline 288.36 & RICE_3yr_494 & 0.094 & 0.249 & 0.018 & 0.076 & 0.015 & 0.001 & 0.011 & 0.001 & 0.011 & 0.001 & 0.006 & 0.001 & 0.001 & 0.001 \\
\hline 288.63 & RICE_3yr_495 & 0.110 & 0.275 & 0.023 & 0.081 & 0.017 & 0.002 & 0.012 & 0.002 & 0.009 & 0.001 & 0.005 & 0.001 & 0.001 & 0.001 \\
\hline 288.90 & RICE_3yr_496 & 0.139 & 0.522 & 0.027 & 0.100 & 0.021 & 0.002 & 0.018 & 0.002 & 0.014 & 0.003 & 0.007 & 0.001 & 0.002 & 0.001 \\
\hline 289.19 & RICE_3yr_497 & 0.113 & 0.352 & 0.023 & 0.084 & 0.017 & 0.002 & 0.011 & 0.002 & 0.011 & 0.002 & 0.005 & $<0.001$ & 0.001 & 0.001 \\
\hline 289.35 & RICE_3yr_498 & 0.187 & 0.667 & 0.036 & 0.124 & 0.027 & 0.003 & 0.017 & 0.003 & 0.017 & 0.002 & 0.008 & 0.002 & 0.001 & 0.001 \\
\hline 289.70 & RICE_3yr_499 & 0.108 & 0.372 & 0.020 & 0.079 & 0.013 & 0.001 & 0.013 & 0.002 & 0.010 & 0.001 & 0.004 & 0.001 & 0.001 & 0.002 \\
\hline 289.98 & RICE_3yr_500 & 0.071 & 0.464 & 0.013 & 0.056 & 0.010 & $<0.001$ & 0.007 & 0.001 & 0.008 & 0.001 & 0.004 & $<0.001$ & 0.001 & $<0.001$ \\
\hline 290.25 & RICE_3yr_501 & 0.083 & 0.248 & 0.017 & 0.067 & 0.014 & 0.001 & 0.010 & 0.001 & 0.007 & 0.001 & 0.003 & $<0.001$ & 0.001 & 0.001 \\
\hline 290.51 & RICE_3yr_502 & 0.140 & 0.391 & 0.027 & 0.101 & 0.028 & 0.002 & 0.018 & 0.002 & 0.015 & 0.002 & 0.006 & 0.001 & 0.001 & 0.001 \\
\hline 290.78 & RICE_3yr_503 & 0.185 & 0.476 & 0.036 & 0.128 & 0.025 & 0.002 & 0.017 & 0.003 & 0.019 & 0.003 & 0.010 & 0.001 & 0.002 & 0.001 \\
\hline
\end{tabular}




\begin{tabular}{|c|c|c|c|c|c|c|c|c|c|c|c|c|c|c|c|}
\hline 291.06 & RICE_3yr_504 & 0.181 & 0.429 & 0.034 & 0.129 & 0.023 & 0.002 & 0.015 & 0.002 & 0.017 & 0.003 & 0.007 & 0.001 & 0.002 & 0.001 \\
\hline 291.32 & RICE_3yr_505 & 0.107 & 0.255 & 0.021 & 0.082 & 0.013 & 0.001 & 0.010 & 0.002 & 0.009 & 0.001 & 0.004 & 0.001 & 0.001 & 0.001 \\
\hline 291.57 & RICE_3yr_506 & 0.108 & 0.264 & 0.021 & 0.077 & 0.014 & 0.001 & 0.014 & 0.002 & 0.012 & 0.001 & 0.005 & 0.001 & 0.001 & 0.001 \\
\hline 291.86 & RICE_3yr_507 & 0.091 & 0.913 & 0.016 & 0.070 & 0.012 & 0.002 & 0.013 & 0.001 & 0.008 & 0.001 & 0.005 & 0.001 & $<0.001$ & 0.001 \\
\hline 292.12 & RICE_3yr_508 & 0.129 & 0.349 & 0.025 & 0.097 & 0.017 & 0.002 & 0.014 & 0.002 & 0.012 & 0.002 & 0.006 & 0.001 & 0.001 & 0.001 \\
\hline 292.38 & RICE_3yr_509 & 0.087 & 0.219 & 0.016 & 0.062 & 0.009 & $<0.001$ & 0.009 & 0.001 & 0.008 & 0.001 & 0.004 & $<0.001$ & 0.001 & 0.001 \\
\hline 292.63 & RICE_3yr_510 & 0.115 & 0.298 & 0.021 & 0.079 & 0.016 & 0.002 & 0.015 & 0.002 & 0.013 & 0.002 & 0.006 & 0.001 & 0.001 & 0.001 \\
\hline 292.94 & RICE_3yr_511 & 0.105 & 0.340 & 0.022 & 0.081 & 0.015 & 0.001 & 0.012 & 0.002 & 0.011 & 0.002 & 0.006 & 0.001 & 0.001 & $<0.001$ \\
\hline 293.17 & RICE_3yr_512 & 0.170 & 0.336 & 0.033 & 0.114 & 0.019 & 0.004 & 0.016 & 0.003 & 0.016 & 0.003 & 0.009 & 0.001 & 0.002 & 0.001 \\
\hline 293.42 & RICE_3yr_513 & 0.089 & 0.234 & 0.019 & 0.078 & 0.017 & 0.001 & 0.006 & 0.002 & 0.010 & 0.001 & 0.005 & 0.001 & $<0.001$ & 0.001 \\
\hline 293.71 & RICE_3yr_514 & 0.093 & 0.247 & 0.018 & 0.065 & 0.011 & $<0.001$ & 0.009 & 0.001 & 0.006 & 0.001 & 0.003 & 0.001 & 0.001 & $<0.001$ \\
\hline 293.97 & RICE_3yr_515 & 0.086 & 0.221 & 0.018 & 0.062 & 0.014 & 0.001 & 0.008 & 0.002 & 0.008 & 0.001 & 0.006 & 0.001 & 0.001 & 0.001 \\
\hline 294.25 & RICE_3yr_516 & 0.078 & 0.185 & 0.015 & 0.056 & 0.011 & $<0.001$ & 0.010 & 0.001 & 0.010 & 0.001 & 0.004 & $<0.001$ & 0.001 & 0.001 \\
\hline 294.50 & RICE_3yr_517 & 0.076 & 0.193 & 0.016 & 0.056 & 0.007 & 0.001 & 0.007 & 0.001 & 0.009 & 0.001 & 0.004 & $<0.001$ & 0.001 & $<0.001$ \\
\hline 294.76 & RICE_3yr_518 & 0.109 & 1.045 & 0.021 & 0.075 & 0.017 & 0.001 & 0.014 & 0.002 & 0.008 & 0.001 & 0.006 & 0.001 & 0.001 & $<0.001$ \\
\hline 295.02 & RICE_3yr_519 & 0.131 & 0.349 & 0.024 & 0.089 & 0.014 & 0.001 & 0.011 & 0.002 & 0.011 & 0.001 & 0.006 & 0.001 & 0.001 & 0.001 \\
\hline 295.29 & RICE_3yr_520 & 0.172 & 0.411 & 0.033 & 0.109 & 0.021 & 0.002 & 0.014 & 0.003 & 0.014 & 0.002 & 0.008 & 0.001 & 0.001 & 0.001 \\
\hline 295.57 & RICE_3yr_521 & 0.138 & 0.302 & 0.024 & 0.101 & 0.019 & 0.002 & 0.014 & 0.002 & 0.013 & 0.002 & 0.007 & 0.001 & 0.001 & 0.001 \\
\hline 295.85 & RICE_3yr_522 & 0.221 & 1.605 & 0.032 & 0.114 & 0.024 & 0.002 & 0.017 & 0.003 & 0.017 & 0.002 & 0.010 & 0.002 & 0.002 & 0.001 \\
\hline 296.07 & RICE_3yr_523 & 0.154 & 0.399 & 0.029 & 0.109 & 0.019 & 0.003 & 0.019 & 0.002 & 0.013 & 0.002 & 0.007 & 0.001 & 0.002 & 0.001 \\
\hline 296.33 & RICE_3yr_524 & 0.135 & 0.394 & 0.028 & 0.099 & 0.021 & 0.002 & 0.014 & 0.002 & 0.017 & 0.002 & 0.006 & 0.001 & 0.001 & 0.001 \\
\hline 296.59 & RICE_3yr_525 & 0.102 & 0.285 & 0.021 & 0.080 & 0.014 & 0.001 & 0.013 & 0.001 & 0.011 & 0.001 & 0.005 & $<0.001$ & 0.001 & 0.001 \\
\hline 296.85 & RICE_3yr_526 & 0.131 & 0.339 & 0.025 & 0.098 & 0.019 & 0.001 & 0.015 & 0.002 & 0.012 & 0.002 & 0.005 & 0.001 & 0.001 & $<0.001$ \\
\hline 297.11 & RICE_3yr_527 & 0.131 & 0.360 & 0.028 & 0.101 & 0.018 & 0.002 & 0.015 & 0.002 & 0.013 & 0.001 & 0.006 & 0.001 & 0.001 & $<0.001$ \\
\hline 297.40 & RICE_3yr_528 & 0.093 & 0.238 & 0.019 & 0.079 & 0.012 & 0.001 & 0.014 & 0.002 & 0.011 & 0.001 & 0.005 & $<0.001$ & 0.001 & $<0.001$ \\
\hline 297.61 & RICE_3yr_529 & 0.094 & 0.256 & 0.018 & 0.065 & 0.013 & 0.001 & 0.009 & 0.001 & 0.012 & 0.001 & 0.006 & 0.001 & 0.001 & $<0.001$ \\
\hline 297.89 & RICE_3yr_530 & 0.121 & 1.469 & 0.024 & 0.100 & 0.024 & 0.003 & 0.017 & 0.002 & 0.013 & 0.002 & 0.007 & 0.001 & 0.002 & 0.001 \\
\hline 298.12 & RICE_3yr_531 & 0.153 & 0.413 & 0.029 & 0.105 & 0.022 & 0.002 & 0.019 & 0.002 & 0.019 & 0.002 & 0.009 & 0.001 & 0.001 & 0.001 \\
\hline 298.40 & RICE_3yr_532 & 0.102 & 0.317 & 0.021 & 0.076 & 0.019 & 0.001 & 0.011 & 0.003 & 0.009 & 0.002 & 0.005 & 0.001 & 0.001 & 0.002 \\
\hline 298.61 & RICE_3yr_533 & 0.214 & 0.625 & 0.046 & 0.157 & 0.037 & 0.003 & 0.028 & 0.003 & 0.021 & 0.003 & 0.010 & 0.001 & 0.001 & 0.001 \\
\hline 298.92 & RICE_3yr_534 & 0.164 & 2.416 & 0.034 & 0.137 & 0.028 & 0.003 & 0.019 & 0.003 & 0.022 & 0.003 & 0.010 & 0.001 & 0.002 & 0.001 \\
\hline 299.14 & RICE_3yr_535 & 0.172 & 0.507 & 0.033 & 0.116 & 0.023 & 0.002 & 0.017 & 0.002 & 0.019 & 0.003 & 0.009 & 0.001 & 0.001 & 0.001 \\
\hline 299.43 & RICE_3yr_536 & 0.072 & 0.211 & 0.016 & 0.057 & 0.010 & $<0.001$ & 0.010 & 0.002 & 0.011 & 0.002 & 0.006 & 0.001 & 0.001 & 0.001 \\
\hline 299.67 & RICE_3yr_537 & 0.173 & 0.515 & 0.036 & 0.130 & 0.030 & 0.002 & 0.015 & 0.003 & 0.014 & 0.002 & 0.007 & 0.001 & 0.001 & 0.001 \\
\hline 299.90 & RICE_3yr_538 & 0.123 & 0.340 & 0.023 & 0.090 & 0.016 & $<0.001$ & 0.015 & 0.002 & 0.011 & 0.002 & 0.007 & 0.001 & 0.001 & 0.001 \\
\hline 300.17 & RICE_3yr_539 & 0.083 & 0.232 & 0.017 & 0.070 & 0.009 & $<0.001$ & 0.009 & 0.001 & 0.010 & 0.002 & 0.004 & $<0.001$ & $<0.001$ & 0.001 \\
\hline 300.44 & RICE_3yr_540 & 0.219 & 0.473 & 0.039 & 0.138 & 0.026 & 0.003 & 0.019 & 0.003 & 0.017 & 0.004 & 0.010 & 0.001 & 0.002 & 0.001 \\
\hline 300.69 & RICE_3yr_541 & 0.161 & 0.379 & 0.031 & 0.114 & 0.024 & 0.002 & 0.016 & 0.002 & 0.013 & 0.003 & 0.010 & 0.001 & 0.001 & 0.001 \\
\hline 300.95 & RICE_3yr_542 & 0.167 & 1.290 & 0.034 & 0.131 & 0.026 & 0.002 & 0.016 & 0.002 & 0.014 & 0.002 & 0.006 & 0.001 & 0.001 & 0.001 \\
\hline 301.19 & RICE_3yr_543 & 0.111 & 0.323 & 0.022 & 0.082 & 0.009 & 0.001 & 0.014 & 0.002 & 0.010 & 0.001 & 0.007 & 0.001 & 0.001 & $<0.001$ \\
\hline 301.40 & RICE_3yr_544 & 0.109 & 0.289 & 0.020 & 0.070 & 0.016 & 0.001 & 0.011 & 0.002 & 0.010 & 0.001 & 0.006 & 0.001 & 0.001 & $<0.001$ \\
\hline 301.65 & RICE_3yr_545 & 0.114 & 0.283 & 0.023 & 0.080 & 0.016 & 0.001 & 0.009 & 0.001 & 0.009 & 0.001 & 0.004 & 0.001 & 0.001 & 0.001 \\
\hline 301.94 & RICE_3yr_546 & 0.153 & 0.540 & 0.030 & 0.107 & 0.021 & 0.002 & 0.019 & 0.003 & 0.016 & 0.001 & 0.008 & 0.001 & 0.001 & 0.001 \\
\hline 302.17 & RICE_3yr_547 & 0.132 & 0.328 & 0.026 & 0.091 & 0.019 & 0.001 & 0.015 & 0.002 & 0.012 & 0.002 & 0.006 & $<0.001$ & 0.001 & 0.001 \\
\hline 302.42 & RICE_3yr_548 & 0.163 & 0.374 & 0.029 & 0.108 & 0.022 & 0.002 & 0.018 & 0.003 & 0.016 & 0.003 & 0.008 & 0.001 & 0.001 & 0.001 \\
\hline 302.66 & RICE_3yr_549 & 0.194 & 0.475 & 0.038 & 0.147 & 0.028 & 0.005 & 0.019 & 0.004 & 0.021 & 0.003 & 0.009 & 0.002 & 0.002 & 0.001 \\
\hline 302.93 & RICE_3yr_550 & 0.431 & 1.189 & 0.095 & 0.369 & 0.075 & 0.015 & 0.060 & 0.008 & 0.046 & 0.007 & 0.023 & 0.003 & 0.004 & 0.002 \\
\hline 303.20 & RICE_3yr_551 & -0.002 & -0.003 & -0.001 & -0.003 & -0.001 & 0.004 & $<0.001$ & -0.001 & -0.001 & -0.001 & $<0.001$ & $<0.001$ & $<0.001$ & $<0.001$ \\
\hline 303.48 & RICE_3yr_552 & 0.547 & 1.848 & 0.119 & 0.443 & 0.094 & 0.017 & 0.075 & 0.012 & 0.068 & 0.010 & 0.033 & 0.005 & 0.007 & 0.003 \\
\hline 303.67 & RICE_3yr_553 & 0.473 & 1.492 & 0.104 & 0.375 & 0.077 & 0.013 & 0.062 & 0.009 & 0.058 & 0.009 & 0.025 & 0.004 & 0.006 & 0.003 \\
\hline 303.90 & RICE_3yr_554 & 0.370 & 1.090 & 0.066 & 0.231 & 0.050 & 0.007 & 0.034 & 0.005 & 0.035 & 0.005 & 0.016 & 0.002 & 0.004 & 0.002 \\
\hline 304.16 & RICE_3yr_555 & 0.285 & 0.654 & 0.052 & 0.199 & 0.037 & 0.005 & 0.029 & 0.004 & 0.024 & 0.004 & 0.012 & 0.002 & 0.002 & 0.001 \\
\hline 304.42 & RICE_3yr_556 & 0.173 & 0.453 & 0.033 & 0.117 & 0.024 & 0.003 & 0.017 & 0.003 & 0.020 & 0.002 & 0.008 & 0.001 & 0.002 & 0.001 \\
\hline 304.65 & RICE_3yr_557 & 0.150 & 0.403 & 0.031 & 0.115 & 0.019 & 0.003 & 0.017 & 0.002 & 0.016 & 0.001 & 0.007 & 0.001 & 0.001 & 0.001 \\
\hline 304.89 & RICE_3yr_558 & 0.210 & 1.351 & 0.043 & 0.163 & 0.036 & 0.004 & 0.026 & 0.003 & 0.026 & 0.002 & 0.011 & 0.002 & 0.003 & 0.001 \\
\hline 305.16 & RICE_3yr_559 & 0.171 & 0.496 & 0.037 & 0.141 & 0.029 & 0.004 & 0.019 & 0.003 & 0.020 & 0.002 & 0.009 & 0.001 & 0.002 & 0.001 \\
\hline 305.40 & RICE_3yr_560 & 0.127 & 0.364 & 0.026 & 0.102 & 0.016 & 0.002 & 0.018 & 0.002 & 0.014 & 0.002 & 0.006 & 0.001 & 0.001 & 0.001 \\
\hline 305.62 & RICE_3yr_561 & 0.116 & 0.306 & 0.024 & 0.078 & 0.015 & 0.001 & 0.013 & 0.002 & 0.012 & 0.001 & 0.005 & 0.001 & 0.001 & 0.001 \\
\hline 305.85 & RICE_3yr_562 & 0.220 & 0.463 & 0.042 & 0.161 & 0.029 & 0.004 & 0.021 & 0.003 & 0.019 & 0.003 & 0.013 & 0.001 & 0.002 & 0.001 \\
\hline 306.13 & RICE_3yr_563 & 0.133 & 0.345 & 0.027 & 0.090 & 0.021 & 0.003 & 0.015 & 0.002 & 0.013 & 0.001 & 0.005 & 0.001 & 0.002 & 0.001 \\
\hline 306.37 & RICE_3yr_564 & 0.155 & 0.395 & 0.030 & 0.108 & 0.024 & 0.002 & 0.015 & 0.003 & 0.013 & 0.002 & 0.008 & 0.001 & 0.002 & 0.001 \\
\hline 306.61 & RICE_3yr_565 & 0.103 & 0.241 & 0.020 & 0.070 & 0.015 & 0.001 & 0.009 & 0.002 & 0.010 & 0.001 & 0.006 & 0.001 & 0.001 & $<0.001$ \\
\hline 306.83 & RICE_3yr_566 & 0.183 & 0.941 & 0.041 & 0.148 & 0.030 & 0.003 & 0.025 & 0.003 & 0.022 & 0.003 & 0.009 & 0.001 & 0.002 & 0.001 \\
\hline
\end{tabular}




\begin{tabular}{|c|c|c|c|c|c|c|c|c|c|c|c|c|c|c|c|}
\hline 307.10 & RICE_3yr_567 & 0.109 & 0.292 & 0.022 & 0.069 & 0.015 & 0.001 & 0.012 & 0.002 & 0.009 & 0.002 & 0.005 & 0.001 & 0.001 & 0.001 \\
\hline 307.31 & RICE_3yr_568 & 0.166 & 0.413 & 0.030 & 0.108 & 0.018 & 0.002 & 0.017 & 0.002 & 0.014 & 0.002 & 0.006 & 0.001 & 0.001 & 0.001 \\
\hline 307.56 & RICE_3yr_569 & 0.146 & 0.358 & 0.028 & 0.104 & 0.017 & 0.002 & 0.013 & 0.002 & 0.013 & 0.002 & 0.007 & 0.001 & 0.002 & 0.001 \\
\hline 307.79 & RICE_3yr_570 & 1.307 & 3.340 & 0.392 & 1.600 & 0.258 & 0.048 & 0.154 & 0.014 & 0.053 & 0.005 & 0.015 & 0.001 & 0.002 & 0.001 \\
\hline 308.04 & RICE_3yr_571 & 0.169 & 0.363 & 0.032 & 0.107 & 0.019 & 0.001 & 0.011 & 0.002 & 0.011 & 0.002 & 0.007 & 0.001 & 0.001 & 0.001 \\
\hline 308.25 & RICE_3yr_572 & 0.140 & 0.334 & 0.028 & 0.100 & 0.022 & 0.002 & 0.015 & 0.002 & 0.013 & 0.002 & 0.007 & 0.001 & 0.002 & 0.001 \\
\hline 308.50 & RICE_3yr_573 & 0.143 & 0.340 & 0.028 & 0.104 & 0.020 & 0.003 & 0.014 & 0.002 & 0.013 & 0.001 & 0.006 & 0.001 & 0.001 & $<0.001$ \\
\hline 308.75 & RICE_3yr_574 & 0.148 & 0.312 & 0.026 & 0.090 & 0.015 & 0.002 & 0.013 & 0.002 & 0.010 & 0.001 & 0.006 & 0.001 & 0.001 & 0.001 \\
\hline 308.98 & RICE_3yr_575 & 0.095 & 0.225 & 0.020 & 0.065 & 0.015 & 0.001 & 0.008 & $<0.001$ & 0.008 & 0.001 & 0.005 & 0.001 & 0.001 & $<0.001$ \\
\hline 309.19 & RICE_3yr_576 & 0.078 & 0.201 & 0.016 & 0.054 & 0.008 & 0.001 & 0.012 & 0.001 & 0.007 & 0.001 & 0.005 & 0.001 & 0.001 & $<0.001$ \\
\hline 309.44 & RICE_3yr_577 & 0.075 & 0.196 & 0.017 & 0.061 & 0.013 & 0.001 & 0.009 & 0.001 & 0.008 & 0.001 & 0.004 & 0.001 & 0.001 & $<0.001$ \\
\hline 309.69 & RICE_3yr_578 & 0.138 & 0.735 & 0.027 & 0.087 & 0.029 & 0.003 & 0.015 & 0.002 & 0.017 & 0.001 & 0.005 & 0.001 & 0.002 & 0.001 \\
\hline 309.93 & RICE_3yr_579 & 0.129 & 0.354 & 0.026 & 0.085 & 0.018 & 0.001 & 0.013 & 0.001 & 0.011 & 0.002 & 0.005 & 0.001 & 0.001 & 0.001 \\
\hline 310.15 & RICE_3yr_580 & 0.088 & 0.225 & 0.020 & 0.065 & 0.011 & 0.001 & 0.005 & 0.001 & 0.010 & 0.001 & 0.004 & 0.001 & 0.001 & $<0.001$ \\
\hline 310.36 & RICE_3yr_581 & 0.157 & 0.346 & 0.028 & 0.089 & 0.018 & 0.001 & 0.011 & 0.002 & 0.010 & 0.002 & 0.005 & 0.001 & 0.001 & $<0.001$ \\
\hline 310.60 & RICE_3yr_582 & 0.194 & 1.955 & 0.036 & 0.129 & 0.026 & 0.003 & 0.019 & 0.002 & 0.020 & 0.002 & 0.010 & 0.001 & 0.002 & $<0.001$ \\
\hline 310.84 & RICE_3yr_583 & 0.166 & 0.435 & 0.033 & 0.121 & 0.024 & 0.003 & 0.018 & 0.002 & 0.016 & 0.003 & 0.010 & 0.001 & 0.002 & 0.002 \\
\hline 311.09 & RICE_3yr_584 & 0.133 & 0.309 & 0.024 & 0.074 & 0.015 & 0.002 & 0.013 & 0.001 & 0.010 & 0.002 & 0.005 & 0.001 & 0.002 & 0.001 \\
\hline 311.29 & RICE_3yr_585 & 0.087 & 0.210 & 0.018 & 0.058 & 0.010 & 0.001 & 0.005 & 0.001 & 0.008 & 0.001 & 0.005 & 0.001 & 0.001 & $<0.001$ \\
\hline 311.55 & RICE_3yr_586 & 0.140 & 0.357 & 0.031 & 0.096 & 0.020 & 0.003 & 0.013 & 0.002 & 0.012 & 0.002 & 0.007 & 0.001 & 0.001 & 0.001 \\
\hline 311.79 & RICE_3yr_587 & 0.186 & 0.472 & 0.038 & 0.134 & 0.026 & 0.003 & 0.019 & 0.002 & 0.019 & 0.002 & 0.006 & 0.002 & 0.002 & 0.001 \\
\hline 312.02 & RICE_3yr_588 & 0.142 & 0.322 & 0.027 & 0.100 & 0.023 & 0.001 & 0.013 & 0.002 & 0.014 & 0.002 & 0.005 & $<0.001$ & 0.001 & 0.001 \\
\hline 312.26 & RICE_3yr_589 & 0.088 & 0.231 & 0.019 & 0.064 & 0.012 & 0.001 & 0.011 & 0.001 & 0.011 & 0.001 & 0.004 & 0.001 & 0.001 & 0.001 \\
\hline 312.45 & RICE_3yr_590 & 0.136 & 0.317 & 0.026 & 0.088 & 0.019 & 0.002 & 0.015 & 0.002 & 0.013 & 0.002 & 0.005 & 0.001 & 0.001 & 0.001 \\
\hline 312.68 & RICE_3yr_591 & 0.073 & 0.482 & 0.015 & 0.053 & 0.010 & 0.002 & 0.010 & 0.001 & 0.006 & 0.001 & 0.004 & $<0.001$ & 0.001 & $<0.001$ \\
\hline 312.96 & RICE_3yr_592 & 0.080 & 0.210 & 0.017 & 0.054 & 0.012 & $<0.001$ & 0.007 & 0.001 & 0.008 & 0.001 & 0.003 & 0.001 & 0.001 & $<0.001$ \\
\hline 313.15 & RICE_3yr_593 & 0.494 & 0.977 & 0.097 & 0.498 & 0.101 & 0.020 & 0.041 & 0.008 & 0.051 & 0.008 & 0.020 & 0.005 & 0.019 & 0.005 \\
\hline 313.41 & RICE_3yr_594 & 0.474 & 0.953 & 0.095 & 0.470 & 0.089 & 0.019 & 0.051 & 0.009 & 0.047 & 0.007 & 0.017 & 0.005 & 0.020 & 0.004 \\
\hline 313.60 & RICE_3yr_595 & 0.110 & 0.246 & 0.020 & 0.075 & 0.016 & 0.001 & 0.011 & 0.002 & 0.013 & 0.002 & 0.005 & $<0.001$ & 0.001 & $<0.001$ \\
\hline 313.82 & RICE_3yr_596 & 0.155 & 1.787 & 0.030 & 0.114 & 0.021 & 0.003 & 0.016 & 0.003 & 0.019 & 0.024 & 0.007 & 0.001 & 0.002 & 0.001 \\
\hline 314.09 & RICE_3yr_597 & 0.141 & 0.434 & 0.026 & 0.102 & 0.014 & 0.001 & 0.013 & 0.003 & 0.012 & 0.002 & 0.005 & 0.001 & 0.001 & $<0.001$ \\
\hline 314.31 & RICE_3yr_598 & 0.132 & 0.351 & 0.026 & 0.093 & 0.016 & 0.002 & 0.012 & 0.002 & 0.010 & 0.001 & 0.005 & 0.001 & 0.002 & 0.001 \\
\hline 314.51 & RICE_3yr_599 & 0.080 & 0.233 & 0.016 & 0.058 & 0.011 & 0.001 & 0.010 & 0.002 & 0.008 & 0.001 & 0.003 & $<0.001$ & 0.001 & $<0.001$ \\
\hline 314.74 & RICE_3yr_600 & 0.113 & 0.294 & 0.022 & 0.077 & 0.017 & 0.001 & 0.011 & 0.002 & 0.008 & 0.002 & 0.006 & 0.001 & 0.001 & $<0.001$ \\
\hline 314.97 & RICE_3yr_601 & 0.111 & 0.271 & 0.024 & 0.082 & 0.020 & 0.002 & 0.015 & 0.002 & 0.013 & 0.002 & 0.006 & 0.001 & 0.001 & 0.001 \\
\hline 315.18 & RICE_3yr_602 & 0.111 & 0.258 & 0.022 & 0.075 & 0.014 & 0.002 & 0.010 & 0.002 & 0.010 & 0.001 & 0.006 & 0.001 & 0.001 & 0.001 \\
\hline 315.43 & RICE_3yr_603 & 0.181 & 0.408 & 0.039 & 0.137 & 0.028 & 0.004 & 0.014 & 0.003 & 0.013 & 0.002 & 0.004 & 0.001 & 0.001 & $<0.001$ \\
\hline 315.63 & RICE_3yr_604 & 0.080 & 0.181 & 0.014 & 0.050 & 0.006 & 0.001 & 0.007 & 0.001 & 0.007 & $<0.001$ & 0.003 & 0.001 & $<0.001$ & $<0.001$ \\
\hline 315.85 & RICE_3yr_605 & 0.085 & 1.784 & 0.017 & 0.055 & 0.014 & 0.002 & 0.008 & 0.001 & 0.007 & 0.001 & 0.004 & $<0.001$ & 0.001 & $<0.001$ \\
\hline 316.07 & RICE_3yr_606 & 0.080 & 0.223 & 0.017 & 0.056 & 0.011 & 0.001 & 0.009 & 0.001 & 0.009 & 0.001 & 0.004 & 0.001 & 0.001 & 0.001 \\
\hline 316.29 & RICE_3yr_607 & 0.084 & 0.248 & 0.017 & 0.064 & 0.009 & 0.001 & 0.010 & 0.001 & 0.009 & 0.001 & 0.004 & 0.001 & 0.001 & $<0.001$ \\
\hline 316.56 & RICE_3yr_608 & 0.095 & 0.264 & 0.022 & 0.083 & 0.016 & 0.002 & 0.012 & 0.001 & 0.010 & 0.001 & 0.008 & 0.001 & 0.001 & 0.001 \\
\hline 316.75 & RICE_3yr_609 & 0.148 & 0.397 & 0.030 & 0.108 & 0.018 & 0.003 & 0.018 & 0.002 & 0.013 & 0.002 & 0.006 & 0.001 & 0.002 & 0.001 \\
\hline 316.96 & RICE_3yr_610 & 0.126 & 1.563 & 0.025 & 0.091 & 0.020 & 0.002 & 0.015 & 0.002 & 0.012 & 0.002 & 0.006 & 0.001 & 0.001 & 0.001 \\
\hline 317.22 & RICE_3yr_611 & 0.113 & 0.318 & 0.023 & 0.077 & 0.015 & 0.001 & 0.012 & 0.001 & 0.008 & 0.002 & 0.005 & 0.001 & 0.001 & $<0.001$ \\
\hline 317.43 & RICE_3yr_612 & 0.106 & 0.292 & 0.021 & 0.084 & 0.011 & 0.001 & 0.011 & 0.002 & 0.009 & 0.001 & 0.005 & 0.001 & 0.001 & $<0.001$ \\
\hline 317.67 & RICE_3yr_613 & 0.065 & 0.177 & 0.014 & 0.045 & 0.007 & 0.001 & 0.005 & 0.001 & 0.006 & $<0.001$ & 0.003 & 0.001 & 0.001 & $<0.001$ \\
\hline 317.88 & RICE_3yr_614 & 0.156 & 0.361 & 0.031 & 0.098 & 0.019 & 0.002 & 0.014 & 0.001 & 0.011 & 0.001 & 0.005 & 0.001 & 0.001 & $<0.001$ \\
\hline 318.13 & RICE_3yr_615 & 0.093 & 0.217 & 0.020 & 0.065 & 0.008 & 0.001 & 0.012 & 0.001 & 0.007 & 0.001 & 0.003 & 0.001 & $<0.001$ & $<0.001$ \\
\hline 318.33 & RICE_3yr_616 & 0.097 & 0.228 & 0.019 & 0.066 & 0.010 & 0.002 & 0.010 & 0.001 & 0.010 & 0.001 & 0.003 & $<0.001$ & 0.001 & $<0.001$ \\
\hline 318.57 & RICE_3yr_617 & 0.081 & 0.202 & 0.016 & 0.059 & 0.009 & 0.001 & 0.010 & 0.001 & 0.008 & 0.001 & 0.004 & 0.001 & 0.001 & 0.001 \\
\hline 318.75 & RICE_3yr_618 & 0.097 & 5.495 & 0.018 & 0.062 & 0.013 & 0.001 & 0.008 & 0.002 & 0.009 & 0.001 & 0.005 & 0.001 & 0.001 & 0.001 \\
\hline 319.02 & RICE_3yr_619 & 0.072 & 0.932 & 0.017 & 0.048 & 0.011 & 0.001 & 0.010 & 0.001 & 0.007 & 0.001 & 0.004 & 0.001 & 0.001 & $<0.001$ \\
\hline 319.23 & RICE_3yr_620 & 0.101 & 0.411 & 0.020 & 0.072 & 0.016 & 0.002 & 0.010 & 0.002 & 0.011 & 0.001 & 0.005 & 0.001 & 0.001 & $<0.001$ \\
\hline
\end{tabular}

RICE deep core combined 40m to 320m samples, relative standard deviation (RSD, \%).

Top Depth

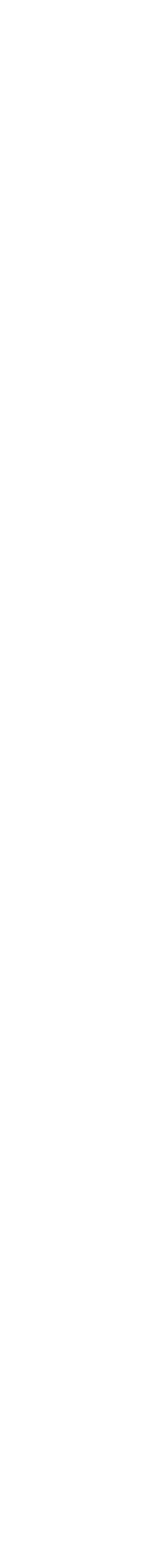

$\begin{array}{llllllllllllllll}\text { (m) } & \text { Sample ID } & \text { La139 } & \text { Ce140 } & \text { Pr141 } & \text { Nd146 } & \text { Sm147 } & \text { Eu153 } & \text { Gd157 } & \text { Tb159 } & \text { Dy163 } & \text { Ho165 } & \text { Er166 } & \text { Tm169 } & \text { Yb172 } & \text { Lu175 }\end{array}$

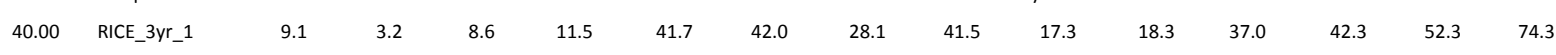

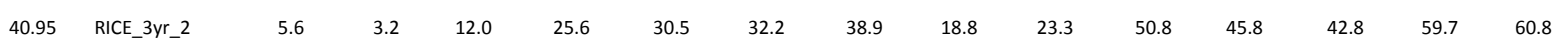

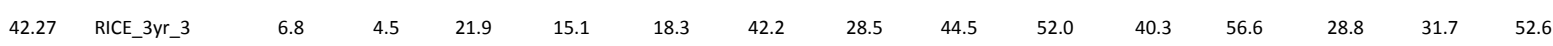

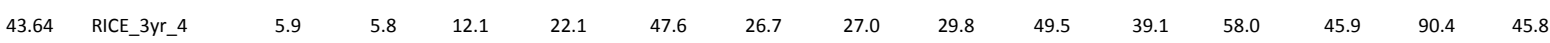




\begin{tabular}{|c|c|c|c|c|c|c|c|c|c|c|c|c|c|c|c|}
\hline 44.68 & RICE_3yr_5 & 4.4 & 6.1 & 23.4 & 31.8 & 55.4 & 29.5 & 35.3 & 23.6 & 42.8 & 89.6 & 112.9 & 38.9 & 92.6 & 71.9 \\
\hline 45.61 & RICE_3yr_6 & 6.1 & 2.1 & 21.2 & 24.1 & 33.5 & 44.9 & 32.7 & 19.5 & 27.1 & 36.9 & 46.8 & 49.4 & 84.8 & 63.1 \\
\hline 46.60 & RICE_3yr_7 & 9.3 & 6.5 & 9.0 & 16.7 & 25.1 & 36.2 & 27.4 & 32.7 & 26.5 & 42.3 & 70.5 & 65.6 & 83.8 & 68.9 \\
\hline 47.59 & RICE_3yr_8 & 10.3 & 3.6 & 15.4 & 28.8 & 27.7 & 41.7 & 43.7 & 70.6 & 26.7 & 40.5 & 55.9 & 46.2 & 33.2 & 98.1 \\
\hline 48.56 & RICE_3yr_9 & 7.4 & 6.4 & 14.7 & 35.2 & 59.1 & 48.5 & 45.4 & 36.8 & 36.6 & 26.7 & 48.7 & 65.6 & 76.6 & 85.5 \\
\hline 49.58 & RICE_3yr_10 & 8.1 & 5.1 & 17.8 & 31.8 & 39.5 & 27.5 & 46.8 & 34.7 & 39.3 & 56.0 & 30.1 & 73.4 & 82.2 & 86.9 \\
\hline 50.50 & RICE_3yr_11 & 5.5 & 6.5 & 21.1 & 7.8 & 21.9 & 41.8 & 32.5 & 27.9 & 29.1 & 30.3 & 58.9 & 39.9 & 63.0 & 73.5 \\
\hline 51.41 & RICE_3yr_12 & 5.1 & 3.7 & 20.9 & 24.0 & 63.3 & 44.9 & 23.7 & 37.4 & 31.7 & 101.3 & 27.3 & 42.9 & 132.7 & 73.7 \\
\hline 52.34 & RICE_3yr_13 & 14.9 & 4.9 & 14.3 & 20.9 & 34.8 & 24.9 & 35.1 & 38.9 & 37.4 & 45.0 & 41.4 & 55.0 & 40.0 & 93.0 \\
\hline 53.31 & RICE_3yr_14 & 11.3 & 2.1 & 12.3 & 24.1 & 25.9 & 50.5 & 38.5 & 56.3 & 38.3 & 20.5 & 100.7 & 46.2 & 79.3 & 84.0 \\
\hline 54.19 & RICE_3yr_15 & 2.9 & 6.4 & 24.5 & 16.7 & 35.8 & 63.1 & 43.8 & 52.8 & 51.6 & 56.4 & 64.0 & 77.5 & 52.0 & 117.4 \\
\hline 55.17 & RICE_3yr_16 & 5.5 & 8.2 & 24.4 & 24.4 & 74.8 & 52.0 & 54.9 & 46.0 & 48.1 & 38.4 & 90.8 & 43.8 & 73.2 & 74.2 \\
\hline 56.02 & RICE_3yr_17 & 5.9 & 4.0 & 12.8 & 17.3 & 50.5 & 25.5 & 53.4 & 36.8 & 50.1 & 21.2 & 51.1 & 82.1 & 61.0 & 107.0 \\
\hline 56.89 & RICE_3yr_18 & 4.6 & 7.5 & 29.7 & 8.7 & 52.9 & 22.4 & 49.9 & 30.6 & 30.4 & 64.1 & 67.6 & 133.1 & 71.3 & 104.2 \\
\hline 57.77 & RICE_3yr_19 & 6.1 & 10.2 & 18.8 & 22.3 & 37.0 & 27.0 & 47.1 & 51.3 & 63.8 & 56.4 & 53.6 & 84.0 & 123.7 & 65.7 \\
\hline 58.69 & RICE_3yr_20 & 8.8 & 5.4 & 21.3 & 19.3 & 45.4 & 89.9 & 48.2 & 44.2 & 70.9 & 57.4 & 16.0 & 73.8 & 92.9 & 126.3 \\
\hline 59.52 & RICE_3yr_21 & 8.3 & 1.4 & 14.9 & 14.8 & 49.9 & 40.0 & 44.7 & 15.0 & 24.5 & 48.3 & 49.0 & 92.7 & 85.0 & 100.3 \\
\hline 60.40 & RICE_3yr_22 & 6.4 & 6.2 & 20.1 & 21.3 & 37.3 & 50.4 & 41.2 & 52.7 & 49.7 & 59.8 & 43.9 & 56.4 & 101.1 & 74.7 \\
\hline 61.36 & RICE_3yr_23 & 7.8 & 5.6 & 16.5 & 18.6 & 67.0 & 43.1 & 26.5 & 64.2 & 36.6 & 62.1 & 94.2 & 67.0 & 99.1 & 88.5 \\
\hline 62.17 & RICE_3yr_24 & 7.3 & 3.5 & 8.2 & 20.5 & 40.7 & 35.2 & 47.4 & 38.8 & 46.0 & 39.7 & 44.7 & 83.4 & 84.1 & 90.6 \\
\hline 63.08 & RICE_3yr_25 & 13.8 & 3.7 & 8.1 & 6.4 & 21.3 & 22.4 & 25.8 & 36.5 & 36.0 & 14.8 & 39.8 & 66.0 & 25.0 & 208.6 \\
\hline 63.92 & RICE_3yr_26 & 7.7 & 6.3 & 5.0 & 13.9 & 29.2 & 32.6 & 16.4 & 22.1 & 23.1 & 34.7 & 21.5 & 36.2 & 51.3 & 191.4 \\
\hline 64.76 & RICE_3yr_27 & 7.6 & 5.4 & 12.6 & 15.1 & 43.0 & 23.2 & 50.8 & 38.0 & 58.5 & 64.6 & 42.4 & 62.6 & 63.3 & 44.7 \\
\hline 65.61 & RICE_3yr_28 & 8.2 & 5.7 & 16.6 & 21.3 & 42.6 & 40.6 & 51.2 & 29.5 & 22.3 & 64.3 & 26.5 & 70.3 & 82.9 & 65.0 \\
\hline 66.45 & RICE_3yr_29 & 2.4 & 5.8 & 14.1 & 26.7 & 31.2 & 64.5 & 55.6 & 36.4 & 82.0 & 62.7 & 65.1 & 97.0 & 55.7 & 69.7 \\
\hline 67.32 & RICE_3yr_30 & 14.6 & 6.5 & 19.2 & 36.0 & 41.0 & 49.1 & 71.0 & 63.4 & 75.5 & 49.6 & 52.4 & 66.6 & 64.0 & 74.2 \\
\hline 68.14 & RICE_3yr_31 & 6.5 & 4.0 & 19.9 & 24.1 & 64.1 & 73.3 & 48.0 & 82.9 & 29.3 & 21.4 & 37.9 & 72.9 & 111.0 & 70.4 \\
\hline 68.97 & RICE_3yr_32 & 14.4 & 5.6 & 9.8 & 11.7 & 45.2 & 38.5 & 30.6 & 55.4 & 32.5 & 80.5 & 85.2 & 57.5 & 78.0 & 30.1 \\
\hline 69.80 & RICE_3yr_33 & 9.9 & 9.4 & 18.6 & 26.0 & 30.4 & 41.3 & 13.8 & 76.7 & 45.9 & 29.4 & 77.3 & 41.0 & 55.4 & 216.9 \\
\hline 70.65 & RICE_3yr_34 & 12.9 & 4.9 & 9.2 & 23.2 & 38.4 & 53.7 & 49.4 & 40.2 & 58.3 & 38.5 & 73.1 & 75.1 & 73.5 & 237.4 \\
\hline 71.46 & RICE_3yr_35 & 14.9 & 5.4 & 15.4 & 29.4 & 53.2 & 30.3 & 52.2 & 33.2 & 53.4 & 54.8 & 57.7 & 95.4 & 76.4 & 73.8 \\
\hline 72.30 & RICE_3yr_36 & 12.0 & 5.3 & 18.3 & 30.6 & 48.1 & 51.0 & 47.9 & 64.3 & 83.2 & 35.9 & 68.5 & 63.9 & 102.8 & 99.6 \\
\hline 73.15 & RICE_3yr_37 & 6.3 & 6.4 & 29.2 & 26.0 & 38.5 & 41.0 & 45.8 & 33.4 & 28.3 & 54.6 & 39.5 & 67.3 & 97.2 & 90.2 \\
\hline 73.93 & RICE_3yr_38 & 7.7 & 6.4 & 12.6 & 29.4 & 39.4 & 44.2 & 35.8 & 60.2 & 51.8 & 64.4 & 53.5 & 67.2 & 88.6 & 102.7 \\
\hline 74.75 & RICE_3yr_39 & 9.0 & 3.6 & 19.3 & 15.3 & 37.6 & 45.7 & 52.9 & 53.4 & 63.5 & 30.4 & 35.9 & 61.0 & 70.6 & 117.5 \\
\hline 75.54 & RICE_3yr_40 & 6.2 & 4.0 & 17.2 & 22.8 & 45.8 & 52.3 & 23.9 & 43.1 & 20.6 & 19.8 & 26.5 & 58.9 & 53.4 & 30.5 \\
\hline 76.31 & RICE_3yr_41 & 7.7 & 2.7 & 12.8 & 24.6 & 25.5 & 56.2 & 27.4 & 28.6 & 31.3 & 35.1 & 57.7 & 43.4 & 66.2 & 109.3 \\
\hline 77.14 & RICE_3yr_42 & 6.7 & 6.8 & 16.7 & 26.4 & 34.8 & 37.7 & 31.2 & 27.4 & 38.4 & 28.6 & 44.3 & 50.0 & 131.5 & 114.4 \\
\hline 77.94 & RICE_3yr_43 & 53.5 & 4.2 & 14.9 & 19.5 & 34.3 & 29.3 & 43.9 & 51.7 & 32.5 & 46.1 & 63.9 & 52.7 & 83.9 & 64.1 \\
\hline 78.75 & RICE_3yr_44 & 10.9 & 12.4 & 17.0 & 19.4 & 47.5 & 56.1 & 38.9 & 65.2 & 36.6 & 65.2 & 65.1 & 32.6 & 69.7 & 69.3 \\
\hline 79.51 & RICE_3yr_45 & 11.7 & 3.8 & 7.5 & 19.7 & 69.8 & 40.4 & 46.8 & 63.5 & 51.9 & 27.0 & 37.2 & 64.3 & 85.1 & 140.4 \\
\hline 80.32 & RICE_3yr_46 & 8.1 & 3.9 & 19.2 & 25.5 & 31.4 & 45.9 & 39.5 & 44.2 & 62.6 & 50.6 & 85.7 & 48.3 & 37.4 & 71.5 \\
\hline 81.06 & RICE_3yr_47 & 13.2 & 5.1 & 23.9 & 18.3 & 36.5 & 61.1 & 37.0 & 45.9 & 39.9 & 54.4 & 59.7 & 58.0 & 4.3 & 139.6 \\
\hline 81.86 & RICE_3yr_48 & 4.2 & 3.3 & 16.8 & 29.2 & 34.3 & 27.5 & 69.6 & 38.2 & 27.2 & 43.1 & 21.7 & 41.8 & 53.0 & 118.2 \\
\hline 82.64 & RICE_3yr_49 & 6.4 & 5.5 & 26.3 & 10.1 & 49.5 & 56.5 & 39.6 & 25.6 & 54.7 & 30.1 & 40.6 & 56.1 & 79.3 & 91.0 \\
\hline 83.51 & RICE_3yr_50 & 11.7 & 1.8 & 9.1 & 14.4 & 27.4 & 40.1 & 40.8 & 59.4 & 36.3 & 39.1 & 42.0 & 57.8 & 137.5 & 92.2 \\
\hline 84.29 & RICE_3yr_51 & 12.9 & 4.6 & 9.1 & 16.5 & 25.6 & 51.4 & 52.1 & 25.4 & 42.4 & 51.8 & 23.7 & 39.6 & 61.6 & 58.8 \\
\hline 85.01 & RICE_3yr_52 & 11.6 & 4.5 & 22.3 & 20.4 & 56.0 & 64.0 & 42.7 & 97.0 & 62.2 & 41.7 & 82.0 & 43.7 & 76.5 & 117.6 \\
\hline 85.80 & RICE_3yr_53 & 7.1 & 7.2 & 5.8 & 18.4 & 30.6 & 39.8 & 25.3 & 69.2 & 45.3 & 76.1 & 60.5 & 63.6 & 41.1 & 78.3 \\
\hline 86.57 & RICE_3yr_54 & 7.6 & 4.6 & 10.0 & 15.5 & 36.0 & 81.6 & 44.2 & 46.6 & 41.4 & 26.1 & 53.9 & 32.0 & 81.8 & 91.5 \\
\hline 87.32 & RICE_3yr_55 & 7.0 & 2.1 & 23.2 & 16.6 & 32.5 & 23.2 & 27.1 & 62.9 & 30.0 & 24.1 & 82.5 & 75.3 & 82.1 & 71.7 \\
\hline 88.09 & RICE_3yr_56 & 10.5 & 175.4 & 20.9 & 22.9 & 62.4 & 39.5 & 30.0 & 35.2 & 57.1 & 66.6 & 44.5 & 116.5 & 80.8 & 82.5 \\
\hline 88.84 & RICE_3yr_57 & 5.5 & 6.0 & 12.7 & 9.3 & 53.6 & 58.1 & 50.1 & 30.4 & 18.3 & 31.4 & 24.8 & 86.0 & 67.6 & 64.1 \\
\hline 89.57 & RICE_3yr_58 & 7.7 & 5.4 & 10.0 & 16.4 & 41.1 & 23.7 & 36.8 & 38.5 & 22.6 & 53.6 & 25.4 & 59.3 & 60.0 & 51.2 \\
\hline 90.30 & RICE_3yr_59 & 7.9 & 2.7 & 35.1 & 28.2 & 36.3 & 54.0 & 27.9 & 47.2 & 85.8 & 69.2 & 75.9 & 76.3 & 70.8 & 112.4 \\
\hline 91.05 & RICE_3yr_60 & 7.8 & 4.2 & 14.1 & 23.7 & 47.3 & 50.2 & 34.6 & 37.7 & 47.6 & 33.2 & 69.8 & 101.7 & 131.5 & 111.2 \\
\hline 91.80 & RICE_3yr_61 & 7.7 & 3.6 & 14.5 & 13.7 & 37.0 & 55.9 & 40.4 & 68.2 & 38.0 & 40.5 & 98.7 & 59.0 & 42.8 & 115.2 \\
\hline 92.56 & RICE_3yr_62 & 4.9 & 3.0 & 11.9 & 21.2 & 26.9 & 19.4 & 50.7 & 44.6 & 41.2 & 28.8 & 28.4 & 41.0 & 52.1 & 49.6 \\
\hline 93.30 & RICE_3yr_63 & 3.9 & 7.8 & 13.0 & 33.5 & 28.7 & 34.0 & 37.5 & 62.2 & 57.6 & 60.8 & 90.4 & 84.7 & 105.7 & 68.9 \\
\hline 93.99 & RICE_3yr_64 & 13.2 & 4.5 & 18.9 & 27.4 & 54.0 & 55.7 & 34.8 & 22.9 & 113.1 & 49.9 & 48.7 & 128.1 & 101.1 & 136.8 \\
\hline 94.75 & RICE_3yr_65 & 14.2 & 7.4 & 24.3 & 14.3 & 46.8 & 29.5 & 40.4 & 88.7 & 45.4 & 62.6 & 45.8 & 41.3 & 55.7 & 80.7 \\
\hline 95.50 & RICE_3yr_66 & 10.7 & 4.8 & 10.5 & 29.6 & 34.8 & 68.2 & 40.0 & 37.1 & 48.2 & 84.8 & 44.0 & 108.1 & 102.1 & 113.4 \\
\hline 96.21 & RICE_3yr_67 & 6.1 & 7.0 & 27.9 & 19.3 & 52.3 & 39.2 & 39.9 & 41.8 & 38.0 & 38.5 & 50.6 & 67.9 & 54.2 & 76.1 \\
\hline
\end{tabular}




\begin{tabular}{|c|c|c|c|c|c|c|c|c|c|c|c|c|c|c|c|}
\hline 96.92 & RICE_3yr_68 & 7.6 & 3.5 & 14.5 & 19.5 & 23.7 & 45.6 & 32.6 & 64.6 & 20.8 & 52.4 & 156.0 & 59.6 & 99.2 & 181.9 \\
\hline 97.67 & RICE_3yr_69 & 9.1 & 3.5 & 21.5 & 25.4 & 46.1 & 42.7 & 59.8 & 56.6 & 33.3 & 53.7 & 43.9 & 86.5 & 87.5 & 89.2 \\
\hline 98.40 & RICE_3yr_70 & 10.2 & 5.6 & 40.4 & 43.2 & 46.4 & 50.8 & 86.8 & 70.4 & 48.9 & 48.1 & 98.5 & 53.5 & 139.9 & 83.5 \\
\hline 99.09 & RICE_3yr_71 & 4.6 & 3.5 & 14.8 & 23.5 & 67.3 & 65.7 & 61.2 & 22.1 & 44.2 & 46.8 & 106.2 & 59.2 & 97.2 & 80.1 \\
\hline 99.78 & RICE_3yr_72 & 13.7 & 6.0 & 19.2 & 25.6 & 54.4 & 23.6 & 74.3 & 80.4 & 52.4 & 66.6 & 65.9 & 80.0 & 63.0 & 127.3 \\
\hline 100.51 & RICE_3yr_73 & 9.9 & 6.5 & 19.4 & 13.8 & 34.9 & 53.5 & 39.8 & 60.4 & 14.0 & 73.1 & 75.4 & 70.1 & 94.9 & 62.7 \\
\hline 101.23 & RICE_3yr_74 & 17.1 & 4.6 & 20.5 & 35.7 & 48.7 & 30.4 & 33.6 & 38.8 & 43.7 & 59.3 & 70.7 & 89.7 & 98.8 & 109.2 \\
\hline 101.92 & RICE_3yr_75 & 9.4 & 2.8 & 18.4 & 22.5 & 75.1 & 45.6 & 63.3 & 55.3 & 129.0 & 43.6 & 79.1 & 48.1 & 81.4 & 102.7 \\
\hline 102.67 & RICE_3yr_76 & 7.5 & 2.6 & 19.5 & 34.7 & 42.2 & 31.1 & 58.2 & 46.5 & 73.2 & 62.1 & 81.8 & 66.1 & 108.4 & 111.4 \\
\hline 103.36 & RICE_3yr_77 & 13.5 & 3.9 & 22.8 & 25.7 & 68.1 & 48.2 & 47.1 & 66.6 & 43.7 & 36.6 & 61.9 & 78.1 & 51.7 & 62.6 \\
\hline 104.04 & RICE_3yr_78 & 10.4 & 8.2 & 22.4 & 16.2 & 29.7 & 31.4 & 50.0 & 31.4 & 46.9 & 54.7 & 86.1 & 35.7 & 122.5 & 245.0 \\
\hline 104.77 & RICE_3yr_79 & 11.4 & 7.4 & 9.1 & 48.5 & 67.7 & 47.5 & 60.4 & 54.2 & 93.5 & 27.9 & 45.5 & 46.3 & 90.1 & 90.7 \\
\hline 105.47 & RICE_3yr_80 & 10.6 & 5.8 & 23.2 & 15.3 & 46.4 & 33.7 & 35.9 & 29.6 & 30.4 & 40.7 & 42.0 & 84.8 & 77.5 & 63.6 \\
\hline 106.18 & RICE_3yr_81 & 7.2 & 7.2 & 17.5 & 17.3 & 55.7 & 24.0 & 38.2 & 41.0 & 60.2 & 59.3 & 49.1 & 31.3 & 68.0 & 61.8 \\
\hline 106.91 & RICE_3yr_82 & 9.9 & 3.3 & 16.4 & 14.2 & 22.8 & 44.6 & 41.3 & 49.5 & 15.6 & 36.2 & 17.5 & 57.6 & 92.2 & 148.8 \\
\hline 107.56 & RICE_3yr_83 & 8.0 & 3.5 & 15.7 & 16.7 & 38.8 & 58.0 & 45.0 & 55.5 & 61.7 & 32.5 & 44.5 & 42.8 & 23.2 & 232.2 \\
\hline 108.25 & RICE_3yr_84 & 6.6 & 4.6 & 10.0 & 13.0 & 54.4 & 11.6 & 46.6 & 40.1 & 43.2 & 36.1 & 27.3 & 36.8 & 36.5 & 34.5 \\
\hline 108.96 & RICE_3yr_85 & 5.5 & 3.1 & 19.5 & 10.0 & 59.9 & 25.6 & 36.9 & 82.3 & 43.7 & 42.1 & 59.0 & 41.7 & 56.0 & 47.0 \\
\hline 109.62 & RICE_3yr_86 & 9.4 & 2.7 & 16.6 & 19.3 & 33.3 & 19.0 & 31.8 & 42.9 & 67.3 & 35.8 & 46.0 & 41.1 & 69.6 & 89.2 \\
\hline 110.31 & RICE_3yr_87 & 8.4 & 5.6 & 14.1 & 11.8 & 32.3 & 23.2 & 38.8 & 40.8 & 34.7 & 37.6 & 39.5 & 77.6 & 96.6 & 86.2 \\
\hline 111.04 & RICE_3yr_88 & 9.2 & 9.1 & 12.0 & 59.4 & 24.2 & 29.9 & 37.5 & 33.6 & 33.0 & 46.6 & 42.3 & 34.5 & 69.2 & 68.6 \\
\hline 111.71 & RICE_3yr_89 & 6.6 & 4.3 & 9.8 & 21.6 & 53.3 & 39.6 & 72.9 & 32.2 & 49.0 & 53.9 & 28.3 & 90.5 & 54.5 & 91.6 \\
\hline 112.38 & RICE_3yr_90 & 6.4 & 3.2 & 19.5 & 11.5 & 37.6 & 23.9 & 23.9 & 35.4 & 58.0 & 28.9 & 67.2 & 87.0 & 88.0 & 64.7 \\
\hline 113.06 & RICE_3yr_91 & 4.6 & 5.2 & 16.4 & 20.0 & 37.7 & 52.7 & 39.0 & 51.5 & 41.3 & 46.7 & 28.3 & 43.1 & 72.5 & 52.3 \\
\hline 113.73 & RICE_3yr_92 & 6.1 & 6.8 & 23.9 & 18.3 & 46.7 & 65.6 & 47.2 & 39.4 & 49.4 & 56.6 & 75.1 & 64.7 & 108.5 & 190.4 \\
\hline 114.39 & RICE_3yr_93 & 16.6 & 9.1 & 14.4 & 14.1 & 66.3 & 35.2 & 47.7 & 59.2 & 64.7 & 27.8 & 89.6 & 90.6 & 100.8 & 159.8 \\
\hline 115.11 & RICE_3yr_94 & 8.8 & 1.3 & 16.8 & 9.6 & 31.6 & 48.8 & 35.1 & 32.4 & 19.1 & 46.2 & 46.9 & 44.6 & 63.4 & 63.0 \\
\hline 115.78 & RICE_3yr_95 & 9.1 & 4.2 & 9.4 & 13.6 & 41.9 & 43.3 & 21.3 & 26.7 & 24.3 & 43.3 & 63.6 & 59.6 & 69.8 & 47.7 \\
\hline 116.44 & RICE_3yr_96 & 8.5 & 5.2 & 16.9 & 25.6 & 42.9 & 25.3 & 40.2 & 39.7 & 20.2 & 61.9 & 40.8 & 68.1 & 62.6 & 175.2 \\
\hline 117.12 & RICE_3yr_97 & 8.8 & 3.8 & 15.5 & 20.4 & 40.5 & 42.7 & 61.2 & 73.8 & 37.5 & 39.1 & 62.2 & 49.5 & 51.7 & 72.8 \\
\hline 117.76 & RICE_3yr_98 & 6.1 & 9.5 & 15.2 & 18.8 & 62.3 & 64.3 & 72.1 & 85.3 & 48.8 & 28.8 & 56.6 & 70.8 & 95.2 & 143.1 \\
\hline 118.41 & RICE_3yr_99 & 7.3 & 3.4 & 6.8 & 18.0 & 50.3 & 52.3 & 35.7 & 57.8 & 45.8 & 31.5 & 37.4 & 63.1 & 66.9 & 91.8 \\
\hline 119.08 & RICE_3yr_100 & 4.3 & 3.8 & 19.2 & 26.5 & 45.8 & 46.0 & 43.8 & 63.1 & 60.9 & 42.1 & 35.1 & 31.6 & 70.2 & 62.3 \\
\hline 119.75 & RICE_3yr_101 & 4.6 & 4.8 & 19.1 & 11.3 & 29.2 & 55.9 & 27.4 & 31.5 & 55.1 & 45.8 & 63.9 & 53.2 & 42.4 & 215.8 \\
\hline 120.44 & RICE_3yr_102 & 12.9 & 9.4 & 7.7 & 15.6 & 41.2 & 54.4 & 72.4 & 47.8 & 69.5 & 39.8 & 115.8 & 91.3 & 103.3 & 93.1 \\
\hline 121.05 & RICE_3yr_103 & 12.3 & 6.3 & 12.3 & 32.7 & 50.0 & 41.5 & 84.1 & 45.5 & 56.1 & 60.4 & 83.1 & 48.2 & 113.4 & 44.8 \\
\hline 121.74 & RICE_3yr_104 & 10.0 & 5.9 & 17.6 & 23.4 & 26.3 & 44.5 & 31.4 & 61.7 & 55.8 & 40.2 & 53.6 & 44.3 & 70.9 & 98.5 \\
\hline 122.37 & RICE_3yr_105 & 7.3 & 7.1 & 24.2 & 19.7 & 36.3 & 51.9 & 80.4 & 46.4 & 44.2 & 60.1 & 77.2 & 51.5 & 84.1 & 126.2 \\
\hline 123.04 & RICE_3yr_106 & 10.2 & 8.1 & 18.4 & 27.9 & 47.2 & 70.2 & 65.6 & 18.9 & 44.7 & 76.9 & 85.0 & 69.5 & 64.5 & 106.3 \\
\hline 123.69 & RICE_3yr_107 & 8.4 & 5.9 & 28.4 & 23.2 & 47.7 & 56.9 & 48.0 & 52.0 & 44.5 & 57.3 & 48.1 & 110.8 & 92.0 & 140.2 \\
\hline 124.33 & RICE_3yr_108 & 6.2 & 3.3 & 17.7 & 33.2 & 23.2 & 71.7 & 76.2 & 59.9 & 77.5 & 63.0 & 64.9 & 136.3 & 63.5 & 83.3 \\
\hline 124.94 & RICE_3yr_109 & 5.4 & 3.1 & 11.0 & 18.2 & 45.6 & 41.0 & 49.3 & 50.9 & 69.0 & 46.4 & 56.4 & 63.6 & 90.5 & 75.4 \\
\hline 125.59 & RICE_3yr_110 & 9.6 & 5.3 & 12.0 & 24.1 & 51.7 & 18.2 & 42.5 & 40.2 & 64.8 & 39.1 & 95.2 & 79.3 & 78.4 & 126.6 \\
\hline 126.25 & RICE_3yr_111 & 12.9 & 6.7 & 10.1 & 19.1 & 50.3 & 33.1 & 70.3 & 29.3 & 63.2 & 42.8 & 37.7 & 32.0 & 110.0 & 120.5 \\
\hline 126.89 & RICE_3yr_112 & 11.8 & 3.3 & 17.1 & 22.6 & 37.7 & 48.5 & 46.1 & 38.0 & 49.0 & 63.6 & 40.1 & 79.5 & 55.2 & 244.6 \\
\hline 127.53 & RICE_3yr_113 & 4.0 & 4.9 & 9.1 & 20.2 & 70.6 & 78.6 & 36.1 & 23.1 & 38.6 & 36.5 & 54.9 & 47.0 & 64.5 & 64.9 \\
\hline 128.17 & RICE_3yr_114 & 7.8 & 7.3 & 10.3 & 12.5 & 53.5 & 48.3 & 18.7 & 41.9 & 27.9 & 32.3 & 37.0 & 36.0 & 61.5 & 122.0 \\
\hline 128.81 & RICE_3yr_115 & 11.2 & 3.7 & 21.3 & 5.4 & 56.7 & 62.2 & 58.3 & 29.1 & 44.3 & 15.5 & 62.5 & 87.2 & 85.0 & 81.8 \\
\hline 129.45 & RICE_3yr_116 & 3.7 & 1.6 & 15.1 & 23.7 & 43.3 & 41.8 & 48.5 & 35.5 & 31.6 & 59.0 & 50.2 & 75.9 & 70.5 & 118.1 \\
\hline 130.06 & RICE_3yr_117 & 4.4 & 8.9 & 22.3 & 16.7 & 33.1 & 23.5 & 42.9 & 40.8 & 72.9 & 64.8 & 50.3 & 64.7 & 70.2 & 141.4 \\
\hline 130.71 & RICE_3yr_118 & 8.6 & 5.0 & 14.8 & 13.0 & 59.7 & 19.6 & 41.6 & 24.3 & 50.6 & 52.3 & 76.6 & 70.1 & 40.5 & 100.7 \\
\hline 131.32 & RICE_3yr_119 & 8.1 & 6.4 & 14.1 & 9.9 & 45.3 & 55.3 & 10.6 & 45.4 & 47.0 & 45.8 & 45.6 & 63.4 & 67.3 & 113.7 \\
\hline 131.95 & RICE_3yr_120 & 2.9 & 3.4 & 17.9 & 24.4 & 52.1 & 57.5 & 39.9 & 36.1 & 25.1 & 27.5 & 76.1 & 42.6 & 68.6 & 72.8 \\
\hline 132.61 & RICE_3yr_121 & 22.7 & 3.9 & 21.7 & 33.4 & 40.9 & 72.7 & 79.4 & 66.1 & 39.3 & 60.4 & 33.2 & 102.1 & 64.0 & 98.8 \\
\hline 133.20 & RICE_3yr_122 & 9.9 & 3.1 & 23.8 & 21.9 & 59.1 & 26.0 & 36.2 & 26.9 & 33.7 & 55.0 & 70.5 & 107.7 & 112.3 & 119.7 \\
\hline 133.83 & RICE_3yr_123 & 7.4 & 5.5 & 31.7 & 23.6 & 50.4 & 43.3 & 62.4 & 21.3 & 46.6 & 56.6 & 80.8 & 95.3 & 90.8 & 79.8 \\
\hline 134.45 & RICE_3yr_124 & 12.8 & 7.5 & 17.4 & 31.0 & 60.9 & 42.7 & 60.6 & 25.6 & 58.8 & 94.2 & 76.2 & 55.3 & 137.6 & 141.3 \\
\hline 135.10 & RICE_3yr_125 & 11.3 & 4.8 & 12.9 & 22.9 & 79.4 & 60.7 & 64.7 & 43.9 & 36.8 & 70.4 & 58.9 & 37.1 & 82.3 & 99.5 \\
\hline 135.69 & RICE_3yr_126 & 7.4 & 2.7 & 10.3 & 14.1 & 42.8 & 53.5 & 44.8 & 22.5 & 34.5 & 48.7 & 40.9 & 66.4 & 62.9 & 100.0 \\
\hline 136.33 & RICE_3yr_127 & 7.5 & 5.2 & 22.8 & 26.6 & 54.3 & 24.8 & 29.8 & 62.0 & 60.1 & 57.6 & 60.1 & 83.2 & 131.6 & 140.7 \\
\hline 136.92 & RICE_3yr_128 & 12.3 & 6.9 & 24.9 & 23.1 & 49.7 & 25.9 & 25.5 & 66.0 & 48.0 & 29.8 & 39.7 & 81.4 & 63.8 & 63.6 \\
\hline 137.52 & RICE_3yr_129 & 4.6 & 5.9 & 16.3 & 26.4 & 48.9 & 44.0 & 68.1 & 49.9 & 45.7 & 31.0 & 93.0 & 55.5 & 62.2 & 70.8 \\
\hline 138.15 & RICE_3yr_130 & 13.9 & 5.0 & 16.2 & 21.2 & 47.1 & 55.7 & 55.7 & 42.6 & 92.6 & 54.2 & 31.0 & 48.7 & 95.6 & 168.3 \\
\hline
\end{tabular}




\begin{tabular}{|c|c|c|c|c|c|c|c|c|c|c|c|c|c|c|c|}
\hline 138.77 & RICE_3yr_131 & 10.5 & 2.0 & 18.4 & 27.9 & 35.7 & 31.9 & 25.7 & 35.3 & 25.4 & 52.6 & 52.6 & 64.4 & 84.2 & 113.1 \\
\hline 139.36 & RICE_3yr_132 & 9.4 & 6.5 & 27.3 & 29.6 & 83.2 & 74.5 & 57.4 & 20.3 & 43.0 & 45.3 & 50.3 & 116.7 & 54.6 & 41.3 \\
\hline 139.97 & RICE_3yr_133 & 10.1 & 3.7 & 18.6 & 12.9 & 49.8 & 19.0 & 43.1 & 42.2 & 60.3 & 26.5 & 68.8 & 74.6 & 103.5 & 68.4 \\
\hline 140.59 & RICE_3yr_134 & 7.0 & 7.4 & 21.4 & 18.1 & 37.5 & 35.7 & 46.6 & 47.4 & 65.2 & 41.6 & 54.2 & 75.2 & 52.9 & 87.4 \\
\hline 141.18 & RICE_3yr_135 & 7.1 & 4.2 & 7.6 & 31.6 & 40.4 & 56.0 & 39.6 & 77.5 & 82.3 & 71.9 & 93.1 & 85.8 & 70.6 & 91.9 \\
\hline 141.78 & RICE_3yr_136 & 11.7 & 2.5 & 31.7 & 23.2 & 36.4 & 30.2 & 39.3 & 36.3 & 47.3 & 54.2 & 84.4 & 63.3 & 103.9 & 103.1 \\
\hline 142.37 & RICE_3yr_137 & 10.6 & 3.4 & 21.2 & 24.6 & 47.5 & 67.5 & 46.6 & 41.2 & 23.0 & 45.2 & 39.0 & 46.4 & 84.9 & 83.7 \\
\hline 142.97 & RICE_3yr_138 & 13.6 & 4.7 & 15.4 & 12.4 & 36.0 & 49.9 & 68.6 & 59.4 & 50.3 & 66.1 & 60.2 & 97.6 & 67.7 & 80.1 \\
\hline 143.59 & RICE_3yr_139 & 12.5 & 3.8 & 13.5 & 27.7 & 36.6 & 93.8 & 50.1 & 60.3 & 69.3 & 34.7 & 41.0 & 106.8 & 67.8 & 121.4 \\
\hline 144.19 & RICE_3yr_140 & 8.9 & 7.0 & 9.8 & 23.1 & 65.7 & 51.9 & 30.5 & 51.7 & 32.1 & 48.9 & 89.9 & 63.5 & 29.8 & 115.2 \\
\hline 144.76 & RICE_3yr_141 & 8.0 & 4.3 & 24.0 & 20.6 & 60.1 & 57.2 & 46.7 & 59.5 & 34.7 & 69.1 & 42.5 & 83.0 & 70.3 & 167.2 \\
\hline 145.32 & RICE_3yr_142 & 14.4 & 7.2 & 31.6 & 27.8 & 88.2 & 47.0 & 47.0 & 88.6 & 43.7 & 37.8 & 98.5 & 57.7 & 69.3 & 182.2 \\
\hline 145.91 & RICE_3yr_143 & 11.6 & 5.4 & 25.0 & 27.9 & 67.9 & 56.4 & 39.2 & 46.5 & 61.4 & 36.1 & 42.8 & 84.5 & 42.0 & 55.7 \\
\hline 146.48 & RICE_3yr_144 & 7.7 & 3.9 & 19.5 & 8.7 & 28.7 & 59.8 & 85.4 & 29.6 & 18.2 & 40.2 & 38.1 & 77.5 & 75.1 & 44.8 \\
\hline 147.08 & RICE_3yr_145 & 10.9 & 4.2 & 13.0 & 20.7 & 34.3 & 35.4 & 45.9 & 49.5 & 55.2 & 57.1 & 25.6 & 54.9 & 89.3 & 85.4 \\
\hline 147.67 & RICE_3yr_146 & 8.6 & 5.4 & 9.6 & 22.6 & 29.2 & 19.6 & 29.7 & 25.6 & 58.9 & 31.7 & 74.4 & 54.6 & 74.0 & 126.1 \\
\hline 148.28 & RICE_3yr_147 & 13.4 & 2.6 & 24.3 & 23.5 & 48.3 & 49.4 & 32.0 & 23.2 & 63.2 & 40.3 & 76.0 & 120.0 & 35.9 & 124.5 \\
\hline 148.84 & RICE_3yr_148 & 5.6 & 3.8 & 15.5 & 21.9 & 141.1 & 9.8 & 33.1 & 46.8 & 49.7 & 51.1 & 73.1 & 78.9 & 70.2 & 83.5 \\
\hline 149.44 & RICE_3yr_149 & 12.0 & 3.2 & 15.0 & 12.3 & 34.8 & 71.0 & 67.5 & 41.5 & 69.8 & 41.4 & 98.4 & 65.4 & 111.5 & 92.4 \\
\hline 150.03 & RICE_3yr_150 & 7.1 & 3.0 & 14.7 & 6.5 & 32.1 & 64.4 & 25.5 & 38.6 & 37.2 & 54.6 & 33.0 & 64.3 & 91.6 & 92.2 \\
\hline 150.61 & RICE_3yr_151 & 10.1 & 4.0 & 19.2 & 21.7 & 41.5 & 62.1 & 48.8 & 46.3 & 58.6 & 53.9 & 159.3 & 72.2 & 63.3 & 49.0 \\
\hline 151.20 & RICE_3yr_152 & 10.4 & 6.2 & 30.6 & 16.8 & 78.2 & 75.0 & 38.2 & 51.9 & 37.1 & 149.6 & 112.0 & 50.5 & 155.1 & 111.4 \\
\hline 151.77 & RICE_3yr_153 & 6.9 & 5.9 & 21.6 & 18.3 & 60.8 & 81.3 & 50.8 & 39.7 & 20.8 & 66.2 & 57.3 & 63.8 & 78.2 & 81.4 \\
\hline 152.32 & RICE_3yr_154 & 9.9 & 4.2 & 22.5 & 31.4 & 54.5 & 44.0 & 48.0 & 93.6 & 37.4 & 58.6 & 63.8 & 72.5 & 55.2 & 100.6 \\
\hline 152.91 & RICE_3yr_155 & 13.3 & 1.3 & 7.5 & 25.3 & 39.0 & 28.7 & 35.7 & 48.7 & 35.6 & 51.5 & 52.3 & 41.3 & 88.7 & 102.4 \\
\hline 153.49 & RICE_3yr_156 & 2.9 & 6.1 & 28.4 & 10.0 & 43.0 & 64.7 & 31.9 & 22.3 & 58.4 & 41.1 & 73.3 & 23.7 & 53.6 & 182.1 \\
\hline 154.04 & RICE_3yr_157 & 4.8 & 3.8 & 10.4 & 19.0 & 43.4 & 27.4 & 29.0 & 26.8 & 45.9 & 39.3 & 50.0 & 68.0 & 94.4 & 87.8 \\
\hline 154.61 & RICE_3yr_158 & 5.2 & 3.0 & 13.8 & 10.0 & 38.2 & 28.5 & 32.3 & 10.5 & 27.9 & 35.5 & 57.3 & 40.7 & 57.7 & 73.2 \\
\hline 155.21 & RICE_3yr_159 & 12.5 & 5.5 & 7.7 & 13.0 & 87.4 & 38.0 & 30.8 & 40.1 & 31.3 & 38.6 & 40.2 & 47.2 & 118.1 & 69.1 \\
\hline 155.75 & RICE_3yr_160 & 5.3 & 4.1 & 19.6 & 27.0 & 61.4 & 44.6 & 29.9 & 42.3 & 37.3 & 54.1 & 46.4 & 65.8 & 61.3 & 78.7 \\
\hline 156.34 & RICE_3yr_161 & 6.4 & 7.3 & 20.6 & 20.9 & 39.0 & 45.3 & 64.8 & 62.1 & 33.0 & 59.5 & 34.4 & 60.6 & 72.3 & 129.3 \\
\hline 156.90 & RICE_3yr_162 & 10.3 & 6.1 & 9.0 & 20.2 & 41.0 & 39.9 & 35.1 & 39.6 & 25.7 & 50.2 & 71.5 & 95.6 & 122.5 & 70.1 \\
\hline 157.45 & RICE_3yr_163 & 4.5 & 5.4 & 10.0 & 21.6 & 53.0 & 35.1 & 61.6 & 17.0 & 34.2 & 56.5 & 41.2 & 42.0 & 32.6 & 62.2 \\
\hline 157.97 & RICE_3yr_164 & 10.6 & 4.0 & 16.6 & 4.8 & 37.7 & 43.4 & 70.8 & 9.5 & 32.0 & 40.8 & 55.8 & 56.0 & 65.9 & 139.6 \\
\hline 158.54 & RICE_3yr_165 & 1.7 & 4.3 & 17.8 & 21.7 & 35.8 & 17.6 & 32.4 & 36.0 & 45.9 & 29.1 & 38.8 & 27.2 & 87.1 & 72.0 \\
\hline 159.13 & RICE_3yr_166 & 4.7 & 5.5 & 12.0 & 17.4 & 49.9 & 41.1 & 47.6 & 33.4 & 41.6 & 48.3 & 63.5 & 47.8 & 128.7 & 159.8 \\
\hline 159.67 & RICE_3yr_167 & 6.3 & 4.9 & 12.8 & 18.4 & 46.1 & 47.5 & 48.6 & 47.5 & 26.9 & 51.6 & 43.8 & 53.7 & 68.6 & 60.7 \\
\hline 160.24 & RICE_3yr_168 & 10.2 & 4.6 & 17.8 & 28.1 & 61.9 & 49.7 & 63.9 & 58.6 & 57.0 & 60.8 & 49.6 & 61.0 & 245.0 & 63.7 \\
\hline 160.79 & RICE_3yr_169 & 14.4 & 4.2 & 31.7 & 15.2 & 20.8 & 29.3 & 59.6 & 23.1 & 39.4 & 31.9 & 34.8 & 34.1 & 41.4 & 130.2 \\
\hline 161.32 & RICE_3yr_170 & 7.0 & 3.5 & 24.9 & 21.6 & 56.0 & 53.9 & 32.5 & 49.8 & 50.9 & 35.9 & 22.1 & 50.0 & 49.6 & 102.5 \\
\hline 161.87 & RICE_3yr_171 & 6.6 & 2.3 & 13.9 & 13.7 & 26.3 & 30.3 & 13.7 & 15.8 & 30.4 & 28.4 & 17.7 & 39.3 & 46.3 & 27.4 \\
\hline 162.44 & RICE_3yr_172 & 4.7 & 5.2 & 38.1 & 30.0 & 41.6 & 28.7 & 44.7 & 47.6 & 48.6 & 17.1 & 40.5 & 42.3 & 40.7 & 41.9 \\
\hline 162.97 & RICE_3yr_173 & 7.3 & 6.5 & 14.0 & 15.0 & 37.4 & 62.1 & 49.7 & 77.5 & 66.5 & 46.3 & 69.0 & 34.3 & 82.9 & 91.4 \\
\hline 163.54 & RICE_3yr_174 & 10.2 & 4.4 & 18.5 & 13.4 & 43.6 & 45.3 & 25.8 & 36.9 & 18.0 & 26.8 & 54.6 & 65.3 & 82.1 & 60.5 \\
\hline 164.06 & RICE_3yr_175 & 8.9 & 4.5 & 7.8 & 22.0 & 43.7 & 25.7 & 24.1 & 26.5 & 21.7 & 36.6 & 47.1 & 26.5 & 41.1 & 81.4 \\
\hline 164.62 & RICE_3yr_176 & 6.5 & 4.4 & 10.0 & 16.0 & 32.9 & 37.9 & 56.5 & 25.7 & 19.1 & 34.8 & 28.7 & 60.3 & 68.4 & 90.6 \\
\hline 165.14 & RICE_3yr_177 & 13.6 & 11.8 & 26.7 & 34.3 & 60.6 & 70.5 & 36.6 & 35.4 & 61.8 & 53.6 & 81.7 & 62.3 & 55.2 & 84.0 \\
\hline 165.68 & RICE_3yr_178 & 6.2 & 5.7 & 16.3 & 15.8 & 50.5 & 33.6 & 44.5 & 61.5 & 51.4 & 55.9 & 86.7 & 83.0 & 81.5 & 91.1 \\
\hline 166.26 & RICE_3yr_179 & 7.6 & 2.4 & 15.9 & 21.3 & 25.1 & 62.0 & 51.8 & 35.6 & 42.3 & 66.8 & 53.9 & 104.9 & 73.4 & 113.1 \\
\hline 166.80 & RICE_3yr_180 & 6.7 & 3.8 & 6.6 & 38.2 & 43.8 & 52.4 & 41.6 & 20.4 & 70.0 & 49.1 & 50.6 & 37.1 & 108.8 & 82.4 \\
\hline 167.35 & RICE_3yr_181 & 15.4 & 7.8 & 21.5 & 16.6 & 72.5 & 76.2 & 104.6 & 59.3 & 67.3 & 66.4 & 90.1 & 59.9 & 99.3 & 77.5 \\
\hline 167.88 & RICE_3yr_182 & 15.1 & 4.0 & 11.0 & 38.8 & 29.3 & 86.8 & 40.1 & 32.7 & 62.8 & 60.3 & 95.8 & 84.9 & 73.6 & 76.2 \\
\hline 168.39 & RICE_3yr_183 & 13.1 & 6.1 & 23.7 & 27.3 & 73.7 & 30.8 & 54.1 & 49.5 & 47.7 & 36.0 & 43.4 & 98.3 & 79.4 & 87.8 \\
\hline 168.94 & RICE_3yr_184 & 6.9 & 8.1 & 18.8 & 19.0 & 42.9 & 31.6 & 50.8 & 36.2 & 58.8 & 61.3 & 99.0 & 80.2 & 36.9 & 159.7 \\
\hline 169.45 & RICE_3yr_185 & 7.4 & 2.5 & 18.3 & 22.8 & 50.0 & 27.0 & 42.6 & 59.2 & 23.9 & 38.8 & 58.0 & 88.2 & 90.8 & 118.0 \\
\hline 170.02 & RICE_3yr_186 & 3.5 & 2.9 & 16.2 & 19.8 & 44.6 & 62.8 & 36.9 & 84.0 & 19.2 & 37.5 & 26.3 & 61.0 & 76.6 & 113.6 \\
\hline 170.55 & RICE_3yr_187 & 7.6 & 4.7 & 16.4 & 25.8 & 20.3 & 56.3 & 32.4 & 55.7 & 57.5 & 42.2 & 65.9 & 75.3 & 66.7 & 64.7 \\
\hline 171.07 & RICE_3yr_188 & 7.3 & 3.3 & 11.3 & 21.0 & 55.9 & 69.0 & 54.1 & 52.2 & 47.8 & 44.5 & 74.4 & 75.2 & 79.3 & 109.5 \\
\hline 171.59 & RICE_3yr_189 & 9.1 & 4.4 & 21.1 & 19.2 & 39.9 & 41.2 & 35.5 & 44.8 & 36.0 & 27.8 & 64.6 & 66.4 & 102.7 & 63.7 \\
\hline 172.10 & RICE_3yr_190 & 5.4 & 3.4 & 26.3 & 27.4 & 49.5 & 52.5 & 31.1 & 59.4 & 47.0 & 45.8 & 52.6 & 100.6 & 113.2 & 97.8 \\
\hline 172.63 & RICE_3yr_191 & 7.5 & 1.7 & 14.7 & 21.7 & 67.1 & 22.4 & 47.4 & 35.5 & 39.7 & 52.6 & 69.3 & 80.0 & 100.2 & 89.2 \\
\hline 173.16 & RICE_3yr_192 & 13.8 & 5.3 & 17.5 & 35.2 & 55.1 & 54.1 & 25.2 & 74.3 & 66.1 & 52.7 & 125.1 & 29.2 & 80.4 & 81.2 \\
\hline 173.66 & RICE_3yr_193 & 6.4 & 3.1 & 20.0 & 20.8 & 69.4 & 55.2 & 39.3 & 52.2 & 58.1 & 48.6 & 64.2 & 59.8 & 98.6 & 72.2 \\
\hline
\end{tabular}




\begin{tabular}{|c|c|c|c|c|c|c|c|c|c|c|c|c|c|c|c|}
\hline 174.18 & RICE_3yr_194 & 5.3 & 6.9 & 9.6 & 6.8 & 39.0 & 39.4 & 36.5 & 22.0 & 39.9 & 56.1 & 78.6 & 25.8 & 32.8 & 31.8 \\
\hline 174.71 & RICE_3yr_195 & 4.4 & 6.3 & 8.2 & 34.7 & 47.1 & 51.4 & 58.7 & 26.4 & 51.7 & 51.2 & 72.5 & 81.4 & 57.8 & 82.0 \\
\hline 175.23 & RICE_3yr_196 & 12.2 & 4.6 & 7.4 & 19.3 & 49.2 & 44.9 & 23.4 & 44.6 & 9.5 & 50.1 & 62.9 & 80.4 & 75.0 & 122.7 \\
\hline 175.76 & RICE_3yr_197 & 7.3 & 5.2 & 16.7 & 16.3 & 59.5 & 47.6 & 36.4 & 53.5 & 29.4 & 54.1 & 82.9 & 81.6 & 96.4 & 128.7 \\
\hline 176.26 & RICE_3yr_198 & 6.6 & 5.6 & 14.8 & 24.2 & 34.4 & 43.4 & 45.8 & 57.4 & 35.0 & 72.0 & 68.7 & 68.8 & 64.3 & 118.0 \\
\hline 176.79 & RICE_3yr_199 & 11.3 & 3.9 & 18.6 & 15.4 & 39.1 & 50.9 & 44.5 & 33.1 & 18.8 & 40.9 & 34.3 & 61.3 & 45.6 & 68.9 \\
\hline 177.32 & RICE_3yr_200 & 8.7 & 52.6 & 19.2 & 28.0 & 46.6 & 46.4 & 34.1 & 43.3 & 72.7 & 44.3 & 76.0 & 93.3 & 117.6 & 86.9 \\
\hline 197.84 & RICE_3yr_241 & 2.3 & 2.5 & 2.8 & 8.2 & 14.0 & 20.4 & 30.2 & 47.0 & 27.5 & 17.7 & 32.8 & 43.5 & 44.3 & 48.6 \\
\hline 198.27 & RICE_3yr_242 & 1.6 & 5.5 & 3.9 & 11.0 & 16.0 & 30.0 & 31.9 & 26.6 & 17.8 & 35.0 & 30.4 & 30.1 & 32.6 & 52.5 \\
\hline 198.78 & RICE_3yr_243 & 1.0 & 9.2 & 2.0 & 13.7 & 17.6 & 21.2 & 15.8 & 40.3 & 45.8 & 28.2 & 25.5 & 27.4 & 70.1 & 64.8 \\
\hline 199.25 & RICE_3yr_244 & 2.4 & 4.1 & 5.9 & 10.6 & 18.8 & 39.1 & 31.6 & 23.5 & 35.4 & 19.0 & 29.5 & 20.6 & 69.7 & 58.8 \\
\hline 199.69 & RICE_3yr_245 & 1.4 & 5.4 & 4.4 & 9.8 & 11.8 & 15.3 & 24.3 & 28.6 & 31.7 & 29.2 & 21.1 & 20.1 & 39.2 & 38.4 \\
\hline 200.15 & RICE_3yr_246 & 1.6 & 4.1 & 3.3 & 8.4 & 8.5 & 21.5 & 24.9 & 25.4 & 26.3 & 6.9 & 16.1 & 31.7 & 22.6 & 32.9 \\
\hline 200.63 & RICE_3yr_247 & 1.8 & 4.4 & 2.8 & 12.1 & 11.6 & 9.8 & 28.1 & 35.1 & 35.5 & 31.5 & 14.5 & 27.2 & 30.8 & 24.5 \\
\hline 201.08 & RICE_3yr_248 & 1.3 & 2.7 & 3.9 & 11.2 & 10.6 & 25.7 & 23.4 & 27.5 & 17.5 & 12.1 & 22.0 & 35.0 & 54.3 & 7.3 \\
\hline 201.56 & RICE_3yr_249 & 3.2 & 7.8 & 4.0 & 6.8 & 9.4 & 28.0 & 23.5 & 17.5 & 38.3 & 14.8 & 20.8 & 29.5 & 33.3 & 32.7 \\
\hline 201.99 & RICE_3yr_250 & 1.4 & 9.5 & 7.0 & 15.6 & 8.4 & 35.7 & 18.5 & 20.3 & 24.9 & 46.5 & 12.8 & 24.8 & 53.4 & 31.9 \\
\hline 202.45 & RICE_3yr_251 & 0.7 & 3.8 & 3.4 & 11.1 & 13.1 & 26.8 & 28.5 & 26.3 & 19.9 & 17.1 & 25.7 & 62.4 & 46.5 & 32.3 \\
\hline 202.89 & RICE_3yr_252 & 1.2 & 3.9 & 2.2 & 4.3 & 11.1 & 18.5 & 32.0 & 23.3 & 20.2 & 16.7 & 17.2 & 32.2 & 56.5 & 24.3 \\
\hline 203.34 & RICE_3yr_253 & 1.8 & 4.1 & 3.2 & 6.9 & 7.4 & 33.0 & 43.5 & 25.2 & 15.8 & 20.1 & 8.4 & 18.3 & 43.8 & 29.4 \\
\hline 203.80 & RICE_3yr_254 & 2.7 & 9.7 & 3.2 & 4.9 & 12.0 & 28.1 & 22.8 & 34.0 & 12.9 & 35.2 & 14.4 & 31.0 & 37.9 & 53.4 \\
\hline 204.29 & RICE_3yr_255 & 2.6 & 4.9 & 4.8 & 11.7 & 9.7 & 20.5 & 14.7 & 14.1 & 24.6 & 27.8 & 29.2 & 13.0 & 25.5 & 65.3 \\
\hline 204.70 & RICE_3yr_256 & 2.5 & 7.7 & 4.6 & 6.2 & 16.2 & 24.6 & 24.1 & 29.6 & 29.8 & 34.9 & 29.2 & 31.3 & 48.1 & 43.3 \\
\hline 205.19 & RICE_3yr_257 & 3.1 & 4.2 & 4.3 & 9.9 & 14.3 & 45.0 & 22.4 & 25.7 & 47.1 & 44.4 & 18.7 & 30.0 & 40.4 & 58.3 \\
\hline 205.62 & RICE_3yr_258 & 1.7 & 2.9 & 3.9 & 11.5 & 7.9 & 19.9 & 43.6 & 13.0 & 19.5 & 25.6 & 15.8 & 27.2 & 37.0 & 35.9 \\
\hline 206.07 & RICE_3yr_259 & 2.6 & 3.8 & 2.5 & 6.3 & 10.1 & 38.8 & 11.5 & 17.8 & 28.5 & 21.2 & 29.4 & 16.9 & 36.7 & 27.9 \\
\hline 206.50 & RICE_3yr_260 & 1.8 & 3.9 & 4.7 & 3.5 & 9.6 & 10.1 & 22.1 & 49.9 & 10.4 & 33.7 & 23.5 & 26.5 & 55.9 & 25.8 \\
\hline 206.95 & RICE_3yr_261 & 7.9 & 15.5 & 11.0 & 20.9 & 17.7 & 32.9 & 20.8 & 33.3 & 29.5 & 24.1 & 41.2 & 14.9 & 45.4 & 47.7 \\
\hline 207.41 & RICE_3yr_262 & 0.9 & 6.7 & 2.7 & 5.0 & 14.4 & 29.9 & 17.1 & 16.8 & 24.0 & 32.5 & 24.2 & 24.8 & 41.0 & 25.0 \\
\hline 207.85 & RICE_3yr_263 & 2.6 & 6.1 & 3.6 & 7.5 & 17.6 & 23.5 & 25.1 & 31.3 & 26.4 & 19.1 & 44.1 & 17.6 & 37.8 & 30.0 \\
\hline 208.30 & RICE_3yr_264 & 1.9 & 6.7 & 4.1 & 14.2 & 14.5 & 15.5 & 29.8 & 30.3 & 16.1 & 23.4 & 19.9 & 24.4 & 47.1 & 43.5 \\
\hline 208.72 & RICE_3yr_265 & 2.3 & 3.3 & 3.3 & 10.3 & 9.9 & 14.4 & 14.7 & 30.0 & 13.1 & 27.1 & 25.3 & 23.1 & 39.6 & 39.6 \\
\hline 209.19 & RICE_3yr_266 & 2.5 & 6.1 & 4.7 & 13.8 & 18.5 & 22.7 & 21.4 & 42.5 & 21.6 & 16.6 & 21.7 & 37.1 & 31.4 & 22.9 \\
\hline 209.61 & RICE_3yr_267 & 2.1 & 4.3 & 3.1 & 11.6 & 7.5 & 16.1 & 28.6 & 34.9 & 29.0 & 34.6 & 29.5 & 49.3 & 35.0 & 40.1 \\
\hline 210.04 & RICE_3yr_268 & 1.9 & 3.6 & 2.3 & 11.2 & 21.7 & 51.6 & 22.3 & 35.2 & 26.7 & 25.4 & 29.6 & 51.4 & 45.5 & 51.1 \\
\hline 210.49 & RICE_3yr_269 & 1.3 & 5.3 & 2.6 & 6.2 & 17.0 & 33.4 & 23.9 & 37.8 & 20.4 & 31.4 & 26.1 & 32.6 & 50.8 & 29.7 \\
\hline 210.93 & RICE_3yr_270 & 1.6 & 3.2 & 2.9 & 8.4 & 5.9 & 20.3 & 26.3 & 22.9 & 32.2 & 30.7 & 29.2 & 31.6 & 61.5 & 66.1 \\
\hline 211.38 & RICE_3yr_271 & 1.5 & 5.2 & 2.8 & 11.8 & 6.5 & 15.8 & 28.7 & 58.6 & 32.2 & 39.7 & 13.4 & 39.4 & 44.0 & 34.5 \\
\hline 211.80 & RICE_3yr_272 & 2.5 & 4.3 & 3.8 & 8.8 & 9.1 & 16.1 & 22.1 & 16.7 & 26.9 & 27.4 & 27.7 & 16.3 & 69.1 & 47.4 \\
\hline 212.25 & RICE_3yr_273 & 1.5 & 5.0 & 3.6 & 7.0 & 10.1 & 21.7 & 21.8 & 30.5 & 20.6 & 33.5 & 36.3 & 48.8 & 44.2 & 28.9 \\
\hline 212.67 & RICE_3yr_274 & 3.2 & 5.5 & 3.0 & 8.6 & 15.9 & 22.4 & 23.9 & 30.5 & 34.0 & 27.4 & 23.6 & 30.5 & 53.1 & 32.7 \\
\hline 213.08 & RICE_3yr_275 & 1.8 & 5.2 & 3.7 & 6.9 & 14.7 & 16.0 & 31.1 & 22.9 & 25.3 & 17.7 & 20.8 & 19.7 & 58.9 & 41.4 \\
\hline 213.51 & RICE_3yr_276 & 1.3 & 5.5 & 4.2 & 5.7 & 20.9 & 22.5 & 21.3 & 49.3 & 38.1 & 22.7 & 33.5 & 28.9 & 43.3 & 29.2 \\
\hline 213.94 & RICE_3yr_277 & 1.4 & 6.2 & 3.7 & 7.9 & 13.9 & 39.9 & 38.0 & 28.2 & 23.7 & 39.0 & 18.0 & 16.3 & 53.9 & 34.8 \\
\hline 214.39 & RICE_3yr_278 & 2.6 & 7.7 & 4.9 & 10.8 & 18.9 & 34.9 & 21.8 & 33.2 & 11.4 & 18.5 & 20.6 & 44.6 & 45.0 & 35.7 \\
\hline 214.78 & RICE_3yr_279 & 3.4 & 3.7 & 2.7 & 12.3 & 11.2 & 21.1 & 44.6 & 33.8 & 27.7 & 23.6 & 25.8 & 39.5 & 59.8 & 35.4 \\
\hline 215.23 & RICE_3yr_280 & 1.3 & 2.7 & 5.2 & 13.0 & 8.1 & 41.0 & 20.1 & 31.5 & 31.1 & 39.0 & 13.8 & 16.7 & 31.2 & 62.9 \\
\hline 215.66 & RICE_3yr_281 & 1.6 & 3.0 & 3.2 & 11.0 & 4.3 & 17.7 & 12.8 & 10.3 & 24.1 & 31.1 & 16.0 & 23.2 & 17.8 & 49.6 \\
\hline 216.07 & RICE_3yr_282 & 1.8 & 3.6 & 2.9 & 9.7 & 17.4 & 29.3 & 41.9 & 21.7 & 32.6 & 24.4 & 19.1 & 30.8 & 55.8 & 44.5 \\
\hline 216.50 & RICE_3yr_283 & 0.4 & 3.6 & 6.0 & 7.8 & 6.1 & 30.5 & 25.2 & 23.6 & 20.8 & 22.9 & 17.3 & 24.8 & 58.2 & 47.7 \\
\hline 216.92 & RICE_3yr_284 & 3.0 & 7.4 & 6.8 & 8.8 & 3.9 & 24.1 & 32.9 & 16.3 & 32.8 & 37.4 & 29.3 & 42.1 & 56.8 & 61.2 \\
\hline 217.32 & RICE_3yr_285 & 1.7 & 5.1 & 5.5 & 11.5 & 12.4 & 24.4 & 18.3 & 19.4 & 18.7 & 28.6 & 21.7 & 34.1 & 38.5 & 61.6 \\
\hline 217.77 & RICE_3yr_286 & 1.4 & 8.2 & 2.8 & 7.4 & 8.7 & 32.7 & 29.3 & 25.4 & 43.6 & 10.4 & 7.1 & 52.8 & 78.5 & 21.5 \\
\hline 218.17 & RICE_3yr_287 & 1.5 & 4.5 & 2.4 & 14.0 & 14.4 & 38.6 & 36.7 & 23.6 & 26.0 & 17.7 & 38.4 & 19.6 & 48.2 & 37.3 \\
\hline 218.61 & RICE_3yr_288 & 1.4 & 1.0 & 4.2 & 7.7 & 8.2 & 8.8 & 4.5 & 10.0 & 8.8 & 14.8 & 9.9 & 14.1 & 23.5 & 21.9 \\
\hline 219.00 & RICE_3yr_289 & 3.6 & 5.2 & 6.6 & 6.0 & 11.7 & 33.7 & 16.0 & 42.5 & 16.1 & 20.8 & 15.8 & 42.2 & 46.4 & 44.0 \\
\hline 219.43 & RICE_3yr_290 & 0.9 & 4.9 & 2.8 & 6.1 & 6.0 & 22.5 & 37.9 & 30.7 & 31.9 & 33.7 & 14.8 & 32.5 & 37.8 & 24.2 \\
\hline 219.85 & RICE_3yr_291 & 4.6 & 6.8 & 5.2 & 5.1 & 11.1 & 29.3 & 31.1 & 22.3 & 21.7 & 13.8 & 11.1 & 14.5 & 51.0 & 20.2 \\
\hline 220.28 & RICE_3yr_292 & 1.9 & 8.4 & 6.5 & 15.3 & 10.1 & 29.1 & 25.5 & 16.6 & 26.6 & 32.0 & 19.9 & 33.2 & 63.6 & 39.7 \\
\hline 220.66 & RICE_3yr_293 & 1.9 & 7.4 & 4.5 & 8.2 & 8.5 & 19.4 & 36.7 & 16.3 & 27.5 & 28.9 & 34.5 & 26.0 & 46.5 & 33.3 \\
\hline 221.11 & RICE_3yr_294 & 1.3 & 5.5 & 2.6 & 8.4 & 15.1 & 30.4 & 17.5 & 25.8 & 17.3 & 30.4 & 19.7 & 55.4 & 45.5 & 46.3 \\
\hline 221.52 & RICE_3yr_295 & 2.2 & 4.4 & 1.8 & 13.2 & 7.3 & 38.4 & 13.8 & 15.8 & 20.0 & 23.0 & 32.0 & 18.1 & 31.7 & 44.3 \\
\hline 221.91 & RICE_3yr_296 & 1.7 & 6.7 & 2.5 & 9.5 & 7.4 & 18.6 & 27.0 & 21.6 & 11.5 & 13.3 & 15.7 & 18.8 & 59.0 & 47.3 \\
\hline
\end{tabular}




\begin{tabular}{|c|c|c|c|c|c|c|c|c|c|c|c|c|c|c|c|}
\hline 222.33 & RICE_3yr_297 & 1.9 & 6.3 & 5.0 & 10.6 & 3.9 & 21.6 & 20.7 & 9.4 & 12.0 & 15.4 & 28.3 & 23.9 & 26.4 & 52.8 \\
\hline 222.71 & RICE_3yr_298 & 2.4 & 5.4 & 2.2 & 10.4 & 11.9 & 23.2 & 19.1 & 21.3 & 15.9 & 14.0 & 11.6 & 10.6 & 34.1 & 27.3 \\
\hline 223.16 & RICE_3yr_299 & 1.4 & 1.8 & 3.2 & 6.5 & 11.9 & 33.3 & 33.4 & 30.1 & 19.0 & 30.6 & 33.7 & 25.6 & 30.4 & 26.8 \\
\hline 223.54 & RICE_3yr_300 & 4.5 & 3.2 & 3.4 & 9.7 & 11.6 & 36.1 & 13.6 & 16.7 & 19.5 & 24.5 & 22.4 & 30.8 & 46.2 & 47.4 \\
\hline 223.96 & RICE_3yr_301 & 0.9 & 5.5 & 2.2 & 9.5 & 9.3 & 18.6 & 16.6 & 14.1 & 18.7 & 10.2 & 17.5 & 20.3 & 20.8 & 33.4 \\
\hline 224.35 & RICE_3yr_302 & 3.3 & 8.3 & 5.5 & 6.6 & 9.6 & 18.4 & 16.4 & 26.3 & 9.0 & 23.7 & 17.6 & 32.9 & 46.2 & 17.6 \\
\hline 224.76 & RICE_3yr_303 & 1.1 & 5.4 & 1.8 & 6.7 & 15.5 & 27.6 & 21.4 & 30.3 & 29.1 & 35.9 & 30.7 & 35.2 & 56.9 & 13.0 \\
\hline 225.14 & RICE_3yr_304 & 2.0 & 4.0 & 2.7 & 13.9 & 6.7 & 20.0 & 21.4 & 20.7 & 26.8 & 11.7 & 12.4 & 25.3 & 40.7 & 35.5 \\
\hline 225.54 & RICE_3yr_305 & 1.6 & 2.4 & 3.9 & 11.6 & 16.4 & 38.0 & 37.1 & 18.8 & 26.4 & 16.7 & 22.3 & 41.8 & 81.4 & 44.9 \\
\hline 225.96 & RICE_3yr_306 & 1.5 & 5.6 & 6.0 & 5.4 & 16.4 & 33.8 & 24.0 & 53.1 & 30.0 & 20.5 & 17.8 & 29.8 & 80.1 & 32.0 \\
\hline 226.42 & RICE_3yr_307 & 1.1 & 5.5 & 3.4 & 6.7 & 9.3 & 21.6 & 17.8 & 13.9 & 27.2 & 35.0 & 17.9 & 37.7 & 67.9 & 32.4 \\
\hline 226.79 & RICE_3yr_308 & 1.1 & 6.9 & 4.6 & 9.7 & 11.7 & 18.8 & 29.4 & 39.1 & 22.9 & 23.5 & 31.8 & 30.9 & 34.0 & 46.2 \\
\hline 227.22 & RICE_3yr_309 & 2.9 & 3.6 & 2.7 & 2.1 & 6.8 & 11.4 & 19.1 & 18.6 & 22.6 & 13.9 & 10.2 & 29.2 & 31.5 & 49.0 \\
\hline 227.58 & RICE_3yr_310 & 3.5 & 6.0 & 3.2 & 5.8 & 8.9 & 37.3 & 23.5 & 16.1 & 39.1 & 9.6 & 22.3 & 25.9 & 60.7 & 39.0 \\
\hline 228.00 & RICE_3yr_311 & 1.4 & 6.7 & 4.2 & 6.4 & 8.3 & 25.8 & 34.2 & 26.7 & 14.4 & 29.8 & 16.6 & 22.2 & 61.1 & 41.8 \\
\hline 228.41 & RICE_3yr_312 & 2.6 & 9.3 & 6.0 & 6.2 & 10.7 & 35.6 & 31.8 & 21.8 & 15.4 & 28.1 & 24.4 & 21.9 & 43.6 & 30.4 \\
\hline 228.77 & RICE_3yr_313 & 3.1 & 8.8 & 1.8 & 11.5 & 13.0 & 24.5 & 21.5 & 27.7 & 20.1 & 23.4 & 28.3 & 29.4 & 30.9 & 34.2 \\
\hline 229.17 & RICE_3yr_314 & 2.8 & 6.6 & 4.6 & 10.1 & 4.5 & 34.1 & 24.6 & 22.9 & 23.7 & 15.6 & 22.5 & 24.1 & 51.5 & 19.8 \\
\hline 229.57 & RICE_3yr_315 & 5.8 & 13.5 & 8.5 & 16.5 & 13.9 & 20.7 & 23.0 & 17.3 & 23.8 & 10.4 & 26.3 & 33.7 & 45.4 & 35.2 \\
\hline 229.97 & RICE_3yr_316 & 2.5 & 6.2 & 6.0 & 7.4 & 15.6 & 14.8 & 25.6 & 4.8 & 10.9 & 16.9 & 37.0 & 22.8 & 51.1 & 21.7 \\
\hline 230.37 & RICE_3yr_317 & 2.4 & 14.8 & 9.8 & 10.4 & 13.3 & 20.1 & 28.5 & 14.3 & 28.1 & 27.0 & 20.3 & 36.9 & 45.7 & 59.8 \\
\hline 230.76 & RICE_3yr_318 & 1.2 & 3.6 & 5.9 & 5.1 & 13.6 & 16.6 & 14.7 & 26.1 & 16.5 & 13.5 & 15.5 & 28.0 & 43.6 & 24.6 \\
\hline 231.12 & RICE_3yr_319 & 4.1 & 6.3 & 2.8 & 8.2 & 13.9 & 19.7 & 22.1 & 20.0 & 15.4 & 18.4 & 16.5 & 25.4 & 38.9 & 31.7 \\
\hline 231.53 & RICE_3yr_320 & 1.6 & 3.5 & 4.9 & 10.7 & 17.1 & 21.7 & 19.1 & 28.3 & 25.4 & 27.0 & 28.3 & 17.0 & 41.0 & 26.7 \\
\hline 231.90 & RICE_3yr_321 & 0.8 & 7.9 & 4.3 & 13.6 & 8.2 & 16.9 & 29.0 & 22.0 & 26.5 & 20.0 & 25.1 & 27.8 & 51.4 & 42.1 \\
\hline 232.33 & RICE_3yr_322 & 2.8 & 2.8 & 4.6 & 3.8 & 6.4 & 10.8 & 30.1 & 18.6 & 24.6 & 11.6 & 13.7 & 20.3 & 71.1 & 38.3 \\
\hline 232.71 & RICE_3yr_323 & 2.2 & 3.0 & 2.1 & 5.1 & 5.2 & 12.4 & 29.2 & 27.8 & 15.7 & 21.8 & 34.9 & 31.5 & 46.9 & 47.8 \\
\hline 233.07 & RICE_3yr_324 & 1.3 & 8.2 & 4.2 & 7.7 & 11.9 & 38.6 & 25.1 & 30.3 & 20.1 & 27.2 & 25.3 & 20.7 & 65.5 & 36.4 \\
\hline 233.45 & RICE_3yr_325 & 1.1 & 7.1 & 2.9 & 5.3 & 11.2 & 10.2 & 37.1 & 35.3 & 15.8 & 17.4 & 11.4 & 21.9 & 40.3 & 22.7 \\
\hline 233.85 & RICE_3yr_326 & 2.6 & 7.2 & 7.0 & 16.3 & 15.7 & 19.9 & 20.1 & 33.9 & 23.7 & 22.8 & 30.1 & 27.3 & 12.3 & 39.7 \\
\hline 234.25 & RICE_3yr_327 & 3.4 & 11.0 & 7.5 & 9.5 & 10.9 & 18.2 & 21.8 & 10.0 & 12.4 & 20.8 & 29.8 & 30.9 & 36.7 & 48.0 \\
\hline 234.63 & RICE_3yr_328 & 0.6 & 6.2 & 5.9 & 13.3 & 8.3 & 30.4 & 21.0 & 26.0 & 22.2 & 16.8 & 28.7 & 21.5 & 46.1 & 30.6 \\
\hline 235.02 & RICE_3yr_329 & 3.8 & 5.0 & 5.8 & 14.1 & 12.9 & 46.1 & 14.8 & 14.0 & 29.1 & 28.4 & 16.8 & 21.7 & 56.4 & 53.9 \\
\hline 235.36 & RICE_3yr_330 & 2.5 & 4.6 & 6.3 & 9.9 & 9.0 & 21.0 & 33.0 & 16.9 & 26.8 & 21.3 & 19.3 & 20.0 & 26.1 & 42.2 \\
\hline 235.75 & RICE_3yr_331 & 1.5 & 5.9 & 5.3 & 3.9 & 13.9 & 24.3 & 35.3 & 32.3 & 46.1 & 37.1 & 28.8 & 46.4 & 35.2 & 54.8 \\
\hline 236.14 & RICE_3yr_332 & 1.8 & 5.0 & 3.2 & 8.4 & 12.3 & 25.2 & 24.2 & 34.4 & 38.4 & 34.3 & 25.1 & 20.8 & 66.7 & 57.9 \\
\hline 236.49 & RICE_3yr_333 & 1.8 & 9.2 & 6.8 & 9.8 & 11.5 & 26.5 & 31.3 & 15.5 & 14.7 & 22.6 & 13.7 & 30.2 & 49.3 & 21.1 \\
\hline 236.88 & RICE_3yr_334 & 2.9 & 2.3 & 3.5 & 2.6 & 5.1 & 18.3 & 17.8 & 13.7 & 13.8 & 8.4 & 13.9 & 14.6 & 12.2 & 24.8 \\
\hline 237.29 & RICE_3yr_335 & 2.8 & 9.6 & 11.9 & 8.7 & 26.1 & 31.6 & 22.1 & 36.8 & 15.3 & 23.2 & 25.7 & 39.5 & 42.2 & 30.2 \\
\hline 237.64 & RICE_3yr_336 & 3.1 & 8.6 & 3.4 & 5.0 & 8.6 & 25.6 & 25.8 & 9.6 & 31.4 & 23.3 & 28.4 & 16.7 & 45.2 & 56.1 \\
\hline 238.03 & RICE_3yr_337 & 2.0 & 3.9 & 4.4 & 11.6 & 10.9 & 24.8 & 13.7 & 18.9 & 31.0 & 29.9 & 24.2 & 25.2 & 34.1 & 44.7 \\
\hline 238.39 & RICE_3yr_338 & 1.1 & 6.5 & 3.8 & 15.9 & 7.0 & 22.1 & 28.5 & 31.5 & 19.1 & 30.9 & 35.2 & 39.0 & 75.7 & 43.9 \\
\hline 238.78 & RICE_3yr_339 & 2.3 & 4.6 & 3.6 & 8.9 & 15.0 & 18.2 & 21.9 & 30.7 & 19.5 & 35.3 & 27.0 & 23.9 & 40.8 & 41.3 \\
\hline 239.15 & RICE_3yr_340 & 2.1 & 13.3 & 8.6 & 9.4 & 10.6 & 19.2 & 24.0 & 31.5 & 29.9 & 27.0 & 17.4 & 20.4 & 17.9 & 23.1 \\
\hline 239.51 & RICE_3yr_341 & 2.7 & 9.9 & 4.5 & 12.3 & 19.0 & 16.1 & 27.1 & 35.7 & 38.8 & 33.9 & 25.0 & 45.6 & 55.7 & 60.5 \\
\hline 239.86 & RICE_3yr_342 & 1.7 & 5.8 & 3.2 & 5.2 & 7.7 & 25.1 & 16.5 & 23.2 & 13.6 & 27.8 & 28.3 & 28.5 & 38.1 & 79.5 \\
\hline 240.23 & RICE_3yr_343 & 1.6 & 6.0 & 8.9 & 15.2 & 18.4 & 24.3 & 36.7 & 18.8 & 26.6 & 29.5 & 26.0 & 33.8 & 76.8 & 35.2 \\
\hline 240.60 & RICE_3yr_344 & 2.0 & 1.5 & 4.7 & 15.9 & 17.6 & 28.2 & 37.1 & 37.3 & 24.4 & 33.3 & 26.3 & 24.3 & 31.9 & 63.8 \\
\hline 240.96 & RICE_3yr_345 & 2.3 & 9.2 & 5.8 & 6.6 & 10.8 & 20.2 & 13.1 & 10.6 & 17.8 & 11.0 & 17.1 & 10.7 & 21.4 & 31.3 \\
\hline 241.37 & RICE_3yr_346 & 1.2 & 9.6 & 4.6 & 15.3 & 18.4 & 49.1 & 32.1 & 22.3 & 19.8 & 22.4 & 16.6 & 29.3 & 68.8 & 50.7 \\
\hline 241.69 & RICE_3yr_347 & 1.5 & 4.2 & 8.4 & 14.3 & 10.5 & 43.8 & 33.3 & 24.6 & 30.2 & 32.9 & 10.3 & 18.5 & 79.4 & 40.0 \\
\hline 242.07 & RICE_3yr_348 & 3.3 & 7.4 & 8.4 & 6.4 & 18.6 & 29.0 & 39.6 & 41.2 & 17.6 & 34.7 & 34.2 & 22.4 & 49.4 & 42.3 \\
\hline 242.46 & RICE_3yr_349 & 1.7 & 8.2 & 10.6 & 16.3 & 21.6 & 24.2 & 20.1 & 26.4 & 25.9 & 25.9 & 12.6 & 33.1 & 29.7 & 23.1 \\
\hline 242.79 & RICE_3yr_350 & 2.0 & 14.4 & 13.7 & 15.2 & 10.2 & 34.1 & 31.2 & 24.0 & 20.7 & 14.0 & 42.4 & 30.6 & 18.1 & 34.1 \\
\hline 243.15 & RICE_3yr_351 & 4.1 & 6.1 & 3.3 & 14.6 & 14.9 & 26.4 & 25.8 & 33.7 & 40.5 & 14.5 & 25.2 & 43.2 & 74.1 & 51.4 \\
\hline 243.54 & RICE_3yr_352 & 1.2 & 9.8 & 7.9 & 4.1 & 12.4 & 29.2 & 25.9 & 19.8 & 15.1 & 25.2 & 30.6 & 38.5 & 42.3 & 58.6 \\
\hline 243.89 & RICE_3yr_353 & 2.1 & 6.5 & 6.6 & 9.6 & 9.1 & 24.5 & 29.3 & 37.9 & 27.3 & 15.0 & 23.4 & 30.2 & 27.6 & 57.0 \\
\hline 244.24 & RICE_3yr_354 & 1.2 & 5.8 & 4.7 & 9.2 & 8.5 & 22.9 & 28.4 & 21.4 & 15.3 & 18.4 & 21.1 & 15.9 & 17.8 & 46.3 \\
\hline 244.63 & RICE_3yr_355 & 1.1 & 8.8 & 6.7 & 11.6 & 6.4 & 45.5 & 18.0 & 19.9 & 16.9 & 13.5 & 17.1 & 19.7 & 28.1 & 30.1 \\
\hline 245.00 & RICE_3yr_356 & 2.5 & 11.1 & 11.3 & 10.0 & 21.0 & 38.1 & 28.5 & 20.6 & 33.2 & 24.5 & 28.7 & 15.2 & 83.7 & 34.0 \\
\hline 245.35 & RICE_3yr_357 & 2.2 & 8.6 & 4.1 & 7.7 & 14.6 & 25.6 & 31.3 & 14.3 & 26.4 & 19.9 & 29.6 & 28.7 & 72.5 & 48.6 \\
\hline 245.68 & RICE_3yr_358 & 1.3 & 4.9 & 5.6 & 9.1 & 9.0 & 14.5 & 23.7 & 22.4 & 23.3 & 21.9 & 31.6 & 56.0 & 36.4 & 40.5 \\
\hline 246.07 & RICE_3yr_359 & 2.1 & 2.9 & 3.9 & 12.3 & 24.2 & 25.1 & 21.6 & 32.3 & 44.1 & 16.9 & 22.5 & 28.5 & 54.8 & 45.8 \\
\hline
\end{tabular}




\begin{tabular}{|c|c|c|c|c|c|c|c|c|c|c|c|c|c|c|c|}
\hline 246.40 & RICE_3yr_360 & 2.3 & 5.4 & 6.2 & 7.7 & 5.5 & 26.9 & 19.5 & 22.8 & 18.4 & 21.4 & 15.0 & 14.8 & 13.5 & 39.5 \\
\hline 246.78 & RICE_3yr_361 & 1.8 & 2.9 & 2.2 & 5.9 & 9.2 & 17.4 & 19.1 & 14.8 & 22.9 & 20.2 & 17.3 & 16.5 & 15.6 & 10.3 \\
\hline 247.14 & RICE_3yr_362 & 2.9 & 5.9 & 3.2 & 8.4 & 12.4 & 31.0 & 25.5 & 26.3 & 17.6 & 30.8 & 24.3 & 21.7 & 21.6 & 30.3 \\
\hline 247.48 & RICE_3yr_363 & 3.7 & 4.2 & 3.7 & 8.5 & 11.8 & 16.0 & 11.3 & 13.0 & 19.1 & 14.3 & 22.8 & 27.7 & 32.4 & 31.5 \\
\hline 247.85 & RICE_3yr_364 & 1.8 & 4.9 & 4.3 & 7.7 & 12.9 & 31.8 & 30.9 & 33.4 & 27.1 & 23.8 & 17.9 & 24.1 & 38.6 & 34.4 \\
\hline 248.17 & RICE_3yr_365 & 2.4 & 4.3 & 3.4 & 6.3 & 9.5 & 16.8 & 15.9 & 26.8 & 20.2 & 21.8 & 12.8 & 16.2 & 39.2 & 17.5 \\
\hline 248.54 & RICE_3yr_366 & 1.3 & 2.8 & 3.3 & 7.1 & 11.0 & 28.3 & 15.5 & 21.6 & 10.3 & 19.0 & 22.7 & 25.6 & 35.8 & 18.2 \\
\hline 248.88 & RICE_3yr_367 & 1.2 & 4.6 & 4.1 & 4.8 & 12.6 & 9.3 & 23.9 & 11.9 & 33.7 & 18.3 & 11.2 & 22.8 & 19.8 & 26.1 \\
\hline 249.25 & RICE_3yr_368 & 3.0 & 8.9 & 4.9 & 11.9 & 10.1 & 42.9 & 30.1 & 39.4 & 37.2 & 49.6 & 22.5 & 50.4 & 44.8 & 28.2 \\
\hline 249.59 & RICE_3yr_369 & 1.6 & 4.3 & 6.7 & 12.9 & 16.4 & 30.1 & 19.9 & 19.5 & 25.7 & 18.9 & 21.3 & 32.5 & 33.5 & 31.9 \\
\hline 249.97 & RICE_3yr_370 & 1.6 & 4.8 & 3.6 & 12.5 & 10.3 & 17.6 & 15.6 & 19.3 & 22.4 & 5.8 & 17.4 & 28.1 & 13.6 & 24.1 \\
\hline 250.28 & RICE_3yr_371 & 10.9 & 17.8 & 3.5 & 10.9 & 3.7 & 13.5 & 7.7 & 13.3 & 10.5 & 11.9 & 10.1 & 6.6 & 18.2 & 11.9 \\
\hline 250.65 & RICE_3yr_372 & 6.6 & 8.4 & 3.6 & 7.6 & 8.3 & 45.0 & 32.3 & 36.6 & 19.2 & 24.7 & 26.0 & 23.7 & 63.4 & 73.6 \\
\hline 250.97 & RICE_3yr_373 & 3.8 & 3.9 & 5.5 & 8.5 & 17.7 & 25.4 & 29.5 & 26.9 & 30.4 & 16.2 & 20.5 & 43.3 & 34.0 & 75.2 \\
\hline 251.34 & RICE_3yr_374 & 3.7 & 8.1 & 5.7 & 15.8 & 16.1 & 35.3 & 44.4 & 39.4 & 18.9 & 19.5 & 15.5 & 34.8 & 47.6 & 48.4 \\
\hline 251.66 & RICE_3yr_375 & 3.1 & 7.5 & 5.9 & 11.9 & 14.4 & 31.2 & 16.2 & 35.9 & 25.5 & 18.8 & 23.8 & 34.9 & 33.2 & 57.1 \\
\hline 252.03 & RICE_3yr_376 & 0.5 & 6.7 & 6.8 & 12.3 & 9.5 & 24.4 & 20.1 & 28.2 & 24.1 & 16.6 & 17.3 & 30.0 & 29.4 & 64.4 \\
\hline 252.38 & RICE_3yr_377 & 1.7 & 6.4 & 2.3 & 8.2 & 6.8 & 37.5 & 39.3 & 25.6 & 15.5 & 35.8 & 14.0 & 19.5 & 43.8 & 30.8 \\
\hline 252.76 & RICE_3yr_378 & 1.6 & 2.2 & 3.2 & 7.8 & 13.6 & 33.6 & 13.8 & 7.2 & 38.3 & 19.2 & 23.4 & 49.8 & 35.7 & 29.7 \\
\hline 253.08 & RICE_3yr_379 & 3.1 & 3.6 & 5.4 & 11.1 & 16.5 & 24.1 & 22.0 & 32.4 & 49.9 & 32.9 & 25.5 & 55.3 & 48.8 & 41.5 \\
\hline 253.44 & RICE_3yr_380 & 1.6 & 5.5 & 5.2 & 19.9 & 15.8 & 25.0 & 44.2 & 37.6 & 21.3 & 23.0 & 33.9 & 17.2 & 57.7 & 47.6 \\
\hline 253.77 & RICE_3yr_381 & 3.9 & 7.3 & 3.2 & 16.4 & 12.1 & 26.7 & 30.8 & 30.1 & 24.7 & 17.1 & 20.7 & 47.8 & 66.1 & 24.0 \\
\hline 254.14 & RICE_3yr_382 & 3.3 & 3.1 & 3.2 & 4.0 & 17.8 & 18.8 & 18.6 & 21.4 & 23.0 & 14.3 & 29.1 & 21.5 & 23.4 & 24.3 \\
\hline 254.46 & RICE_3yr_383 & 0.8 & 3.1 & 3.0 & 4.1 & 11.0 & 20.8 & 28.7 & 18.7 & 25.4 & 20.5 & 17.1 & 26.0 & 58.6 & 30.5 \\
\hline 254.80 & RICE_3yr_384 & 2.6 & 7.0 & 4.9 & 9.4 & 11.7 & 32.8 & 30.3 & 28.1 & 15.9 & 33.2 & 32.6 & 23.4 & 28.5 & 36.3 \\
\hline 255.13 & RICE_3yr_385 & 3.1 & 3.5 & 2.8 & 10.2 & 15.6 & 28.1 & 46.3 & 25.8 & 16.5 & 35.5 & 20.5 & 26.7 & 46.0 & 61.9 \\
\hline 255.47 & RICE_3yr_386 & 3.3 & 2.6 & 7.7 & 11.0 & 17.0 & 30.9 & 47.3 & 31.8 & 16.8 & 36.8 & 25.5 & 56.3 & 48.0 & 29.1 \\
\hline 255.80 & RICE_3yr_387 & 3.6 & 4.8 & 3.8 & 10.9 & 7.5 & 17.9 & 11.8 & 31.9 & 20.1 & 26.8 & 28.2 & 33.4 & 55.5 & 37.4 \\
\hline 256.13 & RICE_3yr_388 & 3.3 & 6.9 & 7.5 & 9.1 & 7.1 & 37.9 & 20.6 & 26.1 & 11.3 & 13.3 & 10.1 & 34.8 & 33.0 & 45.6 \\
\hline 256.49 & RICE_3yr_389 & 2.9 & 5.9 & 6.1 & 8.0 & 10.1 & 19.7 & 26.6 & 17.8 & 19.6 & 19.7 & 20.4 & 35.3 & 53.7 & 39.2 \\
\hline 256.80 & RICE_3yr_390 & 2.0 & 3.1 & 1.4 & 13.0 & 7.2 & 13.2 & 26.1 & 23.0 & 15.9 & 32.8 & 26.7 & 41.0 & 64.2 & 24.0 \\
\hline 257.15 & RICE_3yr_391 & 1.4 & 3.4 & 1.9 & 4.1 & 4.5 & 15.0 & 21.2 & 21.6 & 26.8 & 12.4 & 10.4 & 23.2 & 34.3 & 23.4 \\
\hline 257.49 & RICE_3yr_392 & 3.6 & 13.9 & 5.3 & 4.0 & 7.5 & 21.4 & 27.6 & 23.5 & 34.2 & 36.5 & 28.3 & 31.1 & 40.0 & 53.5 \\
\hline 257.80 & RICE_3yr_393 & 2.1 & 6.9 & 6.6 & 5.6 & 6.1 & 27.9 & 23.8 & 26.0 & 19.1 & 36.6 & 24.5 & 31.7 & 52.6 & 42.8 \\
\hline 258.14 & RICE_3yr_394 & 1.5 & 5.2 & 4.0 & 8.9 & 4.7 & 32.9 & 13.2 & 13.5 & 27.2 & 31.1 & 19.7 & 40.4 & 27.7 & 39.3 \\
\hline 258.47 & RICE_3yr_395 & 2.4 & 4.9 & 3.4 & 7.2 & 14.2 & 32.1 & 34.9 & 21.6 & 9.4 & 35.1 & 19.1 & 24.6 & 22.3 & 44.4 \\
\hline 258.81 & RICE_3yr_396 & 4.2 & 6.8 & 4.4 & 6.2 & 10.5 & 22.5 & 24.6 & 15.3 & 24.3 & 32.8 & 24.8 & 15.1 & 64.8 & 28.8 \\
\hline 259.14 & RICE_3yr_397 & 4.1 & 7.4 & 3.1 & 10.0 & 14.2 & 29.0 & 23.9 & 24.6 & 31.4 & 25.5 & 27.0 & 21.9 & 98.4 & 33.2 \\
\hline 259.47 & RICE_3yr_398 & 1.8 & 5.5 & 4.5 & 5.4 & 6.5 & 17.4 & 40.8 & 22.6 & 18.1 & 31.7 & 14.0 & 28.2 & 26.8 & 35.9 \\
\hline 259.82 & RICE_3yr_399 & 2.0 & 8.3 & 5.5 & 14.3 & 7.2 & 17.6 & 34.8 & 22.1 & 30.0 & 31.4 & 17.8 & 37.6 & 63.8 & 39.5 \\
\hline 260.13 & RICE_3yr_400 & 1.5 & 2.1 & 2.7 & 10.2 & 10.5 & 31.8 & 21.4 & 20.8 & 29.3 & 21.9 & 25.1 & 40.8 & 32.0 & 63.7 \\
\hline 260.44 & RICE_3yr_401 & 1.4 & 5.4 & 3.8 & 10.8 & 12.8 & 20.7 & 17.9 & 21.5 & 22.2 & 16.9 & 10.0 & 23.1 & 16.7 & 36.4 \\
\hline 260.76 & RICE_3yr_402 & 2.8 & 6.5 & 5.4 & 8.9 & 12.1 & 19.7 & 37.6 & 14.5 & 25.1 & 31.1 & 18.2 & 21.2 & 48.9 & 46.4 \\
\hline 261.14 & RICE_3yr_403 & 2.2 & 6.3 & 3.3 & 6.1 & 10.5 & 18.4 & 17.6 & 14.5 & 18.4 & 21.6 & 15.0 & 13.1 & 23.2 & 40.3 \\
\hline 261.47 & RICE_3yr_404 & 3.2 & 4.5 & 7.5 & 11.1 & 15.0 & 32.8 & 18.5 & 26.1 & 32.4 & 21.7 & 27.7 & 25.9 & 34.8 & 29.2 \\
\hline 261.81 & RICE_3yr_405 & 2.1 & 3.7 & 1.5 & 5.6 & 7.2 & 26.7 & 29.2 & 15.1 & 23.3 & 13.6 & 12.7 & 11.8 & 27.5 & 25.9 \\
\hline 262.14 & RICE_3yr_406 & 2.8 & 8.8 & 2.4 & 10.1 & 10.0 & 16.0 & 19.1 & 36.0 & 7.4 & 27.6 & 13.8 & 37.1 & 63.8 & 43.2 \\
\hline 262.46 & RICE_3yr_407 & 2.1 & 3.4 & 3.5 & 12.8 & 10.7 & 19.5 & 27.2 & 23.7 & 34.4 & 22.2 & 24.9 & 29.5 & 36.6 & 25.3 \\
\hline 262.77 & RICE_3yr_408 & 1.6 & 3.9 & 3.1 & 8.0 & 8.4 & 23.8 & 32.8 & 11.3 & 23.4 & 16.0 & 23.3 & 28.9 & 44.4 & 51.4 \\
\hline 263.09 & RICE_3yr_409 & 3.0 & 3.8 & 7.2 & 17.1 & 14.3 & 36.2 & 34.9 & 12.8 & 25.5 & 27.4 & 19.3 & 24.9 & 33.1 & 49.2 \\
\hline 263.42 & RICE_3yr_410 & 2.7 & 3.4 & 2.2 & 3.4 & 11.6 & 25.5 & 35.1 & 12.8 & 27.1 & 36.3 & 23.5 & 22.0 & 55.7 & 30.2 \\
\hline 263.75 & RICE_3yr_411 & 1.5 & 4.3 & 2.4 & 10.2 & 12.3 & 11.9 & 38.8 & 28.7 & 18.0 & 9.8 & 15.0 & 25.1 & 55.3 & 30.4 \\
\hline 264.08 & RICE_3yr_412 & 4.0 & 7.4 & 4.9 & 10.3 & 10.4 & 23.6 & 30.0 & 34.7 & 12.6 & 32.0 & 19.4 & 33.4 & 67.7 & 48.7 \\
\hline 264.41 & RICE_3yr_413 & 2.1 & 5.2 & 4.6 & 11.7 & 10.3 & 24.6 & 22.0 & 31.8 & 31.5 & 25.4 & 12.0 & 36.1 & 51.9 & 39.3 \\
\hline 264.75 & RICE_3yr_414 & 1.2 & 4.7 & 2.4 & 9.2 & 7.8 & 20.5 & 28.0 & 31.6 & 22.3 & 16.9 & 21.4 & 16.5 & 61.2 & 56.4 \\
\hline 265.04 & RICE_3yr_415 & 3.9 & 4.2 & 5.5 & 6.6 & 5.6 & 26.0 & 16.8 & 28.1 & 5.8 & 38.3 & 23.2 & 40.3 & 20.0 & 40.0 \\
\hline 265.34 & RICE_3yr_416 & 1.9 & 8.0 & 5.4 & 11.2 & 7.8 & 14.2 & 18.6 & 23.1 & 30.1 & 27.6 & 31.4 & 33.6 & 42.9 & 48.5 \\
\hline 265.66 & RICE_3yr_417 & 1.7 & 5.3 & 4.8 & 7.1 & 12.4 & 36.7 & 23.1 & 9.3 & 34.6 & 35.2 & 26.9 & 43.5 & 46.8 & 38.2 \\
\hline 265.98 & RICE_3yr_418 & 1.2 & 4.4 & 3.2 & 16.8 & 13.0 & 23.0 & 18.9 & 30.5 & 17.5 & 16.9 & 9.5 & 12.9 & 30.5 & 24.1 \\
\hline 266.30 & RICE_3yr_419 & 1.8 & 4.8 & 1.9 & 6.9 & 14.0 & 38.5 & 14.5 & 26.8 & 28.4 & 30.2 & 19.1 & 10.6 & 27.4 & 26.9 \\
\hline 266.58 & RICE_3yr_420 & 2.5 & 2.1 & 2.6 & 6.6 & 8.9 & 19.8 & 28.6 & 20.8 & 20.9 & 20.4 & 20.9 & 34.3 & 20.6 & 33.4 \\
\hline 266.91 & RICE_3yr_421 & 1.3 & 2.5 & 2.0 & 4.8 & 4.4 & 13.7 & 11.1 & 16.7 & 18.2 & 16.2 & 14.1 & 22.2 & 28.8 & 16.1 \\
\hline 267.21 & RICE_3yr_422 & 3.8 & 4.4 & 3.7 & 15.0 & 8.4 & 23.9 & 29.0 & 24.1 & 32.6 & 17.2 & 24.4 & 25.3 & 74.5 & 50.3 \\
\hline
\end{tabular}




\begin{tabular}{|c|c|c|c|c|c|c|c|c|c|c|c|c|c|c|c|}
\hline 267.54 & RICE_3yr_423 & 2.7 & 7.3 & 4.6 & 16.6 & 8.4 & 24.1 & 32.6 & 31.4 & 17.8 & 18.0 & 28.4 & 17.3 & 65.3 & 38.9 \\
\hline 267.84 & RICE_3yr_424 & 3.2 & 3.5 & 3.2 & 14.1 & 4.9 & 16.1 & 18.2 & 23.8 & 19.4 & 9.3 & 12.9 & 19.9 & 31.0 & 40.3 \\
\hline 268.19 & RICE_3yr_425 & 1.7 & 5.1 & 5.6 & 14.6 & 10.8 & 30.5 & 16.9 & 41.8 & 47.4 & 29.1 & 8.0 & 37.6 & 36.5 & 46.7 \\
\hline 268.47 & RICE_3yr_426 & 0.9 & 5.9 & 2.7 & 9.7 & 9.0 & 30.3 & 27.7 & 24.9 & 11.6 & 27.2 & 12.8 & 32.2 & 19.0 & 31.0 \\
\hline 268.79 & RICE_3yr_427 & 3.7 & 5.2 & 4.4 & 7.5 & 6.7 & 24.1 & 24.6 & 38.1 & 20.6 & 22.7 & 19.0 & 18.8 & 68.6 & 17.9 \\
\hline 269.09 & RICE_3yr_428 & 1.1 & 3.2 & 3.0 & 10.2 & 7.1 & 34.3 & 17.2 & 25.2 & 33.9 & 16.1 & 15.9 & 30.3 & 52.5 & 18.8 \\
\hline 269.40 & RICE_3yr_429 & 1.9 & 4.4 & 2.7 & 12.0 & 15.7 & 24.4 & 24.8 & 37.9 & 23.4 & 21.4 & 21.4 & 36.0 & 66.4 & 29.9 \\
\hline 269.72 & RICE_3yr_430 & 3.1 & 3.1 & 3.4 & 9.9 & 8.7 & 24.8 & 30.1 & 32.1 & 20.8 & 24.8 & 18.7 & 14.2 & 59.2 & 32.2 \\
\hline 270.05 & RICE_3yr_431 & 1.1 & 6.1 & 2.5 & 5.2 & 8.8 & 21.8 & 30.6 & 28.4 & 13.0 & 29.0 & 29.0 & 26.1 & 33.3 & 34.1 \\
\hline 270.34 & RICE_3yr_432 & 2.9 & 4.9 & 5.7 & 9.1 & 9.9 & 16.1 & 24.7 & 23.9 & 22.1 & 23.2 & 23.0 & 33.3 & 52.4 & 43.3 \\
\hline 270.65 & RICE_3yr_433 & 2.9 & 5.7 & 5.8 & 8.3 & 13.3 & 17.0 & 26.6 & 9.8 & 20.1 & 11.1 & 6.2 & 21.1 & 32.1 & 55.1 \\
\hline 270.96 & RICE_3yr_434 & 3.0 & 4.1 & 5.4 & 6.8 & 9.9 & 17.9 & 38.0 & 29.5 & 29.7 & 30.3 & 22.5 & 16.8 & 77.0 & 49.2 \\
\hline 271.27 & RICE_3yr_435 & 1.0 & 5.8 & 4.0 & 9.1 & 3.7 & 25.3 & 21.9 & 20.4 & 24.0 & 32.4 & 24.3 & 21.5 & 42.9 & 22.5 \\
\hline 271.56 & RICE_3yr_436 & 1.8 & 4.5 & 6.7 & 11.8 & 20.0 & 31.2 & 23.1 & 29.2 & 31.2 & 22.1 & 9.9 & 35.4 & 68.7 & 57.1 \\
\hline 271.86 & RICE_3yr_437 & 2.1 & 6.4 & 4.3 & 7.0 & 15.7 & 50.1 & 18.8 & 24.0 & 16.2 & 39.7 & 14.6 & 35.6 & 50.7 & 61.1 \\
\hline 272.20 & RICE_3yr_438 & 2.1 & 2.6 & 3.9 & 11.6 & 10.0 & 19.5 & 26.0 & 46.2 & 34.8 & 34.9 & 27.4 & 31.5 & 42.2 & 17.7 \\
\hline 272.47 & RICE_3yr_439 & 2.4 & 4.0 & 6.2 & 6.7 & 5.2 & 22.2 & 19.8 & 4.7 & 23.0 & 14.3 & 36.4 & 33.1 & 60.0 & 38.2 \\
\hline 272.82 & RICE_3yr_440 & 1.8 & 6.0 & 5.1 & 6.0 & 10.5 & 13.4 & 14.3 & 41.1 & 19.8 & 17.1 & 19.9 & 25.2 & 33.7 & 37.7 \\
\hline 273.10 & RICE_3yr_441 & 0.9 & 3.0 & 5.4 & 8.8 & 5.2 & 28.6 & 33.7 & 19.0 & 30.5 & 37.6 & 10.7 & 24.4 & 17.7 & 50.0 \\
\hline 273.39 & RICE_3yr_442 & 2.2 & 6.4 & 4.4 & 8.9 & 11.1 & 21.4 & 30.6 & 24.0 & 40.2 & 26.0 & 25.5 & 35.2 & 51.7 & 32.0 \\
\hline 273.70 & RICE_3yr_443 & 2.4 & 10.1 & 8.8 & 6.9 & 10.5 & 14.6 & 13.0 & 17.3 & 33.3 & 21.9 & 17.6 & 26.1 & 50.3 & 45.7 \\
\hline 274.01 & RICE_3yr_444 & 1.4 & 8.7 & 7.7 & 11.6 & 12.0 & 32.7 & 17.4 & 47.0 & 21.6 & 33.5 & 20.8 & 12.7 & 16.0 & 16.9 \\
\hline 274.30 & RICE_3yr_445 & 2.4 & 9.2 & 10.2 & 16.1 & 10.2 & 40.6 & 18.0 & 32.1 & 25.4 & 40.1 & 23.9 & 41.6 & 74.4 & 50.0 \\
\hline 274.62 & RICE_3yr_446 & 1.9 & 4.5 & 2.8 & 5.8 & 10.9 & 29.0 & 24.2 & 29.3 & 20.0 & 13.8 & 14.8 & 21.4 & 66.3 & 42.5 \\
\hline 274.88 & RICE_3yr_447 & 3.5 & 7.4 & 6.3 & 6.4 & 7.9 & 23.2 & 27.4 & 22.8 & 17.2 & 16.1 & 12.1 & 43.0 & 23.3 & 26.5 \\
\hline 275.19 & RICE_3yr_448 & 2.5 & 5.0 & 5.4 & 7.1 & 10.0 & 39.7 & 32.8 & 32.5 & 28.9 & 16.1 & 20.9 & 35.9 & 26.9 & 21.0 \\
\hline 275.51 & RICE_3yr_449 & 2.7 & 6.4 & 1.7 & 7.3 & 9.3 & 24.2 & 25.4 & 9.8 & 17.8 & 19.8 & 25.4 & 38.0 & 41.5 & 36.4 \\
\hline 275.82 & RICE_3yr_450 & 1.5 & 2.5 & 1.9 & 3.0 & 5.2 & 7.0 & 6.0 & 5.2 & 7.1 & 6.8 & 9.2 & 6.8 & 6.4 & 13.6 \\
\hline 276.12 & RICE_3yr_451 & 1.8 & 2.5 & 3.3 & 4.9 & 8.1 & 17.5 & 8.6 & 18.4 & 5.8 & 23.9 & 13.5 & 23.9 & 42.5 & 14.2 \\
\hline 276.40 & RICE_3yr_452 & 1.4 & 5.4 & 2.9 & 9.2 & 11.6 & 27.4 & 19.2 & 20.4 & 17.4 & 22.0 & 24.3 & 22.7 & 34.3 & 26.3 \\
\hline 276.72 & RICE_3yr_453 & 4.4 & 5.9 & 5.7 & 4.7 & 4.9 & 16.5 & 15.2 & 10.1 & 20.6 & 14.8 & 13.6 & 8.7 & 30.0 & 27.9 \\
\hline 276.98 & RICE_3yr_454 & 4.0 & 6.9 & 4.0 & 8.5 & 8.4 & 11.9 & 34.9 & 8.0 & 16.4 & 9.7 & 14.8 & 25.7 & 21.7 & 20.6 \\
\hline 277.28 & RICE_3yr_455 & 2.4 & 6.7 & 2.8 & 11.4 & 22.0 & 24.7 & 32.4 & 24.2 & 17.5 & 11.9 & 25.6 & 38.2 & 28.4 & 24.1 \\
\hline 277.60 & RICE_3yr_456 & 2.1 & 4.6 & 4.6 & 3.4 & 12.8 & 18.7 & 31.9 & 29.8 & 20.1 & 19.8 & 13.8 & 23.0 & 42.3 & 29.5 \\
\hline 277.89 & RICE_3yr_457 & 2.0 & 4.3 & 3.6 & 7.7 & 5.7 & 33.3 & 23.8 & 24.2 & 23.2 & 12.0 & 13.0 & 36.4 & 50.5 & 31.9 \\
\hline 278.20 & RICE_3yr_458 & 3.1 & 6.4 & 4.2 & 6.8 & 13.7 & 19.9 & 7.6 & 27.7 & 14.5 & 14.0 & 23.1 & 44.8 & 56.6 & 37.1 \\
\hline 278.48 & RICE_3yr_459 & 4.0 & 8.4 & 5.8 & 4.9 & 10.0 & 13.4 & 17.6 & 24.9 & 21.6 & 28.4 & 23.6 & 19.0 & 41.0 & 36.8 \\
\hline 278.76 & RICE_3yr_460 & 2.2 & 14.9 & 6.8 & 16.8 & 5.5 & 14.6 & 20.3 & 30.6 & 22.0 & 22.3 & 18.2 & 22.4 & 71.7 & 34.6 \\
\hline 279.06 & RICE_3yr_461 & 2.3 & 3.3 & 1.9 & 5.6 & 8.9 & 12.1 & 25.9 & 15.2 & 10.7 & 15.9 & 14.0 & 26.3 & 34.0 & 31.4 \\
\hline 279.35 & RICE_3yr_462 & 2.2 & 3.9 & 2.9 & 3.9 & 5.2 & 26.8 & 22.6 & 18.9 & 20.1 & 16.9 & 12.5 & 22.9 & 33.4 & 19.6 \\
\hline 279.63 & RICE_3yr_463 & 2.2 & 9.1 & 6.8 & 11.2 & 13.1 & 24.3 & 38.9 & 21.9 & 17.0 & 16.9 & 15.7 & 28.0 & 34.3 & 31.4 \\
\hline 279.91 & RICE_3yr_464 & 1.1 & 5.1 & 4.8 & 3.6 & 16.1 & 14.4 & 32.3 & 18.8 & 12.1 & 23.5 & 15.8 & 28.4 & 26.4 & 14.6 \\
\hline 280.21 & RICE_3yr_465 & 3.5 & 5.5 & 4.1 & 15.0 & 11.8 & 22.9 & 22.0 & 28.0 & 42.4 & 33.3 & 27.9 & 53.2 & 49.1 & 61.9 \\
\hline 280.51 & RICE_3yr_466 & 3.7 & 6.5 & 5.6 & 6.2 & 9.4 & 35.8 & 37.7 & 12.5 & 31.8 & 15.7 & 20.2 & 25.5 & 38.1 & 84.2 \\
\hline 280.77 & RICE_3yr_467 & 2.2 & 6.2 & 4.4 & 8.0 & 11.5 & 31.9 & 21.4 & 20.1 & 28.6 & 15.7 & 24.6 & 18.5 & 56.3 & 30.5 \\
\hline 281.06 & RICE_3yr_468 & 2.6 & 6.2 & 7.9 & 160.2 & 11.3 & 11.2 & 26.8 & 27.5 & 24.5 & 17.3 & 11.0 & 21.7 & 26.1 & 50.6 \\
\hline 281.35 & RICE_3yr_469 & 2.4 & 7.0 & 6.8 & 9.6 & 12.4 & 21.1 & 21.8 & 18.4 & 28.8 & 16.4 & 29.1 & 23.0 & 31.5 & 37.5 \\
\hline 281.65 & RICE_3yr_470 & 0.8 & 10.1 & 4.1 & 8.4 & 11.4 & 20.5 & 57.8 & 33.0 & 17.8 & 19.0 & 40.8 & 39.7 & 50.5 & 43.3 \\
\hline 281.91 & RICE_3yr_471 & 2.3 & 4.3 & 3.2 & 7.6 & 12.7 & 28.0 & 29.3 & 22.3 & 22.5 & 25.1 & 18.5 & 27.1 & 63.2 & 40.9 \\
\hline 282.23 & RICE_3yr_472 & 15.4 & 93.3 & 93.4 & 90.7 & 88.3 & 81.6 & 49.6 & 88.3 & 77.9 & 86.6 & 82.9 & 100.4 & 91.0 & 90.0 \\
\hline 282.48 & RICE_3yr_473 & 3.0 & 9.0 & 8.3 & 14.0 & 8.5 & 27.0 & 18.5 & 26.1 & 25.4 & 20.2 & 21.8 & 19.1 & 60.9 & 49.9 \\
\hline 282.79 & RICE_3yr_474 & 2.0 & 4.2 & 5.2 & 6.5 & 5.9 & 28.1 & 20.7 & 21.0 & 35.3 & 17.9 & 29.6 & 26.8 & 28.3 & 41.7 \\
\hline 283.05 & RICE_3yr_475 & 2.4 & 5.0 & 4.0 & 8.1 & 10.6 & 24.9 & 32.0 & 21.9 & 21.1 & 19.7 & 14.7 & 34.2 & 43.6 & 35.6 \\
\hline 283.32 & RICE_3yr_476 & 3.3 & 5.7 & 6.8 & 7.1 & 17.2 & 20.3 & 11.7 & 17.7 & 18.2 & 23.5 & 25.9 & 26.1 & 34.4 & 27.3 \\
\hline 283.64 & RICE_3yr_477 & 3.2 & 6.4 & 5.6 & 7.0 & 19.1 & 14.8 & 37.7 & 35.6 & 44.9 & 17.3 & 35.2 & 24.8 & 79.1 & 55.1 \\
\hline 283.89 & RICE_3yr_478 & 3.4 & 5.5 & 6.0 & 10.2 & 11.8 & 19.4 & 20.7 & 16.3 & 19.0 & 17.6 & 18.6 & 23.4 & 17.0 & 43.7 \\
\hline 284.18 & RICE_3yr_479 & 2.8 & 4.7 & 5.1 & 7.3 & 14.7 & 17.1 & 30.1 & 19.5 & 31.1 & 19.5 & 22.1 & 41.6 & 43.2 & 33.7 \\
\hline 284.45 & RICE_3yr_480 & 3.1 & 5.3 & 3.7 & 9.7 & 9.8 & 17.6 & 16.6 & 32.8 & 21.7 & 40.7 & 24.1 & 21.7 & 73.7 & 27.0 \\
\hline 284.74 & RICE_3yr_481 & 1.9 & 5.2 & 6.2 & 5.8 & 13.2 & 22.7 & 40.6 & 19.2 & 31.3 & 38.0 & 12.3 & 16.8 & 51.4 & 38.1 \\
\hline 285.02 & RICE_3yr_482 & 1.2 & 3.0 & 3.4 & 10.9 & 6.9 & 22.9 & 25.1 & 43.0 & 34.8 & 19.3 & 15.1 & 19.4 & 54.7 & 41.7 \\
\hline 285.32 & RICE_3yr_483 & 2.2 & 4.7 & 2.9 & 9.5 & 6.2 & 25.2 & 28.3 & 36.0 & 23.8 & 42.5 & 23.7 & 36.7 & 41.4 & 50.7 \\
\hline 285.57 & RICE_3yr_484 & 4.0 & 4.8 & 3.2 & 9.1 & 10.4 & 20.1 & 20.6 & 21.0 & 15.4 & 24.2 & 15.0 & 24.2 & 21.7 & 40.2 \\
\hline 285.86 & RICE_3yr_485 & 1.8 & 8.1 & 3.5 & 4.3 & 9.2 & 16.8 & 20.6 & 17.5 & 32.9 & 21.9 & 26.4 & 41.6 & 47.1 & 16.0 \\
\hline
\end{tabular}




\begin{tabular}{|c|c|c|c|c|c|c|c|c|c|c|c|c|c|c|c|}
\hline 286.15 & RICE_3yr_486 & 1.6 & 3.5 & 3.9 & 11.3 & 9.7 & 36.4 & 34.7 & 26.9 & 27.0 & 19.2 & 29.8 & 23.1 & 28.2 & 39.2 \\
\hline 286.41 & RICE_3yr_487 & 1.8 & 3.8 & 5.3 & 13.0 & 13.8 & 21.6 & 33.6 & 14.7 & 20.0 & 25.3 & 20.5 & 25.5 & 44.2 & 41.6 \\
\hline 286.68 & RICE_3yr_488 & 2.3 & 6.2 & 3.7 & 6.2 & 19.4 & 28.4 & 26.6 & 22.4 & 33.0 & 22.5 & 32.8 & 18.3 & 37.3 & 57.9 \\
\hline 286.99 & RICE_3yr_489 & 2.8 & 1.1 & 2.4 & 11.3 & 5.8 & 21.1 & 27.5 & 18.8 & 27.7 & 24.3 & 22.3 & 28.0 & 57.0 & 28.2 \\
\hline 287.28 & RICE_3yr_490 & 2.6 & 5.4 & 2.6 & 9.9 & 3.6 & 25.1 & 21.2 & 32.0 & 13.7 & 15.2 & 14.7 & 23.7 & 44.3 & 30.1 \\
\hline 287.55 & RICE_3yr_491 & 1.6 & 2.7 & 4.5 & 8.9 & 9.5 & 22.8 & 30.3 & 28.1 & 42.9 & 12.7 & 20.0 & 36.5 & 37.8 & 27.3 \\
\hline 287.80 & RICE_3yr_492 & 2.9 & 5.9 & 4.6 & 8.9 & 10.9 & 24.1 & 30.2 & 19.5 & 16.4 & 28.1 & 19.3 & 40.2 & 48.2 & 22.8 \\
\hline 288.05 & RICE_3yr_493 & 3.0 & 5.9 & 4.7 & 12.3 & 5.3 & 24.1 & 11.4 & 20.2 & 25.3 & 11.2 & 13.2 & 20.3 & 44.5 & 35.3 \\
\hline 288.36 & RICE_3yr_494 & 2.1 & 6.2 & 7.1 & 16.3 & 12.0 & 18.9 & 32.2 & 15.1 & 25.9 & 20.8 & 24.9 & 21.8 & 42.9 & 33.1 \\
\hline 288.63 & RICE_3yr_495 & 2.4 & 3.5 & 3.8 & 10.6 & 11.5 & 19.0 & 28.5 & 23.3 & 27.7 & 34.2 & 17.9 & 29.6 & 54.7 & 49.4 \\
\hline 288.90 & RICE_3yr_496 & 2.5 & 3.7 & 1.8 & 7.1 & 12.0 & 20.5 & 22.9 & 24.0 & 44.3 & 25.8 & 10.7 & 37.6 & 50.6 & 25.3 \\
\hline 289.19 & RICE_3yr_497 & 1.3 & 3.3 & 4.6 & 10.0 & 12.9 & 17.1 & 46.6 & 23.9 & 32.1 & 15.0 & 10.9 & 22.9 & 44.1 & 38.1 \\
\hline 289.35 & RICE_3yr_498 & 1.4 & 9.2 & 8.7 & 11.0 & 10.0 & 37.8 & 22.1 & 19.7 & 14.3 & 32.6 & 14.9 & 29.9 & 18.7 & 28.3 \\
\hline 289.70 & RICE_3yr_499 & 1.5 & 9.4 & 4.0 & 7.2 & 4.4 & 22.7 & 26.7 & 14.3 & 26.3 & 24.8 & 26.8 & 42.3 & 35.3 & 26.4 \\
\hline 289.98 & RICE_3yr_500 & 3.2 & 5.8 & 4.6 & 9.8 & 15.2 & 30.4 & 16.4 & 17.1 & 24.9 & 27.8 & 30.4 & 28.8 & 28.4 & 49.4 \\
\hline 290.25 & RICE_3yr_501 & 1.7 & 3.9 & 4.7 & 10.5 & 10.0 & 23.9 & 25.1 & 32.7 & 25.7 & 26.3 & 18.9 & 28.6 & 52.8 & 41.8 \\
\hline 290.51 & RICE_3yr_502 & 2.4 & 2.3 & 4.9 & 9.9 & 9.3 & 20.7 & 24.4 & 30.3 & 23.8 & 19.3 & 21.2 & 26.1 & 35.7 & 46.4 \\
\hline 290.78 & RICE_3yr_503 & 2.9 & 4.9 & 7.2 & 10.0 & 14.6 & 20.0 & 20.7 & 21.1 & 30.5 & 15.6 & 22.6 & 51.0 & 42.0 & 33.1 \\
\hline 291.06 & RICE_3yr_504 & 2.8 & 4.9 & 3.6 & 9.3 & 11.8 & 15.6 & 15.2 & 23.9 & 16.8 & 29.5 & 12.5 & 14.8 & 54.0 & 17.3 \\
\hline 291.32 & RICE_3yr_505 & 1.1 & 3.8 & 4.7 & 11.5 & 10.6 & 27.3 & 19.4 & 17.2 & 47.0 & 20.3 & 21.4 & 29.5 & 46.3 & 26.1 \\
\hline 291.57 & RICE_3yr_506 & 2.8 & 5.4 & 3.0 & 4.9 & 6.7 & 22.8 & 30.9 & 28.3 & 29.0 & 17.1 & 26.0 & 29.9 & 45.8 & 45.0 \\
\hline 291.86 & RICE_3yr_507 & 3.6 & 28.8 & 6.8 & 16.6 & 16.0 & 26.9 & 50.4 & 37.3 & 33.2 & 28.4 & 15.1 & 16.4 & 48.0 & 46.5 \\
\hline 292.12 & RICE_3yr_508 & 2.1 & 9.1 & 8.0 & 5.2 & 18.2 & 21.2 & 23.8 & 13.0 & 22.8 & 25.2 & 24.8 & 35.2 & 39.9 & 61.6 \\
\hline 292.38 & RICE_3yr_509 & 3.6 & 12.0 & 12.9 & 10.8 & 21.1 & 10.7 & 19.0 & 35.6 & 38.0 & 21.9 & 12.4 & 25.4 & 25.9 & 59.4 \\
\hline 292.63 & RICE_3yr_510 & 2.0 & 7.3 & 5.6 & 16.4 & 8.2 & 19.2 & 18.7 & 18.3 & 29.7 & 34.4 & 26.1 & 43.7 & 41.8 & 55.0 \\
\hline 292.94 & RICE_3yr_511 & 2.5 & 5.0 & 3.7 & 10.2 & 6.4 & 26.7 & 26.5 & 27.2 & 25.5 & 14.9 & 18.7 & 21.2 & 47.3 & 52.5 \\
\hline 293.17 & RICE_3yr_512 & 3.1 & 9.1 & 9.3 & 12.1 & 12.7 & 19.2 & 23.8 & 24.0 & 23.1 & 18.2 & 14.4 & 18.3 & 29.1 & 34.7 \\
\hline 293.42 & RICE_3yr_513 & 2.7 & 4.5 & 4.8 & 15.8 & 9.8 & 25.0 & 39.6 & 27.4 & 35.6 & 37.3 & 11.6 & 32.4 & 54.8 & 52.7 \\
\hline 293.71 & RICE_3yr_514 & 2.3 & 6.6 & 4.3 & 6.9 & 19.7 & 27.9 & 24.0 & 16.4 & 12.1 & 12.0 & 24.6 & 35.3 & 68.2 & 46.5 \\
\hline 293.97 & RICE_3yr_515 & 2.0 & 6.2 & 5.7 & 10.9 & 11.8 & 25.4 & 18.1 & 22.5 & 33.5 & 31.0 & 19.1 & 22.5 & 31.3 & 33.6 \\
\hline 294.25 & RICE_3yr_516 & 2.5 & 6.5 & 7.1 & 20.1 & 18.1 & 54.8 & 29.4 & 30.4 & 31.7 & 28.5 & 19.5 & 44.5 & 93.8 & 34.6 \\
\hline 294.50 & RICE_3yr_517 & 2.2 & 6.0 & 6.8 & 11.7 & 11.6 & 27.4 & 29.8 & 19.2 & 32.7 & 20.4 & 22.5 & 60.7 & 51.6 & 64.5 \\
\hline 294.76 & RICE_3yr_518 & 2.0 & 5.0 & 4.8 & 11.1 & 11.6 & 28.0 & 27.3 & 37.7 & 32.9 & 23.6 & 20.8 & 20.0 & 59.1 & 48.1 \\
\hline 295.02 & RICE_3yr_519 & 2.3 & 6.7 & 4.5 & 10.0 & 5.7 & 23.9 & 35.1 & 10.3 & 28.5 & 27.1 & 22.8 & 35.7 & 65.5 & 18.8 \\
\hline 295.29 & RICE_3yr_520 & 3.0 & 5.6 & 5.1 & 8.5 & 6.0 & 23.5 & 30.4 & 23.6 & 11.3 & 21.0 & 13.5 & 27.0 & 52.8 & 39.7 \\
\hline 295.57 & RICE_3yr_521 & 3.3 & 2.1 & 3.4 & 3.3 & 6.1 & 25.5 & 35.7 & 28.9 & 12.4 & 30.5 & 14.8 & 33.2 & 65.8 & 42.2 \\
\hline 295.85 & RICE_3yr_522 & 4.1 & 8.1 & 7.8 & 11.6 & 6.3 & 26.8 & 25.6 & 26.9 & 32.0 & 20.0 & 27.9 & 27.4 & 40.7 & 38.8 \\
\hline 296.07 & RICE_3yr_523 & 2.1 & 10.4 & 4.4 & 12.5 & 16.3 & 8.4 & 32.2 & 17.6 & 24.2 & 9.9 & 24.5 & 37.7 & 32.3 & 44.9 \\
\hline 296.33 & RICE_3yr_524 & 2.2 & 6.3 & 6.0 & 9.6 & 11.9 & 41.6 & 20.7 & 35.4 & 23.7 & 28.2 & 15.1 & 25.5 & 28.5 & 12.1 \\
\hline 296.59 & RICE_3yr_525 & 3.4 & 12.8 & 6.1 & 13.8 & 21.2 & 22.2 & 41.9 & 25.5 & 19.5 & 36.9 & 17.9 & 39.1 & 58.4 & 56.7 \\
\hline 296.85 & RICE_3yr_526 & 3.8 & 9.2 & 3.0 & 5.6 & 7.4 & 16.2 & 27.9 & 18.6 & 28.9 & 28.6 & 28.8 & 20.7 & 36.4 & 58.5 \\
\hline 297.11 & RICE_3yr_527 & 2.6 & 6.3 & 3.8 & 14.1 & 8.2 & 34.3 & 21.6 & 25.9 & 18.0 & 18.5 & 31.9 & 13.7 & 36.1 & 55.5 \\
\hline 297.40 & RICE_3yr_528 & 1.7 & 6.9 & 2.8 & 6.3 & 17.6 & 22.5 & 40.3 & 19.1 & 30.6 & 27.9 & 23.9 & 24.8 & 76.9 & 29.1 \\
\hline 297.61 & RICE_3yr_529 & 1.9 & 2.2 & 4.4 & 10.9 & 14.6 & 19.3 & 39.7 & 35.7 & 16.3 & 32.2 & 25.4 & 21.5 & 30.9 & 41.1 \\
\hline 297.89 & RICE_3yr_530 & 2.2 & 5.2 & 4.5 & 12.6 & 10.3 & 24.9 & 36.3 & 29.2 & 36.2 & 22.6 & 19.4 & 30.8 & 52.2 & 28.2 \\
\hline 298.12 & RICE_3yr_531 & 1.2 & 3.9 & 2.0 & 6.6 & 9.2 & 20.2 & 17.6 & 21.0 & 32.0 & 17.7 & 48.4 & 17.6 & 49.5 & 55.7 \\
\hline 298.40 & RICE_3yr_532 & 4.4 & 7.4 & 2.8 & 9.4 & 11.2 & 10.0 & 41.3 & 16.5 & 27.7 & 37.9 & 15.2 & 29.9 & 56.6 & 43.1 \\
\hline 298.61 & RICE_3yr_533 & 2.7 & 3.1 & 6.2 & 9.4 & 14.5 & 29.5 & 37.1 & 18.6 & 24.6 & 21.2 & 14.8 & 11.5 & 48.8 & 46.6 \\
\hline 298.92 & RICE_3yr_534 & 4.2 & 5.3 & 2.4 & 10.8 & 5.5 & 11.4 & 31.4 & 17.9 & 27.5 & 22.5 & 20.4 & 37.0 & 47.9 & 33.8 \\
\hline 299.14 & RICE_3yr_535 & 2.0 & 4.9 & 4.7 & 8.6 & 12.5 & 10.0 & 24.4 & 24.4 & 47.7 & 19.3 & 28.4 & 30.8 & 57.2 & 38.4 \\
\hline 299.43 & RICE_3yr_536 & 3.4 & 4.0 & 3.9 & 8.0 & 16.7 & 35.2 & 25.9 & 33.2 & 21.3 & 27.9 & 26.4 & 24.0 & 34.5 & 54.6 \\
\hline 299.67 & RICE_3yr_537 & 1.8 & 3.9 & 3.9 & 7.9 & 6.3 & 24.7 & 24.4 & 17.0 & 21.1 & 28.9 & 12.3 & 11.9 & 36.4 & 41.8 \\
\hline 299.90 & RICE_3yr_538 & 2.4 & 3.8 & 3.9 & 8.8 & 10.0 & 18.2 & 29.2 & 32.7 & 34.1 & 14.5 & 9.5 & 30.5 & 38.7 & 31.3 \\
\hline 300.17 & RICE_3yr_539 & 2.2 & 4.0 & 3.0 & 9.2 & 10.8 & 36.0 & 33.5 & 40.5 & 27.6 & 23.1 & 15.5 & 25.6 & 25.4 & 57.4 \\
\hline 300.44 & RICE_3yr_540 & 1.0 & 7.0 & 4.7 & 10.0 & 17.4 & 10.4 & 9.0 & 26.6 & 16.8 & 11.7 & 5.1 & 18.2 & 28.2 & 45.5 \\
\hline 300.69 & RICE_3yr_541 & 1.9 & 6.8 & 2.4 & 6.2 & 10.3 & 15.4 & 24.3 & 25.0 & 12.5 & 18.1 & 27.5 & 22.1 & 41.3 & 39.2 \\
\hline 300.95 & RICE_3yr_542 & 15.4 & 15.3 & 11.8 & 15.2 & 14.1 & 19.9 & 10.0 & 19.3 & 27.9 & 23.8 & 25.6 & 31.6 & 44.3 & 27.6 \\
\hline 301.19 & RICE_3yr_543 & 2.1 & 5.6 & 7.3 & 8.5 & 9.4 & 28.5 & 33.3 & 24.7 & 23.8 & 21.4 & 20.9 & 33.4 & 54.5 & 34.8 \\
\hline 301.40 & RICE_3yr_544 & 2.8 & 7.8 & 5.3 & 13.4 & 10.3 & 30.9 & 38.7 & 30.2 & 30.9 & 18.1 & 36.7 & 49.3 & 30.1 & 29.5 \\
\hline 301.65 & RICE_3yr_545 & 3.4 & 7.8 & 6.9 & 5.9 & 13.4 & 29.5 & 27.5 & 22.0 & 36.5 & 35.7 & 30.5 & 14.2 & 34.7 & 28.3 \\
\hline 301.94 & RICE_3yr_546 & 1.8 & 10.0 & 8.7 & 3.9 & 10.9 & 14.7 & 25.3 & 17.1 & 18.4 & 21.2 & 22.3 & 25.4 & 72.2 & 46.3 \\
\hline 302.17 & RICE_3yr_547 & 4.1 & 7.1 & 8.0 & 11.4 & 13.7 & 27.8 & 29.9 & 39.8 & 17.1 & 24.8 & 14.4 & 21.6 & 29.4 & 36.8 \\
\hline 302.42 & RICE_3yr_548 & 3.3 & 6.0 & 2.5 & 9.6 & 11.3 & 19.2 & 14.7 & 19.5 & 36.3 & 14.3 & 34.4 & 26.6 & 35.4 & 50.0 \\
\hline
\end{tabular}




\begin{tabular}{|c|c|c|c|c|c|c|c|c|c|c|c|c|c|c|c|}
\hline 302.66 & RICE_3yr_549 & 2.3 & 6.3 & 3.1 & 7.2 & 8.7 & 23.6 & 10.3 & 29.0 & 17.0 & 20.9 & 24.1 & 24.9 & 49.5 & 19.5 \\
\hline 302.93 & RICE_3yr_550 & 1.9 & 4.7 & 1.1 & 5.4 & 3.0 & 18.2 & 24.9 & 15.1 & 7.5 & 9.9 & 10.3 & 24.1 & 26.9 & 8.2 \\
\hline 303.20 & RICE_3yr_551 & 44.5 & 33.5 & 62.4 & 38.6 & 39.6 & 113.9 & 86.2 & 48.9 & 63.1 & 50.5 & 73.2 & 96.5 & 105.4 & 92.7 \\
\hline 303.48 & RICE_3yr_552 & 3.8 & 3.2 & 2.7 & 3.8 & 8.7 & 10.9 & 6.0 & 16.8 & 9.8 & 14.6 & 13.0 & 19.3 & 21.3 & 14.2 \\
\hline 303.67 & RICE_3yr_553 & 1.6 & 3.1 & 2.2 & 3.8 & 5.9 & 10.3 & 19.3 & 11.0 & 12.6 & 9.5 & 14.6 & 15.4 & 18.7 & 25.8 \\
\hline 303.90 & RICE_3yr_554 & 2.3 & 5.0 & 2.8 & 8.8 & 7.6 & 30.2 & 15.3 & 16.0 & 16.5 & 13.2 & 17.2 & 24.1 & 20.3 & 19.6 \\
\hline 304.16 & RICE_3yr_555 & 1.9 & 4.7 & 2.6 & 4.6 & 13.9 & 19.0 & 9.0 & 22.4 & 20.8 & 22.5 & 16.7 & 19.0 & 28.8 & 52.2 \\
\hline 304.42 & RICE_3yr_556 & 2.9 & 2.7 & 3.4 & 9.6 & 8.9 & 24.0 & 33.9 & 25.8 & 17.9 & 9.9 & 15.2 & 27.0 & 73.5 & 28.6 \\
\hline 304.65 & RICE_3yr_557 & 3.3 & 4.2 & 4.3 & 9.3 & 14.8 & 23.5 & 11.9 & 14.6 & 21.4 & 30.5 & 17.8 & 19.0 & 28.8 & 23.9 \\
\hline 304.89 & RICE_3yr_558 & 3.5 & 6.9 & 5.5 & 8.9 & 13.9 & 12.1 & 27.9 & 15.9 & 23.1 & 24.5 & 24.3 & 27.8 & 21.7 & 14.2 \\
\hline 305.16 & RICE_3yr_559 & 2.0 & 6.4 & 8.4 & 12.2 & 13.4 & 22.1 & 17.6 & 17.1 & 21.7 & 11.9 & 22.3 & 39.3 & 20.4 & 29.5 \\
\hline 305.40 & RICE_3yr_560 & 1.5 & 6.9 & 4.5 & 9.4 & 2.6 & 32.9 & 19.3 & 23.7 & 22.1 & 31.4 & 24.7 & 35.2 & 36.2 & 32.9 \\
\hline 305.62 & RICE_3yr_561 & 1.6 & 4.9 & 4.2 & 6.2 & 7.0 & 27.1 & 26.9 & 9.2 & 29.9 & 16.6 & 20.4 & 21.9 & 44.6 & 26.1 \\
\hline 305.85 & RICE_3yr_562 & 3.5 & 5.9 & 3.2 & 4.5 & 7.7 & 24.5 & 31.5 & 15.2 & 16.5 & 19.2 & 10.2 & 25.8 & 38.4 & 13.5 \\
\hline 306.13 & RICE_3yr_563 & 2.0 & 6.0 & 2.5 & 8.8 & 12.3 & 30.1 & 20.5 & 24.8 & 22.9 & 19.6 & 18.6 & 31.0 & 41.9 & 49.8 \\
\hline 306.37 & RICE_3yr_564 & 2.0 & 3.0 & 4.2 & 10.5 & 9.5 & 23.7 & 31.3 & 25.9 & 34.4 & 17.1 & 24.1 & 40.2 & 26.6 & 24.2 \\
\hline 306.61 & RICE_3yr_565 & 4.8 & 4.0 & 8.7 & 7.6 & 14.4 & 16.4 & 40.2 & 21.1 & 27.0 & 32.6 & 36.3 & 27.2 & 29.2 & 36.1 \\
\hline 306.83 & RICE_3yr_566 & 2.0 & 5.5 & 7.4 & 6.4 & 9.7 & 34.6 & 19.6 & 8.3 & 28.6 & 16.7 & 15.6 & 35.3 & 20.5 & 39.2 \\
\hline 307.10 & RICE_3yr_567 & 2.3 & 4.2 & 3.0 & 6.7 & 14.5 & 26.5 & 37.0 & 24.0 & 27.1 & 17.8 & 29.9 & 57.7 & 52.2 & 45.1 \\
\hline 307.31 & RICE_3yr_568 & 2.3 & 4.2 & 4.2 & 5.9 & 9.1 & 24.2 & 33.3 & 19.4 & 22.7 & 37.7 & 23.9 & 26.9 & 61.5 & 56.4 \\
\hline 307.56 & RICE_3yr_569 & 4.5 & 5.8 & 3.8 & 8.2 & 9.0 & 22.6 & 13.0 & 23.9 & 19.0 & 23.3 & 25.8 & 44.6 & 22.5 & 54.4 \\
\hline 307.79 & RICE_3yr_570 & 1.4 & 4.1 & 3.2 & 3.9 & 6.0 & 5.8 & 5.8 & 9.4 & 12.8 & 15.0 & 14.6 & 19.3 & 41.4 & 31.2 \\
\hline 308.04 & RICE_3yr_571 & 1.4 & 3.5 & 2.9 & 10.4 & 8.4 & 33.3 & 48.3 & 37.0 & 32.7 & 34.7 & 24.6 & 28.9 & 38.5 & 38.1 \\
\hline 308.25 & RICE_3yr_572 & 2.2 & 3.1 & 3.1 & 5.4 & 8.9 & 19.6 & 23.2 & 36.0 & 17.9 & 21.7 & 25.1 & 41.3 & 61.7 & 49.7 \\
\hline 308.50 & RICE_3yr_573 & 2.8 & 6.6 & 6.1 & 10.7 & 4.8 & 16.8 & 32.5 & 25.3 & 29.7 & 21.5 & 32.7 & 18.9 & 51.6 & 31.1 \\
\hline 308.75 & RICE_3yr_574 & 1.2 & 9.1 & 9.0 & 11.4 & 12.6 & 39.0 & 34.8 & 35.5 & 29.9 & 39.0 & 46.0 & 24.8 & 31.8 & 27.0 \\
\hline 308.98 & RICE_3yr_575 & 2.3 & 4.7 & 8.7 & 9.1 & 7.2 & 36.7 & 26.2 & 25.2 & 29.0 & 42.8 & 27.2 & 33.2 & 42.2 & 52.0 \\
\hline 309.19 & RICE_3yr_576 & 1.8 & 5.7 & 5.1 & 8.0 & 20.4 & 33.2 & 10.4 & 29.5 & 32.0 & 15.7 & 18.7 & 62.7 & 57.2 & 41.3 \\
\hline 309.44 & RICE_3yr_577 & 1.1 & 3.7 & 3.2 & 8.7 & 9.5 & 28.5 & 18.6 & 31.8 & 14.6 & 36.0 & 28.7 & 34.7 & 57.3 & 29.9 \\
\hline 309.69 & RICE_3yr_578 & 11.1 & 8.2 & 6.5 & 8.0 & 5.1 & 27.1 & 36.4 & 25.9 & 23.8 & 26.7 & 19.1 & 36.2 & 62.5 & 31.4 \\
\hline 309.93 & RICE_3yr_579 & 1.1 & 4.9 & 4.2 & 7.3 & 24.0 & 24.2 & 32.5 & 10.7 & 14.7 & 11.6 & 22.9 & 30.6 & 29.9 & 54.6 \\
\hline 310.15 & RICE_3yr_580 & 1.6 & 7.1 & 6.0 & 9.2 & 13.4 & 27.2 & 30.4 & 66.5 & 46.9 & 28.1 & 20.7 & 33.3 & 68.8 & 28.8 \\
\hline 310.36 & RICE_3yr_581 & 2.6 & 5.1 & 4.8 & 12.5 & 13.6 & 18.9 & 27.4 & 19.4 & 23.5 & 22.9 & 11.6 & 37.0 & 68.9 & 28.8 \\
\hline 310.60 & RICE_3yr_582 & 1.5 & 9.2 & 7.2 & 13.5 & 7.7 & 17.1 & 17.1 & 31.7 & 24.3 & 20.2 & 21.8 & 24.0 & 48.4 & 46.2 \\
\hline 310.84 & RICE_3yr_583 & 2.2 & 5.0 & 4.1 & 4.7 & 16.7 & 23.6 & 32.1 & 26.4 & 26.0 & 17.1 & 14.3 & 27.1 & 23.7 & 41.2 \\
\hline 311.09 & RICE_3yr_584 & 1.8 & 5.7 & 3.4 & 8.8 & 10.7 & 17.6 & 42.6 & 31.6 & 22.8 & 14.2 & 25.4 & 33.5 & 34.6 & 52.7 \\
\hline 311.29 & RICE_3yr_585 & 2.3 & 6.6 & 4.3 & 7.8 & 14.4 & 42.0 & 48.9 & 17.3 & 28.1 & 42.9 & 37.5 & 15.7 & 83.6 & 34.1 \\
\hline 311.55 & RICE_3yr_586 & 2.1 & 5.0 & 2.8 & 9.0 & 9.7 & 13.5 & 5.8 & 23.3 & 29.1 & 24.7 & 13.3 & 31.6 & 50.8 & 45.8 \\
\hline 311.79 & RICE_3yr_587 & 2.5 & 3.8 & 2.8 & 7.9 & 5.8 & 19.4 & 23.3 & 18.2 & 39.1 & 14.3 & 20.5 & 37.4 & 38.5 & 11.7 \\
\hline 312.02 & RICE_3yr_588 & 3.9 & 7.7 & 4.5 & 7.1 & 14.1 & 29.1 & 16.0 & 15.4 & 28.3 & 35.5 & 21.5 & 45.9 & 54.3 & 17.0 \\
\hline 312.26 & RICE_3yr_589 & 1.0 & 4.3 & 3.4 & 10.3 & 12.8 & 35.3 & 33.7 & 33.9 & 18.0 & 27.0 & 24.1 & 44.9 & 27.5 & 30.8 \\
\hline 312.45 & RICE_3yr_590 & 2.2 & 3.9 & 3.6 & 9.1 & 12.3 & 23.1 & 23.4 & 38.4 & 25.9 & 20.3 & 22.4 & 45.8 & 64.2 & 28.6 \\
\hline 312.68 & RICE_3yr_591 & 1.7 & 3.8 & 3.9 & 12.6 & 10.1 & 41.7 & 34.8 & 24.4 & 8.7 & 40.2 & 33.1 & 17.4 & 93.2 & 41.8 \\
\hline 312.96 & RICE_3yr_592 & 3.3 & 10.2 & 2.6 & 18.1 & 21.6 & 28.6 & 36.5 & 42.1 & 33.1 & 28.2 & 27.0 & 27.7 & 45.6 & 74.7 \\
\hline 313.15 & RICE_3yr_593 & 1.3 & 2.3 & 1.9 & 6.2 & 4.1 & 16.3 & 20.2 & 21.4 & 10.4 & 20.9 & 17.9 & 31.4 & 32.0 & 18.8 \\
\hline 313.41 & RICE_3yr_594 & 2.3 & 4.6 & 2.2 & 6.4 & 1.5 & 19.4 & 11.6 & 20.6 & 10.3 & 9.4 & 20.4 & 23.0 & 16.9 & 9.7 \\
\hline 313.60 & RICE_3yr_595 & 0.9 & 3.2 & 4.2 & 8.9 & 14.0 & 13.6 & 36.3 & 33.9 & 32.6 & 37.9 & 13.0 & 22.5 & 71.8 & 40.9 \\
\hline 313.82 & RICE_3yr_596 & 1.1 & 4.1 & 2.3 & 8.0 & 15.6 & 15.4 & 19.0 & 34.4 & 12.6 & 28.3 & 204.2 & 39.0 & 29.3 & 26.4 \\
\hline 314.09 & RICE_3yr_597 & 0.9 & 5.5 & 2.9 & 13.9 & 9.5 & 45.1 & 29.9 & 26.1 & 39.9 & 15.7 & 27.7 & 16.2 & 23.2 & 72.9 \\
\hline 314.31 & RICE_3yr_598 & 2.1 & 12.0 & 4.6 & 10.7 & 8.1 & 26.8 & 21.8 & 22.7 & 17.2 & 42.0 & 18.8 & 24.2 & 43.7 & 32.0 \\
\hline 314.51 & RICE_3yr_599 & 1.6 & 8.4 & 5.2 & 17.1 & 13.2 & 49.1 & 32.8 & 41.2 & 28.3 & 18.1 & 28.3 & 42.1 & 40.3 & 42.2 \\
\hline 314.74 & RICE_3yr_600 & 3.9 & 6.4 & 4.4 & 11.9 & 16.9 & 20.4 & 15.1 & 23.5 & 27.4 & 32.4 & 23.9 & 37.2 & 48.8 & 28.3 \\
\hline 314.97 & RICE_3yr_601 & 2.4 & 5.4 & 6.1 & 7.7 & 8.9 & 7.4 & 16.9 & 12.9 & 31.8 & 20.3 & 26.8 & 20.2 & 70.4 & 53.4 \\
\hline 315.18 & RICE_3yr_602 & 2.4 & 6.9 & 7.2 & 6.9 & 13.4 & 39.3 & 35.7 & 25.7 & 26.5 & 21.2 & 15.0 & 28.0 & 41.6 & 51.6 \\
\hline 315.43 & RICE_3yr_603 & 7.0 & 8.2 & 9.0 & 10.4 & 10.9 & 18.1 & 15.7 & 49.0 & 21.6 & 20.2 & 40.6 & 30.1 & 40.7 & 33.5 \\
\hline 315.63 & RICE_3yr_604 & 2.9 & 3.8 & 5.5 & 11.8 & 23.0 & 67.8 & 37.0 & 43.8 & 35.6 & 41.7 & 41.0 & 33.4 & 41.2 & 39.6 \\
\hline 315.85 & RICE_3yr_605 & 1.8 & 6.0 & 3.3 & 15.4 & 17.5 & 30.0 & 18.1 & 32.1 & 16.7 & 38.2 & 21.7 & 31.2 & 87.0 & 63.1 \\
\hline 316.07 & RICE_3yr_606 & 3.9 & 14.6 & 4.6 & 15.6 & 25.7 & 21.5 & 32.1 & 32.6 & 20.9 & 31.3 & 24.7 & 72.0 & 64.5 & 55.3 \\
\hline 316.29 & RICE_3yr_607 & 2.7 & 8.1 & 7.0 & 7.9 & 8.2 & 17.9 & 37.7 & 49.3 & 23.0 & 38.5 & 32.8 & 30.1 & 78.2 & 59.6 \\
\hline 316.56 & RICE_3yr_608 & 4.3 & 5.1 & 3.5 & 5.9 & 12.9 & 17.5 & 18.2 & 20.7 & 51.1 & 16.2 & 17.7 & 28.6 & 49.8 & 57.6 \\
\hline 316.75 & RICE_3yr_609 & 2.1 & 9.6 & 4.0 & 7.9 & 11.1 & 27.8 & 37.6 & 16.8 & 26.4 & 14.8 & 18.7 & 37.8 & 54.5 & 34.0 \\
\hline 316.96 & RICE_3yr_610 & 2.1 & 9.5 & 7.3 & 9.5 & 12.6 & 13.0 & 18.1 & 22.0 & 12.8 & 28.1 & 22.8 & 29.8 & 41.8 & 65.2 \\
\hline 317.22 & RICE_3yr_611 & 3.5 & 7.1 & 5.8 & 12.1 & 9.2 & 9.7 & 22.1 & 21.5 & 48.0 & 20.0 & 29.4 & 20.6 & 46.1 & 44.7 \\
\hline
\end{tabular}




\begin{tabular}{|c|c|c|c|c|c|c|c|c|c|c|c|c|c|c|c|}
\hline 317.43 & RICE_3yr_612 & 5.2 & 5.3 & 2.1 & 3.8 & 11.8 & 16.3 & 29.8 & 20.9 & 38.8 & 44.1 & 16.6 & 19.1 & 48.9 & 27.7 \\
\hline 317.67 & RICE_3yr_613 & 0.8 & 9.8 & 5.5 & 12.3 & 18.7 & 15.8 & 32.7 & 24.5 & 30.2 & 39.5 & 45.1 & 42.8 & 46.4 & 46.8 \\
\hline 317.88 & RICE_3yr_614 & 1.6 & 3.0 & 3.5 & 7.7 & 19.3 & 21.9 & 35.5 & 25.7 & 24.0 & 25.0 & 18.9 & 27.1 & 33.4 & 36.3 \\
\hline 318.13 & RICE_3yr_615 & 1.7 & 6.3 & 3.3 & 7.6 & 11.4 & 32.2 & 13.8 & 50.6 & 29.5 & 36.5 & 45.8 & 44.2 & 48.6 & 66.8 \\
\hline 318.33 & RICE_3yr_616 & 2.5 & 5.6 & 7.4 & 10.0 & 6.0 & 21.8 & 27.1 & 41.7 & 29.0 & 38.9 & 34.7 & 36.6 & 88.8 & 42.3 \\
\hline 318.57 & RICE_3yr_617 & 1.8 & 5.8 & 2.8 & 8.2 & 12.2 & 31.8 & 36.5 & 35.9 & 23.5 & 34.3 & 27.0 & 25.5 & 63.2 & 60.8 \\
\hline 318.75 & RICE_3yr_618 & 1.2 & 2.1 & 1.5 & 8.2 & 14.7 & 22.5 & 43.3 & 32.6 & 24.0 & 30.4 & 15.6 & 20.5 & 53.8 & 29.4 \\
\hline 319.02 & RICE_3yr_619 & 2.3 & 6.2 & 2.7 & 11.8 & 20.6 & 24.3 & 10.1 & 39.9 & 28.7 & 30.9 & 30.7 & 46.4 & 60.7 & 48.5 \\
\hline 319.23 & RICE_3yr_620 & 2.2 & 4.8 & 4.8 & 8.1 & 9.7 & 14.9 & 25.6 & 17.1 & 13.4 & 28.9 & 27.4 & 30.8 & 74.5 & 44.7 \\
\hline
\end{tabular}

